Tesis para optar al título de

Doctorado en Relaciones Internacionales

\title{
Estado-empresas transnacionales:
}

cambios en el régimen de solución de controversias inversor-Estado y redefinición de la soberanía a la luz de la protección de los derechos humanos

María Magdalena Bas Vilizzio

Director:

Lincoln Bizzozero
Co-Director:

Norberto Consani

Año 
Ojalá seamos dignos de tu desesperada esperanza. (...)

Ojalá podamos ser capaces de seguir caminando los caminos del viento, a pesar de las caídas y las traiciones y las derrotas, porque la historia continúa, más allá de nosotros, y cuando ella dice adiós, está diciendo: hasta luego.

Ojalá podamos mantener viva la certeza de que es posible ser compatriota y contemporáneo de todo aquel que viva animado por la voluntad de justicia y la voluntad de belleza, nazca donde nazca y viva cuando viva, porque no tienen fronteras los mapas del alma ni del tiempo.

Eduardo Galeano

Palabras de agradecimiento en ocasión de recibir el Premio Stig Dagerman

Suecia, 12 de setiembre de 2010 


\section{Resumen Ejecutivo}

Este trabajo aborda como tema central la relación entre los principales actores vinculados a la inversión extrajera, Estados y empresas transnacionales, en el marco del régimen de solución de controversias inversor-Estado. En un menor nivel de abstracción, dicha relación se manifiesta, en primer lugar, en el planteo de alternativas al régimen de solución de controversias inversor-Estado tradicional. Se constatan dos alternativas, a saber: el abandono del régimen y los tratados que buscan un equilibrio. El abandono del régimen por parte de Bolivia, que en 2007 se convierte en el primer Estado en el mundo en retirarse del Centro de Arreglo de Diferencias relativas a Inversiones, seguido por Ecuador (2009, con cambios en su postura en 2018) y Venezuela (2012). El hito inicial se complementa con la terminación de tratados bilaterales de inversión por parte de Bolivia, Ecuador, y Sudáfrica como un disidente africano. Por otra parte, las alternativas se presentan en forma de tratados que buscan un nuevo equilibrio o excluir total o parcialmente el régimen actual. En este punto se analizan los acuerdos de cooperación y facilitación de inversiones de Brasil, las exclusiones sectoriales del Acuerdo Integral y Progresivo de Asociación Transpacífico, y el nuevo modelo de tratado bilateral de inversiones de India (2016).

En segundo lugar, este trabajo examina la relación Estado-empresas transnacionales mediante la determinación del impacto de la extensión de la regulación estatal en materia de derechos humanos en casos concretos de arbitrajes de inversiones contra Estados de Sudamérica y la Unión Europea. Ejemplo de lo anterior son los casos Pac Rim contra El Salvador (medioambiente), Masdar contra España (transición energética), Philip Morris contra Uruguay (medidas de control del tabaco), Bear Creek contra Perú (derechos de las comunidades locales), entre otros analizados. Se constata que tanto en situaciones de avance o retroceso de la regulación en materia de derechos humanos, los inversores extranjeros han iniciado arbitrajes contra los Estados huéspedes.

En tercer y último lugar, el binomio Estado-empresas transnacionales se analiza desde la transición hacia un nuevo concepto de soberanía, no abordado por Krasner en su cuádruple proyección (soberanía de interdependencia, westfaliana, legal internacional e interna). El concepto de soberanía regulatoria se basa en la defensa del espacio de política pública, cuyo corazón es el derecho de regular. En este sentido, se analiza la evolución del régimen internacional para contextualizar el reconocimiento, por la 
UNCTAD en 2003, de la erosión del espacio de política pública por los mecanismos de solución de disputas inversor-Estado. Se presentan los caminos de defensa que los Estados y la doctrina han propuesto y particularmente se interpela la situación de la Unión Europea: a su interior (arbitrajes intra-Unión Europea) y a su exterior (el sistema de tribunales de inversiones del Acuerdo Económico y Comercial Global con Canadá). El círculo cierra con el examen de la soberanía regulatoria, como concepto en transición, sus manifestaciones empíricas y los motivos de su surgimiento en el marco de la slowbalisation y la crisis del multilateralismo.

Dentro de las principales conclusiones a las que arriba este trabajo se destaca que las alternativas estatales (a nivel de tratados) tienen raíces jurídicas, políticas y coyunturales, esto es, en la experiencia de los Estados ante el régimen. En segundo lugar, la transición hacia el nuevo concepto de soberanía regulatoria se conecta directamente con la defensa del espacio de política pública, habiendo los Estados comprobado su erosión en las mencionadas disputas. Finalmente, la soberanía regulatoria no abarca exclusivamente la dimensión doméstica del Estado sino que se extiende hacia el exterior, dando pasos tendientes a moldear las instituciones internacionales.

\section{Palabras clave}

Estado, Empresa transnacional, Solución de controversias inversor-Estado, Soberanía 


\section{Prefacio}

En 2019 se cumplen los cien años de la primera cátedra de Política Internacional en el mundo, dando origen a una fecunda tradición de enseñanza e investigación universitaria en relaciones internacionales. Asimismo, han pasado sesenta años desde la firma del primer tratado bilateral de inversiones, entre Alemania y Pakistán, y setenta y cinco de la creación de las instituciones de Bretton Woods. Cien, sesenta y setenta y cinco pueden ser solo números, pero demuestran el pasaje del tiempo en el estudio de una disciplina dinámica, profunda y amplia. En el siglo XXI pensar en relaciones internacionales es pensar en la necesidad de normas básicas de Derecho Internacional pero también en nuevas normas que den respuesta a recientes desarrollos en otras áreas, es pensar en el aporte de la inteligencia artificial a la política exterior, o en medidas domésticas comprometidas con el desarrollo de sus pueblos y que impactan en la estructuras internacionales.

Reflexionar sobre la disciplina implica reconsiderar el rol y las características de sus actores conforme a la coyuntura actual, volver a pensar en el atributo de la soberanía y en las empresas transnacionales como posibles sujetos de Derecho Internacional Público. Es pensar en los impactos sistémicos del cruce entre protección de derechos humanos y protección de inversiones. Trabajar en la disciplina conlleva una profunda reflexión sobre márgenes difusos de un área del conocimiento que día a día se extiende hacia nuevos tópicos y nuevos desafíos. En efecto, investigar en relaciones internacionales trae consigo el desafío de estudiar fenómenos a la par de su desarrollo. Pensar en relaciones internacionales, en definitiva, es romper el corset clásico de los límites de la disciplina.

Es en este contexto que mi trabajo pretende avanzar en la relación Estado-empresa transnacional en el marco de la solución de controversias inversor-Estado, desde una óptica de las relaciones internacionales, que permita ampliar la mirada tradicional del Derecho Internacional. La realización del Doctorado en Relaciones Internacional del Instituto de Relaciones Internacional (Universidad Nacional de La Plata) me dio la posibilidad de aprender, reflexionar y discutir sobre las diferentes aristas de la disciplina y enfocarme en la solución de controversias inversor-Estado. Agradezco a los docentes del doctorado (Alejandro Simonoff, Cecilia Onaha, Juan Ignacio Piovani, Leandro Sánchez, Diego Buffa, Lorenza Sebesta, Norberto Consani) y a todos los colegas que 
trabajan en el Instituto de Relaciones Internacionales. En especial destaco su generosidad y el haberme brindado un espacio para profundizar en temas relevantes para la región y el mundo. Una especial mención merece su director, Norberto Consani, quien constantemente me ha impulsado en el desarrollo de mi carrera.

Adicionalmente, quisiera reconocer a todos los colegas de los que recibí sugerencias, críticas constructivas y aliento, en particular a los entrevistados para este trabajo, quienes compartieron conmigo su tiempo y sus conocimientos. En este sentido, muchas gracias a José Augusto Fontoura Costa, Alejandro Garro, Carlos Gianelli, Juan Hernández Zubizarreta, Felipe Michelini, Fabio Morosini, Cecilia Olivet y Saskia Sassen. Sin sus aportes el resultado no hubiera sido el mismo. De los errores u omisiones que pudieran existir, solo yo soy responsable.

En el proceso de investigación, participé de seminarios y congresos en los que pude exponer e intercambiar ideas sobre esta línea de investigación. A modo de ejemplo, puedo destacar las V Jornadas de Relaciones Internacionales (FLACSO Argentina, 2017), el IX Congreso de Relaciones Internacionales (Universidad Nacional de La Plata, 2018), la Conferencia regional FLACSO-International Studies Association (FLACSO Ecuador, 2018), las VII Jornadas de Relaciones Internacionales (Universidad de la República, 2019), la Conferencia sobre inversiones y sustentabilidad ecológica (Universidad Nacional de San Martín, University of Dundee, Transnational Institute, Fundación Ebert, 2019), el IX Encuentro del Centro de Reflexión en Política Internacional y la VII Jornada del Centro de Estudios Sudamericanos (Universidad Nacional de La Plata, 2019), entre otras instancias. Gracias a todos los panelistas y participantes de estos eventos académicos por sus comentarios, críticas y sugerencias.

De este trabajo también surgieron publicaciones que me dieron un espacio para compartir parte de las respuestas a las interrogantes que dan origen a esta investigación. Particularmente quisiera agradecer por la evaluación y publicación de mis trabajos a la Revista Relaciones Internacionales (Universidad Nacional de La Plata), Revista de la Secretaría del Tribunal Permanente de Revisión (Mercosur), Revista Iberoamericana de Derecho Internacional y de la Integración (IJ Editores), Revista Diplomática (Ministerio de Relaciones Exteriores Uruguay), Anuario de Política Exterior y Política Internacional (Facultad de Ciencias Sociales de la Universidad de la República, Uruguay), Comisión Sectorial de Investigación Científica (Universidad de la República, Uruguay), y Fundación Carolina (España). 
El desarrollo de esta línea de investigación me llevó a complementar mi trabajo de tesis con una investigación apoyada por la Comisión Sectorial de Investigación Científica de la Universidad de la República de Uruguay. Asimismo, me permitió ser orientadora de tesis de grado y posgrado. Mi reconocimiento a quienes confiaron en mí para ser su tutora en un área poco desarrollada en Uruguay: Clara Araújo, Verónica Besso, Gabriela Bustamante, Luciana Chanquet, Camila Ganduglia, Diego Larrauri. También mi agradecimiento a mis orientados en otras áreas de las relaciones internacional y el Derecho Internacional Público, Rodrigo Alonso, Yanina Almada, Joanna De Oliveira, Ximena Ottado, Natalia Costa, Sabina Barone, Claudia Díaz, Luciana Brito. Con todos ellos aprendí a ser mejor tutora y mejor investigadora.

El haber ejercido el mencionado rol me permite apreciar particularmente la tarea realizada por mi tutor, Lincoln Bizzozero Revelez, quien confió en mí desde el primer día y se convirtió en mi padre académico. Al cierre de este trabajo se cumplen dos años de la partida de su madre, el recuerdo de Manuela Revelez estuvo presente durante la última etapa de orientación y corrección.

Finalmente, quisiera agradecer a mi familia, así como a mis colegas y amigos que siempre me apoyaron: Mónica Nieves, Diego Escuder, Ana María Pastorino, Guzmán Moresco, Brian Rodríguez, Eleonora Liotti, Cecilia Rivas, Giselle Barquet, Sandra Dene, Nazaret Ogeda, Elizabeth González, Ana Santos, Florencia Valetta, Jimmy Voss, Angélica Guerra Barón, y María José Orellano, quien se fue demasiado pronto. Gracias por ser parte de este y muchos otros caminos. 


\section{Índice}

Resumen Ejecutivo ........................................................................................ ii

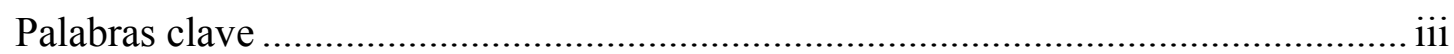

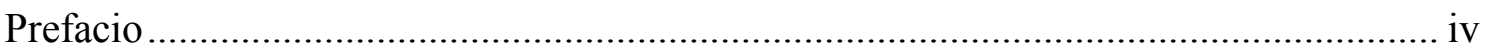

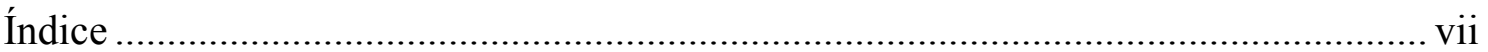

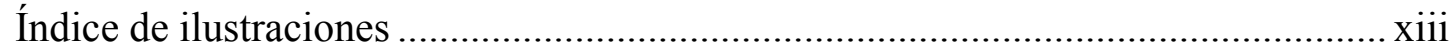

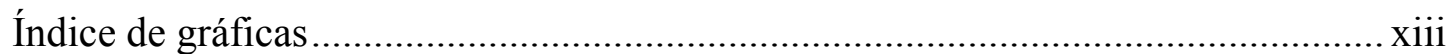

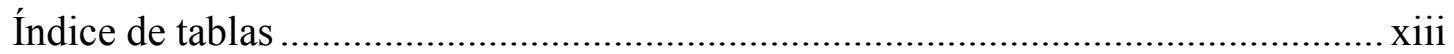

Índice de flujogramas ...................................................................................... xiv

Lista de siglas y abreviaturas................................................................................. XV

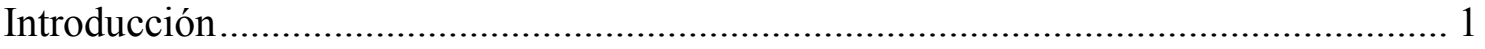

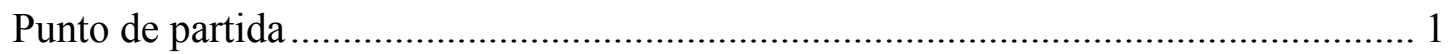

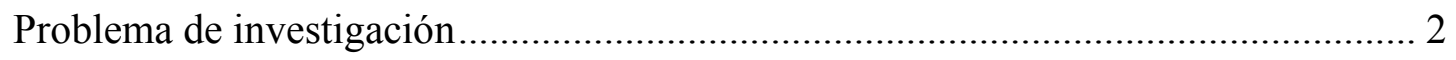

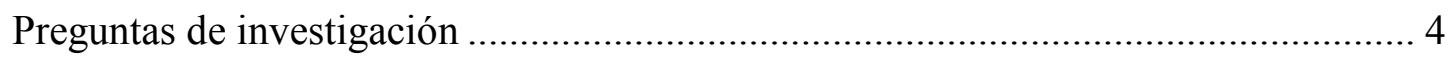

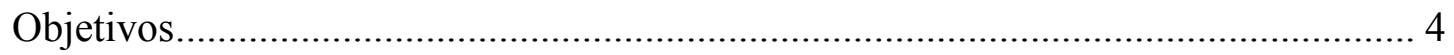

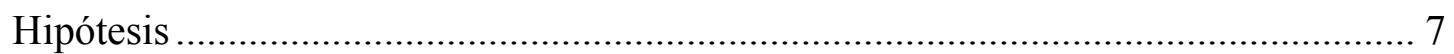

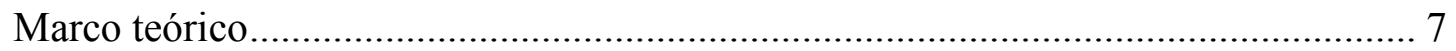

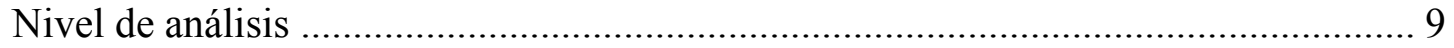

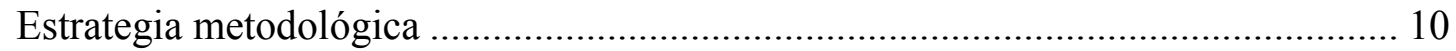

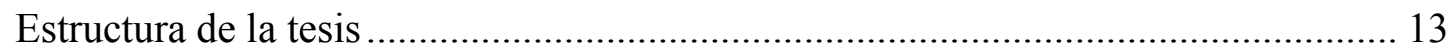

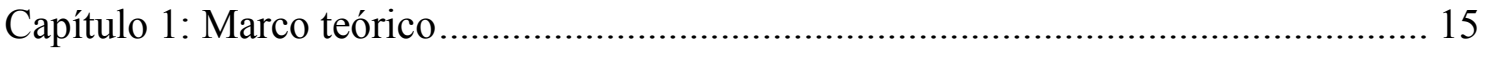

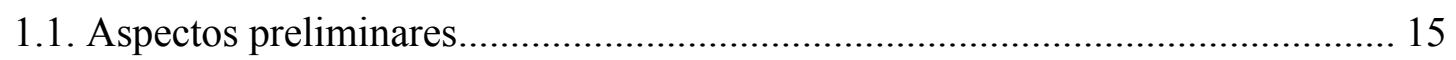

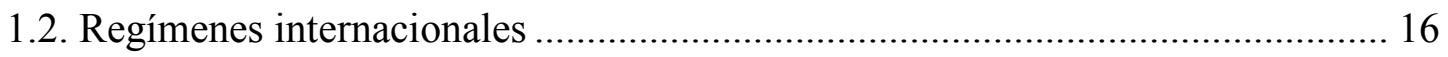

1.2.1. Teoría de los regímenes internacionales: conceptualización........................... 16

1.2.2. Tipos de regímenes internacionales .......................................................... 18 
1.2.3. Régimen internacional de protección de inversiones y régimen internacional de solución de controversias inversor-Estado

1.3. Régimen internacional de solución de controversias inversor-Estado en el marco de los modelos institucional y relacional 27

1.4. Estado: soberanía y autonomía 31

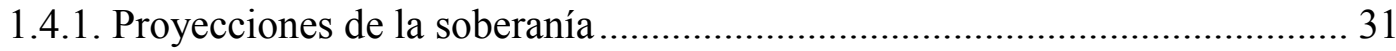

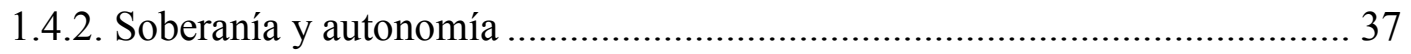

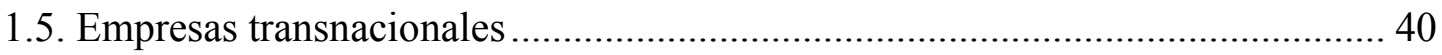

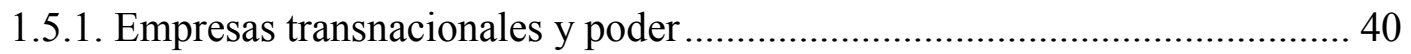

1.5.2. Empresas transnacionales como sujetos de Derecho Internacional.............. 46

1.6. Una aproximación en conjunto.

Círculo 1: Alternativas al régimen internacional de solución de controversias inversorEstado 55

Capítulo 2: Abandono del régimen de solución de controversias inversor-Estado......... 56

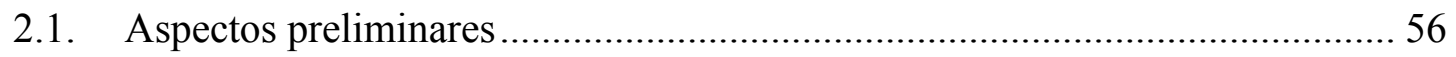

2.2. Sudamérica dividida en tres: los miembros, los disidentes y el externo.......... 57

2.2.1. Antecedentes: del apego a la doctrina Calvo al consenso de Washington 57

2.2.2. Siglo XXI y la división sudamericana...... 63

2.3. Bolivia, Ecuador y Venezuela: los disidentes sudamericanos .........................66

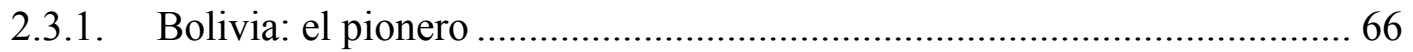

2.3.2. Ecuador: un proceso con auditoría ciudadana .......................................... 69

2.3.3. Venezuela: en defensa de la soberanía y los recursos estratégicos .............. 77

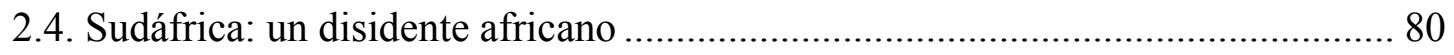

2.4.1. Sudáfrica y el sistema de protección de inversiones extranjeras: del apartheid

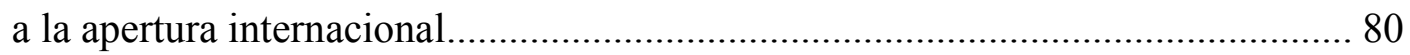

2.4.2. Los costos de la igualdad: el caso Piero Foresti ....................................... 83

2.4.3. La reforma del sistema de protección de inversiones en Sudáfrica.............. 85

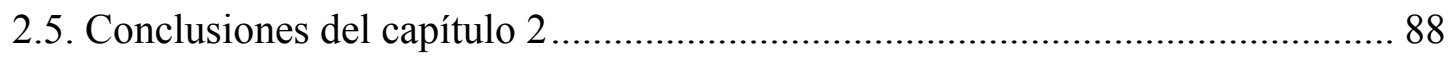


Capítulo 3: Nuevos acuerdos: entre un nuevo equilibrio en el régimen y la exclusión del arbitraje inversor-Estado

3.1. Aspectos preliminares. 91

3.2. Exclusión total de régimen de solución de controversias inversor-Estado: el caso de Brasil, un tradicional externo al régimen.

3.2.1. El inicio del proceso: celebración de TBI y limitaciones constitucionales .. 92

3.2.2. La consolidación del proceso: nuevo modelo de acuerdo en materia de inversiones

3.2.3. El Protocolo de Cooperación y Facilitación de Inversiones intra-Mercosur: siguiendo el camino de Brasil 96

3.3. Exclusión sectorial del régimen de solución de controversias inversor-Estado: las medidas de control del tabaco en el CPTPP.

3.3.2. La solución de controversias inversor-Estado: aspectos procesales. 100

3.3.3. Las excepciones a la solución de controversias inversor-Estado 104

3.4. Reforzamiento de la jurisdicción doméstica: el caso del modelo de TBI de la

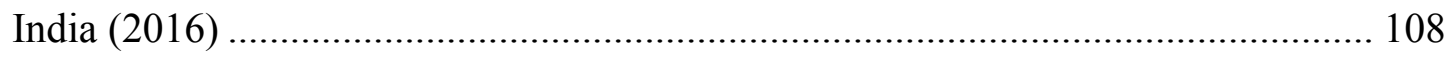

3.4.1. Reforma del sistema de protección de inversiones en India....................... 108

3.4.2. El agotamiento de la jurisdicción doméstica como requisito previo para el

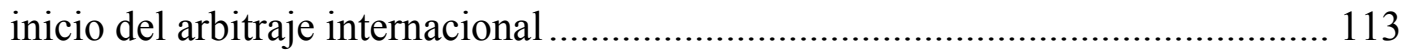

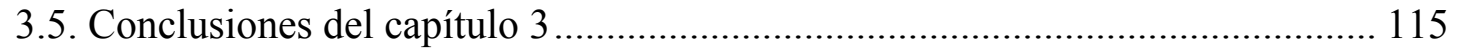

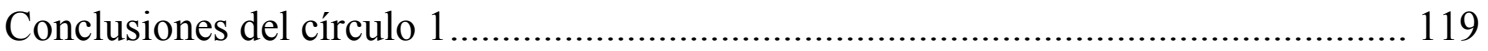

Círculo 2: Controversias inversor-Estado que involucran a los derechos humanos..... 121

Capítulo 4: Controversias que involucran el derecho a un medioambiente sano y equilibrado

4.1. Aspectos preliminares

4.2. Caso Pac Rim contra El Salvador.

4.2.1. El Salvador y el permiso de la discordia

4.2.2. Los siete años de litigio y el peso de la sociedad civil organizada. 
4.2.3. El laudo del 14 de octubre de 2016 y después......................................... 128

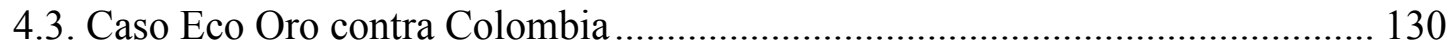

4.3.1. Colombia: el arbitraje de inversiones y la protección de los páramos ....... 130

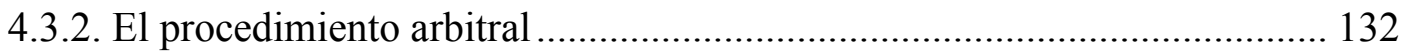

4.4. Caso Masdar contra España.......................................................................... 136

4.4.1. España y las energías renovables.......................................................... 136

4.4.2. Las objeciones de jurisdicción y el efecto Achmea................................... 138

4.4.3. La responsabilidad estatal y la "tormenta Micula"................................... 141

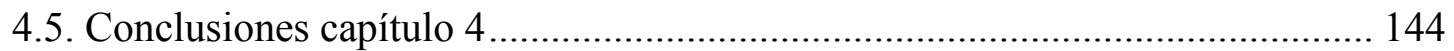

Capítulo 5: Controversias que involucran los derechos a la salud, al agua y de los

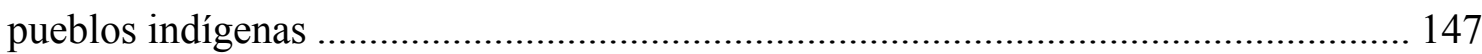

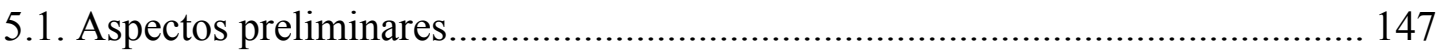

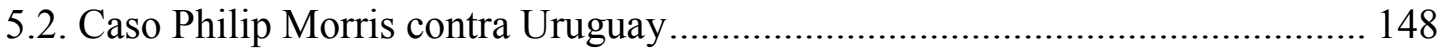

5.2.1. El germen de la disputa: Uruguay y las medidas de control del consumo del tabaco.

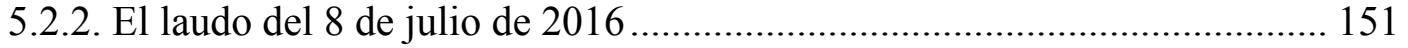

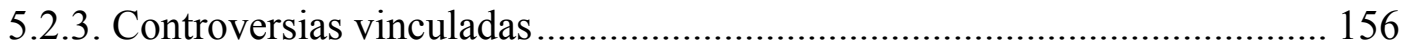

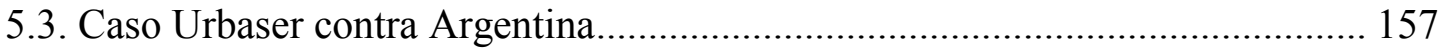

5.3.1. Argentina, la crisis de 2001 y los arbitrajes de inversiones....................... 157

5.3.2. El arbitraje de inversiones y el derecho humano al agua ........................ 160

5.3.3. El laudo del 8 de diciembre de 2017: ¿son los derechos humanos el as bajo la

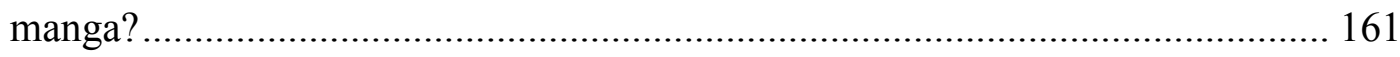

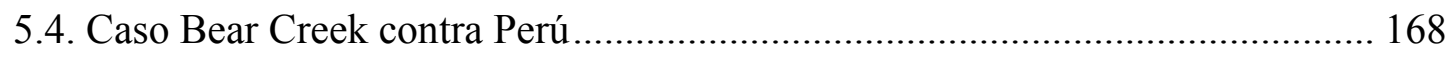

5.4.1. Perú: la minería en Santa Ana y la resistencia social .............................. 168

5.4.2. La discusión sobre la licencia social....................................................... 169

5.4.3. El laudo y la opinión parcialmente disidente............................................ 173

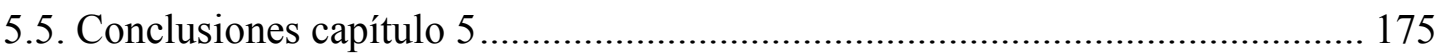

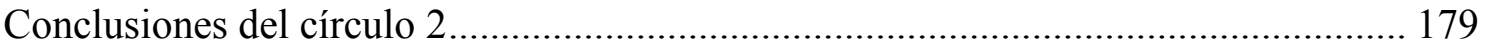


Círculo 3: ¿Transición hacia un nuevo concepto de soberanía?.

Capítulo 6: El espacio de política pública como base de la soberanía

6.2. Evolución del régimen de protección de inversiones hacia el reconocimiento de la necesidad de un espacio de política pública

6.3. ¿Hay un lugar para el espacio de política pública?

6.3.1. El reconocimiento del espacio de política pública condicionado.....

6.3.2. Los caminos hacia la salida del laberinto

6.4. El caso de la Unión Europea: ¿reivindicación de un espacio de política pública regional?

6.4.1. Las dos gotas que rebasaron el vaso de los arbitrajes intra-Unión Europea: los casos Micula y Achmea

6.4.2. El Acuerdo Económico y Comercial Global entre la UE y Canadá (CETA): un ejemplo del primer eslabón de la cadena. 203

6.4.3. La compatibilidad del CETA con el Derecho de la Unión 207

6.4.4. Hacia un sistema multilateral de tribunales de inversiones 210

6.5. Conclusiones del capítulo 6

Capítulo 7: Soberanía regulatoria, un concepto en transición 215

7.1. Aspectos preliminares 215

7.2. Estados, empresas transnacionales y solución de controversias en un mundo en crisis 216

7.2.1. Reflejos de la crisis de la globalización. 216

7.2.2. Reflejos de la crisis del multilateralismo....... 219

7.2.3. ¿Otro botón de la muestra? La crisis del Órgano de Apelación de la OMC 221

7.3. Reequilibrando el régimen: proyecto del instrumento vinculante sobre empresas $\mathrm{y}$ derechos humanos 227 
7.3.3. Aspectos generales del proyecto revisado ............................................ 231

7.3.4. Responsabilidad y derechos de las víctimas ............................................. 233

7.3.5. Otras disposiciones: derecho aplicable, prevención e institucionalidad .... 235

7.4. Soberanía regulatoria: transición hacia el nuevo concepto ............................. 237

7.4.1. De las cuatro proyecciones de la soberanía a la soberanía regulatoria....... 237

7.4.2. Autoridad, control y legitimidad en la soberanía regulatoria .................... 240

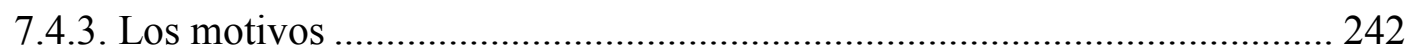

7.4.4. Las manifestaciones de la transición hacia la soberanía regulatoria: una

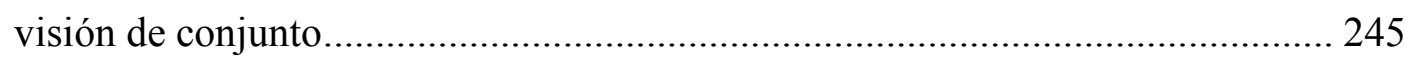

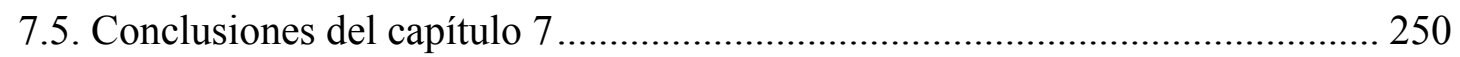

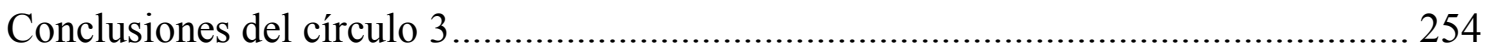

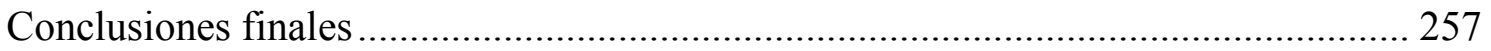

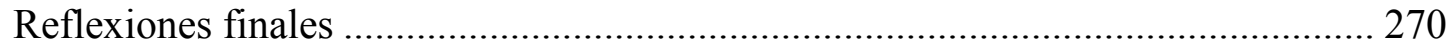

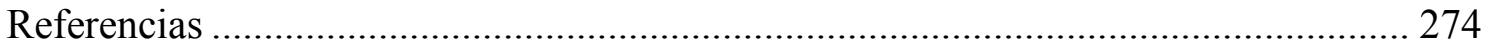

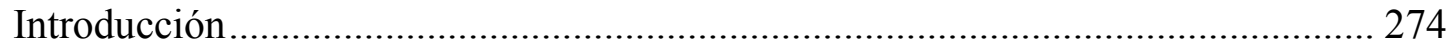

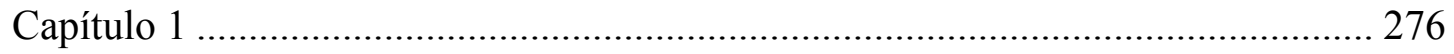

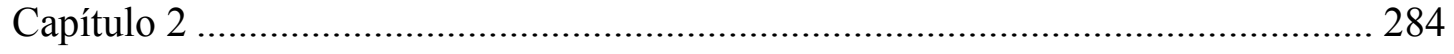

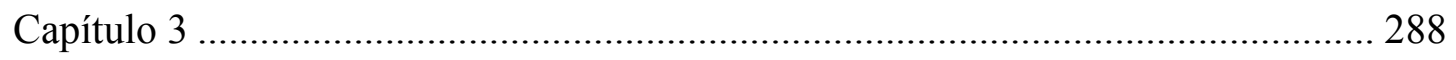

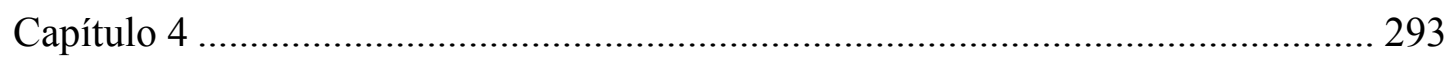

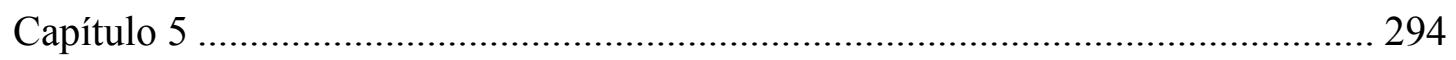

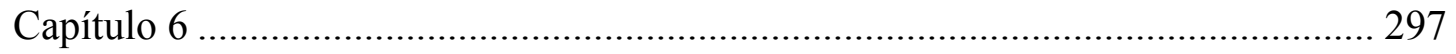

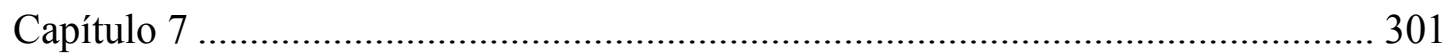

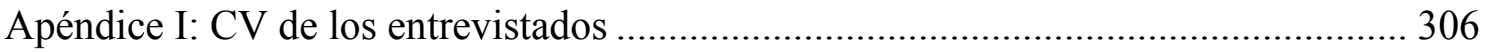

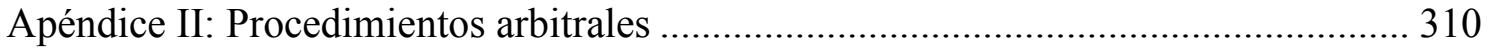

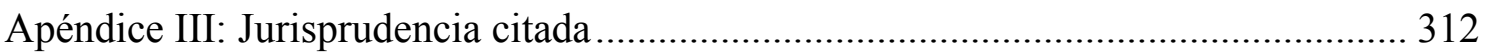




\section{Índice de ilustraciones}

Ilustración 1: Principios del régimen internacional de inversiones. Especial referencia al régimen internacional de solución de controversias inversor-Estado (régimen derivado)

Ilustración 2: Marco teórico 54

Ilustración 3: Clasificación de las propuestas estatales conforme a su grado de cambio respecto al régimen internacional predominante

Ilustración 4: Tipología de Estados según su posición en torno al régimen de solución de controversias inversor-Estado.

Ilustración 5: Relación Estado-empresas transnacionales: una síntesis 270

\section{Índice de gráficas}

Gráfica 1: Instituciones administradoras de arbitrajes inversor-Estado. Porcentaje sobre número total de casos conocidos basados en tratados . 28

Gráfica 2: Número de TBI celebrados por Estados Sudamericanos en la década de los noventa en comparación con otros períodos 63

Gráfica 3: Número de TBI celebrados por década (total de Estados del mundo) 185

Gráfica 4: Número de acuerdos internacionales de inversiones celebrados por década (total de Estados del mundo) 185

Gráfica 5: Número de controversias conocidas según año de inicio. 186

\section{Índice de tablas}

Tabla 1: Estatus de ratificaciones del Convenio de Washington por Estado Sudamericano 59

Tabla 2: Tipología de Estados Sudamericanos ante el régimen de solución de controversias inversor-Estado.

Tabla 3: TBI terminados por denuncia unilateral de Bolivia

Tabla 4: TBI terminados por denuncia unilateral de Ecuador 75

Tabla 5: TBI terminados por denuncia unilateral de Sudáfrica 82

Tabla 6: Principales áreas temáticas del Protocolo de Cooperación y Facilitación de Inversiones intra-Mercosur 96

Tabla 7: Miembros del TPP que son parte del Convenio de Washington de 1965 ....... 102

Tabla 8: Estatus de los TBI celebrados por India 
Tabla 9: Disputas contra Argentina en el sector aguas y saneamiento......................... 160

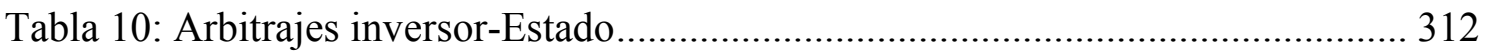

Tabla 11: Corte Internacional de Justicia y la Corte Permanente de Justicia................ 314

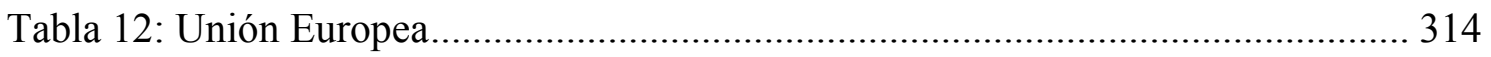

Tabla 13: Corte Interamericana de Derechos Humanos ............................................ 315

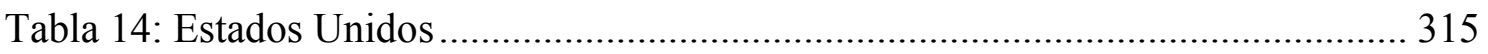

Tabla 15: Organización Mundial del Comercio .......................................................... 315

\section{Índice de flujogramas}

Flujograma 1: Procedimiento arbitral ordinario en el CIADI ..................................... 310

Flujograma 2: Procedimiento arbitral del Reglamento de Arbitraje de la UNCITRAL

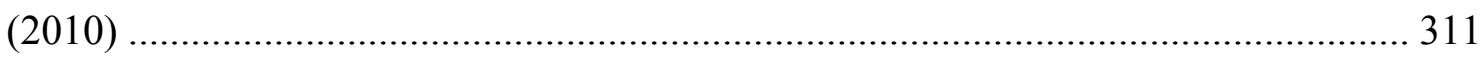




\section{Lista de siglas y abreviaturas}

ACFI

AMI

CCI

CDI

CETA

CIADI

CNMF

CPA

CPJ

СРTPP

GATS

GATT

GTI

OEA

OIT

$\mathrm{OMC}$

ONG

ONU

PCFI

PO

SOE

TBI
Acuerdo de Cooperación y Facilitación de Inversiones (Brasil)

Acuerdo Multilateral de Inversión

Cámara de Comercio Internacional

Comisión de Derecho Internacional de la Organización de Naciones Unidas

Comprehensive Economic and Trade Agreement (Acuerdo Económico y Comercial Global entre la UE y Canadá)

Centro Internacional de Arreglo de Diferencias relativas a Inversiones

Cláusula de la nación más favorecida

Corte Permanente de Arbitraje

Corte Permanente de Justicia

Comprehensive and Progressive Transpacific Partnership (Acuerdo Integral y Progresivo de Asociación Transpacífico)

General Agreement on Trade in Services (Acuerdo General sobre Comercio de Servicios)

General Agreement on Tariffs and Trade (Acuerdo General sobre Aranceles y Comercio)

Grupo de Trabajo intergubernamental de composición abierta sobre las empresas transnacionales y otras empresas con respecto a los derechos humanos (Consejo de Derechos Humanos)

Organización de Estados Americanos

Organización Internacional del Trabajo

Organización Mundial del Comercio

Organización no gubernamental

Organización de las Naciones Unidas

Protocolo de Cooperación y Facilitación de Inversiones intra Mercosur

Protocolo de Olivos para la solución de controversias en el Mercosur

State owned enterprises (Empresas de propiedad estatal)

Tratado bilateral de inversiones 
TJUE Tribunal de Justicia de la Unión Europea

TLC Tratado de libre comercio

TPP Transpacific Partnership (Acuerdo de Asociación Transpacífica)

TTIP Transatlantic Trade and Investment Partnership (Acuerdo Transatlántico de Comercio e Inversiones)

UE Unión Europea

UNASUR Unión de Naciones Sudamericanas

UNCITRAL United Nations Commission on International Trade Law (Comisión de las Naciones Unidas para el Derecho Mercantil Internacional)

UNCTAD United Nations Conference for Trade and Developmet (Conferencia de las Naciones Unidas sobre Comercio y Desarrollo) 


\section{Introducción}

\section{Punto de partida}

Hace sesenta años, el 25 de noviembre de 1959, Alemania y Paquistán celebraron el primer tratado bilateral de inversión (TBI) de la historia. En la actualidad, son más de 3000 los instrumentos jurídicos que componen la red de acuerdos internacionales de inversiones, entre TBI, capítulos en tratados de libre comercio (TLC) o disposiciones en tratados regionales o multilaterales de diversas materias ${ }^{1}$. Estos instrumentos contienen reglas y principios que conforman un régimen internacional en cuyo centro se encuentra el principio general de la promoción y protección de la inversión extranjera en el territorio de un Estado huésped. Del principio fundamental se desprenden otros derivados que regulan el comportamiento de los principales actores vinculados a la inversión extranjera, esto es, Estados e inversores. Estos son: 1) trato nacional; 2) trato justo y equitativo; 3) garantía y compensación por expropiación; 4) garantía de libre traspaso de fondos y transferencia de capitales y ganancias al exterior; 5) solución de controversias inversor-Estado mediante la prórroga de jurisdicción al arbitraje internacional prevista por escrito ${ }^{2}$.

El principio de solución de controversias inversor-Estado, dada su complejidad y características propias, se comporta como un régimen internacional en sí mismo. Este régimen tiene dos particularidades que lo distinguen de otros sistemas de solución de disputas a nivel internacional. En primer lugar son los inversores extranjeros, ya sean personas físicas o jurídicas, quienes tienen locus standi y jus standi, no así los Estados, aspecto que trae al debate el creciente peso internacional de los actores no estatales. En segundo lugar, el régimen se erige como un mecanismo de control externo de la legalidad de los actos del Estado receptor de la inversión (Hernández González, 2017; Postiga: 2013: 182; Van Hurten y Loughlin, 2016: 149).

Asimismo, producto de la expansión de temas susceptibles de regulación internacional y la consecuente fragmentación del Derecho Internacional en regímenes jurídicos

\footnotetext{
${ }^{1}$ Conforme a datos del Investment Policy Hub de la UNCTAD, actualizados al 31 de diciembre de 2018 y recuperados el 13 de marzo de 2019, el número de tratados bilaterales de inversiones celebrados alcanza a 2932 (80\% en vigor) y el de otros acuerdos con disposiciones en materia de inversiones a $384(82 \%$ en vigor).

${ }^{2}$ La prórroga de jurisdicción puede estar prevista en un TBI, un capítulo de inversiones de un TLC o tratados multilaterales en los cuales el Estado huésped o receptor de la inversión y el Estado de nacionalidad del inversor sean parte, así como leyes de inversiones del Estado receptor o contratos puntuales entre empresas extranjeras y Estados huéspedes.
} 
autocontenidos, la segunda característica de la solución de controversias inversorEstado se complementa con el hecho que las medidas domésticas cuestionadas por los inversores extranjeros pueden tener diversa índole, incluso estar vinculadas a temas de protección del medioambiente, salud pública, acceso al agua potable, o derechos humanos en general. Acuerdos modernos prevén límites al respecto, aunque en el año 2019 el uso de estas disposiciones sigue siendo excepcional en la materia, como por ejemplo el Acuerdo Integral y Progresivo de Asociación Transpacífico (CPTPP por su sigla en inglés) en cuyo articulado está prevista la excepción de las medidas de control del tabaco (artículo 29.5).

En este contexto, el objeto material de esta investigación, esto es, la parcela de la realidad que se pretende conocer, es la relación empresas transnacionales-Estados en el marco de la solución de controversias inversor-Estado, desde el 2007 -año en que Bolivia se convierte en el primer Estado del mundo en abandonar el Centro Internacional de Arreglo de Diferencias relativas a Inversiones (CIADI)- hasta el presente. Si bien el objeto material tiene vinculación directa con el núcleo del Derecho Internacional Público: el Estado como sujeto y la solución pacífica de controversias como uno de los principios fundamentales del sistema, el objeto formal de este trabajo son las relaciones internacionales. La perspectiva desde la que aborda el objeto material excede el análisis estrictamente jurídico, ampliándose la mirada desde y hacia las relaciones internacionales. En consecuencia, se prevé como objetivo general analizar la dinámica de la relación entre los principales actores vinculados a la inversión extranjera, Estados y empresas transnacionales, en el marco del régimen de solución de controversias inversor-Estado.

\section{Problema de investigación}

El régimen internacional de protección de inversiones tuvo su auge en la década del noventa durante el consenso de Washington cuyos postulados propulsaban la celebración de TBI y la apertura a capitales externos. No obstante, el régimen de solución de controversias inversor-Estado, parte integrante del anterior, comenzó a ser empleado por los inversores tímidamente una vez entrada la década del noventa y con especial énfasis en la primera década del siglo XXI con las demandas contra Argentina por las medidas tomadas para hacer frente a la crisis económica del año 2001 particularmente por la pesificación de las tarifas de los servicios públicos-. Conforme a 
datos del Investment Policy Hub de la UNCTAD, hasta el año 2000 inclusive, el número de arbitrajes iniciados fue 57, mientras que entre el 2001 y 2018 inclusive la cifra aumentó a 885 procedimientos ${ }^{3}$. Estos hitos en el régimen de solución de controversias inversor-Estado son en sí mismos hitos en la relación entre los actores principales en torno a la inversión extranjera, Estados y empresas transnacionales.

Adicionalmente, en los últimos años el régimen bajo análisis ha sido centro de fuertes críticas, a saber: inexistencia de una jurisprudencia consistente; ausencia de una instancia de apelación; procesos arbitrales como órganos de control externo de la actividad o inactividad estatal, incluso en materias de interés público que involucran la protección de los derechos humanos o áreas sensibles (energía, aguas y saneamiento, salud, medioambiente, derechos de los pueblos indígenas, etc.); demandas o amenazas de demandas que derivan en un congelamiento o parálisis normativa en temas de interés público; su incidencia sobre el espacio de política pública (policy space) y por ende el derecho de regular de los Estados, entre otras. Estas críticas tienen como punto de partida la percepción de un desbalance de poder a favor de los inversores y en detrimento de los poderes estatales, que se manifiesta en las disposiciones incluidas en los TBI y otros instrumentos jurídicos celebrados por los Estados.

Dichas críticas derivan en cambios en el discurso de un número inicialmente limitado de Estados y se cristalizan con los retiros del CIADI de Bolivia (2007), Ecuador (2009) y Venezuela (2012), así como una serie de propuestas reformistas y/o alternativas en torno al arbitraje de inversiones desde diversas partes del globo. Más recientemente, se agrega el pronunciamiento del Tribunal de Justicia de la Unión Europea (TJUE) respecto a la incompatibilidad de los arbitrajes inversor-Estado con el Derecho comunitario, cuando estos involucran inversores y Estados de la Unión (caso Achmea), el comunicado de la Comisión Europea respecto al tema (COM(2018) 547) y la declaración de 22 de los miembros de la Unión Europea (UE) (15 de enero de 2019) manifestando que se comprometen a terminar todos los TBI intra-UE hecho efectivo el 24 de octubre de 2019 mediante un acuerdo plurilateral.

En suma, la dinámica de la relación Estado-empresas transnacionales ${ }^{4}$, en el marco del régimen de solución de controversias inversor-Estado (variable a explicar), se explica en

\footnotetext{
${ }^{3}$ Datos actualizados al 31 de diciembre de 2018 y recuperados el 13 de marzo de 2019.

${ }^{4} \mathrm{Si}$ bien se trata de una relación de poder entre dos actores de las relaciones internacionales, y el poder en un aspecto se aborda transversalmente en diferentes capítulos, este trabajo no se centra exclusivamente en el estudio de la relación de poder per se sino como parte de la ecuación del régimen de solución de controversias inversor-Estado.
} 
base a tres elementos fundamentales: 1) las alternativas al régimen de solución de controversias inversor-Estado en materia de tratados; 2) los casos concretos de controversias que involucran temas de derechos humanos; 3) la evolución o transición hacia un nuevo concepto de soberanía estatal basado en la defensa del espacio de política pública de los Estados (variables explicativas).

\section{Preguntas de investigación}

En vista del problema de investigación planteado en el apartado anterior, esta tesis busca contestar las siguientes preguntas de investigación:

1. ¿Cuál es el fundamento de las alternativas que se plantearon frente al régimen de solución de controversias inversor-Estado (período 2007-presente)? ¿Qué papel jugaron los actores involucrados?

2. ¿Cuál es el impacto de la regulación estatal sobre temas vinculados a derechos humanos en casos concretos de controversias inversor-Estado que involucren a Estados de Sudamérica y la UE?

3. ¿Ha evolucionado el concepto de soberanía hacia una nueva definición, que parte de supuestos diferentes a los que propone Krasner, explicativa de los cambios en el régimen de solución de controversias inversor-Estado? De ser así, ¿qué características tiene y en qué se fundamenta?

\section{Objetivos}

El objetivo general de este trabajo de investigación consiste en analizar la dinámica de la relación entre los principales actores vinculados a la inversión extranjera, Estados y empresas transnacionales, en el marco del régimen de solución de controversias inversor-Estado. Desprendiéndose del objetivo general y en consonancia con las preguntas de investigación, se delimitan los siguientes objetivos específicos:

1. Examinar las alternativas que se plantearon frente al régimen de solución de controversias inversor-Estado (período 2007- presente), su fundamento y el rol de los actores involucrados.

2. Determinar cuál es el impacto de la regulación estatal sobre temas vinculados a derechos humanos en casos concretos de controversias inversor-Estado que involucren a Estados de Sudamérica y la UE. 
3. Valorar si el concepto de soberanía ha evolucionado hacia una nueva definición, que parte de supuestos diferentes a los que propone Krasner, explicativa de los cambios en el régimen de solución de controversias inversor-Estado, y en caso afirmativo identificar sus características y su fundamento.

Cabe destacar que dado el dinamismo de la relación Estados-empresas transnacionales a lo largo del tiempo, el recorte temporal propuesto en los objetivos de esta investigación responde a que el año 2007 es un punto de quiebre en el régimen internacional de solución de controversias inversor-Estado, ya que el 2 de mayo de 2007 Bolivia se convierte en el primer Estado en el mundo en notificar la denuncia al Convenio de Washington sobre Arreglo de Diferencias relativas a Inversiones entre Estados y Nacionales de Otros Estados de 1965 (Convenio de Washington) y por ende abandonar el $\mathrm{CIADI}^{5}$. El inicio del recorte temporal también tiene implicancias sistémicas, ya que coincide con la antesala de la crisis financiera en los países desarrollados en el año 2008. Esta instancia abre una nueva etapa en que se cuestiona el modelo de gobernanza neoliberal que, estructurado desde la década del noventa, dio cabida a la fase de construcción y auge del régimen de protección de inversiones ${ }^{6}$.

El escenario internacional de la globalización económica en el que irrumpe el crack de 2008 (ruptura de la burbuja inmobiliaria en Estados Unidos y su expansión al sistema financiero internacional) se estructura en torno al debilitamiento del Estado frente al fortalecimiento de los actores no estatales; la dispersión o descentralización del poder; las nuevas dinámicas de dependencia, desigualdad, dominación y exclusión (del Arenal, 2009). Asimismo, esta etapa se caracteriza por dos lógicas que tienen un impacto directo en el régimen bajo análisis: la desregulación del mercado y privatización de la economía, así como el desarrollo de zonas del mundo segregadas únicamente incluidas bajo la lógica del extractivismo (Sassen, 2011:21).

\footnotetext{
${ }^{5}$ Conforme al artículo 71 del mencionado tratado, la denuncia se hace efectiva seis meses después de su notificación, esto es, el 3 de noviembre de 2007.

${ }^{6}$ Sornarajah (2015) plantea que existen cuatro fases en la evolución del régimen, en cada una identifica fuerzas en pugna que forman, universalizan, construyen o destruyen el régimen internacional de protección de inversiones. De esta forma, se identifican: 1) la fase formativa caracterizada por la puja entre la protección diplomática sin restricciones (propulsada especialmente desde Estados Unidos) y la doctrina Calvo (América Latina); 2) la fase de universalización de los conflictos cuyo centro es la colisión entre la fórmula Hull relativa a la expropiación y debida compensación (Estados Unidos y aliados) y la universalización de la doctrina Calvo junto a la defensa de la soberanía permanente sobre los recursos naturales; 3) la fase neoliberal que tiene como foco al consenso de Washington y la construcción del régimen internacional de protección de inversiones enmarcado en un red de más de $3000 \mathrm{TBI}$; 4) la fase actual es la que presenta la lucha entre la continuación de la fase neoliberal y la resistencia al neoliberalismo a fin que el régimen no proteja exclusivamente a la inversión extranjera. Esta evolución es desarrollada en extenso en el punto 6.2 en relación a la introducción de la idea de erosión del espacio de política pública que realiza la UNCTAD (2003).
} 
En consecuencia, la crisis se presenta como resultado de al menos dos desequilibrios en el sistema internacional: desequilibrio entre Estados que acumulan ahorro y Estados que gastan por encima de su presupuesto, y desequilibrio entre el Estado y el mercado producto de la desregulación de la economía y las finanzas (Sanahuja, 2009: 57). Su irrupción, su rápida expansión a nivel global e incluso su impacto tanto a Estados desarrollados, emergentes y en desarrollo, en definitiva pusieron de manifiesto la inexistencia de normas internacionales que sujeten la conducta de los actores no estatales o institucionales multilaterales que fueran capaces de dar respuesta a las situaciones de quiebre en el sistema internacional en términos de relación Estadomercado7. Políticamente se reclamó el "retorno del Estado" (Sanahuja, 2009: 58), idea antitética a la "retirada del Estado" que Strange (2001) señalaba como característica del modelo que precisamente se comienza a quebrar.

A la luz de lo anterior, el análisis de este trabajo se extiende hasta el presente (2019) de modo de incorporar una mirada crítica a los hechos que sucedieron a posteriori del retiro de Bolivia del CIADI y la crisis del 2008, puntualmente en el régimen de solución de controversias inversor-Estado. En este sentido se examinan otras denuncias al Convenio de Washington (por ejemplo Ecuador y Venezuela), y tratados que proponen alternativas como ser las excepciones sectoriales (por ejemplo las medidas de control del consumo de tabaco en el CPTPP), o casos concretos de controversias pendientes o finalizadas a 2019 (como ser las controversias Philip Morris contra Uruguay, Eco Oro contra Colombia, Masdar contra España, entre otras).

Desde un punto de vista geográfico, se opta por un recorte centrado en los Estados de Sudamérica y la UE, seleccionándose casos concretos de análisis ya sea por Estado u organización regional, teniendo en cuenta las particularidades distintivas que cada uno de estos presente. No obstante, se aportan elementos puntuales de la experiencia de Estados de otras regiones, como por ejemplo Sudáfrica y El Salvador que estuvieron involucrados en disputas emblemáticas: casos Piero Foresti (caso CIADI número ARB(AF)/07/1) y Pac Rim (caso CIADI número ARB/09/12) respectivamente, o el nuevo modelo de TBI de India (2016) que aporta elementos innovadores respecto al agotamiento de la jurisdicción doméstica.

\footnotetext{
${ }^{7}$ Jomo y Rodríguez (2011: 114) afirman que el multilateralismo ha sido amenazado por las decisiones impuestas a la comunidad internacional por un grupo de Estados poderosos. Las alternativas al G7 y/o G20 fortalecerían un multilateralismo inclusivo, cuya ausencia quedó demostrada con la incapacidad de las instituciones multilaterales de resolver la crisis de 2008.
} 


\section{Hipótesis}

Cerrando el triángulo que tiene como dos primeros vértices las preguntas de investigación y los objetivos, en este trabajo se parte de las hipótesis enunciadas a continuación, como conjeturas que se pretende corroborar a lo largo de la investigación.

1. Las alternativas que se presentaron al régimen de solución de controversias inversor- Estado son la terminación de tratados bilaterales de inversión, el retiro del CIADI y la celebración de nuevos tratados balanceados (exclusión total o sectorial de la solución de controversias inversor-Estado), y están motivadas, principalmente, en cambios en normas fundamentales a nivel doméstico.

2. La extensión de la regulación estatal lleva a las empresas transnacionales a iniciar controversias inversor-Estado que cuestionan el avance de los Estados en medidas de mayor protección de derechos humanos.

3. El concepto de soberanía estatal ha evolucionado hacia una nueva definición que se construye desde la defensa del espacio de política pública, generando cambios en las instituciones internacionales: régimen de solución de controversias inversor- Estado (proceso desde el interior al exterior del Estado).

\section{Marco teórico}

Una teoría está formada por un conjunto de proposiciones relacionadas deductivamente en torno a conceptos interconectados, de forma racional y abstracta, necesariamente debe tener un anclaje en la realidad (Bericat, 1998: 92-93). Teniendo en mente la "fecunda imbricación" entre teoría y aconteceres reales que propone el autor, el marco teórico de esta investigación se construye partiendo de un paradigma prioritariamente interpretativo. En este sentido, no se abandonan algunos postulados del paradigma neopositivista, como ser el análisis por variables o el uso de técnicas no obstructivas de recolección de datos combinadas con la realización de entrevistas en profundidad (Corbetta, 2007), como se indicará más adelante en este capítulo.

Para este trabajo se utilizará la teoría de los regímenes internacionales (teoría general en términos de Sautú y otros (2005)) a los efectos de analizar el funcionamiento del sistema internacional en lo que concierne a las relaciones entre Estados y empresas transnacionales. Dicha elección tiene como fundamento la consideración del régimen de solución de controversias inversor-Estado como un régimen internacional integrante de un régimen mayor: el régimen de protección internacional de inversiones. En este 
sentido, un régimen internacional es "un conjunto implícito o explícito de principios, normas, reglas y procedimientos de toma de decisión alrededor de los cuales las expectativas de los distintos actores convergen en un área determinada de las relaciones internacionales" (Krasner: 1983, 2).

A nivel de teorías sustantivas, en palabras de Sautú y otros (2005), en primer lugar se sigue el análisis propuesto por Consani $(2008,2016)$ respecto a los modelos en pugna en las relaciones internacionales. En el mencionado régimen internacional el modelo institucional de las relaciones internacionales se presenta de manera preponderante, dado su alto grado de institucionalización y subordinación del poder al Derecho ${ }^{8}$. Sin embargo, el modelo relacional continúa ejerciendo tensiones, que no son más que manifestaciones de la soberanía de los Estados. De hecho, la elección de ingresar, permanecer o abandonar un régimen está directamente vinculada al atributo de la soberanía. El análisis de este atributo de los Estados independientes se realiza mediante los aportes de Krasner (2001) en "Soberanía. Hipocresía organizada", de forma de ampliar el abordaje jurídico-normativo clásico del tema e incorporar como teoría sustantiva las diferentes proyecciones que el concepto ha tenido a lo largo del tiempo: soberanía de interdependencia, interna, westfaliana y legal internacional.

Al mismo nivel de teoría sustantiva, los aportes de Krasner respecto a la soberanía dialogarán con las teorías de la autonomía, como ser Puig (1980, 1986), Jaguaribe (1979), Russell y Tokatlian (2001). La autonomía, siguiendo a Puig (1980, 148) es "la máxima capacidad de decisión propia que se puede tener, tomando en cuenta los condicionamientos del mundo real". Por tanto, es el efectivo goce de la autonomía, y no necesariamente el atributo de la soberanía, lo que le permite al Estado articular y lograr objetivos de manera independiente de las demandas o intereses de entidades internas o externas (Russell y Tokatlian, 2001). Este análisis se complementa con el planteo de Rapoport y Miguez (2014) respecto a la pérdida de poder de decisión de los Estados durante el período de auge del consenso de Washington y la necesidad de recuperar el control sobre los movimientos de capital y las inversiones, entre otros puntos, para fortalecer para una mejor relación de los Estados de la región con el resto del mundo. La capacidad de acción de los Estados también puede verse menguada frente a las presiones de empresas transnacionales, por intermedio de demandas o amenazas de

\footnotetext{
${ }^{8}$ Consani plantea un abordaje dialéctico abierto entre el poder y el Derecho en el cual se enmarcan ambos modelos, dado que los modelos son ideales y no se presentan de manera pura en las relaciones internacionales.
} 
demandas y la consecuente parálisis o congelamiento normativo. La construcción del marco teórico se completa con el análisis de la dimensión del poder en la relación entre Estados y empresas transnacionales y su afectación a la soberanía estatal, tomando los aportes teóricos sustantivos de Strange (2001), Arato (2015), entre otros.

\section{Nivel de análisis}

Como indica Sánchez (2013: 18), es la perspectiva intelectual del investigador la que determina el nivel de análisis internacional que debe emplearse, y por ende, los métodos y teorías que se seleccionen. El nivel de análisis puede ser micro o macro, en atención a los fenómenos examinados, si estos son relevantes para el sistema internacional en su conjunto, el nivel de análisis será macro. Si los fenómenos estudiados son relevantes para un actor o pequeño grupo de actores en particular, el nivel de análisis será micro (Sánchez: 2013, 19).

Si bien la identificación del nivel de análisis internacional puede hacerse exclusivamente en términos de las categorías macro y micro, esta categorización puede complementarse por la propuesta de Kegley y Blanton (2012: 14-15) en torno a tres niveles de análisis: el individual, el estatal y el global. El nivel individual consiste en las características personales de los seres humanos tomadores de decisiones que obligan a los Estados y actores no estatales, así como de los ciudadanos cuyo comportamiento tiene consecuencias políticas importantes. El nivel estatal o doméstico refiere a la toma de decisiones de las entidades gubernamentales que tiene efecto en la policía exterior, sumado a los atributos internos de los propios Estados. Finalmente, el nivel de análisis global se centra en la interacción de los actores estatales y no estatales globalmente, y cómo estos son capaces de dar forma al sistema internacional mediante su comportamiento.

En el caso de esta investigación, se analiza la relación entre Estados y empresas transnacionales y cómo esta incide en tres aspectos: las alternativas al régimen internacional de solución de controversias inversor-Estado (2007-presente); los casos concretos de controversias vinculadas a temas de derechos humanos; y la concepción de la soberanía estatal para las relaciones internacionales a partir de la tipología propuesta por Krasner. En vista de lo anterior, el nivel de análisis empleado es macro o global, puesto que los fenómenos examinados son relevantes para el sistema internacional. 
Como en la mayoría de los temas de las relaciones internacionales, el tema elegido puede incidir en la toma de decisiones de un actor en particular (nivel micro), ya sean Estados, empresas transnacionales o incluso organizaciones de la sociedad civil. En el caso puntual de los Estados es posible que el tema permee en la construcción jurídicoinstitucional doméstica, como por ejemplo las reformas constitucionales que establecieron limitaciones a la jurisdicción internacional en materia de inversiones, como en los casos de Bolivia y Ecuador. No obstante, el abordaje teórico desde el que se parte brinda la óptica necesaria para el estudio del tema desde una perspectiva macro y por ende sistémica, dándole mayor relevancia al estudio de la incidencia a nivel del contexto global con independencia de la situación de un Estado en particular.

\section{Estrategia metodológica}

El diseño de investigación es un protocolo de todas las tareas que demanda la ejecución de la investigación, por tanto comprende un conjunto de decisiones interconectadas relativas al marco teórico, los objetivos y la metodología (Sautú y otros, 2005). Habiendo hecho referencia a los dos primeros, en este apartado se analiza la estrategia metodológica de esta investigación. En primer lugar, conforme a sus objetivos esta investigación es explicativa, en tanto busca establecer por qué ocurre un fenómeno internacional en concreto, en qué condiciones y por qué se relacionan diferentes variables (Hernández Sampieri y otros, 2010: 84)ํ. En relación a la dimensión temporal, se trata de un estudio longitudinal, ya que el fenómeno es observado a lo largo de un período de tiempo extenso (2007-presente) a los efectos de comprender su propia dinámica.

La unidad de análisis es la relación Estado-empresa transnacional en tanto actores de las relaciones internacionales, y en términos del Derecho Internacional Público, la relación existente entre el Estado como sujeto originario, pleno e indiscutido y la empresa transnacional como un sujeto nuevo, limitado y discutido. Si bien se trata de una relación de poder, en este trabajo el foco está puesto en la dinámica de la relación en el marco del régimen de solución de controversias inversor-Estado y no en el análisis del poder per se.

\footnotetext{
${ }^{9}$ Los estudios explicativos no abandonan los demás tipos de estudios, puesto que al tener mayor grado de estructuración, también implica una descripción de las características de los fenómenos y/o variables que se examinan y su correlación.
} 
En vista de lo anterior, las unidades de observación son tres: 1) la red de tratados que sostiene el régimen de solución de controversias inversor-Estado, al prever el arbitraje ad hoc como mecanismo para resolver las disputas que puedan surgir; 2) los casos concretos de controversias que son dirimidas por los tribunales arbitrales ad hoc, tanto las terminadas como las pendientes; 3) las alternativas al régimen de solución de controversias inversor-Estado, tanto en términos de creación de una nueva institucionalidad, tratados que plantean exclusiones sectoriales o totales del arbitraje inversor-Estado, o disidencia (retiro del régimen al que se pertenecía). El universo de análisis se verá acotado por el recorte temporal (2007-presente) y geográfico (Estados de Sudamérica y la UE), sin perjuicio de aportar elementos contrafácticos para analizar la evolución de los conceptos involucrados o brindar perspectivas desde otras regiones del globo, con el fin de enriquecer el análisis y no perder la visión sistémica que esta temática requiere.

En relación a las fuentes, este trabajo de investigación no tiene como base exclusivamente el análisis e incorporación de citas de obras de doctrina, sino que adicionalmente se examinan fuentes primarias y secundarias. Ejemplo de fuentes primarias son los textos normativos, en particular los TBI, tratados comerciales que incluyan capítulos de inversiones, y otros acuerdos vinculados disponibles en los repositorios online del Investment Policy Hub de la UNCTAD, Ministerios de Relaciones Exteriores de los Estados involucrados, Sistema Interamericano de Comercio Exterior, y el sitio web Investment Treaty Arbitration; los comunicados u otros documentos emitidos por los Ministerios de Relaciones Exteriores y la Unión Europea en relación a los temas bajo análisis; y los documentos públicos en el marco de procesos de solución de controversias inversor-Estado (demandas, contestaciones, alegatos, decisiones intermedias, órdenes de procedimiento y laudos) disponibles en repositorios online (CIADI, Investment Policy Hub de la UNCTAD, Corte Permanente de Arbitraje (CPA), Investment Treaty Arbitration). Cabe destacar que el análisis del número de controversias conocida tendrá como fecha de cierre el 31 de diciembre de 2018, al ser el último año del cual se encuentran registros completos.

En relación a las fuentes secundarias se destacan los reportes de organizaciones internacionales (como ser la UNCTAD, la Organización de Naciones Unidas (ONU), el CIADI, la Organización Mundial del Comercio (OMC)) y los artículos de prensa que den cuenta de las posiciones y propuestas de los principales actores involucrados. 
En el último punto cabe señalar la limitación que implica que las partes en un proceso arbitral tengan la potestad de no dar publicidad a los documentos de manera completa o parcial. Asimismo, en los procesos arbitrales no institucionalizados no suele haber un repositorio en línea que permita el acceso a la documentación presentada por las partes o emitida por el tribunal en el marco del arbitraje. Teniendo en mente como principio rector el acceso a la información, se trabajó descartando aquellos casos concretos de controversias cuyos documentos resultaron inaccesibles y por tanto no se disponía de información relevante o suficiente. De tratarse de controversias fundamentales, ilustrativas o complementarias para el análisis, se intentó cubrir la carencia mediante la realización de entrevistas en profundidad a informantes calificados a fin de recabar su percepción sobre los fenómenos.

Se opta por una estrategia de integración de los métodos cualitativo y cuantitativo, como propone Bericat (1998: 38-39), en concreto la combinación de un método subsidiario (cuantitativo) en el método principal (cualitativo). El fin de la combinación es fortalecer la validez del último mediante la compensación de sus debilidades con las fortalezas del primero. Consecuentemente, las técnicas empleadas son de dos tipos: técnicas no obstructivas de recolección de información, complementadas por entrevistas en profundidad a informantes calificados. En las técnicas no obstructivas, el investigador no está involucrado directamente en la obtención de la información de los sujetos, por tanto son técnicas no reactivas ya que se presume que evitan cualquier distorsión a causa de la mera presencia del investigador (Webb y otros, 1981; Lee, 2000: 1).

En este sentido, y gracias a la adaptabilidad de las técnicas no obstructivas, en esta investigación se emplea el análisis documental de textos normativos, reportes de organizaciones internacionales, comunicados u otros documentos de los Ministerios de Relaciones Exteriores, jurisprudencia, artículos de prensa y doctrina. Adicionalmente, con el fin de evitar, o intentar evitar, que el empleo de una sola técnica de investigación condicione los resultados, tornándolos artificiales y parciales, las técnicas anteriores se complementan con la realización de entrevistas semiestructuradas a informantes calificados del ámbito gubernamental, la sociedad civil y la academia. A través de las entrevistas se busca recolectar información sobre la visión de los entrevistados respecto a los temas bajo análisis y otros aspectos del objeto de estudio que no son observables en forma directa, reforzando la ventaja del empleo de múltiples técnicas de investigación. Cabe destacar que se incluye breve $\mathrm{CV}$ de cada entrevistado en el 
apéndice I y que todos los entrevistados citados dieron su consentimiento para ser citados por su nombre.

\section{Estructura de la tesis}

Este trabajo comienza con el desarrollo del marco teórico y a continuación se estructura en tres círculos, uno por cada objetivo específico. El primer círculo, de carácter explicativo, parte de la identificación y descripción de las alternativas al régimen de solución de controversias inversor-Estado actual, planteadas por los Estados entre 2007 $\mathrm{y}$ el presente, su fundamento y el rol de los actores involucrados, especialmente los actores estatales incluidos dentro del marco geográfico de la investigación. Puntualmente se analiza: el abandono del régimen internacional por parte de Bolivia, Ecuador (con cambios en 2018), Venezuela y Sudáfrica en menor medida (capítulo 2); 2) las propuestas de tratados que buscan reequilibrar el sistema: los acuerdos de cooperación y facilitación de inversiones (ACFI) de Brasil, la excepción de las medidas de control de tabaco en el CPTPP y el agotamiento de la jurisdicción doméstica en el modelo de TBI de India (2016) (capítulo 3).

En el segundo círculo, se procede a identificar y explicar cómo el ejercicio de la regulación estatal en temas vinculados a derechos humanos impacta en casos concretos de controversias inversor-Estado que involucran a Estados de Sudamérica y la UE. El análisis se divide en dos partes: 1) las disputas relativas al derecho a vivir en un medioambiente sano (capítulo 4); 2) otros derechos humanos: salud pública, acceso al agua y derechos de las comunidades indígenas (capítulo 5). Este círculo tiene carácter explicativo, ya que pretende comprender las interacciones entre el régimen de protección de derechos humanos y el régimen de protección de inversiones, en el marco de la fragmentación del Derecho Internacional.

El tercer círculo busca valorar si existe una transición hacia un concepto de soberanía regulatoria, que parte de supuestos diferentes a los que propone Krasner (cuádruple proyección: soberanía westfaliana, soberanía legal internacional, soberanía interna y soberanía de interdependencia). Dado que su base es la defensa del espacio de política pública, el capítulo 6 se dedica a su análisis y contextualización del reconocimiento de su erosión o condicionamiento por los mecanismos de solución de controversias inversor-Estado. Se incluye el estudio particular de la situación de la UE que presenta la dualidad de considerar contrarios al Derecho de la Unión los arbitrajes intra-UE, no así 
los mecanismos que involucran a terceros Estados. Por ejemplo el sistema de tribunales de inversiones en el Acuerdo Económico y Comercial Global entre la UE y Canadá (CETA por su sigla en inglés). El capítulo 7 se enfoca en el concepto de soberanía regulatoria, su contextualización en la crisis de la globalización y el multilateralismo, los motivos y las manifestaciones visualizadas en las conductas de los Estados bajo análisis.

El trabajo cierra con un capítulo destinado a las conclusiones finales, incluyendo las interacciones entre los tres círculos que conforman la investigación. Se acompañan tres apéndices en los que se encuentran: los CV de los entrevistados (apéndice I); los flujogramas de los procedimientos arbitrales más acudidos por los inversores (apéndice II); el listado de casos jurisprudenciales citados (apéndice III). 


\section{Capítulo 1: Marco teórico}

\subsection{Aspectos preliminares}

El marco teórico se compone de un "corpus de conceptos de diferentes niveles de abstracción articulados entre sí que orientan la forma de aprehender la realidad" (Sautú y otros, 2005: 34). Por tanto, en un mayor nivel de abstracción, en primer lugar incluye la teoría general formada por supuestos generales que dan una visión sobre los procesos y fenómenos de la sociedad que se pretende analizar, el sistema internacional en este caso. La teoría general se desagrega en teorías sustantivas que explican diferentes aspectos de la realidad bajo examen.

Partiendo de la idea que el régimen de solución de controversias inversor-Estado puede conceptualizarse como un régimen internacional, esta investigación toma como teoría general a la teoría de los regímenes internacionales, basándose en los aportes de Ruggie (1975), Krasner (1983), Keohane $(1982,1988)$ entre otros autores. La teoría general se complementa con tres teorías sustantivas que permiten aportar ideas y conceptos específicos y que expliquen las diferentes aristas del problema de investigación. En primer lugar se incorpora el análisis de los dos modelos que propone Consani (2008): el modelo institucional y el modelo relacional. En segundo lugar, la posición del Estado se analiza desde el enfoque de las cuatro proyecciones de la soberanía estatal que propone Krasner (2001), teoría que dialoga con los aportes de los autores autonomistas latinoamericanos: Puig (1980, 1986), Jaguaribe (1979), Russell y Tokatlian (2001), Rapoport y Miguez (2014), entre otros.

También a nivel de teoría sustantiva, el marco teórico se completa con el abordaje que realiza Strange (2001) respecto al desbalance de poder entre Estados y empresas transnacionales, complementado por los análisis de Sassen $(2007,2010)$ y Arato (2015), así como el informe 2015 del ex Experto Independiente sobre la promoción de un orden internacional democrático y equitativo de la ONU (2012-2018), Alfred-Maurice de Zayas. Para una mejor comprensión del poder ganado por las empresas transnacionales frente a los Estados, sujetos originarios del Derecho Internacional, el capítulo cierra con el estudio de la subjetividad jurídica internacional de las empresas transnacionales. 


\subsection{Regímenes internacionales}

\subsubsection{Teoría de los regímenes internacionales: conceptualización}

Desde la introducción del término regímenes internacionales por Ruggie (1975) y su profundización en el debate académico desde la óptica del institucionalismo neoliberal, realismo y cognitivismo de las relacionales internacionales (Hasenclever y otros, 1999) ${ }^{10}$, estos han servido para explicar diferentes segmentos del sistema internacional en torno a los cuales se generan acuerdos formales e informales entre diferentes actores. Este abordaje, analizado a continuación, se tomará como teoría general para la presente investigación.

En este sentido, Ruggie afirma que un regimen internacional es "a set of mutual expectations, rules and regulations, plans, organizational energies and financial commitments, which have been accepted by a group of states"11 (Ruggie, 1975: 570).

De este concepto puede destacarse como elemento central la existencia de expectativas recíprocas, reglas y compromisos aceptados por un grupo particular de actores, los Estados. Krasner (1983) profundiza sobre el tema proponiendo una definición más amplia, que puede abarcar otros actores, entendido que se trata de "un conjunto implícito o explícito de principios, normas, reglas y procedimientos de toma de decisión alrededor de los cuales las expectativas de los distintos actores convergen en un área determinada de las relaciones internacionales" (Krasner, 1983: 186).

Dichos principios, normas y reglas establecen acciones, prohibiciones y obligaciones, formando la estructura fundamental en el marco de la cual se dan la interacción entre actores y condiciona la toma de decisiones, individuales y conjuntas, en función de la conducta esperada de los demás miembros. Los principios son creencias que explican el funcionamiento del sistema, las normas son reglas generales de comportamiento que generan derechos y obligaciones, las reglas son prescripciones en torno a áreas determinadas, y los procesos de toma de decisión refieren a prácticas generalmente seguidas para la negociación y adopción de resoluciones colectivas (Ruggie, 2009: 188;

\footnotetext{
${ }^{10}$ Excede el objeto de este trabajo el estudio particular de los regímenes a la luz de cada una de las mencionadas escuelas de pensamiento. Para un análisis de este tema puede verse Hasenclever y otros (1999) y Bizzozero (2011: 151-153) entre otros.

11 “Un conjunto de expectativas reciprocas, reglas y regulaciones, planes, energías organizacionales y compromisos financieros, los cuales han sido aceptados por un grupo de Estado." (Traducción propia)
} 
Bizzozero, 2011: 153) ${ }^{12}$. Cada uno de estos elementos deriva en el siguiente, traduciéndose en un menor nivel de abstracción.

Los regímenes no son meros arreglos temporarios, ni representan fines en sí mismos, por tanto su existencia afecta el comportamiento de sus miembros (Ferro: 1999, 9). Es por ello que los Estados que forman parte de uno o más regímenes internacionales, no lo hacen porque estos sean buenos per se, sino por elección propia. Los Estados como actores internacionales, forman parte de un régimen siempre que perciban una reciprocidad de intereses o relación ganar-ganar. En otros términos, los beneficios que se reciban una vez que el Estado se haya incorporado al régimen deben ser mayores, o al menos iguales, a que los que percibían antes de su incorporación, de lo contrario no formarían parte del mismo. De hecho, es factible que un régimen sea abandonado cuando los Estados entiendan que los costos de permanecer en él son mayores a las alternativas externas. Aun así, la salida del régimen es una opción que siempre está presente, más allá de la existencia de alternativas externas o costos internos a enfrentar (Keohane, 1988: 137, 1982: 331). En este sentido, en un régimen internacional o en el sistema internacional en general, los actores pueden comportarse como hacedores, quebradores o tomadores. (Krasner, 2009: 6) ${ }^{13}$.

En el caso de los actores más débiles, entre los beneficios de pertenecer a un régimen internacional se destacan especialmente la percepción de mayor nivel de protección frente a la posible arbitrariedad de los actores más poderosos gracias a la existencia de reglas e instituciones, la facilitación de acuerdos entre los actores producto del efecto derrame, la certeza en cuanto al cumplimiento de reglas de juego, o las acciones frente al incumplimiento. Dado que los Estados poderosos pueden elegir los instrumentos que se adapten mejor a sus intereses (Krasner, 2001: 17), tanto de manera arbitraria como influenciando sobre los otros actores (poder funcional) o en las estructuras en las que se asienta el régimen (poder estructural) ${ }^{14}$, los beneficios que estos perciben en los

\footnotetext{
${ }^{12}$ Estos elementos no pueden ser consecuencia directa de los intereses exclusivos de un actor en particular, sino que debe existir una noción de obligatoriedad de las normas, más allá del interés particular de cada actor en su cumplimiento. No solo se trata de reglas formales de carácter legal y otras normas sino también reglas formales e informales de carácter moral (Hurrell, 1992: 649, 656, 662).

${ }^{13}$ El autor realiza la afirmación refiriendo a los Estados, pero se interpreta que la afirmación puede extenderse a cualquier actor del sistema internacional.

${ }^{14}$ Krasner (2011: 21305) explica que aun en el caso de los Estados más poderosos, estos no pueden cambiar las reglas a su antojo y el costo de cambiar las reglas siempre es alto. Si bien esto es cierto, también lo es que los Estados poderosos tienen capacidad de influenciar en las estructuras de un régimen internacional conforme a sus intereses, no así los Estados débiles.
} 
regímenes internacionales responden a mantener un status quo beneficioso y continuar teniendo injerencia en la toma de decisiones (Hurrell, 92: 655).

En general, los regímenes maximizan las ganancias de las partes y desarrollan sistemas de reciprocidad, introduciendo la creencia que si en determinada situación un integrante colabora o evita dañar a los demás, los últimos se comportarán de la misma manera en el futuro (Keohane, 1982: 335, 342). Como explica Peña, "el predominio de reglas de juego de calidad, libremente consentidas en la relación entre asociados de desigual poder relativo, constituye una cierta garantía de la preservación de la reciprocidad de intereses nacionales que es lo que permite sustentar el vínculo asociativo a través del tiempo" (Peña, 2003: 3) ${ }^{15}$. Por tanto, los costos de incumplimiento son mayores a las ganancias que proporciona la existencia de un orden regulador de la conducta de los miembros.

\subsubsection{Tipos de regímenes internacionales}

La doctrina clasifica a los regímenes conforme a las características de las relaciones entre los miembros, los fines perseguidos, las particularidades de los acuerdos resultantes, y las posibilidades de ingreso de nuevos integrantes. Dougherty y Pfaltzgraff (1993: 180-181) distinguen entre regímenes formales e informales. Los primeros, en ocasiones surgidos en marco de una organización internacional, cuentan con estructuras burocráticas y órganos de gobierno, y los segundos están fundados en el consenso entre los miembros generando acuerdos ad hoc. Asimismo, existen regímenes basados en una comunidad de intereses, a los cuales los actores ingresan voluntariamente en pos de metas comunes y mantienen relaciones de colaboración, y regímenes basados en el rechazo común a un tema, en los cuales los actores coordinan sus políticas sin llegar a darse relaciones de colaboración. Como última clasificación, los mencionados autores proponen una distinción entre regímenes de colaboración o cooperación, y aquellos fundados en la voluntad impuesta de una potencia dominante, como eran los regímenes coloniales o imperialistas.

Dicha categorización tiene puntos de contacto con la propuesta por Peña (2004), quien distingue entre regímenes rule-oriented y power-oriented, caracterizándose los primeros por relaciones orientadas por reglas de juego efectivas y legítimas (principio de

\footnotetext{
${ }^{15} \mathrm{Si}$ bien en este punto Peña se refiere a los regímenes regionales en torno a los procesos de integración, es posible aplicar estos conceptos al estudio de los regímenes internacionales en general.
} 
efectividad $^{16}$ ) y los segundos por relaciones orientadas en función del poder del más fuerte (Peña, 2004: 222). En consecuencia, en los regímenes rule-oriented, una conducta contraria o violatoria al régimen no solo afecta al Estado contra quien se dirige, sino que también a todos los miembros del sistema. La consecuente evaluación negativa de estos actores hace necesario que la controversia sea resuelta y por ende, se ponga en marcha de un mecanismo de solución de controversias jurisdiccional o diplomático, que permita la restitución del status quo.

Finalmente, Ferro (1999: 11-13) propone una triple categorización según la posibilidad de ingreso de nuevos integrantes al grupo. Así, existen regímenes restringidos, que admiten un número limitado de integrantes; regímenes condicionalmente abiertos, compuesto por aquellos Estados que sigan un interés común; y regímenes abiertos, que permiten el ingreso de un número ilimitado de integrantes.

\subsubsection{Régimen internacional de protección de inversiones y régimen internacional de solución de controversias inversor-Estado}

En el caso puntual del régimen internacional de protección de inversiones, es posible afirmar que las expectativas de los Estados integrantes convergen en torno al principio fundamental de la promoción y protección de inversiones. Esto es, los Estados emisores de inversión extranjera directa ven garantizadas las inversiones de los particulares de su nacionalidad y los Estados receptores cuentan con instrumentos que brindan certeza jurídica al inversor extranjero como forma de promocionar la recepción de capital extranjero. Conforme al Derecho internacional consuetudinario, los Estados tienen derecho a regular y excluir la inversión extranjera en su territorio, como expresión de su soberanía (Dolzer y Schreuer, 2008: 7), en consecuencia, también tienen capacidad de decisión de integrar el régimen (miembros), permanecer fuera al celebrar o no acuerdos internacionales en materia de inversión (externos) o abandonar el régimen (disidentes). Incluso puede optar por impulsar la construcción de regímenes alternativos (Bas Vilizzio, 2017). En el último quinquenio se ha constatado la presenta de un nuevo tipo de Estado que si bien no opta por abandonar el régimen, cambia su posición inicial de miembro y lo enfrenta, al menos parcialmente (confrontadores).

\footnotetext{
${ }^{16}$ El principio de efectividad implica que una norma penetra en la realidad siempre que se logren los resultados buscados con su creación, y no el mero cumplimiento de las mismas en la medida de lo posible. Reglas de juego no efectivas derivan en un proceso que pierde credibilidad tanto para los ciudadanos, las empresas, la sociedad civil y terceros Estados.
} 
Si bien el régimen surge como una creación europea-estadounidense, este se expandió de forma global y sus principios y reglas son aplicables a lo largo y ancho del mundo, salvo excepciones (Estados externos o disidentes). Del principio fundamental de promoción y protección de inversiones se desprenden otros derivados que regulan el comportamiento de los principales actores vinculados a la inversión extranjera, esto es, Estados e inversores. Dichos principios derivados son: 1) trato nacional; 2) trato justo y equitativo; 3) garantía y compensación por expropiación; 4) garantía de libre traspaso de fondos y transferencia de capitales y ganancias al exterior; 5) solución de controversias inversor-Estado mediante la prórroga de jurisdicción al arbitraje internacional ${ }^{17}$. El principio de solución de controversias inversor-Estado, dada su complejidad y características propias, se comporta como un régimen internacional en sí mismo. Se trata de un régimen de tipo: 1) formal, basado en la estructura institucional del organismo internacional y las disposiciones previstas en los TBI en relación a la materia; 2) condicional abierto, ya que los Estados interesados pueden solicitar su ingreso al CIADI, organización internacional que administra el mayor número de arbitrajes en la actualidad, e iniciar la práctica tendiente a la firma de TBI con prórroga de jurisdicción al arbitraje internacional; 3) rule-oriented, puesto que las relaciones entre los miembros son efectivas y legítimas; 4) de comunidad de intereses, en el entendido que los integrantes compartes intereses en común, más allá de diferencias de tipo económico, político y/o cultural.

El régimen se erige sobre el derecho de los inversores extranjeros de demandar a los Estados receptores de la inversión en caso que vean vulnerados sus derechos y amparados en un instrumento jurídico escrito que prevea una prórroga de jurisdicción a favor del arbitraje internacional. Dicha prórroga de jurisdicción puede estar prevista en un tratado bilateral de inversiones, un capítulo de inversiones de un tratado de libre comercio (bilateral o multilateral) o tratados multilaterales en los cuales el Estado huésped o receptor de la inversión y el Estado de nacionalidad del inversor sean parte,

\footnotetext{
${ }^{17}$ Estos principios derivados suelen formar parte de la estructura básica de los tratados bilaterales de inversiones o los capítulos de inversiones en tratados de libre comercio. En este sentido, las disposiciones de los mencionados instrumentos normativos regulan diversas áreas que pueden agruparse en: 1) Normas generales de trato de la inversión, como ser alcance y definición de inversión, trato nacional, cláusula de la nación más favorecida, trato justo y equitativo; 2) Protección de las inversiones, esto es garantías y compensaciones por expropiación, garantías de libre traspaso de fondos y transferencia de capitales y ganancias al exterior, prohibición o límites a los requisitos de desempeño; 3) Excepciones, modificaciones y terminación del tratado; 4) Solución de controversias tanto sean mecanismos de solución de controversias Estado-Estado e inversor-Estado (Salacuse: 2010: 127 - 128).
} 
así como también en leyes de inversiones del Estado receptor o contratos entre empresas extranjeras y Estados huéspedes.

Los textos constitutivos de las instituciones que administran arbitrajes a las que remiten los mencionados instrumentos jurídicos pueden establecer requisitos adicionales. Por ejemplo en el caso del CIADI, el artículo 25 del Convenio sobre Arreglo de Diferencias relativas a Inversiones entre Estados y Nacionales de Otros Estados de 1965 (Convenio de Washington) constitutivo del Centro establece que la institución tiene jurisdicción para entender en aquellas controversias inversor-Estado que sean de naturaliza jurídica, que tengan una relación directa con una inversión entre un Estado parte y un nacional de otro Estado parte de dicho tratado, y en las que exista una cláusula de prórroga de jurisdicción por escrito.

Siete reglas específicas derivan del principio anterior, estas son:

1) El inversor extranjero tiene locus standi y jus standi: Esta es una de las características más destacables del régimen. Es el particular quien cuenta con locus standi in judicio, esto es, los inversores extranjeros pueden demandar a los Estados en foros jurisdiccionales (capacidad procesal). De hecho, se ha dado un paso más al reconocerse su jus standi, esto es, la titularidad de la acción y el consecuente acceso directo a los tribunales internacionales. Por tanto, en este régimen no resulta de aplicación el instituto de la protección diplomática, según el cual es el Estado de la nacionalidad del particular afectado quien hace propio el reclamo frente al Estado incumplidor y no el particular (Torreja Mateu, 2012, 317; Burgos-De la Ossa y LozadaPimiento, 2009: 272).

2) Período de enfriamiento: La casi totalidad de los acuerdos internacionales establecen un período de enfriamiento, esto es, un período en el que las partes en el conflicto intentan resolver sus controversias de manera amigable. Este lapso de tiempo habitualmente se extiende por entre tres y seis meses desde que el inversor extranjero notifica la existencia del conflicto al Estado receptor de la inversión.

3) No obligatoriedad de agotamiento previo de la jurisdicción doméstica: El agotamiento de los recursos internos es una opción, no una obligación como proponía la doctrina Calvo ${ }^{18}$. No obstante, aún en aquellos instrumentos que se establecen la

18 Esta doctrina, elaborada en 1868 por el jurista argentino Carlos Calvo y recogida en varias constituciones latinoamericanas, se basa en los principios de igualdad soberana, no intervención y trato igualitario entre extranjeros y nacionales. Los Estados, como soberanos, tienen derecho determinar libremente sus políticas internas y externas, sin injerencia extranjera, y dado que los extranjeros tienen 
obligación de agotamiento de los recursos internos pueden presentar lo que Fach Gómez denomina una "versión suave" de la cláusula Calvo al permitir pasar al arbitraje internacional una vez sometida la controversia a la jurisdicción doméstica, se puede pasar al arbitraje por vencimiento de plazo de tiempo determinado (Fach Gómez, 2011: 196). No obstante, en aquellos tratados que prevén obligatoriamente el agotamiento previo de los recursos domésticos, por el juego de la cláusula de la nación más favorecida puede eludirse dicha obligación ${ }^{19}$.

4) Tribunales arbitrales ad hoc: Las disputas son sometidas a tribunales ad hoc, esto es, no permanentes, que se conforman para el caso concreto mediante ternas arbitrales o árbitro único elegidos de listas previamente registradas en una institución que administra arbitrajes. Este es el caso del CIADI, la CPA, la Cámara de Comercio Internacional (CCI), la Cámara de Comercio de Estocolmo, la Corte Internacional de Arbitraje de Londres, entre otros.

5) Inapelabilidad de los laudos: Los laudos arbitrales no son pasibles de apelación, y los recursos de anulación o revisión se prevén para casos específicos que no constituyen una segunda instancia de decisión. Por ejemplo en el Convenio de Washington se establece que el recurso de anulación a solicitud de una de la partes si el tribunal se constituyó incorrectamente, este se ha extralimitado manifiestamente en sus facultades, si hubo corrupción de parte de algún miembro, si se ha quebrantado gravemente una norma de procedimiento o el laudo no contiene expresamente los motivos en que se funda (artículo 52). El recurso de revisión, en cambio, puede solicitarse dentro de los 90 días de emisión del laudo en caso de descubrimiento de algún hecho que hubiera podido influir decisivamente y al momento de su emisión hubiera sido desconocido por el tribunal (artículo 51).

6) Cláusula de ultractividad: Los tratados de inversiones suelen incluir dentro de su articulado cláusulas que establecen que las demás disposiciones del tratado mantienen su vigencia durante un período determinado subsiguiente a su terminación, por lo general 5, 10, 15 o 20 años, y por tanto la posibilidad de poner en marcha un mecanismo de solución de controversias a pesar que el acuerdo que lo sustenta ya está terminado.

iguales derechos a los nacionales, estos deben agotar todos los recursos de la jurisdicción doméstica sin pedir la protección y/o intervención diplomática de su Estado de su nacionalidad (Tamburini, 2002: 82).

${ }^{19}$ Esta práctica se denomina treaty shopping o cherry picking, esto es seleccionar "el mejor" Derecho Interno o el tratado internacional conforme a los intereses de una de las partes. 
7) Cláusula de la nación más favorecida (CNMF): Se trata de una disposición que permite el acceso al mejor trato que un Estado decide ofrecer a los inversores en el marco de otro acuerdo. Como afirma Banifatemi, "a State is undeniably at liberty not to offer better treatment to other investors or not to enter into a most-favoured-nation clause. However, once it has freely embarked on both paths, it must abide by its obligations" (Banifatemi, 2009: 273) ${ }^{20}$. La cláusula es aplicable a cualquier disposición del acuerdo, incluso la no obligatoriedad de agotar la jurisdicción doméstica previo al pasaje al arbitraje internacional, como lo reconoce la jurisprudencia por primera vez en la Decisión sobre jurisdicción de fecha 25 de enero de 2000 del caso Emilio Agustín Maffezini contra España (CIADI caso número ARB/97/7).

En este caso, el demandante somete la controversia en base al TBI entre Argentina y España cuyo artículo $\mathrm{X}$ numeral 3 establece que se puede pasar al arbitraje internacional: a) si en un plazo de dieciocho meses no hay sentencia en la jurisdicción doméstica; b) cuando haya decisión pero subsista la controversia; o, c) por acuerdo de partes. En función de la CNMF del TBI en cuestión, el demandante solicita la aplicación de las disposiciones más favorables del TBI entre España y Chile. En el último acuerdo, luego de procurar obtener una solución amigable en un plazo de seis meses, la jurisdicción doméstica se presenta como una opción para el inversor, junto a la jurisdicción arbitral internacional: CIADI, mecanismo complementario del CIADI, tribunal arbitral ad hoc según el Reglamento de Arbitraje de la UNCITRAL (artículo $10)$.

En este sentido, en la decisión sobre jurisdicción de fecha 25 de enero de $2000^{21}$, el tribunal considera que,

\begin{abstract}
"si un tratado con un tercero contiene disposiciones para la solución de controversias que sean más favorables para la protección de los derechos e intereses del inversor que aquellos del tratado básico, tales disposiciones pueden extenderse al beneficiario de la cláusula de la nación más favorecida pues son plenamente compatibles con el principio ejusdem generis. Naturalmente que el tratado con el tercero tiene que referirse a la misma materia del tratado básico, sea ésta la protección de inversiones extranjeras o la promoción del comercio, puesto que las disposiciones sobre solución de controversias se aplicarán en el contexto de estas materias; de otro modo se incurriría en contravención de dicho principio." (párrafo 54) ${ }^{22}$
\end{abstract}

\footnotetext{
20 “Un Estado tiene, sin duda, la libertar de no ofrecer un mejor trato a los inversores o no obligarse por una cláusula de la nación más favorecida. Sin embargo, una vez que libremente tomó alguno de esos caminos, debe cumplir con sus obligaciones. " (Traducción propia)

${ }^{21}$ Texto disponible en el sitio web del CIADI: https://icsid.worldbank.org/

${ }^{22}$ Con este precedente, en oportunidades posteriores, otros tribunales arbitrales del CIADI hacen lugar a la CNMF en relación a los mecanismos de solución de controversias, como ser: Gas Natural SDG SA contra Argentina (CIADI caso número ARB/03/10); Suez, Sociedad General de Aguas de Barcelona SA e InterAguas Servicios Integrales del Agua SA contra Argentina (CIADI caso número ARB/03/17); National Grid PLC contra Argentina (caso bajo el Reglamento de Arbitraje de la UNCITRAL); Suez,
} 
En la acera contraria se encuentra el caso Plama Consortium contra Bulgaria (CIADI caso número $\mathrm{ARB} / 03 / 24$ ), en el cual el tribunal arbitral entiende que la $\mathrm{CNMF}$ es aplicable únicamente a las cuestiones de fondo relativas a los mecanismos de solución de controversias, no así a las procesales. Siguiendo esta línea de interpretación restringida de la CNMF, en el caso Telenor Mobile Communications AS contra Hungría (CIADI caso número ARB/04/15), el tribunal arbitral reconoce la importancia de tener en cuenta las intenciones de las partes en el TBI de incluir o excluir el trato de nación más favorecida a determinadas cuestiones, esto es, la interpretación de la cláusula debe ser acorde a las limitaciones previstas en el propio acuerdo.

En definitiva, como explican Dolzer y Schreuer (2008: 256), los argumentos es ambos laudos son contradictorios e imposibles de reconciliar, ya que uno de los tribunal ad hoc busca eliminar los obstáculos procedimentales mientras que el otro tribunal busca evitar que se extienda el ámbito de aplicación originario de un tratado. La respuesta sobre la aplicabilidad o no de la CNMF a las disposiciones sobre solución de controversias inversor-Estado estará, en efecto, en el texto del tratado. La dificultad está en determinar si una cláusula con una redacción amplia debe aplicarse exclusivamente a los aspectos sustanciales o también a la solución de controversias (Dolzer y Schreuer, 2008: 257).

La ilustración 1 sintetiza la estructura del régimen internacional de inversiones, focalizándose en el principio derivado de solución de controversias inversor-Estado mediante prórroga de jurisdicción al arbitraje internacional. No se incluyen las reglas derivadas de los demás principios del régimen internacional de inversiones por exceder el objeto de este trabajo.

Sociedad General de Aguas de Barcelona S.A. y Vivendi SA contra Argentina (CIADI caso número $\mathrm{ARB} / 03 / 19)$. 
Ilustración 1: Principios del régimen internacional de inversiones. Especial referencia al régimen internacional de solución de controversias inversor-Estado (régimen derivado)

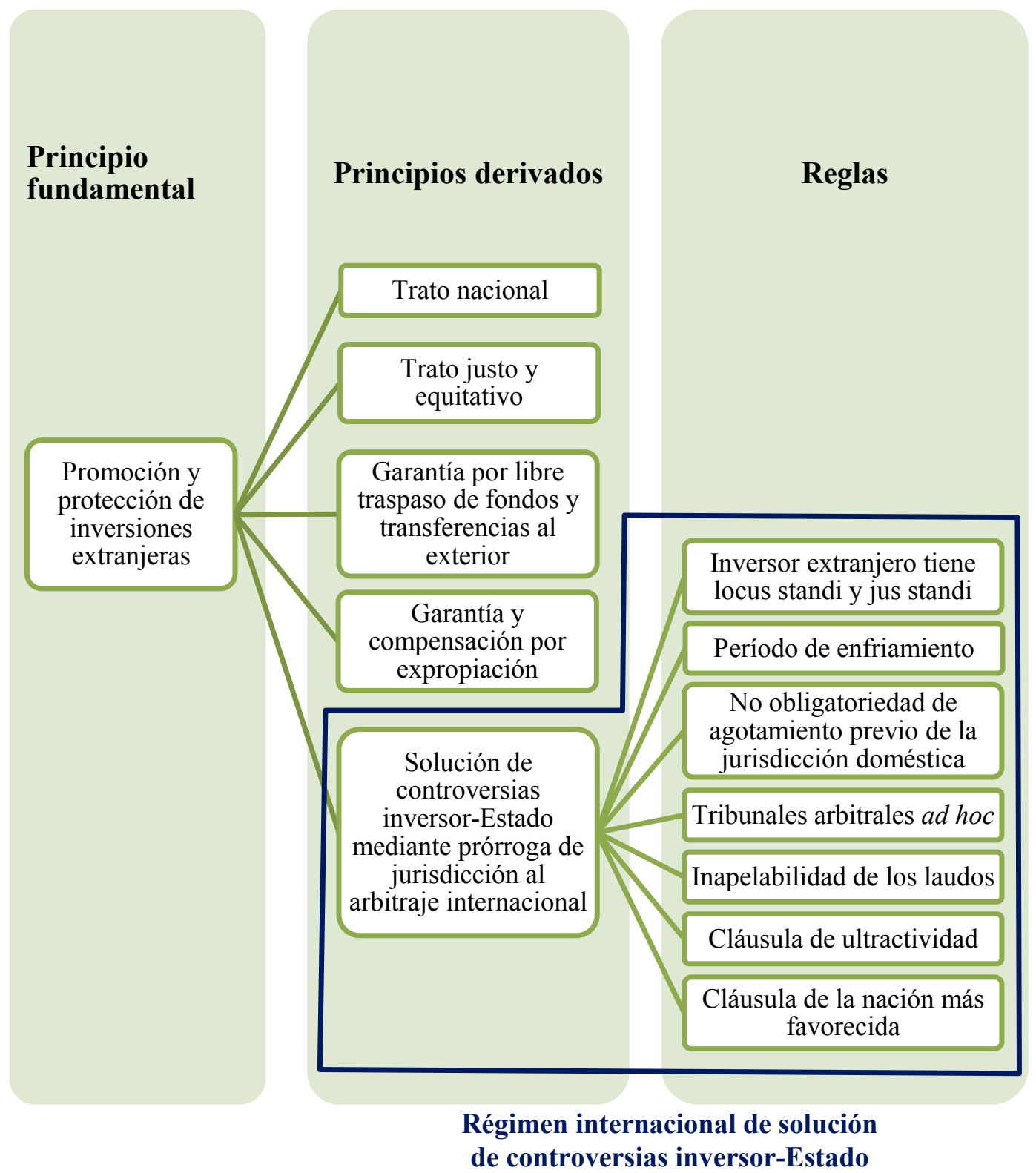

Fuente: Bas Vilizzio, 2018: 168.

Cabe señalar que desde el punto del Derecho Internacional, el régimen de protección de inversiones es un régimen jurídico autocontenido. En los últimos años, la comunidad internacional ha sido testigo de la fragmentación del Derecho Internacional en diferentes regímenes jurídicos autocontenidos (self-contained regimes). El tema ha sido analizado por la Comisión de Derecho Internacional de la Asamblea General de la ONU, estando los resultados de tal análisis plasmados en el "Informe sobre la Fragmentación del Derecho Internacional: dificultades derivadas de la diversificación y expansión del Derecho Internacional” (ONU, 2006). Como explica el informe: 
"La fragmentación del mundo social internacional adquiere significado jurídico al ir acompañada de la aparición de normas o conjuntos de normas, instituciones jurídicas y esferas de práctica jurídica especializados y (relativamente) autónomos. Lo que antes aparecía regido por el «derecho internacional general» se ha convertido en campo de operaciones para sistemas especializados tales como el "derecho mercantil», el "derecho de los derechos humanos», el «derecho ambiental», el «derecho del mar», el «derecho europeo», e incluso conocimientos tan sumamente especializados como el "derecho de las inversiones» o el "derecho internacional de los refugiados», etc., cada uno de los cuales posee sus propios principios e instituciones." (ONU, 2006: párrafo 243)

En otros términos, la fragmentación tiene como origen la extensión y diversificación del elenco de materias susceptibles de ser reguladas internacionalmente, sumado a la prerrogativa de los Estados de ser parte o no de los tratados internacionales (Nasser, 2015). En este sentido, los regímenes autocontenidos son espacios de regulación especiales que cuentan con reglas, valores, principios e incluso fuentes jurídicas propias (Lima, 2014: 220), los cuales no necesariamente son compartidos con el Derecho Internacional General u otros regímenes autocontenidos. Adicionalmente, la existencia de regímenes jurídicos autocontenidos genera una extensión de las jurisdicciones especiales para resolver conflictos internos de cada régimen, sin necesariamente tener en cuenta que el Estado puede estar al mismo tiempo obligado por normas de otro régimen.

Esta situación abona la tesis del pluralismo jurídico, la cual se funda en tres postulados fundamentales, a saber: 1) los inevitables conflictos resultado de la diversidad en las normas básicas y preconceptos legales en términos de la teoría kelseniana; 2) los diferentes intereses, prioridades y valores de los actores jurídicos de cada sistema que refuerzan la necesidad de conformar estructuras e instituciones especializadas; y, 3) la racionalidad particular de cada régimen producto de los susbsistemas sociales a los cuales están vinculados (por ejemplo: protección del capital - protección del ser humano) que deriva en normas y recursos jurídicos en conflicto (Dupuy y Vuñuales, 2015; Petersmann, 2016).

Drnas de Clèment (2012: 29) complementa la idea al afirmar que en una concepción extrema el pluralismo "es la antitesis del "derecho" en su concepción puramente jurídica, en tanto se basa en el pluralismo interpretativo, en el no reconocimiento de jerarquías normativas, o incluso, en la negación llana del Derecho internacional”. En definitiva el pluralismo jurídico tira por tierra una concepción integral del Derecho y de los principios de justicia, especialmente cuando los regímenes autocontenidos no conviven armónicamente sino que sus normas colisionan entre sí. A pesar que la Comisión de Derecho Internacional ha analizado el tema en profundidad, en su informe 
final (ONU, 2006) plantea criterios y pautas de interpretación que no terminan de resolver cuestiones como la planteada anteriormente, colisión entre regímenes autocontenidos, sino que se enfoca en la relación de los regímenes autocontenidos con el Derecho Internacional General.

\subsection{Régimen internacional de solución de controversias inversor-Estado en el marco de los modelos institucional y relacional}

Para completar el análisis desde la teoría general, se propone un abordaje desde la teoría sustantiva elaborada por Consani $(2008,2016)$ sobre los modelos en la sociedad internacional. La dinámica del régimen de solución de controversias inversor-Estado puede leerse desde uno de los dos modelos ideales antagónicos de las relaciones internacionales, el modelo relacional y el modelo institucional, o bien puede plantearse un abordaje dialéctico abierto entre el poder y el Derecho en el cual se enmarcan ambos modelos.

Como explica Consani (2008: 2-3, 2016: 10-11), el modelo relacional en estado puro describe un sistema internacional cuyos únicos actores son los Estados soberanos y en el que la relación Derecho-poder se da de manera horizontal. Por tanto sus características son la dispersión, la incondicionalidad y la violencia del poder. En el modelo institucional se da la situación inversa. Este presenta un sistema en el cual el Derecho y el poder se encuentran en relación vertical, dando lugar a nuevos actores en las relaciones internacionales: las organizaciones internacionales y el individuo. En consecuencia este modelo se caracteriza por la concentración, condicionalidad y represión del poder (Consani, 2008: 3,2016: 11-13).

Los arbitrajes inversor-Estado, si bien son ad hoc, se dirimen mayoritariamente en el seno de instituciones internacionales que los administran. Conforme a datos del Investment Policy Hub de la UNCTAD, al 31 de diciembre de 2018 se conocen 942 controversias basadas en tratados, por tanto la cifra no incluye las controversias basadas en normas domésticas o contratos con el Estado. De las 942 controversias conocidas, el $63,1 \%$ se resolvieron o se encuentran en proceso de resolución en el marco del CIADI. En segundo lugar se encuentra la CPA congregando el 14,5\% de los casos, y el porcentaje restante se reparte entre instituciones privadas -que no son sujetos de Derecho Internacional-, arbitrajes sin institución administradora o no hay datos disponibles (ver gráfica 1). 
Gráfica 1: Instituciones administradoras de arbitrajes inversor-Estado. Porcentaje sobre número total de casos conocidos basados en tratados

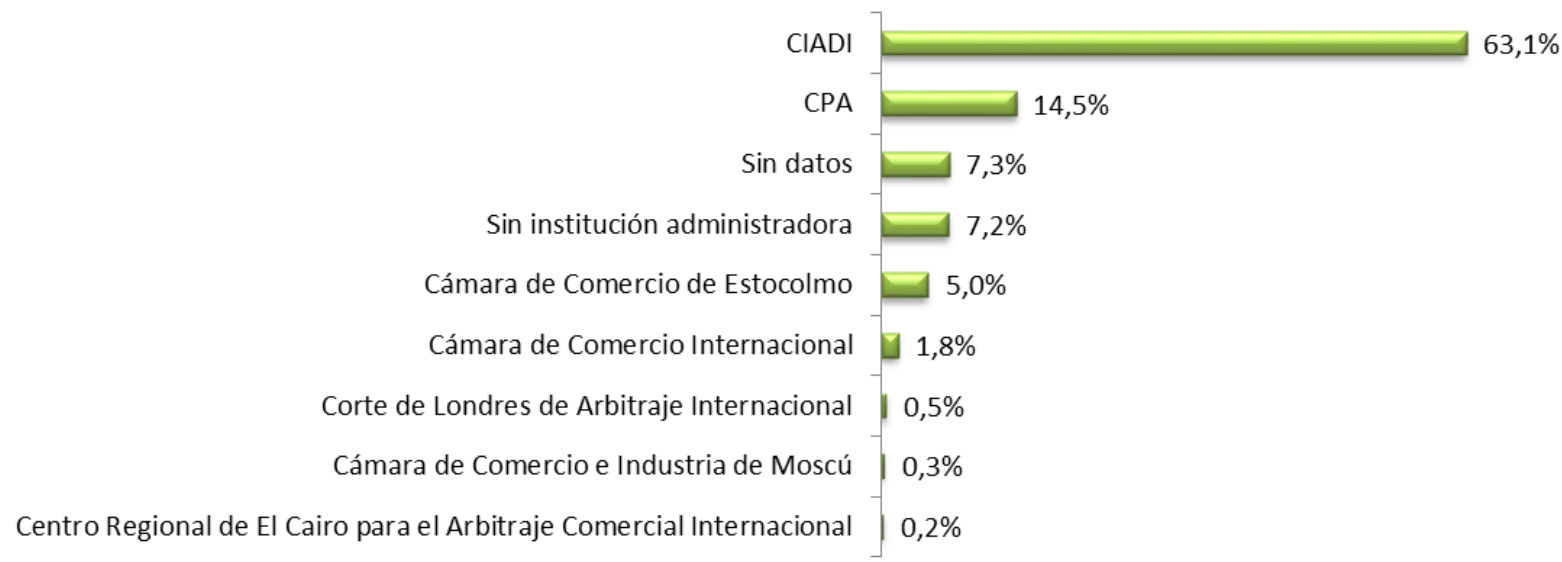

Fuente: Elaboración propia en base a datos del Investment Policy Hub de la UNCTAD, actualizados al 31 de diciembre de 2018. Fecha de consulta: 8 de setiembre de 2019

En relación a la idea de exclusividad del modelo institucional, dos elementos coadyuvan a su afirmación: la concentración del poder y la represión del poder. En primer lugar el modelo institucional sitúa al Estado como miembro de organizaciones internacionales (concentración del poder) (Consani, 2008: 3, 2016: 12). En materia de acuerdos de inversiones, sean TBI $u$ otros tratados bilaterales o multilaterales, el peso de instituciones como el CIADI surge de manera clara al ser el foro a cual remiten en mayor número. Para dar un ejemplo, si a los TBI en vigor en Sudamérica se le suman los acuerdos celebrados pero no ratificados por Brasil y los acuerdos denunciados por Bolivia y Ecuador, el $89 \%$ de estos remiten al CIADI como foro para resolver las controversias inversor-Estado (Bas Vilizzio, 2017: 32) ${ }^{23}$.

En segundo lugar, el modelo institucional dispone la represión del poder por tanto el uso y la amenaza de la fuerza están prohibidos como principio básico (artículo 2.4 de la Carta de la Organización de la ONU). Como corolario, las disputas deben ser resueltas de manera pacífica entre los Estados. Cabe señalar que el rol de los Estados emisores de la inversor en la solución de controversias en materia de inversiones fue evolucionando a la largo del tiempo. Inicialmente tuvieron una participación activa mediante la protección diplomática de sus nacionales, para pasar a ser un mero vector para que las

\footnotetext{
${ }^{23}$ Los acuerdos pueden remitir a una o más instituciones administradoras de arbitrajes a elección del inversor.
} 
corporaciones de su nacionalidad tuvieran locus standi y jus standi para demandar a los Estados receptores en foros especializados.

En este sentido, inicialmente, los Estados eran los únicos capaces de reclamar frente a otros Estados y para tal fin crean el instituto de la protección diplomática. De esta manera el Estado hace propio el reclamo del particular de su nacionalidad afectado frente al Estado incumplidor, sin posibilidad que el particular pudiera iniciar procesos de solución de controversia en un foro internacional (Torreja Mateu, 2012: 317; BurgosDe la Ossa y Lozada-Pimiento, 2009: 272). La protección diplomática es un derecho del Estado que la ejerce y sus requisitos han evolucionado a lo largo del tiempo. En la actualidad tanto la doctrina mayoritaria como el Proyecto de artículos sobre protección diplomática de la Comisión de Derecho Internacional de la ONU (2006) condicionan el ejercicio de la protección diplomática a que el particular afectado tenga un vínculo de nacionalidad con el Estado reclamante, y que agote previamente de los recursos internos en el Estado incumplidor.

Como se indicara anteriormente, si bien en la actualidad el instituto de la protección diplomática no ha caído en desuso, no resulta de aplicación en materia de protección de inversiones ya que los más de 3000 acuerdos internacionales en la materia otorgan a los inversores extranjeros el derecho de recurrir a la vía arbitral para demandar al Estado receptor, en caso de ver sus derechos vulnerados. Más aún, un número importante de tratados no establece el requisito del agotamiento precio de la jurisdicción doméstica, y en los que sí se establece, el juego de la cláusula de la nación más favorecida permite evitarlo, como se explicara anteriormente. A modo de ejemplo, en Sudamérica el 88\% de los TBI permite el pasaje a la vía arbitral sin necesidad de agotar los recursos internos conforme a datos de 2017 (Bas Vilizzio, 2017: 25).

En relación a la condicionalidad del poder, tercera característica del modelo institucionalista, su aplicación al régimen de solución de controversias inversor-Estado es más difusa. Si se toma en exclusividad el régimen del CIADI, los Estados miembros condicionan su poder al ingresar a la organización, en particular en lo que refiere al seguimiento de un procedimiento predeterminado para la solución de disputas y la elección de árbitros en base a la lista que los propios miembros registran en la Secretaría General. No obstante, son los inversores extranjeros quienes eligen el foro en el cual iniciar el arbitraje internacional en base a los tratados aplicables, los cuales suelen incluir más de una opción, así como también son de su elección las reglas aplicables. De hecho, podría darse un arbitraje en el que la institución administradora sea el CIADI 
pero que se aplique el Reglamento de Arbitraje de la UNCITRAL como normas de procedimiento. En el apéndice II se incluyen los flujogramas de los procesos arbitrales conforme a las Reglas del CIADI y el Reglamento de Arbitraje de la UNCITRAL (2010).

Sin perjuicio de lo anterior, debe reconocerse que el modelo institucional es un modelo ideal, no existe de manera perfecta (Consani, 2008: 2, 2016: 13). En consecuencia el modelo relacional aun resiste dentro del régimen de solución de controversias inversorEstado en tres aspectos fundamentales: las resistencias estatales manifestadas en el retiro del CIADI y la propuesta de mecanismos alternativos de resolución de disputas, así como la recuperación de la competencia de resolver en los tribunales locales aquellos conflictos jurídicos surgidos con inversores extranjeros, competencia cedida a instituciones internacionales mediante prórroga de jurisdicción ${ }^{24}$. Cabe destacar que las resistencias implican una mayor reivindicación del Estado como sujeto central del modelo relacional, puesto que, como indica el autor, en el modelo institucional el Estado "es sólo parte" y no el núcleo en torno al cual se erige el sistema (Consani, 2008: 7$)^{25}$.

Dado que este trabajo se focaliza en la relación Estado-empresa transnacional en el régimen internacional de solución de diferencias inversor-Estado, en los apartados subsiguientes se analizarán las notas fundamentales del Estado como sujeto de Derecho Internacional Público y las empresas transnacionales en tanto actores de las relaciones internacionales y sujetos discutidos de Derecho Internacional Público. En el caso del Estado el estudio se abordará desde su elemento distintivo: la soberanía, realizando especial referencia a su relación con el concepto de autonomía. En el caso de las empresas transnacionales se estudiará su avance de poder en el marco del sistema internacional y su condición de sujeto discutido para el Derecho Internacional Público.

\footnotetext{
${ }^{24}$ A modo de ejemplo puede mencionarse: 1) el retiro del CIADI por parte de Bolivia (2007), Ecuador (2009) y Venezuela (2012); 2) la propuesta de la Comisión Europea en torno a un sistema de tribunales de inversiones y el pronunciamiento del Tribunal de la UE sobre la incompatibilidad de los arbitrajes intraUE con el Derecho Comunitario (Caso Achmea, C-284); 3) el retorno a la jurisdicción doméstica en materia de inversiones incluido en la Ley de inversiones sudafricana (2015). Estos ejemplos serán analizados en los siguientes capítulos de este trabajo.

${ }^{25}$ Un estudio específico del régimen de solución de controversias inversor-Estado desde la perspectiva de los dos modelos de las relaciones internacionales puede verse en Bas Vilizzio (2018).
} 


\subsection{Estado: soberanía y autonomía}

\subsubsection{Proyecciones de la soberanía}

El elemento que diferencia al Estado de cualquier otro sujeto de Derecho Internacional o cualquier otro actor de las relaciones internacionales es la soberanía. El concepto de soberanía ha evolucionado a lo largo de la historia y no es exclusivo del ámbito del Derecho Internacional Público ni de las relaciones internacionales, es un concepto que engloba diferentes áreas del conocimiento, como la ciencia política, la sociología, la filosofía, el Derecho Público, entre otros. Por tanto el énfasis en el análisis varía según el autor y el momento histórico bajo examen.

Si bien a nivel del Derecho Internacional Público una definición muy difundida refiere a la soberanía como un atributo de los Estados independientes y que se reconocen como jurídicamente iguales (reconocimiento mutuo, no intervención e igualdad jurídica), este trabajo busca ampliar la mira estrictamente jurídica. Por tanto, se tomará como teoría sustantiva los aportes de Krasner en "Soberanía, hipocresía organizada" (2001) respecto a las cuatro proyecciones de la soberanía, conforme a la etapa histórica y los elementos en los que se focalizan los Estados.

Las definiciones propuestas son: 1) soberanía de interdependencia, vinculada al control estatal de los movimientos a través de sus fronteras nacionales; 2) soberanía westfaliana, aquella que aparece históricamente en función de las notas fundamentales de la Paz de Westfalia de 1648 y que consolida un sistema de Derecho basado en el principio de no intervención en los asuntos internos; 3) soberanía interna, relacionada a la existencia de estructuras de autoridad domésticas capaces de ejercer control efectivo dentro de fronteras; y 4) soberanía legal internacional, referida al reconocimiento mutuo entre Estados.

Como explica el autor, las cuatro proyecciones de la soberanía se caracterizan por su vinculación a tres conceptos fundamentales: la autoridad, el control y la legitimidad. En este sentido, la soberanía legal internacional y la westfaliana están vinculadas a la autoridad y la legitimación pero no contienen notas de control. Por su parte la soberanía interna está atada a los conceptos de autoridad, control y legitimidad de una autoridad dentro de las fronteras de un Estado, sin perjuicio de los límites y condiciones que el ejercicio de dicha autoridad implica. Finalmente, la soberanía interdependiente se arraiga exclusivamente en el control (Krasner, 2001: 14-15). Es la nota de control la que lleva a que en estudios posteriores, Krasner plantee la incorporación de la soberanía de 
interdependencia a la soberanía interna (Krasner, 2009, 2009b), pasando a analizar solo tres proyecciones: soberanía westfaliana o vatteliana, soberanía legal internacional y soberanía interna.

La soberanía, por tanto, no es un concepto unívoco ni estático, sino que siempre ha sido desafiado a lo largo de la historia conforme al contexto en el que los Estados desarrollan sus relaciones externas. Por tanto, en este punto es importante destacar que, si bien el uso de la mencionada tipología pareciera indicar que a lo largo de su historia un Estado evoluciona de un tipo de soberanía a otro como mecanismo de adaptación a los nuevos contextos internacionales, no necesariamente debe ser siempre así. De hecho, en un momento determinado un Estado puede ostentar un tipo de soberanía y no otra, y no por eso dejar de ser considerado un Estado o transformarse en una entidad diferente (Krasner, 2001: 15) ${ }^{26}$. Asimismo, el ejercicio de una de las proyecciones de la soberanía puede condicionar o limitar el ejercicio de otra de ellas. Un ejemplo de lo anterior son los compromisos que el Estado asume internacionalmente de manera voluntaria, en ejercicio de su soberanía legal internacional, que condicionan o limitan otras proyecciones de la soberanía.

Estos compromisos son denominados por Krasner como "invitaciones" en contraposición a la intervención, acto contrario a la voluntad del Estado objeto de esta. En el tema concreto de esta tesis, la celebración de un TBI y su posterior entrada en vigor puede condicionar la soberanía interna del firmante, particularmente en lo que refiere a la autoridad para ejercer los actos del Estado. Como se analizará en los próximos capítulos, el condicionamiento puede tomar diferentes formas, desde el congelamiento o parálisis regulatoria, hasta la revisión y el control de legalidad de los actos del Estado en la esfera pública por parte de entidades externas (tribunales arbitrales internacionales), incluso en casos de ejercicio válido del derecho de regular en materia de derechos humanos.

Dentro de las modalidades de compromisos se encuentran aquellos de carácter voluntario: los convenios internacionales y los contratos, así como aquellos de carácter no voluntario: la coerción y la imposición. Krasner (2001: 43-44) propone que en los

\footnotetext{
${ }^{26}$ Krasner $(2009,2011)$ afirma que no hay alternativa aceptada frente a la soberanía. Incluso en tiempos de globalización que cuestionan la autoridad estatal, es más factible que esta última sea vea alterada a que sea creada una nueva forma de organizar la vida política diferente al Estado. Los cambios que puedan darse en base a reglas que emerjan en la evolución del sistema internacional coexisten pero no suplantan a la soberanía, esta es resiliente (Krasner 2001b). En definitiva, aunque la soberanía pueda verse modificada y surjan nuevos conceptos, como se propone en esta tesis, esta seguirá constituyendo el elemento distintivo del Estado como única forma de organizar la vida política.
} 
convenios los gobernantes se obligan a seguir ciertas reglas con independencia de lo que hagan los demás, en los contratos se siguen determinadas conductas a cambio de un beneficio, en la coerción los gobernantes son sometidos de modo que su poder relativo disminuye, y finalmente en la imposición el gobernante no tiene capacidad de resistencia.

El autor plantea ejemplos vinculados a los tratados de protección de derechos humanos o que involucran la jurisdicción penal internacional para describir el condicionamiento de la soberanía westfaliana frente al ejercicio voluntario de la soberanía legal internacional. Este fenómeno es lo que lo lleva a sostener que en la actualidad la soberanía se caracteriza por la hipocresía organizada, esto es, normas como el principio de no intervención pueden ser violadas de manera legítima por acuerdos internacionales en materia de derechos humanos (contratos). Si bien el autor no lo plantea, similar razonamiento puede hacer con los TBI u otros instrumentos internacionales que prevén disposiciones en materia de protección de inversiones, celebrados en ejercicio válido de la soberanía legal internacional, y su impacto sobre la soberanía interna, particularmente la autoridad para ejercer actos estatales en materia de políticas públicas.

Habitualmente los acuerdos en materia de inversión son celebrados entre Estados desarrollados y Estados en desarrollo, en el caso de los tratados internacionales, o entre empresas, originarias de Estados desarrollados, y Estados en desarrollo en el caso de los contratos de inversión ${ }^{27}$. No se trata de una violación del principio de no intervención desde el punto de vista militar, ni realizada de forma directa por otro Estado como plantea Krasner en los ejemplos que maneja. Estos no entran en contradicción con la soberanía legal internacional, puesto que son una proyección de su ejercicio, sin embargo condicionan la soberanía interna al limitar el desarrollo de las acciones del Estado dentro de fronteras. Se trata de un proceso desde el exterior al interior del Estado, siendo un ejemplo cómo las estructuras domésticas pueden ser influenciadas por los actores externos, ya que para ingresar al régimen internacional de protección de inversiones, los Estados deben celebrar acuerdos en la materia en ejercicio de su soberanía legal internacional.

Krasner no propone una definición de soberanía basada en el espacio de política pública, en cuya defensa los Estados están dando pasos hacia la modificación de

\footnotetext{
${ }^{27}$ El léxico puede resultar confuso, por tanto en este punto es importante realizar la siguiente aclaración: un contrato de inversión es un acuerdo de voluntades entre un inversor extranjero y un Estado huésped. Desde el punto de vista de las modalidades de compromiso propuestas por Krasner, los contratos de inversión son contratos. Pero no todos los contratos, en el sentido krasneriano, refieren a dicha materia.
} 
instituciones externas (proceso desde el interior al exterior del Estado), como se analizará en el círculo 3 de esta investigación (quinta proyección de la soberanía que se suma a las cuatro propuestas por Krasner). Si bien esta nueva definición de soberanía tiene notas de la soberanía interna, presenta diferencias al proyectarse hacia el exterior y moldear las instituciones internacionales conforme a los intereses domésticos (protección del espacio de política pública).

Del entramado de acuerdos internacionales de inversión se derivan los principios y reglas que enmarcan la conducta de los Estados, pero que a su vez pueden condicionar sus estructuras internas. Como se indicara previamente en este capítulo, este es el caso de la solución de controversias inversor-Estado en tribunales arbitrales internacionales que con capacidad para revisar y controlar la conducta del Estado huésped en la esfera pública, incluso sin el requisito de agotamiento previo de la jurisdicción doméstica. Adicionalmente, la experiencia internacional indica que la pertenencia puede derivar en situaciones en las que la regulación de ciertas áreas sea enlentecida, suspendida o directamente evitada a los efectos de no recibir una demanda por parte de un inversor extranjero. Este es el caso de Nueva Zelanda con la implementación de la cajilla de cigarrillos plana (plain packaging) o de El Salvador en relación a la ley que prohíbe la minería metálica. Ambos casos se examinarán en los siguientes capítulos.

Cabe señalar que, a diferencia de lo planteado por Krasner, y desde un punto de vista estrictamente jurídico, la Corte Permanente de Justicia (CPJ) en la sentencia sobre el fondo del asunto del vapor Wimbledon, de fecha 17 de agosto de 1923, afirma que la soberanía estatal no puede verse erosionada por la asunción de compromisos internacionales, puesto que esta actividad se realiza justamente en ejercicio de la soberanía. Puntualmente, indica:

\footnotetext{
"The Court declines to see in the conclusion of any Treaty by which a State undertakes to perform or refrain from performing a particular act an abandonment of its sovereignty. No doubt any convention creating an obligation of this kind places a restriction upon the exercise of the sovereign rights of the State, in the sense that it requires them to be exercised in a certain way. But the right of entering into international engagements is an attribute of State sovereignty. "28 (párrafo 35 in fine)
}

Autores como Raustiala (2003: 844-847) y Barreiros (2008: 53-56) continúan abonando la tesis de la CPJ al entender que los tratados internacionales pueden tener un impacto

\footnotetext{
28 "La Corte rechaza que la celebración de cualquier tratado por el cual un Estado se obligue a hacer o no hacer determinado acto, implique un abandono de la su soberanía. No hay duda que una convención que crea obligaciones de este tipo restrinja el ejercicio de los derechos soberanos del Estado, en el sentido que requiere que ellos sean ejercidos de determinada manera. Pero el derecho de ser parte de compromisos internacionales es un atributo de la soberanía estatal”. (Traducción propia).
} 
sobre la conducta de los Estados pero no afectan su soberanía. Estos mantienen su capacidad de tomar decisiones a pesar de los tratados celebrados y en vigor, capacidad que constituye el núcleo de la soberanía según los autores ${ }^{29}$. Si bien la soberanía es la base para el jus tractatum, capacidad de celebrar acuerdos internacionales, la afirmación anterior es discutible en relación a los límites del ejercicio de los derechos emanados de la soberanía, en particular cuando condicionan el derecho de regular. Asimismo, es cuestionable si los autores no refieren al concepto de autonomía en vez de soberanía en sentido krasneriano o incluso jurídico, aspecto que se desarrollará en el siguiente apartado.

En relación a los límites del ejercicio de los derechos emanados de la soberanía, este ejercicio se ve especialmente erosionado cuando los tratados condicionan el derecho de regular o el poder de policía del Estado. Este refiere a la "actividad de la Administración que restringe la libertad general del ciudadano en defensa del orden público" (Hernández González, 2017: 11), esto es, el poder del Estado de regular limitando libertades particulares con el fin de proteger un bien jurídico superior: el orden público. El derecho de regular puede ser entendido como un menor nivel de abstracción del concepto de espacio de política pública (policy space), esto es, el conjunto de medidas tomadas en las áreas susceptibles de decisión pública.

El derecho de regular es justamente el que establece el freno a los acuerdos internacionales, o en términos del Estado condicionando su propia soberanía. Siguiendo a Titi (2014), el derecho de regular "denotes the legal right exceptionally permitting the host state to regulate in derogation of international commitments it has undertaken by means of an investment agreement without incurring a duty to compensate" ${ }^{30}$ (2014: 18). La noción de derecho de regular o de poder de policía del Estado suele ser invocada en casos de expropiación, especialmente expropiación indirecta, cuando el Estado actuó

\footnotetext{
${ }^{29}$ Cabe señalar que en su trabajo Barreiros concluye que la noción de soberanía nunca ha sido absoluta, sino que es a partir de la sentencia en el caso Lotus de la CPJ, de fecha 7 de setiembre de 1927, que la disciplina comenzó a preocuparse por las situaciones de condicionamiento o erosión de la soberanía. En este trabajo no se comparte tal afirmación desde el punto de vista jurídico (Barreiros, 2008: 47-48). Desde el punto de vista de las relaciones internacionales, se siguen las ideas de Krasner respecto al condicionamiento que el ejercicio de un tipo de soberanía puede suponer sobre otro/s, partiendo de conceptos que demuestran que la soberanía es absoluta, pensar en ceder o limitar soberanía es un oxímoron. Se es soberano o no se es, por tanto se es Estado o no se es. Sin perjuicio de esto, la soberanía puede verse o condicionada por conductas que tienen cabida en un sistema basado en la hipocresía organizada y hacen que el concepto se soberanía se transforme pero no desaparezca como elemento distintivo del Estado o con carácter absoluto.

30 "Denota el derecho que permite, excepcionalmente, al Estado anfitrión regular en derogación de los compromisos internacionales que ha contraído mediante acuerdos de inversión, sin que por esto incurra en el deber de compensar" (Traducción propia).
} 
en protección del interés general (ejemplo: salud pública como en la disputa entre Philip Morris y Uruguay, caso CIADI número ARB/10/7), presentándose como una excepción de la doctrina Hull. En definitiva, esta doctrina busca un balance entre los derechos de los inversores y el interés general cuyo guardián es el Estado (Pellet, 2015).

A nivel de la UNCTAD, el "Informe sobre las inversiones en el mundo" del año 2003 introduce por primera vez en sus análisis el concepto de national policy space (espacio de política nacional), marcando la posible tensión entre la liberalización del mercado y la necesidad de los Estados de regular para maximizar los beneficios y minimizar los riesgos de la apertura (Ghiotto, 2017: 69). En este sentido, el Informe indica respecto al espacio de política pública nacional que

"Its foundation is the right to regulate, a sovereign prerogative that arises out of a State's control over its own territory and that is a fundamental element in the international legal regime of State sovereignty. Although host countries already limit their regulatory autonomy as a result of liberalization policies - and have their autonomy limited as part of the wider process of economic globalization-IIAs create distinctive issues in this connection. Such international agreements, like other legal texts, are specifications of legal obligations that limit the sovereign autonomy of the parties. "31 (UNCTAD, 2003: 145)

La afirmación de la UNCTAD reconoce la limitación que genera la celebración de acuerdos internacionales en lo que respecta al juego de la soberanía legal internacional y la soberanía interna en términos de Krasner, o una quinta proyección como se analizará en el capítulo 7. En este sentido, autores como Mayer (2009: 376) afirman que el espacio de política pública es una combinación de decisiones sobre las políticas soberanas de jure y la autonomía nacional de facto. La autonomía y su relación con la soberanía también será objeto de análisis del siguiente apartado.

El desafío, en particular para los Estados en desarrollo, lo constituye el balance entre la liberalización económica y las políticas de desarrollo sostenible (Ghiotto, 2017: 65, 69), tema que se profundizará en el círculo 3 de este trabajo al profundizar sobre el espacio de política pública como base de la nueva definición de soberanía. Puntualmente en lo que respecta a la relación Estado-empresa transnacional el condicionamiento de la soberanía estatal tendría efecto directo en la posibilidad de iniciar procesos arbitrales inversor-Estado, y en definitiva operarían como una barrera de contención a la parálisis

\footnotetext{
31 "Su base es el derecho de regular, una prerrogativa soberana que deriva del control del Estado sobre su territorio y es un elemento fundamental en el régimen jurídico internacional de los Estados soberanos. A pesar que los Estados receptores de la inversión limitan su autonomía regulatoria como resultado de políticas de liberalización -y tienen su autonomía limitada por ser parte de un proceso más amplio de globalización económica- los acuerdos internacionales de inversiones generan problemas particulares en relación a este punto. Estos acuerdos internacionales, como otros textos legales, son especificaciones de obligaciones legales que limitan la autonomía soberana de las partes." (Traducción propia).
} 
o enfriamiento regulatorio. Además de condicionar la soberanía desde un punto de vista interno (autoridad para ejercer los actos del Estado), los acuerdos que dejan afuera de su articulado la protección del derecho de regular condicionan la autonomía estatal al limitar su capacidad de toma de decisiones. Si bien Krasner (1999: 40) analiza la autonomía dentro de la soberanía westfaliana, como la condición en la que la autoridad estatal es independiente de cualquier poder externo, soberanía y autonomía no son conceptos sinónimos ni uno es parte del otro como se desarrollará a continuación.

\subsubsection{Soberanía y autonomía}

Ninguno de los TBI $\mathrm{u}$ otros instrumentos con disposiciones en materia de inversiones representa una violación de la soberanía ya que los Estados como soberanos son quienes ingresan a dichos acuerdos en modalidad de invitación (soberanía legal internacional), pero a su vez confrontan la soberanía ya que condicionan o erosionan las estructuras internas de los signatarios, especialmente si son Estados con menor poder relativo (soberanía interna). Asimismo, como señala Krasner (2001: 39), esta situación impacta de manera negativa sobre la autonomía interna el Estado condicionándola. En consecuencia, como tercera teoría sustantiva, este trabajo se asienta sobre los aportes de los autonomistas latinoamericanos.

Si bien el concepto de autonomía no ha sido unívoco en materia de relaciones internacionales, este trabajo parte del concepto propuesto por Puig (1980: 148) quien señala que la autonomía es "la máxima capacidad de decisión propia que se puede tener, tomando en cuenta los condicionamientos del mundo real". Por tanto, la autonomía es una condición del Estado que le permite articular y alcanzar metas políticas de manera independiente ${ }^{32}$, y el goce de la autonomía es lo que permite al Estado articular y lograr sus objetivos de manera independiente de las demandas o intereses de entidades internas o externas, más que el atributo de la soberanía. Si bien el abordaje de Puig tiene como centro al Estado, reconoce el protagonismo internacional de otros actores no estatales como las empresas transnacionales. Mismas ideas pueden verse en Jaguaribe (1979).

\footnotetext{
${ }^{32}$ Russell y Tokatlian identifican dos significados más. El primero refiere a la autonomía como sinónimo de la soberanía westfaliana conforme a Krasner en el sentido que ningún actor externo puede ejercer autoridad dentro del territorio de un Estado. El segundo indica que la autonomía es uno de los intereses nacionales del Estado, siendo los otros dos la supervivencia y el bienestar económico (Russell y Tokatlian, 2001: 71-73).
} 
La existencia de actores no estatales también impacta en la autonomía de los Estados, especialmente porque esta no es una propiedad estable sino que fluctúa conforme a la coyuntura. En efecto, Jaguaribe afirma que "la autonomía no es una conquista estable y permanente" (1979: 96), por tanto un Estado puede transitar de situaciones de autonomía completa a dependencia completa. Como señala Puig (1986: 58), "la dinámica autonomista suele ser cíclica y desarrollarse por etapas. Es algo así como un ir y venir; un proceso de avances y retrocesos". Ahora bien, este proceso de fluctuaciones no necesariamente impacta sobre la soberanía estatal, ya que un Estado podría perder o disminuir su autonomía, como condición política y económica, pero aun así ser soberano. La autonomía es una condición y la soberanía un atributo que hace que el Estado sea precisamente ese sujeto/actor y no otro, para el ejercicio de la primera es condición que el Estado sea soberano, pero no viceversa.

En materia de solución de controversias inversor-Estado, el primer hito relacionado a la autonomía internacional de los Estados latinoamericanos tiene lugar durante la reunión anual de la Junta de Gobernadores del Banco Mundial, el 9 de setiembre de 1964 en la ciudad de Tokio. Diecinueve Estados latinoamericanos ${ }^{33}$ junto a Irak y Filipinas ejercen su autonomía internacional al tomar la decisión de votar en contra del borrador preliminar del Convenio de Washington constitutivo del CIADI, con el llamado "no de Tokio". La decisión es tomada en base a la tradición jurídica latinoamericana en torno a la doctrina Calvo, contenida en la mayoría de las constituciones de la época, y el interés de no otorgar al inversor extranjero derechos superiores a los inversiones nacionales al permitirles demandar a los Estados fuera de su territorio (Polanco, 2014).

No obstante, a fines de la década de los ochenta los Estados Latinoamericanos comienzan transitar un camino de dependencia y pérdida de autonomía al seguir a rajatabla las recetas propuestas por el Fondo Monetario Internacional, el Banco Mundial y el Departamento del Tesoro de Estados Unidos, el denominado consenso de Washington. En las dos organizaciones internacionales el sistema de votación pondera a las grandes potencias, particularmente Estados Unidos, por tanto, las propuestas del consenso reflejaban con claridad los intereses de la potencia hegemónica del momento. El consenso propulsaba reformas estructurales basadas en la desregulación del mercado, la apertura comercial mediante la rebaja de aranceles y eliminación de barreras no

\footnotetext{
${ }^{33}$ Argentina, Bolivia, Brasil, Chile, Colombia, Costa Rica, República Dominicana, Ecuador, El Salvador, Guatemala, Haití, Honduras, México, Nicaragua, Panamá, Paraguay, Perú, Uruguay y Venezuela (Boeglin, 2012).
} 
arancelarias, la privatización de servicios públicos y la liberalización de las barreras a la inversión extranjera directa (Fernández Alonso, 2013: 48 - 50; Bohoslavsky, 2010: 18). El paquete propuesto generó el clima propicio para que los gobiernos neoliberales de los noventa comenzaran la práctica de celebrar tratados bilaterales de inversión (TBI) y consoliden la adhesión al Convenio de Washington, reforzándose una pérdida de poder de decisión y consecuente dependencia de los Estados centrales (Rapoport y Míguez, 2015: 146). De hecho, los TBI son, en su mayoría, celebrados entre Estados desarrollados y Estados en desarrollo, buscando la protección de la inversión de las empresas de los primeros en los ordenamientos jurídicos de los segundos.

La práctica tendiente a la celebración de TBI o inclusión de capítulos de inversiones en los tratados de libre comercio y otros acuerdos se mantiene hasta el día de hoy en América Latina y el mundo. Sin perjuicio de lo anterior, se han planteado cambios al régimen de protección de inversiones, especialmente en lo que refiere al régimen de solución de controversias inversor-Estado como régimen derivado del anterior. Estos cambios tienen como base la reivindicación de la autonomía y defensa de la soberanía, particularmente la soberanía interna. Ejemplos de este punto son los casos de Brasil, El Salvador y Bolivia. La situación de la UE respecto a los arbitrajes intra-UE se analizará si puede interpretarse como un caso de defensa de la soberanía y reivindicación de la autonomía. No obstante, también se perfila una transición hacia una nueva concepción de soberanía en cuyo núcleo duro está el espacio de política pública. Todos los ejemplos serán analizados en los siguientes capítulos de este trabajo.

Dado que el sistema internacional es dinámico, los actores que lo componen también lo son, tanto en sus características como diversidad. Es por esto que en lo que refiere al Estado, particularmente su soberanía, los cambios y alternativas propuestas al régimen internacional de protección de inversiones avizoran una nueva proyección de la soberanía estatal diferente a las estudiadas por Krasner. Es por este motivo que en el último círculo de este trabajo se analizará si el concepto de soberanía estatal ha evolucionado hacia una nueva definición que se construye desde la defensa del espacio de política pública en busca de la protección del interés general, generando cambios en las instituciones internacionales: régimen de solución de controversias inversor- Estado (proceso desde el interior al exterior del Estado). 


\subsection{Empresas transnacionales}

\subsubsection{Empresas transnacionales y poder}

El sistema internacional se caracteriza por la heterogeneidad y multiplicidad de actores y una agenda extensa y menos jerarquizada (Tomassini, 2006), temas que impactan directamente en los aportes desde las relaciones internacionales que han sido tradicionalmente estadocéntricos. Incluso autores cuyo centro de análisis era el Estado, incorporaron una mirada más amplia a los fenómenos internacionales. Este es el caso de Puig que en 1980 ya destacaba como "la creciente transnacionalización del mundo, o sea, la realización de actividades políticas, económicas y sociales en diversas naciones por entidades que no forman parte del gobierno strictu sensu de un Estado, ha añadido nuevos 'actores' al protagonismo internacional' (Puig, 1980, 140).

El creciente número de actores, su mayor incidencia en la escena internacional, y la heterogeneidad de la agenda dan pie a cambios estructurales en la naturaleza, fuentes y redistribución del poder (Sanahuja, 2007: 379). Es en esta nueva geografía de poder, como la define Sassen (2010), que las empresas trasnacionales han aumentado su relevancia como actores internacionales, incluso ocupando parcelas de poder que tradicionalmente pertenecían a los Estados (Strange, 2001: 101). Este escenario internacional ha sido el marco para que más de 3000 tratados internacionales le hayan otorgado a los inversores extranjeros el derecho de iniciar procesos arbitrales ante tribunales ad hoc administrados por organizaciones internacionales intergubernamentales e instituciones privadas, en caso que entiendan que sus derechos son vulnerados. Incluso sin agotar previamente la jurisdicción doméstica.

En vista de lo anterior, a nivel de teoría sustantiva también se incorporan los aportes de Strange (2001). La autora plantea un vuelco en el equilibro de poder Estado-empresas en detrimento del primero, aunque no significa que las empresas transnacionales hayan desplazado a los Estados o que estos vayan a desaparecer como actores del sistema internacional. En el contexto actual, como se indicara en los apartados anteriores, la soberanía se encuentra condicionada o limitada producto de la propia conducta estatal. No obstante, la soberanía no desapareció como atributo del Estado, más allá de su evolución, ni han desaparecido los Estados como forma de organización política.

El fenómeno del condicionamiento de la soberanía interna y la autonomía estatal, así como la erosión del espacio de política pública, por parte del régimen internacional de protección de inversiones, particularmente el régimen de solución de controversias 
inversor-Estado, se presenta de una manera diferente a la tradicional intervención en sentido militar que erosionaría la soberanía westfaliana. Aun así, se percibe una pérdida progresiva de la autoridad real del Estado, fenómeno que no se ha dado porque las empresas le hayan quitado poder a los Estados, sino que fueron estos los que le otorgan dicho poder y minimizan sus competencias (Strange, 2001: 73 - 74) y se autolimitaron en busca de inversiones de manos de empresas transnacionales (Bermejo García, 2015: 95).

Desde el punto de vista jurídico, se evidencia la aparición de un Derecho global sin Estado, esto es, la construcción de un ordenamiento jurídico que parece dejar de lado al Estado en su rol activo en la creación de normas y la solución de controversias (Teubner, 1997). Este autor plantea como principales ejemplos de este fenómeno la difusión y extensión de la lex mercatoria y el uso del arbitraje como mecanismo para resolver conflictos. En el marco de una suerte de "multilateralismo corporativo", como acertadamente señala Tussie (2019: 110), desde un análisis sociológico de la globalización, Sassen (2010: 107-108) plantea que este nuevo orden institucional se caracteriza por la privatización y desnacionalización de políticas que anteriormente pertenecían a la esfera pública; la privatización normativa; y las transformaciones dentro del Estado que lo hacen funcionar en base a la lógica del capital global.

Frente a un Estado que desregula y actores no estatales que privatizan parte de la producción normativa, Sassen (2010: 110) cuestiona si “¿(e)l papel del Estado es simplemente el de reducir su autoridad (...)? ¿o también requieren nuevos tipos de regulación, leyes y decisiones judiciales, en resumen, la producción de un nuevo conjunto completo de nuevas "legalidades"?". Concluye que si bien los Estados perdieron exclusividad en la producción de normas, mantienen un rol fundamental, aunque el avance de la globalización requiere que el Estado regule o vuelva a regular aspectos vinculados a la razón de Estado (la raison d'Etat). La autora ya había afirmado en “¿Perdiendo el control?” (2001) que el Estado no puede quedar limitado a una significación declinante y que una reducción en su capacidad de regular no se explica exclusivamente porque opera en un mundo globalizado (Sassen, 2001: 45) ${ }^{34}$.

Adicionalmente, este aumento del dominio privado se está institucionalizando mediante el desarrollo de mecanismos de gobernanza privados, fenómeno que afecta la

\footnotetext{
${ }^{34}$ En el 2019, la literatura discute si se ha alcanzado una etapa de desglobalización, estancamiento de la globalización, ralentización, etc. Este aspecto será analizado en el apartado 7.2 para enmarcar temporalmente la transición hacia un nuevo concepto de soberanía.
} 
exclusividad de la autoridad del Estado y del Derecho Internacional (Sassen, 2010: 133). En el caso del régimen de solución de controversias inversor-Estado, la retirada del Estado se manifiesta justamente en la competencia de resolver disputas que involucran al propio Estado. Los mecanismos de la solución de controversias inversorEstado pueden interpretarse como una suerte de privatización de la justicia, más aún en los casos que el agotamiento previo de la jurisdicción doméstica no sea obligatorio. La retirada del Estado determina que sean los tribunales arbitrales ad hoc los encargados de resolver las disputas, tribunales internacionales, con fuerte arraigo jurídico-institucional e histórico en el Derecho Privado, cuyo fin último es controlar la legalidad de la actividad o inactividad estatal.

Es pertinente considerar las características del abandono de las parcelas de poder en las que anteriormente regulaba el Estado. Este es voluntario, incondicionado y temporal. Es voluntario porque los Estados celebran acuerdos internacionales que le permiten ingresar al régimen, no es un caso de coerción. Es incondicionado porque al momento del ingreso al régimen el Estado no pone condiciones, aunque espera obtener ventajas por ser parte del régimen. Finalmente, es temporal porque los tratados no son pactos a perpetuidad, sino que se mantienen en vigor por un plazo determinado que puede renovarse o no. Por tanto, es el propio Estado que mediante la celebración de tratados internacionales en materia de inversiones en ejercicio válido de su soberanía legal internacional, erosiona su soberanía interna, siguiendo el razonamiento de Krasner (2001).

En este punto, al hablar de la retirada del Estado de ciertas parcelas de poder, es fundamental conceptualizar qué se entiende por poder. El poder es definido por Strange (2001: 38) como la "capacidad de una persona o de un grupo de personas para influir en los resultados de tal forma que sus preferencias tengan prioridad sobre las preferencias de los demás”. Sanahuja (2007: 324) explica que es necesario distinguir entre el poder "de quién" (poder referido a los actores, capacidades y recursos), "sobre quién" (poder relacional), y "sobre qué" (poder relacional). Poder relacional es la capacidad o propiedad de un actor que le permite influir sobre otro actor, mientras que el poder estructural "confers the power to decide how things shall be done, the power to shape frameworks within which states relate to each other" (Strange, 1994: posición $668)^{35}$. En otros términos, el poder estructural es la capacidad la que le permite a un

\footnotetext{
${ }^{35}$ El poder estructural "confiere el poder de decidir cómo deberán hacerse las cosas, el poder de moldear las estructuras dentro de las cuales los Estados se relacionan entre si”" (Traducción propia).
} 
actor ser quien defina las reglas de juego, de manera que las conductas de los demás actores se acompasen a sus intereses puesto que estos determinan cuáles son las conductas legítimas o permitidas.

Dentro del concepto de poder estructural, Strange propone cuatro estructuras primarias entre las cuales este divide el poder estructural y que, a su vez, se comportan como fuentes de poder. Estas son la estructura de la seguridad, de la producción, del crédito y las finanzas, y del conocimiento. Ninguna de ellas tiene preeminencia sobre las demás, sino que cada una se relaciona y apoya sobre las otras. A su vez, plantea cuatro estructuras secundarias: la estructura del comercio, de la energía, del transporte, y del bienestar (welfare).

Si bien en la década del ochenta y comienzos de la década del noventa Strange presenta un análisis casi exclusivamente estadocéntrico, en estudios posteriores amplía la mirada a otros actores no estatales que fueron ganando poder en las diferentes estructuras. Es por esto que en "Estados y Mercados", la autora afirma que la estructura de la seguridad está construida en base a la figura del Estado (Strange, 1994: posición 1049). De hecho, el Estado fue por mucho tiempo el actor que tenía el monopolio del uso de la fuerza, aunque en la actualidad el crimen internacional organizado, las redes terroristas, las comunidades beligerantes o los movimientos nacionales de liberación también emplean la fuerza armada, de manera ilícita o lícita en el último caso. Por tanto, el poder en la estructura de la seguridad lo tienen aquellos actores que tienen los medios para ejercer el control de la seguridad, y en consecuencia obtienen beneficios materiales políticos y/o de estatus (Sanahuja, 2007: 325).

La estructura de la producción es el conjunto de acuerdos en los que se establece qué se produce, quién lo hace y para quién, con qué métodos y bajo qué términos (Strange, 1994: posición 1434). Es en esta estructura que la autora ya visualiza la creciente dominación de las empresas transnacionales, que en el régimen de protección de inversiones puede verse reflejada en el ingreso de empresas extranjeras en el proceso de privatización de los servicios públicos dentro de las medidas propuestas por el consenso de Washington, así como la creciente atracción de inversiones en las industrias extractivas. Como se analizará más adelante en el círculo 2, uno de los sectores económicos con mayor número de controversias inversor-Estado es el sector petróleo, gas y minería. Asimismo, Argentina es el Estado más demandado del mundo por las medidas tomadas para paliar los efectos de la crisis económica de 2001, y gran número 
de esas demandas son de manos de empresas proveedoras de servicios públicos privatizados.

En tercer lugar, la estructura de las finanzas es el conjunto de acuerdos relativos a la disponibilidad del capital, mediante la aceptación o rechazo a otorgar créditos, y el control de los tipos de cambio de una moneda respecto a otras (Strange, 1994: posición 1990). Los actores privados también han aumentado su poder en esta estructura, particularmente los bancos y fondos de inversión. A nivel del régimen de protección de inversiones se destaca la presencia de dos entidades internacionales que fortalecen la presencia de empresas extranjeras que invierten en Estados en desarrollo. La primera es la Corporación Financiera Internacional, agencia del Grupo Banco Mundial, que brinda préstamos a empresas privadas que invierten en Estados en desarrollo, y la segunda es el Organismo Multilateral de Garantía de Inversiones, también agencia del Grupo Banco Mundial, cuyo fin es brindar garantías a las inversiones de empresas privadas en Estados en desarrollo.

Finalmente, la estructura del conocimiento, la menos desarrollada por Strange, es aquella que se relaciona con el desarrollo de nuevos conocimientos, su almacenamiento y comunicación (Strange, 1994: posición 2609). En materia de solución de controversias inversor-Estado esta estructura se ve cuestionada en los dos casos presentados por la tabacalera Philip Morris Asia contra Australia (en base a las normas que establecen la cajilla plana) y Philip Morris contra Uruguay (en función de la regla de la presentación única y la regla del 80/80). En ambos casos el inversor puso foco en la propiedad intelectual, en concreto el uso de una marca, como una inversión protegida por una norma de fuente convencional que es presuntamente violada por el Estado receptor de la inversión. Una marca permite al consumidor identificar al productor y diferenciarlo de sus competidores, y por ende confiar en el conocimiento aplicado y/o desarrollado por la empresa para el producto que consume.

En suma, las empresas transnacionales en el marco del régimen de solución de controversias inversor-Estado ejercen tanto poder relacional como poder estructural, ya sea al negociar directamente los Estados u ocupar parcelas de poder que ellos abandonaron y moldear las normas que las regulan. En "La retirada del Estado" (2001), Strange ya muestra con claridad el avance de otros actores no estatales respondiendo a las lógicas de los mercados, particularmente el aumento de poder de las empresas transnacionales. Por tanto, la autora concluye que aunque 
"las empresas transnacionales no han desplazado a los gobiernos de los Estados, sin duda se han hecho con algunas de sus parcelas de poder. Es cada vez mayor la autoridad que ejercen en paralelo a la de los gobiernos, en materia de dirección económica con respecto a la localización de la industria y de la inversión, a la orientación de la innovación tecnológica, a la gestión de las relaciones laborales y a la imposición fiscal sobre los beneficios." (Strange, 2001: 101).

En este punto es pertinente tener en cuenta la afirmación de Sornarajah (2015: 23) en torno a que el régimen internacional de protección de inversiones presenta cambios respecto a otras áreas del Derecho Internacional, destacando, en primer lugar, el cambio en el poder puesto que el poder estatal y el poder corporativo en ocasiones actúan como un tándem frente a otros Estados receptores netos de inversiones. De esta manera el desbalance de poder detectado por Strange no solo se refleja en la situación de los Estados frente a las empresas transnacionales, sino que existe un desbalance entre los propios Estados según su lugar en relación a la figura de los inversores (Estado de nacionalidad de la empresa o Estado receptor de la inversión).

Dado que la teoría del poder estructural es desarrollada por Strange entre las décadas de los ochenta y los noventa, no tiene en cuenta los cambios que se han plasmado en el sistema internacional en los últimos años. Se destaca el esfuerzo analítico que realiza Sanahuja (2007) en torno al desplazamiento de poder de los Estados a otras entidades en cada una de las cuatro estructuras primarias. En relación al tema central de este trabajo, no estudiado por los mencionados autores, los cambios más significativos están reflejados en primer lugar en la posibilidad que presentan las empresas extranjeras de demandar a los Estados ante tribunales arbitrales, no así los Estados, y en segundo lugar en las situaciones de congelamiento o parálisis normativa. Este último efecto es de particular importancia dado que implica la abstención de regular o continuar un proceso normativo (discusión, elaboración, sanción, implementación o entrada en vigor) frente a una demanda o amenaza de demanda. Incluso, el congelamiento o parálisis normativa puede darse en otros Estados que, al encontrarse en una situación similar, sean disuadidos de regular.

Ambos puntos coadyuvan a que las empresas transnacionales puedan ser percibidas como creadoras (indirectas) de normas, ya que las demandas o amenazas de demandas impactan sobre la producción normativa doméstica. Este planteo y otros temas se analizarán en el siguiente apartado, reservado a los debates en torno a la subjetividad jurídica internacional de las empresas transnacionales. Cabe preguntarse si en este punto todos los Estados cumplen con su papel en la negociación entre el Derecho Nacional y las actividades de los actores económicos extranjeros en el territorio nacional que 
Sassen (2007: 50) destaca como participación necesaria en la nueva geografía de $\operatorname{poder}^{36}$.

\subsubsection{Empresas transnacionales como sujetos de Derecho Internacional}

Si bien el centro de esta investigación no es la subjetividad jurídica de las empresas transnacionales, se considera un análisis complementario que permitirá una mejor comprensión del poder ganado por las empresas transnacionales como actores de las relaciones internacionales, en particular en parcelas de poder que anteriormente eran ocupadas por los Estados (capacidad procesal y acceso directo a la solución de controversias inversor-Estado). Asimismo, dado que las empresas transnacionales habitualmente son los antagonistas ${ }^{37}$ de los Estados en los procesos arbitrales, el tema resulta pertinente habida cuenta que históricamente la subjetividad jurídica en Derecho Internacional Público ha estado vinculada con la soberanía. Por tanto, únicamente los entes que detentaran dicho atributo eran considerados sujetos.

Los Estados fueron durante mucho tiempo, además de sujetos originarios y plenos, los únicos sujetos del sistema. En consecuencia, esta rama del Derecho fue tradicionalmente considerada como un conjunto de normas creadas por los Estados para regular exclusivamente relaciones interestatales. No obstante, en la medida que el Derecho Internacional Público evolucionó y logró desligarse de su exclusividad soberanista, es que se reconoce la subjetividad jurídica internacional de otros actores de las relaciones internacionales, con diferente naturaleza y que cuentan con características no compartidas con los Estados. En esta línea se pronuncia la Corte Internacional de Justicia (CIJ) en la opinión consultiva relativa a las reparaciones a los daños sufridos al servicio de la ONU, de fecha 11 de abril de 1949, al indicar que

"The subjects of law in any legal system are not necessarily identical in their nature or in the extent of their rights, and their nature depends upon the needs of the community. Throughout its history, the development of international law has been influenced by the requirements of international life, and the progressive increase in the collective activities of States has already

\footnotetext{
36 Como respuesta a la nueva realidad que Strange ya percibía en 1995, la autora propone una "transnational coalition of forces concerned for the long-term welfare and indeed survival of global civil society and of the managed market economy that sustains it" (Strange, 1995: 294). ("una coalición trasnacional de fuerzas preocupadas por el bienestar a largo plazo y la supervivencia de la sociedad civil global y el manejo de la economía de mercado que lo sostiene" (Traducción propia)). En otras palabras, la autora impulsa una acción colectiva que proteja al Estado y frene su declive en el sistema internacional.

${ }^{37}$ Se emplea el adverbio "habitualmente" ya que la condición de inversor extranjero también puede ser ostentada por parte de una persona física, aunque esta particularidad se da en un menor número de casos. A los efectos de este trabajo se analiza la situación de los inversores personas jurídicas.
} 
given rise to instances of action upon the international plane by certain entities which are not States. "38 (página 8)

Dicha afirmación destaca la existencia de otros sujetos, además de los Estados, cuya personalidad jurídica internacional se basa en las propias necesidades del sistema internacional y que cuya naturaleza o extensión de derechos no es idéntica entré sí o en relación a otros sujetos, incluso los originarios. Sin perjuicio de lo anterior, cumplen con los requisitos determinados por la doctrina para ser sujeto de un sistema de coordinación, que como explican Jiménez de Aréchaga y otros son: participación directa en todas las etapas de creación, su interpretación, aplicación y castigo a los infractores de las normas (Jiménez de Aréchaga y otros, 2005: 180). Además de la capacidad normativa, habitualmente relacionada con el jus tractatum, la doctrina suele afirmar que para ser sujeto se requiere capacidad de enviar y recibir representantes (jus legationem) y capacidad procesal internacional (locus standi), en seguimiento de los atributos que clásicamente se asignan a los Estados.

En consecuencia, actualmente se aceptan como sujetos indiscutidos a los Estados, sujetos plenos y originarios, y a un grupo de sujetos secundarios y con personalidad jurídica funcional o específica a ciertas competencias, como ser las organizaciones internacionales tanto intergubernamentales como supranacionales, cuya actuación se enmarca en el principio de especialidad; los movimientos nacionales de liberación, surgidos en torno al proceso de descolonización; y las comunidades beligerantes. Asimismo, se acepta la subjetivad pasiva del ser humano individual. A su vez, en la práctica, la doctrina mayoritaria reconoce como sujetos al Comité Internacional de la Cruz Roja, la Soberana Orden de Malta y la Santa Sede (Jiménez de Aréchaga y otros, 2005).

Finalmente, existen entes que si bien son actores indiscutidos de las relaciones internacionales, en el ámbito del Derecho Internacional Público su subjetividad jurídica sigue estando en discusión. Este es el caso del ser humano individual con subjetividad activa, además de pasiva, los pueblos, las minorías, los movimientos terroristas, y ciertas fuerzas transnacionales como las organizaciones no gubernamentales y las empresas transnacionales (Remiro Brotóns, 2007).

\footnotetext{
38 "Los sujetos de derecho en cualquier sistema legal no son necesariamente idénticos en naturaleza o extensión de sus derechos, y su naturaleza depende de las necesidades de la comunidad. A través de la historia, el desarrollo del Derecho Internacional ha estado influenciado por los requerimientos de la vida internacional, y el aumento progresivo de las actividades colectivas de los Estados ha dado lugar, en el plano internacional, a la acción de ciertas entidades que no son Estados" (Traducción propia).
} 
En el caso particular de las empresas transnacionales, su personalidad jurídica en el Derecho Interno así como su creciente rol en las relaciones internacionales están fuera de discusión. En efecto, Strange (2001) resalta el desbalance de poder en el sistema internacional dado el auge de las empresas como actores políticos, ganando parcelas de poder que años atrás se encontraban dentro de la órbita estatal. Como explica Bizzozero, el reconocimiento de la subjetividad jurídica de las empresas transnacionales daría lugar a mayor transparencia en su funcionamiento, así como el planteo de instrumentos internacionales que establezcan su responsabilidad y obligaciones, y no exclusivamente derechos relacionados con el comercio y las inversiones (Bizzozero, 2017: 7-8).

En consecuencia, es posible cuestionarse si el Derecho Internacional Público acompaña el devenir de los hechos y reconoce a las empresas transnacionales el rol que, aunque limitado, le han dado los Estados. La doctrina se divide en dos: quienes aceptan la subjetividad internacional de las empresas transnacionales y quienes la niegan. Una posición intermedia la representan autores como Pérez Bernárdez (2010: 212) que afirman que las empresas transnacionales se encaminan a convertirse en sujetos (tertium genus) aunque actualmente no lo sean.

Quienes niegan la subjetividad internacional de las empresas transnacionales lo hacen comparándolas con los Estados, como tradicionalmente la doctrina ha comparado a los sujetos indiscutidos derivados o no plenos. Los argumentos en contra pueden sintetizarse en que este ente no cuenta con jus tractatum, ni jus legationem, ni locus standi en general, salvo en casos excepcionales como el arbitraje de inversor-Estado, y en la UE mediante la interposición de recursos ante el Tribunal General y recursos de casación, anulación y omisión ante el Tribunal de Justicia Europeo. En consecuencia, a continuación se analiza si las empresas transnacionales cumplen con los atributos clásicos asignados a los sujetos de Derecho Internacional.

El primero de los atributos es el jus tractatum. Aun si es cierto que las empresas transnacionales no participan de forma directa en la elaboración de tratados internacionales, el poder que ejercen sobre los Estados, influye de manera directa en la toma de decisiones en torno a la elaboración de normas internas como la firma, adhesión y/o cumplimiento de tratados internacionales. En esta línea, el ex Experto Independiente sobre la promoción de un orden internacional democrático y equitativo de la ONU (2012-2018), Alfred-Maurice de Zayas, analizó en el cuarto informe elevado a la Asamblea General la situación particular de las empresas transnacionales y el arbitraje inversor-Estado. Así, afirma que las demandas o amenazas de demandas de 
manos de inversores extranjeros, que pueden derivar en una "parálisis normativa" $o$ incluso una “congelación”, impidiendo a los Estados adoptar reglamentos" en áreas sensibles como la protección del medioambiente o la salud pública (ONU, 2015: 5). Asimismo, "podría disuadir en el futuro a los Estados, de tomar medidas para respetar, proteger y cumplir sus obligaciones en materia de derechos humanos y, por lo tanto, tiene un efecto negativo en el orden internacional democrático y equitativo" (ONU, 2015: 12).

La parálisis normativa se hace extensiva a los tratados internacionales al punto que los Estados pueden verse renuentes a aplicar normas programáticas como las contenidas en el artículo 11 del Convenio Marco de la Organización Mundial de la Salud sobre el Control de Tabaco respecto al empaque de los cigarrillos. El caso de Nueva Zelanda es una prueba fehaciente de lo anterior, puesto que en 2012 paraliza la sanción de una norma de empaque genérico de cigarrillos hasta tanto no fuera emitido el laudo del arbitraje iniciado por Philip Morris Asia contra Australia en la CPA (caso 2012-2). La demandante argumenta que la Ley de empaquetado genérico de los cigarrillos (2011) y sus normas modificatorias y complementarias constituían una violación de las disposiciones del Tratado Bilateral de Inversiones entre Hong Kong y Australia, en particular los artículos relativos al trato justo y equitativo y expropiación de la propiedad intelectual.

El proceso se cierra el 17 de diciembre de 2015 cuando el tribunal acepta la objeción de Australia en relación a que constituye abuso de derecho que el demandante realizara una restructuración en Hong Kong, poco antes del inicio del arbitraje. El laudo favorable a Australia deriva en que Nueva Zelanda retome la senda tendiente a la sanción de una ley de empaque genérico de cigarrillos, anunciando los cambios en la Enmienda sobre empaque genérico a la Ley de Ambientes libres de humo de tabaco del 14 de setiembre de $2016^{39}$ y el Decreto sobre Ambientes libres de humo de tabaco del 6 de junio de $2017^{40}$, que establecen los mecanismos de implementación del empaque genérico y su aplicación a partir del 14 de marzo de 2018. En definitiva, teniendo en cuenta los tiempos del arbitraje y la sanción de las normas internas, las medidas sobre empaque genérico en Nueva Zelanda estuvieron paralizadas por casi cinco años.

39 Texto 
Una situación similar se evidencia en el caso de El Salvador frente al arbitraje iniciado por la minera Pac Rim, que se analizará en profundidad en el círculo 2. El germen de la disputa se centra en la obtención de los permisos de explotación minera de oro y plata del Proyecto El Dorado en el departamento de Cabañas y la detención de facto de la emisión o renovación de permisos hasta tanto no se aprobara una nueva ley de minería. Dado que la empresa considera que su inversión perdió valor y que El Salvador modificó ilegítimamente el régimen jurídico en el marco del cual invirtió, se presenta ante el CIADI y solicita una indemnización de 314 millones de dólares (caso número $\mathrm{ARB} / 09 / 12)$.

En el laudo del 14 de octubre de 2016, el tribunal desestima las pretensiones de Pac Rim, al considerar que, a la fecha del anuncio del Presidente Saca, la empresa no tenía derechos de explotación en vigor, por tanto el reclamo de daños y perjuicios no es amparado por el Derecho Salvadoreño ni el Derecho Internacional. Asimismo la condena al pago de parte de los gastos legales incurridos por el Estado durante el litigio. Si bien el fallo es favorable al Estado, se repite la situación de parálisis normativa, la ley que prohíbe la minería metálica en suelo y subsuelo termina siendo sancionada el 29 de marzo de 2017, siete años después del inicio del litigio.

En este sentido, Arato afirma que la parálisis normativa termina por perfilar a las empresas multinacionales como creadoras de normas vinculantes para los Estados, lo cual "threatens local and global public values, as diverse as economic development, human rights, and the protection of public health and the environment" (Arato 2015: $283)^{41}$. Incluso situaciones como las anteriores podrían llegar a cuestionar si el atributo de creación de normas internacionales no es indirectamente ejercido por las empresas transnacionales al ejercer presión sobre los Estados en las diferentes etapas de la formación de los tratados.

Continuando con el segundo atributo de los sujetos, es innegable que las empresas no poseen jus legationem. Sin embargo, en lo que refiere al tercer atributo, el locus standi in judicio, las empresas que ofician de inversores extranjeros pueden demandar a los Estados en foros jurisdiccionales como el CIADI o la CPA, siempre que cumplan con determinados requisitos. En el caso particular del CIADI, el artículo 25 del Convenio del Washington establece que la institución tiene jurisdicción para entender en aquellas

${ }^{41}$ En este sentido, Arato afirma que la parálisis normativa termina por perfilar a las empresas multinacionales como creadoras de normas vinculantes para los Estados, lo cual "amenaza valores públicos locales y regionales, tan diversos como el desarrollo económicos, los derechos humanos y la protección de la salud o el medioambiente" (Traducción propia). 
controversias inversor-Estado que sean de naturaleza jurídica, que tengan una relación directa con una inversión entre un Estado parte y un nacional de otro Estado parte de dicho tratado, y en las que exista una cláusula de prórroga de jurisdicción por escrito. La prórroga de jurisdicción puede encontrarse en un tratado bilateral de inversiones, el capítulo de inversiones de un tratado de libre comercio, un tratado regional, un contrato entre la empresa y el Estado receptor de la inversión o una ley de inversiones.

Por tanto, al ser titulares de la acción, las empresas no solo tienen locus standi en el arbitraje de inversiones, sino que se ha dado un paso más al reconocerse su jus standi, esto es, la titularidad de la acción y el consecuente acceso directo a los tribunales internacionales. Este punto puede ser de especial trascendencia puesto que en el caso del ser humano no goza de acceso directo a la Corte Interamericana de Derechos Humanos en el actual Sistema Interamericano de Derechos Humanos ${ }^{42}$.

En vista de lo anterior, las empresas transnacionales pueden ser consideradas sujetos de Derecho Internacional Público, si bien de carácter menor. Asimismo, como expresa Bermejo García, su personalidad jurídica es relativa y funcional. Relativa porque no tiene carácter erga omnes sino que es oponible al Estado que la haya reconocido; y funcional porque está limitada al cumplimiento de las obligaciones que se establecen en los acuerdos internacionales (Bermejo García, 2015: 103). Sin perjuicio de lo anterior, es posible agregar que los Estados reconocen virtualmente a todas las empresas transnacionales cuyo centro de negocios se encuentre en determinado Estado con el cual se celebre, por ejemplo, un TBI. Asimismo, la personalidad jurídica de estos sujetos está limitada no solo a las obligaciones específicas que deban cumplir sino también a los derechos específicos que se les otorga.

La problemática analizada respecto a la subjetividad jurídica de las empresas transnacionales se acrecienta, habida cuenta que Derecho Internacional contemporáneo no ha sido suficiente para dar solución al problema de las empresas transnacionales como titulares de obligaciones (Theilbörger y Ackermann, 2017). Ahora bien, en materia de derechos humanos Droubi (2016) afirma que la obligación de las empresas de respetarlos ha sido indirectamente incluida en el artículo 30 de la Declaración Universal de Derechos Humanos con redacción suficientemente laxa como para incluir

\footnotetext{
${ }^{42}$ Para un análisis específico de este tema ver: Rosas Castañeda (2007) y Cançado Trindade (2007).
} 
la obligación de las empresas a respetar los derechos humanos ${ }^{43}$, pero también ha tenido un tratamiento directo en las resoluciones 14/5 y 21/5 del Consejo de Derechos Humanos. Sin embargo, el autor indica que

\begin{abstract}
"This reiterated affirmation of the obligation seems to constitute an embryonic U.N. practice that reflects the opinio juris of many states and directs the progressive crystallization of a legal norm requiring TNCs to respect international human rights law-either as a customary norm or, more likely given the general character of the norm, a principle of international law. On this perspective, the TNC obligation to respect human rights will not be directly derived from existing human rights instruments but rather from an emerging norm-a new instrument that may expressly set forth the obligation. ${ }^{, 44}$ (Droubi, 2016: 129-130).
\end{abstract}

Si bien este trabajo tiene como foco la relación Estado-empresas transnacionales en el marco del régimen de solución de controversias inversor-Estado, y no las violaciones corporativas a los derechos humanos per se, esta problemática es de relevancia porque en el régimen bajo análisis son las empresas las que tienen la legitimación activa para iniciar arbitrajes, no así los Estados. La elaboración de normas internacionales que determine la responsabilidad empresarial en materia de derechos humanos en caso de actividades transnacionales, con mecanismos jurisdiccionales efectivos, puede actuar como contracara del régimen de solución de controversias inversor-Estado. Este punto será objeto de análisis en el círculo 3.

\title{
1.6. Una aproximación en conjunto
}

En una aproximación en conjunto, el marco teórico de este trabajo parte de la teoría de los regímenes internacionales (Ruggie, 1975, Krasner, 1983, Keohane, 1982, 1988) como teoría general que explica el régimen de solución de controversias inversorEstado en el cual se enmarca la parcela de la realidad bajo análisis: la relación Estadoempresa transnacional. Desde el punto de vista jurídico, los regímenes están conformados por normas jurídicas que recogen principios y reglas que no necesariamente son compartidos por otros regímenes. Este fenómeno, actualmente se conoce con el nombre de fragmentación del Derecho Internacional General en

\footnotetext{
${ }^{43}$ Artículo 30: "Nada en esta Declaración podrá interpretarse en el sentido de que confiere derecho alguno al Estado, a un grupo o a una persona, para emprender y desarrollar actividades o realizar actos tendientes a la supresión de cualquiera de los derechos y libertades proclamados en esta Declaración."

44 "Esta reiterada afirmación en torno a las obligaciones de las empresas parece constituir una práctica embrionaria de la ONU que refleja la opinio juris de muchos Estados y que se dirige a una progresiva cristalización normativa que determine el respecto del Derecho Internacional de los Derechos Humanos por parte de las empresas transnacionales o, tal vez más factible dado el carácter general de la norma, un principio de Derecho Internacional. Desde esta perspectiva, la obligación de las empresas transnacionales de respetar los derechos humanos no van a derivar directamente de los instrumentos actuales que regulan la materia sino de normas emergentes, un nuevo instrumento que expresamente contenga la obligación". (Traducción propia).
} 
regímenes autocontenidos. La extensión de los temas susceptibles de regulación internacional retroalimenta la existencia de los regímenes y una potencial tensión cuando las normas que componen cada uno de los conjuntos brindan soluciones opuestas.

La teoría general se desagrega en otras sustantivas, que permiten una mejor comprensión de las diferentes aristas del problema de investigación. Así, la relación Estado-empresas transnacionales en el régimen de solución de controversias inversorEstado se da en el marco de un modelo institucionalizado (abordaje desde los modelos de las relaciones internacionales propuestos por Consani, 2008, 2016). Asimismo, surge la necesidad de examinar el atributo de la soberanía estatal, dado que la elección de ingresar, permanecer o abandonar un régimen está directamente vinculada a este. Así, se introducen los aportes de Krasner $(2001,2009$, 2011) en relación a las diferentes proyecciones que el concepto ha tenido a lo largo del tiempo (soberanía de interdependencia, interna, westfaliana y legal internacional). Al mismo nivel de teoría sustantiva, los aportes de Krasner respecto a la soberanía dialogarán con las teorías de la autonomía, como condición que le permite al Estado articular y lograr sus objetivos de manera independiente (Puig, 1980, 1986, Jaguaribe, 1979, Russel y Tokatlian, 2001, Rapoport y Miguez, 2015, entre otros).

Finalmente, en lo que respecta al rol de las empresas transnacionales, se siguen los aportes de Strange respecto al poder estructural (1994) y a la retirada del Estado (2001) de ciertas parcelas de poder frente al avance de los actores no estatales y el mercado. Este análisis se realiza tomando en consideración los debates en torno a la subjetividad internacional de las empresas transnacionales y su obligación de respeto de los derechos humanos.

En suma, los diferentes elementos que se articulan en el marco teórico de este trabajo se sintetizan en la siguiente ilustración. 


\section{Ilustración 2: Marco teórico}

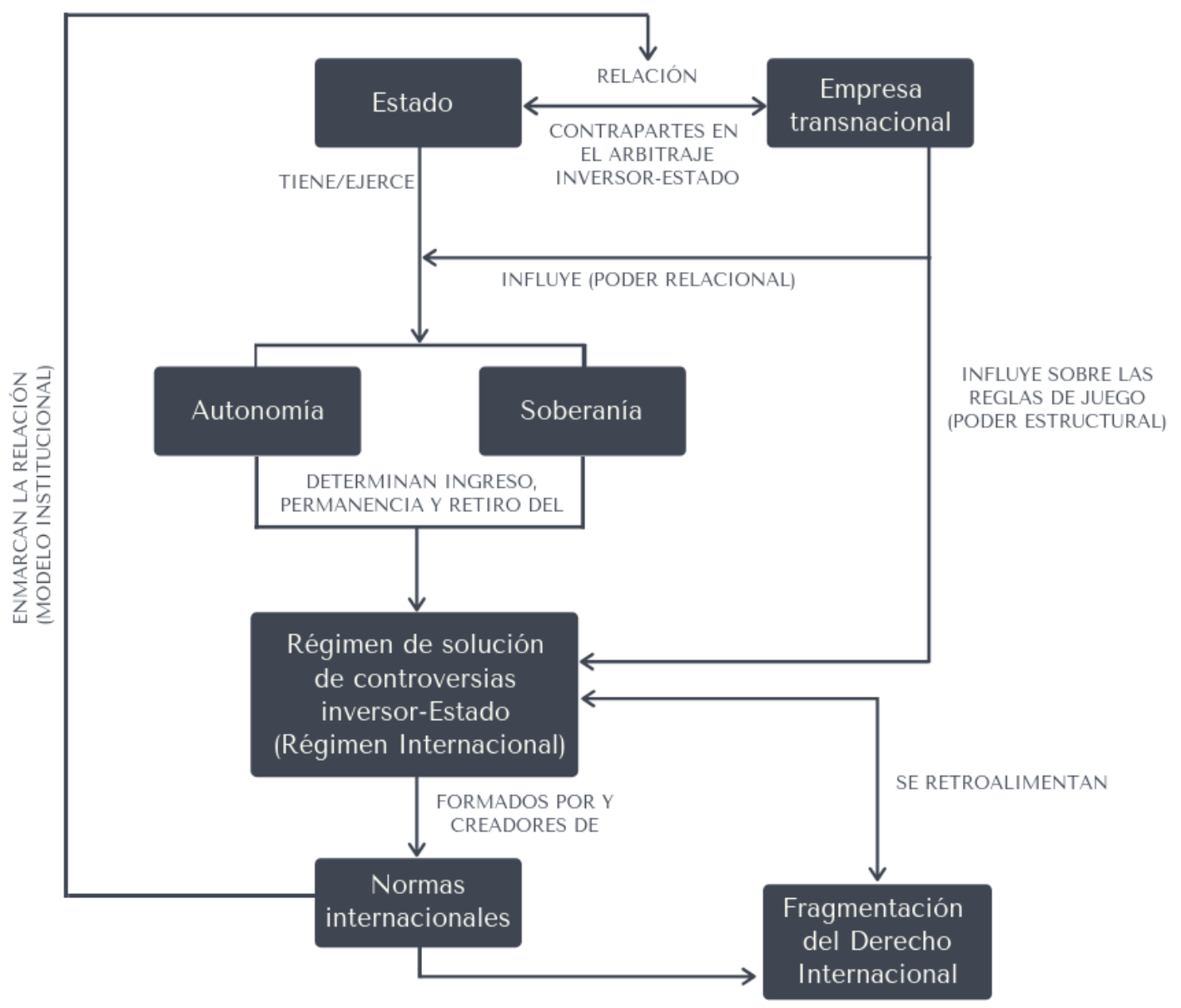

Fuente: Elaboración propia. 
Círculo 1: Alternativas al régimen internacional de solución de controversias inversor-Estado 


\section{Capítulo 2: Abandono del régimen de solución de controversias inversor-Estado}

\subsection{Aspectos preliminares}

El primer círculo de esta investigación busca responder la pregunta: ¿cuál es el fundamento de las alternativas que se plantearon frente al régimen de solución de controversias inversor-Estado (período 2007-presente)? ¿Qué papel jugaron los actores involucrados? La hipótesis mediante la cual se busca responder dicha pregunta de investigación es: "las alternativas que se presentaron al régimen de solución de controversias inversor- Estado son la terminación de tratados bilaterales de inversión, el retiro del CIADI y la celebración de nuevos tratados balanceados (exclusión total o sectorial de la solución de controversias inversor-Estado), y están motivadas, principalmente, en cambios en normas fundamentales a nivel doméstico”.

En la hipótesis se manejan tres dimensiones: 1) terminación de los TBI; 2) retiro del CIADI; 3) celebración de tratados balanceados. En un mayor nivel de abstracción, las primeras dos dimensiones pueden agruparse en abandono del régimen de solución de controversias inversor-Estado por parte de Estados que previamente eran miembros. Por tanto, a los efectos de una mejor comprensión de la situación de los Estados involucrados, se analizarán en forma conjunta. En consecuencia, el primer círculo se estructura en dos capítulos, uno de ellos dedicado al abandono del régimen y otro a los nuevos tratados que proponen alternativas institucionales o cambios en los sectores o medidas susceptibles de resolución de controversias entre inversores extranjeros y Estados huéspedes.

El presente capítulo se dedica al análisis de evolución histórica de la situación de Sudamérica, actualmente fragmentada en tres grupos: los miembros del sistema (Argentina, Colombia, Chile, Guyana, Paraguay, Perú, Surinam y Uruguay), los disidentes (Bolivia, Ecuador y Venezuela) y el externo (Brasil). El foco se pone en el caso de Bolivia, Ecuador y Venezuela que constituyen los primeros Estados en América del Sur, y el mundo, en abandonar el CIADI, notificando la denuncia al Convenio de Washington sobre arreglo de diferencias relativas a inversiones entre Estados y nacionales de otros Estados (Convenio de Washington), el 1 de mayo de 2007, el 2 de julio de 2009 y el 24 de enero de 2012 respectivamente ${ }^{45}$. Asimismo, Bolivia y Ecuador

\footnotetext{
${ }^{45}$ De acuerdo al artículo 71 del Convenio de Washington, las denuncias son efectivas seis meses después de su notificación.
} 
inician procesos de terminación de los TBI en vigor, motivados por disposiciones constitucionales con diferente grado de apertura a las jurisdicciones regionales o internacionales.

El capítulo cierra con el estudio de la situación de Sudáfrica, Estado que no forma parte del recorte geográfico determinado a los efectos metodológicos, pero cuyo análisis se incluye para aportar elementos contrafácticos. Sudáfrica atraviesa por una experiencia similar a los Estados disidentes sudamericanos a consecuencia del caso Piero Foresti y otros, que tiene como corolario una reforma del sistema de protección de inversiones sudafricano. Esta reforma determina un regreso a la jurisdicción doméstica y la denuncia inicial de nueve TBI con Estados europeos y más recientemente con Argentina.

\subsection{Sudamérica dividida en tres: los miembros, los disidentes y el externo ${ }^{46}$}

\subsubsection{Antecedentes: del apego a la doctrina Calvo al consenso de Washington}

Hasta entrada la década del ochenta, América Latina presenta una posición uniforme frente al arbitraje internacional inversor-Estado, cuya base se encuentra en la identificación con la doctrina Calvo y generó una evidente diferenciación del resto de los Estados o grupos de Estados en todo el globo. La mencionada doctrina, elaborada en 1868 por el jurista argentino Carlos Calvo y recogida en varias constituciones latinoamericanas, tenía como sustento los principios de igualdad soberana, no intervención y trato igualitario entre extranjeros y nacionales. Los Estados, como soberanos, tienen derecho determinar libremente sus políticas internas y externas, sin injerencia extranjera, y dado que los extranjeros tienen iguales derechos a los nacionales, estos deben agotar todos los recursos de la jurisdicción doméstica antes de pedir la protección diplomática del Estado de su nacionalidad a fin de hacer efectiva la responsabilidad internacional del otro Estado (Tamburini, 2002: 82).

La protección diplomática establece que el Estado de la nacionalidad del particular afectado es quien hace propio el reclamo frente al Estado incumplidor y no el particular (Torreja Mateu, 2012, 317; Burgos-De la Ossa y Lozada-Pimiento, 2009: 272). Actualmente, a diferencia de lo que sucedía durante el desarrollo y consolidación de la doctrina Calvo, la doctrina mayoritaria así como el Proyecto de artículos sobre

\footnotetext{
${ }^{46}$ La tipología de Estados empleada para este apartado fue elaborada en una investigación anterior cuyos resultados se recogen en Bas Vilizzio (2017). Para esta tesis se reestructuró la tipología, incluyendo al grupo de los confrontadores, el cual no está presente en América del Sur. Véase apartado 6.2.
} 
protección diplomática de la Comisión de Derecho Internacional de la ONU del año 2006, condiciona el ejercicio de la misma a que el particular afectado tenga un vínculo de nacionalidad con el Estado reclamante, y que agote previamente los recursos internos en el Estado incumplidor. Una parte minoritaria de la doctrina exige adicionalmente que el particular no haya contribuido con su conducta al hecho que le ha causado el daño (Torroja Mateu, 2012: 322).

En materia de protección de inversiones extranjeras, la limitación implica el agotamiento de la jurisdicción doméstica como condición para que el inversor extranjero inicie un arbitraje contra el Estado anfitrión. No obstante, una versión más restringida de la doctrina Calvo, incluida en diferentes contratos entre inversores extranjeros y Estados Latinoamericanos, es la denominada "cláusula Calvo". Esta disposición determina que el inversor no está habilitado a recurrir a la protección diplomática de su Estado de nacionalidad, ya fuera implementada o no mediante medios pacíficos de solución de controversias internacionales ${ }^{47}$ (Polanco, 2014: 5).

Es en el plano multilateral que la unidad sudamericana cobra especial valor frente al borrador de tratado internacional que estableciera el arbitraje internacional ad hoc como mecanismo para la solución de controversias inversor-Estado elaborado por el Banco Mundial. Este tiene como fin la constitución de una institución que deberá atender arbitrajes bajo una serie de parámetros, esto es, controversias entre un inversor nacional de un Estado signatario del mencionado acuerdo y un Estado también signatario, directamente relacionadas con una inversión, siempre y cuando existiera prórroga de jurisdicción por escrito. Quien iniciaba el arbitraje era necesariamente el inversor extranjero que veía incumplida la protección que el Estado anfitrión estaba obligado a brindar, y no viceversa, asimismo nada se establece respecto a la obligatoriedad de agotar la jurisdicción doméstica.

En la reunión anual de la Junta de Gobernadores del Banco Mundial el 9 de setiembre de 1964 en la ciudad de Tokio, movidos por la tradición jurídica en torno a la doctrina Calvo y por ende en protección de premisas constitucionales, diecinueve Estados Latinoamericanos (Argentina, Bolivia, Brasil, Chile, Colombia, Costa Rica, República Dominicana, Ecuador, El Salvador, Guatemala, Haití, Honduras, México, Nicaragua, Panamá, Paraguay, Perú, Uruguay y Venezuela (Schreuer, 2009: 2 - 3; Fach Gómez,

\footnotetext{
${ }^{47}$ Cabe señalar que en este momento no estaba en vigor la Carta de la ONU, por tanto la prohibición del uso o amenaza de la fuerza en las relaciones entre Estados no constituía un principio del Derecho Internacional Público.
} 
2011: 2; Boeglin, 2012)), junto a Irak y Filipinas votan en contra del borrador preliminar del Convenio de Washington constitutivo del CIADI.

En el discurso realizado por el representante de Chile en la Junta de Gobernadores se resumen los principales puntos del de ahí en más conocido "No de Tokio", en particular el hecho que

"El nuevo sistema que se ha sugerido daría al inversionista extranjero, sólo en virtud del hecho de que es un extranjero, el derecho a demandar a un Estado soberano fuera de su territorio nacional, prescindiendo de sus tribunales de justicia. Esta disposición es contraria a los principios jurídicos aceptados de nuestros países $y$, de hecho, otorgaría un privilegio al inversionista extranjero, colocando a los nacionales del país de que se trate en una posición de inferioridad" (citado por Polanco, 2014: 10).

Aun sin el apoyo de los Estados Latinoamericanos el Convenio constitutivo del CIADI es aprobado y entra en vigor en 1966. Con el consenso de Washington el "no de Tokio" comienza a revertirse en la mayoría de los Estados Sudamericanos. A octubre de 2019, todos los Estados del "no de Tokio" son parte del Convenio de Washington (véase tabla 1), Filipinas adhirió en 1978, Irak y México lo hicieron recientemente en 2015 y 2018 respectivamente. La excepción sigue siendo Brasil que nunca ingresó al acuerdo por adhesión y República Dominicana que adhirió en el año 2000 pero no lo ratificó. Asimismo, el convenio es denunciado por Bolivia, Ecuador y Venezuela (véase punto 2.3).

Tabla 1: Estatus de ratificaciones del Convenio de Washington por Estado Sudamericano

\begin{tabular}{|c|c|c|c|c|}
\hline Estado & Adhesión & $\begin{array}{c}\text { Depósito del } \\
\text { instrumento de adhesión }\end{array}$ & Entrada en vigor & Observaciones \\
\hline Argentina & 21 mayo 1991 & 19 octubre 1994 & 18 noviembre 1994 & - \\
\hline Bolivia & 3 mayo 1991 & 23 junio 1995 & 23 julio 1995 & $\begin{array}{c}\text { Terminado por denuncia } \\
\text { unilateral notificada } 1 \\
\text { mayo } 2007\end{array}$ \\
\hline Brasil & - & - & - & - \\
\hline Chile & 25 enero 1991 & 24 setiembre 1991 & 24 octubre 1991 & - \\
\hline Colombia & 18 mayo 1993 & 15 julio 1997 & 14 agosto 1997 & - \\
\hline Ecuador & 15 enero 1986 & 15 enero 1986 & 14 febrero 1986 & $\begin{array}{c}\text { Terminado por denuncia } \\
\text { unilateral notificada } 2 \\
\text { julio } 2009\end{array}$ \\
\hline Guyana & 3 julio 1969 & 11 julio 1969 & 10 agosto 1969 & - \\
\hline Paraguay & 27 julio 1981 & 7 enero 1983 & 6 febrero 1983 & - \\
\hline Perú & 4 setiembre 1991 & 9 agosto 1993 & 8 setiembre 1993 & - \\
\hline Surinam & - & - & - & - \\
\hline
\end{tabular}




\begin{tabular}{|c|c|c|c|c|}
\hline Estado & Adhesión & $\begin{array}{c}\text { Depósito del } \\
\text { instrumento de adhesión }\end{array}$ & Entrada en vigor & Observaciones \\
\hline Uruguay & 28 mayo 1992 & 9 agosto 2000 & 8 setiembre 2000 & - \\
\hline Venezuela & 18 agosto 1993 & 2 mayo 1995 & 1 junio 1995 & $\begin{array}{c}\text { Terminado por denuncia } \\
\text { unilateral notificada 24 } \\
\text { enero 2012 }\end{array}$ \\
\hline
\end{tabular}

Fuente: Elaboración propia en base a datos del CIADI. Fecha de consulta: 25 de agosto de 2019.

El consenso de Washington es un paquete de medidas macroeconómicas propulsado por el Fondo Monetario Internacional, el Banco Mundial y el Departamento del Tesoro de Estados Unidos, todos con sede en la ciudad de Washington, de ahí su denominación. Los diez puntos de la agenda son: La agenda incluía 10 puntos: 1) Disciplina fiscal; 2) Reordenación de las prioridades del gasto público; 3) Reforma fiscal; 4) Liberalización financiera; 5) Tipo de cambio competitivo; 6) Liberalización del comercio; 7) Liberalización de la inversión extranjera directa; 8) Privatizaciones; 9) Desregulación; 10) Derechos de propiedad asegurados (Martínez Rangel y Reyes Garmendia, 2012: 46 - 48; Fernández Alonso, 2013: 48 - 50; Bohoslavsky, 2010: 18; Gianelli, 2012: 20).

Por tanto, el paquete propuesto genera el clima propicio para que los gobiernos neoliberales de los noventa comiencen la práctica de celebrar TBI y consoliden la adhesión al Convenio de Washington. Los TBI se presentan como instrumentos capaces de compensar los riesgos políticos o no comerciales, especialmente en países en desarrollo, evitando cualquier cambio en la legislación nacional que sea factible de afectar tales inversiones y generando un clima de seguridad política para el inversor (De Azevedo, 2001: 4). Asimismo, el intento fallido de concretar el Acuerdo Multilateral de Inversión (AMI) impulsado por la Organización para la Cooperación y el Desarrollo en $1995^{48}$, tratado que pretendía vincular incluso Estados no miembros de la organización, deriva en celebración de mayor número de TBI.

Siguiendo el modelo del Acuerdo de Libre Comercio de Norteamérica, el último borrador disponible del AMI (22 de abril de 1998) muestra un acuerdo que profundiza la estructura a los TBI celebrados en el década del noventa. Sus disposiciones se agrupan en los siguientes puntos: 1) Disposiciones generales; 2) Ámbito de aplicación, destacándose una definición amplia de inversión; 3) Trato a los inversores y las inversiones, destacándose la CNMF, el trato nacional, la transparencia, no disminución del estándar mínimo en materia laboral o medioambiental, etc.; 4) Protección de las

\footnotetext{
48 Texto del último borrador datado 22 de abril de 1998 se encuentra disponible en: http://www1.oecd.org/daf/mai/pdf/ng/ng987r1e.pdf
} 
inversiones, esto es garantías y compensaciones por expropiación, garantías de libre traspaso de fondos y transferencia de capitales y ganancias al exterior, protección de inversiones existentes; 5) Solución de controversias Estado-Estado e inversor-Estado ${ }^{49}$; 6) Excepciones y salvaguardias; 7) Disposiciones específicas para servicios financieros; 8) Disposiciones específicas en materia tributaria; 9) Excepciones por Estado; 10) Relación con otros tratados internacionales, citándose únicamente el Acuerdo del Fondo Monetario Internacional y las Líneas directrices de la OCDE sobre empresas multinacionales, aunque este último no es un tratado internacional; 11) Implementación y operación; 12) Disposiciones finales. Si bien el texto es de mayor complejidad al tener en cuenta las características de una multiplicidad de eventuales Estados parte, en líneas generales sigue la categorización de capítulos que analiza Salacuse (2010: 127-128) para los TBI.

El AMI tuvo una fuerte resistencia. Tres fueron los temas más controvertidos: la compatibilidad del acuerdo con los tratados previos de integración regional, la ambigüedad de los aspectos sociales, laborales y medioambientales y el amplio margen a la interpretación a la hora de reclamar su protección; y la situación del sector cultural el cual es tratado como una industria y no contempla la protección de la diversidad cultural y lingüística (Borrás, 1998: 26). La resistencia provino tanto de los Estados en desarrollo como algunos europeos, en particular señalando la preocupación de la amenaza a la soberanía.

En efecto, el argumento empleado por el Primer Ministro Francés Lionel Jospin al retirarse de la negociación el 14 de octubre de 1998, fue que este constituía una amenaza inaceptable a la soberanía nacional (Muchlinski, 1999: 1048). Esta idea, explica Fontoura Costa (2010: 249), está basada en dos elementos: la amplitud en la liberalización y protección previa al establecimiento de la inversión, y la restricción de la capacidad regulatoria del Estado en la fase de posterior al establecimiento. En particular, el autor señala el amplio margen de interpretación que deja el uso de conceptos imprecisos como el de trato justo y equitativo y las medidas equivalentes a la

\footnotetext{
${ }^{49}$ En cuanto a la solución de controversias inversor-Estado, tema central de este trabajo, el AMI cuenta con un ámbito de aplicación amplio ya que, por intermedio de una cláusula paraguas, hace aplicable los mecanismos al incumplimiento de cualquier otro instrumento o autorización entre el Estado y el inversor. La disputa debe ser resuelta mediante consultas (sin indicación de período de enfriamiento), y de no prosperar existen dos posibilidades: 1) jurisdicción doméstica (como opción, no como requisito previo), 2) arbitraje internacional bajo las Reglas de Arbitraje del CIADI, el Mecanismo Adicional del CIADI, las Reglas de Arbitraje de la UNCITRAL, o las Reglas de Arbitraje de la CCI. Las normas previstas no distan demasiado de los tradicionales TBI de la década del noventa, incluso por la ausencia del requisito de agotamiento previo de la jurisdicción doméstica.
} 
expropiación.

Desde la sociedad civil el rechazo por el acuerdo estuvo centrado en la estructura de su negociación: falta de transparencia, no participación de otras partes interesadas, y por ende déficit democrático. Asimismo, se criticó que el acuerdo aceleraría la globalización y restringiría la capacidad de los Estados de tomar decisiones, sin proteger de manera clara áreas sensibles como el medioambiente, la dimensión laboral, la dimensión social y los derechos humanos o dar respuesta a la inestabilidad económica de los Estados más pobres (Borrás, 1999). En consecuencia, las acciones de los grupos de presión tanto a nivel de la OCDE como de los Estados negociadores, así como la propia estructura del acuerdo "excessivamente protetor dos investimentos estrangeiros, desestimulou os própios membros da $O C D E^{, 50}$ terminó en fracaso (Fontoura Costa, 2010: 253).

Este fracaso del AMI fortaleció el auge de los acuerdos bilaterales. Como señala Fontoura Costa (2010: 127), la década de los noventa coincide con el mayor número de TBI celebrados aún por Estados tradicionalmente partidarios de la doctrina Calvo. De los 203 TBI celebrados en los Estados Sudamericanos al 31 de diciembre de 2018, estén en vigor o no, 155 son firmados en la década de los noventa. Se destaca Argentina con 55 TBI celebrados en dicha década y solo 6 en otros períodos (véase gráfica 2).

\footnotetext{
${ }^{50} \mathrm{La}$ propia estructura del acuerdo "excesivamente protector de las inversiones extranjeras, desalentó a los propios miembros de la OCDE” (Traducción propia).
} 
Gráfica 2: Número de TBI celebrados por Estados Sudamericanos en la década de los noventa en comparación con otros períodos

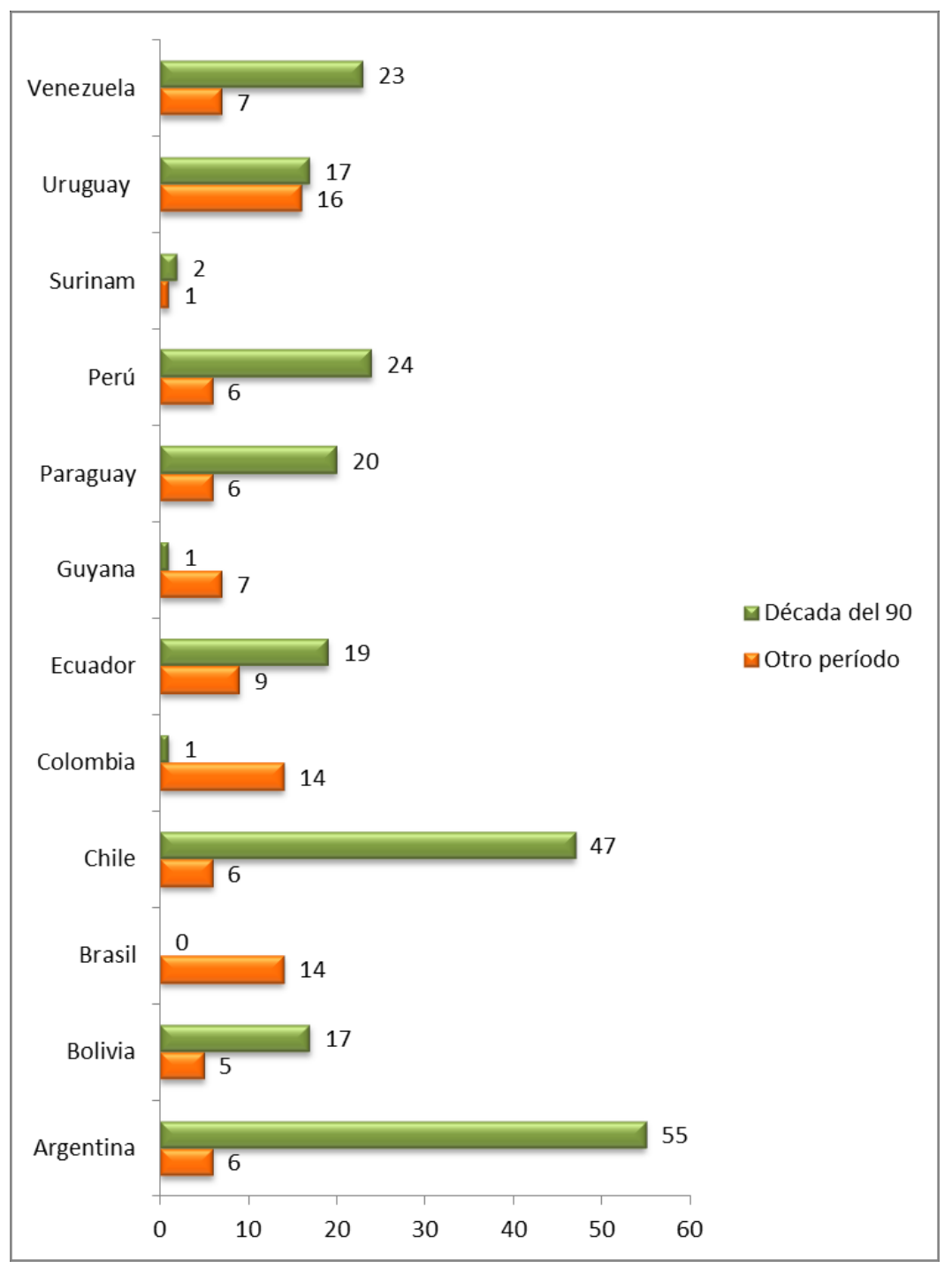

Fuente: Elaboración propia en base a datos del Investment Policy Hub de la UNCTAD. Fecha de consulta: 21 de abril de 2019. No incluye los acuerdos de cooperación y facilitación de inversiones celebrados por Brasil (2015-presente).

\subsubsection{Siglo XXI y la división sudamericana}

La primera década del siglo XXI y los años siguientes se han caracterizado por un importante aumento en el número de demandas contra los Estados Latinoamericanos, muchas de ellas reclamando cuantiosas indemnizaciones. A modo de ejemplo, en el Caso Occidental Petroleum Corporation y Occidental Exploration and Production Company contra Ecuador (CIADI caso número ARB/06/11), el tribunal arbitral hace lugar a la solicitud de indemnización de casi 1800 millones de dólares. Particularmente, 
se destacan aquellas demandas que cuestionan nueva legislación doméstica relativa a sectores sensibles como ser petróleo, gas y minería, energía eléctrica y otras fuentes de energía, aguas y servicios de saneamiento, finanzas, instrumentos de deuda, entre otros. Estos sectores involucran temas que no quedan exclusivamente en el ámbito económico, sino que desbordan hacia otras áreas del Derecho, como ser los derechos humanos, tema que será de análisis en el círculo 2 de este trabajo.

Es en este contexto que los Estados Sudamericanos comienzan a quebrar su tradicional postura monolítica frente al régimen internacional de solución de controversias inversor-Estado. En este sentido, siguiendo la teoría de los regímenes internacionales, el continente se divide en tres grupos: los miembros del régimen, los disidentes y el externo. En el caso de los miembros, sus expectativas convergen en la protección de inversiones, lo cual implica la existencia de mecanismos de solución de controversias, usualmente arbitraje ad hoc. Para ser parte del sistema, los Estados deben celebrar TBI y ser miembros del CIADI, adhiriendo al Convenio de Washington. Ejemplo de este tipo de Estados es Argentina, Chile, Colombia, Paraguay, Perú y Uruguay.

Es particularmente interesante el caso de Argentina, puesto que es el Estado con mayor número de TBI en vigor en Sudamérica $\left(50^{51}\right)$ y mayor número de demandas de inversores tanto sea tomando el conjunto de Estados Sudamericanos como el mundo entero $\left(60^{52}\right)$. Este último punto se debe a que las empresas concesionarias de servicios públicos ${ }^{53}$ privatizadas en la década del noventa inician procesos arbitrales al verse afectadas por las medidas tomadas a partir de diciembre de 2001 para paliar la crisis económico-social. Se destaca la Ley de Emergencia Pública y Reforma del Régimen Cambiario (Ley 24.561 sancionada el 6 de enero de 2002), norma que deja sin efecto las cláusulas de ajuste en dólares u otras monedas extranjeras y las cláusulas basadas en parámetros internacionales, como ser los índices de precios de otros Estados, y la conversión de los precios y tasas incluidos en contratos públicos (Fernández Alonso, 2013: 58, Ricaurte Herrera, 2012: 156).

En relación al siguiente grupo de Estados, los externos, son aquellos que entienden que los beneficios recibidos una vez incorporado en el régimen, no son mayores ni iguales a los que se percibían antes de su incorporación y eligen permanecer fuera. Por

\footnotetext{
${ }^{51}$ Datos del Investment Policy Hub de la UNCTAD actualizados al 31 de diciembre de 2018. Fecha de consulta: 21 de abril de 2019.

${ }^{52}$ Datos del Investment Policy Hub de la UNCTAD actualizados al 31 de diciembre de 2018. Fecha de consulta: 21 de abril de 2019.

${ }^{53}$ Los principales sectores económicos involucrados son: petróleo y gas, energía eléctrica, aguas y saneamiento, informática y comunicaciones (particularmente telefonía).
} 
consiguiente no firman, adhieren y/o ratifican el Convenio de Washington ni TBI. Este grupo está formado por un único Estado: Brasil. Finalmente, los disidentes son aquellos Estados que en algún momento fueron miembros del régimen pero decidieron dejar de serlo, terminando los TBI en vigor y denunciando el Convenio de Washington. El proceso de abandono es motivado por la percepción que los costos de permanecer en el régimen son mayores a los de estar fuera del mismo. Este es el caso de Bolivia, Ecuador y Venezuela, cada uno de los cuales serán analizados en el siguiente apartado. En la tabla 2 se resumen las tres posiciones que conforman la tipología de Estados Sudamericanos ante el régimen de solución de controversias inversor-Estado.

Tabla 2: Tipología de Estados Sudamericanos ante el régimen de solución de controversias inversor-Estado

\begin{tabular}{|c|c|c|c|}
\hline \multicolumn{3}{|c|}{ Miembros } & Disidentes \\
\hline $\begin{array}{l}\text { Estados que lo } \\
\text { componen }\end{array}$ & $\begin{array}{l}\text { Argentina; Chile; Colombia; } \\
\text { Guyana; Paraguay; Perú; } \\
\text { Surinam; Uruguay. }\end{array}$ & Brasil. & $\begin{array}{l}\text { Bolivia ( desde 2007); Ecuador } \\
\text { (desde 2009); Venezuela (desde } \\
\text { 2012). }\end{array}$ \\
\hline $\begin{array}{l}\text { Número de } \\
\text { TBI en vigor } \\
\text { por Estado }\end{array}$ & $\begin{array}{l}\text { Argentina: 49; Chile: } 36 ; \\
\text { Colombia: 6; Guyana: 5; } \\
\text { Paraguay: 22; Perú: } 29 ; \\
\text { Surinam: 1; Uruguay: } 30 .\end{array}$ & $\begin{array}{l}\text { Ninguno. Desde } 2015 \text { celebra } \\
\text { ACFI: } 12 \text { suscritos, } 1 \text { en vigor. }\end{array}$ & $\begin{array}{l}\text { Bolivia: } 0 \text { (denunció 21); } \\
\text { Ecuador: } 3 \text { (denunció 23); } \\
\text { Venezuela: } 25 \text { (denunció 1). }\end{array}$ \\
\hline $\begin{array}{l}\text { Parte del } \\
\text { Convenio de } \\
\text { Washington }\end{array}$ & $\begin{array}{l}\text { Argentina (18 noviembre 1994); } \\
\text { Chile (24 octubre 1993); } \\
\text { Colombia (14 agosto 1997); } \\
\text { Guyana (10 agosto 1963); } \\
\text { Paraguay (6 febrero 1983); Perú } \\
\text { (8 setiembre 1993); Uruguay (8 } \\
\text { setiembre 2000). }\end{array}$ & No. & $\begin{array}{l}\text { Denunciado por Bolivia ( } 1 \text { mayo } \\
\text { 2007); Ecuador ( } 2 \text { julio 2009) y } \\
\text { Venezuela ( } 24 \text { enero 2012); en } \\
\text { todos los casos las denuncias } \\
\text { son efectivas seis meses } \\
\text { después. }\end{array}$ \\
\hline $\begin{array}{l}\text { Demandas en } \\
\text { su contra } \\
\text { (conocidas, } \\
\text { basadas en } \\
\text { tratados, en } \\
\text { cualquier } \\
\text { foros) }\end{array}$ & $\begin{array}{l}\text { Argentina: } 60 \text {; Chile: } 5 \text {; } \\
\text { Colombia: } 11 \text {; Guyana: } 1 \text {; } \\
\text { Paraguay: } 3 \text {; Perú: } 15 \text {; Surinam: } \\
\text { 0; Uruguay: } 5^{54} \text {. }\end{array}$ & Ninguna. & $\begin{array}{l}\text { Bolivia: } 16 \text {; Ecuador: } 23 \text {; } \\
\text { Venezuela: } 47 .\end{array}$ \\
\hline $\begin{array}{l}\text { Característica } \\
\text { de la posición }\end{array}$ & $\begin{array}{l}\text { Los Estados tienden a celebrar } \\
\text { TBI y estos se mantienen en } \\
\text { vigor. En general adhirieron al } \\
\text { Convenio de Washington. }\end{array}$ & $\begin{array}{l}\text { Celebró } 14 \text { TBI pero ninguno } \\
\text { entró en vigor por haber sido } \\
\text { retirados del Congreso por parte } \\
\text { del Poder Ejecutivo. Desde } 2015 \\
\text { celebra ACFI (nuevo modelo de } \\
\text { acuerdo) que excluye de su } \\
\text { articulado la solución de } \\
\text { controversias inversor-Estado. }\end{array}$ & $\begin{array}{l}\text { Los tres Estados enunciaron el } \\
\text { Convenio de Washington, y } \\
\text { Bolivia y Ecuador terminaron } \\
\text { los TBI en vigor (por denuncia } \\
\text { unilateral o no renovación), } \\
\text { Venezuela solo denunció el TBI } \\
\text { con Holanda. }\end{array}$ \\
\hline
\end{tabular}

\footnotetext{
${ }^{54}$ Se incluye la controversia Latin American Regional Aviation Holding S. de R.L. contra Uruguay (caso CIADI ARB/19/16) no incluida en la base de datos del Investment Policy Hub de la UNCTAD por haber sido registrada en el CIADI con fecha 23 de mayo de 2019.
} 


\begin{tabular}{|c|c|c|c|}
\hline & Miembros & Externos & Disidentes \\
\hline $\begin{array}{l}\text { Fundamento } \\
\text { de la posición }\end{array}$ & $\begin{array}{l}\text { Apego a los postulados del } \\
\text { consenso de Washington, } \\
\text { especialmente la necesidad de } \\
\text { atraer inversión extranjera } \\
\text { directa. }\end{array}$ & $\begin{array}{l}\text { Evitar el compromiso del Estado } \\
\text { por períodos muy extensos; } \\
\text { priorización del inversor } \\
\text { extranjero por sobre el nacional; } \\
\text { y problemas de } \\
\text { constitucionalidad, } \\
\text { particularmente el arbitraje } \\
\text { internacional como mecanismo } \\
\text { de solución de controversias } \\
\text { inversor-Estado. }\end{array}$ & $\begin{array}{l}\text { Coyunturales (gran número de } \\
\text { demandas en contra o sumas } \\
\text { reclamadas), políticos } \\
\text { (gobiernos de corte progresista } \\
\text { que priorizaron los derechos } \\
\text { sociales, mediambientales y } \\
\text { protección de los recursos } \\
\text { estratégicos), y jurídicos } \\
\text { (prohibición de prórroga de } \\
\text { jurisdicción, salvo a tribunales } \\
\text { de procesos de integración } \\
\text { latinoamericanos y caribeños, } \\
\text { consagración de derechos de la } \\
\text { naturaleza o sectores } \\
\text { estratégicos, foco de gran parte } \\
\text { de las demandas). }\end{array}$ \\
\hline
\end{tabular}

Fuente: Actualización de Bas Vilizzio (2017: 85-86) en base a datos del Investment Policy Hub de la UNCTAD al 31 de diciembre de 2018. Fecha de consulta: 18 de agosto de 2019.

\subsection{Bolivia, Ecuador y Venezuela: los disidentes sudamericanos}

\subsubsection{Bolivia: el pionero}

Como se indicara anteriormente Bolivia representa el primer Estado del mundo en denunciar el Convenio de Washington, notificándolo el 1 de mayo de 200755, y el Estado que más ha avanzado al denunciar o no renovar la totalidad de los 21 TBI que se encontraban en vigor y vinculaban al Estado con: Alemania, Argentina, Austria, Bélgica y Luxemburgo, Chile, China, República de Corea, Cuba, Dinamarca, Ecuador, Estados Unidos, España, Francia, Italia, Países Bajos, Paraguay, Perú, Reino Unido, Rumania, Suecia, y Suiza.

El precedente más remoto es la denominada "guerra del agua" y el caso Aguas del Tunari (CIADI caso número ARB/02/3). Los hechos que originaron la demanda, comenzaron en 1999, con la privatización del servicio de aguas y alcantarillado sanitario de Cochabamba, que pasó a manos de la empresa Aguas del Tunari, empresa cuyo capital mayoritario pertenecía a la estadounidense Betchel. A pocos meses del proceso privatizador, el precio del servicio de aguas se elevó a más del 50\%, provocando importantes protestas populares organizadas en torno a la Coordinadora por

\footnotetext{
${ }^{55}$ Conforme al artículo 71 del Convenio de Washington las denuncias son efectivas seis meses después de su notificación.
} 
la Defensa del Agua y de la Vida. Como consecuencia, el gobierno de Bolivia rescindió la concesión y Aguas del Tunari se retira del país (Shultz, 2008).

En el entendido que había tenido lugar una violación del TBI Bolivia-Países Bajos, el 12 de noviembre de 2001 Aguas del Tunari se presentó ante el CIADI solicitando un arbitraje. En el memorial, reclamó una indemnización de aproximadamente 50 millones de dólares, a pesar de haber invertido poco menos de 1 millón. Frente a las excepciones de competencia presentadas por Bolivia, entre ellas que Aguas del Tunari no estaba controlada directa o indirectamente por nacionales de Países Bajos, el 21 de octubre de 2005 el CIADI determina su jurisdicción en el caso ${ }^{56}$. Esta decisión derivó en duras críticas al tribunal de parte de los movimientos sociales, en particular por considerarla una medida de apoyo a las políticas neoliberales y un evidente caso de forum shopping ${ }^{57}$ (Sornarajah, 2010: 326 - 327).

Sin perjuicio de lo anterior, ante a la presión de la opinión pública internacional, el 19 de enero de 2006 la empresa decidió retirar el caso, luego de acordar el traspaso de sus acciones al Estado por la suma simbólica de 2 bolivianos (aproximadamente 0,25 dólares) (Ministerio de Relaciones Exteriores y Cultos de Bolivia, 2008: 101). Adicionalmente, otros antecedentes están dados en el año 2006 con el inicio del proceso de nacionalización de empresas anteriormente privatizadas, que gestionan recursos estratégicos, especialmente el sector de los hidrocarburos ${ }^{58}$; así como con la demanda de la empresa ETI Euro Telecom International N.V. en 2007 (CIADI caso número $\mathrm{ARB} / 07 / 28)$. Este arbitraje es suspendido por solicitud del actor, luego de hacer acordado con el Estado el pago de 100 millones de dólares.

Los tres casos, con especial énfasis en Aguas del Tunari, constituyeron la antesala de Bolivia para retirarse del CIADI y terminar los TBI en vigor, y por ende marcar cierta resistencia del modelo relacional en el marco de un modelo predominantemente institucional como lo es el régimen de solución de controversias inversor-Estado. Asimismo, es una demostración de defensa de la soberanía interna y del espacio de política pública, haciendo ejercicio de la soberanía legal internacional al denunciar unilateralmente los tratados que el Estado entiende que son contrarios a sus intereses.

\footnotetext{
${ }^{56}$ Decisión sobre jurisdicción disponible en: http://www.italaw.com/sites/default/files/casedocuments/ita0021_0.pdf

57 Se denomina forum shopping a la selección de uno o más foros de solución de controversias, ya sea mediante la búsqueda de la protección de un tratado en particular o por aplicación de la cláusula de la nación más favorecida.

${ }^{58}$ El Decreto Supremo 28701 del 1 de mayo de 2006, determina la nacionalización de toda la producción de petróleo y gas, la cual pasa a manos de Yacimientos Petrolíferos Fiscales Bolivianos.
} 
Dentro de las razones esgrimidas por el Ministerio de Relaciones Exteriores y Cultos de Bolivia para abandonar el CIADI se destacan la incompatibilidad con la doctrina Calvo incorporada en la Constitución de 1967 vigente en ese momento; temas de procedimiento (conflictos de interés entre los actores y los árbitros, doble enjuiciamiento, jurisprudencia libre, forum shopping, treaty shopping y cherry picking ${ }^{59}$ ); los altos costos de los procedimientos; la minoría de laudos a favor de los Estados; y los conflictos de interés en el Banco Mundial como propulsor de las políticas de ajuste estructural que llevaron a la privatización de empresas que al ser estatizadas reclaman cuantiosas compensaciones (Ministerio de Relaciones Exteriores y Cultos de Bolivia, 2008: 108 - 124).

En adición, se realizaron cambios sustanciales en el Derecho Interno, como ser el artículo 320 inciso II de la Constitución Política del Estado promulgada el 7 de febrero de 2009, último año de la primera presidencia de Evo Morales, que reza: "toda inversión extranjera estará sometida a la jurisdicción, a las leyes y a las autoridades bolivianas, y nadie podrá invocar situación de excepción, ni apelar a reclamaciones diplomáticas para obtener un tratamiento más favorable”. Siguiendo a Cervantes (2017: 83), este artículo contiene una cláusula de aislamiento absoluto ya que no admite excepciones a la prohibición. La norma se complementa con la disposición transitoria novena, la cual da un plazo de cuatro años desde la elección del nuevo Órgano Ejecutivo, 6 de diciembre de 2009, para renegociar o denunciar aquellos tratados, anteriores a la Constitución, que sean incompatibles.

El mandato constitucional derivó en la terminación de los TBI con Países Bajos, Italia, Estados Unidos, España, Francia, Alemania, Austria, Suecia, Bélgica y Luxemburgo, Argentina y Dinamarca, en orden cronológico entre el 1 de noviembre de 2009 y el 13 de mayo de 2014. El TBI Ecuador-Bolivia es denunciado unilateralmente por Ecuador, dando lugar a su terminación el día 19 de mayo de 2018. No obstante, debe tenerse en cuenta que en la gran mayoría de los casos, existen cláusulas de ultractividad que determina las disposiciones del TBI se mantienen en vigor por cinco, diez, quince o veinte años más, para aquellas inversiones realizadas con anterioridad a la notificación de terminación (véase tabla 3). Permanecen en vigor los TBI que vinculan a Bolivia con

\footnotetext{
${ }^{59}$ Se denomina treaty shopping o cherry picking a la práctica de selección de disposiciones entre diferentes TBI, en función de la cláusula de la nación más favorecida.
} 
Cuba, Chile, China, República de Corea, Paraguay, Perú, Rumania, Suiza y Reino Unido, conforme a datos del Investment Policy Hub de la UNCTAD ${ }^{60}$.

Tabla 3: TBI terminados por denuncia unilateral de Bolivia

\begin{tabular}{|c|c|c|c|c|c|}
\hline No. & Contraparte & Fecha de firma & $\begin{array}{c}\text { Fecha de entrada } \\
\text { en vigor }\end{array}$ & $\begin{array}{c}\text { Fecha de } \\
\text { terminación }\end{array}$ & $\begin{array}{l}\text { Cláusula de } \\
\text { ultractividad }\end{array}$ \\
\hline 1 & Alemania & 23/03/1987 & 09/11/1990 & $13 / 05 / 2013$ & 20 años \\
\hline 2 & Argentina & $17 / 03 / 1994$ & 01/05/1995 & $13 / 05 / 2014$ & 15 años \\
\hline 3 & Austria & $04 / 04 / 1997$ & $01 / 07 / 2002$ & $01 / 07 / 2013$ & 10 años \\
\hline 4 & $\begin{array}{c}\text { Bélgica y } \\
\text { Luxemburgo }\end{array}$ & $25 / 04 / 1990$ & $10 / 01 / 2004$ & $10 / 01 / 2014$ & 10 años \\
\hline 5 & Dinamarca & $12 / 03 / 1995$ & 22/03/1997 & $13 / 05 / 2014$ & 10 años \\
\hline 6 & Estados Unidos & $17 / 04 / 1998$ & 06/06/2001 & $10 / 06 / 2012$ & 10 años \\
\hline 7 & España & $29 / 10 / 2001$ & $09 / 07 / 2002$ & $09 / 07 / 2012$ & 10 años \\
\hline 8 & Francia & $25 / 10 / 1989$ & $12 / 10 / 1996$ & $06 / 05 / 2013$ & 10 años \\
\hline 9 & Italia & $30 / 04 / 1990$ & $22 / 02 / 1992$ & $22 / 02 / 2012$ & 5 años \\
\hline 10 & Países Bajos & 10/03/1992 & $01 / 11 / 1994$ & $01 / 11 / 2009$ & 15 años \\
\hline 11 & Suecia & 20/09/1990 & 03/07/1992 & $04 / 07 / 2013$ & 20 años \\
\hline
\end{tabular}

Fuente: Elaboración propia en base a datos del Investment Policy Hub de la UNCTAD. Fecha de consulta: 21 de abril de 2019.

\subsubsection{Ecuador: un proceso con auditoría ciudadana}

\subsubsection{El inicio del proceso: Lago Agrio, Chevron y TBI}

Ecuador sigue el camino iniciado en 2007 por Bolivia, y entre 2008 y 2009 se embarca en un proceso de terminación de parte de los TBI en vigor y retiro del CIADI. En el mes de enero de 2008, Ecuador notifica la denuncia de nueve de los 26 TBI en vigor, aquellos en base a los cuales no se habían registrado inversiones recíprocas. Se trata de los acuerdos celebrados con Cuba, El Salvador, Guatemala, Honduras, Nicaragua, Paraguay, República Dominicana, Rumania y Uruguay (Guerra, 2012: 43) ${ }^{61}$. Asimismo, el retiro del CIADI se oficializa con la notificación de denuncia del Convenio de Washington el 2 de julio de 2009.

\footnotetext{
${ }^{60}$ Cabe señalar que en una investigación anterior al no contarse con datos precisos se consultó a informantes calificados quienes afirmaron que todos los TBI habían sido denunciados unilateralmente. En este sentido, véase: Bas Vilizzio, 2017.

${ }^{61}$ Cabe destacar que los TBI denunciados presentan cláusulas de ultractividad que extiende la vigencia de sus disposiciones por cinco, diez o quince años, salvo en el caso del acuerdo celebrado con Uruguay.
} 
El contexto en el que se inicia el proceso de recuperación de la autonomía tiene raíces jurídicas, especialmente en relación a la reforma constitucional de 2008, instrumento en el que por primera vez se consagran derechos de la naturaleza y se establece que las controversias que involucren al Estado deben resolverse en la jurisdicción de organizaciones regionales latinoamericanas (artículo 422). Conforme a Cervantes (2017: 83) se trata de una cláusula de aislamiento relativa, a diferencia del caso boliviano, ya que se prevé como excepción a la norma general los tratados que incluyan solución de controversias entre Estados y ciudadanos en Latinoamérica a resolverse en instancias arbitrales regionales o por órganos jurisdiccionales de designación de los países signatarios.

Asimismo, los altos montos indemnizatorios reclamados por inversores extranjeros en torno al sector petrolero consolidan el caldo de cultivo perfecto para la toma de decisiones en esta materia. Entre otros, se destaca el caso Chevron III (CPA caso número 2009-23) con un reclamo de 9.500 millones de dólares, tercer hito en este camino. Este es uno de los casos más emblemáticos del régimen de solución de controversias inversor-Estado, no solo por la evidente colisión entre las normas de protección de inversiones y las de protección del medioambiente sino también por los costos ambientales (ríos y suelos contaminados) y humanos (comunidades que fueron afectadas en términos sociales y culturales: desplazamiento, impacto en sus costumbres y actividades productivas). Como explica Sassen, las economías basadas en el extractivismo, por mucho tiempo fueron parte del modelo de desarrollo económico deseable. Sin embargo, el paso del tiempo demostró que "that economic growth as we have known it brought with it massive environmental destruction even under the best circumstances"62 (Sassen, 2016: 683). El caso Chevron es un ejemplo claro de esta realidad.

Ahora bien, Chevron III no es un caso aislado, sino que es parte de una serie de procesos jurisdiccionales domésticos e internacionales que tuvieron lugar en Estados Unidos, Ecuador y la CPA, en virtud de la responsabilidad por contaminación en una zona de aproximadamente 20.000 kilómetros cuadrados de la Amazonía Ecuatoriana (región de Lago Agrio, Napo, oriente de Ecuador) por la exploración y producción de petróleo (1964 - 1992) y el consecuente programa de remediación ambiental

\footnotetext{
62 "Ese crecimiento económico, como lo hemos conocido, trajo consigo una destrucción ambiental masiva, incluso en las mejores circunstancias" (Traducción propia).
} 
desarrollados por un consorcio empresarial del cual Texaco era parte y se encargaba de su operación hasta 1990.

Al momento en que Texaco se retiró de la explotación petrolera del Oriente Ecuatoriano, celebró acuerdos sucesivos con el Gobierno Central de Ecuador, el Gobierno Provincial de Sucumbíos y el Consorcio de Municipios de Napo en relación a la liberación de la responsabilidad por impacto ambiental una vez completadas las acciones de reparación y el pago de una compensación a Ecuador mediante la financiación de proyectos de desarrollo comunitario. Luego de la fusión de Chevron con Texaco (2001), comenzó ante los tribunales domésticos de Ecuador lugar el llamado juicio de Lago Agrio (2003) contra Chevron, Este proceso terminó en 2011 con una condena a la empresa por 9.500 millones de dólares.

A nivel internacional Chevron demanda dos veces a Ecuador ante la CPA. La primera demanda fue presentada en el año 2006 por denegación de justicia al entender que existía retraso indebido en el proceso judicial en la jurisdicción ecuatoriana, con laudo a favor de la empresa (CPA caso número 2007-02, conocido como caso Chevron II). La segunda demanda dio lugar al caso Chevron III, en el cual la empresa solicitó, entre otros, que se declarase la ausencia de responsabilidad u obligación de su parte por los impactos ambientales en la región de Lago Agrio, que se declare que Ecuador o Petroecuador son los únicos responsables en el juicio de Lago Agrio; y se determine el incumplimiento por parte del Estado de los acuerdos firmados entre Texaco y Ecuador y el TBI Estados Unidos-Ecuador ${ }^{63}$ (párrafo 76).

Conforme a lo expresado por Ecuador, es la empresa la que incumplió los acuerdos de remediación ambiental, al punto que actualmente "el petróleo sigue brotando de estas piscinas e infiltrándose en las fuentes de agua subterránea que son usadas para el consumo humano" y la indemnización que debía pagar la empresa de acuerdo a los tribunales ecuatorianos será usada para la "reparación ambiental, implementación de un sistema integral de agua potable, así como uno de salud, pago de una indemnización a los afectados, entre otros" (Ministerio de Relaciones Exterior y Movilidad Humana de Ecuador, 2015: 8).

El 12 de marzo de 2015 el tribunal ad hoc de la CPA emitió la Decisión sobre el Track (primer laudo parcial), que resulta favorable al demandado porque reconoce que la

\footnotetext{
${ }^{63}$ Particularmente las disposiciones relativas a trato justo y equitativo; protección y seguridad plenas; medios eficaces de hacer respetar los derechos; trato no arbitrario y no discriminatorio; trato nacional y trato de la nación más favorecida; inobservancia de los compromisos contraídos en virtud de los acuerdos de inversión (CPA, 2009: párrafo 69).
} 
demanda en el juicio de Lago Agrio tiene como centro derechos individuales que no forman parte del ámbito de aplicación del Acta final de liberación (1998). Tampoco considera que el contrato de transacción (1995) constituya cosa juzgada que impida iniciar el mencionado proceso, e incluye derechos similares a los de juicio Aguinda (párrafo 186) ${ }^{64}$.

Sin perjuicio de lo anterior, el segundo laudo parcial, Decisión sobre el Track II de fecha 30 de agosto de 2018, fue favorable a la empresa puesto que establece la responsabilidad de Ecuador por incumplimiento del TBI Ecuador-Estados Unidos, destacándose la violación a las disposiciones de denegación de justicia y trato justo y equitativo $^{65}$. Por tanto determinó la anulación de la mencionada sentencia dictada en la jurisdicción ecuatoriana respecto al daño ambiental ocasionado por la empresa y la indemnización a los damnificados. Esta decisión presentó un revés para las medidas tomadas en pos de la protección del medioambiente en ejercicio válido del derecho de regular y pone en evidencia los riesgos de la fragmentación del Derecho Internacional.

Siguiendo a Rapoport y Míguez, uno de los aspectos esenciales para la recuperación de la autonomía perdida por los Estados Latinoamericanos, al seguir los postulados del consenso de Washington, es la protección del territorio y el control de la explotación los recursos naturales. El caso Chevron III muestra la "depredación de los recursos en los países dependientes, por parte de las potencias” (Rapoport y Míguez: 2015: 148 149), en este caso por una empresa cuyo principal establecimiento comercial se encuentra en Estados Unidos. La situación es agravada por los efectos nocivos de dicha explotación con el episodio de contaminación de Lago Agrio (conocido popularmente como "la mano negra de Chevron") y el no reconocimiento de su responsabilidad respecto al programa de reparación ambiental.

La capacidad del Estado para tomar decisiones podría haberse visto limitada frente a la presión de la empresa transnacional mediante sucesivas demandas. No obstante, el Gobierno de Correa opta por defenderse a nivel internacional, dar a conocer el caso, y comenzar un proceso que implica el retiro del CIADI (2009) y terminación de los TBI en vigor, así como la propuesta de un centro de arreglo de diferencias en materia de inversiones en la UNASUR que oficie de alternativa al CIADI. Si bien el texto

\footnotetext{
${ }^{64}$ Decisión disponible en: https://jusmundi.com/en/document/decision/en-chevron-corporation-andtexaco-petroleum-company-v-the-republic-of-ecuador-ii-decision-on-track-1b-thursday-12th-march2015\#decision 296

${ }^{65}$ Decisión disponible en: https://pcacases.com/web/sendAttach/2453
} 
constitutivo del mencionado centro está terminado a nivel jurídico, no se avanzó en la firma del acuerdo para su posterior entrada en vigor.

Los dos últimos puntos, son ejemplos de otros de los aspectos señalados por Rapoport y Míguez (2015: 150 - 154) como elementos centrales para la recuperación de la autonomía: la recuperación del control sobre los movimientos de capital y las inversiones y, las alianzas estratégicas con países pares, en este caso no para negociar con las grandes potencias sino como alternativa a las instituciones creadas y sostenidas por ellas $^{66}$. El proceso de terminación de los TBI en vigor culminó en el año 2017 una vez conocido por el Presidente Correa el informe de la Comisión para la Auditoría Integral Ciudadana de los Tratados de Protección Recíproca de Inversiones y del Sistema de Arbitraje Internacional en Materia de Inversiones (CAITISA), tema que se analiza en el siguiente aportado.

\subsubsection{La consolidación del proceso: estructuras domésticas y auditoría ciudadana}

Ecuador complementó el proceso iniciado con la Constitución de 2008 con cambios en sus estructuras domésticas que le permiten solidificar su posición hacia la recuperación de la autonomía. Conforme a la Constitución y en base a fundamentos neoconstitucionalistas, para la denuncia de los TBI debe seguirse un procedimiento que da intervención a la Corte Constitucional y la Asamblea Nacional. El procedimiento se compone por las siguientes etapas: 1) Oficio de la Presidencia a la Corte Constitucional solicitando que se pronuncie sobre la denuncia; 2) Dictamen de la Corte Constitucional; 3) Oficio de la Presidencia a la Asamblea Nacional solicitando la denuncia en base al dictamen de la Corte Constitucional; 4) Informe de la Comisión especializada permanente de soberanía, integración, relaciones internacionales y seguridad integral de la Asamblea Nacional (Comisión especializada); 5) Resolución del Pleno de la Asamblea Nacional en base al informe de la Comisión especializada; 6) Notificación escrita de la denuncia a la contraparte en el TBI.

El primer acuerdo en completar el procedimiento fue el TBI Ecuador-Finlandia, cuya denuncia es notificada a la contraparte en fecha 23 de noviembre de 2010. Si bien el Pleno de la Asamblea Nacional aprobó la denuncia de los TBI celebrados con Alemania, Reino Unido, Francia y Suecia el 14 de setiembre de 2010 en los dos primeros casos y el 15 de marzo de 2011 en los dos últimos, ninguna de las denuncias

\footnotetext{
${ }^{66}$ Los otros dos aspectos son: la existencia de un mercado interno amplio y de una economía de base nacional, promover un intercambio comercial equilibrado (Rapoport y Míguez, 2015).
} 
fue notificada a la contraparte, por tanto los procedimientos quedaron incompletos. Para el caso de los TBI celebrados con Chile, China, Venezuela y Países Bajos, su denuncia fue considerada en 2010 y 2011 pero no se alcanzaron los votos suficientes para llevarla a cabo (Andes, 2017).

Finalmente, los cambios de estructuras domésticas se completaron con la creación de la CAITISA, el 6 de mayo de 2013 (Decreto Ejecutivo 1506). La misma está compuesta por cuatro expertos o investigadores en materia de inversiones y Derecho Internacional vinculados a organizaciones de la sociedad civil, y cuatro representantes del Estado Ecuatoriano. Dentro de sus competencias se encuentra el estudio de los TBI y otros acuerdos internacionales en vigor, las normas de arbitraje internacional de inversiones y los procesos arbitrales iniciados contra el Estado. Si bien el mandato original de la Comisión preveía su actuación hasta diciembre de 2014, el informe final fue entregado públicamente al Presidente Rafael Correa el 8 de mayo de 2017, pocos días antes del fin de su mandato (24 de mayo de 2017).

El Informe de la CAITISA concluye que los TBI celebrados por Ecuador contienen disposiciones incompatibles con la Constitución en vigor así como otras normas de Derecho Interno, en particular se destaca que los acuerdos contienen disposiciones relativas al sometimiento del Estado a la jurisdicción arbitral internacional; el trato diferenciado entre inversores extranjeros y nacionales, dada la posibilidad de demandar ante los tribunales arbitrales internacionales; y las cláusulas de expropiación indirecta que van en contra del derecho de expropiación y nacionalización. Asimismo, el informe identifica que los pagos realizados por el Estado Ecuatoriano por laudos negativos y gastos de abogados y administrativos de los arbitrajes alcanzan los 1.498 millones de dólares, cifra equivalente al 5,6\% del presupuesto general del Estado para el año 2017 (CAITISA, 2017: 94-95).

Por tanto, la CAITISA recomienda que se concluya el procedimiento de denuncia de los TBI y se negocien nuevos instrumentos entre el Estado e inversores extranjeros, proponiendo líneas centrales para un modelo alternativo de tratado de inversión que consagre el derecho de regular del Estado; excluya o replantee los privilegios hasta el momento otorgados a los inversores extranjeros (trato nacional, trato justo y equitativo, expropiación indirecta, etc.); y establezca como obligatoria la jurisdicción doméstica para la resolución de disputas, dentro de los principales puntos a destacar (CAITISA, 2017: 99-105). En vista de lo anterior, el 3 de mayo de 2017 el Pleno de la Asamblea Nacional aprueba la denuncia de los doce TBI que no habían alcanzado esa etapa, esto 
es, los acuerdos celebrados con Argentina, Bolivia, Canadá, Chile, China, España, Estados Unidos, Italia, Países Bajos, Perú, Suiza y Venezuela. Conforme a datos del Investment Policy Hub de la UNCTAD, los únicos tratados que continúan en vigor son aquellos que vinculan a Ecuador con Italia, España y Países Bajos, a pesar de la decisión de la Asamblea Nacional (véase tabla 4).

Tabla 4: TBI terminados por denuncia unilateral de Ecuador

\begin{tabular}{|c|c|c|c|c|c|}
\hline No. & Contraparte & Fecha de firma & $\begin{array}{c}\text { Fecha de entrada } \\
\text { en vigor }\end{array}$ & $\begin{array}{c}\text { Fecha de } \\
\text { terminación }\end{array}$ & $\begin{array}{l}\text { Cláusula de } \\
\text { ultractividad }\end{array}$ \\
\hline 1 & Alemania & $21 / 03 / 1996$ & $12 / 02 / 1999$ & $18 / 05 / 2018$ & 15 años \\
\hline 2 & Argentina & 18/02/1994 & 01/12/1995 & $18 / 05 / 2018$ & 15 años \\
\hline 3 & Bolivia & $25 / 05 / 1995$ & $15 / 08 / 1997$ & $19 / 05 / 2018$ & 10 años \\
\hline 4 & Canadá & 29/04/1996 & 06/06/1997 & $19 / 05 / 2018$ & 15 años \\
\hline 5 & Chile & $23 / 10 / 1993$ & $21 / 02 / 1996$ & $19 / 05 / 2018$ & 10 años \\
\hline 6 & China & 21/03/1994 & 01/07/1997 & $19 / 05 / 2018$ & 10 años \\
\hline 7 & Cuba & $25 / 05 / 1995$ & $15 / 08 / 1997$ & $18 / 01 / 2008$ & 10 años \\
\hline 8 & Estados Unidos & 27/08/1993 & $11 / 05 / 1997$ & $18 / 05 / 2018$ & 10 años \\
\hline 9 & EI Salvador & $16 / 05 / 1994$ & 14/01/1996 & $18 / 01 / 2008$ & 10 años \\
\hline 10 & Finlandia & $18 / 04 / 2001$ & $16 / 12 / 2001$ & $09 / 12 / 2010$ & 10 años \\
\hline 11 & Francia & 07/09/1994 & 10/06/1996 & $18 / 05 / 2018$ & 15 años \\
\hline 12 & Guatemala & $14 / 08 / 2002$ & $25 / 05 / 2005$ & $18 / 01 / 2008$ & 10 años \\
\hline 13 & Honduras & $26 / 06 / 2000$ & $11 / 04 / 2005$ & $18 / 01 / 2008$ & 10 años \\
\hline 14 & Nicaragua & $02 / 06 / 2000$ & $21 / 05 / 2001$ & $18 / 01 / 2008$ & 10 años \\
\hline 15 & Paraguay & 28/01/1994 & $18 / 09 / 1995$ & $18 / 01 / 2008$ & 10 años \\
\hline 16 & Perú & 07/04/1999 & 09/12/1999 & 19/11/2017 & 10 años \\
\hline 17 & Reino Unido & 10/05/1994 & $24 / 08 / 1995$ & $18 / 05 / 2018$ & 15 años \\
\hline 18 & $\begin{array}{c}\text { República } \\
\text { Dominicana }\end{array}$ & 26/06/1998 & 21/06/1999 & $18 / 01 / 2008$ & 5 años \\
\hline 19 & Rumania & 21/03/1996 & 18/07/1997 & $18 / 01 / 2008$ & 10 años \\
\hline 20 & Suecia & $31 / 05 / 2001$ & $01 / 03 / 2002$ & $18 / 05 / 2018$ & 15 años \\
\hline 21 & Suiza & $02 / 05 / 1968$ & 09/11/1969 & $11 / 09 / 2018$ & 10 años \\
\hline 22 & Uruguay & $31 / 07 / 1985$ & $31 / 07 / 1985$ & $18 / 01 / 2008$ & $\begin{array}{l}\text { Sin cláusula de } \\
\text { ultractividad }\end{array}$ \\
\hline 23 & Venezuela & 18/11/1993 & 01/02/1995 & $19 / 05 / 2018$ & 10 años \\
\hline
\end{tabular}

Fuente: Elaboración propia en base a datos del Investment Policy Hub de la UNCTAD. Fecha de consulta: 21 de abril de 2019.

En vista de lo anterior, el camino parecía sólidamente marcado hacia la exclusión del régimen de solución de controversias inversor-Estado, incluso el nuevo modelo de 
convenio bilateral de inversiones elaborado por la Cancillería Ecuatoriana es presentado con ánimo de renegociar los acuerdos denunciados desde una estrategia que otorgue prioridad al interés nacional ${ }^{67}$. No obstante, pocos meses después, se visualizan intentos de dar marcha atrás en el camino recorrido, tanto desde el Poder Ejecutivo como del Legislativo. En este sentido, el primer intento lo constituye el avance en la negociación de un tratado de libre comercio con Estados Unidos, el cual, de seguir la tendencia estadounidense $^{68}$, incluiría un capítulo de inversiones que prevé la solución de conflictos inversor-Estado mediante el arbitraje ad hoc en el CIADI o en otras instituciones internacionales.

Sin perjuicio de lo anterior, el momento más claro de inicio de la marcha atrás tiene lugar el 28 de junio de 2018 cuando la Asamblea Nacional remitió a la Corte Constituyente una consulta respecto a si el artículo 422 de la Constitución también incluye la solución de controversias en el marco de TBI, puesto que podría interpretarse que solamente se refiere a tratados comerciales y no de inversiones. Adicionalmente, el 7 de agosto de 2018 la Asamblea Nacional aprobó la nueva Ley Orgánica para el fomento productivo, atracción de inversiones, generación de empleo y estabilidad y equilibrio fiscal ${ }^{69}$. El artículo 37 modifica el Código Orgánico de la Producción, Comercio e Inversiones, al establecer la obligación de pactar el arbitraje nacional o internacional para la resolución de disputas en el marco de contratos de inversión. Si dichos contratos superan los 10.000 millones de dólares, la controversia deberá resolverse conforme al Reglamento de la UNCITRAL en la CPA, el Reglamento de la CCI, o la Comisión Interamericana de Arbitraje Comercial, entre otros. La ley incorpora el texto del veto parcial del Presidente Moreno $^{70}$ en lo que respecta al arbitraje internacional de inversiones (Cecilia Olivet, comunicación personal, 25 de julio de 2018).

\footnotetext{
${ }^{67}$ Información disponible en: https://www.cancilleria.gob.ec/cancilleria-presenta-los-nuevos-conveniosbilaterales-de-inversion/

68 El texto de los acuerdos en vigor celebrados por Estados Unidos está disponible en: https://ustr.gov/trade-agreements/free-trade-agreements

${ }_{69}$ El texto está disponible en: https://www.registroficial.gob.ec/index.php/registro-oficialweb/publicaciones/suplementos/item/10838-suplemento-al-registro-oficial-no-309.html

70 El texto del veto parcial está disponible en: https://www.asambleanacional.gob.ec/sites/default/files/private/asambleanacional/filesasambleanacionaln ameuid-29/Leyes\%202013-2017/563-fomento/op-fomento-productivo-17-07-2018.pdf
} 


\subsubsection{Venezuela: en defensa de la soberanía y los recursos estratégicos}

Venezuela formaliza la denuncia del Convenio de Washington el 24 de enero de 2012. En un comunicado fechado al día siguiente, el Ministerio del Poder Popular para Relaciones Exteriores, alega cuatro motivos: 1) la adhesión del Estado a dicho tratado se da en 1993, en el marco de un proceso de "desmantelamiento de la soberanía nacional venezolana" por parte de un gobierno débil que actuaba bajo presión de las empresas transnacionales $^{71}$; 2) la Constitución de 1999 contiene disposiciones contrarias al convenio, ya que en su artículo 151 indica que las controversias suscitadas sobre contratos de interés público deben ser resueltas por la jurisdicción nacional, aun cuando no exista una cláusula contractual expresa que así lo indique ${ }^{72}$; 3 ) la jurisdicción del CIADI ha laudado 232 de 234 veces en contra de los Estados; 4) la defensa de la soberanía nacional, en el marco de la cual el trabajo continúa en materia de la propiedad de activos estratégico ${ }^{73}$.

El entonces presidente Hugo Chávez, en su programa "Aló Presidente" número 376, del 8 de enero de $2012^{74}$, ya había anunciado la intención de denunciar el Convenio de Washington y no dar cumplimiento a ningún laudo del CIADI. A la fecha de la denuncia del convenio, Venezuela había sido demandada en 47 oportunidades ante el CIADI, destacándose los procedimientos iniciados por las empresas Venezuela Holdings BV, Mobil Cerro Negro Holding Ltd., Mobil Venezolana de Petróleos Hondings Inc., Mobil Cerro Negro Ltd. y Mobil Venezolana de Petróleos Inc. (CIADI caso número ARB/07/27, sector petróleo y gas, pendiente); ConocoPhillips Petrozuata BV, ConocoPhillips Hamaca BV y ConocoPhillips Gulf of Paria BV (CIADI caso número $\mathrm{ARB} / 07 / 30$, sector petróleo y gas, concluido con condena de 8.436 millones de

\footnotetext{
${ }^{71}$ De acuerdo a Mezgravis (2012), la denuncia del Convenio de Washington es una mala decisión jurídica "porque estar fuera del CIADI no va a garantizar que Venezuela no siga siendo demandada", y cuestiona que se trate de una acción tendiente a la protección de la soberanía nacional, puesto que "cuando 146 países son miembros de un sistema como el CIADI, no es posible pensar que todos han renunciado a su soberanía”.

${ }^{72}$ Artículo 151 de la Constitución Venezolana de 1999: "En los contratos de interés público, si no fuere improcedente de acuerdo con la naturaleza de los mismos, se considerará incorporada, aun cuando no estuviere expresa, una cláusula según la cual las dudas y controversias que puedan suscitarse sobre dichos contratos y que no llegaren a ser resueltas amigablemente por las partes contratantes, serán decididas por los tribunales competentes de la República, de conformidad con sus leyes, sin que por ningún motivo ni causa puedan dar origen a reclamaciones extranjeras".

${ }^{73}$ Texto completo del comunicado disponible en el sitio web del Ministerio del Poder Popular para las Relaciones Exteriores de Venezuela, recuperado de: http://www.mre.gov.ve/index.php?option=com_content\&view=article\&id=18939:mppre\&catid=3:comun icados\&Itemid $=108$

${ }^{74}$ Video recuperado de: https://www.youtube.com/watch?v=dD6DzX7OW1w
} 
dólares ${ }^{75}$ ); Gold Reserve Inc. (CIADI caso número $\mathrm{ARB}(\mathrm{AF}) / 09 / 1$, sector minería, concluido con una condena por 740 millones de dólares ${ }^{76}$ ); y Crystallex International Corporation (CIADI caso número $\mathrm{ARB}(\mathrm{AF}) / 11 / 2$, sector minería, concluido con condena de 1.202 millones de dólares ${ }^{77}$ ). En otro foro, la CCI, son de interés los casos Mobil Cerro Negro Ltd. (CCI caso número 15416/JRF, sector petróleo y gas, concluido con una condena de 907,6 millones de dólares ${ }^{78}$ ) y Phillips Petroleum Company Venezuela Ltd. y ConocoPhillips Petrozuata BV (CCI caso número 16848/JRF/CA, sector petróleo y gas, concluido con condena de 66,9 millones de dólares más intereses $^{79}$ ).

En cuanto a los TBI, Venezuela cuenta con 25 acuerdos en vigor, que lo vinculan con: Alemania, Argentina, Barbados, Bélgica y Luxemburgo, Bielorrusia, Canadá, Chile, Costa Rica, Cuba, Dinamarca, España, Francia, Irán, Lituania, Paraguay, Perú, Portugal, Reino Unido, República Checa, Rusia, Suecia, Suiza, Uruguay, y Vietnam. Únicamente ha denunciado el tratado con Países Bajos en fecha 1 de noviembre de $2008^{80}$, puesto que hasta ese momento 6 de las 11 demandas en su contra registradas en el CIADI, estaban basadas en el mencionado tratado ${ }^{81}$. Sin perjuicio de lo anterior, por el efecto de la cláusula de ultractividad del artículo 14 numeral 3, que establece que las restantes disposiciones continúen en vigor durante quince años más (hasta el año 2023), nueve casos nuevos fueron presentados en el CIADI invocando el mencionado tratado ${ }^{82}$. Asimismo, el 19 de mayo de 2018 Ecuador termina mediante denuncia unilateral el TBI que lo vinculaba con Venezuela. En este caso, la cláusula de ultractividad es por diez años.

La reforma del sistema venezolano de promoción y protección de inversiones, ha dado otro paso el 17 de noviembre de 2014 con la sanción de la nueva Ley de inversiones extranjeras (Decreto 1438 con rango, valor y fuerza de ley), la cual entró en vigor al día siguiente con su publicación en la Gaceta Oficial. Esta norma reafirma que las inversiones extranjeras están sujetas a la jurisdicción de los tribunales domésticos

\footnotetext{
${ }^{75}$ Laudo de fecha 8 de marzo de 2019.

${ }^{76}$ Laudo de fecha 22 de setiembre de 2014.

${ }^{77}$ Laudo de fecha 4 de abril de 2016.

${ }^{78}$ Laudo de fecha 23 de diciembre de 2011, apartado p.

${ }^{79}$ Laudo de fecha 17 de setiembre de 2012, párrafo 333.

${ }^{80}$ En este punto Venezuela presenta diferencias con los procesos desarrollados en Bolivia y Ecuador.

${ }^{81}$ Entre ellos los mencionados Venezuela Holdings BV, Mobil Cerro Negro Holding Ltd., Mobil Venezolana de Petróleos Hondings Inc., Mobil Cerro Negro Ltd. y Mobil Venezolana de Petróleos Inc. (CIADI caso número ARB/07/27); y ConocoPhillips Petrozuata BV, ConocoPhillips Hamaca BV y ConocoPhillips Gulf of Paria BV (CIADI caso número ARB/07/30).

${ }^{82}$ Datos de la base de casos del CIADI, consultada el 21 de abril de 2019.
} 
conforme a las disposiciones constitucionales, y agrega la posibilidad de hacer uso de los mecanismos de solución de controversias previstos en el marco de los procesos de integración de Latinoamérica y el Caribe (artículo 5). Este último punto presenta similitudes al Derecho Interno Ecuatoriano (artículo 422 de la Constitución de 2008). La experiencia venezolana es un caso de defensa de la soberanía en sentido westfaliano, no obstante no hay un ejercicio completo de las posibilidades que le otorga la soberanía legal internacional puesto que únicamente se denuncia el Convenio de Washington y un solo TBI. En definitiva, el efectivo goce de la autonomía parece quedar restringido a la denuncia de aquellos acuerdos que se no se consideran beneficiosos y no la construcción de una alternativa consistente y clara, independientemente de los impulsos a la creación de instancias de estudio y discusión de la temática en la región que no tuvieron gran desarrollo a lo largo del tiempo.

En este sentido, el 10 de setiembre de 2014, se creó el Observatorio del Sur sobre Inversiones y Transnacionales, en el seno de la II Conferencia Ministerial de Estados Afectados por Intereses Transnacionales desarrollada en Caracas. En dicha conferencia participan Ecuador, República Dominicana, Cuba, Bolivia, San Vicente y las Granadinas y Venezuela (Estados suscriptores de la I Conferencia Ministerial de Estados Afectados por Intereses Transnacionales celebrada en Guayaquil, el 22 de abril de $2013^{83}$ ), representantes de Guatemala, El Salvador, Argentina, México y Honduras (Estados observadores), y Antigua y Barbuda, Granada, Uruguay ${ }^{84}$, Angola, Argelia, Barbados, Qatar, Chile, Colombia, Indonesia, Jamaica, Laos, Malasia, Namibia, Palestina, Paraguay, Perú, Zimbabwe, Costa Rica, Panamá, India y Rusia (Estados invitados).

Previamente, en la I Conferencia se establecieron como objetivos del observatorio, entre otros, dar cuenta de las controversias internacionales en materia de inversiones; 2) identificar procedimientos de monitoreo de los foros internacionales de arbitraje en materia de inversiones; 3) analizar y proponer una reforma a los foros existentes; 4) analizar y apoyar la creación de mecanismos alternativos de solución de disputas inversor-Estado; 5) ser un foro de intercambio para expertos en controversias de inversiones de los países del Sur; 6) promover mecanismos de coordinación y consulta

\footnotetext{
${ }^{83} \mathrm{El}$ texto completo de la declaración de la I Conferencia puede encontrarse en: http://cancilleria.gob.ec/wp-content/uploads/2013/04/22abr_declaracion_transnacionales_esp.pdf Además de los Estados suscriptores, participan como invitados: Argentina, Guatemala, El Salvador, Honduras y México.

${ }^{84}$ Uruguay se incorpora como Estado observador en la II Conferencia (punto 6 de la declaración).
} 
entre los sistemas judiciales latinoamericanos; 7) elaborar un compendio de normativa, políticas y tratados internacionales relativos a la materia en pro de la adopción de estrategias conjuntas; 8) analizar y crear estrategias conjuntas por parte de los Estados; 9) examinar y asesorar a los Estados en relación a sus contratos comerciales y de inversiones con empresas transnacionales; 10) establecer mecanismos de interlocución con movimientos sociales. En definitiva, el observatorio buscaba constituirse como una "plataforma de generación de debates, discusiones, reflexiones e intercambio de conocimientos y experiencias en materia de inversiones entre los países del Sur" (punto 3 de la Declaración de la II Conferencia ${ }^{85}$ ).

Si bien el impulso inicial generó la participación e interés de los Estados de la región, este proyecto no ha tenido avances desde 2015. La situación de la UNASUR y la propia situación política-institucional interna de Venezuela hacen que sea posible afirmar que el proyecto quedó inoperante.

\subsection{Sudáfrica: un disidente africano}

\subsubsection{Sudáfrica y el sistema de protección de inversiones extranjeras: del apartheid a} la apertura internacional

La situación de Sudáfrica es diferente a la de los Estados analizados precedentemente. No se trata de un Estado cuya reforma constitucional determine cambios en su política exterior, por introducción de nuevos derechos o modificación de la jurisdicción cuando el Estado es parte de una disputa. Tampoco se trata de un Estado que haya denunciado el Convenio de Washington constitutivo del CIADI ya que no lo firmó y hasta el momento no adhirió. No obstante, Sudáfrica forma parte del grupo de los primeros Estados que deciden terminar los acuerdos internacionales de inversiones en vigor, grupo en el que también participan Bolivia y Ecuador.

Dado que el contexto histórico, político-institucional, socio-económico y jurídico es diferente al de los Estados Sudamericanos ya examinados y a los efectos de aportar elementos contrafácticos, resulta pertinente incorporar el estudio del caso sudafricano. De hecho, si de desarrollo y transformación económica, social y política se habla, Sudáfrica y la superación del apartheid es uno de los ejemplos que se destacan en África y probablemente el mundo entero.

\footnotetext{
${ }^{85} \mathrm{El}$ texto completo de la declaración de la II Conferencia puede encontrarse en: http://rcci.net/globalizacion/2014/fg1896.htm
} 
Los antecedentes más remotos del apartheid datan de la "Ley de moralidad" implementada en 1685 por los colonos holandeses, que prohibía los matrimonios entre blancos y negros. No obstante fue en 1948, cuando el Partido Nacional llega al gobierno, que la minoría blanca comenzó a legislar de manera sistematizada en el territorio en busca de la segregación racial con el objetivo de que cada etnia desarrollara una estructura nacional propia y separada de las demás (Alonso Ollacarizqueta, 2011: $107-108)$.

A nivel económico la segregación estaba presente en el acceso a la propiedad en materia de explotación de recursos naturales, reservados a hombres blancos y residentes en ciudades, dejando fuera a la población rural, los hombres que no eran blancos y las mujeres. Adicionalmente, el régimen se caracterizó por el aislamiento en términos internacionales, aislamiento voluntario e impuesto por la comunidad internacional. Por ejemplo en materia de TBI, de los 50 celebrados, solo uno de ellos fue firmado durante este período ${ }^{86}$. En tercer lugar, el desarrollo económico sudafricano se basa en las materias primas, especialmente minerales, no escapando a la maldición de los recursos o enfermedad holandesa que se suele acreditar a todo el continente ${ }^{87}$.

Por tanto la salida del apartheid (1990 - 1991), redacción conjunta de la nueva constitución (1991 - 1994) y elección del nuevo Gobierno (1994) implicaron profundas transformaciones de tipo político, social y económico, concebidas por muchos autores como un verdadero milagro. En este sentido, la nueva etapa significó tres revoluciones: reingreso del Estado a la comunidad y mercado internacional, transformación social en base a la no segregación, y pasaje de una economía basada en las materias primas a una economía manufacturera de exportación (Alonso Ollacarizqueta, 2011: 112).

A propósito de la libertad económica, concretamente en materia de inversiones, esta quedó plasmada cuando, a partir de 1994, Sudáfrica se une a la tendencia global a la firma y ratificación de TBI conforme a las reformas de política económica promovidas en el marco del consenso de Washington. En general los 50 TBI celebrados por Sudáfrica siguen la estructura clásica indicada por Salacuse (2010: 127-128) al contener

\footnotetext{
${ }^{86}$ Se trata del TBI con Paraguay firmado el 3 de abril de 1974, en vigor desde el 16 de junio del mismo año.

${ }^{87}$ La maldición de los recursos o enfermedad holandesa se basa en la idea que la abundancia de recursos naturales, especialmente minerales y petróleo, no es positiva para los países menos adelantados ya que al dedicarse pura y exclusivamente a la explotación y exportación de dicha materia prima su desarrollo económico se ve afectado al entrar en el círculo vicioso de importar el resto de los bienes en vez de producir. Si bien parte de la doctrina afirma que este fenómeno suele acompañarse de altos niveles de corrupción, gobernanza ineficiente y violencia política, no existe evidencia histórica de tales extremos ni es sostenido por la totalidad de los autores (Di John, 2010: 1).
} 
disposiciones que pueden agruparse en: 1) Normas generales de trato de la inversión: alcance y definición de inversión, trato nacional, cláusula de la nación más favorecida, trato justo y equitativo; 2) Protección de las inversiones: garantías y compensaciones por expropiación, garantías de libre traspaso de fondos y transferencia de capitales y ganancias al exterior, prohibición o límites a los requisitos de desempeño; 3) Excepciones, modificaciones y terminación del tratado; 4) Solución de controversias: mecanismos de solución de controversias Estado-Estado e inversor-Estado.

Actualmente, 13 de estos acuerdos se encuentran en vigor ${ }^{88}, 27$ no fueron ratificados ${ }^{89}$, y finalmente 10 fueron terminados por denuncia unilateral por parte de Sudáfrica (véase tabla 5). Asimismo, poco más del 50\% de los acuerdos son celebrados en la década de los noventa, una vez terminado el aislamiento bajo el apartheid, hecho que es visto como una señal diplomática de reingreso del país a la comunidad internacional (Carim, 2015: 4).

Tabla 5: TBI terminados por denuncia unilateral de Sudáfrica

\begin{tabular}{|c|c|c|c|c|}
\hline $\begin{array}{c}\text { Contraparte } \\
\text { Fecha de firma }\end{array}$ & $\begin{array}{c}\text { Fecha de entrada } \\
\text { en vigor }\end{array}$ & $\begin{array}{c}\text { Fecha de } \\
\text { terminación }\end{array}$ & $\begin{array}{c}\text { Cláusula de } \\
\text { ultractividad }\end{array}$ \\
\hline Alemania & $11 / 09 / 1995$ & $10 / 04 / 1998$ & $22 / 10 / 2014$ & 20 años \\
\hline Argentina & $23 / 07 / 1998$ & $01 / 01 / 2001$ & $31 / 03 / 2017$ & 15 años \\
\hline Austria & $28 / 11 / 1996$ & $01 / 01 / 1998$ & $11 / 10 / 2014$ & 20 años \\
\hline $\begin{array}{c}\text { Bélgica- } \\
\text { Luxemburgo }\end{array}$ & $14 / 08 / 1998$ & $14 / 03 / 2003$ & $07 / 09 / 2012$ & 10 años \\
\hline Dinamarca & $22 / 02 / 1996$ & $23 / 04 / 1997$ & $31 / 08 / 2014$ & 10 años \\
\hline España & $30 / 09 / 1998$ & $23 / 12 / 1999$ & $23 / 12 / 2013$ & 10 años \\
\hline Francia & $11 / 10 / 1995$ & $22 / 06 / 1997$ & $01 / 09 / 2014$ & 10 años \\
\hline Holanda & $09 / 05 / 1995$ & $01 / 05 / 1999$ & $01 / 11 / 2013$ & 15 años \\
\hline Suiza & $27 / 06 / 1995$ & $29 / 11 / 1997$ & $01 / 11 / 2013$ & 10 años \\
\hline Reino Unido & $20 / 09 / 1994$ & $27 / 05 / 1998$ & $01 / 09 / 2014$ & 20 años \\
\hline
\end{tabular}

Fuente: Elaboración propia en base a datos del Investment Policy Hub de la UNCTAD. Fecha de consulta: 21 de abril de 2019 .

\footnotetext{
88 TBI con China; Cuba; Finlandia; Grecia; Irán; Italia; Corea; Mauricio; Mozambique; Nigeria; Paraguay; Rusia y Suecia.

89 TBI con Angola; Argelia; Brunei Darussalam; Canadá; Chile; Congo (2004); Congo (2005); Egipto; Guinea Ecuatorial; Etiopía; Gabón; Ghana; Guinea; Israel; Libia; Madagascar; Qatar; Ruanda; República Checa; Senegal; Tanzania; Túnez; Turquía; Uganda; Yemen; Zimbabue. La mayoría de ellos fueron firmados después del año 2000.
} 


\subsubsection{Los costos de la igualdad: el caso Piero Foresti}

Como se indicara precedentemente, la década del noventa generó el clima propicio para la firma y ratificación de TBI en Sudáfrica y el mundo. Sin embargo, otras reformas que se gestan en el corazón de la economía sudafricana van a contrapelo con las normas de protección de inversiones en vigor, evidenciando los riesgos del sistema de solución de controversias inversor-Estado y los costos de la equidad, o en términos más generales, la colisión entre regímenes jurídicos autocontenidos. En concreto, la colisión se visibiliza con la sanción de normas internas relacionadas con actividades económicas que históricamente habían estado en manos de las minorías blancas privilegiadas por el status quo anterior ${ }^{90}$.

Ejemplo de lo anterior son la Ley de desarrollo de recursos minerales y petróleo del 3 de octubre de 2002, vigente desde el 1 de mayo de 2004, y la Carta de Minería del 13 de agosto de 2004 que tienen como objetivo promover el acceso equitativo a la explotación de los recursos mineros y del petróleo y especialmente ampliar las posibilidades de acceso a tales industrias a los grupos históricamente desfavorecidos, incluyendo a las mujeres (capítulo 2 de Ley de desarrollo de recursos minerales y petróleo), y reparar las consecuencias de la discriminación racial y de género en las mencionadas industrias así como aquellas industrias vinculadas (artículo 3 de la Carta de Minería). En consecuencia, el artículo 4.7 de la Carta de Minería establece cuatro formas de involucramiento de los mencionados grupos históricamente desfavorecidos: 1) control del 50\% más un voto de las empresas (incluye control ejecutivo); 2) joint-ventures o asociaciones que impliquen el control del 25\% más un voto (incluye control conjunto); 3) participación mayoritaria en inversiones colectivas; 4) propiedad de un porcentaje mayor a 0 y menor a 100 que no implique control ejecutivo.

En el marco de estas normas es que, el 1 de noviembre de 2006, los inversores italianos Piero Foresti, Laura de Carli, Dora Foresti, Maria Teresa Suardo, Paola Suardo, Franca Conti y Daniela Conti ${ }^{91}$, así como la empresa establecida en Luxemburgo, Finstone SARL, solicitaron el inicio de un arbitraje de inversiones mediante el mecanismo

\footnotetext{
${ }^{90}$ Bond y Sharife (2009) afirman que las empresas transnacionales no solo se beneficiaban del apartheid sino que también lo sustentaban, en consecuencia frente al cambio de régimen emplearon estrategias como la presión social y el ejercicio de poder en los tribunales. Además del caso bajo análisis, un ejemplo lo constituye el caso Bowoto (Nigeria) contra Chevron en la Corte de Distrito de San Francisco (2008).

${ }^{91}$ A posteriori se suman tres reclamantes más, a saber: Antonio Foresti, Luigi Foresti y Massimiliano Foresti.
} 
adicional del $\mathrm{CIADI}^{92}$ en base a las disposiciones de los TBI entre Sudáfrica e Italia (1997) y Sudáfrica y Bélgica-Luxemburgo (1998). La solicitud fue aceptada por el Secretario General del CIADI el día 8 de enero de 2007.

Los reclamantes entendieron que, dado que entre 2009 y 2014 los inversores están obligados a desinvertir el 26\% del capital invertido en explotaciones mineras, el Estado incumple las disposiciones del TBI relativas a expropiación y compensación, sin tener certeza del monto de compensación, estimando que este resulta menor al previsto por el tratado (párrafos 54, 57 y 62 del laudo de fecha 4 de agosto de 2010). En consecuencia consideraron que fueron incumplidas las disposiciones sobre trato justo y equitativo y trato nacional conforme a los acuerdos (párrafo 78), y reclamaron una indemnización de 350 millones de dólares ${ }^{93}$.

Por su parte el Gobierno Sudafricano respondió que la expropiación prevista en el Derecho Interno se sustenta en múltiples e importantes motivos que van desde la simplificación y modernización del sistema económico minero, pasando por la protección del medioambiente y las comunidades y la reducción de los perjuicios de la concentración de la propiedad de los recursos mineros, hasta la reparación de la privación de derechos y otros efectos sociales negativos causados por el apartheid en general y la Ley de minería de 1991 en particular, principal herramienta de defensa de los privilegios de los blancos en el sector minero (párrafo 69).

Asimismo, el Gobierno afirma que los reclamantes no usaron los procedimientos internos previstos para obtener la compensación, por tanto ellos eran los únicos responsables de las pérdidas alegadas (párrafo 71). Sobre este punto, autores como Sornarajah (2010: 382) son de la idea que cuando la reestructura empresarial se realiza en base a objetivos económicos y políticos que permitan evitar inequidades económicas del pasado, la desinversión resultante no era pasible de compensación, puesto que dichas medidas deben ser consideradas como un riesgo comercial más.

\footnotetext{
${ }^{92}$ Al no ser parte del Convenio de Washington, no es de aplicación para Sudáfrica la jurisdicción del centro en base al artículo 25. En este sentido es que los reclamantes demandan en base al mecanismo adicional que permite que el Secretariado del CIADI administre: 1) procedimientos de conciliación y arbitraje para resolver diferencias basadas en una inversión de carácter jurídico que no sean competencia del CIADI, ya sea porque el Estado receptor inversor no sea nacional de un Estado parte; 2) procedimiento de conciliación y arbitraje en el marco de una controversia que no surja de una inversión que no sean competencia del CIADI, por los mismos motivos anteriores; 3) procedimientos de comprobación de hechos (artículo 2 del Reglamento del mecanismo complementario).

93 Cifra indicada por el Investment Policy Hub de la UNCTAD. Disponible en: http://investmentpolicyhub.unctad.org/ISDS/Details/262
} 
El laudo del 4 de agosto de 2010 fue dictado una vez que el tribunal arbitral acordó con las partes la suspensión del proceso conforme a lo solicitado por los inversores, y en consecuencia resuelve respecto a los costos, sin llegar a pronunciarse sobre el fondo del asunto. Si bien la experiencia para Sudáfrica no fue negativa, al no ser condenado al pago de la indemnización reclamada, la propia demanda evidencia los riesgos que entraña el sistema de solución de controversias inversor-Estado en casos de colisión entre regímenes autocontenidos: el de protección de las inversiones y el de protección de los derechos humanos, sumado a la inexperiencia del Estado en el sistema y el consecuente desgaste de tener que seguir un proceso de casi cuatro años.

\subsubsection{La reforma del sistema de protección de inversiones en Sudáfrica}

En fechas cercanas al inicio del arbitraje bajo análisis (2008), Sudáfrica se embarcó en un proceso de análisis de su sistema de protección de inversiones basado en la experiencia del caso Piero Foresti, la constatación de la inexistencia de una relación directa entre los TBI en vigor y la atracción de inversiones, la identificación de inconsistencias entre las disposiciones de la red de TBI en vigor y los preceptos de lo Constitución post-apartheid (1994) (Carim, 2015: 4). El análisis concluyó que las disposiciones de los TBI limitaban el espacio regulatorio del Estado para legislar en relación a los efectos negativos del apartheid en materia social y económica (Snider, 2016: 1).

En consecuencia, en 2010 el Gabinete de Sudáfrica, compuesto por el Presidente, el Vicepresidente y los Ministros, tomó las siguientes decisiones: 1) no celebración de nuevos TBI; 2) revisión de los TBI en vigor con vistas a su terminación o posible renegociación en base a un nuevo modelo de acuerdo a ser elaborado; 3 ) mejora de la legislación interna de protección de inversiones de modo que incluya como excepciones legítimas a la protección brindada por ciertas políticas públicas, por ejemplo la seguridad nacional, la salud, el medioambiente o la reparación de inequidades históricas; 4) creación de un Comité Interministerial que se encargue de la gestión de las siguientes etapas (Carim, 2015: 4).

Por tanto, la primera medida a tomar fue la notificación de terminación por denuncia unilateral (artículos 54 y 56 de la Convención de Viena sobre Derecho de los tratados entre Estados) de los acuerdos en vigor con los Estados europeos, a saber: Alemania, Bélgica-Luxemburgo, Dinamarca, España, Francia, Grecia, Holanda, Italia, Reino 
Unido, Suecia y Suiza (2012-2014). En 2017 se sumó la denuncia del tratado con Argentina. Si bien se concretó la denuncia de diez acuerdos, todos ellos contienen cláusulas de ultractividad que establecen la protección de las inversiones realizadas en su marco durante un período de tiempo posterior a su terminación de diez, quince o veinte años según el caso (véase tabla 5). Esto significa que aun sin estar en vigor, el Estado receptor continúa comprometido por las cláusulas del tratado y por tanto un inversor, que considere que sus derechos fueron vulnerados, está en condiciones de iniciar un arbitraje contra el Estado amparado en el acuerdo terminado.

La segunda etapa del proceso de reforma la constituye la nueva Ley de inversiones (Ley número 22 de 2015) firmada por el Presidente Zuma el 13 de diciembre de 2015 y en vigor desde su publicación en la Gaceta Oficial en fecha 19 de diciembre del mismo año. Forere (2018: 283) afirma que la nueva norma puede considerarse un escudo para el Estado pero a la vez una herramienta para regular la inversión extranjera conforme al mandato constitucional, sin llegar a ser una espada contra los inversores. En este sentido, se evidencia un intento de reforzar el Derecho Interno como mecanismo para sustituir los acuerdos internacionales existentes (Bernasconi-Osterwalder, 2015: 7).

La nueva ley busca regular las inversiones realizadas por inversores nacionales y extranjeros con los que el país no tenga un acuerdo en vigor o dentro del período de ultractividad. Si bien el nivel de protección de la norma es menor que el habitualmente incluido en los TBI, conteniendo disposiciones relativas a: definiciones; inversión; interpretación de la ley; propósito de la ley; ámbito de aplicación; trato justo en materia administrativa; establecimiento; trato nacional; seguridad en materia de propiedad; protección legal de las inversiones; repatriación de capitales; derecho de regular; solución de controversias; regulaciones; disposiciones transitorias; título corto y entrada en vigor.

Asimismo, la nueva ley innova en dos aspectos: inclusión del derecho de regular y exclusión de la solución de controversias inversor-Estado. La primera innovación otorga al Estado la facultad de implementar normas en áreas de interés público como ser las políticas públicas soberanas relativas a reparación histórica, social y económicas de inequidades e injusticias; principios y valores de la Constitución; derechos garantizados en la Constitución; promoción y preservación de la herencia cultural, conocimiento indígena y recursos naturales; desarrollo económico e industrialización; desarrollo progresivo de los derechos sociales y económicos; protección del medio ambiente y conservación de los recursos naturales (artículo 12). 
Este es un punto de especial importancia en la reforma del sistema de protección de inversiones en Sudáfrica y se presenta como ejemplo para una reforma regional o en el sistema-mundo, La presión de una empresa extranjera puede poner en jaque políticas públicas en Estados en desarrollo, generando, en palabras del anterior Experto Independiente sobre la promoción de un orden internacional democrático y equitativo de la ONU (2012-2018), Alfred-Maurice de Zayas, una parálisis o congelamiento normativo (ONU, 2015: 5) y en consecuencia limitando el espacio regulatorio del Estado. Asimismo, pone en evidencia una eventual colisión entre los compromisos asumidos por el Estado de proteger inversiones extranjeras y sus obligaciones en materia de derechos humanos.

La otra innovación la constituye la exclusión de la solución de controversias inversorEstado. El texto normativo prevé el empleo de métodos alternativos de solución de conflictos, como ser la mediación, y la posibilidad de recurrir a la jurisdicción doméstica. Asimismo, deja abierta la puerta para posibles arbitrajes Estado-Estado, debiendo ser el Estado de nacionalidad del inversor quien haga propio el reclamo (artículo 13). Este punto plantea un retorno al régimen de protección diplomática.

De esta manera, Sudáfrica representa un caso de recuperación de la autonomía, manifestada en la competencia de resolución de conflictos con inversores extranjeros cedida a instituciones internacionales mediante prórroga de jurisdicción en los TBI celebrados. Si bien Sudáfrica nunca firmó ni adhirió el Convenio de Washington, los inversores extranjeros contaban con la posibilidad de demandar al Estado mediante el mecanismo adicional del CIADI - previsto especialmente para aquellos Estados que no son parte del Convenio de Washington-. Por tanto, a pesar de no ser miembro del CIADI, tenía a disposición un mecanismo que le permitía cederle una competencia propia (resolución de conflictos con inversores extranjeros), extremo que con la nueva ley de inversiones y la terminación de los TBI logra recuperar para sí, consolidando su espacio de política pública.

En suma, la experiencia del caso Piero Foresti determina una respuesta del Gobierno Sudafricano, implementando una reforma del sistema de protección de inversiones a los efectos de evitar nuevas controversias que pongan de manifiesto la colisión entre las normas en materia de inversiones y las normas que buscan garantizar la igualdad y la reparación social y económica a la población afectada por el apartheid. Así, esta controversia repite parte de la historia sudafricana, caracterizada por el "empeño de unos 
por mantener sus privilegios y la resistencia de otros por defender sus derechos fundamentales" (Alonso Ollacarizqueta, 2011: 110).

\subsection{Conclusiones del capítulo 2}

La denuncia del Convenio de Washington por parte de Bolivia, Ecuador y Venezuela, el proceso de no renovación o denuncia de TBI por parte de Bolivia, Ecuador y fuera de la región, Sudáfrica, son ejemplos del abandono del régimen de solución de controversias inversor-Estado por parte de Estados que inicialmente formaban parte de este. Un miembro abandona un régimen internacional cuando entiende que las ganancias de estar fuera de este son superiores o al menos iguales a las ganancias actuales como miembro. Los motivos tienen raíces jurídicas, especialmente en normas constitucionales que determinan una jurisdicción diferente a la hora de resolver disputas que involucran al Estado con inversores extranjeros (Bolivia, Ecuador y Venezuela) y/o la protección de derechos humanos: derechos de la naturaleza, en el caso de Bolivia y Ecuador, y el derecho a la igualdad, en el caso de Sudáfrica post-apartheid. Adicionalmente, se destacan los motivos político-ideológicos de los gobiernos involucrados y los aspectos coyunturales, en particular la experiencia en el régimen como demandados (montos de las demandas, sectores económicos involucrados, impacto social y ambiental de las demandas).

Así como la soberanía interna es comprometida mediante la soberanía legal internacional en ejercicio del jus tractatum, la defensa de la primera se ejerce mediante la segunda. Es la soberanía legal internacional la que le permite al Estado celebrar, denunciar o no renovar acuerdos internacionales. En definitiva, los Estados analizados terminan con las invitaciones, en términos de Krasner, que habían aceptado voluntariamente en una etapa anterior ligada al consenso de Washington (década de los noventa). Sin perjuicio de lo anterior, Krasner no aborda el tema desde la perspectiva de la protección del espacio de política pública, siendo necesario retomar este aspecto en otros capítulos de este trabajo.

Las cláusulas de ultractividad contenidas en los TBI no permiten que la recuperación de la autonomía en materia de competencia para resolver conflictos sea inmediata. Por el contrario, ya que el contenido de las disposiciones de los tratados permanece vigente por el período previsto en la mencionada cláusula, los tribunales internacionales ad hoc pueden seguir registrando demandas de inversores extranjeros, y por tanto actuando 
como instituciones de control externo de la legalidad de la conducta de los Estados. Este no es un aspecto a desatender, dado que en los cuatro casos bajo análisis los Estados comienzan a recorrer el camino del abandono del régimen en función de la experiencia con una o más controversias, ya sea por los altos montos indemnizatorios demandados o los sectores o derechos involucrados.

Ahora bien, es importante tener en cuenta la visión política del fenómeno de los disidentes. Además de los motivos jurídicos, los Estados son movidos por motivos ideológicos de los gobernantes de turno. El apego a las recetas neoliberales propuestas por las organizaciones económicas internacionales en el consenso de Washington, llevó a que la gran mayoría de los Estados Sudamericanos comenzaran la práctica de celebrar TBI y adherir al Convenio de Washington, inicialmente rechazado por seguir los postulados de la doctrina $\mathrm{Calvo}^{94}$. El arribo al gobierno de mandatarios de corte progresista, con interés en la protección de derechos de la naturaleza y recursos estratégicos, sumado a las mencionadas experiencias negativas en relación a demandas de inversores extranjeros, llevó a Bolivia, Ecuador y en parte Venezuela, a abandonar el régimen internacional. Los cambios políticos en Ecuador durante la presidencia de Lenin Moreno, determinaron un retorno a la etapa anterior.

El caso de Sudáfrica es sustancialmente diferente. Políticamente el cambio jurídico iniciado por la constitución de 1994, profundizado en el Código de Minería, tiene como raíces el reconocimiento y la defensa de los derechos humanos de toda la población sin discriminación. La salida del apartheid no solo se debió a un cambio políticoideológico, sino a la presión de la comunidad internacional, el cumplimiento del estado de Derecho y el respeto de los derechos humanos.

En suma, si bien Bolivia, Ecuador, Venezuela y Sudáfrica son los primeros disidentes, otros Estados han dado pasos que los alejan del núcleo central del régimen, en mayor o menor medida, aunque no hayan tomado la decisión de abandonarlo. Esta es la situación de Nueva Zelanda y Australia en el marco del CPTPP que mediante notas reversales han acordado no emplear el sistema de solución de controversias inversor-Estado con otros Estados parte. Como se verá en el apartado 6.2, dichos Estados pueden incluirse en el nuevo grupo denominado confrontadores, esto es, Estados que sin abandonar el régimen presentan cambios en su posición original, especialmente mediante la propuesta de creación de un régimen alternativo o paralelo o buscan un escaso empleo del actual.

\footnotetext{
${ }^{94}$ En Sudamérica la excepción son Surinam y Brasil. El caso de Brasil se analizará en el siguiente capítulo (apartado 3.2).
} 
La situación de Brasil es diferente ya que casi desde el inicio de la etapa de auge del régimen decidió comportarse como un externo y no aprobar parlamentariamente los TBI que había firmado el Poder Ejecutivo por considerarlos inconstitucionales. Estos temas serán desarrollados en el siguiente capítulo. 


\section{Capítulo 3: Nuevos acuerdos: entre un nuevo equilibrio en el régimen y la exclusión del arbitraje inversor-Estado}

\subsection{Aspectos preliminares}

Completando el primer círculo de esta investigación, este capítulo se dedica al examen de los nuevos modelos de tratados que proponen alternativas institucionales $o$ excepciones para ciertos sectores o medidas susceptibles de resolución de controversias entre inversores extranjeros y Estados huéspedes. Los acuerdos que proponen alternativas y excepciones se mueven entre un nuevo equilibrio en el régimen y la exclusión del arbitraje inversor-Estado, alcanzando mayor o menor nivel de cambio frente al régimen actual. En vista de lo anterior, este capítulo se estructura en cuatro partes, cada una de ellas dedicada a un tratado en concreto, o tipo de tratado en general, según el caso. En primer lugar se examinan los ACFI de Brasil, modelo alternativo al tradicional TBI, negociado desde 2015 por el único Estado Sudamericano que se ha mantenido como externo al régimen internacional de inversiones. El modelo es innovador al excluir de su articulado la solución de controversias inversor-Estado, priorizando los mecanismos alternativos de solución de disputas y el arbitraje EstadoEstado en última instancia.

En segundo lugar se presenta la propuesta del TPP, a posteriori incluida dentro del CPTPP, que da la posibilidad a los Estados partes de excluir de la solución de controversias inversor-Estado las medidas de control del tabaco. En tercer lugar, con el objetivo de aportar elementos contrafácticos de otras regiones del mundo, se incorpora el estudio del nuevo modelo de TBI de India (2016) que refuerza las etapas previas y mandatorias para el inicio de un arbitraje internacional, particularmente en lo que respecta al procedimiento para agotar la jurisdicción doméstica.

Cabe aclarar que, sin perjuicio de reconocer la labor que están realizando, para este capítulo se optó por excluir del análisis los procesos de reforma que se están gestando en el CIADI y la UNCTAD ${ }^{95}$, a nivel particular y general respectivamente. Motiva la anterior decisión el hecho que no se trata de propuestas alternativas (exclusión total o sectorial, creación de una nueva institucionalidad, reforzamiento de la jurisdicción

\footnotetext{
${ }^{95}$ Parte de la propuesta de reforma impulsada por la UNCTAD será analizada en el círculo 3 cuando se trate el tema del derecho de regular.
} 
doméstica que limita el acceso al arbitraje internacional). Por el contrario, se trata de procesos que tienen como fin el mantenimiento y mejora del régimen actual.

\subsection{Exclusión total de régimen de solución de controversias inversor-Estado: el caso de Brasil, un tradicional externo al régimen}

\subsubsection{El inicio del proceso: celebración de TBI y limitaciones constitucionales}

Brasil es un Estado paradigmático en América Latina ya que históricamente se ha comportado como un externo al régimen internacional de protección de inversiones en general, y del régimen de solución de controversias inversor-Estado ${ }^{96}$. Incluso cuando en los últimos años elaboró un nuevo modelo de acuerdo bilateral, el denominado acuerdo de cooperación y facilitación de inversiones (ACFI), este excluye el cuestionado arbitraje inversor-Estado. Asimismo, cabe resaltar que ha marcado su liderazgo regional al transmitir la impronta del modelo ACFI a las relaciones entre los miembros del Mercosur con la celebración del Protocolo de cooperación y facilitación de inversiones intra-Mercosur (7 de abril de 2017).

Inicialmente, Brasil también fue parte del proceso latinoamericano de la década de los noventa, tendiente a la celebración de TBI en el marco del consenso de Washington. En este sentido, además de adherir al Convenio constitutivo del Organismo Multilateral de Garantía de Inversiones (Seúl, 1985) en el año 1994, celebra 14 acuerdos con: Alemania; Bélgica y Luxemburgo; Chile; República de Corea; Cuba; Dinamarca; Finlandia; Francia; Italia; Países Pajos; Portugal; Reino Unido; Suiza; Venezuela. Luego que los seis primeros acuerdos ${ }^{97}$ fueron enviados por el Poder Ejecutivo al Congreso para su aprobación, en marzo de 2002 se crea un Grupo de Trabajo Interministerial para el análisis de su compatibilidad con el ordenamiento jurídico doméstico. El Grupo determina "la conveniencia de retirar dichos acuerdos del congreso, cuestión que se produjo en diciembre de 2002” (Actis, 2014: 23).

De Azevedo (2001: 9) destaca que los inconvenientes para la aprobación de los TBI por parte del Congreso se centran en temas directamente vinculados con la autonomía. La autora destaca que los mencionados tratados comprometen al Estado por períodos muy extensos, riesgos en la balanza de pagos por consagrar la libre transferencia de capitales,

\footnotetext{
${ }^{96}$ Una tipología de Estados Sudamericanos respecto a su posición frente al CIADI y los TBI (miembros, externo y disidentes) es parte de una investigación anterior cuyos resultados se recogen en Bas Vilizzio (2017) y brevemente se indican en el apartado 2.2.2 de este trabajo.

${ }_{97}$ En 1996, los TBI con Suiza, Portugal, Chile y Reino Unido; y en 2000, con Francia y Alemania (De Azevedo, 2001:6).
} 
además de presentar problemas de constitucionalidad al establecer una jurisdicción diferente a la doméstica para la resolución de disputas entre inversores y el Estado, además de privilegiar más al inversor extranjero en detrimento del nacional al darle derecho de iniciar un arbitraje internacional contra el Estado. Ejemplo de lo anterior sería la vulneración del artículo 4 numeral 34 que reza:

\footnotetext{
"Todos son iguales ante la ley, sin distinción de cualquier naturaliza, garantizándose a los brasileños y a los extranjeros residentes en el País la inviolabilidad del derecho a la vida, a la libertad, a la igualdad, a la seguridad y a la prioridad, en los siguientes términos: (...) la ley no excluirá de la apreciación del Poder Judicial la lesión o la amenaza de derechos" (artículo 4 numeral 34 de la Constitución de Brasil)
}

La protección de la autonomía, cristalizada en la defensa de la constitución y el consecuente rechazo a la aprobación de los TBI firmados es una demostración de resistencia a la dependencia a los organismos económicos internacionales. Asimismo, Brasil es un ejemplo en sí mismo de un Estado receptor de inversiones extranjeras aun sin tener TBI en vigor, hecho que cuestiona la presión de las empresas de los Estados desarrollados para contar con este tipo de acuerdos para obtener garantías jurídicas a sus inversiones en países en desarrollo. En clave autonomista, Brasil frena los intereses de Estados como Estados Unidos, quien se había convertido en banquero, accionista de empresas y gendarme del mundo (Cardoso y Faletto 2003: 172), y de sus élites dirigentes de participar con diferentes roles en las relaciones transnacionales, asegurando "varias formas de predominio de los intereses americanos, públicos y privados" (Jaguaribe, 1979: 95).

\subsubsection{La consolidación del proceso: nuevo modelo de acuerdo en materia de inversiones}

Enmarcado en un flujo de inversiones que había dejado de ser unidireccional para convertirse en bidireccional y una política exterior de fuerte relacionamiento sur-sur (Morosini y Sánchez Badin, 2018: 247), en 2015 Brasil consolida su postura autonomista mediante la presentación de un instrumento jurídico alternativo a los TBI. Luego de un proceso de doce años de negociación y elaboración interna, la dirección de la Secretaría de Comercio Exterior del Ministerio de Desarrollo, Industria y Comercio presenta el nuevo modelo de tratado de inversiones: los ACFI. El nuevo modelo de tratado se enmarca en la tendencia global, especialmente en el ámbito de OMC, relativa a la "simplificación de los trámites administrativos y, especialmente de los procesos 
regulatorios para los inversores extranjeros y operadores económicos, con el fin de alivianar la carga regulatoria" (Ghiotto, 2018: 4).

Si bien los ACFI comparten algunas similitudes con los TBI respecto a la protección de la inversión extranjera (cláusulas de trato nacional, nación más favorecida, expropiación y compensación, etc.), se distinguen al excluir de su articulado el tradicional arbitraje inversor-Estado. A la fecha de cierre de este trabajo, Brasil ha firmado doce ACFI, cinco con Estados africanos: Mozambique (30 de marzo de 2015), Angola (1 de abril de 2015, único en vigor desde el 11 de octubre de 2017), Malaui (25 de junio de 2015) y Etiopía (11 de abril de 2018), Marruecos (13 de junio de 2019), seis con Estados Latinoamericanos: México (26 de mayo de 2015) ${ }^{98}$, Colombia (9 de octubre de 2015), Chile (23 de noviembre de 2015), Surinam (2 de mayo de 2018), Guyana (13 de diciembre de 2018) y Ecuador (26 de setiembre de 2019) 99 ; y uno con Estados de Medio Oriente: Emiratos Árabes Unidos (15 de marzo de 2019). Asimismo, en el Acuerdo de Profundización Económico Comercial entre Perú y Brasil (28 de abril de 2016) se incorpora un capítulo de inversiones (capítulo 2) que sigue el formato de los ACFI.

Aun siendo discutible el valor jurídico vinculante de los preámbulos de los tratados internacionales, cabe señalar que en los acuerdos celebrados por Brasil con Mozambique, Angola, Malaui, Perú, Etiopía, Surinam, Guyana y Emiratos Árabes Unidos se reconoce la autonomía de los Estados y su facultad para implementar políticas públicas. Con una redacción diferente, los ACFI firmados con Colombia y México reconocen que las partes tienen derecho a regular las inversiones extranjeras en su territorio para alcanzar los objetivos que estén previstos en políticas públicas vinculadas, por ejemplo, a salud, seguridad o medioambiente. Más allá de la terminología empleada, en cualquiera de los casos el foco se pone en reconocer el poder de decisión del Estado en materia de inversiones, aspecto que al no estar presente en los TBI tradicionales, ha sido germen de gran parte de los arbitrajes existentes o, en su defecto, generaron situaciones de congelamiento normativo. Tema especialmente cuestionado cuando se trata de áreas sensibles para el Estado o relacionadas a la protección de los derechos humanos, como ser salud pública, medioambiente, acceso al agua potable, etc.

\footnotetext{
${ }^{98}$ Un análisis particular del ACFI Brasil-México puede verse en Ghiotto y Arroyo Picard (2017).

${ }^{99}$ A la fecha de cierre de este trabajo no se dispone el texto del ACFI Brasil-Ecuador al no encontrarse publicado en sitios web oficiales de los Estados parte ni en el Investment Policy Hub de la UNCTAD. Por tanto el análisis del contenido de los acuerdos se realizará omitiendo las características de este.
} 
En lo que respecta a solución de controversias, aspecto determinante para la no aprobación de los anteriores TBI por parte del Congreso Brasilero, el nuevo modelo de tratado es innovador al excluir los mecanismos de solución de disputas inversor-Estado, incorporando un sistema de prevención de controversias Estado-Estado basado en: 1) la existencia de Puntos Focales u Ombudsman (defensores del pueblo) en cada Estado para la prevención de disputas y facilitación de su resolución; 2) la conformación de un Comité Conjunto, compuesto por representantes gubernamentales de ambos Estados, que se encarga de evaluar la controversia mediante consultas y negociaciones entre las partes, como requisito previo para el inicio de la vía arbitral Estado-Estado.

Cada acuerdo presenta particularidades en el arbitraje Estado-Estado. Los ACFI firmados con Angola, Malaui, Mozambique y Emiratos Árabes Unidos prevén que si las partes deciden someterse al arbitraje pueden optar por cualquier mecanismo de solución de controversias en materia de inversiones interestatal (artículos 15, 13, 15 у 19 respectivamente). El ACFI con México, además de lo anterior, agrega la posibilidad de crear un tribunal arbitral ad hoc (artículo 19). Adicionalmente, los acuerdos celebrados con Colombia, Etiopía, Surinam, Guayana y Emiratos Árabes Unidos refieren al arbitraje mediante un tribunal ad hoc o, en su defecto, cualquier institución arbitral permanente (artículos 23 numeral 2, 24 numeral 2, 25 numeral 2, 25 numeral 1, у 25 numeral 1 respectivamente), siendo esta última opción compartida por el capítulo de inversiones del acuerdo con Perú.

Los últimos acuerdos celebrados, los ACFI con Colombia, Perú, Etiopía, Surinam, Guyana y Emiratos Árabes, coinciden en excluir del arbitraje las siguientes áreas: responsabilidad social corporativa, lucha contra la corrupción y la ilegalidad, medio ambiente, asuntos laborales, salud y seguridad conforme a su regulación en los tratados (artículos 23 numeral 3, 2.21 numeral 3, 24 numeral 3, 25 numeral 3, 25 numeral 3 у 25 numeral 3 respectivamente). De esta manera, se visualiza una evolución normativa hacia una mayor protección de la autonomía del Estado para tomar decisiones en materias sensibles sin que estas puedan ser objeto de un arbitraje.

En definitiva, los ACFI resuelven parte de los problemas que tradicionalmente atañen a los TBI, esto es, mitigan los riesgos y eventuales controversias con la presencia del Ombudsman; y eliminan las típicas cláusulas draconianas que brindan mayores ventajas a los inversores extranjeros frente a los nacionales (Actis, 2015) al darles la posibilidad unilateral de presentar acciones ante tribunales arbitrales internacionales. La jurisdicción doméstica, conforme con las disposiciones constitucionales, sigue siendo la 
opción existente para la solución de disputas iniciadas por inversores extranjeros, confirmando que la defensa de la autonomía estatal es pieza clave de la política externa brasilera en materia de inversiones.

\subsubsection{El Protocolo de Cooperación y Facilitación de Inversiones intra-Mercosur: siguiendo el camino de Brasil}

El 7 de abril de 2017, los Cancilleres de los miembros fundadores del Mercosur celebraron el Protocolo de cooperación y facilitación de inversiones intra-Mercosur (PFCI), cuyo texto consta como anexo a la decisión 03/17. Dicha decisión deroga a texto expreso la decisión 11/93 en cuyo anexo se incluía el Protocolo de Colonia para la promoción y protección recíproca de inversiones en el Mercosur de 1994 (Protocolo de Colonia). El PFCI tiene una duración indefinida, sin perjuicio del derecho de las partes a revisarlo, y a diferencia de su antecesor no es parte integrante del Tratado de Asunción. Su entrada en vigor, prevista a los 60 días del depósito en Paraguay del segundo instrumento de ratificación, se cumplió el 30 de julio de 2019 para Uruguay y Brasil. El PCFI regula ocho temas centrales, los cuales se sistematizan en la tabla 6.

Tabla 6: Principales áreas temáticas del Protocolo de Cooperación y Facilitación de Inversiones intra-Mercosur

\begin{tabular}{|c|c|}
\hline Área temática & Descripción \\
\hline Trato de la inversión & $\begin{array}{l}\text { Alcance y definición de inversión; trato nacional; trato no menos favorable } \\
\text { que a inversores de nacionalidad extra Mercosur, excluyendo cláusula de la } \\
\text { nación más favorecida y trato justo y equitativo (artículos } 3 \text { a 5) }\end{array}$ \\
\hline $\begin{array}{l}\text { Protección de inversiones } \\
\text { por parte del Estado } \\
\text { receptor }\end{array}$ & $\begin{array}{l}\text { Garantías y compensaciones por expropiación directa exclusivamente } \\
\text { (excluye expropiación indirecta); transparencia; libre traspaso de fondos y } \\
\text { transferencia de capitales y ganancias al exterior (artículos } 6 \text { a 9) }\end{array}$ \\
\hline $\begin{array}{l}\text { Excepciones a la } \\
\text { responsabilidad del Estado } \\
\text { receptor }\end{array}$ & $\begin{array}{l}\text { No obligación de extender beneficios de acuerdos actuales o futuros en } \\
\text { materia de doble tributación; no responsabilidad por medidas prudenciales } \\
\text { en materia financiera; excepciones de seguridad (artículos } 10 \text { a 12) }\end{array}$ \\
\hline $\begin{array}{l}\text { Obligaciones de los } \\
\text { inversores }\end{array}$ & $\begin{array}{l}\text { Cumplimiento de las normas del Estado receptor en relación a la inversión y } \\
\text { en materia tributaria, de transparencia, lucha contra la corrupción, } \\
\text { medioambiente, asuntos laborales y salud; y compromiso de adopción de } \\
\text { prácticas de responsabilidad social empresarial (artículos } 13 \text { a 16) }\end{array}$ \\
\hline Gobernanza institucional & $\begin{array}{l}\text { Creación de una Comisión que administra el PCFI; designación de Puntos } \\
\text { Focales u "Ombudsmen"; intercambio de información, interacción con el } \\
\text { sector privado; cooperación entre organismos nacionales encargados de } \\
\text { promoción de inversiones (artículos } 17 \text { a } 22 \text { ) }\end{array}$ \\
\hline
\end{tabular}




\begin{tabular}{|c|l|}
\hline $\begin{array}{c}\text { Área temática } \\
\text { controversias entre } \\
\text { Estados }\end{array}$ & $\begin{array}{l}\text { Procedimiento de prevención de controversias Estado-Estado como etapa } \\
\text { previa mandatoria a la solución de controversias Estado-Estado; empleo de } \\
\text { los mecanismos de solución de controversias en el Mercosur para dirimir } \\
\text { disputas entre Estados; excepciones (responsabilidad social empresarial, } \\
\text { medidas de lucha contra la corrupción y la legalidad, medioambiente, } \\
\text { asuntos laborales y salud); opción de foro; exclusión de los mecanismos de } \\
\text { solución de controversias inversor-Estado (artículos 23 y 24) }\end{array}$ \\
\hline $\begin{array}{c}\text { Agenda para cooperación } \\
\text { y facilitación de } \\
\text { inversiones }\end{array}$ & $\begin{array}{l}\text { Dentro de las funciones de la Comisión está el desarrollo y discusión de una } \\
\text { agenda de temas relevantes que será discutida por los Estados Parte, cuyos } \\
\text { resultados podrán constituir protocolos adicionales o instrumentos } \\
\text { independientes (artículo 25) }\end{array}$ \\
\hline $\begin{array}{c}\text { Otras disposiciones } \\
\text { Objetivo; ámbito de aplicación; duración; entrada en vigor (artículos 1, } 2 \text { y } \\
26)\end{array}$ \\
\hline
\end{tabular}

Fuente: Bas Vilizzio (2018: 55).

El nuevo instrumento jurídico sigue el modelo ACFI de Brasil e introduce en el Mercosur la idea de la cooperación y facilitación de inversiones como alternativa a la clásica promoción y protección de inversiones en el sentido de los TBI o el propio Protocolo de Colonia que replicaba este modelo. Las diferencias más importantes con los anteriores pueden encontrarse en la exclusión del trato justo y equitativo, la cláusula de la nación más favorecida, y la solución de controversias inversor-Estado, disposiciones ampliamente criticadas en los TBI. Como explica Rojas (2017: 13), el PCFI da fortaleza a los Estados, ya que el sistema de resolución de disputas interestatales resulta "consistente con el paradigma de retomada parcial del control estatal sobre los flujos de IED, protegiendo las relaciones oficiales de potenciales daños causados por disputas inconsistentes iniciadas por inversionistas".

El PCFI es innovador para el bloque regional al proponer un mecanismo obligatorio de prevención de controversias Estado-Estado en el marco de la nueva gobernanza que establece el acuerdo. Si un Estado entiende que otro Estado adoptó una medida en incumplimiento del acuerdo puede presentar un escrito inicial a la Comisión, con copia a los demás Estados. La presidencia de la Comisión debe convocar a una reunión de modo que se evalúe el escrito inicial, se intente alcanzar una solución y las conclusiones sean recogidas en un informe. Si la disputa afecta a un inversor específico, este debe ser identificado en el escrito inicial, pudiendo ser invitado a participar de las reuniones de la Comisión y se dejará constancia en el informe sobre los eventuales incumplimientos del inversor. Asimismo, un Estado puede rechazar que la Comisión entienda en relación a una disputa que previamente haya sido presentada ante los mecanismos previstos en 
otros acuerdos, como por ejemplo un TBI. Esta disposición es de vital importancia porque excluiría estos casos de la siguiente etapa, evitando un doble pronunciamiento sobre el mismo tema.

En caso que la disputa no sea resuelta o uno de los Estados involucrados no haya participado de las reuniones queda abierta la siguiente etapa de resolución mediante el mecanismo vigente para la resolución de disputas entre Estados en el Mercosur, actualmente previsto en el Protocolo de Olivos (PO). En este punto, el PCFI se aparta parcialmente del modelo ACFI dado que en los siete acuerdos bilaterales celebrados se prevé el arbitraje internacional Estado-Estado, y el PO establece un sistema arbitral regional que cuenta con un mecanismo de revisión, similar a una apelación. Los ACFI firmados con Angola, Malaui y Mozambique prevén que si las partes deciden someterse al arbitraje pueden optar por cualquier mecanismo de solución de controversias en materia de inversiones.

Otro elemento a considerar es que el PCFI excluye de la solución de controversias Estado-Estado las medidas tomadas en materia de responsabilidad social empresarial, lucha contra la corrupción y la ilegalidad, medio ambiente, asuntos laborales y salud (artículos 14, 15 párrafo 1 y 16 párrafo 2). En este aspecto existe coincidencia con los ACFI celebrados entre Brasil y Colombia, Perú, Etiopia, Surinam, Guyana y Emiratos Árabes Unidos, constituyendo una evolución hacia el reconocimiento del derecho de regular del Estado como ejercicio válido de la soberanía. Asimismo, es de destacar que el protocolo establece una opción de foro en el sentido que si una controversia es sometida a los procedimientos de prevención o solución del PCFI no podrá ser sometida a los procedimientos arbitrales previstos en TBI $\mathrm{u}$ otros instrumentos jurídicos.

El PCFI es una prueba el liderazgo regional de Brasil en esta temática, liderazgo que se ha extendido al ámbito multilateral con la presentación ante la OMC de un proyecto de acuerdo multilateral sobre facilitación de inversiones (Herreros, 2018: 13), distribuido a los miembros de la organización mediante el documento JOB/GC/169 del 1 de febrero de 2018. El proyecto tampoco incluye mecanismos de solución de diferencias inversorEstado y prevé que las diferencias que puedan surgir entre los Estados Parte se dirimirán en aplicación del sistema de la OMC conforme a artículos XXII y XXIII del Acuerdo General de Aranceles y Comercio de 1994 y el Entendimiento sobre Solución de Diferencias, salvo en lo que respecta a la suspensión de concesiones en el marco de otro acuerdo (artículo 22 numeral 3 literal c). 
Otros Estados han presentado propuestas en la OMC bajo el paraguas de la facilitación de inversiones, como ser la planteada por Rusia en el documento JOB/GC/120 (31 de marzo de 2017); México, Indonesia, Corea, Turquía y Australia con el documento JOB/GC/121 (6 de abril de 2017); China con el documento JOB/GC/123 (26 de abril de 2017); Argentina y Brasil en conjunto con el documento JOB/GC/124 (26 de abril de 2017). Se destaca que la propuesta rusa plantea que las controversias sean resuelvas en la jurisdicción doméstica de los Estados miembros, una suerte de retorno a la doctrina Calvo ${ }^{100}$.

\subsection{Exclusión sectorial del régimen de solución de controversias inversor-Estado: las medidas de control del tabaco en el CPTPP}

\subsubsection{Del TPP al CPTPP}

Tras casi seis años de negociaciones, el 4 de febrero de 2016 doce Estados con costas al Océano Pacífico firmaron en Auckland el tratado constitutivo de la Asociación Transpacífica (TPP por su sigla en inglés). Los firmantes son Australia, Brunei, Canadá, Chile, Estados Unidos, Japón, Malasia, México, Nueva Zelanda, Perú, Singapur y Vietnam. No obstante, pocos días después de la llegada de Donald Trump a la presidencia, Estados Unidos retiró su firma del acuerdo el 23 de enero de 2017. Los once Estados restantes, renegociaron el texto sin la presencia estadounidense.

El texto resultante, el acuerdo CPTPP, fue firmado el 8 de marzo de 2018, en Santiago de Chile y entró en vigor el 30 de diciembre de 2018 con la ratificación de Australia, Canadá, Japón, México, Nueva Zelanda y Singapur, y el 14 de enero de 2019 se agregó Vietnam. Para los Estados restantes entra en vigor 60 días después de que completen los procesos domésticos para la aprobación y/o ratificación del acuerdo.

Si bien el tratado mantiene sus características generales respecto al capítulo de inversiones, se destaca que en el caso de Nueva Zelanda, mediante notas reversales de fecha 8 de marzo de 2018, el Estado acordó con Australia, Brunei Darussalam, Malaysia, Perú y Vietnam la exclusión de las disposiciones relativas a los mecanismos de solución de controversias inversor-Estado para sus relaciones recíprocas. En otros

\footnotetext{
${ }^{100}$ Otros puntos vinculados a la solución de controversias inversor-Estado que destacan Ghiotto y Guamán (2018) es la oportunidad que debe brindarse a las partes interesadas para comentar la nueva normativa estatal, o las referencias a la modificación de marcos normativos internos relativos a procesos que faciliten la llegada, operación y retiro de inversiones. En este punto las autoras llaman la atención en la incidencia que el sector privado y los demás Estados pueden tener sobre el mecanismo regulador de cada Estado (Ghiotto y Guamán, 2018: 7).
} 
términos, ningún inversor neozelandés podrá recurrir a los mecanismos previstos en el capítulo 9 (Inversión) sección B del acuerdo CPTPP contra los Estados mencionados, y viceversa. Dichos acuerdos bilaterales entran en vigor al momento que lo haga el acuerdo CPTPP entre ambos Estados.

Siguiendo la tipología propuesta con base en la teoría de los regímenes internacionales, en este punto es posible preguntarse si Nueva Zelanda se perfila a convertirse en un externo al régimen de solución de controversias inversor-Estado. En una interpretación estricta, la respuesta es negativa dado que no optan por abandonar el régimen, como sí lo hicieron Bolivia, Ecuador y Venezuela (véase apartado 2.3), sino que excluye la aplicación del mismo para aquellos Estados con los que así lo haya acordado. Al mismo tiempo mantiene en vigor dos TBI y 14 acuerdos que incluyen las tradicionales disposiciones sobre protección de inversiones. Nueva Zelanda se encuentra en el rol de confrontador, como se verá en el apartado 6.2 para la situación de la UE e India. Se trata de Estados que sin abandonar el régimen presentan cambios en su posición original, especialmente mediante la propuesta de creación de un régimen alternativo o paralelo o buscan un escaso empleo del actual.

\subsubsection{La solución de controversias inversor-Estado: aspectos procesales}

La Sección B del Capítulo de Inversión se ocupa de las controversias surgidas por reclamos de inversores extranjeros de nacionalidad de alguno de los miembros del СРТPP frente a otros miembros que sean receptores de la inversión. Si bien se trata de una sección extensa y colmada de excepciones, dentro y fuera del capítulo, en este apartado se realizará un estudio de sus principales artículos, en particular aquellos que han generado mayor discusión doctrinaria tanto en el CPTPP como su antecesor, el TPP.

Como afirman Schill y Vidigal (2018: 13) el texto del acuerdo CPTPP en materia de solución de controversias inversor-Estado opera en el marco del tradicional arbitraje de inversiones. En primer lugar, el proceso de resolución de disputas comienza con un período de enfriamiento (cooling-off period) por un plazo de seis meses. Durante este, las partes deben intentar resolver la controversia mediante consultas y negociación, con o sin la participación no vinculante de buenos oficiantes o mediadores (artículo 9.18). La solución amigable suele ser habitual en los TBI y/o capítulos de inversiones previstos en los TLC, como etapa previa obligatoria al sometimiento de la controversia 
al arbitraje internacional. De esta manera se evita que las partes en el conflicto se involucren en un arbitraje que podría haberse evitado mediante una solución mutuamente convenida producto de negociaciones directas.

Por tanto, una vez cumplido el período de enfriamiento y de no haberse arribado a una solución mutuamente convenida, queda abierta la vía arbitral. El inicio de la vía arbitral debe cumplir con dos requisitos: 1) requisito ratione personae: el inversor debe tener nacionalidad de uno de los Estados parte del Acuerdo CPTPP, y debe actuar en nombre propio o por cuenta de una empresa en el país del demandado bajo su control directo o indirecto; 2) requisito ratione materiae: el reclamo debe basarse en una materia de naturaleza jurídica, esto es, un caso de incumplimiento, por parte del Estado receptor de la inversión, de compromisos explicitados en la Sección A del capítulo, una autorización de inversión o un contrato de inversión, que le generó daño económico al demandante (artículo 9.19.1).

Es el demandante quien tiene la opción de foro (forum shopping) entre el arbitraje ad hoc en el CIADI si los Estados son parte del Convenio de Washington de 1965 (véase tabla 7); el mecanismo complementario del CIADI para los Estados que no sean parte del mencionado convenio (actualmente solo es el caso de Vietnam); las Reglas de arbitraje de la Comisión de las Naciones Unidas para el Derecho Mercantil Internacional (CNUDMI); o cualquier otra institución arbitral u otras reglas de arbitraje si así lo acuerda con el demandado (artículo 9.19.4). Sea cual sea el foro elegido, el solo sometimiento del reclamo a la vía arbitral implica que los Estados signatarios han otorgado su consentimiento de prorrogar la jurisdicción a favor del foro en cuestión, conforme a las normas aplicables a cada uno de los casos (artículo 9.20).

En vista de lo anterior, la norma se limita a indicar un elenco de foros externos ante los cuales el demandante puede efectivizar su reclamo. No se presentan cambios sustantivos, ni se resuelven los cuestionamientos respecto a la solución de disputas por parte de tribunales ad hoc y por ende sin permanencia, que no han generado una jurisprudencia uniforme, y si bien no cuenta con un órgano de apelación prevé su posible existencia en el futuro (artículo 9.23 numeral 11). Por tanto, las diferentes propuestas de reforma al sistema en general no son contempladas por los autores del tratado.

Es importante tener en cuenta que se trata de instituciones externas al CPTPP y que no necesariamente responden a las lógicas jurídicas del conjunto de naciones de una vasta región como la transpacífica. En otras instancias en América del Sur se ha intentado la 
regulación de un sistema de solución de controversias inversor-Estado propio de la región, tal fue el caso del Centro de Solución de Controversias en Materia de Inversiones de la UNASUR, pero con el retiro de cinco miembros (Argentina, Brasil, Chile, Colombia, Paraguay) entre 2018 y 2019 y la autosuspensión de Perú por tiempo indefinido, no se prevén avances.

Tabla 7: Miembros del TPP que son parte del Convenio de Washington de 1965

\begin{tabular}{|c|c|c|c|}
\hline \multicolumn{1}{|c|}{ Estado } & Firma 0 adhesión & Depósito de ratificación & Entrada en vigor \\
\hline Australia & 24 marzo 1975 & 2 mayo 1991 & 1 junio 1991 \\
\hline Brunei & 16 setiembre 2002 & 16 setiembre 2002 & 16 octubre 2002 \\
\hline Canadá & 15 diciembre 2006 & 1 noviembre 2013 & 1 diciembre 2013 \\
\hline Chile & 25 enero 1991 & 24 setiembre 1991 & 24 octubre 1991 \\
\hline Japón & 23 setiembre 1965 & 17 agosto 1967 & 16 setiembre 1967 \\
\hline Malasia & 22 octubre 1965 & 8 agosto 1966 & 14 octubre 1966 \\
\hline México & 11 enero 2018 & 27 julio 2018 & 26 agosto 2018 \\
\hline Nueva Zelanda & 2 setiembre 1970 & 2 abril 1980 & 8 mayo 1980 \\
\hline Perú & 4 setiembre 1991 & 9 agosto 1993 & 13 noviembre 1968 \\
\hline Singapur & 3 febrero 1968 & 14 octubre 1968 & \\
\hline Vietnam & - & - & - \\
\hline
\end{tabular}

Elaboración propia en base a datos del CIADI. Fecha de consulta: 4 de mayo de 2019.

Por otra parte, el texto no prevé el agotamiento previo de la jurisdicción doméstica como requisito para el inicio de la vía arbitral internacional, en contra de las ideas de la doctrina Calvo (1868) respecto a la obligación de los extranjeros de agotar los recursos internos previo a la protección o intervención diplomática del Estado de su nacionalidad. En términos de Schill y Vidigal (2018: 13), el CPTPP opera en paralelo al sistema doméstico al no establecerse su agotamiento como requisito previo al arbitraje internacional. Consecuentemente, la entrada en vigor del CPTPP entraña la existencia de un nuevo instrumento jurídico en el entramado internacional que con cuenta con tal requisito. Por tanto, las mayores ventajas podrían ser invocadas por los inversores de terceros Estados en función de una cláusula de la nación más favorecida prevista otro 
tratado que vincule a un tercer Estado con un Estado parte del CPTPP, aun en los casos que el requisito sea obligatorio ${ }^{101}$.

Tampoco se prevé la jurisdicción doméstica como opción junto al arbitraje internacional a la hora de resolver las disputas entre inversores y Estados. No obstante, existe una excepción respecto a los tres Estados parte Latinoamericanos: Chile, México y Perú, junto a Vietnam, en el sentido que si un inversor extranjero decide presentar un reclamo ante sus tribunales administrativos o judiciales internos, tal elección es definitiva y exclusiva. Esta opción se asienta en la cláusula Calvo y deriva en que el inversor no tenga la posibilidad de someter el caso ante tribunales arbitrales internacionales, perdiendo por ende una segunda oportunidad de resolución (Anexo $9-\mathrm{J}$ ).

Para los casos que la opción doméstica sea ejercida, se refuerza la soberanía interna, al no permitir que tribunales internacionales puedan juzgar la legalidad de la actuación doméstica del Estado. Por tanto el Estado actúa sin injerencia de actores externos: los tribunales internacionales. Sin embargo, la autonomía no necesariamente sale fortalecida, ya que el Estado igualmente puede ser objeto de congelamiento normativo a causa de un juicio doméstico, y de esta manera no articular y/o alcanzar de forma independiente sus metas políticas.

Otro elemento a destacar es el principio de transparencia y publicidad de los diferentes documentos, actuaciones y audiencias a lo largo del proceso arbitral, salvo que se trata de información confidencial cuya divulgación deberá ser protegida (artículo 9.24). Esta disposición demuestra la evolución positiva que el sistema ha tenido a lo largo del tiempo, especialmente en relación al reconocimiento a las normas internas que consagran al derecho de acceso a la información pública y que, de acuerdo a la interpretación que realizara Tung (2015: 22) del idéntico texto del TPP, podrá generar mayor conocimiento social de casos controversiales. En la vereda opuesta, Johnson y Sachs (2015: 12-13) afirman que se trata de un paso atrás en relación a los principios de publicidad presentes en los modelos de acuerdos comerciales de Estados Unidos. Asimismo, entienden que aún deja afuera a los diferentes interesados en el proceso, cuya única vía de acceso continúa siendo la presentación de un escrito como amicus curiae, cuya aceptación es potestad del tribunal arbitral que entienda en el caso concreto.

\footnotetext{
${ }^{101}$ Para un análisis más profundo de la cláusula de la nación más favorecida en la solución de controversias inversor-Estado véase: Banifatemi (2009).
} 
Finalmente es innegable el avance en relación al Código de Conducta al que estarán sujetos los árbitros (artículo 9.22.6), siendo de aplicación las disposiciones generales sobre solución de diferencias del Acuerdo CPTPP (capítulo 28). De acuerdo a Johnson y Sachs (2015: 8), los árbitros internacionales no suelen tener los mismos requisitos de imparcialidad e independencia que los jueces en los sistemas judiciales domésticos, y de hecho, gran parte de las críticas al sistema de solución de controversias inversor-Estado radican en este punto.

\subsubsection{Las excepciones a la solución de controversias inversor-Estado}

\subsubsection{Las excepciones son la regla}

La sabiduría popular indica que "la excepción hace la regla". No obstante, las excepciones del texto precedente, así como del CPTPP son precisamente la regla, no la excepción. Como explica Bollyky (2016) las excepciones están presentes en todos los capítulos incluso en el preámbulo, bajo diferentes formas, como ser excepciones a principios generales, excepciones a excepciones, exclusiones explícitas o implícitas, aclaraciones, limitación de la normativa aplicable, etc.

En materia de solución de controversias inversor-Estado además de la excepción anteriormente analizada relativa a la jurisdicción doméstica como opción para la resolución de disputas en el caso de Chile, México, Perú y Vietnam (Anexo 9-J), las excepciones más destacables son las medidas de control del tabaco (artículo 29.5) y la deuda soberana (Anexo 9-G).

\subsubsection{Medidas de control del tabaco}

El artículo 29.5, ubicado en el Capítulo Excepciones y Disposiciones Generales y no en el de Inversiones, prevé la que tal vez sea la disposición más innovadora de todo el tratado, y sin duda la excepción más importante del sistema de solución de controversias inversor-Estado previsto. La norma indica que un Estado parte puede optar por que las medidas de control de tabaco que decida tomar no sean susceptibles de reclamaciones en el marco de la Sección B del Capítulo 9, y por tanto un inversor nacional de otro Estado parte no pueda iniciar un arbitraje por tales motivos. La opción puede ser ejercida en cualquier momento, incluso al inicio o durante el proceso arbitral. La inclusión de esta disposición responde a las características especiales del tabaco, como único bien de consumo que cuenta con un tratado internacional que controla y 
previene su consumo (Bollyky, 2016), el Convenio Marco de la Organización Mundial de la Salud para el Control del Tabaco, celebrado el 21 de mayo de 2003 y en vigor desde el 27 de febrero de 2005, que cuenta con 181 Estados parte $^{102}$.

Asimismo, Australia y Nueva Zelanda fueron dos de los Estados parte del Acuerdo TPP y actualmente CPTPP que más presionaron para la inclusión de la excepción del control del tabaco ${ }^{103}$. El primer Estado tiene la experiencia de la demanda de la tabacalera Philip Morris en la Corte Permanente de Arbitraje (caso 2012-2), en base a la Ley de empaquetado genérico de los cigarrillos (2011) y sus normas modificatorias y complementarias. El argumento del inversor se basaba en la supuesta violación de las disposiciones del TBI Hong Kong - Australia relativas al trato justo y equitativo y expropiación de la propiedad intelectual. El 17 de diciembre de 2015, el tribunal aceptó la objeción de Australia en relación a que constituye abuso de derecho que el demandante realizara una restructuración en Hong Kong, poco antes del inicio del arbitraje $^{104}$.

Un arbitraje similar es el iniciado por Philip Morris Brand Sàrl, Philip Morris Products S.A. y Abal Hermanos S.A. contra Uruguay (CIADI caso ARB/10/7) por entender que las medidas relativas a la presentación única por marca comercial y el uso de pictogramas con advertencias sanitarias del 80\% del frente y el reverso de las cajillas, representaban un incumplimiento del TBI Uruguay-Suiza. El 8 de julio de 2016, el tribunal arbitral ad hoc emite un laudo que no hace lugar a las pretensiones de la tabacalera, reconociendo el poder soberano de policía del Estado para regular la salud pública, y condenando a la empresa al pago de los gastos del tribunal arbitral y administrativos del CIADI, así como un reintegro de parte de los costos pagados por Uruguay (véase apartado 5.2).

Adicionalmente, la situación de Nueva Zelanda es prueba fehaciente que, como explica de Zayas, Experto Independiente sobre la promoción de un orden internacional democrático y equitativo nombrado por el Consejo de Derechos Humanos de la ONU. (2012-2018), las demandas o amenazas de demandas de manos de inversores extranjeros pueden derivar en una "“parálisis normativa” o incluso una

\footnotetext{
${ }^{102}$ Conforme a datos de la Organización Mundial de la Salud al 4 de mayo de 2019.

${ }^{103}$ Independientemente del impulso de Australia y Nueva Zelanda en este punto, son interesantes los cambios que este tratado implica a la posición de ambos frente a la solución de controversias inversorEstado. Según Álvarez (2016: 31), ambos países optaron por excluirla de los TBI celebrados desde el año 2011 (año en que se registra la demanda de Philip Morris Asia).

104 Laudo de jurisdicción y admisibilidad del 17 de diciembre de 2015 disponible en: https://pcacases.com/web/sendAttach/1711
} 
“congelación”, impidiendo a los Estados adoptar reglamentos" en áreas tales como la salud pública (ONU, 2015: 5). En este caso concreto, Nueva Zelanda paraliza la sanción de una norma de empaque genérico de cigarrillos hasta tanto no fuera emitido el laudo del arbitraje contra Australia. En consecuencia, frente al laudo positivo para Australia, el congreso neozelandés aprueba la Enmienda sobre empaque genérico a la Ley de Ambientes libres de humo de tabaco (14 de setiembre de 2016) y el Decreto sobre Ambientes libres de humo de tabaco (6 de junio de 2017), que crean los mecanismos de implementación del empaque genérico y su aplicación comienza a partir del 14 de marzo de 2018.

Johnson y Sachs (2015: 3) señalan que la excepción de las medidas de control del tabaco es necesaria para proteger a los Estados de reclamos como los anteriormente indicados, pero que el acuerdo no se pronuncia respecto a otras áreas objeto de políticas públicas soberanas, como ser el medio ambiente, la salud o la seguridad pública. De esta manera la soberanía interna, el espacio de política pública y la autonomía pueden verse condicionadas y, en palabras de Arato (2015: 283), posicionar a las empresas transnacionales como creadoras de normas jurídicas.

La excepción de las medidas de control del tabaco es una innovación que ya ha comenzado a replicarse en otros acuerdos comerciales, puntualmente en el artículo 22 del capítulo 8 (Inversiones) del TLC Singapur-Australia (enmienda firmada el 13 de octubre de 2016, en vigor desde el 1 de diciembre de 2017) ${ }^{105}$, y el artículo 13 del TBI Singapur - Kazajistán (celebrado el 21 de noviembre de 2018, no vigente) ${ }^{106}$. Este último con un espectro mayor ya que no refiere exclusivamente a las medidas de control del tabaco, sino a cualquier medida respecto al tabaco o productos relacionados.

Sin perjuicio de la importancia de lo anterior, ni el texto del acuerdo CPTPP ni de los otros acuerdos tienen en cuenta otras políticas públicas que requieren protección en base al derecho de regular del Estado. Tal es el caso de otras medidas entorno a la protección del medio ambiente o la salud pública, como ser el control del consumo de bebidas alcohólicas, bebidas azucaradas, comidas procesadas con grasas saturadas, azúcar o sodio en exceso. El consumo de cualquiera de los anteriores es uno de los factores de riesgo de las enfermedades crónicas no transmisibles, como las enfermedades cardiovasculares, cáncer, enfermedades pulmonares crónicas y diabetes.

105 Texto disponible en: https://dfat.gov.au/trade/agreements/in-force/safta/Documents/agreement-toamend-the-singapore-australia-free-trade-agreement.pdf

${ }^{106}$ Texto disponible en: https://investmentpolicy.unctad.org/international-investment-agreements/treatyfiles/5700/download 
En el documento "«Mejores inversiones»y otras intervenciones recomendadas para la prevención y el control de las enfermedades no transmisibles" (OMS, 2017), se proponen las mejores medidas en relación costo-eficacia, destacándose el etiquetado con advertencias sanitarias, las restricciones en cuanto a los envases (ejemplo: tamaño), y otras medidas en el ámbito de la publicidad y el marketing. Las medidas planteadas para el etiquetado de alimentos y bebidas son asimilables a las controvertidas por la tabacalera Philip Morris en las disputas con Uruguay y Australia, hecho que hace cuestionarse a autores como Brewin (2018) si no es cuestión de tiempo que las empresas del sector interpongan demandas ante tribunales de inversiones.

Si bien la disposición del CPTPP es innovadora y parece marcar tendencia en la escena internacional, la exclusión de la solución de controversias inversor-Estado de otras medidas tomadas en ejercicio válido del derecho de regular en pro de la salud pública sería un paso para la protección de la soberanía y la autonomía estatal. Esta disposición simboliza un cambio hacia el reconocimiento del derecho de regular en un tema de interés público, pero también es un ejemplo de la dificultad que tienen los Estados para resolver los problemas que el régimen de solución de controversias inversor-Estado entraña (Lencucha, 2016).

Contrarios a una exclusión de este tipo, Lester y Mercurio (2017) afirman que existen mejores mecanismos para evitar la vulneración del derecho de regular y limitación del espacio de política pública, ya que las exclusiones son injustas e innecesarias. Estas focalizan en un sector o sectores determinados, corriendo el riesgo de vulnerar el principio de trato justo y equitativo ya que el Estado tiene carta blanca para favorecer a la industria local frente a los inversores extranjeros, incluso dejando sin recurso a un inversor extranjero frente a situaciones de incumplimiento de normas de defensa de la competencia o anticorrupción. Los autores proponen la incorporación de excepciones generales en los acuerdos, como lo hacen, por ejemplo, el Acuerdo General de Aranceles y Comercio (GATT por su sigla en inglés) el Acuerdo General de Comercio de Servicios (GATS por su sigla en inglés).

En suma, vistas las posiciones doctrinarias y sin pretender desconocer el impacto que una disposición como esta puede tener en el sistema internacional, es esencial reafirmar que la disposición bajo análisis le da al Estado un opción de excluir o no del sistema de solución de controversias inversor-Estado las medidas de control del tabaco, en definitiva un ejercicio de la soberanía legal internacional de hacer o no hacer. Aun así, el entramado de acuerdos internacionales en materia de inversiones puede determinar 
que un Estado que haya ejercido la opción aun pueda ser demandado por una empresa nacional de otro Estado parte del CPTPP, dada la existencia de otro acuerdo vigente en la materia o cláusulas de ultractividad típicas de los TBI.

\subsubsection{Deuda pública}

El Anexo 9-G establece que dado que la compra de deuda soberana es una empresa de riesgo, no podrán emitirse laudos arbitrales a favor del demandante en caso de reclamos por incumplimiento o falta de pago de títulos de deuda soberana emitida por una de las Partes del acuerdo. La excepción a la excepción la constituyen las violaciones a los compromisos emanados de la Parte A del Capítulo de Inversiones, estando la carga de la prueba sobre los hombros del demandante.

Diferente es el caso de la reestructuración de deuda, dado que no pueden ser sometidos a un arbitraje internacional, o continuar en uno si ya fueron sometidos, siempre se trate de una reestructuración negociada al momento o después del sometimiento. La norma no explicita si la disposición incluye aquellos casos en que los títulos de deuda no establezcan cláusulas de acción colectiva ${ }^{107}$, y una parte de los acreedores estén habilitados para decidir no ingresar en el proceso de reestructuración (acreedores disidentes o holdouts). Por tanto cabe preguntarse si la norma abarca o no a los acreedores disidentes.

\subsection{Reforzamiento de la jurisdicción doméstica: el caso del modelo de TBI de la} India (2016)

\subsubsection{Reforma del sistema de protección de inversiones en India}

El laudo en el arbitraje iniciado por la empresa White Industries Australia Limited (30 de noviembre de 2011) ${ }^{108}$, en el marco de un tribunal ad hoc establecido en Singapur, constituyó el detonante del proceso de reforma del sistema de protección de inversiones en India. La empresa argumentó que el Estado no había otorgado los medios para asegurar recursos jurídicos efectivos y hacer valer sus derechos, estándar habitual en la protección de inversiones. Si bien el TBI India-Australia no contiene una cláusula que

\footnotetext{
${ }^{107}$ Las cláusulas de acción colectiva establecen que una mayoría calificada determinada de acreedores tiene la potestad de modificar los términos más importantes previstos en los títulos de deuda soberana, obligando a la totalidad de acreedores, de forma de impedir las acciones individuales de acreedores disidentes (Ranieri, 2015).

${ }^{108}$ Laudo disponible en: https://www.italaw.com/sites/default/files/case-documents/ita0906.pdf
} 
recoja el principio de protección efectiva, por el juego de la CNMF (artículo 4 numeral 2) el inversor argumentó la aplicación del TBI India-Kuwait (artículo 4 numeral 5). En consecuencia, el tribunal concluyó que India incumplió con la protección de los medios efectivos para hacer valer sus derechos. Por consiguiente condenó al Estado al pago de casi 5 millones de dólares australianos más intereses.

El caso White Industries despertó en India la preocupación sobre el impacto de los tratados de inversiones sobre los poderes regulatorios del Estado (Nedumpara, 2018: 214). Hecho que llevó a India a embarcarse en un proceso de reforma de su sistema de protección de inversiones. Este proceso tiene tres pilares: 1) la terminación por no renovación de los TBI en vigor que estaban cercanos a su fecha de expiración (actualmente 61 TBI terminados), 2) la renegociación de los 25 TBI que aún no habían completado su período de duración inicial ${ }^{109}$, enviando una propuesta de declaración conjunta interpretativa, y 3) la elaboración de un nuevo modelo de TBI. El estatus de los TBI celebrados por India puede ver en la tabla 8.

Tabla 8: Estatus de los TBI celebrados por India

\begin{tabular}{|c|c|c|c|c|}
\hline Contraparte & Estatus & Fecha de firma & $\begin{array}{c}\text { Fecha de entrada en } \\
\text { vigor }\end{array}$ & $\begin{array}{l}\text { Fecha de } \\
\text { terminación }\end{array}$ \\
\hline Alemania & Terminado & 10 julio 1995 & 13 julio 1998 & 3 junio 2017 \\
\hline Arabia Saudita & En vigor & 25 enero 2006 & 20 mayo 2008 & - \\
\hline Argentina & Terminado & 20 agosto 1999 & 12 agosto 2002 & 30 agosto 2013 \\
\hline Armenia & Terminado & 23 mayo 2003 & 30 mayo 2006 & 22 marzo 2017 \\
\hline Australia & Terminado & 26 febrero 1999 & 4 mayo 2000 & 23 marzo 2017 \\
\hline Austria & Terminado & 8 de noviembre 1999 & 1 marzo 2001 & 24 marzo 2017 \\
\hline Bahréin & Terminado & 13 enero 2004 & 5 diciembre 2007 & 4 diciembre 2017 \\
\hline Bangladesh & En vigor & 9 febrero 2009 & 7 julio 2011 & - \\
\hline Bélgica-Luxemburgo & Terminado & 31 octubre 1997 & 8 enero 2001 & 22 marzo 2017 \\
\hline Bielorrusia & Firmado & 24 setiembre 2018 & - & - \\
\hline Bielorrusia & Terminado & 27 noviembre 2002 & 23 noviembre 2003 & 22 marzo 2017 \\
\hline $\begin{array}{c}\text { Bosnia y } \\
\text { Herzegovina }\end{array}$ & En vigor & 12 setiembre 2006 & 13 febrero 2008 & - \\
\hline Brunei Darussalam & En vigor & 22 mayo 2008 & 18 enero 2009 & - \\
\hline Bulgaria & Terminado & 29 octubre 1998 & 23 setiembre 1999 & 22 marzo 2017 \\
\hline China & Terminado & 21 noviembre 2006 & 1 agosto 2007 & 3 octubre 2018 \\
\hline
\end{tabular}

${ }^{109}$ En el momento del inicio los proceso los Estados eran: Arabia Saudita, Bahréin, Bangladesh, Bosnia y Herzegovina, Brunei, China, Colombia, Finlandia, Islandia, Jordania, Kuwait, Laos, Letonia, Libia, Lituania, Macedonia, México, Mozambique, Myanmar, Senegal, Serbia, Sudán, Siria, Trinidad y Tobago, y Turquía. A la fecha de cierre de este trabajo de investigación los TBI con Bahréin, Kuwait, Laos, Macedonia, Omán, y Trinidad y Tobago se encuentran terminados, sin perjuicio de las cláusulas de ultractividad. 


\begin{tabular}{|c|c|c|c|c|}
\hline Contraparte & Estatus & Fecha de firma & $\begin{array}{c}\text { Fecha de entrada en } \\
\text { vigor }\end{array}$ & $\begin{array}{l}\text { Fecha de } \\
\text { terminación }\end{array}$ \\
\hline Chipre & Terminado & 9 abril 2002 & 12 enero 2004 & 22 marzo 2017 \\
\hline Colombia & Firmado & 10 noviembre 2009 & - & - \\
\hline Congo & Firmado & 13 abril 2010 & - & - \\
\hline Croacia & Terminado & 4 mayo 2001 & 19 enero 2002 & 25 abril 2017 \\
\hline Dinamarca & Terminado & 6 setiembre 1995 & 28 agosto 1996 & 13 mayo 2017 \\
\hline Egipto & Terminado & 9 abril 1997 & 22 noviembre 2000 & 29 marzo 2016 \\
\hline Emiratos Árabes & En vigor & 12 diciembre 2013 & 21 agosto 2014 & - \\
\hline Eslovaquia & Terminado & 25 setiembre 2006 & 27 setiembre 2007 & 22 marzo 2017 \\
\hline Eslovenia & Terminado & 14 junio 2011 & Sin datos & 22 marzo 2017 \\
\hline España & Terminado & 30 setiembre 1997 & 15 diciembre 1998 & 23 setiembre 2016 \\
\hline Etiopia & Terminado & 5 julio 2007 & Sin datos & 22 marzo 2017 \\
\hline Filipinas & En vigor & 28 enero 2000 & 29 enero 2001 & - \\
\hline Finlandia & En vigor & 7 noviembre 2002 & 9 abril 2003 & - \\
\hline Francia & Terminado & 2 setiembre 1997 & 17 mayo 2000 & 22 marzo 2017 \\
\hline Ghana & Terminado & 5 agosto 2002 & Sin datos & 22 marzo 2017 \\
\hline Grecia & Terminado & 26 abril 2007 & 10 abril 2008 & 22 marzo 2017 \\
\hline Hungría & Terminado & 3 noviembre 2003 & 2 enero 2006 & 29 marzo 2017 \\
\hline Indonesia & Terminado & 10 febrero 1999 & 22 enero 2004 & 7 abril 2016 \\
\hline Islandia & En vigor & 29 junio 2007 & 16 diciembre 2008 & - \\
\hline Israel & Terminado & 29 enero 1996 & 18 febrero 1997 & 25 marzo 2017 \\
\hline Italia & Terminado & 23 noviembre 1995 & 26 marzo 1998 & 23 marzo 2017 \\
\hline Jordania & En vigor & 30 noviembre 2006 & 22 enero 2009 & - \\
\hline Kazajistán & Terminado & 9 diciembre 1996 & 26 julio 2001 & 22 marzo 2017 \\
\hline Kirguistán & Terminado & 16 mayo 1997 & 12 mayo 2000 & 22 marzo 2017 \\
\hline Kuwait & Terminado & 27 noviembre 2001 & 28 junio 2003 & 27 junio 2018 \\
\hline Laos & Terminado & 9 noviembre 2000 & 5 enero 2003 & 22 marzo 2017 \\
\hline Letonia & En vigor & 18 febrero 2010 & 27 noviembre 2010 & - \\
\hline Libia & En vigor & 26 mayo 2007 & 23 marzo 2009 & - \\
\hline Lituania & En vigor & 31 marzo 2011 & 1 diciembre 2011 & - \\
\hline Macedonia & Terminado & 17 marzo 2008 & 17 noviembre 2008 & 16 octubre 2018 \\
\hline Malasia & Terminado & 3 agosto 1995 & 12 abril 1997 & 23 marzo 2017 \\
\hline Marruecos & Terminado & 13 febrero 1999 & 22 febrero 2001 & 22 marzo 2017 \\
\hline Mauricio & Terminado & 4 setiembre 1998 & 20 junio 2000 & 22 marzo 2017 \\
\hline México & En vigor & 21 mayo 2007 & 23 febrero 2008 & - \\
\hline Mongolia & Terminado & 3 enero 2001 & 29 abril 2002 & 22 marzo 2017 \\
\hline Mozambique & En vigor & 19 febrero 2009 & 23 setiembre 2009 & - \\
\hline Myanmar & En vigor & 24 junio 2008 & 8 febrero 2009 & - \\
\hline Nepal & Terminado & 21 octubre 2011 & Sin datos & 22 marzo 2017 \\
\hline Omán & Terminado & 2 abril 1997 & 13 octubre 2000 & 22 marzo 2017 \\
\hline Países Bajos & Terminado & 6 noviembre 1995 & 1 diciembre 1996 & 1 diciembre 2016 \\
\hline Polonia & Terminado & 7 octubre 1996 & 31 diciembre 1997 & 22 marzo 2017 \\
\hline
\end{tabular}




\begin{tabular}{|c|c|c|c|c|}
\hline Contraparte & Estatus & Fecha de firma & $\begin{array}{c}\text { Fecha de entrada en } \\
\text { vigor }\end{array}$ & $\begin{array}{l}\text { Fecha de } \\
\text { terminación }\end{array}$ \\
\hline Portugal & Terminado & 28 junio 2000 & 19 julio 2002 & 22 marzo 2017 \\
\hline Qatar & Terminado & 7 abril 1999 & 15 diciembre 1999 & 22 marzo 2017 \\
\hline Reino Unido & Terminado & 14 marzo 1994 & 6 enero 1995 & 22 marzo 2017 \\
\hline República Checa & Terminado & 11 octubre 1996 & 6 febrero 1998 & 25 abril 2017 \\
\hline República de Corea & Terminado & 26 febrero 1996 & 7 mayo 1996 & 22 marzo 2017 \\
\hline Rumania & Terminado & 17 noviembre 1997 & 9 diciembre 1999 & 22 marzo 2017 \\
\hline Rusia & Terminado & 23 diciembre 1994 & 5 agosto 1996 & 27 abril 2017 \\
\hline Senegal & En vigor & 3 julio 2008 & 17 octubre 2009 & - \\
\hline Serbia & En vigor & 31 enero 2003 & 24 febrero 2009 & - \\
\hline Seychelles & Terminado & 2 junio 2010 & Sin datos & 22 marzo 2017 \\
\hline Siria & En vigor & 18 junio 2008 & 22 enero 2009 & - \\
\hline Sri Lanka & Terminado & 22 enero 1997 & 13 febrero 1998 & 22 marzo 2017 \\
\hline Sudán & En vigor & 22 octubre 2003 & 18 octubre 2010 & - \\
\hline Suecia & Terminado & 4 julio 2000 & 1 abril 2001 & 22 marzo 2017 \\
\hline Suiza & Terminado & 4 abril 1997 & 16 febrero 2000 & 6 abril 2017 \\
\hline Tailandia & Terminado & 10 julio 2000 & 13 julio 2001 & 22 marzo 2017 \\
\hline Taiwán & Terminado & 17 octubre 2002 & 28 noviembre 2002 & 21 marzo 2018 \\
\hline Tayikistán & Terminado & 13 diciembre 1995 & 14 noviembre 2003 & 22 marzo 2017 \\
\hline Trinidad y Tobago & Terminado & 12 marzo 2007 & 7 octubre 2007 & 15 agosto 2018 \\
\hline Turkmenistán & Terminado & 20 setiembre 1995 & 27 febrero 2006 & 22 marzo 2017 \\
\hline Turquía & En vigor & 17 setiembre 1998 & 18 octubre 2007 & - \\
\hline Ucrania & Terminado & 1 diciembre 2001 & 12 agosto 2003 & 22 marzo 2017 \\
\hline Uruguay & Terminado & 11 febrero 2008 & Sin datos & 22 marzo 2017 \\
\hline Uzbekistán & Terminado & 18 mayo 1999 & 28 julio 2000 & 22 marzo 2017 \\
\hline Vietnam & Terminado & 8 marzo 1997 & 1 diciembre 1999 & 22 marzo 2017 \\
\hline Yemen & Terminado & 1 octubre 2002 & 10 febrero 2004 & 22 marzo 2017 \\
\hline Yibuti & Terminado & 19 mayo 2003 & Sin datos & 22 marzo 2017 \\
\hline Zimbabue & Terminado & 10 febrero 1999 & Sin datos & 22 marzo 2017 \\
\hline
\end{tabular}

Fuente: Elaboración propia en base a datos del Investment Policy Hub de la UNCTAD. Fecha de consulta: 26 de mayo de 2019.

En lo que respecta a los TBI que continúan en vigor, se propone la celebración de una declaración conjunta interpretativa de las disposiciones relativas a la definición de inversor, definición de inversión, exclusión de las medidas tributarias, trato justo y equitativo, trato nacional, $\mathrm{CNMF}$, cláusula paraguas, definición de expropiación, la solución de controversias Estado-Estado y la solución de controversias inversor-Estado. En este último punto, la nota interpretativa indica que el inversor debe demostrar que ha sufrido un daño real, excluyendo daños especulativos, producto de un incumplimiento 
directo del TBI. Asimismo, las demandas deben ser aptas para su resolución, esto es, si acumulativamente cumplen con los siguientes tres requisitos: 1) las demandas estén basadas en una conducta estatal, 2) la conducta estatal sea final y legalmente vinculante, y 3) la conducta produzca un daño concreto que pueda enmarcarse en un incumplimiento del instrumento jurídico. En otras palabras debe tratarse de una controversia jurídica, no política, en base a una conducta estatal de carácter final y que haya ocasionado un daño conforme al texto del TBI en cuestión.

Otras disposiciones vinculadas o que impactan directamente en la solución de controversias inversor-Estado refieren a la cláusula paraguas y CNMF. La primera cláusula tiene como efecto brindar la protección del paraguas del TBI a los acuerdos de tipo contractual celebrados entre inversores y Estados (Douglas, 2009: 237), por tanto reclamos de base contractual pasan a tener como base jurídica un tratado internacional. En este sentido, la declaración conjunta aclara que el mecanismo de solución de disputas inversor-Estado previsto en un TBI puede ser invocado exclusivamente si el contrato no cuenta con tal mecanismo. Esta disposición hace que se reduzca el ámbito de aplicación de la cláusula paraguas y refuerza la distinción entre arbitraje comercial y arbitraje inversor-Estado, distinción que se desdibuja por la propia disposición (Malhotra, 2016).

En relación a la CNMF, disposición que fuera el centro del caso White Industries, la declaración conjunta aclara que la cláusula no es aplicable a los mecanismos de solución de disputas inversor-Estado previstos en los TBI o cualquier otro proceso jurisdiccional, sin exclusiones (párrafo 9). Teniendo en cuenta la jurisprudencia en la materia, la aclaración es de real importancia ya que los antecedentes jurisprudenciales contienen interpretaciones diferentes de la aplicabilidad de la CNMF a las disposiciones sobre solución de controversias. Ejemplo de esto son los laudos en los ya mencionados casos Emilio Agustín Maffezini contra España (CIADI caso número ARB/97/7), Plama Consortium contra Bulgaria (CIADI caso número ARB/03/24), Telenor Mobile Communications AS contra Hungría (CIADI caso número ARB/04/15), el primero a favor y los dos últimos en contra (véase apartado 1.2.3 de este trabajo).

Dos declaraciones interpretativas se han celebrado a la fecha de cierre de este trabajo. La primera es la que aclara los términos del TBI India-Bangladesh (2009) de fecha 4 de octubre de $2017^{110}$, y la segunda es la que interpreta los términos del TBI India-

\footnotetext{
${ }^{110}$ Texto disponible en: https://investmentpolicy.unctad.org/international-investment-agreements/treaty-
} files/5725/download 
Colombia (2009) de fecha 4 de octubre de $2018^{111}$. En ambos textos, en lo que refiere a la solución de controversias inversor-Estado, establece que la CNMF es inaplicable a la materia. En segundo lugar aclara que el actor (inversor extranjero) debe demostrar que el demandado (Estado) ha incumplido con una obligación conforme al tratado, excluyendo, aun sin referencia directa, una interpretación amplia en base a una cláusula paraguas. Adicionalmente, establece los tres requisitos del documento general para el inicio de un arbitraje internacional.

\subsubsection{El agotamiento de la jurisdicción doméstica como requisito previo para el inicio del arbitraje internacional}

El nuevo modelo de TBI de India fue adoptado a partir del 14 de enero de $2016^{112}$. Si bien el texto contiene cambios sustanciales en diversas reglas típicas del régimen de protección de inversiones (véase el apartado 1.2.3), a los efectos de este trabajo se analizarán aquellas que refieren a la solución de controversias inversor-Estado o impactan directamente en ella. Asimismo, cabe destacar que la propuesta india no se trata de un cambio institucional a nivel del sistema internacional, sino un cambio en las normas domésticas. Sin perjuicio de lo anterior, el nuevo texto introduce obstáculos significativos al inversor para acceder al arbitraje internacional (Schill y Vidigal, 2018: 10), en consecuencia tiene un impacto directo en el sistema internacional y en la relación Estado-empresa transnacional, haciendo que su análisis sea pertinente para esta investigación.

El artículo 14 es el que regula la solución de controversias inversor-Estado y cuenta con innovaciones únicas a nivel global. Sin perjuicio de no innovar en la obligatoriedad de agotar la jurisdicción doméstica, ya que sigue la línea de la doctrina Calvo (véanse los apartados 1.2.3 y 2.2.1), el modelo de TBI 2016 es innovador en el período mínimo que requiere para agotar la jurisdicción doméstica y que sea abierta la vía arbitral: cinco años. Los cinco años se cuentan desde el momento que en que inversor tiene conocimiento de la medida en cuestión y del daño o pérdida respecto a su inversión, o bien el momento en que el inversor debió haber tenido conocimiento. El mismo

\footnotetext{
${ }^{111}$ Texto disponible en: https://investmentpolicy.unctad.org/international-investment-agreements/treatyfiles/5726/download

${ }^{112}$ La nota que acompaña al texto es del 28 de diciembre de 2015 pero su adopción es del 14 de enero de 2016 (Ranjan y otros, 2018: 10).
} 
momento es el punto de inicio del plazo de un año que tiene el inversor para someter el caso a la jurisdicción doméstica.

Una vez agotada la jurisdicción doméstica, o probado que no existían recursos disponibles, el primer paso para pasar al arbitraje internacional es el envío de una notificación de controversia al Estado receptor de la inversión, momento a partir del cual comienza a transcurrir el período de enfriamiento de seis meses. Si no hubiera solución amigable, el inversor puede someter el reclamo siempre que cumpla con cuatro requisitos: 1) que no hayan transcurrido más de seis años entre la fecha en que conoció o debió conocer la medida cuestionada; 2) que no hayan transcurrido más de doce meses desde el término del procedimiento seguido en la jurisdicción doméstica; 3) que transcurran al menos 90 días desde el envío de una notificación de arbitraje ${ }^{113}$; y 4) que renuncie a iniciar o continuar cualquier procedimiento bajo el Derecho Interno del Estado huésped.

Ranjan y Anand (2017) explican que la sumatoria de todos los requisitos necesarios para el inicio del arbitraje internacional hace muy difícil o casi imposible que un inversor extranjero pueda hacer uso efectivo de los mecanismos de solución de controversias inversor-Estado. Por tanto, el cuestionamiento aquí sería si no se estaría vulnerando el derecho del inversor a acceder a los tribunales, especialmente si se trata de una persona física y entran en juego las normas internacionales de derechos humanos. La respuesta necesariamente debe ser negativa puesto que el inversor no tiene vedado el acceso a la jurisdicción doméstica, por tanto India cumple con la protección de su derecho fundamental.

Otra disposición de trascendencia para la solución de controversias inversor-Estado es la del artículo 12.2 del nuevo modelo de TBI. La disposición establece que los inversores deben cumplir el Derecho del Estado huésped, principio general en la materia y que ha sido reconocido en laudos arbitrales (véase, por ejemplo, el caso Pac Rim en el capítulo 4). Por tanto, como explica Venkatesh (2019) esta obligación implica el cumplimiento de las normas vinculadas al medioambiente, conservación de recursos naturales y derechos humanos, entre otras. Sin perjuicio de lo anterior, el artículo 12.2 profundiza estableciendo que los inversores y sus inversiones deben reconocer y operar respetando los derechos, tradiciones y costumbres de las comunidades locales y población indígena. Esta disposición es reforzada por el artículo 14.11 que permite a un

${ }^{113}$ La notificación de arbitraje es un documento diferente a la notificación de disputa. 
Estado accionar contra un inversor en caso de incumplimiento del artículo 12, en línea con el proyecto revisado del Instrumento vinculante sobre empresas y derechos humanos (véase apartado 7.3).

El único TBI celebrado por India a posteriori del nuevo modelo es el nuevo TBI con Bielorrusia, de fecha 24 de setiembre de 2018. Anteriormente regía entre ambos Estados el TBI de fecha 27 de noviembre de 2002, que terminó el 22 de marzo de 2017. En este contexto, India aún tiene que avanzar por tres caminos: consolidar su régimen jurídico doméstico y el nuevo modelo de TBI para prevenir abusos en materia de derechos humanos, implementar las 58 renegociaciones de los TBI terminados, y aclarar la aplicación del artículo 12 y 14.11 para los 23 Estados con quienes mantiene un TBI en vigor pero no han celebrado la declaración conjunta interpretativa (Venkatesh, 2019). En suma, la reforma del sistema de protección de inversiones indio es comparable a la reforma transitada por Sudáfrica (véase el apartado 2.4), especialmente porque el punto de quiebre se encuentra en la experiencia ante una controversia internacional que hace que los Estados replanteen sus políticas públicas. No obstante la base jurídica no es idéntica, ya que en el caso de India no existen normas constitucionales que proteger y que determinen las modificaciones, como tampoco es idéntico el proceso de cambio. Sudáfrica terminó con diez TBI y dio prioridad al Derecho Interno mediante una ley de protección de inversiones, mientras que India continúa apostando a los acuerdos internacionales en la materia mediante la propuesta de un texto innovador y que protege los derechos de los inversores, la soberanía y autonomía del Estado.

\subsection{Conclusiones del capítulo 3}

El régimen internacional de solución de controversias inversor-Estado, basado esencialmente en el arbitraje ad hoc inversor-Estado se encuentra en un momento de fuertes críticas y consecuentemente algunos Estados o grupos de Estados han desarrollado alternativas al régimen predominante haciendo uso de su soberanía legal internacional. Las alternativas podrían ser catalogadas como "tratados balanceados". Sin embargo su análisis demuestra que la disparidad en el contenido de las propuestas torna imposible generalizar en este aspecto. Todas las propuestas buscan un balance pero lo hacen de diferente manera, por tanto resulta más adecuado examinar su alcance jurídico de la modificación propuesta en relación al régimen predominante y la mayor 
consideración de otros regímenes (ejemplo: protección del medioambiente, protección de los derechos humanos).

Teniendo en cuenta el alcance de la propuesta con respecto al régimen internacional actual, mayor o menor será la reivindicación de la soberanía interna, o el concepto en transición de soberanía regulatoria que se analizará más adelante (véase capítulo 7), como atributo que permita ejercer la autonomía como condición del Estado. En otros términos, mayor o menor será el rechazo o apego a las invitaciones, en palabras de Krasner, aceptadas por los Estados en la década del noventa y continuadas hasta la actualidad.

Los ACFI representan el mayor nivel de cambio ya que excluyen de su articulado la solución de controversias inversor-Estado, enfocándose en los medios alternativos para resolver disputas interestatales y el arbitraje Estado-Estado en última instancia. Se trata de la propuesta más avanzada, con tratados que efectivamente entraron en vigor y otros en proceso. Asimismo, si bien el modelo es originario de Brasil, actualmente ya se ha regionalizado con la entrada en vigor del Protocolo de Cooperación y Facilitación de Inversiones en el Mercosur y no es de descartar su multilateralización si tiene éxito la propuesta presentada en la OMC. El análisis del éxito o fracaso de esta propuesta excede los objetivos de este trabajo.

En el centro se encuentra el Modelo de TBI de la India del año 2016. El arbitraje inversor-Estado tradicional está previsto en su articulado pero para acceder a este, los inversores extranjeros deben transitar un complejo camino con una estructuración de tiempos y etapas que dificulta su concreción. Así la jurisdicción doméstica se ve reforzada y repercute directamente en la soberanía como atributo que permite el ejercicio de la autonomía estatal. Por último, presentando excepciones concretas aunque de menor entidad se encuentran el CPTPP y su antecesor el TPP. Es innegable que demuestran la existencia de cambios, pero los cambios no abarcan todas las áreas problemáticas ni tiene en cuenta todas las aristas de la materia. Por ejemplo son los árbitros los que van a determinar para cada caso concreto si se trata de una excepción, por tanto las excepciones podrían verse desdibujadas ante decisiones arbitrales contrapuestas. A largo plazo su aplicación puede ser desigual y los tribunales arbitrales siguen siendo órganos externos de contralor de la actividad estatal.

Asimismo, otro elemento que surge del examen realizado es que, salvo para la situación de Brasil, que es un externo al régimen, existe una relación causa-efecto entre la experiencia en el régimen internacional (demandas en su contra y su resolución en 
términos de áreas de regulación involucradas) y los cambios normativos. Esto es, los Estados del TPP y CPTPP e India ejercen su soberanía legal internacional para la celebración de tratados con elementos innovadores a consecuencia de controversias emblemáticas. Para los Estados parte del TPP y el CPTPP el detonante es el caso Philip Morris Asia contra Australia aunque en cierta medida también lo fue el caso Philip Morris contra Uruguay por tratarse de medidas de control del tabaco relacionadas con la presentación de las cajillas de cigarrillos. Mientras que para India el caso emblemático es la controversia White Industries. En el círculo 2 (capítulos 4 y 5) se analizará el caso Philip Morris contra Uruguay así como otras disputas que involucran temas de derechos humanos.

En la ilustración 3 puede verse una clasificación de los tres ejemplos de las propuestas estatales analizadas en este capítulo.

Ilustración 3: Clasificación de las propuestas estatales conforme a su grado de cambio respecto al régimen internacional predominante

Mayor nivel de cambio

Menor nivel de cambio

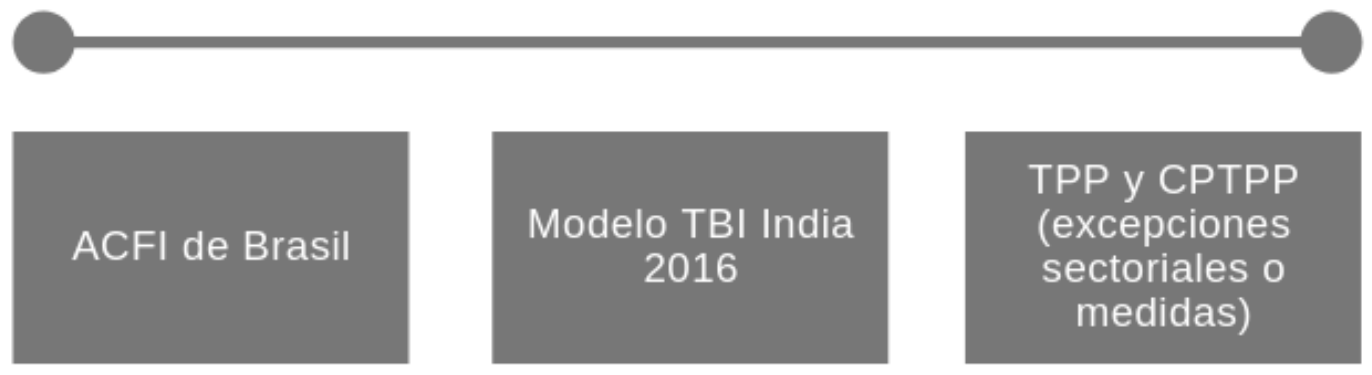

Fuente: Elaboración propia.

En suma, son los Estados que proponen alternativas con mayor o menor nivel de cambio respecto al régimen internacional preponderante conforme a la experiencia en los arbitrajes (aspectos coyunturales), en defensa o reforzamiento de su jurisdicción doméstica. En definitiva se constata un planteo de la defensa del espacio de política pública. Los acuerdos analizados muestran diferentes propuestas para reequilibrar el 
régimen actual, evitando el condicionamiento de la soberanía del Estado frente a las demandas de los inversores extranjeros. 


\section{Conclusiones del círculo 1}

El círculo 1 de esta investigación buscó contrastar la hipótesis número 1, esta es: "Las alternativas que se presentaron al régimen de solución de controversias inversorEstado son la terminación de tratados bilaterales de inversión, el retiro del CIADI y la celebración de nuevos tratados balanceados (exclusión total o sectorial de la solución de controversias inversor-Estado), y están motivadas, principalmente, en cambios en normas fundamentales a nivel doméstico". Se estructuró el análisis de los cambios bajo dos categorías: 1) el abandono del régimen ya sea mediante la terminación de los TBI (Bolivia, Ecuador, Sudáfrica) y/o el retiro del CIADI (Bolivia, Ecuador y Venezuela); y 2) los nuevos acuerdos que operan entre el balance del régimen y la exclusión del arbitraje inversor-Estado (ACFI de Brasil, TPP y CPTPP, modelo de TBI de India de 2016).

En ambas categorías surgen transversalmente dos elementos. En primer lugar la necesidad de los Estados de proteger su soberanía interna y su espacio de política pública, mediante su soberanía legal internacional. En otros términos, la firma de acuerdos internacionales, su terminación o renegociación. La protección de la soberanía, como atributo del Estado, le permite ejercer cabalmente su autonomía (condición). Los Estados demuestran así la necesidad no solo de extender sino también recuperar su regulación en materias de interés público, esto es, fortalecer su derecho de regular.

El segundo elemento que atraviesa los cambios analizados es que la existencia de disputas emblemáticas ha dado impulso ya sea al abandono del régimen o a la generación de propuestas de cambio. En otros términos, es la propia experiencia en el régimen la que opera como detonante, aunque no de manera generalizada. No todos los Estados con experiencia negativa deciden abandonar el régimen o proponer modificaciones. Factores como la protección del medioambiente y los recursos estratégicos (Bolivia, Ecuador y Venezuela) o los derechos humanos bajo un régimen democrático (Sudáfrica) también aparecen en escena pero son excluyentes de los aspectos político-ideológicos y coyunturales, en particular la experiencia como demandados (sectores económicos involucrados, montos de las demandas, impacto social y ambiental).

En definitiva, en las dos categorías de alternativas se visualiza una tendencia al retorno del Estado a parcelas de poder de las que previamente el Estado se había retirado. No 
solamente en lo que respecta a la jurisdicción para entender en disputas de inversores extranjeros contra los Estados, sino también en la elección de las áreas que no serán susceptibles de controversias en la materia. El retorno no es generalizado pero es a paso firme.

Por los motivos anteriores, la hipótesis 1 es confirmada parcialmente. Esto es, las alternativas que se presentaron al régimen de solución de controversias inversorEstado, en materia de tratados, son la terminación de los TBI, el retiro del CIADI y la celebración de nuevos acuerdos que buscan un balance en el régimen. Su fundamento se encuentra en aspectos jurídicos (cambios constitucionales, especialmente mayor protección de derechos humanos o sectores estratégicos para el Estado), políticos y coyunturales, especialmente la experiencia en el régimen. Ahora bien, la experiencia en el régimen pone en el tapete los riesgos de la fragmentación del Derecho Internacional, en particular la colisión del régimen de protección de inversiones y el régimen de protección de los derechos humanos. En el círculo 2 se analizarán algunos casos que se han convertido en emblemáticos para la materia. 
Círculo 2: Controversias inversor-Estado que involucran a los derechos humanos 


\section{Capítulo 4: Controversias que involucran el derecho a un medioambiente sano y equilibrado}

\subsection{Aspectos preliminares}

El segundo círculo de esta investigación busca responder la pregunta: ¿cuál es el impacto de la regulación estatal sobre temas vinculados a derechos humanos en casos concretos de controversias inversor-Estado que involucren a Estados de Sudamérica y la UE? La hipótesis mediante la cual se pretende arribar a una respuesta es que "la extensión de la regulación estatal lleva a las empresas transnacionales a iniciar controversias inversor-Estado que cuestionan el avance de los Estados en medidas de mayor protección de derechos humanos".

Teniendo en cuenta las dimensiones que componen la hipótesis (casos concretos de controversias y medidas estatales de protección de los derechos humanos cuestionadas por los inversores extranjeros), el segundo círculo se estructuró en dos partes conforme a los derechos humanos involucrados en la disputa: derecho a un medioambiente sano y equilibrado (capítulo 4) y otros derechos humanos especialmente derecho a la salud, derecho al agua y derechos de los pueblos indígenas (capítulo 5). Se optó por la división en dichas categorías dado que en la primera (capítulo 4) se agrupan las disputas en los sectores que nuclear el mayor número de casos en cada zona geográfica bajo análisis: minería e industrias extractivas en Sudamérica (54 de $185^{114}$ ) y energía eléctrica en la UE (84 de $229 \operatorname{casos}^{115}$ ). En la segunda categoría (capítulo 5) se congregaron controversias vinculadas al derecho humano al agua, seleccionándose un caso contra Argentina por ser el Estado más demandado en el mundo en este sector (10 de 38 $\left.\operatorname{casos}^{116}\right)$, y dos temas que impactaron recientemente en el régimen de solución de controversias inversor-Estado: las medidas de control del tabaco y los derechos de los pueblos indígenas en caso de explotación en su territorio.

En cada capítulo se examinaron en profundidad tres controversias emblemáticas que involucran a Estados Sudamericanos y Europeos, agregando a El Salvador para presentar elementos contrafácticos. Se complementó con una breve comparación con otras disputas vinculadas ya sea por la materia o el tipo de medida cuestionada por los inversores extranjeros. Para el capítulo 4 se analizaron las siguientes controversias: 1)

\footnotetext{
${ }^{114}$ Datos del Investment Policy Hub de la UNCTAD. Fecha de consulta: 17 de julio de 2019.

115 Datos del Investment Policy Hub de la UNCTAD. Fecha de consulta: 17 de julio de 2019.

${ }^{116}$ Datos del Investment Policy Hub de la UNCTAD. Fecha de consulta: 17 de julio de 2019.
} 
Pac Rim contra El Salvador (caso CIADI número ARB/09/12) en relación a la no renovación de un permiso de explotación minera; 2) Eco Oro contra Colombia (caso CIADI número $\mathrm{ARB} / 16 / 41$ ) relativo a la no autorización de una licencia de explotación minera en base a la Ley de protección de páramos; 3) Masdar contra España (caso CIADI número ARB/14/1) vinculado a la transición energética, en concreto a medidas contrarias a los subsidios al sector energías renovables (recortes y posterior suspensión) con el objetivo de mitigar los efectos de la crisis económica española (2008-2014).

Para el capítulo 5 se incluyen las disputas: 1) Philip Morris contra Uruguay (caso CIADI ARB/10/7) relativo a las medidas de control del tabaco instrumentadas en protección del derecho humano a la salud pública y en seguimiento a normas de la Organización Internacional de la Salud; 2) Bear Creek contra Perú (caso CIADI número $\mathrm{ARB} / 14 / 21$ ) en el que el tribunal se expide sobre la vinculación entre los conflictos sociales y la no obtención de una licencia social por parte de la empresa conforme a las normas de la Organización Internacional del Trabajo; 3) Urbaser contra Argentina (caso CIADI número $\mathrm{ARB} / 07 / 26)$, disputa en la que por primera vez un tribunal arbitral incorpora la perspectiva de derechos humanos (derecho humano al agua) en base a la reconvención de Argentina.

Para cada controversia se estudiaron los hechos, los laudos de jurisdicción y fondo (según el caso), otras decisiones de los tribunales, presentaciones de amici curiae, así como las normas jurídicas en materia de protección de inversiones y derechos humanos en pugna producto de la fragmentación del Derecho Internacional General. De esta manera se buscó trazar paralelismos entre ellos y respecto al avance de la protección estatal en materia de derechos humanos.

La elección de los casos responde a tres motivos. En primer lugar, se trata de controversias que han marcado tendencia por su vinculación con los derechos humanos, pero que en general no tuvieron un análisis reiterado en la literatura. En todas las disputas los inversores extranjeros cuestionan medidas estatales vinculadas a una profundización en materia de derechos humanos, salvo en el caso Masdar contra España que se da la situación opuesta. Es precisamente por ello que se seleccionó ese caso en particular, como muestra de una de las 47 demandas que enfrenta España en el sector energías renovables y para aportar elementos contrafácticos en relación al retroceso en la protección del derecho humano a vivir en un medioambiente sano y equilibrado.

En segundo lugar, las disputas se seleccionaron por la existencia de documentos disponibles en relación a las diferentes etapas del arbitraje en las cuales se encuentran al 
momento de cierre de este trabajo. Por este motivo se priorizaron las disputas dirimidas en tribunales ad hoc administrados por el CIADI (véase el procedimiento en el flujograma 1, anexo $\mathrm{II}^{117}$ ), ya que al ser arbitrajes institucionalizados existe mayor y mejor acceso a la información a través de la página web del centro, salvo que las partes acuerden el carácter de reservado de alguno o todos los documentos.

El tercer motivo está vinculado con un criterio temporal, se buscaron casos cuyo registro fuera posterior a 2007, año que da inicio al marco temporal de este trabajo. Se dio prioridad a los casos iniciados en el último decenio (2009-2019), extremo que cumplen cinco de los seis casos seleccionados, siendo la excepción Urbaser contra Argentina iniciado en el año 2007. No obstante, el análisis a los efectos de este trabajo tendrá centro en la reconvención presentada por Argentina en $2013^{118}$.

\subsection{Caso Pac Rim contra El Salvador}

\subsubsection{El Salvador y el permiso de la discordia}

El germen de la disputa entre Pac Rim Cayman LLC y El Salvador se encuentra en la obtención de los permisos de explotación minera de oro y plata del Proyecto El Dorado en el departamento de Cabañas. Las empresas salvadoreñas Pres y Dorex eran los titulares de los derechos de explotación de dichos yacimientos cuando en el año 2002 la compañía canadiense Pac Rim las adquiere ${ }^{119}$. Si bien los permisos mineros aún estaban en vigor, vencían el 1 de enero de 2005 por lo cual poco tiempo después de la adquisición, se inician los trámites tendientes a la obtención de una nueva licencia. Con la solicitud aun en trámite, el 10 de marzo de 2008 el Presidente Antonio Saca anunció que, hasta tanto no se promulgara una nueva ley sobre minería, no se concederían permisos para proyectos de minería metálica sin un diagnóstico sobre su impacto ambiental (EFE, 2017). Así, las solicitudes de Pac Rim y de tantas otras empresas quedan en espera, y la minería metálica virtualmente detenida.

Este hecho llevó a que el inversor extranjero se presentara ante el CIADI el día 15 de junio de $2009^{120}$, alegando ser titular de derechos mineros, haber realizado estudios de

\footnotetext{
${ }^{117}$ Los casos seleccionados no siguen el procedimiento de las Reglas de Arbitraje de la UNCITRAL (2010), no obstante por su importancia en el sistema se incluye un diagrama de flujo que sistematiza el procedimiento (véase diagrama 2, anexo II).

${ }^{118} \mathrm{Si}$ bien no es un elemento que haya determinado la elección de los casos a analizarse, todos comparten la característica de ser disputas basadas en tratados.

${ }^{119}$ A los efectos del arbitraje, Pac Rim actúa bajo la subsidiaria Pac Rim Cayman LLC, constituida en Nevada, Estados Unidos.

${ }^{120}$ Caso CIADI número ARB/09/12.
} 
exploración y viabilidad técnica y económica y haber solicitado los permisos ambientales y de explotación minera de oro para el Proyecto El Dorado, con una reserva de más de 1,4 millones de onzas de oro según su propia estimación (laudo, 14 de octubre de 2016, párrafo 3.9). Sin embargo, la prohibición "de facto" de la minería metálica derivó en un “atolladero burocrático” en el Ministerio de Medioambiente y Recursos Naturales (párrafo 3.10), constituyendo un mecanismo mediante el cual se modificó ilegítimamente el régimen jurídico en el cual la empresa confió y bajo el cual invirtió, y fue impulsada por el Gobierno Salvadoreño a invertir. Como consecuencia, dado que la inversión realizada perdió valor (párrafo 3.6), la empresa solicitó una indemnización de 314 millones de dólares (párrafo 3.31).

La respuesta del Estado fue contundente: Pac Rim nunca tuvo derechos legales sobre los yacimientos de oro y plata de El Dorado, dado que adquirió las empresas titulares de derechos poco antes de solicitarse los permisos para nuevas licencias. Aun si hubiera tenido derechos legales, una inversión siempre debe realizarse conforme al Derecho del Estado receptor, principio que el inversor pretende desconocer al entender que el Estado está obligado a otorgarle el permiso. Por ende, Pac Rim no podía solicitar una indemnización por daños y perjuicios por pérdida de valor de derechos que no posee (párrafo 3.22-323).

Es esencial tener en cuenta que el argumento de deber de cumplimiento del Derecho Doméstico es reiterado en la defensa de los Estados, como naturalmente podría considerarse. Es destacable el análisis realizado por el tribunal en el arbitraje entre la empresa británica británico Cortec y Kenia (caso CIADI número ARB/15/29) también en materia de minería, específicamente exploración y explotación de niobio y tierras raras. En el laudo de fecha 22 de octubre de 2018, el tribunal reafirmó la obligación del inversor de cumplir el Derecho Interno, más teniendo en cuenta que la inversión que la empresa alegaba era una licencia minera. Una licencia no es un negocio físico ("bricks and mortar"), sino que se trata de una construcción jurídica conforme al Derecho Doméstico de Kenia y por tanto está regulada por el Derecho Keniano ${ }^{121}$.

\footnotetext{
${ }^{121}$ En este caso el tribunal apoyó la posición de Kenia y en virtud que la licencia de referencia era nula $a b$ initio conforme al Derecho Interno, no podía constituir una inversión protegida por el TBI Reino UnidoKenia (laudo, párrafo 333). En consecuencia, el tribunal desestima el reclamo de Cortec y la condena al pago de su parte de los costos del arbitraje y la mitad de los costos alegados por el Estado. Actualmente el caso se encuentra bajo proceso de anulación parcial del laudo solicitado por el inversor. Texto del laudo disponible en: https://www.italaw.com/cases/3974
} 


\subsubsection{Los siete años de litigio y el peso de la sociedad civil organizada}

Si bien el foco de este capítulo radica en el análisis de las controversias, es fundamental tener en cuenta el contexto social en el que estas se desarrollan. En el caso bajo análisis, el inicio del arbitraje coincide con un momento de especial tensión social en el departamento de Cabañas, generándose una fuerte oposición local a la empresa. En particular se destacan las amenazas y ataques a defensores ambientales, en particular los asesinatos de Marcelo Rivera, Felicita Escheverría, Dora Alicia Resinos Sorto (embarazada de 8 meses), defensores ambientales opositores locales contra la empresa. Si bien no se determinaron los autores de los delitos, la Procuraduría entendió que existen factores que llevan a pensar que "los homicidios y otros eventos pueden estar relacionados y tener un origen común" (amicus curiae, 25 de julio de 2014: 11) ${ }^{122}$.

En este marco, el día 18 de noviembre de 2009 quedó constituido el tribunal arbitral ad hoc administrado por el CIADI, siendo los árbitros Brigitte Stern, Guido Santiago Tawil y V.V. Veeder (Presidente). De acuerdo a la solicitud de las partes, el procedimiento fue dividido en tres etapas: 1) objeciones preliminares; 2) objeciones sobre jurisdicción; 3) fondo del asunto. Si bien este artículo pone el foco en el fondo del asunto, es importante tener en cuenta que en la segunda etapa, el tribunal entendió que tenía jurisdicción conforme a la Ley de Inversiones Salvadoreña. Sin embargo hizo lugar a la excepción de jurisdicción presentada por El Salvador respecto a la aplicación del Tratado de Libre Comercio entre República Dominicana, Centroamérica y Estados Unidos de América (CAFTA-DR), como pretendía la demandante, en virtud que la empresa Pac Rim estaba constituida en Canadá y la creación de Pac Rim Cayman LLC respondía solo al interés de aplicar dicho acuerdo ${ }^{123}$.

Esta práctica, habitualmente empleada en el arbitraje de inversiones, es particularmente peligrosa ya que les da a las empresas habilidades camaleónicas para presentar sus reclamos conforme a las normas que resulten más convenientes para el caso concreto. $\mathrm{Su}$ uso abusivo está siendo contemplado por los tribunales siendo un buen ejemplo el caso Philip Morris Asia contra Australia, en el cual el inversor alegó una presunta violación del Tratado Bilateral de Inversiones entre Hong Kong y Australia. El 17 de diciembre de 2015, el tribunal ad hoc de la Corte Permanente de Arbitraje aceptó la

\footnotetext{
${ }^{122}$ Texto disponible en: https://www.italaw.com/sites/default/files/case-documents/italaw4196.pdf

${ }^{123}$ En el año 2013 Pac Rim Cayman LLC es comprada por la minera australiana OceanaGold, funcionando como una compañía subsidiaria indirecta. OceanaGold continúa el arbitraje desde la fecha de la adquisición.
} 
objeción de Australia en relación a que constituye abuso de derecho que el demandante realizara una restructuración en Hong Kong, poco antes del inicio del arbitraje.

Los siete años de litigio se completan con la etapa procesal relativa al fondo del asunto, momento en el cual surgen dos temas a ponderar: la capacidad del Estado para regular su medioambiente conforme a las normas internacionales específicas que lo protegen, frente a la protección de inversiones esperadas por una empresa extranjera, a pesar de tratarse de un sector como el minero, que por su pronunciado riesgo ambiental suele requerir autorización previa a la explotación. El involucramiento de temas que exceden a la protección de inversiones hace que cada vez sea más importante la voz de la sociedad civil organizada, hecho que lleva a autores como Sornarajah a considerar a las organizaciones no gubernamentales $(\mathrm{ONG})$ como un contrapeso al poder que detentan las empresas multinacionales en el campo del Derecho Internacional de las Inversiones (Sornarajah, 2015: 8).

Si bien inicialmente las reglas de procedimiento del arbitraje en el CIADI no preveían la participación de ONG u otras instituciones que no fueran partes en el arbitraje, la reforma del año 2006 introdujo la regla 37 (2) que autoriza la presentación de escritos de terceros no contendientes con interés significativo en el proceso (amicus curiae). Esto es, una presentación escrita relativa a temas de la controversia que, a entender del tribunal, permitiría la determinación de cuestiones de hecho o de Derecho conforme a un conocimiento o visión diferente a los de las partes.

Es de especial interés la presentación de un escrito amicus curiae por parte del Centro para el Derecho Internacional Ambiental (CIEL) en nombre de seis organizaciones ${ }^{124}$ miembros de la Mesa Nacional Frente a la Minería Metálica de El Salvador, una coalición de organizaciones no gubernamentales y centros de investigación que buscan el diálogo sobre temas de extracción de metales en El Salvador ${ }^{125}$. En el escrito se destaca que las medidas tomadas por El Salvador responden a un marco normativo internacional de protección del medioambiente y los derechos humanos, que obligan al Estado por ser parte: la Declaración de Estocolmo sobre medioambiente humano; el principio 1 de la Declaración de Rio (1992); el artículo 12 del Pacto Internacional de derechos económicos, sociales y culturales; artículo 11 del Pacto Adicional a la

\footnotetext{
${ }^{124}$ Asociación de Comunidades Para El Desarrollo de Chalatenango (CCR); Asociación de Desarrollo Económico y Social (ADES); CORDES; Asociación Para El Desarrollo de El Salvador (CRIPDES); Fundación para el Estudio de la Aplicación de la Ley (FESPAD); Unidad Ecológica Salvadoreña (UNES).

${ }^{125}$ Más información disponible en: http://noalamineria.org.sv/
} 
Convención Americana de derechos humanos en materia de derechos económicos, sociales y culturales.

Por tanto, dado que las industrias extractivas presentan un riesgo ambiental, especialmente en el agua, y el Estado se encuentra obligado a "adoptar medidas idóneas de prevención de afectación de derechos humanos" (CIEL, 2014: 6). Ejemplo de lo anterior es la implementación de requisitos legales y trámites administrativos para la obtención de permisos de explotación minera, que brinden garantías ambientales. El tribunal no tiene en cuenta el contenido del escrito en el laudo final ya que existió consenso entre las partes en la controversia para que las organizaciones accedieran a parte de la prueba presentada, incluida la audiencia que no fue pública. En virtud de las circunstancias no es apropiado tener en cuenta los argumentos esgrimidos por CIEL. Sin perjuicio de lo anterior, los argumentos contenidos en el escrito amicus curiae de CIEL fueron conocidos públicamente en el sistema-mundo y pueden considerarse una demostración de los peligros de la fragmentación del Derecho Internacional, especialmente cuando los derechos humanos entran en juego.

\subsubsection{El laudo del 14 de octubre de 2016 y después}

Después de dos audiencias públicas, la audiencia sobre el fondo del asunto se celebró a puertas cerradas entre el 15 y el 22 de setiembre de 2014, y luego de la etapa de deliberación, el laudo sobre el fondo fue entregado a las partes el 14 de octubre de $2016^{126}$. En este el tribunal desestima las pretensiones de Pac Rim, al considerar que, a la fecha del anuncio del Presidente Saca respecto a la actividad minera, la empresa no tenía derechos de explotación en vigor, por tanto el reclamo de daños y perjuicios no es amparado por el Derecho Salvadoreño ni el Derecho Internacional (párrafo 10.4-10.5). En consecuencia, Pac Rim fue condenada al pago de 8 millones de dólares, más intereses, a favor de El Salvador como parte de los casi 12 millones de dólares ${ }^{127}$ que el Estado sufragó por concepto de gastos legales (párrafo 12.1(4)) ${ }^{128}$.

\footnotetext{
${ }^{126}$ Texto disponible en: https://www.italaw.com/sites/default/files/case-documents/italaw7641_0.pdf

${ }^{127}$ La condena parcial responde a las resoluciones de las tres etapas del arbitraje, siendo la demandante vencedora en las objeciones preliminares, ninguna de las partes en las objeciones de jurisdicción, y la demandada en las cuestiones de fondo.

${ }^{128}$ El pago se hizo efectivo el día 2 de julio de 2017, dos meses después que la Corte Suprema de Justicia de El Salvador ordenada el embargo preventivo de siete cuentas bancarias de la empresa (López, 2017). En total la empresa sufragó 8.097.072 dólares, conforme a la tasa de interés establecida en la Decisión del CIADI del día 28 de marzo de 2017. Texto de la decisión disponible en: https://www.italaw.com/sites/default/files/case-documents/italaw8734_0.pdf
} 
Una vez conocido el contenido del laudo, el 29 de marzo la Asamblea Legislativa de El Salvador aprobó por 69 votos en 84, una ley de orden público que prohíbe la minería metálica en suelo y subsuelo ${ }^{129}$ (Paullier, 2017). La norma también establece que los trámites para la obtención de licencias de explotación minera quedan sin efecto, y que se procederá al cierre de las minas metálicas existentes y la remediación ambiental por los daños causados. En suma, los siete años de litigio tienen como cierre un laudo donde la protección del medioambiente se impone y a posteriori una ley cuyo fin es que el pueblo salvadoreño ejerza su derecho a vivir en un medioambiente sano y equilibrado. El caso Pac Rim presenta similitudes con el caso Vattenfall contra Alemania (II) ${ }^{130}$ al involucrar un cambio normativo que prohíbe una actividad de alto impacto ambiental, sin perjuicio que la relación causa-efecto entre el cambio normativo y la demanda se dan de manera inversa. En El Salvador el cambio normativo se produjo pocos meses después del laudo, a diferencia del apagón nuclear en Alemania que desencadenó la demanda de la compañía estatal sueca Vattenfall (caso CIADI número ARB/12/12). El Parlamento Alemán aprobó el 30 de junio de 2011 la décimo tercera enmienda a la Ley de Energía Nuclear ${ }^{131}$, entrando en vigor el 6 de agosto del mismo año. La norma regula la culminación del uso de energía nuclear para la producción de energía eléctrica en territorio alemán, con el cierre inmediato de las siete plantas más antiguas y el cierre gradual de las otras diez plantas hasta 2022. Las medidas en torno a la transición en materia energética fueron motivadas por el desastre nuclear de Fukushima (Japón) y la necesidad (y el derecho) de Alemania de regular en la materia para evitar situaciones similares (derecho de regular como elemento clave del espacio de política pública, véase apartado 6.3).

Al entender que los derechos protegidos por el Tratado de la Carta de la Energía fueron vulnerados por el inminente cierre de sus plantas nucleares Krümmel y Brunsbüttel, Vattenfall solicitó el inicio de un arbitraje ante el CIADI el día 31 de mayo de 2012. El caso se encuentran pendiente de resolución y la información sobre las diferentes etapas

\footnotetext{
129 El texto de la ley puede consultarse en: http://www.asamblea.gob.sv/eparlamento/indicelegislativo/buscador-de-documentos-legislativos/ley-de-prohibicion-de-la-mineria-metalica

${ }^{130}$ El caso Vattenfall contra Alemania (I) se desarrolló previamente en el CIADI (caso número $\mathrm{ARB} / 09 / 6)$ y refiere a medidas medioambientales aplicadas a la construcción de nuevas plantas de energía a carbón en Hamburgo-Moorberg a orillas del Río Elba. Vattenfall entendió que la licencia respecto a la calidad del agua solicitada era contraria al Tratado de la Carta de la Energía y demandó a Alemania por 1.400 millones de euros. El caso fue acordado entre el inversor y la empresa en 2011, teniendo como consecuencia una disminución en la regulación ambiental a favor de Vattenfall.

131 Texto disponible únicamente en idioma alemán en: https://www.bmu.de/gesetz/13-gesetz-zuraenderung-des-atomgesetzes/
} 
del proceso se mantiene reservada, salvo excepciones. Por tanto escasos documentos han sido publicados, estimándose que el reclamo de la empresa sea superior a 700 millones de euros (Bernasconi-Osterwalder y Rhea Tamara Hoffmann, 2012: 2). Aun así, se trata de una disputa en la que se evidencia la tensión entre la regulación estatal en pos del interés público y las normas de protección de la inversión extranjera, en una situación que no genera enfriamiento regulatorio sino que la regulación es el motivo del inicio de un arbitraje ${ }^{132}$.

\subsection{Caso Eco Oro contra Colombia}

\subsubsection{Colombia: el arbitraje de inversiones y la protección de los páramos}

Si bien Colombia es miembro del régimen internacional de protección de inversiones en general y del régimen de solución de controversias inversor-Estado en particular, en términos de agencia ha tenido notas diferenciales frente al resto de los Estados Sudamericanos. En primer lugar, Colombia tiene un número limitado de TBI en vigor (6) ya que ha optado por la inclusión de capítulos de inversiones en los acuerdos comerciales preferenciales celebrados con Estados o grupos de Estados (14 en vigor) ${ }^{133}$. En segundo lugar, no cuenta con experiencia como demandado en procesos arbitrales hasta el año 2016 con las demandas de las empresas Glencore International y C.I. Prodeco (sector minería de carbón); Eco Oro (sector minería de oro y plata); Cosigo y otros (sector minería de oro); América Móvil (sector telecomunicaciones). A la fecha de cierre de este trabajo son once las demandas contra Colombia, todas pendientes de resolución (nueve en el CIADI y dos sin información disponible sobre la institución administradora $\left.^{134}\right)$.

Si bien no se ha concretado la demanda, la potencial disputa inversor-Estado más conocida fue la del laboratorio Novartis ${ }^{135}$, que con fecha 21 de abril de 2016, remitió una notificación de iniciar consultas con el Gobierno Colombiano en torno a la

\footnotetext{
${ }^{132}$ Excede el objetivo de este trabajo el análisis de otras aristas del caso que pueden resultar de interés para otras investigaciones, como por ejemplo los procesos de inconstitucionalidad seguidos en Alemania respecto a la décimo tercera enmienda o la imposibilidad de los inversores alemanes de iniciar un arbitraje inversor-Estado de similares características al que inició Vattenfall.

${ }^{133}$ Datos del Investment Policy Hub de la UNCTAD. Fecha de consulta: 17 de junio de 2019. Un estudio de la política exterior colombiana y el empleo de los acuerdos con capítulos de inversiones como herramienta de relacionamiento comercial puede verse en Guerra Barón (2011).

${ }^{134}$ Datos del Investment Policy Hub de la UNCTAD. Fecha de consulta: 17 de junio de 2019.

135 Documento filtrado por Public Eye disponible en: https://www.publiceye.ch/fileadmin/img/_migration/Gesundheit/Zwangslizenzen/ISDS_Threat_Novartis_ against_Colombia.pdf
} 
declaración de interés público del fármaco imatinib para el tratamiento del cáncer, especialmente la leucemia mieloide crónica, del cual el laboratorio es titular de la patente y comercializa bajo el nombre Glevic ${ }^{136}$. La notificación se basa en el artículo 11.1 del TBI Colombia-Suiza y buscó llegar a un acuerdo para evitar la declaración de interés público, declaración que se concretó mediante la Resolución 2475 del Ministerio de Salud y Protección Social (14 de junio de 2016) ${ }^{137138}$.

Entre los arbitrajes inversor-Estado efectivamente iniciados, el caso Eco Oro es de especial interés ya que pone en el tapete el derecho de regular en materia de protección ambiental frente a la protección de la inversión extranjera en una actividad de fuerte impacto ambiental como es la minería de oro y plata. Desde 1994 Eco Oro Minerals Corporation $^{139}$, empresa de capitales canadienses, ha desarrollado actividades de exploración y explotación minera en el marco del proyecto “Angostura” en la provincia de Soto Norte (departamento de Santander), contando con 10 contratos de concesión y 3 licencias de explotación (Díaz Poveda, 2018).

En 2011 fue sancionada la ley colombiana número 1450, en cuyo artículo 220 se establece que los ecosistemas de los páramos deben ser delimitados mediante actos administrativos con base a estudios técnicos, económicos, sociales y ambientales del Ministerio de Ambiente, Vivienda y Desarrollo Territorial (actualmente dentro de las competencias del Ministerio de Ambiente y Desarrollo Sostenible ${ }^{140}$ ). En las zonas protegidas se establece la exclusión de actividades agropecuarias, de exploración o explotación de recursos naturales no renovables, ni construcción de refinerías de hidrocarburos, dado que más del $80 \%$ del agua para consumo, riego y generación de energía proviene de ellas.

Las disposiciones legales tienen como base fundamental el artículo 79 de la Constitución Colombiana de 1991, norma que establece el derecho de gozar de un medioambiente sano, y la consecuente obligación del Estado de "proteger la diversidad

\footnotetext{
${ }^{136}$ La declaración de interés público se hizo en el marco del procedimiento previsto en el capítulo 24 del Decreto Único 1074 del 26 de mayo de 2015, en cumplimiento del artículo 65 de la Decisión Andina 486 de 2000. El procedimiento fue modificado dos años después, específicamente en lo que refiere a la composición del Comité Técnico que tiene como función realizar recomendaciones en la materia, pasando a estar constituido por un representante del Ministerio de Comercio y un representante del Ministerio de Planificación (Decreto 670 del 25 de abril de 2017).

137 Texto disponible en https://www.minsalud.gov.co/Normatividad_Nuevo/Resoluci\%C3\%B3n\%202475\%20de\%202016.pdf

${ }^{138}$ Un análisis del tema puede verse en: Díaz Pinilla, Guevara, Lamprea y Lizarazo-Cortés (2016); Baker y Geddes (2017).

${ }_{139}$ Hasta el 19 de agosto de 2011 denominada Greystar.

${ }^{140}$ Conforme al decreto ley 3570 de 2011 y la ley 1753 de 2015.
} 
e integridad del ambiente, conservar las áreas de especial importancia ecológica”, en este caso los páramos. Asimismo, las normas domésticas se dictan en conjunción con el acervo normativo internacional en la materia, léase: la Declaración de Estocolmo sobre medioambiente humano; el principio 1 de la Declaración de Rio (1992); el artículo 12 del Pacto Internacional de derechos económicos, sociales y culturales; artículo 11 del Pacto Adicional a la Convención Americana de derechos humanos en materia de derechos económicos, sociales y culturales.

La nueva normatividad doméstica tuvo consecuencias directas sobre las actividades mineras de Eco Oro, puesto que el proyecto "Angostura" se encuentra en las cercanías de la zona que en 2014 se delimita dentro del Páramo de Santurbán conforme a la resolución 2090 del 19 de diciembre de 2014 (Ministerio de Ambiente y Desarrollo Sostenible). Sin embargo, los cuatro años transcurridos entre el mandato legal y la efectiva delimitación de la zona protegida llevó a la empresa a considerar que la entidad gubernamental “omitió delinear el área del Páramo de Santurbán oportunamente y de esa manera le impidió a Eco Oro ejercer sus derechos en el marco de sus concesiones y permisos" (notificación de intención de someter una reclamación de a arbitraje, 3$)^{141}$. En consecuencia, el 7 de marzo de 2016 presentó al Estado una notificación de someter la disputa al arbitraje internacional una vez cumplido el período de 30 días previsto para la celebración de consultas tendientes a la solución amical, conforme al numeral 1 del artículo 821 del TLC Colombia-Canadá. El tratado no prevé el agotamiento previo de la jurisdicción doméstica, ni esta es una opción frente al arbitraje internacional conforme al Reglamento de Arbitraje del CIADI, el Reglamento del Mecanismo Complementario del CIADI, o el Reglamento de Arbitraje de la Comisión de las Naciones Unidas para el Derecho Mercantil Internacional (UNCITRAL por su sigla en inglés). Por tanto, nueve meses después de enviada la notificación, el 8 de diciembre de 2016 la Secretaria General del CIADI registró la solicitud de arbitraje (caso CIADI número ARB/16/41).

\subsubsection{El procedimiento arbitral}

El 8 de diciembre de 2016 Eco Oro solicitó el inicio de un arbitraje inversor-Estado en el CIADI basado en lo previsto en el artículo 821 (literal a del numeral 1) del TLC Colombia-Canadá. El inversor sostiene que Colombia incumplió con el mencionado acuerdo, particularmente con el seguimiento de un estándar mínimo de tratamiento, que

\footnotetext{
${ }^{141}$ Texto disponible en: https://www.italaw.com/sites/default/files/case-documents/italaw9442.pdf
} 
incluye el tratado justo y equitativo (artículo 805). Dado que las inversiones de Eco Oro tuvieron una pérdida de valor considera que existió una expropiación indirecta sin debida compensación (artículo 811). Si bien la inversión inicial fue de 250 millones de dólares, el monto total reclamado asciende a 764 millones incluyendo el valor justo de mercado antes que la expropiación se haya llevado a cabo (696 millones) más los intereses (68 millones). No solicitó la restitución de la inversión.

El tribunal arbitral ad hoc en el marco del CIADI se constituyó el 11 de setiembre de 2017, compuesto por Horacio Grigera Naón, Philippe Sands y Juliet Blanch (presidenta). Tres órdenes de procedimiento se destacan hasta el momento de cierre de este trabajo. En primer lugar, se encuentra la orden de procedimiento número 2 (28 de junio de 2018) ${ }^{142}$ que determinó la no separación de la decisión sobre la jurisdicción de la decisión sobre el fondo del asunto. Esta decisión permite optimizar recursos ya que los tiempos de arbitraje suelen ser menores que en el tratamiento por separado. En segundo lugar, es destacable la orden de procedimiento número 5 (21 de diciembre de 2018) ${ }^{143}$ que autoriza la extensión de los partes para presentar escritos de las partes, documentación probatoria y escritos amici curiae, y fija como fecha para la realización de las audiencias los días 20 a 31 de enero de 2020.

En tercer lugar, la orden de procedimiento número $6^{144}$ (18 de febrero de 2019) es significativa para este arbitraje en particular así como para los arbitrajes de inversiones que involucran temas de derechos humanos en general. El tribunal rechaza la presentación amicus curiae (18 de diciembre de 2018) firmada por las siguientes organizaciones de la sociedad civil: el Comité para la Defensa del Agua y el Páramo de Santurbán, el Centro para el Derecho Internacional Ambiental (CIEL), la Asociación Interamericana para la Defensa del Ambiente (AIDA), el Observatorio Minero de Canadá, el Instituto de Estudios Políticos, el Proyecto Economía Global y el Centro de Investigación sobre Empresas Multinacionales (SOMO).

Los motivos para el rechazo del escrito se basan en tres factores. Primeramente el tribunal entiende que no hay una relación demostrada entre la disputa y el derecho a vivir en un medioambiente sano (orden de procedimiento 6, párrafo 28). Como consecuencia del factor anterior, el tribunal tampoco considera que el amicus curiae

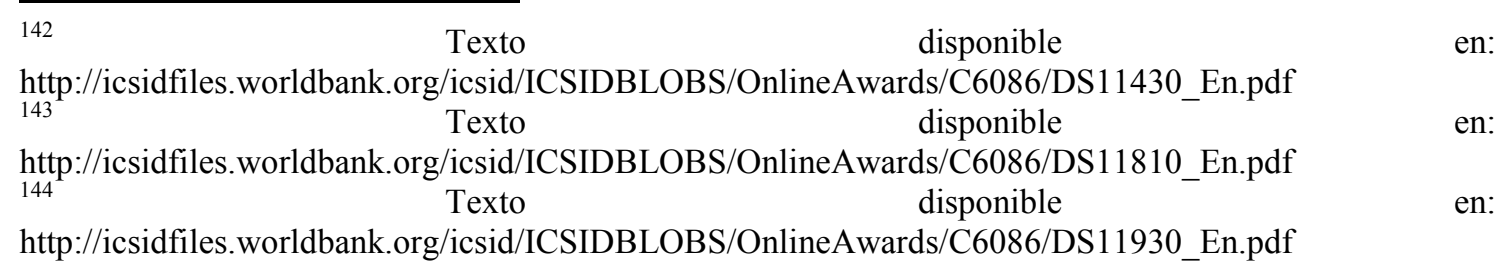


presente conocimiento de temas sociales y ambientales respecto al páramo de Santurbán que sean diferentes a los presentados por las partes (párrafo 33). Finalmente, el tribunal no encuentra que exista un interés significativo en el proceso por parte de las mencionadas organizaciones (párrafo 34).

Es de especial relevancia que en la base del rechazo del amicus curiae de referencia se ubique el argumento de falta de conexión entre el caso y el derecho a vivir en un medioambiente sano, derecho humano protegido constitucionalmente en Colombia y a nivel del Derecho Internacional. Desde una de las organizaciones solicitantes del amicus curiae, CIEL, se emitió un comunicado en el que se pronuncia una de sus representantes indicando que "en el momento en que los Estados de Latinoamérica acogen los principios de democracia ambiental con la adopción del Acuerdo de Escanzú, el CIADI va en dirección contraria" (CIEL, 2019). Este acuerdo regula el acceso a la información, la participación pública y el acceso a la justicia en asuntos ambientales en América Latina y el Caribe y fue celebrado el 4 de marzo de $2018^{145}$.

Asimismo, existen antecedentes jurisprudenciales en los que ya se ha visto un tratamiento incipiente del impacto de la protección de inversiones sobre la protección de los derechos humanos. Se destaca el laudo del caso Urbaser contra Argentina (caso CIADI número ARB/07/26) con el reconocimiento del derecho humano al agua potable y saneamiento, a pesar que el tribunal sea de la idea que las empresas tienen una obligación negativa en materia de derechos humanos y para que exista una obligación positiva esta debe estar prevista a texto expreso, extremo que en el TBI ArgentinaEspaña no se establece.

Otro antecedente lo representa la opinión disidente del árbitro Philippe Sands, adjunta al laudo del caso Bear Creek contra Perú (caso CIADI número ARB/14/21). El árbitro considera que, conforme a los artículos 6 y 15 (párrafo 2) del Convenio 169 de la Organización Internacional del Trabajo sobre Pueblos Indígenas y Tribales en Países Independientes, existe una obligación de la empresa de obtener una "licencia social" para desarrollar su proyecto de inversión y que esta no se obtuvo producto de su propia conducta $^{146}$. El conflicto social motiva la expropiación estatal, por tanto, el árbitro disidente concluye que el monto por el cual se condena al Estado Peruano debe

\footnotetext{
${ }^{145}$ Un análisis particular del acuerdo puede verse en: Hernández Ordoñez (2019).

${ }^{146}$ Incluso en el texto del laudo se hace referencia a este punto indicando que "Aunque el concepto de "licencia social" no se define claramente en el derecho internacional, todos los instrumentos relevantes son claros al establecer que deben realizarse consultas con las comunidades indígenas al efecto de obtener el consentimiento de todas las comunidades involucradas" (párrafo 406) y cita a pie de página el artículo 32 de la Declaración de la ONU sobre los derechos de los pueblos indígenas.
} 
reducirse a la mitad. Cabe destacar que Philippe Sands es árbitro en el arbitraje Eco Oro contra Colombia.

A la fecha de término de este trabajo la disputa entre Eco Oro y Colombia se encuentra pendiente de resolución. Sin perjuicio de lo anterior, es un caso de relevancia dado que presenta un ejemplo claro de la eventual relación antagónica entre los regímenes internacionales que regulan la protección de inversiones extranjeras y la protección del medioambiente. Es de particular interés señalar que, junto al TLC Colombia-Canadá, las partes celebraron el "Acuerdo sobre Medio Ambiente" que en líneas generales contiene normas programáticas y mecanismos de cooperación bilateral. El artículo 2 numeral 4 refiere al eventual antagonismo medioambiente-inversiones o comercio, señalando que “ninguna de las Partes dejará de aplicar ni derogará de algún modo su legislación ambiental de forma tal que debilite o reduzca las protecciones concedidas en dichas leyes de manera tal que promueva el comercio o la inversión entre las Partes".

Independientemente del carácter programático de la norma anterior, como explica Díaz Poveda (2018), Colombia y Canadá “conciertan que la normatividad ambiental que lleguen a promulgar será en pro del mejoramiento en materia ambiental y que en ningún momento puede verse afectada dicha normatividad en favor del comercio”. Si bien en la relación Colombia-Canadá el tema se regula en un tratado concreto sobre medioambiente, en los últimos años se ha visto una tendencia generalizada a nivel mundial de incluir normas de protección ambiental en tratados comerciales, en línea con el concepto de desarrollo sostenible (Sarmiento, 2018: 190).

En el caso puntual del arbitraje Eco Oro se discute si el Estado incumplió con el trato justo y equitativo y la expropiación indirecta sin debida compensación respecto al proyecto "Angostura”. Si las normas ambientales no pueden verse afectadas por las normas comerciales ni de protección de inversiones, las disposiciones en las que la empresa sustenta su demanda ceden frente a la nueva regulación en materia de protección de los páramos colombianos. No obstante, es importante tener en cuenta que la interpretación de la norma en cuestión suele ser laxa y deja un margen de acción amplio para los intérpretes, ya que como señala Sarmiento (2018) se trata de una norma política y programática, y que puede categorizarse como soft law, con su consecuente debilitamiento normativo.

En este margen de acción amplio que el tribunal ad hoc deberá tener en cuenta si los actos estatales fueron tomados de manera arbitraria, injustificada, discriminatoria o en violación del debido proceso, que en definitiva determinarían un incumplimiento del 
trato justo y equitativo (artículo 805 del TLC Colombia-Canadá). Este punto ha sido considerado en arbitrajes similares como Glamis Gold contra Estados Unidos (caso bajo las Reglas de Arbitraje de la UNCITRAL ${ }^{147}$ ); Metalclad contra México (caso CIADI número $\mathrm{ARB}(\mathrm{AF}) / 97 / 1^{148}$ ); Santa Elena contra Costa Rica (caso CIADI número $\left.\mathrm{ARB} / 96 / 1^{149}\right)$, con características que no se encuentran presentes en las normas colombianas controvertidas por Eco Oro (Díaz Poveda, 2018).

Cabe destacar que a la fecha de cierre de este trabajo otras dos solicitudes de arbitraje se han registrado en el CIADI en relación a la delimitación del páramo de Santurbán. La primera de manos de las empresas Red Eagle Exploration Limited (caso CIADI número $\mathrm{ARB} / 18 / 12$ ) y la última por parte de Galway Gold Inc. (caso CIADI número $\mathrm{ARB} / 18 / 13)$, reclamando 40 y 196 millones de dólares respectivamente ${ }^{150}$. Ambas empresas operan en el sector de la minería y son de capitales canadienses. Asimismo, ambas demandas se registraron el 18 de abril de 2018, invocan el TLC ColombiaCanadá y se encuentran pendientes de resolución. Si bien en el arbitraje inversor-Estado no se aplica el sistema del precedente obligatorio y se trata de tribunales ad hoc y no permanentes, la lógica indicaría que las tres controversias tendrían similar resolución al aplicarse las mismas normas jurídicas frente a situaciones desencadenadas por el mismo cambio normativo.

\subsection{Caso Masdar contra España}

\subsubsection{España y las energías renovables}

A diferencia de las disputas anteriormente reseñadas, el caso Masdar Solar \& Wind Cooperatief U.A. contra España (caso CIADI número ARB/14/1) presenta características particulares ya que no se trata de un caso puntual y aislado, sino que forma parte de un grupo de 47 casos en los que empresas de energías renovables demandaron a España conforme a las disposiciones del Tratado de la Carta de la Energía. Esta situación llevó a que España sea el segundo Estado más demandado del

\footnotetext{
${ }^{147}$ Controversia en el marco del capítulo 11 del Tratado de Libre Comercio de América del Norte, laudo del 8 de junio de 2009 cuyo texto se encuentra disponible en: https://www.italaw.com/sites/default/files/case-documents/ita0378.pdf

${ }^{148}$ Controversia en el marco del capítulo 11 del Tratado de Libre Comercio de América del Norte, laudo del 30 de agosto de 2000 cuyo texto se encuentra disponible en: https://www.italaw.com/sites/default/files/case-documents/ita0511.pdf

149 Laudo del 17 de febrero de 2000 cuyo texto se encuentra disponible en: https://www.italaw.com/sites/default/files/case-documents/italaw6340.pdf

${ }_{150}$ Montos según datos del Investment Policy Hub de la UNCTAD. Fecha de consulta: 19 de junio de 2019.
} 
mundo con 51 controversias conocidas en su contra, solo superado por Argentina que cuenta con 61 demandas. Asimismo, es el Estado con mayor paridad entre controversias como Estado demandado (51) y como Estado de nacionalidad del inversor actor (54) ${ }^{151}$. A octubre de 2019, de los 47 casos, el CIADI es la institución administradora del 74,4\% de los casos, la Corte Permanente de Arbitraje en el 4,3\% y la Cámara de Comercio de Estocolmo en el restante $21,3 \%^{152}$. Los dos primeros laudos fueron favorables a España $^{153}$, uno fue anulado ${ }^{154}$ y once fueron contrarios a sus intereses ${ }^{155}$ con condenas que en su conjunto alcanzan más de 800 millones de euros, a pesar que la cifra reclamada por los inversores fuera sensiblemente superior en algunos casos.

El reclamo de Masdar es similar al de los demás inversores en el sector energías renovables. Tuvo como centro la vulneración de los principios de trato justo y equitativo y legítimas expectativas, conforme al marco jurídico en el que confió e invirtieron al estimular la inversión en el sector energías renovables (Real Decreto 661/2007). Este marco jurídico fue modificado por España al establecer recortes y posteriormente cancelar el programa de subsidios a las energías renovables (Real Decreto-ley 14/2010, la Ley 15/2012, el Real Decreto-ley 9/2013, la Orden IET/1045/2014 y normas específicas para la energía solar). Estas disposiciones, argumentó la empresa, irían en contra del compromiso de estabilidad previsto en el artículo 44 numeral 3 del Real Decreto 661/2007, respecto a las instalaciones puestas en servicio antes del 1 de enero de 2012, y el artículo 4 del Real Decreto 1614/2010, para las instalaciones de tecnología social termodinámica inscriptas con carácter definitivo antes del 7 de mayo de 2009. La empresa Masdar, empresa de capitales soberanos de Emiratos Árabes Unidos instalada en Países Bajos ${ }^{156}$ que había invertido en tres plantas de energía solar concentrada, entendió que se encontraba amparada en el compromiso

\footnotetext{
151 Datos del Investment Policy $H u b$ de la UNCTAD actualizados con datos del CIADI. Fecha de consulta: 25 de octubre de 2019.

${ }^{152}$ Datos obtenidos de la base de datos de casos contra España (abril 2019) publicada por el Transnational Institute. Fecha de consulta: 25 octubre de 2019. Actualización por la autora a la fecha de consulta.

${ }^{153}$ Casos Isolux y Charanne.

${ }^{154}$ Caso NovEnergia.

155 Casos Eiser; Antin; Masdar; Foresight Greentech Goresight y GWM; Nextera; REEEF; Cube Infrastructure; 9REN; SolEs Badajoz; Infrared Environment Infrastructure; y Schwab Holding y OperaFund Ecoinvest.

${ }^{156}$ Emiratos Árabes Unidos no es parte del Tratado de la Carta de la Energía, Países Bajos sí. Emiratos Árabes Unidos tampoco tiene un TBI que proteja las inversiones recíprocas con España. La práctica de elegir el tratado más conveniente a los intereses del demandante se denomina treaty shopping, y en algunas controversias se ha extendido a la reconfiguración empresarial posterior al inicio del arbitraje, como sucedió en el caso Philip Morris Asia contra Australia (caso CPA número 2012-2).
} 
de estabilidad incumplido por España y el 11 de febrero de 2014 solicitó el inicio de un arbitraje en el CIADI con base al Tratado de la Carta de la Energía ${ }^{157}$.

La controversia es de especial interés para esta investigación dado que presenta una problemática diferente a los casos Pac Rim y Eco Oro. La demanda del inversor extranjero no es consecuencia de un avance del Estado en materia de protección de los derechos humanos o en defensa del interés público, puntualmente el derecho a un medioambiente sano. Por el contrario, las 47 demandas en el sector energías renovables tienen como foco normas que desandan en materia de protección del medioambiente, recortando y finalmente cancelando programas de atracción a la inversión en energías renovables. Sin perjuicio de lo anterior, en el otro platillo de la balanza se encuentra el derecho de regular de los Estados, esto es, aquellas medidas estatales restrictivas de la libertad general del ciudadano adoptadas en defensa del orden público (Hernández González, 2017: 11). En el caso de España, los recortes y posterior eliminación de los beneficios a las energías renovables forman parte del paquete de medidas tomado para mitigar los efectos de la crisis económica 2008-2014.

Cabe trazar un paralelismo entre la situación de España y la de Argentina, los Estados número 1 y 2 en el ranking de los Estados más demandados del mundo en el arbitraje inversor-Estado. Si bien a España se le cuestionan medidas tomadas en un sector económico puntual, su situación no parece muy diferente a la vivida por Argentina a consecuencia de las medidas tomadas para paliar la crisis económica de 2001 en particular la Ley de Emergencia Pública y Reforma del Régimen Cambiario (Ley 24.561) que convierte a pesos argentinos los precios y tasas en contratos públicos y deja sin efecto las cláusulas de ajuste en monedas extranjeras o parámetros internacionales.

\subsubsection{Las objeciones de jurisdicción y el efecto Achmea}

El tribunal administrado por el CIADI para entender en el caso Masdar, quedó conformado el 18 de julio de 2014 por los árbitros Brigitte Stern, Gary Born y John Beechey (Presidente). En el laudo del 16 de mayo de 2018, en lo que respecta a las objeciones sobre la jurisdicción del tribunal que fueron presentadas por España, el tribunal entendió que no había pruebas suficientes para la excepción de jurisdicción personal del tribunal en función que Masdar era controlada por Emiratos Árabes

\footnotetext{
${ }^{157}$ No solo 47 de los 51 casos contra España tienen como base el Tratado de la Carta de la Energía, este ha sido invocado en numerosas oportunidades contra Italia (11), República Checa (6), Hungría (5) entre otros.
} 
Unidos, Estado no parte del Tratado de la Carta de la Energía (laudo, párrafo 177). Tampoco hizo lugar a la objeción por razón material respecto a que no se trataba de una inversión protegida (laudo, párrafo 202), ni la objeción por consentimiento (rationae voluntatis) ya que España no logró probar que Masdar no tenía actividades importantes en Países Bajos (laudo, párrafo 256). El tribunal aceptó la segunda objeción por rationae voluntatis respecto al impuesto creado por la Ley 15/2012, el cual resulta incluido en la excepción prevista por el Tratado de la Carta de la Energía (artículo 21 numeral 7) (párrafo 295).

No obstante, las dos objeciones que presentan más interés para el régimen de solución de controversias inversor-Estado son aquellas que refieren a los arbitrajes intra-UE. En primer lugar, España afirmó que el Tratado de la Carta de la Energía era inaplicable a las disputas inversor-Estado intra-UE, esto es, disputas entre un inversor nacional de un Estado miembro y otro Estado miembro. El argumento se basa en que el artículo 26 del mencionado tratado regula arbitrajes entre una parte contratante y nacionales de otra parte contratante, y en este caso coinciden en el mismo sujeto: la UE. El amicus curiae presentado por la Comisión Europea, 14 de noviembre de 2014, reafirma la idea anterior al señalar que el Tratado de la Carta de la Energía no puede crear derechos y obligaciones para los inversores de la UE puesto que la propia UE contiene normas que regulan la materia, y que los miembros de la UE no pueden acordar mecanismos de solución de controversias diferentes a los previstos por el Derecho de la Unión (párrafo 305). El tribunal no hizo lugar a la primera objeción argumentando que, aunque la UE sea parte del acuerdo, la disposición sobre solución de controversias en materia de inversiones refiere a los Estados y no a la UE en su conjunto. Por consiguiente, la norma es aplicable.

La segunda objeción puso foco en que el Derecho de la Unión tiene preferencia o prevalencia sobre cualquier otra norma cuando se trata de relaciones intra-comunitarias, incluyendo las normas de solución de controversias (artículo 344 del Tratado de Funcionamiento de la UE). Esta objeción había sido rechazada en laudos anteriores ${ }^{158}$, y siguiendo la misma línea concluye que los sistemas no son incompatibles sino paralelos. En este punto es importante hacer una apreciación, la existencia de sistemas paralelos no genera seguridad jurídica sino por el contrario termina derivando en posibles

\footnotetext{
${ }^{158}$ Electrabel contra Hungría (caso CIADI número ARB/07/19), Charanne contra España (caso Cámara de Comercio de Estocolmo número V2012/062, Isolux contra España (caso Cámara de Comercio de Estocolmo número V2013/153).
} 
soluciones contrapuestas o de imposible ejecución. A largo plazo, sistemas de solución de controversias paralelos y no excluyentes, típicos de la fragmentación del Derecho Internacional, se contraponen a los principios básicos del Derecho.

Cabe destacar que en fecha posterior a la celebración de audiencias en el caso Masdar (19 a 23 de setiembre de 2016), el Tribunal de Justicia de la UE (TJUE) emitió la sentencia en el caso Achmea (asunto C-284/16) ${ }^{159}$, asunto que tiene una conexión directa con las dos objeciones sobre arbitrajes intra-UE. Achmea, empresa de capitales holandeses, invertía en Eslovaquia en el sector de seguros médicos, cuando en 2008 Eslovaquia dejó sin efecto el libre mercado en el sector y prohibió el reparto de beneficios. En consecuencia, la empresa inició un arbitraje contra el Estado, el cual se desarrolló en territorio alemán y bajo el Derecho Alemán, culminando con una condena a Eslovaquia al pago de 22,1 millones de euros. Frente al recurso de casación de Eslovaquia, el Tribunal Supremo de lo Civil y Penal envía una cuestión prejudicial al Tribunal de Justicia de la UE referente a la compatibilidad del TBI Países BajosChecoslovaquia (aplicable conforme a las normas sobre sucesión de Estados) con el Derecho de la Unión.

El 6 de marzo de 2018, el Tribunal Justicia de la UE determinó que el artículo 8 del TBI es incompatible con el acervo normativo de la Unión, destacándose que el tribunal arbitral previsto no forma parte del conjunto de órganos con competencia para interpretar el Derecho Comunitario y en consecuencia no está facultado para remitir una cuestión prejudicial aun estando obligado a interpretar el Derecho de la Unión. De esta manera la autonomía del Derecho de la Unión se ve vulnerada por el arbitraje inversorEstado. La decisión en el caso Achmea, aún sin existir el principio del precedente judicial obligatorio, da luz verde a eventuales recursos de anulación o no ejecución de laudos en arbitrajes intra UE (inversor de un Estado miembro contra otro Estado miembro). Puntualmente en el caso de España, todos los laudos emitidos en su contra conjuntamente cumplen con la condición de ser arbitrajes intra UE y posteriores a la sentencia de Achmea, salvo uno: caso Eiser (caso CIADI número ARB/13/36).

Si bien la sentencia se aplica para el caso concreto, es apoyada por la Comisión en su comunicación al Parlamento de fecha 19 de julio de 2018 (COM(2018) 547) en la que afirma que los TBI celebrados entre miembros de la UE son un riesgo para la autonomía, eficacia, primacía y efecto directo del Derecho de la Unión. En

\footnotetext{
${ }^{159}$ El caso se analizará con más detalle en el capítulo 6.
} 
consecuencia autores como Iruretagoiena (2018) infieren que las disposiciones de los TBI intra-UE no son más aplicables por su incompatibilidad con los Tratados de la UE, presentándose un escenario favorable para los recursos de anulación contra laudos de tribunales arbitrajes con sede en un Estado miembro, y de difícil reconocimiento y ejecución de laudos extranjeros.

Sin perjuicio de lo anterior, el tribunal del caso Masdar entendió que la sentencia del TJUE tiene un efecto limitado, refiere a arbitrajes en el marco de TBI, y no incumbe a ese arbitraje en particular (párrafos 678 y 683). Cabe destacar que si bien el caso Achmea tiene como foco a un mecanismo contenido en un TBI, no va de suyo que el análisis realizado por el TJUE quede restringido a esta clase de acuerdo con exclusión de los multilaterales. El razonamiento del caso Achmea puede ser aplicado a cualquier mecanismo de solución de controversias inversor-Estado sin importar en qué instrumento internacional se encuentre acordado. La clasificación de un tratado por la cantidad de partes no parece ser la seguida por el Tribunal de Justicia sino una clasificación vinculada a la materia que el tratado regula.

\subsubsection{La responsabilidad estatal y la "tormenta Micula"}

Como se analizó en el apartado anterior, el tribunal arbitral del CIADI consideró que tenía competencia para resolver la disputa sin afectación de los recientes desarrollos en la UE. En este contexto, el tribunal concluyó que, si bien España podía modificar su legislación, la estabilidad económica y jurídica no pueden considerarse dentro de las legítimas expectativas (párrafo 485). Sin embargo el Estado no cuenta con un derecho incondicional, y por tanto es responsable en caso de existir compromisos específicos de estabilidad. Este era el caso de las resoluciones tomadas por España en el marco del Real Decreto 661/2007 respecto a todas y cada una de las empresas que operaban en su territorio (párrafo 521). En consecuencia, el tribunal concluyó que España violó el trato justo y equitativo (artículo 10 numeral 1 del Tratado de la Carta de la Energía), y la condenó al pago de 64,5 millones de euros más intereses.

El caso Masdar tiene similitudes con los otros diez casos ganados por los inversores contra España, pero a este escenario debe sumarse otro ingrediente comunitario: el caso Micula contra Rumania (caso CIADI número ARB/05/20) ${ }^{160}$. Rumania al ingresar a la UE cumplió con el requisito de derogar las normas domésticas que establecían

\footnotetext{
${ }^{160}$ El caso se analizará con más detalle en el capítulo 6.
} 
beneficios a inversores en regiones desfavorecidas. Los hermanos Micula y dos empresas, todos de nacionalidad sueca, deciden iniciar un arbitraje en el CIADI por considerar que Rumania había vulnerado sus legítimas expectativas conforme al TBI Suecia-Rumania. El tribunal ad hoc falla a favor de los demandantes y condena al Estado a la indemnización de aproximadamente 178 millones de euros. En consecuencia, Rumania procedió al descuento de parte de la indemnización debida de una deuda tributaria que una de las empresas tenía con el Estado. Al ser informada del hecho, la Comisión Europea afirmó que cualquier forma de indemnización conforme a un laudo arbitral a una empresa de la UE era considerada una ayuda incompatible con el mercado interior e ilícita, y por tanto Rumania debía recuperar el monto indemnizado (Decisión 2015/1470 ${ }^{161}$ ).

Por tanto, mientras España cuenta con el apoyo de la UE en su batalla por la modificación al régimen de incentivos a las energías renovables, once de los catorce laudos emitidos a octubre de 2019 fueron contrarios a sus intereses. Asimismo, en el corto plazo es factible que culminen otros procesos que pueden sumar cerca de 4000 millones de euros más en su contra. Si España abona las indemnizaciones a las que se lo condena en esos laudos, conforme al caso Micula, estaría incumpliendo el Derecho de la Unión por tratase de una ayuda ilícita. Ahora bien, el caso Micula trae en sí mismo el germen de una tormenta: aun si en la UE una indemnización es considerada una ayuda estatal ilícita, empresas como por ejemplo Eiser, con laudo favorable en el CIADI con sede en Washington, se han presentado ante los tribunales domésticos de Estados Unidos para solicitar la ejecución de los bienes inmuebles del Estado español en territorio estadounidense.

En este punto es importante recordar que la Convención de las Naciones Unidas sobre las inmunidades jurisdiccionales de los Estados y de sus bienes (2004) aún no está vigente pero sus disposiciones en general cristalizan las normas consuetudinarias en la materia. En este sentido, el artículo 19 prevé que no pueden adoptarse medidas coercitivas posteriores a un fallo judicial, por ejemplo embargo o ejecución de bienes, salvo tres excepciones. Estas son: consentimiento expreso del Estado, asignación de bienes para satisfacer el objeto del proceso por parte del Estado, y bienes utilizados con fines oficiales no comerciales y al mismo tiempo estén en el territorio del foro y tengan un nexo con el actor en el proceso judicial. No se consideran bienes ejecutables los

\footnotetext{
${ }^{161}$ Disponible en: https://eur-lex.europa.eu/legal-content/ES/TXT/?uri=CELEX\%3A32015D1470
} 
bienes de las misiones diplomáticas y oficinas consulares, bienes militares, bienes del Banco Central, bienes culturales, bienes de una exposición que no estén destinados a la venta (artículo 21). Es importante tener en cuenta que una norma de fuente convencional suele ser más precisa o exacta que una norma de fuente consuetudinaria, por tanto, la precisión de la Convención de 2004 (no vigente) no necesariamente será recogida por la costumbre internacional que los jueces domésticos habrán de aplicar.

Sin perjuicio de lo anterior, sí se encuentra en vigor la Convención de Viena sobre Relaciones Diplomáticas (1961) que establece que los locales, muebles, vehículos y bienes de las misiones diplomáticas no pueden ser objeto de requisa, embargo o ejecución (artículo 22 numeral 3). Con similar redacción la Convención de Viena sobre Relaciones Consulares (1963) indica que los locales, muebles, vehículos y bienes de las oficinas consulares no pueden ser objeto de requisa (artículo 31 numeral 4). En el caso puntual de las acciones de ejecución contra España, esta es propietaria de un importante número de bienes en territorio de otros Estados, entre ellos Estados Unidos. Si bien en el listado de bienes inmuebles, que se encuentra publicado en la página web del Senado Español $^{162}$, se incluyen los locales de las misiones diplomáticas y las oficinas consulares, hay otros que no tienen este carácter y por tanto podrían ser objeto de ejecución.

En virtud del caso Achmea, diferente es la situación de los laudos de los tribunales arbitrales ad hoc administrados por la Cámara de Comercio de Estocolmo o por la Corte Permanente de Arbitraje, ambos foros en territorio comunitario. Este razonamiento no es aplicable a las disputas iniciadas por empresas de nacionalidad diferente a las de los Estados miembros de la UE que aún se encuentran pendientes de resolución, hasta el momento nacionales de Japón y Suiza. A octubre de 2019, cuatro controversias fueron iniciadas por inversores no comunitarios, en alguno de ellos en conjunto con empresas de la UE: 1) Eurus Energy Holdings Corporation (Japón) (caso CIADI número ARB/16/4); 2) EBL (Genossenschaft Elektra Baselland) (Suiza) y Tubo Sol PE2 S.L. contra España (caso CIADI número ARB/18/42); 3) Itochu Corporation (Japón) (caso CIADI número ARB/18/25); 4) DCM Energy GmbH \& Co. Solar 1 KG (Alemania), DCM Energy GmbH \& Co. Solar 2 KG (Alemania), Hannover Leasing Sun Invest 2 Spanien Beteiligungs GmbH (Alemania), Hannover Leasing Sun Invest 2 Spanien

\footnotetext{
${ }^{162}$ Disponible en: http://www.senado.es/web/expedientappendixblobservlet?legis=12\&id1 $=62577 \& \mathrm{id} 2=1$
} 
GmbH \& Co. KG (Alemania), Edisun Power Europe A.G. (Suiza) (caso CIADI número $\mathrm{ARB} / 17 / 41)$.

\subsection{Conclusiones capítulo 4}

El aumento del arbitraje de inversiones entre las décadas de los noventa y primera década del siglo XXI coincidió con una creciente preocupación internacional por la protección del medioambiente (Sornarajah, 2015: 333). Dada la fragmentación del Derecho Internacional General en regímenes jurídicos autocontenidos, el régimen de protección de inversiones y el régimen de protección del medioambiente han colisionado en diversas ocasiones, dando lugar a controversias como las tres analizadas en este capítulo.

Las tres disputas reúnen una similitud y una diferencia. En primer lugar, dado el sector en el que operan los inversores extranjeros (minería y energía solar) las disputas están directamente vinculadas a medidas tomadas por los Estados en ejercicio válido del derecho de regular (en avance o retroceso) en materia de medioambiente. Se trata de casos en los que el Estado hace uso de su espacio de política pública o policy space para tomar medidas que fortalezcan su desarrollo sostenible (casos Pac Ric y Eco Oro), siendo el balance entre desarrollo sostenible y atracción de inversiones el desafío que la UNCTAD marcara desde el año 2003 para los Estados en desarrollo (UNCTAD, 2003). En el caso Masdar, la situación es inversa, las medidas contrarias al avance en materia de desarrollo sostenible se toman a fin de paliar los efectos de la crisis económica española 2008-2014 (este caso es uno de los 47 disputas contra España en el sector energías renovables).

Asimismo, se trata de medidas tomadas por los Estados en ejercicio del principio de soberanía permanente sobre sus recursos naturales. Este es recogido por la Resolución 1803 (XVII) de la Asamblea General, relativa a la soberanía permanente sobre los recursos naturales del 14 de diciembre de 1962 y la Resolución 3281 (XXIX) de la Asamblea General "Carta de Derechos y Deberes Económicos de los Estados" del 12 de diciembre de 1974 (artículos 2 y 3). Es innegable el derecho soberano de los Estados de regular en esta materia, sin perjuicio de la indemnización en caso de expropiación. Como explica Gómez Robledo (2003), aun existiendo matices entre una norma y otra, el principio es un derecho inalienable del Estado 
"que no se limita solamente a la simple explotación de las riquezas y recursos naturales del territorio estatal; está concebido como un derecho que va también más allá del derecho a la gestión y a la participación de los beneficios de las empresas explotadoras, ya que ha sido consagrado para ser aplicado a toda la estructura e infraestructura del sistema económico del Estado" (Gómez Robledo, 2003: 507).

Tanto en el caso Pac Rim como en el caso Eco Oro se percibe el mismo esquema de comportamiento de los inversores extranjeros: a mayor avance en materia de protección del medioambiente, defensa del derecho humano a un medioambiente sano y equilibrado y profundización en la forma en que se ejercerá el principio de soberanía permanente sobre los recursos naturales, los inversores extranjeros presentan un cuestionamiento que culmina en una demanda en un tribunal de inversiones. En otros términos, el ejercicio del derecho de regular tuvo como consecuencia la presentación de demandas por parte de los inversores que entienden que la nueva regulación vulnera sus derechos protegidos en un tratado en materia de inversiones.

El caso Masdar contra España también tiene su centro en el derecho de regular como ejercicio válido de la soberanía estatal. No obstante, el platillo de la balanza que tiene más peso no es la transición de la matriz energética hacia energías más limpias, sino mitigar los efectos de una crisis económica. En este caso, como en los otros 46 casos contra España en el sector energías renovables, en la medida que España retrocede en la protección del medioambiente (recorte y suspensión de beneficios), las empresas entienden que sus derechos son vulnerados e inician arbitrajes en base al Tratado de la Carta de la Energía.

En este punto es fundamental tener en consideración que las empresas también ejercen un derecho consagrado en normas internacionales, como es el derecho a iniciar un arbitraje internacional bajo determinadas condiciones. Se trata de un derecho previsto en una red de más de 3000 tratados internacionales, bilaterales o multilaterales, en materia de inversiones, o con capítulos de inversiones. Pero no se trata de un derecho consagrado como norma de jus cogens como es la igualdad soberana, la autodeterminación, o la soberanía permanente sobre los recursos naturales. En término del artículo 53 de la Convención de Viena sobre Derecho de los tratados entre Estados, una norma de jus cogens o norma imperativa de Derecho Internacional General es "una norma aceptada y reconocida por la comunidad internacional de Estados en su conjunto como norma que no admite acuerdo en contrario y que sólo puede ser modificada por una norma ulterior de derecho internacional general que tenga el 
mismo carácter". Actualmente la mayoría de la doctrina no considera que los derechos humanos integren esta categoría de normas.

Las disputas inversor-Estado seleccionadas para este capítulo fueron brevemente comparadas con otras controversias similares, de manera de presentar un elenco de casos en los que el avance o retroceso del Estado en materia regulatoria tiene como consecuencia un arbitraje. Las empresas transnacionales cuestionan el retorno del Estado a ciertas áreas de regulación, o en términos de Strange, a aquellas parcelas de poder de las que el Estado se había retirado previamente. El carácter de controversias emblemáticas de los casos analizados, sumado a las características de las disputas vinculadas, permite afirmar que es la extensión de la regulación estatal en materias de interés público es un elemento fundamental en el inicio de arbitrajes inversor-Estado por parte de las empresas transnacionales, ya sea cuestionando medidas al alza como a la baja en materia de protección de derechos humanos, en concreto el derecho a un medioambiente sano y equilibrado.

En suma, en los casos analizados se constata que existió un cuestionamiento del Derecho Interno en términos de la protección al derecho humano a un medioambiente sano y equilibrado. Sin embargo, el cuestionamiento no atiende a si las nuevas normas brindan una mayor o menor protección de este derecho. El inversor extranjero basa su demanda en la nueva regulación estatal, o lo que es lo mismo, en el desarrollo del Derecho, alegando que cuenta con legítimas expectativas que el régimen jurídico bajo el cual confió e invirtió no cambiará. Sin perjuicio de lo anterior, la jurisprudencia arbitral ya ha reconocido que el inversor no puede esperar que la legislación general no cambie, y que debe consultar con "antelación respecto de las perspectivas de un cambio en el marco regulatorio a la luz de los cambios vigentes o razonablemente esperables de las condiciones económicas y sociales del Estado receptor" (laudo caso Philip Morris contra Uruguay, párrafo $\left.427^{163}\right)^{164}$.

\footnotetext{
163 El laudo está disponible en: http://medios.presidencia.gub.uy/tav_portal/2016/noticias/NO_U130/laudo_spa1.pdf

${ }^{164}$ Excede los objetivos de este trabajo el análisis de la cláusula de trato justo y equitativo en la cual suelen enmarcarse las legítimas expectativas del inversor, o la necesidad de una cláusula de estabilidad para que el inversor tenga derecho a reclamar ante cualquier cambio normativo.
} 


\section{Capítulo 5: Controversias que involucran los derechos a la salud, al agua y de los pueblos indígenas}

\subsection{Aspectos preliminares}

Para completar el segundo círculo de esta investigación, el presente capítulo se dedica al examen de tres casos que marcaron tendencia en el régimen de solución de controversias inversor-Estado por tratar temas nuevos y vinculados con derechos humanos. En primer lugar se analiza el caso Philip Morris contra Uruguay, cuya importancia para el sistema-mundo deriva de dos aspectos. El primer aspecto se traduce en que es la primera vez que se discute en un tribunal del CIADI un caso vinculado a la presunta expropiación indirecta de una inversión en materia de propiedad intelectual, a saber: el uso de una marca. Asimismo, en el laudo se introduce la idea de que el ejercicio del poder de policía del Estado para regular la salud pública de la población (medidas de control del consumo de tabaco) no determina que el Estado incurra en responsabilidad internacional.

El segundo caso elegido es Urbaser contra Argentina en el sector aguas y saneamiento. La controversia tiene su origen en las medidas de emergencia tomadas por el Estado para paliar los efectos de la crisis económica y social de 2001, en particular aquellas vinculadas a los mecanismos de actualización de tarifas de servicios públicos. La disputa es relevante por dos motivos: Argentina es el Estado más demandado en el mundo en general y en el sector aguas y saneamiento en particular, y por primera vez un tribunal de inversiones analiza las obligaciones de las empresas inversoras extranjeras en relación al derecho humano al agua, conforme a la solicitud del Estado en la demanda reconvencional. La disputa trae al debate la subjetividad jurídica de las empresas transnacionales, las obligaciones en materia de derechos humanos (obligaciones positivas y negativas) y la posibilidad que tienen los Estados de hacer uso de las demandas reconvencionales como canal para jugar una carta en temas de derechos humanos.

Finalmente, el tercer caso gira en torno al sector de extracción minera en Perú, sector con mayor número de demandas en América del Sur (54 de 185 casos $^{165}$ ), incorpora el examen de elementos nuevos para el régimen de solución de controversias inversorEstado. El laudo de la mayoría es contrario al Estado, pero en la opinión parcialmente

${ }^{165}$ Datos conforme al Investment Policy Hub de la UNCTAD. Fecha de consulta: 4 de setiembre de 2019. 
concordante y disidente, el árbitro Sands analiza el valor de la ausencia de una licencia social respecto a las comunidades aymaras a quienes afectaba el proyecto. La introducción de normas del sistema de la Organización Internacional del Trabajo (OIT), en concreto el Convenio 169 sobre pueblos indígenas y tribales (1989), para sugerir la reducción a la mitad del monto indemnizatorio por parte del Estado es un elemento innovador, que permite una mirada holística de los hechos, incluyendo un abordaje desde los derechos humanos y trayendo al debate las voces de todos los actores a quienes la inversión extranjera directa puede afectar de alguna manera. En definitiva, el caso pone en evidencia la necesidad de una mirada holística de la solución de controversias inversor-Estado, más allá de la lógica de la protección y reproducción del capital.

\subsection{Caso Philip Morris contra Uruguay ${ }^{166}$}

\subsubsection{El germen de la disputa: Uruguay y las medidas de control del consumo del tabaco}

La demanda de la empresa Philip Morris constituye una clara respuesta a una serie de medidas tomadas por Uruguay en el marco de la lucha contra el tabaquismo. La piedra fundamental de la política antitabaco es el Decreto 268, de fecha 5 de setiembre de 2005, en el cual se dispone que "todo local cerrado de uso público y toda área laboral, ya sea en la órbita pública o privada destinada a la permanencia en común de personas, deberán ser ambientes 100\% libres de humo de tabaco" (artículo 2). De esta manera, el 1 de marzo de 2006 Uruguay se convirtió en el primer Estado libre de humo de tabaco de las Américas y el séptimo en el mundo (Vázquez, 2009).

Otras normas complementaron la política de control del tabaco, como ser la Ley 18.256 que estableció la prohibición de fumar en lugares cerrados públicos o privados; limitó la publicidad en puntos de venta y prohíbe la publicidad, promoción y patrocinio de los productos de tabaco incluso en eventos deportivos, y autorizó al Ministerio de Salud Pública a adoptar las directrices relativas al análisis y la medición del contenido y las emisiones de productos de tabaco.

La política se reforzó con la sanción de la Ordenanza del Ministerio de Salud Pública Número 514 (18 de agosto de 2008) que obligó a las empresas a ceñirse a una

\footnotetext{
${ }^{166}$ Un análisis de disputa a la luz de la fragmentación del Derecho Internacional puede verse en Bas Vilizzio (2017b).
} 
presentación única versión por marca comercial de cigarrillos con el fin de no emplear descriptores engañosos como light, liviano o suave (regla de la presentación única). Posteriormente, la sanción del Decreto 287 (15 de junio de 2009) y la Ordenanza 466 (1 de setiembre de 2009) complementan el mapa normativo al determinar el uso de una advertencia sanitaria del $80 \%$ de la parte frontal y posterior de la cajilla (regla del 80/80), con el fin de ejemplificar los efectos dañinos del consumo de tabaco. Ambas medidas se tomaron en cumplimiento al artículo 11 del Convenio Marco de la Organización Mundial de la Salud sobre control del tabaco, tratado caracterizado por su elevado número de Estados parte (180 a la fecha del laudo, 181 al cierre de este trabajo) y por ser el único instrumento internacional que regula la prevención y el control del consumo de una mercadería cuya comercialización es lícita.

La figura del Presidente Tabaré Vázquez (primera presidencia: 2005-2010; segunda presidencia: 2015-2020), en tanto autoridad máxima de la política exterior y en cuanto médico oncólogo de profesión, sobresalió en la implementación de dicha política. En su discurso ante la Asamblea General de la ONU del 23 de setiembre de 2009, enfatiza en la necesidad de implementar políticas para mejorar el bienestar de la población en relación al tabaquismo, siendo este el causante de "cinco millones de muertes al año en todo el mundo (...) esto es más que el alcoholismo, los accidentes de tránsito, el SIDA, las drogas ilegales, los homicidios y los suicidios sumados", por tanto, la política antitabaco implementada por Uruguay se muestra como "un avance parcial $y$ auspicioso en la lucha contra esta epidemia” (Vázquez, 2009).

Pocas semanas después del término del primer mandato presidencial de Vázquez, el 26 de marzo de 2010, el secretario General del CIADI registró la solicitud de iniciar un proceso arbitral contra el Estado Uruguayo presentada por las empresas Philip Morris Brand Sàrl (Suiza), Phil Morris Products SA (Suiza) y Abal Hermanos SA (Uruguay). Este hecho sería definido por el entonces ex Presidente como una forma de "dar un escarmiento al Uruguay e intimidar a otros países que están instrumentando políticas públicas para el control del tabaco o se aprestan a hacerlo" (Vázquez, 2010: 243). La comparación con la lucha entre David y Goliat fue inevitable, a razón del poder de la tabacalera, que en el año 2018 registró ingresos netos de 79.823 millones de dólares, 
frente a un Estado Sudamericano de 3,4 millones de habitantes y un PBI de 59.597 millones de dólares en el mismo año ${ }^{167}$.

Las demandantes basaron su reclamo en el supuesto incumplimiento de Uruguay de los artículos 3 (protección y tratamiento de inversiones), 5 (expropiación y compensación), 11 (observancia de los compromisos) del TBI Uruguay - Suiza, en función de los previsto por las disposiciones que establecían la regla de la presentación única y la regla 80/80. A juicio de las demandantes, tales disposiciones restringieron su derecho a usar las marcas de manera adecuada, derecho protegido como inversión por el TBI en cuestión, conforme al artículo 1 numeral 2 literal d. En este marco, solicitaron una indemnización de 22,267 millones de dólares, además de intereses compuestos a devengarse desde la fecha de la violación hasta la fecha de pago, y que quedaran sin efecto las mencionadas disposiciones de Derecho Interno.

El tribunal ad hoc, constituido el 15 de marzo de 2011 con los árbitros Gary Born, James Crawford y Piero Bernardini (presidente), en su primera audiencia decidieron separar los aspectos jurisdiccionales de los aspectos de fondo. Uruguay presentó tres excepciones preliminares respecto a la jurisdicción, a saber: 1) la ausencia de cumplimiento de la obligación de agotar previamente los recursos internos ya que el Tribunal de lo Contencioso Administrativo de Uruguay había sido consultado sobre la legalidad de los actos pero no sobre el cumplimiento del TBI; 2) la exclusión de las medidas de salud pública del alcance de las inversiones protegidas, conforme a lo previsto por el artículo 2 numeral 1 del TBI; y 3) la no constitución de inversiones de las actividades de las demandas, siguiendo lo previsto en el artículo 25 del Convenio de Washington, al no contribuir al desarrollo económico del país. No obstante, el tribunal ad hoc reconoció su competencia para entender en la controversia, desestimando las solicitudes presentadas (decisión, 2 de julio de 2013).

En cuanto a la primera excepción preliminar, el tribunal entendió que ya se había satisfecho el requisito de agotamiento de la jurisdicción doméstica en cuanto a sus objetivos y términos, y reiterar tal procedimiento implicaría una pérdida de tiempo y recursos (párrafo 149). En relación a la segunda excepción, el tribunal consideró que el derecho de no permitir inversiones por razones de salud pública, entre otras, refiere exclusivamente a la etapa de admisión de las inversiones, esto es, previo al

\footnotetext{
${ }^{167}$ Datos de Statista (https://www.statista.com/statistics/500455/net-revenue-of-philip-morris-worldwide/) y el Banco Mundial (https://datos.bancomundial.org/pais/uruguay), respectivamente. Fecha de consulta: 26 de agosto de 2019.
} 
establecimiento del inversor. Por tanto, no se trata de una excepción a las obligaciones del TBI, una vez que estas superan la etapa de admisibilidad (párrafo 174).

Finalmente, respecto a la tercera excepción, el tribunal concluyó que el concepto de inversión debe ser interpretado en sentido amplio siempre que se trate de actividades sustanciales y prolongadas en el tiempo (párrafo 202). Por tanto, corresponde a los Estados definir en el TBI los límites de la inversión a ser protegida, límites que no se extraen del articulado del TBI bajo análisis (párrafo 203).

La etapa referente al fondo del asunto se inició con los escritos de las partes: memorial de la tabacalera (4 de marzo de 2014), memorial de contestación de Uruguay (13 de octubre de 2014), réplica sobre el fondo presentada por la empresa (17 de abril de 2015) y dúplica sobre el fondo de manos del Estado (20 de septiembre de 2015). El siguiente hecho destacable tuvo lugar el 24 de marzo de 2015, con la aceptación de la presentación de la Organización Mundial de la Salud y la Organización Panamericana de la Salud como amicus curiae de acuerdo a la regla $37(2)^{168}$. Motivó la decisión del tribunal el interés público en dicha controversia y los beneficios de contar con el conocimiento y experiencia de instituciones calificadas en la materia en disputa, a la hora de adoptar decisiones. La aceptación de la participación de las dos organizaciones como amicus curiae aporta un análisis profesional del objeto del proceso, en especial de la normativa uruguaya controvertida, a la luz de los compromisos internacionales asumidos en el contexto de la lucha contra el tabaquismo, en definitiva el derecho a la salud.

El siguiente paso fue cumplido con la celebración de las audiencias en Washington (19 al 29 de octubre de 2015), momento a partir del cual el tribunal comenzó a deliberar sobre el fondo del asunto.

\subsubsection{El laudo del 8 de julio de 2016}

El día 8 de julio de 2016, el tribunal entregó a las partes el laudo sobre el fondo del asunto $^{169}$, decisión obligatoria para las partes e inapelable conforme al artículo 53 del Convenio de Washington. En relación al primer punto controvertido por las demandantes, la expropiación indirecta de siete de sus marcas sin debida compensación

\footnotetext{
${ }^{168}$ Otras solicitudes de amici curae, presentadas por Fundación Avaaz y Asociación Interamericana de la Propiedad Intelectual, no fueron aceptadas por el tribunal.

${ }_{169}$ El laudo está en: http://medios.presidencia.gub.uy/tav_portal/2016/noticias/NO_U130/laudo_spa1.pdf .
} 
(artículo 5 del TBI Uruguay-Suiza), asumiendo que las marcas estaban bajo protección de la Ley de Marcas de Uruguay (Ley No. 17.011) el tribunal concluyó que "las Medidas Impugnadas fueron un ejercicio válido del poder de policía de Uruguay para la protección de la salud pública. En este carácter, no pueden constituir una expropiación de la inversión de las Demandantes" (párrafo 307).

El reconocimiento del poder de regular en dicha materia, y no por ello incurrir en responsabilidad internacional, es uno de los elementos con más fuerza del fallo y que probablemente tendrá consecuencias para evitar futuras demandas desde la industria tabacalera. No obstante, dado que no hay precedentes en el área, surge la interrogante sobre posibles arbitrajes relacionados a otras áreas que pongan bajo tela de juicio el espacio de política pública del Estado en materia de salud, como ser los alimentos con exceso de azúcar, exceso de sodio o grasas trans, y en relación a los cuales no existen tratados internacionales que determinen el control de su comercialización, como en el caso del tabaco. Dada la ausencia de precedente judicial obligatorio y la diversidad en la conformación de los tribunales, al ser ad hoc, lo anterior podría significar que conforme a un área u otra vinculada al derecho humano a la salud, la soberanía pueda limitarse por laudos contrarios o congelamiento normativo. Incluso la autonomía puede verse condicionada al determinar que la toma de decisiones en política exterior sea frenada por los intereses de actores no estatales.

En relación al segundo punto reclamado por las empresas, los árbitros desestimaron la violación del trato justo y equitativo (numeral 2) ya que el inversor no podía tener legítimas expectativas de que medidas como las controvertidas no fueran aplicadas, dada la creciente preocupación global sobre los efectos del consumo de tabaco. Por los mismos motivos estimaron que no se trata de un caso de obstaculización del uso y goce de las inversiones (artículo 3 numeral 1), puesto que las medidas no pueden ser consideradas como injustificadas ni arbitrarias (párrafos 445 y 446) ${ }^{170}$.

En tercer lugar, la inobservancia de los compromisos relativos al uso de marcas conforme al artículo 11 del precitado acuerdo, también fue rechazada por el tribunal. Su argumento se basa en que en materia marcaria no existe una promesa de cumplimiento de una obligación por parte del Estado, por tanto "si los inversores pretenden estabilización, deben contratarla" y no pretenderla de un marco jurídico general, que como tal es pasible de modificaciones (párrafo 481). En este sentido, es destacable la

\footnotetext{
${ }^{170}$ Un análisis del tratamiento del principio de trato justo y equitativo en el laudo del caso Philip Morris contra Uruguay puede verse en Díaz Inverso (2018).
} 
tendencia internacional hacia un mayor control del tabaco. Si bien la regulación de la presentación única no tiene precedentes en el mundo, a la fecha de dictado el laudo otros Estados ya contaban con medidas similares a la regla del 80/80, aumentando el espacio correspondiente a las advertencias sanitarias por sobre el mínimo previsto en el Convenio Marco sobre el Control del Tabaco (50\%), a saber: Namibia (55\%), Ecuador (60\%), Canadá (75\%), Sri Lanka (80\%), entre otros. El avance global se ha dirigido hacia la implementación del empaque plano estandarizado, que ya se encuentra en vigor por ejemplo en Australia (2012), Reino Unido (2016), Francia (2016), Irlanda (2017), Nueva Zelanda (2018).

Adicionalmente, las demandantes alegaron denegación de justicia derivada de procesos fundamentalmente injustos y que determina una violación del trato justo y equitativo (artículo 3 numeral 2). En primer lugar, el tribunal se pronunció sobre las sentencias supuestamente contradictorias de la Suprema Corte de Justicia y el Tribunal de lo Contencioso Administrativo respecto al aumento del 50 a $80 \%$ de las advertencias sanitarias por medio de un decreto reglamentario de la Ley 18.256. Los árbitros entienden que si bien este hecho "puede parecer inusual, incluso sorprendente, pero no es impactante $y$ no es lo suficientemente grave en sí misma para constituir una denegación de justicia” (párrafo 529).

El segundo punto refirió a la denegación de justicia dado que, a entender de Philip Morris, la sentencia del Tribunal de lo Contencioso Administrativo en el marco del reclamo de Abal por la regulación de la presentación única es una fotocopia de una sentencia anterior de British American Tobacco. El tribunal considera que la sentencia se dictó con el nombre de Abal, tiene en cuenta sus argumentos a pesar de "parecer haber copiado y pegado grandes porciones de la sentencia de BAT [British American Tobacco] directamente en la sentencia de Abal" en virtud de las similitudes entre ambos casos, lo cual demuestra improcedencias procesales y falta de forma pero no implica denegación de justicia (párrafos 572 y 578). La existencia o no de denegación de justicia es el elemento más cuestionable del laudo al tomarse un estándar amplio y reconocer las improcedencias procesales.

En suma, el tribunal desestimó todos los reclamos de Philip Morris, y decidió que los inversores debe encargarse de sufragar los honorarios y gastos del tribunal y gastos administrativos del CIADI (1.485.714,08 dólares), así como reintegrarle al Estado Uruguayo 7 millones de dólares de los 10.319.833,57 por concepto de los costos que incurrió durante el proceso. 
El árbitro Born, designado por Philip Morris, publicó su opinión concurrente y disidente, en la cual coincide con las conclusiones del laudo respecto al poder de policía de Uruguay o cualquier Estado para regular su salud pública, pero disintiendo en dos puntos vinculados al respeto del trato justo y equitativo. Primeramente, dado que la Suprema Corte de Justicia y el Tribunal de lo Contencioso Administrativo (órganos de máxima jerarquía del Poder Judicial Uruguayo) arribaron a conclusiones opuestas y en ambos casos se rechazó la indemnización a la empresa, sumado a la imposibilidad de recurso ante instancias judiciales superiores, concluyó que se trata de una denegación de justicia. En segundo lugar, conforme a que la regulación de presentación única no tiene precedentes en otros Estados ni es prevista por el Convenio Marco sobre Control del Tabaco, consideró que se trata de un requisito arbitrario y desproporcionado que viola el trato justo y equitativo por parte del Estado receptor.

Si bien el laudo es favorable para el Estado, y la opinión disidente se enfoca en aspectos jurisdiccionales de Derecho Interno, el objeto de la controversia sumado a los seis años de litigio ponen en evidencia la limitación de la soberanía del Estado involucrado en la controversia, especialmente la westfaliana. El siguiente paso previsto por Uruguay en la lucha contra el tabaquismo es el etiquetado neutro o genérico conforme a lo establecido en los artículos 11 y 13 del Convenio Marco para el Control del Tabaco. A nivel doméstico, en primer lugar se sancionó el Decreto 235/018, contra el cual la empresa British American Tobacco presentó una acción de amparo, resultando vencedora en primera instancia no así en segunda ${ }^{171}$.

Para darle mayor jerarquía jurídica, el Ejecutivo decidió presentar un proyecto de ley que estableciera el empaquetado y etiquetado de productos de tabaco, que finalmente fue aprobado mediante la Ley 19.723 (21 de diciembre de 2018), reglamentada por el Decreto 120/019 (29 de abril de 2019). Dos empresas (Montepaz y La Republicana) presentaron acciones de amparo ante los tribunales uruguayos, también favorables al

\footnotetext{
171 Texto de la sentencia de primera instancia disponible en: http://poderjudicial.gub.uy/institucional/download/6411/5337/19

Texto de la sentencia de segunda instancia disponible en: https://www.tobaccocontrollaws.org/files/live/litigation/2597/UY_B.A.T.\%20v.\%20Executive\%20Branc h_1.pdf
} 
Estado $^{172}$. En vista de lo anterior, el empaquetado genérico comenzará a aplicarse en enero de 2020 conforme a declaraciones del Ministro de Salud Pública ${ }^{173}$.

El desbalance de poder Estado-mercado, en términos de Strange, pone de manifiesto el creciente peso de los actores no estatales frente al Estado. Este se hace visible en la propia estrategia de las empresas de dilatar la aplicación de la norma doméstica mediante las acciones de amparo y el cambio en la conducta del Poder Ejecutivo tendiente a dar mayor jerarquía jurídica a una disposición de naturaleza reglamentaria y que tuviera nivel de ley. En efecto, la capacidad de tomar decisiones del Estado se ve cercenada y opera una especie de freno invisible a la autonomía estatal, que sin embargo resiste.

En suma, el caso Philip Morris contra Uruguay desde todas sus aristas constituye un leading case en el régimen de solución de controversias inversor-Estado. El poder de policía como elemento central del laudo de fondo es aplicable a otras acciones en el marco del espacio de política pública estatal, sumado al reconocimiento que el ejercicio de dicho poder no tiene como consecuencia la responsabilidad internacional por incumplimiento de normas de origen convencional. En esta línea, se siguen las palabras del embajador Carlos Gianelli ${ }^{174}$, quien formó parte del equipo que representó a Uruguay ante el CIADI

\begin{abstract}
"el caso Philip Morris contra Uruguay es un punto de referencia más que un quiebre en el régimen de solución de controversias inversor-estado. Es un punto de referencia importante para futuros casos que tengan que ver con demandas a los estados en materia de políticas públicas. En el caso de referencia es específicamente el tema de la salud pública, pero podría extenderse también a los temas de medio ambiente y seguridad, entre otros. Es también una reafirmación del cumplimiento y respeto de normas internacionales vinculantes, como el Acuerdo Marco de Protección contra el Tabaco de la Organización Mundial de la Salud (OMS). Lo anterior no quiere decir que el sistema inversor- estado esté funcionando bien; por el contrario, está siendo muy cuestionado en el actual funcionamiento y es por eso que tanto el CIADI ligado al Banco Mundial, como UNCITRAL ligado a las Naciones Unidas, están impulsando desde hace un año reformas a los procedimientos del sistema. También los principales actores en materia de inversiones extranjeras directas están cuestionando el sistema de solución de controversias inversor-estado. Por ejemplo, la iniciativa de la Unión Europea presenta la realización de cambios de carácter estructural" (comunicación personal, 23 de setiembre de 2019).
\end{abstract}

\footnotetext{
172 Texto de la sentencia disponible en: https://medios.presidencia.gub.uy/tav_portal/2019/noticias/AE_514/Sentencia.pdf

${ }_{173}$ Información en: https://www.presidencia.gub.uy/comunicacion/comunicacionnoticias/justicia-fallo-favor-gobierno-trasaccion-amparo-tabacaleras-respecto-empaquetado

${ }^{174}$ Embajador de Uruguay en Estados Unidos, diplomático de carrera, agente de Uruguay en el caso de las pasteras sobre el Río Uruguay en la CIJ y miembro de la defensa de Uruguay en el caso Philip Morris y otras disputas en el CIADI. Entrevistado para este trabajo.
} 


\subsubsection{Controversias vinculadas}

Para cerrar el análisis del caso Philip Morris contra Uruguay es necesario ampliar la mirada y tener en consideración otras controversias directamente vinculadas por tener como centro medidas de control del tabaco. Como se indicara en el capítulo 3 de este trabajo, el artículo 29.5 del TPP y actual CPTPP prevén la disposición que posiblemente sea la más innovadora de todo el tratado, al permitir que un Estado parte pueda excluir las medidas de control del tabaco de la solución de controversias inversor-Estado. Dicha norma fue inspirada por el caso Philip Morris contra Uruguay, primer reclamo de una tabacalera ante un tribunal de inversiones, así como el caso Philip Morris Asia Limited contra la Mancomunidad de Australia en la CPA (caso número 2012 - 2) (véase apartado 3.3.3).

Las controversias en materia de inversiones no son casos aislados. En otro foro y estando en discusión exclusivamente derechos de propiedad intelectual vinculados con el comercio, existen cinco demandas contra Australia en el marco de la Organización Mundial del Comercio (OMC) ${ }^{175}$. Ucrania ${ }^{176}$, Honduras ${ }^{177}$, República Dominicana ${ }^{178}$, $\mathrm{Cuba}^{179}$, e Indonesia ${ }^{180}$ se presentaron contra Australia al considerar que su Ley de empaquetado genérico de los cigarrillos (2011), sus normas modificatorias y complementarias, son contrarias al párrafo 1 del artículo 1 , el párrafo 1 del artículo 2 , el párrafo 1 del artículo 3, y los artículos 15, 16, 20 y 27 del Acuerdo sobre los Aspectos de los Derechos de Propiedad Intelectual relacionados con el Comercio; los párrafos 1 y 2 del artículo 2 del Acuerdo sobre Obstáculos Técnicos al Comercio; y el párrafo 4 del artículo III del Acuerdo General de Aranceles y Comercio de 1994. El Grupo Especial trató los casos en conjunto, salvo el iniciado por Ucrania cuya competencia quedó sin efecto el 30 de mayo de 2016, puesto que el demandado no solicitó que se reanuden los trabajos luego de la suspensión tramitada doce meses antes.

El Grupo Especial distribuyó su informe el 28 de junio de 2018, entendiendo que las alegaciones de los actores no lograron probar que las medidas adoptadas por Australia en relación al empaquetado genérico de los cigarrillos fueran contrarias a las normas indicadas, no pronunciándose respecto a aquellas que no presentaron argumentos.

\footnotetext{
${ }^{175}$ Uruguay es tercero en los cinco casos.

${ }^{176}$ Diferencia DS434 cuya fecha de solicitud de consultas es el 13 de marzo de 2012.

${ }^{177}$ Diferencia DS435 cuya fecha de solicitud de consultas es el 4 de abril de 2012.

${ }^{178}$ Diferencia DS441 cuya fecha de solicitud de consultas es el 18 de julio de 2012.

${ }^{179}$ Diferencia DS458 cuya fecha de solicitud de consultas es el 3 de mayo de 2013.

${ }^{180}$ Diferencia DS467 cuya fecha de solicitud de consultas es el 20 de setiembre de 2013.
} 
Asimismo, puntualmente para Cuba el Grupo Especial decide que la isla no demostró la existencia de restricciones que impliquen una reducción sustancial del valor de los habanos y del sello de garantía de Cuba. El informe del Grupo Especial fue adoptado por el Órgano de Solución de Diferencias el 27 de agosto de 2018 para Cuba e Indonesia, mientras que Honduras y República Dominicana procedieron a la apelación con fecha 19 de julio de 2018 y 23 de agosto de 2018 respectivamente. El informe del Órgano de Apelación no ha sido emitido a la fecha de cierre de este trabajo.

\subsection{Caso Urbaser contra Argentina}

\subsubsection{Argentina, la crisis de 2001 y los arbitrajes de inversiones}

La posición de Argentina frente al régimen de solución de controversias inversor-Estado merece un análisis particular que excede los objetivos de este trabajo. Argentina es el Estado más demandado de América del Sur y del mundo en el régimen de solución de controversias inversor-Estado, con 60 disputas conocidas en su contra al 31 de diciembre de $2018^{181}$. Asimismo, Argentina es el Estado con mayor número de TBI en vigor de Sudamérica: 50 de los 61 acuerdos que firmó. La experiencia argentina en el régimen de solución de controversias inversor-Estado se ve marcada por una trilogía: 1) apego al consenso de Washington (1990-2002), 2) abandono de la práctica de celebrar nuevos TBI pero manteniendo la membresía en el CIADI y renovando los TBI en vigor (2003-2015), 3) regreso a la firma de TBI (2016 - presente).

La primer etapa coincide con los dos períodos presidenciales de Carlos Menem (19891999) durante las cuales se celebraron 53 de los 60 acuerdos firmados por Argentina. Esta práctica es motivada por el proceso privatizador, especialmente de los servicios públicos, la creencia ideológica en las ventajas de una mayor apertura de la economía, la tendencia internacional a la firma de TBI impulsada por el consenso de Washington, y la necesidad de contar con instrumentos jurídicos que brindaran mayor seguridad jurídica a los inversores extranjeros (Beltramino, 2010, 21). Es por este último punto que 41 de los TBI que se celebraron en este período no exigen el agotamiento de los recursos internos, marcando un claro alejamiento de la tradicional doctrina Calvo.

La crisis económico social de diciembre de 2001 y las medidas tomadas para paliar sus consecuencias negativas marcan el punto de quiebre de la etapa de apego al consenso de Washington. Dentro del paquete de medidas adoptadas se encuentra la Ley de

${ }^{181}$ Datos del Investment Policy Hub de la UNCTAD. Fecha de consulta: 21 de abril de 2019. 
Emergencia Pública y Reforma del Régimen Cambiario (Ley 24.561 sancionada el 6 de enero de 2002), que al dejar sin efecto las cláusulas de ajuste en dólares u otras monedas extranjeras y las cláusulas basadas en parámetros internacionales, como ser los índices de precios de otros Estados, y convierte a pesos los precios y tasas incluidos en contratos públicos (Fernández Alonso, 2013: 58, Ricaurte Herrera, 2012: 156) derivó en 37 demandas en contra del Estado.

Dichos reclamos fueron realizados, en general, por empresas privatizadoras de servicios públicos y se centraron en la ausencia de trato justo y equitativo, trato menos favorable que el otorgado a inversores nacionales y expropiación indirecta, en función de la sanción de las mencionadas normas internas. Constituyen ejemplos de esta situación los casos Azurix Corp. (CIADI caso número ARB/01/12, sector aguas y saneamiento, condena por 165,2 millones de dólares más intereses ${ }^{182}$ ), CMS Gas Transmission Company (CIADI caso número ARB/01/8, sector distribución de gas, condena por 133,2 millones de dólares más intereses ${ }^{183}$ ), Urbaser S.A. y Consorcio de Aguas Bilbao Bizkaia, Bilbao Biskaia Ur Partzuergoa (CIADI caso número ARB/07/26, sector aguas y saneamiento) ${ }^{184}$. Este último se analizará en el siguiente apartado.

La segunda etapa, que abarca los años 2003 y 2015 (gobiernos de Néstor Kirchner y Cristina Fernández), expone un cambio estructural en el país, abandonándose la tendencia a la negociación y ratificación de nuevos TBI. Únicamente se modificó el tratado con Panamá en 2004 y entró en vigor el tratado con Senegal en 2010 que tenía pendiente la ratificación de la nación africana. Sin embargo, se renovaron todos los TBI cuya cláusula de vigencia estaba a término y Argentina se mantuvo como miembro del CIADI. No es una etapa de quiebre, sino de mantenimiento del status quo sin profundizarlo, en otros términos, siguiendo la teoría de los regímenes internacionales Argentina se mantiene como miembro del régimen de solución de controversias inversor-Estado pero con condiciones.

Sin perjuicio de lo anterior, durante el período 2003-2015 en la Cámara de Diputados se presentaron diversos proyectos que sí proponen el abandono del régimen, ya sea mediante la denuncia del Convenio de Washington o los TBI en vigor o la declaración

\footnotetext{
${ }^{182}$ Laudo de fecha 14 de julio de 2006. Argentina solicita la anulación del mismo, la cual es rechazada en su totalidad por decisión del Comité ad hoc del 1 de setiembre de 2009.

${ }^{183}$ Laudo de fecha 12 de mayo de 2005. Argentina solicita la anulación del mismo, la cual es aceptada parcialmente por decisión del Comité ad hoc del 27 de setiembre de 2007, sin afectar el monto indemnizatorio.

${ }^{184}$ Un estudio particular de las controversias contra Argentina derivadas de la crisis de 2001 puede verse en Perrone (2008).
} 
de nulidad absoluta de las mencionadas normas ${ }^{185}$. El primer grupo de proyectos se fundamentó en: 1) las características de las cláusulas habitualmente incluidas en los TBI, en especial la cláusula de estabilidad, la cláusula paraguas y la $\mathrm{CNMF}^{186}$, y 2) la renuncia de soberanía relativa a la jurisdicción territorial de los tribunales nacionales, a favor del CIADI u otros tribunales arbitrales internacionales. El segundo grupo partía de una base diferente, consideraban que los TBI eran absolutamente nulos al colisionar con las disposiciones constitucionales que prevén la jurisdicción de los tribunales locales en todos los asuntos previstos en la Constitución Argentina (1994), como ser contraer empréstitos sobre el crédito de la Nación y arreglar el pago de la deuda interior y exterior de la Nación (artículos 75 incisos 4 y $7^{187}, 116^{188}$ y $117^{189}$ ), ya que son tratados con rango supralegal pero infraconstitucional ${ }^{190}$ (Costante, 2012).

Finalmente, la trilogía cierra con la llegada de Mauricio Macri al gobierno. En 2016 se retomó la práctica afín a los nuevos TBI, celebrándose tres acuerdos: con Qatar (2016), Emiratos Árabes Unidos (2018) y Japón (2018) ${ }^{191}$. La firma de un menor número de TBI que en la etapa menemista tiene una explicación pragmática: Argentina ya contaba con acuerdos en vigor con las principales economías del mundo. Es durante el gobierno macrista que el 8 de diciembre de 2016 es emitido el laudo en el caso Urbaser S.A. y

${ }^{185}$ En el primer grupo se encuentran, por ejemplo, los proyectos con número de trámite parlamentario 8 de 14 de marzo de 2011, 37 de 25 de abril de 2006, 3 de 3 de marzo de 2006, 52 de 13 de mayo de 2000, mientras que en el segundo grupo se incluye, por ejemplo, el proyecto con número de trámite parlamentario 182 de 14 de diciembre de 2012. Los proyectos llevan la firma de diputados de los siguientes partidos políticos: Movimiento Proyecto Sur, Partido Socialista, Soberanía Popular, Emancipación y Justicia, Concertación Entrerriana, Sí por la Unidad Popular, GEN, y/o ARI, según el caso.

${ }^{186}$ Es especialmente interesante el caso de la CNMF, dado que el TBI con Panamá prevé que "ninguna de las Partes Contratantes tomará directa o indirectamente medidas de expropiación o de nacionalización, ni ninguna otra medida similar" (artículo 3). Por efecto de la mencionada cláusula, esta disposición sería aplicable a todos los TBI que Argentina tiene en vigor.

${ }^{187}$ Artículo 75. "Corresponde al Congreso: 4. Contraer empréstitos sobre el crédito de la Nación. (...); 7. Arreglar el pago de la deuda interior y exterior de la Nación."

188 Artículo 116. "Corresponde a la Corte Suprema y a los tribunales inferiores de la Nación, el conocimiento y decisión de todas las causas que versen sobre puntos regidos por la Constitución (...)."”

189 Artículo 117. "En estos casos la Corte Suprema ejercerá su jurisdicción por apelación según las reglas y excepciones que prescriba el Congreso (...)."

${ }^{190}$ De acuerdo al artículo 74 inciso 22 de la Constitución Argentina (1994), los tratados tienen rango supralegal pero infraconstitucional, salvo aquellos enumerados a texto expreso a los que se les otorga jerarquía constitucional. Estos son: la Declaración Americana de los Derechos y Deberes del Hombre; la Declaración Universal de Derechos Humanos; la Convención Americana sobre Derechos Humanos; el Pacto Internacional de Derechos Económicos, Sociales y Culturales; el Pacto Internacional de Derechos Civiles y Políticos y su Protocolo Facultativo; la Convención sobre la Prevención y la Sanción del Delito de Genocidio; la Convención Internacional sobre la Eliminación de todas las Formas de Discriminación Racial; la Convención sobre la Eliminación de todas las Formas de Discriminación contra la Mujer; la Convención contra la Tortura y otros Tratos o Penas Crueles, Inhumanos o Degradantes; la Convención sobre los Derechos del Niño; Convención Interamericana sobre Desaparición Forzada de Personas; Convención sobre imprescriptibilidad de los crímenes de guerra y de los crímenes de lesa humanidad.

${ }^{191}$ Ninguno de ellos en vigor. 
Consorcio de Aguas Bilbao Biskaia, Bilbao Biskaia Ur Partzuergoa contra Argentina (caso CIADI número ARB/07/26). Los aspectos relevante para el binomio protección de inversiones-protección de derechos humanos se examinarán en el siguiente apartado.

\subsubsection{El arbitraje de inversiones y el derecho humano al agua}

Argentina es el Estado más demandado del mundo, alcanzando las 60 demandas como se indicara anteriormente. De estos casos, diez corresponden al sector aguas y saneamiento (véase tabla 9), siendo también el Estado más demandado del mundo en el sector. En otros términos, Argentina es el Estado que cuenta con más demandas que involucran directamente al derecho humano al acceso al agua potable y saneamiento reconocido explícitamente por la Resolución 64/292 de la Asamblea General de la $\mathrm{ONU}^{192}$ como "un derecho humano esencial para el pleno disfrute de la vida y de todos los derechos humanos" (punto 3). Previamente la Observación General número 15 del Comité de Derechos Sociales Económicos y Culturales ${ }^{193}$ había definido el derecho humano al agua como "el derecho de todos a disponer de agua suficiente, salubre, aceptable, accesible y asequible para el uso personal y doméstico” (punto 2). El núcleo duro del cuerpo normativo se completa con los artículos 11 y 12 del Pacto Internacional de Derechos sociales, económicos y culturales que refieren a un nivel de vida adecuado y el más alto nivel posible de salud física y mental, siendo al acceso al agua potable y saneamiento parte fundamental de estos.

Tabla 9: Disputas contra Argentina en el sector aguas y saneamiento

\begin{tabular}{|c|c|c|c|c|c|}
\hline $\begin{array}{c}\text { Nombre } \\
\text { abreviado }\end{array}$ & Inicio & Última decisión & TBI aplicable & Foro & Resultado \\
\hline $\begin{array}{c}\text { Vivendi contra } \\
\text { Argentina (I) }\end{array}$ & 1997 & $\begin{array}{c}2010 \\
\text { (Decisión sobre la } \\
\text { anulación) }\end{array}$ & $\begin{array}{c}\text { TBI Argentina- } \\
\text { Francia (1991) }\end{array}$ & CIADI & $\begin{array}{c}\text { Decidido a favor del } \\
\text { inversor. Monto: } 105 \\
\text { millones de dólares de } \\
\text { los 317 reclamados. }\end{array}$ \\
\hline $\begin{array}{c}\text { Azurix contra } \\
\text { Argentina (I) }\end{array}$ & 2001 & $\begin{array}{c}2009 \\
\text { (Decisión sobre la } \\
\text { anulación) }\end{array}$ & $\begin{array}{c}\text { TBI Argentina- } \\
\text { Estados Unidos } \\
(1991)\end{array}$ & CIADI & $\begin{array}{c}\text { Decidido a favor del } \\
\text { inversor. Monto: } 165,2 \\
\text { millones de dólares de } \\
\text { los 685 reclamados. }\end{array}$ \\
\hline
\end{tabular}

\footnotetext{
192 Texto disponible en: https://www.un.org/ga/search/view_doc.asp?symbol=A/RES/64/292\&Lang=S

193 Texto disponible en: https://www.escr-net.org/es/recursos/observacion-general-no-15-derecho-al-aguaarticulos-11-y-12-del-pacto-internacional
} 


\begin{tabular}{|c|c|c|c|c|c|}
\hline $\begin{array}{l}\text { Nombre } \\
\text { abreviado }\end{array}$ & Inicio & Última decisión & TBI aplicable & Foro & Resultado \\
\hline $\begin{array}{l}\text { Aguas } \\
\text { Cordobesas } \\
\text { contra } \\
\text { Argentina }\end{array}$ & 2003 & Sin datos & $\begin{array}{l}\text { TBI Argentina- } \\
\text { España (1991) } \\
\text { TBI Argentina- } \\
\text { Francia (1991) }\end{array}$ & CIADI & $\begin{array}{l}\text { Acuerdo de partes. } \\
\text { Monto: sin datos. } 112 \\
\text { millones de dólares } \\
\text { reclamados. }\end{array}$ \\
\hline $\begin{array}{l}\text { AWG contra } \\
\text { Argentina }\end{array}$ & 2003 & $\begin{array}{c}2015 \\
\text { (Laudo) } \\
\text { Procedimientos } \\
\text { posteriores en la } \\
\text { jurisdicción doméstica } \\
\text { de Estados Unidos }\end{array}$ & $\begin{array}{l}\text { TBI Argentina-Reino } \\
\text { Unido (1990) }\end{array}$ & $\begin{array}{c}\text { CIADI } \\
\text { (Reglas } \\
\text { UNCITRAL) }\end{array}$ & $\begin{array}{l}\text { Decidido a favor del } \\
\text { inversor. Monto: } 21 \\
\text { millones de dólares de } \\
\text { los 34,1 reclamados. }\end{array}$ \\
\hline $\begin{array}{l}\text { Azurix contra } \\
\text { Argentina (II) }\end{array}$ & 2003 & $\begin{array}{c}2012 \\
\text { (Orden de } \\
\text { discontinuación) }\end{array}$ & $\begin{array}{l}\text { TBI Argentina - } \\
\text { Estados Unidos } \\
\text { (1991) }\end{array}$ & CIADI & $\begin{array}{l}\text { Discontinuado. Monto: } \\
\text { sin datos. }\end{array}$ \\
\hline $\begin{array}{l}\text { Suez e } \\
\text { Interagua } \\
\text { contra } \\
\text { Argentina }\end{array}$ & 2003 & $\begin{array}{c}2018 \\
\text { (Decisión sobre la } \\
\text { anulación) }\end{array}$ & $\begin{array}{l}\text { TBI Argentina- } \\
\text { Francia (1991) } \\
\text { TBI Argentina- } \\
\text { España (1991) }\end{array}$ & CIADI & $\begin{array}{l}\text { Decidido a favor del } \\
\text { inversor. Monto: } 225,7 \\
\text { millones de dólares de } \\
\text { los } 257,7 \text { reclamados. }\end{array}$ \\
\hline $\begin{array}{l}\text { Suez y Vivendi } \\
\text { contra } \\
\text { Argentina (II) }\end{array}$ & 2003 & $\begin{array}{c}2017 \\
\text { (Decisión sobre la } \\
\text { anulación) }\end{array}$ & $\begin{array}{l}\text { TBI Argentina- } \\
\text { Francia (1991) } \\
\text { TBI Argentina- } \\
\text { España (1991) }\end{array}$ & CIADI & $\begin{array}{l}\text { Decidido a favor del } \\
\text { inversor. Monto: } 383,6 \\
\text { millones de dólares de } \\
\text { los } 834,1 \text { reclamados. }\end{array}$ \\
\hline $\begin{array}{l}\text { SAUR contra } \\
\text { Argentina }\end{array}$ & 2004 & $\begin{array}{c}2016 \\
\text { (Decisión sobre la } \\
\text { anulación) }\end{array}$ & $\begin{array}{l}\text { TBI Argentina- } \\
\text { Francia (1991) }\end{array}$ & CIADI & $\begin{array}{l}\text { Decidido a favor del } \\
\text { inversor. Monto: } 39,9 \\
\text { millones de dólares de } \\
\text { los 143,9 reclamados. }\end{array}$ \\
\hline $\begin{array}{l}\text { Impregilo } \\
\text { contra } \\
\text { Argentina (I) }\end{array}$ & 2007 & 2014 & $\begin{array}{l}\text { TBI Argentina-Italia } \\
\text { (1990) }\end{array}$ & CIADI & $\begin{array}{l}\text { Decidido a favor del } \\
\text { inversor. Monto: } 21,29 \\
\text { millones de dólares de } \\
\text { los } 119 \text { reclamados. }\end{array}$ \\
\hline $\begin{array}{l}\text { Urbaser y } \\
\text { CABB contra } \\
\text { Argentina }\end{array}$ & 2007 & $\begin{array}{c}2016 \\
\text { (Laudo) }\end{array}$ & $\begin{array}{l}\text { TBI Argentina- } \\
\text { España (1991) }\end{array}$ & CIADI & $\begin{array}{l}\text { Decisión que estableció } \\
\text { responsabilidades sin } \\
\text { determinar daños. No se } \\
\text { decide a favor del } \\
\text { inversor ni del Estado. } \\
\text { Monto reclamado: } 211,2 \\
\text { millones de dólares. }\end{array}$ \\
\hline
\end{tabular}

Fuente: Elaboración propia en base a datos del Investment Policy Hub de la UNCTAD. Fecha de consulta: 25 de agosto de 2019.

\subsubsection{El laudo del 8 de diciembre de 2017: ¿son los derechos humanos el as bajo la manga?}

En este marco, el caso Urbaser no constituye un caso más, ya que por primera vez un tribunal de inversiones introduce explícitamente el análisis del derecho humano al agua en atención a la demanda reconvencional presentada por Argentina. La controversia 
tiene como punto de partida la concesión del servicio de aguas y saneamiento del Gran Buenos Aires otorgada a inicios del año 2000 a Aguas del Gran Buenos Aires S.A., consorcio de capitales españoles. Con la crisis económica de 2001 y las medidas tomadas por el gobierno argentino a fin de mitigar sus efectos, especialmente aquellas vinculadas al cobro de las tarifas de los servicios públicos, los inversores extranjeros entendieron que perdieron la posibilidad de obtener ganancias justas y razonables y por tanto sus inversiones no eran recuperables (laudo, párrafo 96). En efecto, en ese momento comenzó un proceso de negociación entre inversores y el Estado a los efectos de revisar el contrato de concesión (2003-2005). Sin éxito para los inversores, la concesión fue terminada en julio de 2006.

Por consiguiente, los inversores extranjeros sostuvieron que el nuevo marco normativo constituyó una violación de las cláusulas de trato justo y equitativo y expropiación del TBI entre Argentina y España (artículos III y V) por tratarse de una modificación unilateral del contrato de concesión de manos del Estado (laudos, párrafos 559 y 951). En consecuencia, con fecha 1 de octubre de 2007 las empresas solicitaron el inicio de un arbitraje ante el CIADI. El tribunal ad hoc estuvo compuesto por Alan McLachlan (sucediendo a Ian Brownlie luego de su fallecimiento), Pedro Martínez-Fraga y Andreas Bucher (Presidente). A los efectos de este trabajo, el foco estará puesto no en la demanda de los inversores o su contestación o sino en la demanda reconvencional presentada por Argentina basada en el incumplimiento por parte de los inversores extranjeros del derecho humano al agua.

El tribunal entendió que tenía jurisdicción para decidir sobre la demanda reconvencional conforme al Convenio de Washington (artículos 25 y 46), el artículo X del TBI Argentina-España respecto a la solución de controversias inversor-Estado (laudo, párrafo 1155), y en seguimiento del artículo 46 del Convenio de Washington y la Regla de Arbitraje 40 numeral 2 del CIADI Argentina cumplió la exigencia de presentar la reconvención a más tardar en el memorial de contestación, ya que las partes no habían consensuado otro plazo o renunciado a ello (laudo, párrafo 1150). Asimismo, la demanda y la reconvención tenían el mismo nexo fáctico (la misma inversión) y jurídico (el Derecho Argentino y el contrato de concesión). Por tanto, no hizo lugar a las objeciones de los inversores.

Argentina afirmó que la obligación más importante de los inversores era "garantizar el acceso al agua potable y así garantizar un derecho humano básico" (laudo, párrafo 1157), estando previsto además en el marco regulatorio y el esquema protectorio del 
TBI, y en consecuencia reclamó daños correspondiente a inversiones que los inversores no realizaron (laudo, párrafo 1165) ${ }^{194}$. Las normas de Derecho Internacional en que basó la reconvención son la Declaración Universal de Derechos Humanos (1948), el Pacto Internacional de Derechos Económicos, Sociales y Culturales (1966) y la Resolución 64/292 de la Asamblea General de la ONU (2010). Las dos últimas normas fueron analizadas en el apartado anterior, respecto a la Declaración Universal es de interés la discusión sobre la responsabilidad de las empresas respecto a los derechos humanos. En este sentido, Argentina sostuvo

"La Declaración no incluye ninguna referencia sobre quién sería responsable por los derechos y obligaciones resultantes de ella. Sin embargo, su lectura deja en claro que dichas obligaciones no son vinculantes únicamente para los Estados. El Preámbulo establece expresamente que los deberes recaen tanto sobre las instituciones como sobre los individuos. El Artículo 1 establece que sus disposiciones son aplicables a todos los individuos, incluso en relaciones personales. El Artículo 30 declara que nada en la Declaración podrá interpretarse en el sentido de que confiere derecho alguno al Estado, a un grupo o a una persona, para emprender y desarrollar actividades o realizar actos tendientes a la supresión de cualquiera de los derechos y libertades allí proclamados. El Artículo 29 establece que toda persona tiene deberes respecto a la comunidad. Por lo tanto, las sociedades comerciales y las empresas internacionales se encuentran alcanzadas por las obligaciones resultantes del derecho internacional sobre los derechos humanos." (laudo, párrafo 1159).

La posición argentina es sólida y acorde a Derecho, más teniendo en cuenta la práctica en la ONU respecto a la responsabilidad de las empresas en materia de derechos humanos. Basta recordar el segundo de los tres pilares de 31 principios rectores sobre empresas y derechos humanos: proteger, esto es, la responsabilidad de las empresas de respetar los derechos humanos y de no producir impactos negativos por sus actividades. Asimismo, sigue la línea de razonamiento sobre las obligaciones empresariales por acciones transnacionales conforme al proyecto revisado del Instrumento jurídicamente vinculante para regular, en el marco del Derecho Internacional de los derechos humanos, las actividades de las empresas transnacionales y otras empresas (véase apartado 7.3). En efecto, en su preámbulo prevé que las empresas deben respetar los derechos humanos, especialmente evitando que sus actividades generen o contribuyan a generar consecuencias negativas sobre los derechos humanos, remediándose en caso de incumplimiento ${ }^{195}$

\footnotetext{
${ }^{194}$ Los daños reclamados en la demanda reconvencional ascienden a 191,5 o 80,9 millones de dólares, según el período que se tome en cuenta. En un escrito posterior Argentina propuso otra forma de cálculo que determinaría daños por 61,3 millones de dólares (laudo, párrafo 1166).

${ }^{195}$ En relación a las normas vinculadas a la protección de los derechos humanos y el acceso efectivo a los recursos jurisdiccionales y no jurisdiccionales para las víctimas, la obligación sigue siendo estatal, como en los principios rectores.
} 
Del análisis realizado por el tribunal se destacan dos elementos fundamentales. El primero es de tipo instrumental y tiene que ver con la aplicación de las condiciones más favorables enunciado en el artículo VII del TBI (CNMF). En este sentido, la disposición determina que si una cuestión regulada por el TBI también lo estuviera por otro tratado del que Argentina y España sean partes o por el Derecho Internacional General, se aplicarán las normas más favorables. Por tanto, en materia del derecho humano al agua resultan de aplicación las disposiciones del régimen jurídico autocontenido de derechos humanos (párrafo 1192), como había argumentado Argentina.

Por tanto, el segundo elemento a destacar tiene que ver con los derechos humanos per $s e$. El tribunal entendió que en el pasado existía un principio en Derecho Internacional que sostenía la carencia de subjetividad internacional de las empresas, principio que en este trabajo se discute conforme a lo expresado en el apartado 1.5.2. No obstante, el tribunal afirmó que nada en el TBI indica que una empresa inversora extranjera no pueda ser titular de obligaciones internacionales (párrafo 1194). En efecto, el Derecho Internacional evoluciona y como se indicara en el apartado 1.5.2, ya la CIJ ha sostenido que los sujetos son diferentes en características y naturaleza, por tanto la exigencia de los tres atributos tradicionales ${ }^{196}$ del Estado no es de aplicación para todos los sujetos.

Luego de analizar los instrumentos internacionales que incorporan el derecho humano al agua, pasó a examinar la titularidad de la obligación en torno a garantizar tal derecho. El quid de la resolución del tribunal está en la naturaleza de la obligación de garantizar el derecho humano al agua. Ni el TBI ni el Derecho Internacional General contienen una obligación de hacer cuyo titular sean las empresas inversoras que ingresan a la relación de suministro mediante un contrato. Por tanto es el contrato el instrumento que determina que la fuente de la obligación para la empresa, fruente de Derecho Doméstico y no el Derecho Internacional (laudo párrafos 1208 y 1210). El único titular de la obligación de hacer (garantizar el acceso al agua y saneamiento) es el Estado. Diferente sería el caso de una obligación de no hacer (abstenerse a determinada conducta). Dicha obligación puede ser aplicada de manera inmediata a los Estados, las personas físicas y otros particulares, extremo que no está presente en esta disputa (párrafo 1210).

Este último punto es de especial interés ya que el proyecto revisado del Instrumento jurídico vinculante sobre empresas y derechos humanos (véase apartado 7.3) no distingue entre obligaciones de hacer y obligaciones de no hacer respecto a la conducta

\footnotetext{
${ }^{196}$ Jus tractatum, jus legationem, locus standi.
} 
de las empresas. Tal vez la respuesta se encuentre en que la distinción del tribunal refiere a que los Estados deben proteger los derechos humanos, que podría interpretarse esencialmente como una obligación de hacer, y las empresas deben respetar los derechos humanos, que podría interpretarse como una obligación de no hacer. Sin embargo, esta distinción derivada de la lógica de los pilares de los principios rectores sobre empresas y derechos humanos, no es completamente correcta. Si bien una empresa debe de abstenerse de hacer actos que vulneren los derechos humanos, también debe prevenir o mitigar las consecuencias negativas de sus actividades sobre los derechos humanos (principios 13 y 19), conducta que implica obligaciones de hacer como no hacer.

Como explica el profesor Felipe Michelini ${ }^{197}$

"exigirles (a las empresas) solamente un no hacer no es suficiente para evitar la vulneración de derechos que hacen a la dignidad humana. En este sentido, es posible que ciertas conductas positivas sean debidas por las empresas, por ejemplo, en relación al trato dispensado a sus trabajadores o que el desarrollo de sus actividades no sea conducido en forma discriminatoria dentro de la comunidad en general" (comunicación personal, 28 de setiembre de 2019).

En esta línea vale recordar el artículo 30 de la Declaración Universal de Derechos Humanos que, con una redacción amplia respecto a los sujetos obligados indica, que "Nada en la presente Declaración podrá interpretarse en el sentido de que confiere derecho alguno al Estado, a un grupo o a una persona, para emprender y desarrollar actividades o realizar actos tendientes a la supresión de cualquiera de los derechos y libertades proclamados en esta Declaración". Por tanto, si se tiene en cuenta esta disposición, sumado a las resoluciones 14/5 y 21/5 del Consejo de Derechos Humanos, pensar en restringir las obligaciones de las corporaciones en materia de derechos humanos a obligaciones de no hacer, no sigue la tendencia de las normas de Derecho Internacional. Aun si se aplicara una interpretación restrictiva, es innegable la existencia de una práctica embrionaria a nivel de la ONU que puede cristalizarse en una costumbre internacional o dar lugar a nuevos instrumentos convencionales, de concretarse la celebración y entrada en vigor de un tratado vinculante. La consagración de dichas obligaciones en una norma escrita despejaría cualquier duda y fortalecería la protección de los derechos humanos.

\footnotetext{
197 Profesor de Derecho Humanos de la Universidad de la República, ex legislador de Uruguay. Entrevistado para este trabajo.
} 
En suma, en el laudo del 8 de diciembre de 2016 el tribunal decidió que Argentina había violado el trato justo y equitativo previsto en el TBI Argentina-España, pero no la condenó al pago de una indemnización ya que la mayoría de los supuestos de incumplimiento refieren al contrato de concesión y no al TBI. La demanda reconvencional de Argentina también es desestimada y los derechos humanos no resultaron ser el as bajo la manga. Aun así, la disputa pasará a la historia por la introducción al análisis de las obligaciones de las empresas en torno a los derechos humanos ${ }^{198}$. De este punto se derivan tres reflexiones, la primera es la relación de tensión entre el régimen de protección de derechos humanos y el régimen de protección de inversiones, aun cuando la regulación de los primeros sea considerada por el tribunal al laudar. Ejemplo de ellos son todas las controversias seleccionadas en este capítulo y el anterior y no exclusivamente el caso Urbaser.

Las diferencias entre ambos regímenes jurídicos autocontenidos es evidente. Como discute Echaide (2016), los derechos humanos son normas de naturaleza erga omnes (carácter objetivo, obligaciones del Estado frente a la comunidad internacional en su conjunto) a diferencia de las disposiciones derivadas de los TBI que son de carácter subjetivo al regular una relación bilateral en particular. La relación de las normas erga omnes frente a las demás normas se encuentra en términos de prioridad en su cumplimiento, no refiere a la validez. Diferente sería el caso si se consideran los derechos humanos como normas de jus $\operatorname{cogens}^{199}$, debate que excede los objetivos de este trabajo.

\footnotetext{
${ }^{198}$ Con anterioridad ya se había visto esta práctica en otros casos como Philip Morris contra Uruguay (Sur, 2017). Si bien el tribunal examina disposiciones relativas al Convenio Marco sobre control del Tabaco y reconoce el poder de policía del Estado de regular en materia de salud pública, no incorpora un enfoque de derechos humanos sino de poder regulatorio del Estado. En el laudo no hay una referencia a las obligaciones de los inversores en la materia, sino a que estos deben esperar que las medidas de control de tabaco que tomen los Estados sean cada vez más severas.

${ }^{199}$ Artículo 53 de la Convención de Viena sobre Derecho de los Tratados entre Estados (1969): “(...)Para los efectos de la presente Convención, una norma imperativa de derecho internacional general es una norma aceptada y reconocida por la comunidad internacional de Estados en su conjunto como norma que no admite acuerdo en contrario y que sólo puede ser modificada por una norma ulterior de derecho internacional general que tenga el mismo carácter."

La consecuencia respecto a los tratados impacta en su validez. Esto es, los tratados nacidos en contra de una norma de jus cogens serían absolutamente nulos y sus efectos deben borrarse hacia el pasado (ex tunc) en aplicación de los artículos 53 y 71 numeral 1 de la Convención de Viena sobre Derecho de los Tratados entre Estados. Si un tratado perfectamente válido estuviera en vigor al momento del surgimiento de una norma de una nueva norma de jus cogens, opera, en cambio, de una causal extrínseca de terminación (artículo 64). Por tanto, las partes no están obligadas a continuar cumpliendo con las disposiciones del tratado, los derechos, obligaciones y situaciones jurídicas anteriores a la norma de jus cogens superviniente pueden mantenerse pero sólo podrán mantenerse en el futuro si no se oponen a la nueva normas de jus cogens (efecto ex nunc) conforme al artículo 71 numeral 2.
} 
Como explica Echaide (2016b), ambas categorías (erga omnes y jus cogens) no son idénticas, sin embargo ambas hacen referencia a "un orden público internacional que no puede ser dejado de lado por la simple voluntad de los Estados debido a los valores y principios fundamentales básico sobre los cuales se asienta la existencia misma de la persona humana y la comunidad internacional" (Echaide, 2016b: 146).

Por tanto, frente a este orden público internacional, el tribunal del caso Urbaser interpreta que no existen obligaciones cuyos titulares sean las empresas inversoras extranjeras, ya que en el derecho humano al agua se está frente a una obligación de hacer. Cabe preguntarse, en consecuencia, si es el tipo de obligación el elemento que determina su inclusión como parte de ese orden público internacional, no así su prioridad como obligación erga omnes. La respuesta debe ser negativa en atención a que el régimen internacional de protección de los derechos humanos no plantea distinción alguna según el tipo de obligación de que se trate.

La segunda reflexión refiere a las posibilidades de introducir la defensa de los derechos humanos en el arbitraje inversor-Estado. En los demás casos analizados en el capítulo 4 y 5 de este trabajo su incorporación había sido en base a escritos amici curiae presentados por organizaciones de la sociedad civil (caso Pac Rim contra El Salvador) $\mathrm{u}$ organizaciones internacionales especializadas (caso Philip Morris contra Uruguay). Las demandas reconvencionales constituyen otra instancia para hacer valer la carta de derechos humanos como reafirmación de la autonomía del Estado y defensa de su soberanía, al justificar medidas tomadas en ejercicio válido de estas. Además le confiere al Estado una posibilidad de solicitar indemnización por los daños ocasionados por el inversor extranjero, lo cual es una mejora notable frente a las dos posibilidades anteriores. De esta manera la maquinaría del arbitraje de inversiones podría volverse en contra de los propios inversores (Abel, 2018).

Finalmente, la tercera reflexión pone foco en si son los tribunales de inversiones con sus características actuales el foro más adecuado para decidir en materia de derechos humanos, aun cuanto su respeto sea el fundamento de una demanda reconvencional. Si, como expresa Echaide (2016: 91), el planteo se presenta en términos binarios: derecho al agua - derecho del inversor, el CIADI no parece ser el foro más adecuado por no tratarse de un sistema judicial creado para interpretar el Derecho Internacional General, ni ofrece un tratamiento equilibrado a razón de su materia. El desafío, entonces, es encontrar o crear un mecanismo jurisdiccional adecuado para entender tanto respecto a los derechos como a las obligaciones de los inversores (Perrone, 2019: 21). 


\subsection{Caso Bear Creek contra Perú}

\subsubsection{Perú: la minería en Santa Ana y la resistencia social}

El arbitraje de la minera canadiense Bear Creek Mining Company tuvo su origen en el marco del proyecto de explotación minera de plata en Santa Ana, región ubicada en Puno (Perú) a 50 kilómetros de la frontera con Bolivia. En virtud de la ubicación de los yacimientos estos no podrían ser adquiridos ni poseídos por extranjeros, conforme al artículo 71 de la Constitución Peruana (1993). Dicha norma prevé como única excepción "el caso de necesidad pública expresamente declarada por decreto supremo aprobado por el Consejo de Ministros conforme a ley”.

Entre mayo y noviembre de 2004, la señora Villavicencio ${ }^{200}$ presentó seis solicitudes de autorización de explotación minera en Santa Ana y suscribió con el Gobierno los respectivos contratos de opción para el caso que las autorizaciones fueran concedidas (laudo, 30 de noviembre de 2017, párrafos 128 y 129). En base a una restructuración de la división geográfica de la zona, siete concesiones mineras fueron otorgadas a la señora Villavicencio en abril y junio de 2006, y posteriormente en diciembre del mismo año Bear Creek solicitó la adquisición de las concesiones de Villavicencio e inició el proceso tendiente a la obtención del decreto supremo a los efectos de explotar la zona (párrafos 132 y 140). La cronología se completa con la aprobación de la Evaluación de Impacto Social y Ambiental del Proyecto de Exploración Minera en setiembre de 2007 y la emisión del decreto supremo 083-2007-EM que declaró el proyecto Santa Ana de utilidad pública. En consecuencia autorizó a Bear Creek a adquirir, poseer y operar los derechos derivados de la concesión (párrafos 147 y 149).

El proyecto tuvo fuerte oposición social desde 2008, suscitándose situaciones de violencia y protesta de las comunidades indígenas directamente afectadas por la explotación minera, especialmente por su impacto en el agua potable y la tierra. Bear Creek realizó talleres de información con las comunidades indígenas locales en los Distritos de Kelluyo y Huacullani (comunidades de Huacullani, Ingenio, Challocolo, Cóndor de Aconcagua, Ancomarca, Arconuma) y alcanzó algunos acuerdos que caducaron. Sin perjuicio de lo anterior, desde 2011 la oposición a la minería aumentó, los manifestantes solicitaron la cancelación del proyecto Santa Ana así como la

\footnotetext{
${ }^{200}$ En el proceso arbitral las partes controvierten la relación laboral de la mencionada con la empresa inversora.
} 
protección del Cerro Khapia (tierra sagrada para los aymaras), y se suscitaron huelgas y hechos de violencia, desde bloqueos de carreteras incluidas las carreteras de acceso a Bolivia, y enfrentamiento con las fuerzas policiales, conociéndose a las acciones de resistencia social con el nombre del "aymarazo".

En este marco de confrontación, el Gobierno decidió emitir un conjunto de normas relativas a la minería en Perú. En primer lugar el decreto supremo 032-2011-EM (24 de junio de 2011) derogó el anterior decreto supremo 083-2007-EM que establecía la declaratoria de necesidad pública para que una persona física o jurídica extranjera pudiera adquirir o poseer minas en una zona a 50 kilómetros de la frontera. En consecuencia, Bear Creek perdió el requisito fundamental para poder operar en Santa Ana. Dos normas completaron el elenco: 1) el decreto supremo 033-2011-EM, que suspendió las concesiones mineras en el departamento de Punto durante 36 meses y respecto a las ya otorgadas se realizaría una nueva ronda de consultas a las comunidades locales en cumplimiento al Convenio 169 de la OIT sobre pueblos indígenas y tribales; y 2) el decreto supremo 034-2011-EM, que establece que no serían autorizadas nuevas concesiones sin consulta previa con las comunidades locales.

En el entendido que el decreto supremo 032-2011-EM constituyó una expropiación indirecta de su inversión en el proyecto minero de Santa Ana (artículo 812 y anexo 812.1 del TLC Canadá-Perú), el 11 de agosto de 2014 Bear Creek solicitó el inicio de un arbitraje ante la Secretaria General del CIADI con base en el artículo 824 del mencionado TLC. Por tanto solicita que el Gobierno Peruano proceda a la restitución plena o el equivalente monetario de los daños y perjuicios por el incumplimiento del TLC (al menos 522,2 millones de dólares) ${ }^{201}$. A pesar de las excepciones de jurisdicción presentada por Perú (ausencia de derechos de Bear Creek sobre la reclamación y actuación ilegal o de mala fe), el tribunal compuesto por Michael C. Pryles, Philippe Sands y Karl-Heinz Böckstiegel (presidente) consideró que era competente para entender en el caso.

\subsubsection{La discusión sobre la licencia social}

El arbitraje bajo análisis es de particular interés porque en su marco se estudia la obligación del Estado de consultar a los pueblos indígenas afectados por una explotación minera, el nexo causal entre la no obtención de una licencia social para el

\footnotetext{
${ }^{201}$ A nivel interno, la empresa presentó una acción de amparo a la que finalmente desistió.
} 
desarrollo de dicha actividad y la existencia y el grado de responsabilidad de la empresa frente al conflicto social creciente. En este sentido el caso Bear Creek es una demostración directa de la fragmentación del Derecho Internacional y cómo la ausencia de normas expresas en los acuerdos de inversiones o con capítulos de inversiones, como el TLC Canadá-Perú, pueden determinar situaciones de inseguridad y falta de certeza jurídica ante la colisión de dos regímenes autocontenidos: régimen de protección de inversiones y régimen de protección de los derechos humanos, específicamente derechos de los pueblos indígenas.

Dentro del conjunto normativo que regula los derechos de los pueblos indígenas se destacan el Convenio 169 de la OIT (1989) y más recientemente la Declaración de la ONU sobre pueblos indígenas (2007). Ninguno de los textos contiene un concepto a texto expreso de licencia social. En primer lugar, el artículo 6 del Convenio 169 establece la obligación de los Estados de consultar a "los pueblos interesados, mediante procedimientos apropiados (...) cada vez que se prevean medidas legislativas o administrativas susceptibles de afectarles directamente" (literal a), indicándose que las consultas deben realizarse de buena fe (literal c). La norma se complementa por el artículo 15 relativo a la participación de los pueblos indígenas en la utilización, administración y conservación de los recursos naturales. En este sentido, si el Estado es propietario de recursos minerales, este debe establecer o mantener consultas con los pueblos interesados

\footnotetext{
"a fin de determinar si los intereses de esos pueblos serían perjudicados, y en qué medida, antes de emprender o autorizar cualquier programa de prospección o explotación de los recursos existentes en sus tierras. Los pueblos interesados deberán participar siempre que sea posible en los beneficios que reporten tales actividades, y percibir una indemnización equitativa por cualquier daño que puedan sufrir como resultado de esas actividades. " (numeral 2)
}

El artículo 32 de la Declaración de la ONU da un paso más en la obligación del Estado, puesto que establece la existencia de una obligación de resultado. El Estado debe celebrar consultas y cooperar de buena fe "a fin de obtener su consentimiento libre e informado antes de aprobar cualquier proyecto que afecte a sus tierras o territorios $y$ otros recursos, particularmente en relación con el desarrollo, la utilización o la explotación de recursos minerales, hídricos o de otro tipo" (numeral 2). Similar redacción tiene la Declaración americana sobre los derechos de los pueblos indígenas de la Organización de Estados Americanos (OEA) al consagrar el derecho al desarrollo, específicamente en su artículo XXIX numeral 4. 
Las disposiciones de las declaraciones de la ONU y la OEA tienen una redacción clara en el sentido de establecer que el consentimiento libre e informado es requisito previo para aprobar proyectos mineros. En el Convenio de la OIT no existe tal obligación, como explica Ovejas (2017: 11), "la obtención de un acuerdo o del consentimiento no es un requisito para que la consulta sea válida, sino que se exige únicamente que la consulta tenga el objetivo o propósito de alcanzarlo". En otras palabras, la norma de la OIT no establece un derecho de veto de las comunidades afectadas sino que obliga a los Estados a realizar la consulta, independientemente del resultado. No obstante, debe destacarse que en los tres instrumentos jurídicos la obligación de consultar, con o sin acuerdo según el caso, tiene como titular al Estado receptor de la inversión la obligación sea esta de medios (consultar) o de resultado (obtener un acuerdo).

Puntualmente en el caso Bear Creek, el tribunal entendió que el elemento relevante en el proceso era si el Estado puede probar que legalmente era exigida una mayor divulgación y que su ausencia determinó o contribuyó al conflicto social, de modo de justificar la sanción del decreto supremo 032-2011-EM que derogó la concesión a la empresa (párrafo 408). En otras palabras, si existió nexo causal entre la ausencia de una licencia social y dicho decreto supremo. Siguiendo el laudo del 18 de abril de 2013 en el caso Abengoa contra México (caso CIADI número $\mathrm{ARB}(\mathrm{AF}) / 09 / 2)^{202}$, el tribunal entendió que es necesario probar el nexo causal para determinar la falta de responsabilidad del Estado, extremo que en este caso no se cumple (párrafo 411). Por el contrario, el tribunal consideró que Perú conocía y respaldó las actividades de divulgación y contacto de Bear Creek y no puede a posteriori afirmar que dichas actividades fueron insuficientes (párrafo 412). En suma la derogación del decreto supremo 083-2007-EM constituyó una expropiación indirecta violatoria del TLC Canadá-Perú.

Es destacable que el escrito amicus curiae presentado por la Asociación de Derechos Humanos y Medio Ambiente de Puno (DHUMA) y el Dr. López ${ }^{203}$ afirma que "no existe legitimidad, ni confianza, ni consentimiento de las partes. El conflicto se inició por la falta de transparencia y desinformación por parte de Bear Creek" (amicus curiae, 10 de junio de 2016: 17). Asimismo, el 80\% de los miembros de las comunidades de los distritos más afectados habla como lengua madre el aymara, entiende español pero su manejo no es fluido, particularmente en lo que refiere a terminología técnica (laudo, párrafo 219). El tribunal no tiene en cuenta este dato en su

\footnotetext{
${ }^{202}$ Texto disponible en: https://www.italaw.com/sites/default/files/case-documents/italaw3187.pdf

${ }^{203}$ Texto disponible en: https://www.italaw.com/sites/default/files/case-documents/italaw7515.pdf
} 
resolución, a pesar de no ser un dato menor en el entendido que una comunicación efectiva comienza por el uso de un código (lenguaje) en común. Tomando en cuenta las sentencias de la Corte Interamericana de Derechos Humanos, previas a la Declaración de la OEA, puede cuestionarse si la consulta fue adecuada, accesible e informada dado los talleres y acciones de contacto no fueron realizadas en idioma aymara ${ }^{204}$.

Cabe destacar que el régimen de protección de inversiones en general y el régimen de solución de controversias inversor-Estado en particular no prevén la participación de las comunidades locales. Aun si el Derecho Internacional de las Inversiones es relacional, esto es, define y regula las relaciones entre los actores involucrados y afectados por la inversión extranjera, las comunidades locales son un "actor ausente" (Perrone, 2019: $16)^{205}$. Su participación se ha limitado a la presentación de amici curiae durante un proceso arbitral, ya que no tienen locus standi ante los tribunales de inversiones. Sin embargo, en disputas vinculadas a minería, petróleo y aguas las comunidades locales han jugado un rol central en el origen o desarrollo de la controversia. Ejemplo de lo anterior son la controversias bajo análisis, así como Chevron contra Ecuador y Aguas del Tunari contra Bolivia, respectivamente.

Siguiendo la lógica del proyecto revisado del Instrumento jurídicamente vinculante para regular, en el marco del Derecho Internacional de los derechos humanos, las actividades de las empresas transnacionales y otras empresas (véase apartado 7.3), son los Estados los titulares de la obligación de proteger los derechos humanos. Sin embargo, deben contemplarse los límites al espacio de política pública, por tanto es posible afirmar junto a Perrone que

\begin{abstract}
"It is true that international investment law does not prevent states from regulating to protect local community interests or hinder local courts from finding foreign investors responsible for damages. But there are limitations to this because states need to create a good investment climate, attract foreign investors and, ultimately, face financial constraints to compensate foreign investors, as where they were aware of the foreign investor's misconduct." 206 (Perrone, 2019: 21).
\end{abstract}

\footnotetext{
${ }^{204}$ Del análisis de los casos Pueblo Indígena Kichwa de Sarayaku contra Ecuador; Comunidad Garifuna de Punta Piedra y sus miembros contra Honduras; Comunidad Garifuna de Triunfo de la Cruz y sus miembros contra Honduras, Ovejas (2017: 13) infiere que los requisitos exigidos por la Corte Interamericana de Derechos Humanos respecto a la consulta son que se realice con carácter previo, de buena fe, con el objetivo de alcanzar un acuerdo, sea adecuada, accesible e informada.

${ }^{205}$ Desde una visión holística, en un trabajo anterior Perrone (2016) afirma que el régimen internacional de protección de inversiones abarca mucho más que los derechos de los inversores y los poderes regulatorios del Estado, también incluye el derecho de participación, los derechos de propiedad locales y los valores de las comunidades.

206 "Es verdad que el Derecho Internacional de las Inversiones no impide que los Estados regulen para proteger los intereses de las comunidades locales ni impiden que los tribunales locales juzguen que los inversores extranjeros son responsables de los daños. Pero hay limitaciones a esto porque los Estados necesitan crear un buen clima de inversión, atraer inversores extranjeros y, en última instancia,
} 


\subsubsection{El laudo y la opinión parcialmente disidente}

Sin tener en cuenta la responsabilidad de la empresa en relación al conflicto social, el laudo del 30 de noviembre de 2017 determinó la responsabilidad del Estado Peruano por incumplimiento del TLC Perú-Canadá: expropiación indirecta de la licencia minera y debido proceso durante las reuniones previas a la promulgación del decreto supremo 032-2011-EM. Para el cálculo del monto indemnizatorio, el tribunal consideró que era de aplicación el Derecho Internacional General ya que el TLC no contenía una cláusula que estableciera una regla de indemnización (laudo, párrafo 595). Desestimó el mecanismo propuesto por la actora de calcular los daños en base a la rentabilidad prevista conforme al método de flujo de caja descontado dado que se trata de una actividad productiva en etapa inicial. En consecuencia, estableció que la indemnización debía coincidir con los costos hundidos, estos es, 18,2 millones de dólares más intereses correspondientes al monto invertido entre el decreto supremo 083-2007-EM y el decreto supremo 032-2011-EM (párrafos 661 y 716 ) 207.

Al laudo de la mayoría se adjunta la opinión parcialmente disidente del árbitro Sands, que destaca por su análisis de la responsabilidad del inversor extranjero en relación a la obtención de la licencia social conforme al Convenio 169 de la OIT. Sands manifestó su acuerdo respecto a que Bear Creek tenía una inversión protegida por el TLC CanadáPerú y que conforme al decreto supremo 032-2011-EM, esta fue objeto de una expropiación indirecta en violación de los términos del TLC. No obstante, dada la situación de conflicto social creciente, Perú no tenía "ninguna otra opción más que actuar de alguna forma para proteger el bienestar de sus ciudadanos; sin embargo, el Consejo de Ministros disponía de otras alternativas menos draconianas, incluso la suspensión del Decreto 083-2007 en lugar de la revocación.” (opinión disidente, párrafo 2).

En vista de lo anterior, Sands disiente respecto a la cuantía de los daños, ya que el motivo del colapso del proyecto Santa Ana radicó en que Bear Creek no logró obtener una licencia social de las comunidades directa o indirectamente afectadas (párrafo 6), citando los artículos 13 y 15 del Convenio de la OIT. El Convenio no impone una

enfrentar restricciones financieras para compensar a los inversores extranjeros, incluso cuando son conscientes de la mala conducta del inversor extranjero." (Traducción propia).

${ }^{207}$ A esto deben sumarse los costos de arbitraje de Perú y el 75\% de los costos devengados por Bear Creek, totalizando 6 millones de dólares más intereses (párrafo 736). 
obligación directa a los inversores sino a los Estados, sin embargo la opinión parcialmente disidente recuerda el laudo en el caso Urbaser contra Argentina (caso CIADI ARB/07/26) cuyo tribunal reconoció que en materia de derechos humanos las obligaciones de los Estados son complementadas por "una obligación de todas las partes, tanto públicas como privadas, de no realizar actividades tendientes a suprimir tales derechos" (laudo, 8 de diciembre de 2016, párrafo 1199). Sin embargo, en esa controversia en particular el tribunal entendió que no existía otra obligación, distinta a la general y de carácter positivo (hacer), por parte de las empresas inversoras que proviniera del TBI o el Derecho Internacional

Luego de analizar con qué comunidades indígenas se desarrollaron las acciones de divulgación y contacto, y considerando que estas no abarcan la totalidad de comunidades del pueblo aymara que se manifestaron desde 2008 contra el proyecto Santa Ana, el árbitro Sands concluyó que Bear Creek también tuvo responsabilidad en los hechos que llevaron al Gobierno a aprobar el decreto supremo 032-2011-EM. Por tal motivo, en consecuencia era de la idea que indemnización por daños que recae sobre Perú debía reducirse a la mitad (párrafo 39). En este mismo sentido se había pronunciado en 2016 el tribunal del caso Copper Mesa Mining contra Ecuador (caso CPA número 2012-2) en el entendido que el monto indemnizatorio debía reducirse un $30 \%$ en base a la reputación adquirida por la empresa en relación a intimidación, amenazas, decepción, falsedad y violencia ante los miembros de la comunidad local ${ }^{208}$. En suma, frente a la fragmentación del Derecho Internacional General, dos regímenes jurídicos autocontenidos colisionan en este caso: el régimen de protección de inversiones y el régimen de protección de los derechos humanos, específicamente los derechos de los pueblos originarios. En el análisis del conflicto social, el foco del laudo de la mayoría está puesto en el nexo causal entre el conflicto social y la obtención, o no, de la licencia social a los efectos de establecer la responsabilidad del Estado. No se realiza una ponderación del derecho de los pueblos indígenas a ser consultados de manera adecuada, accesible e informada frente a la responsabilidad del Estado de proteger una inversión. Desde una visión integral del Derecho Internacional, la resolución de una controversia no debería dejar de lado una parte del conjunto de normas aplicables al caso. La situación es de mayor gravedad si se descarta la

\footnotetext{
${ }^{208}$ Laudo disponible en: https://www.italaw.com/sites/default/files/case-documents/italaw7443.pdf
} 
aplicación de disposiciones de derechos humanos, como manifiesta la opinión parcialmente disidente de Sands ${ }^{209}$.

\subsection{Conclusiones capítulo 5}

En este capítulo se examinaron tres controversias que aportan ejemplos de la fragmentación del Derecho Internacional y colisión entre regímenes jurídicos autocontenidos. Se optó por casos que involucraran diferentes derechos para contrastar con el capítulo anterior que el foco se puso en el derecho a un medioambiente sano o principio de protección del medioambiente, de manera de ilustrar la amplitud del impacto del régimen de protección de inversiones en las medidas estatales tomadas en seguimiento de normas del régimen de protección de derechos humanos.

Así como los derechos involucrados son diferentes (derecho a la salud, derecho al agua, derechos de los pueblos indígenas), también lo es el resultado del arbitraje: una disputa a favor del Estado (Philip Morris contra Uruguay), otra donde se determina la responsabilidad estatal pero sin condena por daños (Urbaser contra Argentina), y la última favorable a la empresa (Bear Creek contra Perú). Esta división en partes iguales, útil a los efectos metodológicos, no replica los datos estadísticos disponibles. En efecto, el 35,7\% de los laudos han sido favorables al Estado, 28,7\% favorables al inversor extranjero, 2,2\% fueron decididos a favor de ninguna de las dos partes, $22,8 \%$ terminados por acuerdo de partes, y 10,6\% discontinuados ${ }^{210}$.

Una lectura rápida de estos números puede ser peligrosa y generar una idea errada de la realidad. El Estado que acuerda con un inversor la terminación del proceso arbitral igualmente tiene gastos administrativos y de asesoramiento profesional que enfrentar, incluso si ha sido vencedor puede no serlo por la totalidad de los gastos incurridos. Adicionalmente, el factor tiempo implica un desgaste para el aparato estatal y un gastos presupuestal que podría haberse dedicado a otros rubros, independientemente de la posibilidad de recuperación a futuro.

Por tanto, antes de ingresar en el análisis de la hipótesis que guía este capítulo, es importante hacer dos reflexiones. La primera reflexión con respecto a los tres casos

\footnotetext{
209 En esta línea de pensamiento puede verse el análisis realizado por el Centro Europeo para los Derechos Constitucionales y Humanos (ECCHR) del rechazo del amicus curiae presentado en el marco del caso CIADI número ARB/10/15, Bernhard von Pezold y otros contra Zimbabue. Este afirma que la interdependencia de ambos regímenes y que cualquier laudo que no contemple las normas de derechos humanos estaría legalmente incompleto (ECCHR, 2012).

${ }^{210}$ Datos del Investment Policy Hub de la UNCTAD. Fecha de consulta: 4 de setiembre de 2019.
} 
seleccionados es que el arbitraje inversor-Estado no es indiferente para los Estados involucrados, más aun cuando las medidas controvertidas refieren a temas de derechos humanos y se trata de Estados en desarrollo. En efecto, el desbalance de poder entre el Estado y el mercado señalado por Strange (2001) puede verse con claridad en el cercenamiento o limitación de la soberanía interna y la soberanía regulatoria, como se analizará en el capítulo 7. En efecto, el inicio de los arbitrajes tienen como fin determinar la responsabilidad del Estado por su propia actuación, que si bien puede tener límites, se encuentra dentro del ejercicio válido del derecho de regular no reconocido en los laudos (casos Bear Creek o Urbaser). De aquí la importancia de la afirmación de Perrone (2019: 17) respecto al rol de los tribunales arbitrales al dar forma y por tanto definir el derecho de regular.

En el caso de Uruguay, a posteriori de un laudo favorable en el caso Philip Morris, en los años 2018 y 2019 queda de manifiesto el impacto de la acción de las tabacaleras sobre la autonomía estatal. En concreto, el impacto se visualiza en el término de la parálisis regulatoria en Nueva Zelanda, en función de la reintroducción al Parlamento del proyecto de sobre empaque neutro de cigarrillos, en cumplimiento de las normas internacionales. Asimismo, casos como el de Philip Morris contra Uruguay o Philip Morris contra Australia marcaron huella en el sistema internacional a nivel de nuevos tratados con la excepción de las medidas de control del tabaco. Por ejemplo el CPTPP (véase apartado 3.3), la enmienda del TLC Singapur-Australia y el TBI Singapur Kazajistán.

La segunda reflexión debe realizarse en relación a la presentación de un enfoque de derechos humanos durante los procedimientos arbitrales. ¿Cuál es el mejor canal para que los Estados hagan valer la defensa de los derechos humanos en contraposición a las normas de protección de inversiones? La presentación de escritos amicus curiae por parte de organizaciones no gubernamentales o internacionales, si bien brinda información desde ámbitos de conocimiento y experiencia en la materia, no tiene un peso suficiente para equilibrar la voz silenciada de los verdaderos afectados: la población cuyos derechos el Estado protege.

Sobre este punto, el profesor José Augusto Fontoura Costa ${ }^{211}$ considera que debería analizarse en la reforma del régimen de solución de controversias inversor-Estado es precisamente la participación de amici curiae, por ejemplo la "creación de un órgano

\footnotetext{
${ }^{211}$ Profesor de Derecho Internacional de la Universidad de San Pablo. Entrevistado para este trabajo.
} 
independiente para el control de la participación de amici curiae, un tipo de ombudsperson internacional, quizás dentro de la institucionalidad del CIADI nominado independientemente de los Estados" (comunicación personal, 23 de setiembre de 2019). Si bien dicho control no garantizaría per se que las voces de los verdaderos afectados sean escuchadas o que instituciones con conocimiento técnico en la materia puedan brindar su opinión calificada, daría mayor transparencia a la hora de la aceptación o rechazo de los escritos.

Ahora bien, la presentación de una demanda reconvencional puede ser una opción de balance para el Estado, particularmente por la posibilidad de solicitar una indemnización por daños. Aun así, el acuerdo en el cual se enmarque la controversia debe permitir el empleo de este instituto. En este sentido, el profesor José Augusto Fontoura Costa afirma que "un ensanchamiento de la competencia del tribunal para demandas reconvencionales es dificil de justificar en la teoría del arbitraje” si el acuerdo no lo establece de manera expresa. En consecuencia considera que no es el camino más adecuado para hacer valer la protección de los derechos humanos. Sin embargo, el profesor reconoce que, en el supuesto de aceptarse la generalización de las demandas reconvencionales, "como los costos del litigio podrían elevarse, es esperable una reducción de las ventajas para el reclamante y este verse desincentivado a iniciar procesos arbitrales” (comunicación personal, 23 de setiembre de 2019).

Por su parte, el profesor Alejandro Garro ${ }^{212}$ es de la idea que "cualquier vía es idónea para canalizar la protección de los derechos humanos, aunque la mejor reivindicación es la que persigue remedios más eficaces". En este sentido reflexionó que un "tribunal supranacional encargado de proteger los derechos humanos suele estar en mejor posición jurídica e institucional para proteger los derechos humanos que un tribunal ad hoc atendiendo reclamos patrimoniales" (comunicación personal, 23 de setiembre de 2019).

De concretarse el texto del Instrumento jurídicamente vinculante para regular, en el marco del Derecho Internacional de los derechos humanos, las actividades de las empresas transnacionales y otras empresas, se sumaría una nueva opción, ya que el documento prevé que los afectados puedan reclamar ante la jurisdicción doméstica del Estado donde se produjeron los actos u omisiones o del domicilio de la persona que los haya cometido. Si bien es un paso en el balance del relacionamiento empresa

\footnotetext{
${ }^{212}$ Profesor e Investigador de la Escuela Parker de Derecho Extranjero y Comparado de la Universidad de Columbia. Entrevistado para este trabajo.
} 
transnacional-Estado en materia de solución de controversias, tiene el inconveniente de tratarse de una jurisdicción doméstica y no un tribunal internacional, con la fortaleza jurídico-institucional que destaca Garro. Este punto será analizado en el apartado 7.3.

Retomando la hipótesis que guía este capítulo y el anterior respecto a la extensión de la regulación estatal en derechos humanos y el consecuente inicio de controversias inversor-Estado, las disputas analizadas confirman parcialmente tal afirmación. En dos de los casos los Estados profundizaron sus regulaciones para proteger el derecho a la salud pública (medidas de control de tabaco respecto al empaquetado de los cigarrillos en Philip Morris contra Uruguay) y el medioambiente (prohibición de actividades mineras en los páramos en Bear Creek). Asimismo, Bear Creek presenta un elemento adicional: el valor de la voz de las comunidades locales afectadas por el proyecto minero. Finalmente, el caso Urbaser contra Argentina es sustancialmente diferente, porque el Estado no avanza en materia de protección del derecho humano al agua per se, sino que afirma la obligación de la empresa concesionaria de cumplir con este. El laudo, aunque desestima la demanda reconvencional en materia de derechos humanos, es de relevancia porque por primera vez un tribunal de inversiones examina las obligaciones en torno al derecho humano al agua.

Sin perjuicio de lo anterior, en los tres casos examinados el cuestionamiento del inversor refiere a la extensión de la regulación estatal, pero no exclusiva ni excluyentemente en materia de derechos humanos. Esto sucede en las disputas de Urbaser que el inversor cuestiona medidas de carácter económico-financiero y es el Estado el que introduce la carta de derechos humanos mediante la reconvención. Del mismo modo, aunque con menor incidencia, en Bear Creek el inversor cuestiona medidas de carácter medioambiental pero se introduce indirectamente la consulta vinculante (o no) a los pueblos indígenas.

En consecuencia, en este capítulo se arriba a una conclusión similar a la del capítulo anterior: el inicio de los procesos arbitrales por parte de inversores extranjeros en disputas que involucran derechos humanos es motivado por la extensión de la regulación estatal en cualquier materia. 


\section{Conclusiones del círculo 2}

El segundo círculo que compone esta investigación contrastar la hipótesis número 2: "La extensión de la regulación estatal lleva a las empresas transnacionales a iniciar controversias inversor-Estado que cuestionan el avance de los Estados en medidas de mayor protección de derechos humanos". Se seleccionaron seis controversias para ser analizadas, y más de diez controversias vinculadas. Todas involucran a Estados de Latinoamérica y la UE, agregándose a El Salvador para presentar elementos contrafácticos. En cuanto al marco temporal, se seleccionaron disputas cuya fecha de registro fuera posterior a 2007 (año que da inicio al marco temporal de este trabajo), priorizándose los casos registrados en el último decenio (2009-2019).

A los efectos de un mejor análisis de las seis controversias, se decidió agruparlas en dos categorías. La primera categoría tuvo como centro las disputas vinculadas al derecho a vivir en un medioambiente sano y equilibrado (en tándem con los principios de soberanía permanente sobre los recursos naturales y autodeterminación). La segunda categoría, por su parte, incluyó temas nuevos en el arbitraje de inversiones: derecho a la salud pública, derecho al agua y saneamiento y derechos de los pueblos indígenas.

Del examen realizado surgen tres conclusiones fundamentales. Las empresas transnacionales han ganado espacios de poder en el régimen de solución de controversias inversor-Estado, que da lugar a que estas demanden a los Estados receptores de la inversión. En consecuencia, los tribunales arbitrales ad hoc se comportan como órganos de contralor externo de los actos u omisiones estatales, aun en caso de ejercicio válido del poder de regular. Este elemento, que ha sido señalado por la UNCTAD desde el año 2003, determina un punto de inflexión en el sistema que ha dado lugar a los cambios planteados en el círculo número 1, especialmente cuando los temas involucrados refieren a derechos humanos. Asimismo, su defensa comienza a perfilar un nuevo concepto de soberanía que se analizará en el círculo número 3.

La segunda conclusión es que el objeto de los arbitrajes de inversiones examinados no refiere en exclusividad a medidas de avance en materia de derechos humanos. Aun en situaciones de retroceso, el cuestionamiento del cambio normativo por parte del inversor extranjero determina el inicio de un proceso arbitral. El caso Masdar y los otros 46 casos contra España en el sector de energías renovables son un ejemplo de esta problemática. Incluso en las demás disputas estudiadas se introducen elementos en 
materia de derechos humanos por parte del Estado (caso Urbaser contra Argentina) o son indicados en opiniones disidentes como factores que deberían haberse tenido en cuenta para reducir la condena (caso Bear Creek).

La tercera conclusión retoma las reflexiones del capítulo 5 respecto a los canales existentes para hacer valer, o incluso hacer oír, la defensa de los derechos humanos. Siendo el rol de los amici curiae muy débil, el caso Urbaser demuestra que el uso del instituto de la demanda reconvencional es el canal más viable en la actualidad, siempre que las normas aplicables lo permitan. En el futuro, el Instrumento vinculante en materia de derechos humanos y empresas podrá brindar otras posibilidades, que de mantenerse el texto del borrador actual, será la jurisdicción doméstica. En cualquiera de los casos el camino por recorrer aún es largo.

En suma, teniendo en consideración lo anteriormente examinado, la segunda hipótesis de este trabajo es refutada dado que la extensión de la regulación estatal lleva a las empresas transnacionales a iniciar controversias inversor-Estado que cuestionan el avance de los Estados en medidas en cualquier materia. Incluso en materia de derechos humanos, las medidas cuestionadas son tanto de avance como de retroceso (suspensión, eliminación total o parcial). 
Círculo 3: ¿Transición hacia un nuevo concepto de soberanía? 


\section{Capítulo 6: El espacio de política pública como base de la soberanía}

\subsection{Aspectos preliminares}

El tercer círculo que completa esta investigación busca responder la pregunta: ¿ha evolucionado el concepto de soberanía hacia una nueva definición, que parte de supuestos diferentes a los que propone Krasner, explicativa de los cambios en el régimen de solución de controversias inversor-Estado? De ser así, ¿qué características tiene y en qué se fundamenta? En consecuencia, se toma como hipótesis "El concepto de soberania estatal ha evolucionado hacia una nueva definición que se construye desde la defensa del espacio de política pública, generando cambios en las instituciones internacionales: régimen de solución de controversias inversor- Estado (proceso desde el interior al exterior del Estado)".

Las dimensiones referidas en la hipótesis son el espacio de política pública y la construcción de instituciones internacionales. El círculo 3 se estructuró en dos partes. La primera parte está dedicada al espacio de política pública, el análisis de si el camino recorrido por la UE responde a una defensa del espacio de política pública regional y pretende construir una nueva institucionalidad en materia de solución de controversias inversor-Estado (capítulo 6). La segunda parte se focaliza en las diferentes aristas del concepto en transición de soberanía, el momento histórico en el que se manifiesta: la crisis de la globalización y el multilateralismo, y el proyecto revisado del Instrumento jurídicamente vinculante para regular, en el marco del Derecho Internacional de los derechos humanos, las actividades de las empresas transnacionales y otras empresas como ejemplo de intento de reequilibrar el régimen (capítulo 7).

En el presente capítulo, siguiendo a Sornarajah (2015) se parte del estudio de las cuatro fases de la evolución del régimen de protección de inversiones, comprensivo del régimen de solución de controversias inversor-Estado: fase formativa o inicial, fase de universalización, fase de cambio neoliberal y fase actual. En segundo lugar se examina el concepto de espacio de política pública, su introducción al debate, su erosión o condicionamiento por los tratados que conforman el entramado jurídico del régimen (UNCTAD, 2003). El capítulo cierra con la presentación de la situación de la UE respecto a los arbitrajes intra-UE, como ejemplo de defensa del espacio de política pública regional. 


\subsection{Evolución del régimen de protección de inversiones hacia el reconocimiento de la necesidad de un espacio de política pública}

El régimen de protección de inversiones, que comprende al régimen de solución de controversias inversor-Estado, surge de la necesidad de brindar protección jurídica de fuente internacional a los inversores extranjeros, de manera independiente y/o acumulativa a la protección que pudiera brindarle cada Estado desde su Derecho Doméstico. Por tanto, se trata de una construcción originalmente hegemónica desde dos centros de poder: Estados Unidos y Europa, con el fin de proteger las inversiones de las empresas de su nacionalidad en el resto del mundo, especialmente los Estados en desarrollo. Como se indicara en el apartado 1.2.3., el principio fundamental del régimen, la promoción y protección de la inversión extranjera, y los derivados: 1) trato nacional; 2) trato justo y equitativo; 3) garantía y compensación por expropiación; 4) garantía de libre traspaso de fondos y transferencia de capitales y ganancias al exterior; 5) solución de controversias inversor-Estado mediante la prórroga de jurisdicción al arbitraje internacional, pudiéndose considerar a este último como un régimen en sí mismo dadas sus características particulares.

Siguiendo a Sornarajah (2015), el régimen de protección de inversiones ha pasado por cuatro fases: formativa, universalización, cambio neoliberal y actualidad. En cada fase el autor identifica fuerzas en pugna que forman, universalizan, construyen o destruyen el régimen internacional de protección de inversiones. La UNCTAD estructura la evolución del régimen en cuatro etapas que varían mínimamente con el planteo del mencionado autor, por tanto en cada una se indicarán las coincidencias y diferencias.

La fase inicial o formativa puede situarse previamente a la celebración del primer TBI en 1959 y el inicio de los procesos de descolonización en la ONU. En este régimen en gestación participaban exclusivamente Estados de América del Norte y América del Sur, dado que en el resto del mundo los flujos de inversión extranjera se daban en el marco de procesos coloniales (Sornarajah, 2015: 32). La característica fundamental en materia de solución de controversias inversor-Estado se presenta entre la puja entre dos ideas contrarias respecto al trato de los extranjeros: la protección diplomática sin restricciones, propulsada especialmente desde Estados Unidos, y la doctrina Calvo, propulsada principalmente desde América Latina. La etapa inicial coincide en gran medida con la era de infancia del régimen, como la denomina la UNCTAD, (década del cincuenta a 1964) (UNCTAD, 2015: 121). 
La segunda etapa, que Sornarajah (2015) denomina fase de universalización (1959 1990) tiene como centro la pugna entre la fórmula Hull ${ }^{213}$, relativa a la expropiación y debida compensación, apoyada por Estados Unidos y sus aliados Europeos, y la universalización de la doctrina Calvo junto a la defensa de la soberanía permanente sobre los recursos naturales y la creación de un nuevo orden económico de manos de América Latina y otros Estados en desarrollo ${ }^{214}$. Es por esto que la UNCTAD (2015: 122) denomina a esta fase como la era de la dicotomía y plantea su inicio con dos hitos que muestran un sistema fracturado en dos: la celebración del Acuerdo de Washington constitutivo del CIADI (1964) y el consecuente "no de Tokio" de los Estados Latinoamericanos junto a Filipinas e Irak en seguimiento de la doctrina Calvo (véase apartado 2.2.1).

La segunda fase, si bien cristaliza a nivel global las características del sistema, muestra un número reducido de TBI celebrados (véase gráfica 3) y si el análisis se hace extensivo a otros acuerdos internacionales con disposiciones en materia de inversiones, los resultados siguen la misma tendencia (véase gráfica 4). En relación a las controversias registradas, es en esta fase que se presentó la primera en la historia del régimen (véase gráfica 5), el caso AAPL contra Sri Lanka (caso CIADI número $\mathrm{ARB} / 87 / 3)$ del año 1987.

\footnotetext{
${ }^{213}$ Conforme a la nota del Secretario de Estado de Estados Unidos, Cornell Hull, de fecha 21 de Julio de 1938, una expropiación debe ser indemnizada de forma pronta, adecuada y efectiva. Esto es, que no existan demoras injustificadas en su pago (pronta), que el monto sea equivalente al valor total expropiado conforme al valor de mercado al momento de la expropiación (adecuada) y en una moneda convertible (efectiva) (Nikièma, 2013: 9).

${ }^{214}$ Estos dos últimos basados en las resoluciones de la Asamblea General de la ONU 1803 (XVII) del 14 de diciembre de 1962 y Resolución 3201 (S-VI) del 1 de mayo de 1974.
} 
Gráfica 3: Número de TBI celebrados por década (total de Estados del mundo)

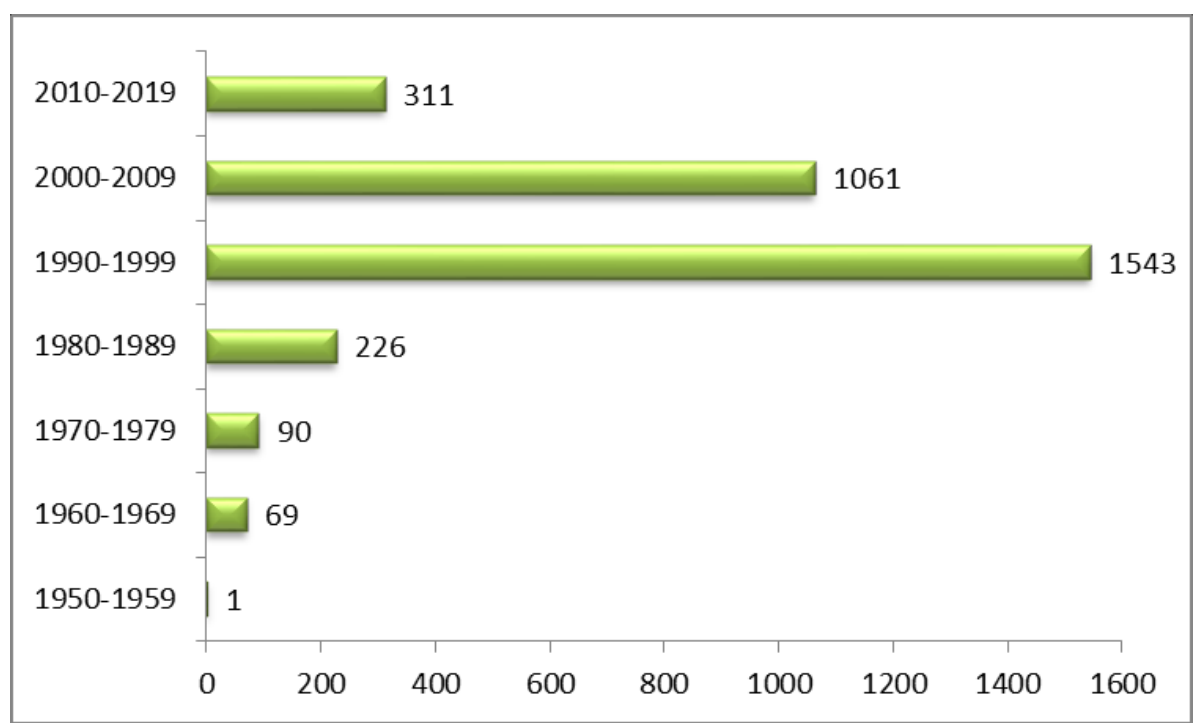

Fuente: Elaboración propia en base a datos del Investment Policy Hub de la UNCTAD, actualizados al 31 de julio de 2019. Fecha de consulta: 8 de setiembre de 2019

Gráfica 4: Número de acuerdos internacionales de inversiones celebrados por década (total de Estados del mundo)

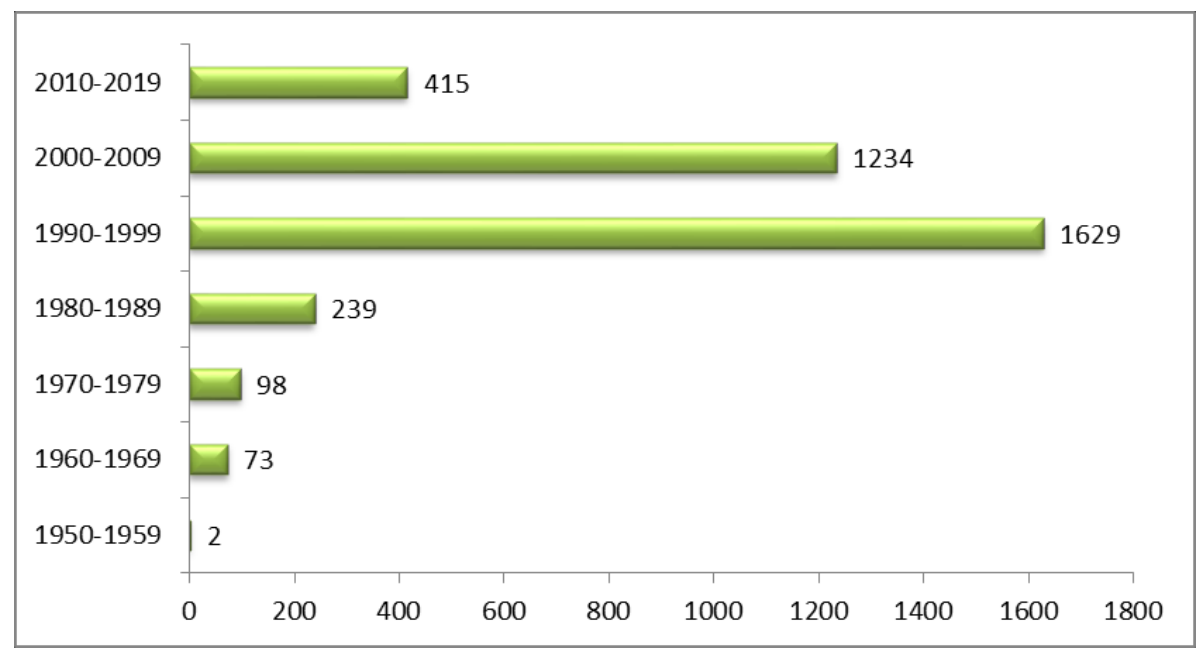

Fuente: Elaboración propia en base a datos del Investment Policy Hub de la UNCTAD, actualizados al 31 de julio de 2019. Fecha de consulta: 8 de setiembre de 2019 
Gráfica 5: Número de controversias conocidas según año de inicio

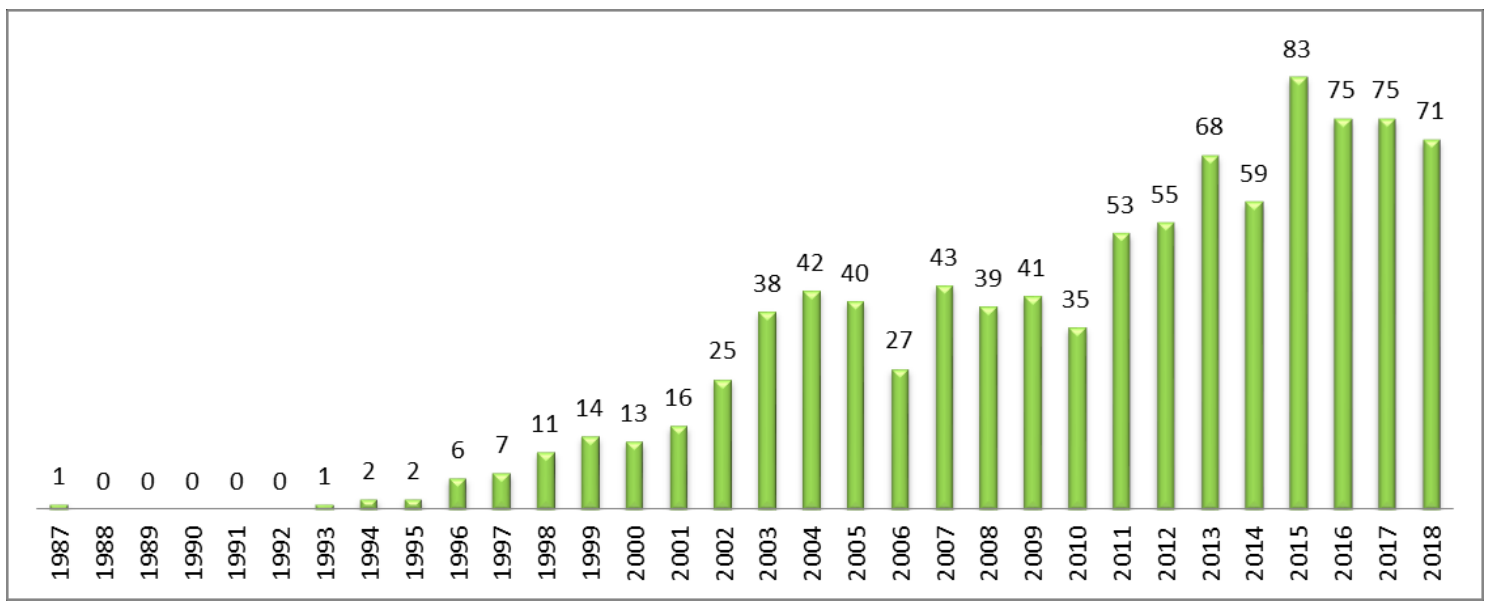

Fuente: Elaboración propia en base a datos del Investment Policy Hub de la UNCTAD, actualizados al 31 de diciembre de 2018. Fecha de consulta: 8 de setiembre de 2019

La tercera fase coincide con el auge de las políticas neoliberales a nivel global que toman a occidente como modelo de gobernanza y se desarrolla entre 1990 y 2004 (Sornarajah, 2015: 32). La UNCTAD denomina a esta etapa la era de la proliferación y marca su inicio en la década de los noventa y su fin en 2007. Este período se acuna en el consenso de Washington, que dentro de sus diez puntos propulsa la apertura a inversiones extranjeras directa, y genera el clima propicio para la construcción de un entramado de 3000 acuerdos de inversiones que forman la red básica del régimen de protección de inversiones actual.

Como explica Cecilia Olivet ${ }^{215}$ en esta etapa se desarrollan las denominadas "bodas masivas", esto es, rondas de negociación de TBI, organizadas por la UNCTAD por regiones: América del Sur, África francófona, etc. Esta práctica se desarrolla hasta el año 2005, fecha que coincide con el retiro de Karl. P. Sauvant como Director de la División de Inversiones de la UNCTAD (Cecilia Olivet, comunicación personal, 14 de octubre de 2019). Coincidentemente, también es este el momento de ingreso de los Estados Sudamericanos al régimen, con la celebración de TBI y la adhesión al Convenio de Washington como principales vías de entrada.

En consecuencia, es la etapa en que se celebra el mayor número de acuerdos de inversiones (aproximadamente el 70\%), tanto a nivel bilateral, como regional y multilateral. Se destacan el Tratado de la Carta de la Energía (1994) a nivel europeo y una serie de acuerdos con disposiciones relativas a inversiones en el marco de la OMC

\footnotetext{
${ }^{215}$ Investigadora del Transnational Institute. Entrevistada para este trabajo.
} 
(1994): el Acuerdo General sobre Comercio de Servicios (GATS por su sigla en inglés), el Acuerdo sobre Medidas en materia de Inversiones relacionadas con el Comercio y el Acuerdo sobre los Aspectos de los Derechos de Propiedad Intelectual relacionados con el Comercio.

Gracias a una interpretación extensiva de sus cláusulas, especialmente el trato justo y equitativo, da lugar a un aumento casi constante en el número de demandas presentadas por inversores extranjeros (véase gráfica 5). Cabe destacar que durante esta fase tiene lugar la crisis económica de Argentina (2001), cuyas medidas paliatorias fueron el germen de 37 demandas y llevaron a Argentina a ser el Estado más demandado del mundo ${ }^{216}$ con 60 demandas al 31 de diciembre de $2018^{217}$.

Ahora bien, a nivel de la gobernanza del sistema se da un punto de inflexión. A fines de esta fase, mediante el "Informe sobre las inversiones en el mundo" del año 2003, la UNCTAD introduce al debate el impacto del arbitraje inversor-Estado sobre el espacio de política pública de los Estados. De esta manera comienza a visualizarse que las demandas o amenazas de demandas tienen como resultado un condicionamiento del espacio de política pública, tema que se analizará en profundidad en el siguiente apartado.

Este aspecto constituye un hito de la etapa actual ya que por primera vez una de las instituciones vinculadas a la gobernanza del régimen identifica una falencia que debe ser considerada a la hora de celebrar nuevos acuerdos internacionales. En efecto, Sornarajah (2015: 39) identifica como punto de quiebre para el avance a la fase actual la celebración de "TBI balanceados", entre los cuales el autor cita el modelo de Estados Unidos del año 2004. Si bien es una práctica que empieza a gestarse, el reconocimiento del espacio de política pública y por ende el derecho de regular en determinadas áreas (principalmente medioambiente, seguridad y salud) se desarrolla con más fuerza y solidez años después.

La fase actual es la que presenta la lucha entre la continuación de la fase neoliberal y la resistencia al neoliberalismo a fin que el régimen no proteja exclusivamente a la inversión extranjera (Sornarajah, 2015), y condicione el espacio de política pública. Es en este sentido que se puede visualizar el segundo hito de la fase actual: el retiro de Bolivia del CIADI en 2007. Bolivia es el primer Estado en denunciar el Convenio de

\footnotetext{
${ }^{216}$ Para un análisis de los arbitrajes de inversiones a consecuencia de la crisis argentina véase: Fernández Alonso (2013), Ricaurte Herrera (2012), Perrone (2008).

${ }^{217}$ Conforme a datos del Investment Policy Hub de la UNCTAD. Fecha de consulta: 27 de setiembre de 2019.
} 
Washington y emprender un proceso de terminación de los TBI que mantenía en vigor. La presencia del primer disidente constituye un hito que marca una resistencia clara al régimen por parte de un Estado que pertenecía a este, presentando vestigios del modelo relacional de las relaciones internacionales en el marco de un sistema que es mayoritariamente institucional.

El tercer hito del período lo constituye el aumento de las demandas. Durante la fase actual la tendencia de crecimiento en el número de controversias registradas continúa en ascenso, aproximadamente el $80 \%$ del total de controversias conocidas fueron iniciadas a posteriori del año 2004. El mayor pico se da en el año 2015, destacándose los arbitrajes contra España en el sector de energías renovables (19 de 83 casos registrados $)^{218}$. Las crisis económicas, como la de España (2008-2014) y Argentina (2001) actúan como catalizadores de las demandas dado que las medidas adoptadas para paliar sus efectos regulan áreas que afectan a los inversores, sean medidas vinculadas a avances o retrocesos en materia de derechos humanos como se concluyera en el círculo 2. Estas críticas se suman a la tradicional de falta de transparencia en el sistema, que se buscó resolver mediante la celebración de la Convención de las Naciones Unidas sobre la Transparencia en los Arbitrajes entre Inversionistas y Estados en el Marco de un Tratado (2014), que con el depósito de tres ratificaciones entró en vigor el 18 de octubre de $2017^{219}$.

Estos tres hitos tienen un impacto directo en la posición de los Estados respecto al régimen de protección de inversiones en general y el de solución de controversias inversor-Estado en particular. Como se explicara para el caso de Sudamérica (véase el apartado 2.2.2 de este trabajo), en una investigación anterior se construyó una tipología que agrupa a los Estados del continente en tres conjuntos: miembros, disidentes y externos siguiente a la teoría de los regímenes internacionales (Bas Vilizzio, 2017). Para este trabajo, dado que se partió de un recorte geográfico más amplio que abarca a los Estados Sudamericanos, miembros de la UE y otros cuyo análisis se incluye en este trabajo para aportar elementos contrafácticos (El Salvador, Sudáfrica, India), se elaboró una tipología que congrega a los Estados en cuatro grupos: conforme a si son parte o no del régimen de solución de controversias inversor-Estado y la existencia o no de cambios en su posición respecto al régimen.

\footnotetext{
${ }^{218}$ Ejemplo de esta problemática es el caso Masdar analizado en el apartado 4.4 de este trabajo.

${ }^{219}$ La convención tiene 23 Estados signatarios y al 27 de setiembre de 2019 fue ratificada por Camerún, Canadá, Gambia, Mauricio y Suiza. El impacto en el régimen es relativo dado el escaso número de Estados parte.
} 
La tipología, que se sintetiza en la ilustración 4, permite agrupar a los Estados bajo análisis en: 1) miembros: los Estados que son parte del régimen y no presentaron cambios en su posición (figura residual); 2) confrontadores: Estados que sin abandonar el régimen presentan cambios en su posición original, especialmente mediante la propuesta de creación de un régimen alternativo o paralelo o buscan un escaso empleo del actual (ejemplo: India con el modelo de TBI de 2016, la UE respecto a los arbitrajes intra-UE más especialmente los 22 miembros que firmaron la declaración del 15 de enero de 2019 y el acuerdo plurilateral del 24 de octubre del mismo año ${ }^{220}$ ); 3) externos: Estados que históricamente se ubicaron fuera del régimen (ejemplo: Brasil); 4) disidentes: Estados que fueron parte del régimen y cambiaron su posición al abandonarlo (ejemplo: Bolivia, Ecuador y Venezuela, y más cercano a los externos pero con características de disidente está Sudáfrica al no haber firmado o adherido al Convenio de Washington).

Ilustración 4: Tipología de Estados según su posición en torno al régimen de solución de controversias inversor-Estado

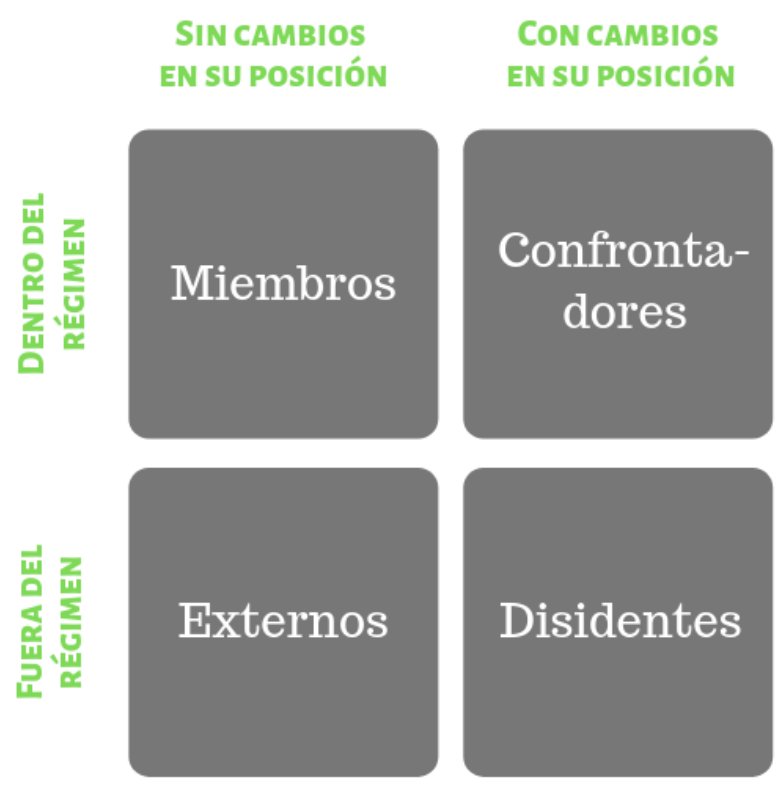

Fuente: Elaboración propia.

El reclamo de un espacio de política pública, sea a nivel nacional o regional, es parte de los cuestionamientos que motivan los movimientos respecto a las posiciones tradicionales ante el régimen (confrontadores) o la ausencia férrea de Brasil en el mismo

\footnotetext{
${ }^{220}$ Se examinará en profundidad en el siguiente apartado.
} 
(externo). Es por este motivo que en el siguiente apartado se examinará cuál es el lugar del espacio de política pública dentro del régimen de solución de controversias inversorEstado, para, en el siguiente apartado, pasar al estudio de la situación de la UE como confrontador que defiende su espacio de política pública regional.

\section{3. ¿Hay un lugar para el espacio de política pública?}

\subsubsection{El reconocimiento del espacio de política pública condicionado}

Como se indicara en el marco teórico de este trabajo, a nivel de la UNCTAD, el "Informe sobre las inversiones en el mundo" del año $2003^{221}$ analiza por primera vez el impacto del régimen de protección de inversiones sobre el espacio de política nacional, marcando la posible tensión entre la liberalización del mercado y la necesidad de los Estados de regular para maximizar los beneficios y minimizar los riesgos de la apertura (Ghiotto, 2017: 69). El reconocimiento del impacto de los acuerdos de inversiones pone en evidencia el desafío que implica para los Estados, particularmente aquellos en desarrollo, lograr un balance entre la liberalización económica y las políticas de desarrollo sostenible (Ghiotto, 2017: 65, 69).

Por tanto, la defensa del espacio de política pública resulta fundamental, especialmente en lo que respecta a la solución de controversias inversor-Estado, régimen en el cual entra en juego el cuestionamiento de las medidas tomadas en su marco. En un menor nivel de abstracción, el derecho de regular es el poder que tiene el Estado de limitar libertades particulares con el fin de proteger un bien jurídico superior: el interés público. En definitiva, los dos conceptos en tensión son la estabilidad (en cuanto a la protección de la inversión extranjera) y la flexibilidad (en cuanto a la protección del espacio de política pública del Estado).

En este sentido, es importante recordar la opinión disidente del Juez Roberts en la sentencia de la Suprema Corte de Justicia de Estados Unidos de fecha 2 de diciembre de 2013, a posteriori del laudo del caso BG Group contra Argentina (arbitraje ad hoc según las Reglas de arbitraje de la UNCITRAL), que con claridad afirma que "by acquiescing to arbitration, a state permits private adjudicators to review its public

\footnotetext{
${ }^{221}$ Si bien el marco temporal de este trabajo es 2007-Presente, en este apartado se amplía la mirada por la relevancia que tiene que una de las instituciones de la gobernanza del régimen identifique la erosión del espacio de política pública.
} 
policies and effectively annul the authoritative acts of its legislature, executive, and judiciary"222 (página 10) 223 .

Asimismo, dos leading cases lo han reconocido de manera expresa: Parkerings Companient AS contra Lituania (caso CIADI ARB/05/8) y Philip Morris contra Uruguay (caso CIADI ARB/10/7), el último ya analizado en el apartado 5.2 de este trabajo. Respecto al laudo en el caso Parkerings Companient AS contra Lituana ${ }^{224}$, el tribunal concluye que, a excepción de la existencia de cláusulas de estabilización, el inversor debe tener en cuenta que el ordenamiento jurídico en el cual invierte evoluciona como consecuencia del derecho de regular de los Estados, por tanto es esperable que existan modificaciones normativas durante el tiempo en que se desarrolle una inversión. El límite opera en el ejercicio de este derecho de manera discriminatoria o injusta. Específicamente afirma que

It is each State's undeniable right and privilege to exercise its sovereign legislative power. A State has the right to enact, modify or cancel a law at its own discretion. Save for the existence of an agreement, in the form of a stabilisation clause or otherwise, there is nothing objectionable about the amendment brought to the regulatory framework existing at the time an investor made its investment. As a matter of fact, any businessman or investor knows that laws will evolve over time. What is prohibited however is for a State to act unfairly, unreasonably or inequitably in the exercise of its legislative power. ${ }^{225}$ (párrafo 332)

Una interpretación más restrictiva puede verse en el caso ADC contra Hungría (caso CIADI número ARB/03/16 $)^{226}$, en cuyo laudo establece que

\begin{abstract}
It is the Tribunal's understanding of the basic international law principles that while a sovereign State possesses the inherent right to regulate its domestic affairs, the exercise of such right is not unlimited and must have its boundaries. As rightly pointed out by the Claimants, the rule of law, which includes treaty obligations, provides such boundaries. Therefore, when a State enters into a bilateral investment treaty like the one in this case, it becomes bound by it and the investment protection obligations it undertook therein must be honoured rather than be ignored by a later argument of the State's right to regulate ${ }^{227}$. (párrafo 423)
\end{abstract}

222 "Al aceptar el arbitraje, un Estado permite a los jueces privados revisar sus politicas públicas y anular efectivamente los actos autorizados de sus Poderes Legislativo, Ejecutivo y Judicial" (Traducción propia)

${ }^{223}$ Sentencia disponible en: https://www.italaw.com/sites/default/files/case-documents/italaw3115.pdf

Opinión disidente disponible en: https://www.italaw.com/sites/default/files/casedocuments/italaw3117.pdf

${ }^{224}$ Laudo disponible en: https://www.italaw.com/sites/default/files/case-documents/ita0619.pdf

225 "Es innegable el derecho y privilegio de un Estado de ejercer los poderes legislativos soberanos. Un Estado tiene el derecho de promulgar, modificar o derogar una ley a su propia discreción. Salvo que exista un acuerdo, bajo la forma de una cláusula de estabilización u otro modo, no hay nada objetable en la modificación presentada en el marco reglamentario existente en el momento en que un inversor realizó su inversión. De hecho, cualquier hombre de negocios o inversionista sabe que las leyes evolucionarán con el tiempo. Sin embargo, lo que está prohibido es que un Estado actúe de manera injusta, irrazonable o inequitativa en el ejercicio de su poder legislativo." (Traducción propia)

${ }^{226}$ Laudo disponible en: https://www.italaw.com/sites/default/files/case-documents/ita0006.pdf

227 "De los principios básicos del Derecho Internacional, el Tribunal entiende que, si bien un Estado soberano posee el derecho inherente de regular sus asuntos internos, el ejercicio de ese derecho no es 
La visión restrictiva del derecho de regular entra en la contradicción de considerar la actividad estatal como límite de la misma, por tanto sería el propio Estado el único causante, por ejemplo, de su propio enfriamiento regulatorio. Desde un enfoque internacionalista, siguiendo a Krasner, la soberanía westfaliana puede ser condicionada por el ejercicio de la soberanía legal internacional. Aunque el autor no lo trata, haciendo una interpretación extensiva, la soberanía interna también puede ser limitada por la soberanía legal internacional desde un punto de vista de la autoridad para ejercer actos estatales. La transición hacia un nuevo concepto de soberanía debe tener en cuenta la posibilidad de limitación o no mediante invitaciones (véase apartado 7.4).

\subsubsection{Los caminos hacia la salida del laberinto}

A nivel de la gobernanza multilateral, en la hoja de ruta para la reforma del régimen internacional de protección de inversiones desarrollada por la UNCTAD (2015), se establecen cinco esferas de acción: 1) reformar la solución de controversias sobre inversiones; 2) promover y facilitar las inversiones; 3) conseguir inversiones responsables; 4) aumentar la coherencia sistémica; 5) salvaguardar el derecho a regular, dando al mismo tiempo protección a las inversiones (UNCTAD, 2015: 128).

Ahora bien, en relación a las normas internacionales, es posible visualizar una evolución, aun no generalizada, a la inclusión de disposiciones en los TBI u otros acuerdos que consagran el derecho de regular en áreas determinadas, como la seguridad o el medioambiente o exclusiones concretas a la aplicación de mecanismos de solución de controversias inversor-Estado (ejemplo: las medidas de control del tabaco en el TPP y posterior CPTPP como se vio en el apartado 3.3). Sin embargo no se trata de un camino directo de salida del laberinto que constriñe el espacio de política pública.

También se excluyen del examen de este apartado las reformas marginales que se dan a nivel de la gobernanza del régimen, sin perjuicio de la opinión de académicos como Alejandro Garro (comunicación personal, 23 de setiembre de 2019) que sostienen que el ámbito más propicio para mejorar el régimen son los foros donde se gestaron los mecanismos como el CIADI o la UNCITRAL. En el CIADI la reforma del sistema

ilimitado y debe tener sus límites. Como han señalado acertadamente los Demandantes, el estado de Derecho, que incluye las obligaciones de los tratados, establece esos límites. Por lo tanto, cuando un Estado celebra un tratado bilateral de inversiones como el del presente asunto, queda vinculado por él y las obligaciones de protección de las inversiones que asumió en él deben cumplirse en lugar de ser ignoradas argumentando posteriormente que el Estado tiene derecho de regular". (Traducción propia). 
refiere exclusivamente a mecanismos $\operatorname{procesales}^{228}$, y en la UNCITRAL (Grupo de trabajo número 3) la discusión profunda sobre el espacio de política pública, vinculado a los aspectos sustantivos de los tratados de inversiones, se dará una vez que se culmine con el debate sobre la reforma del régimen de solución de controversias. No obstante, cabe seguir la reflexión del profesor Fabio Morosini ${ }^{229}$ en torno a que "discutir sobre solución de controversias es discutir el espacio de políticas, no se pueden separar las cuestiones de procedimiento tan fácilmente de las cuestiones sustantivas" (comunicación personal, 4 de octubre de 2019).

Tampoco se analizarán las propuestas de modificaciones a nivel de cláusulas concretas (ejemplo: trato justo y equitativo, estándar mínimo de protección, cláusula de la nación más favorecida, cláusula paraguas, etc.) que por su diversidad pueden llevar a diferentes resultados interpretativos. Por tanto, ¿dónde se pone el foco del análisis de los caminos de salida del laberinto que constriñe el espacio de política pública? El foco está puesto en los caminos directos de consagración de este, visualizándose tres propuestas: 1) el reconocimiento expreso del derecho de regular; 2) la incorporación de excepciones generales en los tratados; y 3) la exclusión del régimen actual y creación de una nueva institucionalidad alternativa a la actual que garantice su protección.

En primer lugar, el derecho de regular puede ser expresamente reconocido de manera general o particular en un sector o sectores de actividad estatal. El TBI más innovador en los últimos tiempos es el TBI Marruecos-Nigeria, celebrado el 3 de diciembre de 2016 y no vigente a la fecha de cierre de este trabajo. El reconocimiento del derecho de regular no es una innovación en el sistema, de hecho uno de los caminos más habituales para su incorporación es su enunciación en los preámbulos de los tratados, buscando balancear el sistema con referencias generales o en materias de interés no económico (Mouyal, 2016: posición 5233 a 5241). Este es el caso de los preámbulos de los ACFI celebrados entre Brasil y Mozambique, Angola, Malaui, Perú, Etiopía, Surinam, Guyana y Emiratos Árabes Unidos en los cuales se reconoce la autonomía de los Estados y su facultad para implementar políticas públicas. No obstante, estos acuerdos excluyen de su articulado los mecanismos de solución de controversias inversor-Estado (véase apartado 3.2.2).

\footnotetext{
${ }^{228}$ Los avances hasta agosto de 2019 pueden encontrarse en CIADI (2019).

${ }^{229}$ Director del Centro para el Derecho, la Globalización y el Desarrollo de la Universidad Federal de Rio Grande del Sur. Entrevistado para este trabajo.
} 
La diferencia del TBI Marruecos-Nigeria respecto a los ACFI radica en que previendo el arbitraje internacional inversor-Estado en tribunales arbitrales ad hoc del CIADI o arbitraje ad hoc mediante el Reglamento de Arbitraje de la UNCITRAL, en su preámbulo reafirma de manera general el derecho de regular y de adoptar medidas domésticas en relación a las inversiones con el fin de alcanzar sus objetivos de política pública. Asimismo, marca la especial necesidad de los Estados en desarrollo de ejercer el derecho de regular. Si bien el preámbulo no forma parte del articulado obligatorio del tratado, es pertinente su análisis a los efectos de la interpretación del texto. En efecto, la Convención de Viena sobre Derecho de los tratados entre Estados (1969) en su artículo 31 al regular la interpretación refiere al "texto incluidos su preámbulo y anexos”. Por tanto es innegable la importancia del reconocimiento del derecho de regular del Estado. Por tanto, siguiendo las recomendaciones de la UNCTAD (2015) sobre el fortalecimiento del derecho de regular, adicionalmente en el artículo 13 el TBI, bajo el acápite "inversiones y medioambiente", reconoce expresamente el derecho de los Estados parte de actuar con discrecionalidad en relación a la regulación, cumplimiento, investigación, acusación y toma de decisiones respecto a la asignación de recursos en temas medioambientales, que el Estado considere que tienen una prioridad más alta (artículo 13 numeral 2). La importancia de esta disposición se erige en el reconocimiento que la protección del medioambiente puede ser prioritaria frente a la inversión extranjera, en otras palabras, la existencia de un bien jurídico superior a proteger ante la protección de las inversiones extranjeras. Por ende, el Estado tiene derecho a regular con amplio margen discrecional (Kendra y otros, 2017).

En segundo lugar, el artículo 13 numeral 4 destaca que nada en el tratado impide a las partes a adoptar, mantener o reforzar medidas consistentes con él y no discriminatorias, que le permitan garantizar que las inversiones en su territorio sean realizadas de forma consistente ("sensible" en inglés) con el medioambiente y las cuestiones sociales. Como explica Gazzini (2017), esta norma debe leerse en conjunción con el artículo 23 numerales 2 y 3 que establecen que la adopción de medidas no discriminatorias en cumplimiento con otras normas internacionales diferentes al TBI no implica un incumplimiento de este. La disposición es esencial en materia de normas internacionales provenientes de los regímenes internacional de protección del medioambiente, salud y derechos humanos, que al colisionar con TBI $\mathrm{u}$ otros acuerdos internacionales de inversiones fueron la base para los casos concretos de controversias analizados en el 
círculo 2 de este trabajo. Esto sería neutralizado si se universalizaran disposiciones como las señaladas.

El último punto a señalar del articulado del TBI Marruecos-Nigeria es que las partes se comprometen a no rebajar la regulación laboral o en derechos humanos, con el fin de atraer o fomentar inversiones (artículo 15). Una previsión expresa de este tipo, que evita una carrera a la baja, es fundamental a pesar de no establecer cuál es el zócalo mínimo de protección en dichas áreas, dando un amplio espacio de interpretación a los tribunales arbitrales ad hoc. Será la práctica derivada de la aplicación del acuerdo la que determine si el camino iniciado por un TBI innovador permea en la realidad de manera de proteger el derecho de regular, cuando las cláusulas pueden ser ambiguas (NwekeEze: 2017). Es en este punto que podría cuestionarse si es posible proteger el espacio de política pública, dándole amplio margen discrecional al Estado para que este pueda regular y ejercer su razón de Estado como indica Sassen (2010), y al mismo tiempo aplicar una política de flexibilidad como propugna la UNCTAD (2003, 2015). Precisamente el riesgo de la flexibilidad es desdibujar los límites de la protección del derecho de regular, y que pasen a ser delineados de manera difusa y no consistente por la jurisprudencia.

El segundo camino de reivindicación lo plasman autores, como Wagner (2014), que proponen la incorporación en futuras reformas del régimen de protección de inversiones la introducción a los tratados de cláusulas similares a las existentes en el régimen multilateral del comercio con los artículos XX del Acuerdo General de Aranceles y Comercio (GATT por su sigla en inglés) y XVI del GATS. En el primer caso, en líneas generales se prevé que las normas del acuerdo no pueden ser interpretadas en forma de vulnerar medidas adoptadas por los Estados en relación a la protección de la moral pública, la salud y la vida, importación de oro y plata, observancia de las normas domésticas que no sean incompatibles con el tratado, artículos fabricados en prisiones, patrimonio nacional artístico, histórico o arqueológico, conservación de recursos no renovables, acuerdos sobre productos básicos, restricciones a la exportación de materias primas en el marco de planes de estabilización, medidas para paliar situaciones de desabastecimiento.

En el caso del GATS, si bien existe un paralelismo mutatis mutandis, el elenco de excepciones previsto a texto expreso es sensiblemente inferior. En síntesis, la norma refiere a que ninguna disposición puede ser interpretada de manera tal de vulnerar medidas estatales relativas a la protección de la moral pública y el orden público, la 
salud y la vida, observancia de las normas domésticas, normas destinadas a garantizar la imposición o recaudación equitativa o efectiva, y acuerdos o disposiciones domésticas para evitar la doble imposición. En cualquiera de los casos el límite es el principio de no discriminación, piedra fundamental del sistema multilateral del comercio.

Lester y Mercurio (2017) siguen la misma línea de Wagner al analizar las disposiciones del CPTPP y anterior TPP que restringen el reconocimiento del espacio regulatorio del Estado a áreas específicas de regulación: seguridad, medioambiente y salud. Los autores afirman que existen mejores mecanismos para evitar la vulneración del derecho de regular y limitación del espacio de política pública, ya que las exclusiones son injustas e innecesarias. Estas focalizan en un sector o sectores determinados, corriendo el riesgo de vulnerar el principio de trato justo y equitativo ya que el Estado tiene carta blanca para favorecer a la industria local frente a los inversores extranjeros, incluso dejando sin recurso a un inversor extranjero frente a situaciones de incumplimiento de normas de defensa de la competencia o anticorrupción.

En consecuencia, Lester y Mercurio proponen trabajar en una mejor redacción de los acuerdos internacionales e incorporar excepciones generales, no específicas para la solución de controversias inversor-Estado. Las excepciones generales podrían tomar como modelos los artículos XX del GATT y XVI del GATT, como en el caso del artículo 22.1 (excepciones generales) del TLC Australia-Corea respecto a las medidas para proteger la vida, animales plantas y salud, asegurar el cumplimiento de normas, protección del patrimonio nacional en materia artística, histórica o arqueológica, conservación de recursos naturales (Lester y Mercurio, 2017: 8). La propuesta de los mencionados autores también es innovadora, aunque de mayor dificultad a la hora de una negociación internacional, especialmente para Estados de menor peso económico relativo.

La tercera posibilidad, esto es, la exclusión del régimen actual y creación de una nueva institucionalidad, se analizará en el siguiente apartado mediante el caso concreto de la UE y la defensa del espacio de política pública regional, que se bilateraliza en los acuerdos con terceros y en el futuro se pretende multilateralizar mediante la creación de un sistema multilateral de tribunales de inversiones. 


\subsection{El caso de la Unión Europea: ¿reivindicación de un espacio de política pública regional?}

\subsubsection{Las dos gotas que rebasaron el vaso de los arbitrajes intra-Unión Europea: los casos Micula y Achmea}

En los últimos años se ha consolidado a nivel institucional de la UE una posición contraria al arbitraje inversor-Estado intra UE, esto es, arbitrajes entre Estados miembros e inversores nacionales de otros Estados miembros. Dos disputas deben atenderse a los efectos de comprender el impacto de la problemática sobre el Derecho de la Unión: el caso Micula contra Rumania (caso CIADI número ARB/05/20) y el caso Achmea contra Eslovaquia (arbitraje ad hoc en territorio alemán).

La controversia de los hermanos Ioan y Viorel Micula y las empresas European Food SA, Starmill S.R.L. y S.C. Multipack S.R.L., de nacionalidad sueca contra Rumania tiene su germen en el proceso de negociación de Rumania tendiente a su ingreso a la UE, efectivizado el 1 de enero de 2007. En este marco Rumania debió adaptar su ordenamiento jurídico doméstico al ordenamiento jurídico comunitario, por tanto con fecha 31 de agosto de 2004 derogó el Decreto de Urgencia 24/1998 por el cual establecía una serie de beneficios a los inversores en regiones desfavorecidas que serían aplicables hasta el año 2009. En consecuencia, haciendo uso de la prórroga de jurisdicción a favor del CIADI prevista en el TBI entre Rumania y Suecia (2003), los hermanos Ioan y Viorel Micula y las empresas European Food SA, Starmill S.R.L. y S.C. Multipack S.R.L. iniciaron un arbitraje en el CIADI al entender que Rumania había incumplido con la protección de sus legítimas expectativas al modificar el marco jurídico en base al cual habían invertido y en el cual confiaban.

El 11 de diciembre de 2013, el tribunal ad hoc consideró que la decisión del Estado había sido injusta, incumpliendo con las legítimas expectativas protegidas en el mencionado TBI, y por tanto condenó al Estado al pago del monto indemnizatorio de 376.433.229 leus rumanos más intereses (aproximadamente 178 millones de euros a la fecha del laudo). En vista de lo anterior, Rumania informó a la Comisión Europea sobre el laudo y la ejecución de parte del pago mediante la cancelación de una deuda impositiva que mantenía una de las empresas demandantes, European Food S.A. (76 millones de euros aproximadamente). La respuesta de la Comisión Europea fue contundente al afirmar que cualquier forma de ejecución o implementación del laudo es considerada como una nueva ayuda incompatible con el Derecho de la Unión 
(Comunicación de la Comisión Europea a Rumania, C(2014) 6848 final230, párrafo 71). Asimismo, le recordó a Rumania que, conforme al Reglamento del Consejo 659/1999, debe recuperar el monto atribuido como ayuda ilícita y debe suspender cualquier acción tendiente a la ejecución o implementación del laudo del CIADI (párrafo 74).

Posteriormente, en los considerandos de la Decisión 2015/1470 231 , la Comisión Europea manifestó que "la aplicación o ejecución del laudo arbitral concede a los demandantes una ventaja económica de la que, de otra forma, no dispondrían en el mercado" (párrafo 96) y dicha aplicación o ejecución tenía un efecto similar al que tenía la medida derogada y cuestionada por los inversores. La Comisión también aclaró que al momento de apreciar si se trata de una ventaja económica, carece de relevancia la forma específica de la medida ya que, conforme al numeral 1 del artículo 107 del Tratado de Funcionamiento de la UE, cualquier ayuda estatal estaba prohibida (párrafo 106). En consecuencia la Comisión decidió que al ser ilegal e incompatible con el acervo jurídico comunitario el pago de la indemnización del laudo del CIADI, Rumania debía recuperar, en forma rápida y efectiva, el monto ya indemnizado más los intereses devengados.

Cabe señalar que, teniendo en cuenta la experiencia del caso Micula y la Comunicación de la Comisión Europea a España número C(2017) 7384 final, en las disputas que involucran a España por los recortes a las energías renovables, el pago de los montos indemnizatorios también debe considerarse una ayuda pública ilegal y no compatible con el mercado interior (párrafo 23). Aun así, en varios de los arbitrajes resueltos a favor del inversor se han iniciado procesos de ejecución del laudo en tribunales domésticos de Estados Unidos y Suecia, con el objetivo de obtener el cobro de manos de España al entender que carece de inmunidad de jurisdicción. Los procesos ante los tribunales estadounidenses están pendientes de resolución ${ }^{232}$, pero en la jurisdicción sueca la Corte de Apelaciones dejó sin efecto de manera indefinida el laudo (laudo del arbitraje Novenergia, 17 de mayo de 2018).

La segunda controversia que determina cambios en la posición de la UE respecto a los arbitrajes intra-UE es el caso Achmea contra Eslovaquia. Achmea era una empresa de base holandesa que invertía en el sector de seguros de enfermedad privados de

\footnotetext{
${ }^{230}$ Texto disponible en: https://www.italaw.com/sites/default/files/case-documents/italaw4066.pdf

${ }^{231}$ Texto disponible en: https://eur-lex.europa.eu/legal-content/ES/TXT/?uri=CELEX:32015D1470

${ }^{232}$ A modo de ejemplo, la solicitud de ejecución de Eiser y Energía Solar Luxemburgo (laudo del (CIADI caso número ARB/13/36) se encuentra disponible en: https://ep00.epimg.net/descargables/2018/08/22/921adc45aa65b7cbd82169022b57bbbb.pdf
} 
Eslovaquia, cuando en 2006 esta dejó sin efecto la liberalización de dicho mercado, prohibiendo en 2008 la distribución de los beneficios resultantes de las actividades. En 2011 el Estado autorizó nuevamente la distribución de beneficios a consecuencia de una sentencia del Tribunal Constitucional. Sin perjuicio de ello, en 2008 Achmea inició un arbitraje en base al artículo 8 del TBI entre Países Bajos y Checoslovaquia (1991) ${ }^{233}$, al considerar que las medidas estatales le ocasionaron un perjuicio económico.

El arbitraje se desarrolló en Alemania y el Derecho aplicable al procedimiento era el alemán. Eslovaquia planteó una excepción de incompetencia del tribunal arbitral al entender que el artículo 8 del TBI en cuestión era incompatible con el Derecho de la UE. La excepción fue desestimada, tampoco prosperaron los recursos ante los tribunales judiciales alemanes. E1 7 de diciembre de 2012 el tribunal arbitral condenó a Eslovaquia a una indemnización por 22,1 millones de euros. El laudo es objeto de recursos de anulación y posterior casación ante el sistema judicial alemán. Es en un este último procedimiento que el Tribunal Supremo de lo Civil y Penal decidió plantear una cuestión prejudicial al TJUE respecto a la compatibilidad del artículo 8 del TBI en cuestión con los siguientes artículos del Tratado de Funcionamiento de la UE: 18 (principio de no discriminación según nacionalidad), 267 (cuestión prejudicial) y 344 (controversias relativas a la interpretación o aplicación de los tratados deben ser resueltas por los mecanismos por ellos previstos).

En la sentencia de fecha 6 de marzo de $2018^{234}$ (caso C-284/16), el TJUE estableció la incompatibilidad del artículo 8 del $\mathrm{TBI}^{235}$ con las normas comunitarias. Su dictamen se funda en que conforme al artículo 344 son los tribunales domésticos de los Estados miembros y el propio Tribunal de Justicia quienes están facultados a interpretar el Derecho de la Unión, cuya piedra angular del sistema jurisdiccional es el procedimiento de remisión prejudicial. El Derecho de la Unión se asienta en los valores del artículo 2 del Tratado de la UE, a saber: respeto de la dignidad humana, libertad, democracia, igualdad, Estado de Derecho y respeto de los derechos humanos. En consecuencia existe

\footnotetext{
${ }^{233}$ Por las normas de sucesión de Estados, el acuerdo era aplicable a las relaciones bilaterales Países Bajos-Eslovaquia, y Países Bajos-República Checa.

${ }^{234}$ Disponible en: https://eur-lex.europa.eu/legal-content/ES/TXT/?uri=CELEX:62016CJ0284

${ }^{235}$ Prevé un período de enfriamiento de seis meses, pasado el cual, de no existir solución amigable, queda abierta la vía arbitral. En este sentido, establece la conformación de un tribunal ad hoc de tres miembros, uno elegido por cada parte y el tercero de común acuerdo. El tribunal determina sus propias reglas de procedimiento en aplicación de las reglas de arbitraje de la UNCITRAL. Para decidir el tribunal tendrá como base el Derecho, tomando en consideración de manera no exclusiva: las normas vigentes para las partes, las disposiciones del TBI, otros acuerdos relevantes entre las partes en el TBI, disposiciones especiales relacionadas a la inversión, los principios generales de Derecho Internacional. El laudo será adoptado por mayoría de votos y será obligatorio para las partes en la controversia.
} 
un principio de confianza mutua entre los Estados miembros de reconocimiento de dichos valores y respeto por el Derecho que los aplica.

El tribunal arbitral previsto en el artículo 8 del TBI no forma parte del sistema jurisdiccional de la UE y excluye la competencia de los órganos jurisdiccionales domésticos de los Estados involucrados. En ocasión de una controversia entre un inversor de un Estado miembro y el otro Estado miembro puede verse obligado a interpretar el Derecho de la Unión así como el TBI que lo crea, sin embargo no está facultado para presentar una solicitud de decisión prejudicial. En efecto, el Tribunal de la UE considera que la disposición bajo análisis pone en peligro el principio de confianza mutua entre los Estados miembros (párrafo 58) y vulnera a la autonomía del Derecho de la Unión (párrafo 59).

Si bien la sentencia se aplica para el caso concreto, es apoyada por la Comisión en su comunicación al Parlamento de fecha 19 de julio de 2018 (COM(2018) 547 $\left.{ }^{236}\right)$ en la que afirma que los TBI celebrados entre miembros de la UE vulneran "el sistema de recursos jurídicos de los Tratados de la UE, con lo que ponen en peligro la autonomía, la eficacia, la primacía y el efecto directo del Derecho de la Unión, así como el principio de mutua confianza entre los Estados" (Comisión Europea, 2018: 3). En este sentido, Iruretagoiena (2018) explica que, conforme al principio de primacía, las disposiciones de los TBI intra-UE no son más aplicables por su incompatibilidad con los Tratados de la UE. Conforme al autor, el caso Achmea da lugar a un escenario favorable para los recursos de anulación contra laudos de tribunales arbitrajes con sede en un Estado miembro, y de difícil reconocimiento y ejecución de laudos extranjeros.

Diferente es el caso de los laudos del CIADI que no son susceptibles de recursos de anulación ante la jurisdicción doméstica. No obstante, Iruretagoiena (2018) se cuestiona si la publicación de la sentencia del caso Achmea no podría constituir un hecho que "hubiera podido influir decisivamente en el laudo, y siempre que, al tiempo de dictarse el laudo, hubiere sido desconocido por el Tribunal y por la parte que inste la revisión y que el desconocimiento de ésta no se deba a su propia negligencia" (artículo 51 del Convenio de Washington). De ser así, cualquiera de las partes en litigio podría solicitar la revisión del laudo.

La mencionada comunicación de la Comisión al Parlamento también establece que en un mercado único las disposiciones de los TBI no son necesarias, por tanto para litigios

\footnotetext{
${ }^{236}$ Disponible en: http://ec.europa.eu/transparency/regdoc/rep/1/2018/ES/COM-2018-547-F1-ES-MAINPART-1.PDF
} 
intra-UE no es posible recurrir a los tribunales creados por los TBI entre Estados miembros o el Tratado sobre la Carta de Energía (artículo 26). Tal afirmación no es menor si se tiene en cuenta que aproximadamente el $20 \%$ del total de controversias conocidas en el mundo, son casos intra-UE, siendo España el principal Estado demandado (UNCTAD, 2018: 1). La disputa entre la empresa Masdar y España es un ejemplo de esta problemática (véase apartado 4.4).

A consecuencia del caso Achmea, 22 de los Estados miembros de la $\mathrm{UE}^{237}$ firmaron el 15 de enero de 2019 una declaración ${ }^{238}$ en la que afirman que el Derecho Comunitario tiene prevalencia sobre los TBI celebrados por los Estados miembros. Por tanto, siendo las cláusulas de solución de disputas inversor-Estado contrarias al Derecho Comunitario, estas son inaplicables, incluidas las cláusulas de ultractividad que regulan la aplicación de las disposiciones de fondo del TBI por cierto período una vez terminado el acuerdo ${ }^{239}$. Asimismo, la declaración señala dos aspectos fundamentales en un momento de discusión de la reforma del régimen de solución de controversias inversorEstado. En primer lugar recuerda que todos los tratados celebrados por la UE, incluso el Tratado de la Carta de Energía, son parte integrante del sistema jurídico de la UE y por tanto deben ser compatibles con los tratados fundamentales. Este punto es central, ya que difiere de la lógica argumentativa del caso Achmea que refiere a TBI intra-UE. En segundo lugar, aclara que los Estados miembros están obligados a proveer los medios adecuados para proteger a los inversores, especialmente el derecho de una protección jurídica efectiva ante los tribunales domésticos.

Por tanto, los 22 firmantes se comprometen a tomar sin demora nueve acciones. De estas se destaca que los Estados miembros en cuyo territorio existen arbitrajes en curso deben informar sobre las consecuencias jurídicas de dichos procesos, así como los Estados demandados están obligados a anunciar a los tribunales que entiendan en arbitrajes intra-UE, incluso en terceros Estados, que los procesos deben terminarse, y de no hacerlo, sus laudos no podrán ejecutarse por falta de validez (punto 2). En la misma línea, todos los Estados signatarios se comprometen a notificar a la comunidad de inversores que no deben iniciarse nuevos procesos intra-UE (punto 3). En relación al

${ }^{237}$ Estos son: Alemania, Austria, Bélgica, Bulgaria, Chipre, Eslovenia, España, Estonia, Dinamarca, Francia, Grecia, Irlanda, Italia, Letonia, Lituania, Países Bajos, Polonia, Portugal, Reino Unido, República Checa, Rumania.

238 Texto disponible en:

https://ec.europa.eu/info/sites/info/files/business_economy_euro/banking_and_finance/documents/19011

7-bilateral-investment-treaties_en.pdf

${ }^{239}$ Habitualmente el período de ultractividad es de 5, 10, 15 o 20 años. 
Tratado de la Carta de Energía, en la declaración del 15 de enero de 2019 los Estados firmantes junto a la Comisión Europea se comprometen a discutir sobre los caminos a seguir en relación a la aplicación de dicho instrumento jurídico a los arbitrajes intra-UE. Tal vez la medida más trascendente es la obligación que se autoimponen los Estados firmantes de terminar todos los TBI entre ellos de forma bilateral o mediante la celebración de un tratado plurilateral (punto 5), haciendo su mejor esfuerzo para que esto suceda antes del 6 de diciembre de 2019 (punto 8). El 24 de octubre de 2019, la Comisión Europea anunció la firma del acuerdo multilateral de denuncia de los TBI intra-UE ${ }^{240}$, lamentando que un pequeño grupo de miembros no participara. Asimismo, recordó su posición respecto al inicio de procedimientos de infracción, por incumplimiento de las obligaciones emanadas de los tratados (artículo 258 del Tratado de Funcionamiento de la $\mathrm{UE}^{241}$ ), respecto a los miembros que no terminen sus TBI intraUE. No hay referencia a los TBI extra-UE.

Como se indicara previamente (véase apartado 4.4.2), el efecto del caso Achmea sobre los arbitrajes intra-UE en curso no se hizo esperar. En el caso Masdar, el tribunal del CIADI interpretó la sentencia del TJUE como un acto de alcance limitado, referida a arbitrajes basado en TBI y por tanto no puede ser incluida en el análisis del caso en particular. Por su parte Italia, en el arbitraje iniciado por la empresa belga Eskosol (caso CIADI número ARB/15/50), el 4 de febrero de 2019 Italia solicitó la terminación del, alegando la declaración del 15 de enero de 2019 por tratarse de un arbitraje intra-UE, y estableciendo como excepción de jurisdicción que el Tratado de la Carta de Energía es inaplicable para disputas intra-UE. El 7 de mayo de 2019, el tribunal rechazó ambas solicitudes $^{242}$, fundamentando su decisión en que el mero hecho que Bélgica e Italia sean signatarios de la declaración, no implica necesariamente que el proceso deba terminarse, y consideró la declaración como un instrumento vinculante para la interpretación del Tratado de la Carta de Energía (párrafo 218). Por tanto, la declaración es interpretada

\footnotetext{
240 Texto del anuncio disponible en: Texto disponible en: https://ec.europa.eu/info/sites/info/files/business_economy_euro/banking_and_finance/documents/19102 4-bilateral-investment-treaties_en.pdf

Al cierre de este trabajo el texto de acuerdo plurilateral no se encuentra disponible públicamente.

${ }^{241}$ Artículo 258: "Si la Comisión estimare que un Estado miembro ha incumplido una de las obligaciones que le incumben en virtud de los Tratados, emitirá un dictamen motivado al respecto, después de haber ofrecido a dicho Estado la posibilidad de presentar sus observaciones.

Si el Estado de que se trate no se atuviere a este dictamen en el plazo determinado por la Comisión, ésta podrá recurrir al Tribunal de Justicia de la Unión Europea."

El recurso de incumplimiento ante el TJUE está regulado en el artículo 260 y siguientes del mismo instrumento jurídico. Para un examen específico, véase: Regí Rodríguez (2016).

${ }^{242}$ Decisión disponible en: https://www.italaw.com/sites/default/files/case-documents/italaw10512.pdf
} 
como un instrumento que informa la posición de los 22 Estados signatarios, sin implicar que los TBI intra-UE o el Tratado de la Carta de Energía estén terminados (párrafo 227).

En suma, el caso Micula y el caso Achmea son las dos gotas que rebasaron el vaso y dieron mayor solidez a la posición que la Comisión Europea venía sosteniendo durante la última década, a la cual se suma el pronunciamiento del TJUE respecto al caso Achmea. La defensa del Derecho de la Unión es una manifestación de la protección del espacio de política pública comunitario y su corazón, el derecho de regular de la UE. Por tanto, su consagración dentro del núcleo duro del Derecho de la Unión determina que este prime por encima de los tratados bilaterales que puedan ser celebrados entre sus miembros, so pena que la Comisión decida iniciar un procedimiento de infracción (artículo 258 del Tratado de Funcionamiento de la UE).

No obstante, con una opinión contraria se presenta Cecilia Olivet, quien entiende que en la oposición a los arbitrajes intra-UE no hay un reconocimiento específico del derecho de regular, como sí puede encontrarse en el dictamen 1/17 del TJUE. Como se verá más adelante, el dictamen afirma que el sistema de tribunales de inversiones previsto en el capítulo 8 del CETA no vulnera el derecho de regular. Olivet reflexiona que aceptar que los arbitrajes intra-UE puedan erosionar el espacio de política pública regional, haría más difícil para las instituciones comunitarias defender la incorporación de estos mecanismos en el acuerdos con terceros Estados. Por tanto, esta dualidad es una "manifestación del doble estándar de la UE: al exterior de la institución impulsan un régimen que al interior no" (Cecilia Olivet, comunicación personal, 14 de octubre de 2019).

\subsubsection{El Acuerdo Económico y Comercial Global entre la UE y Canadá (CETA): un ejemplo del primer eslabón de la cadena}

En paralelo a la problemática analizada en los apartados anteriores, desde el año 2015 la UE impulsó una reforma del régimen de solución de controversias inversor-Estado en dos fases. En una primera instancia, la UE incluye en la negociación o renegociación (modernización) de tratados de comercio y/o inversión con terceros Estados un sistema bilateral de tribunales de inversiones. En la segunda fase, sustitutiva de la anterior, el objetivo es la creación de sistema multilateral cuya negociación estará abierta a todos los Estados interesados, no exclusivamente los miembros del proceso de integración. 
La primera fase fue plasmada en el CETA entre la UE y Canadá ${ }^{243}$, entre otros tratados bilaterales $^{244}$. El CETA es celebrado el 30 de octubre de 2016 y entra en vigor provisionalmente el 21 de setiembre de 2017, dado que las disposiciones relativas a protección de inversiones, inversiones de cartera (no así la inversión extranjera directa) y al sistema de tribunales de inversiones deben ser aprobadas por los parlamentos nacionales, y en algunos casos los parlamentos regionales dado que no se trata de competencias exclusivas de la $\mathrm{UE}^{245}$. Al cierre de este trabajo, este extremo no se ha cumplido, pudiendo considerarse tal situación como otra demostración de cómo el modelo relacional propuesto por Consani (2008) aun manifiesta resistencias en un sistema institucional. Por este motivo, el 22 de mayo de 2018 el Consejo Europeo emitió un documento relativo a la negociación y la celebración de acuerdos comerciales de la UE con terceros $(8622 / 18)$, en el que recomienda la celebración en forma separada de acuerdos comerciales y acuerdos en materia de inversiones ${ }^{246}$.

En relación al CETA, en su capítulo 8 (Inversiones) se establece la creación de dos instituciones permanentes para resolver controversias inversor-Estado: un Tribunal de Inversiones Permanente y un Tribunal de Apelación. Conforme al artículo 8.27, el Tribunal permanente está compuesto por quince jueces elegidos por un período de cinco años renovable por una única vez (cinco nacionales de la UE, cinco de Canadá, y cinco de terceros Estados). Cada caso concreto será resuelto por tres de los quince jueces, manteniéndose las proporciones de nacionalidades previstas para el Tribunal en pleno, y será presidido por el juez nacional del tercer Estado.

Adicionalmente, el texto prevé un Tribunal de Apelaciones que tiene como fin confirmar, modificar o revocar los laudos del Tribunal permanente, y funcionará en divisiones de tres miembros (artículo 8.28). El hecho que ambos tribunales sean permanentes, independientemente de su funcionamiento en divisiones, mitiga parte de las críticas al actual sistema de solución de controversias inversor-Estado, especialmente al CIADI, cuyos tribunales se conforman para el caso concreto y carece de una instancia de apelación. En este sentido, Schill y Vidigal (2018: 15), afirman que el objetivo de esta propuesta es brindar una respuesta a la crítica al tradicional

\footnotetext{
243 Texto disponible en: https:/eur-lex.europa.eu/legalcontent/ES/TXT/PDF/?uri=CELEX:22017A0114(01)\&from=EN

${ }^{244}$ Se destacan el Acuerdo de protección de inversiones con Singapur (celebrado el 15 de octubre de 2018), Vietnam (negociación culminada, no firmado), y México (negociación en curso).

${ }^{245}$ La entrada en vigor del CETA sustituirá los TBI de Canadá con: Croacia, República Checa, Eslovaquia Hungría, Letonia, Malta, Polonia y Rumania.

${ }^{246}$ Texto disponible en: http://data.consilium.europa.eu/doc/document/ST-8622-2018-INIT/en/pdf
} 
mecanismo de designación de los árbitros por las partes, que termina convirtiendo a los tribunales ad hoc en instituciones que presentan un déficit democrático, por la falta de rendición de cuentas de sus miembros, y que pone en riesgo la consistencia y coherencia de la jurisprudencia.

Con el fin de garantizar la transparencia en los procedimientos y la independencia de los miembros de los tribunales se establece a texto expreso que estos no reciben instrucciones de organizaciones o gobiernos en temas vinculados a la controversias, y desde su designación tienen prohibida la actuación como asesores, expertos nombrados por una parte o testigos (artículo 8.30). Este punto es crucial en el sistema, ya que es una de las críticas más fuertes al actual régimen de solución de controversias inversor Estado, en particular desde la sociedad civil organizada ${ }^{247}$.

Otros elementos a resaltar son: la prohibición de procedimientos paralelos tanto en tribunales nacionales como internacionales al mismo tiempo que en el sistema de tribunales de inversiones del CETA (artículos 8.22 y 8.23); la prevención de demandas fraudulentas o manipuladoras en base, por ejemplo, a reestructuraciones empresariales (artículo 8.18); no derogación de la medida impugnada (artículo 8.39); la inclusión de mecanismos alternativos de solución de disputas, como ser la mediación (artículo 8.20). Respecto al derecho de regular, el CETA prevé su consagración general, aunque ejemplifica áreas concretas de regulación, giro en la redacción que puede llevar a interpretaciones diversas: se incluye cualquier área de regulación estatal o únicamente aquellas indicadas a texto expreso. En concreto, los dos primeros numerales del artículo 8.9 (Inversiones y medidas reglamentarias) disponen:

"1. A efectos del presente capitulo, las Partes reafirman su derecho a regular en sus territorios para alcanzar objetivos politicos legítimos, como la protección de la salud pública, la seguridad, el medio ambiente, la moral pública, la protección social o de los consumidores, o la promoción y la protección de la diversidad cultural.

2. Para mayor seguridad, el mero hecho de que una Parte regule, incluso mediante una modificación de su legislación, de tal forma que afecte negativamente a las inversiones o no satisfaga las expectativas de un inversor, incluidas sus expectativas de beneficios, no constituye un incumplimiento de ninguna de las obligaciones establecidas en la presente sección."

Desde la sociedad civil organizada, el Centro Canadiense de Políticas Alternativas, el Corporate Europe Observatory, Amigos de la Tierra Europa, el Foro Alemán de ONG de Medio Ambiente y Desarrollo y el Transnational Institute publicaron un documento de trabajo en el cual ponen a prueba el sistema de tribunales de inversiones propuesto por la UE (Cingotti y otros, 2016), cuyo primer ejemplo se encuentra en el CETA.

${ }^{247}$ En este sentido ver especialmente: Eberhardt y Olivet (2012). 
Respecto al derecho de regular, el documento es claro al dar la voz de alarma ante la redacción del artículo 8.9, en particular señalan que "la vaga formulación de la propuesta deja en manos de los árbitros interpretar qué medidas del Gobierno son "necesarias" para lograr objetivos "legítimos"," (Cingotti y otros, 2016: 9). En consecuencia, su interpretación queda en manos de los jueces, como operadores jurídicos. Del análisis de las disputas inversor-Estado seleccionadas ${ }^{248}$ en el documento, afirman que una interpretación restrictiva de normas que protegen el derecho de los Estado a legislar puede dar cabida a demandas que se dirijan "contra leyes $u$ otras medidas adoptadas por los países para proteger la salud pública, el medio ambiente, las comunidades locales o luchar contra el cambio climático" (Cingotti y otros: 2016: $10)$.

El sistema previsto en la Sección III del Capítulo II (Inversiones) del último borrador del Acuerdo Transatlántico de Asociación (TTIP) -noviembre de 2015- tiene las mismas características y ha sido blanco de diversas críticas. Se destaca, en primer lugar, el análisis de Sornarajah (2016) quien considera que el sistema propuesto no resuelve los problemas de los mecanismos actuales, dado que per se no asegura legitimidad, ni hay una determinación clara de la distribución geográfica de los miembros de los tribunales que corresponden a terceros Estados. Por los mismos motivos, Gaffney (2016) considera que el borrador se queda a mitad de camino entre la construcción de un nuevo sistema y la permanencia en el actual. Finalmente Schill (2016) agrega un elemento más al debate al cuestionar la ausencia de requisito de agotamiento previo de la jurisdicción doméstica, aspecto que puede poner en tela de juicio la autoridad y legitimidad democrática de los tribunales nacionales y quitarles la oportunidad de corregir posibles medidas arbitrarias, discriminatorias o ilegítimas adoptadas por el Gobierno.

Finalmente, cabe señalar que no todos los acuerdos bilaterales negociados $\mathrm{o}$ renegociados por la UE prevén el sistema de tribunales de inversiones, un ejemplo es el Acuerdo Mercosur-UE cuya negociación culminó el 28 de junio de $2019^{249}$. El texto tampoco incluye la tradicional solución de controversias inversor-Estado con prórroga

\footnotetext{
248 Casos Philip Morris contra Uruguay (caso CIADI número ARB/10/7), TransCanada contra Estados Unidos (caso CIADI número ARB/16/21), Lone Pine contra Canadá (caso CIADI número UNCT/15/2), Vattenfall contra Alemania (caso CIADI número ARB/09/6), Bilcon contra Canadá (caso CPA número 2009-04).

249 Textos de los capítulos cuya redacción no se encuentra sujeta a revisión técnica disponible en: https://www.gub.uy/ministerio-relaciones-exteriores/comunicacion/publicaciones/acuerdo-asociacionmercosur-union-europea-sintesis-del-acuerdo-textos
} 
al arbitraje internacional. Si bien podía ser previsible la exclusión de este tema, dado que no estaba en el mandato inicial, tampoco lo estaban las listas negativas o el comercio electrónico y se incluyeron en las sucesivas negociaciones. Tampoco significa que el sistema de tribunales de inversiones sea excluido para siempre de las relaciones entre el Mercosur y la UE. Una posible renegociación del acuerdo puede incluirlo como es el caso del Acuerdo México-UE, o avanzarse hacia el sistema multilateral con apoyo del Mercosur (véase aparatado 6.4.4). Menos aún significa que la relación entre bloques quede exenta del tradicional arbitraje inversor-Estado ya que una extensa red de TBI regula las relaciones bilaterales, salvo para el caso de Brasil (véase apartado 3.2) ) $^{250}$.

\subsubsection{La compatibilidad del CETA con el Derecho de la Unión}

Ahora bien, vista la posición de la Comisión Europea y el TJUE respecto a los casos Achmea y Micula, el 30 de octubre de 2016 Bélgica decidió consultar al Tribunal de la UE respecto a si el CETA es compatible con los tratados, incluidos los derechos fundamentales, en lo que respecta a la solución de controversias inversor-Estado

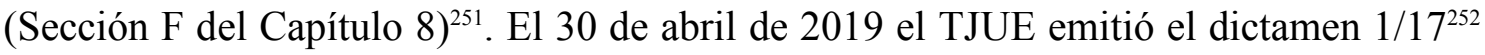
en el que contestó las observaciones realizadas por el Estado miembro que a los efectos de este trabajo se sistematizarán en cuatro puntos: 1) principio de autonomía del Derecho Comunitario; 2) principio de igualdad de trato; 3) principio de efectividad; 4) acceso a un tribunal independiente.

En primer lugar, Bélgica consultó sobre la autonomía del Derecho Comunitario, esto es si es los tribunales del CETA son compatibles con el principio de competencia exclusiva del TJUE para la interpretación del Derecho Comunitario, ya que el CETA no plantea la posibilidad que el tribunal de inversiones por él creado plantee cuestiones prejudiciales. El Tribunal de Justicia recordó que "un acuerdo internacional que prevea la creación de un órgano jurisdiccional encargado de la interpretación de sus disposiciones y cuyas decisiones vinculen a la Unión es, en principio, compatible con el Derecho de la Unión” (párrafo 106). Asimismo, entendió que el mecanismo de solución

\footnotetext{
${ }^{250}$ Para un análisis particular de la solución de controversias inversor-Estado como tema excluido del Acuerdo Mercosur-UE puede verse Bas Vilizzio (2019).

${ }^{251}$ La fecha de la consulta es significativa, dado que esta se realizó a pocas semanas que dos parlamentos regionales de Bélgica votaran en contra del CETA (comunidad francófona de Valonia y federación de Valonia-Bruselas) movidos por la preocupación ante la solución de controversias inversor-Estado (De La Baume, 2016).

$252 \quad$ Texto disponible en:

http://curia.europa.eu/juris/document/document.jsf?text=\&docid=215650\&pageIndex=0\&doclang=ES\& mode $=1$ st\&dir $=\&$ occ $=$ first\&part $=1 \& \operatorname{cid}=12661214$
} 
de disputas entre inversores extranjeros y Estados es externo al sistema jurídico de la UE, y dichos tribunales no pueden interpretar disposiciones de Derecho Comunitario, sean normas originarias o derivadas, sino que aplican e interpretan normas de Derecho Internacional, como el propio CETA y otras disposiciones legales internacionales aplicables a las partes en la disputa. Por tanto, concluyó que no es necesario el establecimiento de un mecanismo de consulta previa al máximo órgano jurisdiccional comunitario, y si lo fuera, también podría ser objeto de consulta en Canadá.

Adicionalmente, el Tribunal de Justicia aclaró que el mecanismo del CETA y los actuales mecanismos de solución de controversias inversor-Estado son diferentes, haciendo especial referencia al caso Achmea. Dos son las principales diferencias: 1) el tribunal previsto en el TBI Países Bajos-Eslovaquia podía interpretar o aplicar el Derecho Comunitario a la hora de resolver las disputas; 2) el asunto involucraba a dos Estados miembros de la UE. Ambas situaciones no se replican en el caso del CETA. En consecuencia, no se vulnera la autonomía del Derecho Comunitario.

En segundo lugar, Bélgica preguntó por la compatibilidad con el principio de igualdad de trato (artículo 20 y 21 de la Carta de derechos fundamentales de la UE), destacándose que la eventual aplicación de una multa por un Estado de la UE pudiera ser considerada como violatoria del CETA, siendo esto contrario al derecho de regular. Apoyándose en precedentes jurisprudenciales, el Tribunal de Justicia manifestó que el principio de igualdad de trato no es aplicable a las relaciones entre la UE y terceros Estados, descartándose en consecuencia la situación del CETA. De existir tal diferencia de trato "está justificada por el objetivo de contribuir a un comercio libre y justo, en el sentido del artículo 3 TUE, apartado 5, y por el de integrar a todos los países en la economía mundial, previsto en el artículo 21 TUE, apartado 2, letra c” (párrafo 84).

Ahora bien, el Tribunal consideró que tampoco se vulneraría este principio si se interpreta que el CETA discrimina entre terceros Estados, ya que no existe ninguna obligación por parte de la UE de "otorgar, en sus relaciones exteriores, un trato igual a los distintos Estados terceros" (párrafo 173). Finalmente, la preocupación respecto a una multa que pudiera considerarse contraria al CETA y en consecuencia violatoria del derecho de regular, el Tribunal entendió que a nivel comunitario el inversor también tendría a su disposición las vías necesarias para hacer valer su derecho, por tanto hay igualdad de trato (párrafo 186).

En tercer lugar, Bélgica consultó sobre la compatibilidad con el principio de efectividad, especialmente ante una eventual indemnización que recibiría una empresa local 
controlada por capitales canadienses en caso de ser vencedora en una controversia, o la desaparición de hecho de los efectos de una multa impuesta por la Comisión o un Estado miembro a un inversor canadiense si los tribunales del CETA establecen una compensación equivalente. El TJUE entendió que los tribunales del CETA difícilmente declararán que una multa aplicada en función del derecho de regular, consagrado en el artículo 8.9 del propio acuerdo, sea violatoria de este. En efecto, el Derecho Comunitario permite la anulación de una multa que adolezca de vicios similares a los que podrían declarar los tribunales del CETA, por tanto no existe la consultada incompatibilidad.

Finalmente, en cuarto lugar, el Estado planteó si el CETA era compatible con el derecho de acceso a un juez independiente, ya que los miembros del tribunal y el tribunal de apelaciones del CETA no tendrían un sueldo fijo y regular sino honorarios mensuales a los que se adicionan honorarios según las controversias en las que intervienen, su nombramiento y destitución no siguen las recomendaciones o Carta Magna de los Jueces del Consejo Consultivo de Jueces Europeos (Documento 2010/3).

El Tribunal de Justicia destaca que se trata de un sistema "híbrido" con características de un tribunal de justicia y los tribunales arbitrales de inversiones tradicionales, y las disposiciones del CETA garantizan la imparcialidad e independencia de los jueces. Señaló que las normas coinciden en general con las previstas a nivel internacional para las mismas situaciones, ejemplo la destitución de los jueces de la Corte Penal Internacional. Por tanto, descartó mayores inconvenientes en torno a la forma de retribución de los jueces y reforzó el rol previsto para el Comité Mixto con el fin de establecer cambios en esta materia.

Conforme al dictamen, tampoco se verá comprometida la accesibilidad al sistema por parte de inversores que sean personas físicas o pequeñas y medianas empresas, dado los costos involucrados en una disputa. El Comité Mixto será el encargado de analizar de qué manera se reducirá la carga financiera.

$\mathrm{Si}$ bien el pronunciamiento es claro respecto a la compatibilidad del sistema de tribunales de inversiones del CETA, y por ende de los demás acuerdos celebrados o en negociación que incluyan este mecanismo, voces desde diferentes ámbitos se han mostrado contrarias a la alternativa europea. La Asociación de Magistrados de Alemania (2016) emitió un comunicado mostrando su oposición al sistema. Particularmente destaca que no lo consideran un sistema necesario, al existir recursos claros en las legislaciones nacionales de los Estados miembros, y que se está creando un 
órgano con potestad de interpretar y aplicar las normas comunitarias sin las exigencias que tienen los tribunales domésticos en dichos casos. Tampoco consideran que el sistema garantice la imparcialidad de los jueces al no cumplirse con la Carta Magna de los Jueces del Consejo Consultivo de Jueces Europeos (Documento 2010/3).

Como se indicara anteriormente, en el documento elaborado por el Centro Canadiense de Políticas Alternativas, el Corporate Europe Observatory, Amigos de la Tierra Europa, el Foro Alemán de ONG de Medio Ambiente y Desarrollo y el Transnational Institute (Cingotti y otros, 2016), se identifican cinco leading-cases inversor-Estado y con ellos ejemplifican como el sistema no cuenta con las garantías suficientes para evitar demandas en áreas vinculadas a la salud pública (sector tabacalero) o la protección del medioambiente (sector petrolero o energía nuclear) ${ }^{253}$. Particularmente destacan el uso de una terminología imprecisa y amplia respecto a conceptos como el trato justo y equitativo o la arbitrariedad manifiesta; la necesidad de interpretar conceptos como el de derecho de regular; la introducción del concepto de expectativas legítimas que podrá dar lugar a un mayor número de controversias; la inclusión de posibles indemnizaciones por pérdida de derechos futuros; y la falta de garantía de jueces públicos e independientes como establece la mencionada Carta Magna.

\subsubsection{Hacia un sistema multilateral de tribunales de inversiones}

Como segunda fase, la UE tiene previsto profundizar y extender su sistema de tribunales de inversiones desde el relacionamiento bilateral al nivel multilateral. Esta fase implica que los mecanismos bilaterales serán sustituidos una vez que la instancia multilateral entre en vigor. Por tanto, el 13 de setiembre de 2017 la Comisión Europea elevó al Consejo una recomendación de decisión por la que se autoriza la apertura de negociaciones sobre un Convenio relativo al establecimiento de un tribunal multilateral para la solución de diferencias en materia de inversiones (Documento COM(2017) 493 final $\left.{ }^{254}\right)$. La autorización y las directrices de negociación son aprobadas con fecha 20 de marzo de 2018 (Documento 12981/17 255 ).

\footnotetext{
${ }^{253}$ Todos los casos surgen como consecuencia de la fragmentación del Derecho Internacional y la colisión entre el régimen de protección de inversiones y los regímenes que engloban las materias señaladas. Es la propia fragmentación del Derecho Internacional la que alimenta la creación de regímenes jurídicos autocontenidos y viceversa.

${ }^{254}$ Disponible en: https://ec.europa.eu/transparency/regdoc/rep/1/2017/ES/COM-2017-493-F1-ESMAIN-PART-1.PDF

${ }^{255}$ Disponible en: http://data.consilium.europa.eu/doc/document/ST-12981-2017-ADD-1-DCL-1/es/pdf
} 
Entre las directrices de negociación se destaca que el sistema contará un órgano de primera instancia y otro de apelación cuyos miembros serán independientes y recibirán una remuneración permanente durante su mandato -limitado a un período de tiempo y no renovable-. La permanencia de los tribunales y sus miembros busca garantizar una jurisprudencia consistente a diferencia de los actuales tribunales ad hoc. Asimismo, los procedimientos deberán ser transparentes y posibilitar la intervención de terceros organizaciones no gubernamentales, grupos de consumidores, asociaciones empresariales, cámaras comerciales, etc.-, de la misma manera que hoy prevé el Reglamento sobre Transparencia de los arbitrajes entre inversionistas y Estados en el marco de un tratado de la UNCITRAL celebrado en 2014.

Una vez en vigor el sistema multilateral de tribunales de inversiones, sustituirá a los tribunales bilaterales previstos en otros acuerdos por el CETA o los TLC celebrados por la UE con Vietnam y Singapur. Todo hace pensar que dado el enlentecimiento en las negociaciones con un actor como Estados Unidos y la autorización a la Comisión Europea para iniciar las negociaciones de un acuerdo multilateral, los debates sobre la reforma del régimen de solución de controversias inversor-Estado se darán con más fuerza a nivel multilateral fuera del CIADI. La UE, por su parte, continuará incluyendo su sistema de tribunales de inversiones en las negociaciones bilaterales. Estas instancias muestran cómo los Estados prefieren resolver vis-à-vis y en un orden paralelo aquellos temas que no encuentran solución en el modelo institucional de las relaciones internacionales, planteándose una reivindicación, al menos puntual, del modelo relacional con mayor centralidad del Estado como actor y sujeto.

La construcción de una nueva institucionalidad tiene como efecto la constitución de un régimen paralelo por parte de Estados que sin abandonar el tradicional régimen de solución de controversias inversor-Estado proponen un régimen internacional alternativo. En otras palabras, la UE en general y los 22 Estados firmantes de la declaración del 15 de enero de 2019 y del acuerdo plurilateral del 24 de octubre de 2019, aun en la etapa previa a concretarse la nueva institucionalidad, conforman un nuevo grupo en Estados confrontadores del régimen actual pero sin abandonarlo (mantienen la membresía en el CIADI y los TBI extra-UE en vigor). A este grupo también puede sumarse India con el reforzamiento de la jurisdicción doméstica previo al arbitraje inversor-Estado, el cual mantiene e incluye en su nuevo modelo de TBI (2016). El grupo de los confrontadores, desde la óptica de los modelos de las relaciones internacionales propuesto por Consani $(2008,2016)$ presenta una demanda de 
protección de la soberanía estatal y defensa de la autonomía (regional o estatal) por tanto constituyen casos de resistencia del modelo relacional en el marco de un modelo mayoritariamente institucional. Como los modelos son ideales y por tanto no se encuentran en la realidad en estado puro, la pugna entre uno y otro son habituales, más allá de la presencia prioritaria de uno de ellos en un momento histórico determinado. El rol de los confrontadores es una manifestación de una mayor reivindicación del Estado como sujeto central del modelo relacional, puesto que en el modelo institucional el Estado ya no es el núcleo en torno al cual se funda el sistema (Consani, 2008: 7).

\subsection{Conclusiones del capítulo 6}

La preocupación por el condicionamiento del derecho de regular por parte de la UNCTAD, como ejemplo institucional de la gobernanza del régimen, fue tardía (casi cinco décadas después de su creación, ya iniciada la etapa actual). Sin perjuicio de lo anterior, este marca un punto de quiebre al poner en evidencia la existencia de la falacia que los TBI son siempre beneficiosos para los Estados. Asimismo, marca un hito al reconocerse la existencia de falencias en el régimen internacional y cómo estas impactan negativamente recortando los poderes regulatorios de los Estados.

Sin embargo, ¿se condiciona la soberanía estatal en el sentido de alguna de la cuatro proyecciones propuestas por Krasner (2001, 2009, 2009b)? Si bien en los anteriores capítulos de este trabajo se hizo referencia al condicionamiento de la soberanía interna, el foco se puso en la autoridad para ejercer actos estatales, noción que la recorta conceptualmente. Ninguna de las proyecciones que propone Krasner tiene como centro el espacio de política pública, dando respuesta al reclamo de los Estados de recuperar los poderes regulatorios, particularmente en casos de crisis económica como indica Sornarajah (2015: 66). Por tanto es necesaria una nueva concepción de soberanía, que tenga como base el espacio de política pública, cuyo corazón es el derecho de regular, como se profundizará en el siguiente capítulo.

Ahora bien, debe distinguirse la nueva noción de soberanía de la elección de los mecanismos que permitan al Estado desarrollarse como mejor lo entienda, y por ende ejercer su condición de soberano. Este segundo concepto es el de autonomía, condición, que como señala Puig (1986: 40), “otorga las posibilidades de adoptar políticas más justas y más equilibradas”. En términos jurídicos, la autonomía se manifiesta en el principio de libre determinación de los pueblos que establece el derecho de estos a 
elegir libremente su condición política, y por tanto determinar de forma autónoma las políticas de desarrollo económico, social y cultural, excluyendo su ejercicio cualquier forma de injerencia externa. Esta norma de jus cogens se encuentra consagrada principalmente y expresamente en los artículos 1 párrafo 2, 55 y 56 de la Carta de la ONU, el artículo 1 del Pacto de Derechos Civiles y Políticos (1966), el artículo 1 del Pacto de Derechos Económicos, Sociales y Culturales (1966) con idéntica redacción que el anterior, y la Declaración 2625 (XXV) (1970).

Siendo el derecho de regular una de las áreas de acción del proceso de reforma del régimen de protección de inversiones impulsado por la UNCTAD, los Estados pueden optar por excluir determinados sectores o temas de la solución de controversias inversor-Estado como forma de protegerlo. Sin embargo no es un camino directo a su protección, sino que presenta un nivel de cambio menor frente al régimen actual. Otros caminos puede determinar una consagración directa del derecho de regular, a saber: su reconocimiento expreso como en el TBI Marruecos-Nigeria, la introducción de excepciones generales tomando como modelo los artículos XX del GATT y XVI del GATS, o la exclusión del régimen actual y creación de una nueva institucionalidad que proteja. Este último es el caso de la UE con la defensa del espacio de política pública regional, al considerar que los arbitrajes intra-UE son contrarios al Derecho de la Unión y por tanto nulos. Aunque Puig (1986) analiza la integración solidaria desde la óptica de los Estados latinoamericanos, es posible identificar en la UE la solidaridad estratégica entre Estados como fuerza superadora que fortalece la autonomía, y defiende el espacio de política pública comunitaria como espejo de la soberanía de sus miembros.

Sin perjuicio de lo anterior, la crítica de las instituciones europeas al tradicional régimen de solución de controversias inversor-Estado para los arbitrajes intra-UE no es más que un efecto reflejo de una problemática interna (crisis económica y aumento desmedido de los arbitrajes en el sector energías renovables son los catalizadores). Si bien su propuesta de un sistema de tribunales de inversiones (fase bilateral y fase multilateral) genera una alternativa real, esta no necesariamente suplanta el régimen actual. Asimismo, muestra una dualidad: los arbitrajes intracomunitarios son rechazados, mientras que los arbitrajes extracomunitarios son impulsados ya sea en el régimen tradicional (no hay propuesta de terminación de los TBI extra-UE) o con la propuesta alternativa. Por tanto, el lugar actual de la UE seguirá siendo de confrontador del régimen, sin llegar a atravesar el umbral hacia la disidencia. 
En suma, la situación de la UE respecto a los arbitrajes intra-UE, complementado con su propuesta de sistema de tribunales de inversiones, constituye una primera demostración de la construcción de un nuevo concepto de soberanía donde prima la defensa del espacio de política pública, aunque en el mediano plazo se convierta en un régimen en paralelo con el régimen actual más que una sustitución real. Esta construcción se inicia en el interior de los Estados y busca moldear el sistema internacional, generando transformaciones en el régimen internacional: principios, reglas e instituciones. Este tema será desarrollado en el siguiente capítulo. 


\section{Capítulo 7: Soberanía regulatoria, un concepto en transición}

\subsection{Aspectos preliminares}

Para completar el tercer círculo de esta investigación, el presente capítulo se dedica al estudio de la soberanía en el siglo XXI. En particular indaga si existe un concepto en transición. Partiendo de un abordaje explicativo, este capítulo inicia posicionándose en el momento histórico en el que las cuatro proyecciones de la soberanía que propone Krasner son interpeladas: la crisis global de 2008 como punto de quiebre en la globalización, aunque no sea su fin, coadyuva a su enlentecimiento. El foco se pone en el impacto de esta crisis en las empresas transnacionales y el cuestionamiento de su "retirada" o transformación como actor internacional.

La crisis de la globalización se solapa con la crisis de legitimidad del multilateralismo en general, y del régimen de solución de controversias inversor-Estado en particular, y por ende las reacciones de las audiencias relevantes ya analizadas en los capítulos anteriores (salida del régimen, propuesta de tratados con mayor balance, alternativa de construcción de una nueva institucionalidad). Por tanto, como segundo punto se examina una propuesta calificada por la UNCTAD (2019: 4) como una manifestación de reequilibrio frente a los actuales mecanismos de solución de controversias inversorEstado: el Borrador cero del Instrumento jurídicamente vinculante para regular, en el marco del Derecho Internacional de los derechos humanos, las actividades de las empresas transnacionales y otras empresas, que el 16 de julio de 2019 ya cuenta con su versión revisada.

Finalmente, el capítulo cierra evaluando si el concepto de soberanía se encuentra en transición, desde las cuatro proyecciones propuestas por Krasner (soberanía de interdependencia, westfaliana, interna y legal internacional) a la soberanía regulatoria. Se examinan las características del concepto en transición, el rol que juegan las notas de autoridad, control y legitimidad, los motivos que hicieron que se manifestara $a$ posteriori de 2007 y se brindan ejemplos de manifestaciones en el régimen de solución de controversias inversor-Estado y fuera de este. 


\subsection{Estados, empresas transnacionales y solución de controversias en un mundo en} crisis

\subsubsection{Reflejos de la crisis de la globalización}

La crisis global de 2008 marcó un punto de quiebre en la globalización, entendida como modelo histórico articulado en torno a dos ideas fuerza: el debilitamiento del Estado y la dispersión del poder para incluir a otros actores no estatales (del Arenal, 2009) como los “dueños de la globalización” (Grabendorff, 2017), y en segundo lugar la presencia de nuevas dinámicas de dependencia, desigualdad, dominación y exclusión (del Arenal, 2009). Si bien la globalización no se desvanece producto de la crisis de 2008, sí coadyuva a generar un momento de transición o transformación (estancamiento, ralentización o "slowbalisation" "256 como la denomina el trend-watcher Adjiedj Bakas $^{257}$ ) o marca un camino hacia el inicio de una nueva etapa (desglobalización, posglobalización).

Sea que la transformación está en proceso o ya se inició una nueva etapa, este momento se manifiesta en cuatro fenómenos identificados por Sanahuja (2018), a saber: 1) modificaciones en la distribución del poder; 2) debilitamiento del modelo económico de transnacionalización de la producción basado en el off-shoring; 3) agotamiento del modelo en términos sociales y medioambientales, especialmente en lo que respecta al extractivismo y a la segregación como plantea Sassen $(2011)$; 4) falencias en la gobernanza doméstica e internacional.

A los efectos de este apartado los dos primeros elementos requieren un examen más profundo. Las modificaciones en la distribución del poder refieren mayoritariamente a la gravitación de los actores estatales, especialmente con el peso que ha ganado China en las últimas dos décadas. Su ingreso a la OMC en el año 2001 y su actual defensa del multilateralismo en el marco de la "guerra comercial" con Estados Unidos son solo dos ejemplos de este nuevo equilibrio de poder a nivel multilateral. La pugna entre potencias debilita el orden mundial diseñado como un traje a medida por y para los Estados occidentales (Tussie, 2019: 107), poniendo en evidencia una nueva multipolaridad que presenta nuevas voces e intereses que complejizan los acuerdos a nivel global (Held, 2019).

\footnotetext{
${ }^{256}$ Este término es empleado incluso en una publicación de la OECD y la OMC titulada "Aid for Trade at a Glance 2019. Economic Diversification and Empowerment". Véase especialmente el capítulo 7.

${ }^{257}$ En su sitio web dedica un espacio al análisis del capitalismo y la slowbalisation. Este se encuentra disponible en: https://www.bakas.nl/kapitalisme-Slowbalisering-TrendLezing\&lang=en
} 
Asimismo, China es un actor fundamental en el avance de un nuevo tipo de empresa transnacional: las empresas de propiedad estatal. Como reflexiona Morosini, aun “queda por saber si el sistema actual de reglas de cuenta de este nuevo tipo de empresa transnacional" (comunicación personal, 4 de octubre de 2019), En particular, este fenómeno puede llevar a la reiteración de antecedentes como el de la disputa entre Masdar (empresa de capitales estatales de Emiratos Árabes) y España (véase apartado 4.4).

Esta transformación en la estructura del tejido empresarial no es la única modificación que puede visualizarse y que impacta sobre los flujos comerciales internacionales. Como sostienen Lund y otros (2019), “(t)he growth of new technologies, such as Internet connectivity and artificial intelligence (AI), are also changing trade patterns ${ }^{\text {"258. }}$. Esto permite dar respuesta a la necesidad de una mayor celeridad y proximidad a los consumidores, especialmente en aquellas regiones de mayor crecimiento y concentración de los flujos comerciales, como ser Europa y Asia. En otros términos, el comercio internacional sigue patrones regionales y geopolíticos, al tiempo que se han acortado las cadenas globales de valor y las normas que regulan el comercio y la inversión no son ajenas a la tendencia a la regionalización ${ }^{259}$ (The Economist, 2019: 26). En consecuencia, tiene lugar un proceso de sustitución del modelo dominante del off-shoring por uno de on-shoring, donde se priorizan el trabajo calificado y las nuevas tecnologías frente a los salarios bajos o el acceso a los recursos.

En este marco, en el mes de enero de 2017, la publicación británica The Economist tituló su artículo central como "The retreat of the global company" ${ }^{260}$ y en él sostiene que la era de las empresas transnacionales tal como las conocíamos a lo largo de las últimas décadas está terminando. Entre sus argumentos, reiterados en enero de 2019 en el artículo "The global list" en un número dedicado a la slowbalisation, The Economist destaca el declive de las ganancias en el exterior (17\% menos en los últimos cinco años); el impacto del aumento de normas domésticas e internacionales en materia de contabilidad global, defensa de la competencia, lavado de dinero o relativas a restricciones para garantizar trabajos locales; el incremento de los aranceles y otras

\footnotetext{
258 "El crecimiento de las nuevas tecnologías, como la conectividad a Internet y la inteligencia artificial (IA), también están cambiando los patrones comerciales”. (Traducción propia)

${ }^{259}$ El TPP, el CPTPP, el Acuerdo Estados Unidos-México-Canadá (sustitutivo del Acuerdo de libre comercio de Norteamérica), y como ejemplos entre inter-regionales pueden citarse el Acuerdo MercosurUE, Acuerdo Mercosur- Asociación Europea de Libre Comercio, el CETA (UE-Canadá).

260 "La retirada de la empresa global”. (Traducción propia)
} 
medidas proteccionistas; y los cambios en los patrones de comercio que tienden a la regionalización (The Economist, 2017, 2019).

Por consiguiente, los viejos argumentos a favor de la internacionalización empresarial están quedando obsoletos y las empresas transnacionales deben reconsiderar las ventajas competitivas. Mirando hacia un escenario futuro, la publicación avizora tres elementos: un número reducido de empresas transnacionales con un énfasis más profundo en los mercados domésticos siguiendo los intereses nacionales, el auge de aquellas empresas vinculadas a la tecnología, y una mayor presencia de empresas pequeñas que se dediquen al comercio electrónico a escala mundial. Este escenario dará lugar a un capitalismo más fragmentado y localista (The Economist, 2017: 18), fenómeno que en el largo plazo generará niveles más profundos de proteccionismo, dejando heridas en el multilateralismo en términos comerciales.

Ahora bien, cabe preguntarse: ¿las empresas transnacionales han perdido su poder? En un momento de slowbalisation, ¿se manifiestan cambios en los actores no estatales en el marco de la nueva distribución de poder que comienza a gestarse? Si bien es cierto que la crisis de la globalización podría leerse desde sus "dueños", como denomina Grabendorff (2017) a los actores no estatales, la idea de una retirada de las empresas transnacionales no se ajusta cabalmente a la realidad del sistema internacional actual. Las empresas transnacionales se han transformado para hacer frente a los cambios en los flujos comerciales internacionales. Asimismo, han ingresado al ruedo nuevos tipos de empresas, como las empresas de propiedad estatal que mencionaba Morosini.

En relación al ámbito del arbitraje inversor-Estado, el artículo de The Economist sentencia que los "global tribunals that multinationals use to bypass national courts have come under attack"261 (The Economist, 2017: 16). La frase es realista, especialmente teniendo en cuenta el análisis realizado en el círculo 1 de este trabajo, las reacciones desde los movimientos sociales y algunos espacios políticos hacia el régimen. También si se consideran los casos que alberga (véase a modo de ejemplo las controversias que involucran temas de derechos humanos analizadas en el círculo 2). Sin embargo, esto no significa que en este ámbito las empresas transnacionales hayan perdido poder. De hecho, en los últimos cinco años el número de demandas ha aumentado casi un $50 \%$ en relación al quinquenio anterior (252 controversias iniciadas en el período 2009-2013 frente a 363 correspondientes a 2014-2018). El aumento se

\footnotetext{
261 "Los tribunales globales que las multinacionales utilizan para eludir los tribunales domésticos están
} bajo ataque" (Traducción propia). 
debió, en parte, al aluvión de demandas registradas basados en el Tratado de la Carta de la Energía, especialmente contra España en el sector energías renovables (un ejemplo es el caso Masdar examinado en el apartado 4.4).

Juan Hernández Zubizarreta ${ }^{262}$ concluye que "lejos de retirarse han crecido en materia económica y jurídica, y están captando poder político" (comunicación personal, 30 de setiembre de 2019), coincidiendo en este último punto con las ideas desarrolladas por Strange (2001). Otro fenómeno a destacar es el hecho que las altas finanzas han mantenido su capacidad. La socióloga Saskia $\operatorname{Sassen}^{263}$ sostiene que en el sistema internacional actual, las altas finanzas funcionan mediante "una serie de circuitos altamente especializados que fácilmente cruzan fronteras, concentran ventajas en actores privados con mucho poder, y tienen inmensas capacidades extractivas. Una vez que extraen, dejan detrás destrucción, al igual que la industria minera” (comunicación personal, 26 de octubre de 2019). Al contrario del comercio, las altas finanzas no buscan fidelizar clientes, sino que trabajan de manera extractiva, hasta agotar el terreno sobre el que operan. La crisis de la deuda de los préstamos universitarios en Estados Unidos es un ejemplo de esto ${ }^{264}$.

En definitiva, la crisis global de 2008 demostró la gran capacidad de adaptación de las empresas transnacionales, presentando a las grandes corporaciones financieras como las principales beneficiadas (Cecilia Olivet, comunicación personal, 14 de octubre de 2019). Es esperable, entonces, que en un momento de slowbalisation, las empresas transnacionales también sean capaces de adaptarse sin necesidad de retirarse del escenario internacional.

\subsubsection{Reflejos de la crisis del multilateralismo}

Al mismo tiempo que se desarrolla la crisis de la globalización, otra crisis dice presente y genera retroalimentación: la crisis del multilateralismo. En lo que refiere al régimen internacional de protección de inversiones, especialmente del régimen de solución de controversias inversor-Estado, se trata de una crisis de legitimidad (Morosini, comunicación personal 4 de octubre de 2019). Siguiendo a Keohane (2006), el concepto de legitimidad puede tener dos acepciones: legitimidad en sentido normativo y

\footnotetext{
${ }^{262}$ Profesor del Departamento de Derecho de la Empresa de la Universidad del País Vasco y miembro de la red Desmantelando el Poder Corporativo. Entrevistado para este trabajo.

${ }^{263}$ Profesora de Sociología de la cátedra Robert S. Lynden de la Universidad de Columbia. Entrevistada para este trabajo.

${ }^{264}$ En este sentido puede verse: Mitchell (2019).
} 
legitimidad en sentido sociológico. Normativamente hablando, una institución es legítima cuando "its practices meet set of standards that have been stated and defended" ${ }^{265}$, y desde el punto de vista sociológico lo es cuando "it is accepted as and appropiate, and worthy of being obeyed, by relevant audiences" (Keohane, 2006: 57). La coincidencia entre ambas se alcanza cuando las audiencias relevantes aceptan, como dignos de ser obedecidos, los principios de un sistema jurídico determinado.

Por tanto, aplicando las ideas del autor al régimen de solución de controversias inversor-Estado, la crisis de legitimidad, tanto jurídica como sociológicamente, se manifiesta cuando las audiencias relevantes rechazan los principios del sistema. Las reacciones pueden sintetizarse en las siguientes: el abandono del régimen (situación de Bolivia, Ecuador y Venezuela en relación al CIADI, véase capítulo 2), la propuesta de tratados que buscan balancear el sistema (situación de los ACFI de Brasil o el modelo de TBI de la India 2016, véase capítulo 3) y la presentación de proyectos alternativos (situación de la UE con el sistema de tribunales de inversiones, véase apartado 6.4).

Teniendo en cuenta que los Estados y las empresas transnacionales son los actores centrales del régimen de solución de controversias inversor, las reacciones que demuestran una crisis de legitimidad desde los Estados y otros actores como la sociedad civil organizada o las comunidades locales. Como se señaló en el análisis del caso Bear Creek contra Perú (véase apartado 5.4), las comunidades locales suelen ser, en palabras de Perrone (2019: 16), un "actor ausente". No obstante, es un actor que recibe los efectos directos de la inversión extranjera, especialmente sobre el territorio que habita.

A su vez, esta crisis de legitimidad coincide con el 75 aniversario de las instituciones gemelas creadas en Bretton Woods, Fondo Monetario Internacional y Banco Mundial, instituciones que están recibiendo críticas en todo el mundo coadyuvando a la presión sin precedentes que enfrenta el multilateralismo (Kapur, 2019). A nivel del CIADI, dentro del Banco Mundial, la discusión de la reforma de las reglas de arbitraje y conciliación, si bien es una reforma marginal al focalizarse en disposiciones procesales y no sustanciales, no deja de ser otra manifestación de la imperante necesidad de cambio y reequilibrio de fuerzas en el régimen de solución de controversias inversorEstado.

\footnotetext{
265 "Normativamente hablando una institución es legítima cuando sus prácticas cumplen con un conjunto de normas que han sido declaradas y defendidas, y desde el punto de vista sociológico lo es cuando las audiencias relevantes la aceptan, apropian y la consideran digna de ser obedecida”. (Traducción propia)
} 
El régimen de solución de controversias inversor-Estado no es el único sistema de solución de disputas que involucran a Estados soberanos que se encuentra embarcado en un momento de fuertes cuestionamientos y plantea una necesidad de ser revisado. A nivel de la OMC, típica institución multilateral, el Órgano de Apelación está atravesando una situación límite: solo están en funciones tres de los siete miembros que prevé el Entendimiento relativo a las normas y procedimientos por los que se rige la solución de diferencias. Asimismo, el mandato de dos de ellos expira el 10 de diciembre de 2019 sin avizorarse una posibilidad de acuerdo. ¿Es una crisis de legitimidad o hay otros factores en juego? Se intentará responder esta pregunta en el siguiente apartado.

\subsection{3. ¿Otro botón de la muestra? La crisis del Órgano de Apelación de la OMC}

Para abordar la crisis del Órgano de Apelación de la OMC, se opta por el trilema propuesto por Zelicovich (2019) respecto a la función negociadora de la organización, función que impacta directamente en una posible reforma del sistema en su totalidad o de la solución de diferencias en particular. La autora afirma que la tensión en las negociaciones comerciales internacionales se manifiesta en la interacción entre la profundidad de los temas, la legitimidad del proceso negociador y la efectividad en su desarrollo, siendo cada uno de estos los vértices de un triángulo (Zelicovich, 2019: 6). El trilema apunta a que no es posible combinar más de dos vértices al mismo tiempo, en consecuencia siempre uno de los tres debe ser relegado.

El vértice de la "profundidad" hace foco en los temas incluidos en la agenda de negociación, sean temas OMC plus u OMC extra ${ }^{266}$. Actualmente pueden clasificarse en dos grupos: aquellos temas pendientes de la Ronda Doha (ejemplo: aranceles, antidumping, subsidios agrícolas entre otros) y los temas nuevos (ejemplo: facilitación del comercio, comercio electrónico, medioamente, aspectos laborales). El vértice de la "efectividad" gira en torno a la producción de resultados, esto es, alcanzar acuerdos en

\footnotetext{
${ }^{266}$ Los temas $\mathrm{OMC}$ plus (OMC+) implican la profundización de temas tratados por la $\mathrm{OMC}$, en tanto los temas $\mathrm{OMC}$ extra (OMCx) se refieren a temas no regulados por la organización. Horn y otros (2009) luego de analizar 28 acuerdos comerciales preferenciales, identifican dentro de los temas OMC plus al comercio de bienes, administración aduanera (hoy en día podría ampliarse a la facilitación del comercio), tributos de exportación, medidas sanitarias y fitosanitarias, obstáculos técnicas al comercio, empresas estatales, medidas antidumping, subsidios, contratación pública, medidas de inversiones relacionadas con el comercio, comercio de servicios y aspectos de los derechos de la propiedad intelectual relacionados con el comercio. Los autores identifican como temas OMC extra a las normas anticorrupción, defensa de la competencia, protección de los consumidores, normas medioambientales, inversiones, movimiento de capitales, normas laborales, agricultura, cooperación cultural, educación y formación, energía, derechos humanos, migración ilegal, diálogo político, cooperación, investigación y tecnología, terrorismo, visas y asilo, entre otros.
} 
base a la negociación mediante el uso de las reglas de consenso y reciprocidad en la toma de decisiones. El tercer y último vértice refiere a la "legitimidad", que implica no solo el apego de los actores involucrados a la conducta prevista en las normas de la institución, sino también la convicción moral respecto a la conducta (Zelicovich, 2019), esto es, legitimidad en sentido jurídico y sociológico conforme a Keohane (2006).

El trilema da lugar a tres escenarios. El primero es de la legitimidad y profundidad, sin efectividad, escenario que se traduce en la parálisis de las negociaciones. La segunda opción es la combinación de la legitimidad y eficacia dejando de lado la profundidad, esto es, la generación de acuerdos light que regulen el comercio multilateral con un elenco mínimo de temas a ser regulados. Finalmente, el tercer escenario da lugar a negociaciones eficaces y profundas pero que no cuentan con legitimidad. En consecuencia los acuerdos plurilaterales resultan más atractivos para los miembros de la OMC y se vuelcan a su firma.

Justamente en relación a la función negociadora, la crisis del sistema de resolución de disputas de la organización se manifiesta en la imposibilidad de alcanzar acuerdos para la designación de los miembros del Órgano de Apelación. Conforme al artículo 17 del Entendimiento relativo a las normas y procedimientos por los que se rige la solución de diferencias, el Órgano de Apelación está compuesto por siete personas nombradas por el Órgano de Solución de Disputas por un mandato de cuatro años, renovable por cuatro años más por única vez (numeral 2). Debe tratarse de "personas de prestigio reconocido, con competencia técnica acreditada en derecho, en comercio internacional $y$ en la temática de los acuerdos abarcados en general" (artículo 17 numeral 3), sin vinculación gubernamental. Su elección debe seguir el criterio de la representatividad de la composición de la $\mathrm{OMC}$, esto es, contemplando las regiones geográficas, el nivel de desarrollo económico, y los sistemas jurídicos (Arredondo y Godio, 2019: 169).

La labor del Órgano de Apelación es resolver los recursos de apelación contra las decisiones de los grupos especiales, actuando en cada caso un grupo de tres de los siete miembros (artículo 17 numeral 1). Dispone de un plazo de 60 días para resolver, pudiendo prorrogarse por motivos justificados, pero el plazo máximo no puede ser superior a 90 días (artículo 17 numeral 6). El informe resultante de su actuación puede "confirmar, modificar o revocar las constataciones y conclusiones jurídicas del grupo especial” (artículo 17 numeral 13). El Órgano de Solución de Disputas debe adoptar el informe del Órgano de Apelación, salvo que en 30 días desde la distribución decida lo contrario (artículo 17 numeral 14). 
El procedimiento es complejo y cuenta con diferentes etapas procesales y plazos determinados, de manera de garantizar una estricta aplicación del Derecho en tiempo prudencial. Asimismo, en 2018 se dio un aumento significativo del número de casos objeto de apelación, alcanzando a 12 disputas en comparación al promedio de siete del quinquenio anterior (2012-2017) (OMC, 2019). Dada la conformación actual del Órgano de Apelaciones, desde la literatura especializada (Schneider-Petsinger, 2019; Hillebrand, 2019; Hoekman y Mavroidis, 2019), e incluso en el último Informe anual del Órgano de Apelación (OMC, 2019), se ha levantado la voz de alarma.

Esta crisis tiene su germen en el año 2017 con el cese, por cumplimiento del segundo mandato consecutivo, de dos de los miembros, a saber: Peter Van den Bossche (20092013, 2013-2017), Ricardo Ramírez-Hernández (2009-2013, 2013-2017), y la renuncia de Hyun Chong Kim (2016-2017). En 2018 se suma la expiración, sin renovación, del primer mandato de Shree Baboo Chekitan Servansing (2014-2018). Con cuatro cargos vacantes, el Órgano de Apelación está compuesto por tres miembros (número mínimo para funcionar): Ujal Singh Bhatia (2011-2015, 2015-2019), Thomas R. Graham (20112015, 2015-2019), Hong Zhao (2016-2020). Los dos primeros culminan la segunda y última renovación de sus mandatos el día 10 de diciembre de $2019^{267}$.

Si bien desde 2017 el tema ha sido analizado en el marco del Órgano de Solución de Disputas y 70 miembros $^{268}$ presentaron una propuesta de solución (documento WT/DSB/W/609 ${ }^{269}$ ), no se ha alcanzado el consenso necesario para nombrar nuevos miembros (OMC, 2019: 4). ¿Cuál es la causa de la falta de consenso? La respuesta a dicha pregunta se encuentra en el bloqueo de Estados Unidos. Su argumento es el desacuerdo con la regla 15 del Procedimiento de trabajo para el examen en apelación (Documento WT/AB/WP/6 del 16 de agosto de 2010), que reza

Transición: 15. Una persona que deje de ser Miembro del Órgano de Apelación podrá, con autorización del Órgano de Apelación y previa notificación al OSD, terminar la sustanciación de cualquier apelación a la que hubiera sido asignada cuando era Miembro y, a tal efecto únicamente, se considerará que sigue siendo Miembro del Órgano de Apelación.

Conforme a la opinión estadounidense, dicha disposición va en contra del Entendimiento sobre solución de diferencias (artículo 17 numeral 2) ya que extiende el

\footnotetext{
${ }^{267}$ Información disponible en: https://www.wto.org/english/tratop_e/dispu_e/ab_members_descrp_e.htm 268 Argentina; Australia; Bolivia; Brasil; Canadá; Chile; China; Colombia; Costa Rica; República Dominicana; Ecuador; El Salvador; UE; Guatemala; Honduras; Hong Kong, China; Islandia; India; Indonesia; Israel; Kazakstán; Corea; México; Nueva Zelanda; Nicaragua; Noruega; Pakistán; Panamá; Paraguay; Perú; Rusia; Singapur; Suiza; Taiwán; Turquía; Ucrania; Uruguay; Venezuela y Vietnam.

${ }^{269}$ Al cierre de este trabajo la última revisión del documento (número 14) se encuentra disponible en: https://docs.wto.org/dol2fe/Pages/SS/directdoc.aspx?filename=s:/WT/DSB/W609R14.pdf
} 
período de actuación de los miembros del Órgano de Apelación más allá del plazo máximo previsto: cuatro años con posibilidad de renovación por única vez por cuatro años más ${ }^{270}$. En caso de considerarse una extensión, Estados Unidos sostiene que el encargado de decidir al respecto es el Órgano de Solución de Diferencias y no el Órgano de Apelación. Por tanto, la oposición estadounidense impide iniciar un proceso para elegir un nuevo miembro, si el reemplazado continúa ejerciendo funciones, hecho acaecido en casos anteriores y que acaece con los miembros a ser reemplazados (Arredondo y Godio, 2019: 171).

Asimismo, Estados Unidos señala otras situaciones de incumplimiento normativo en el funcionamiento del órgano, en particular la prolongación de los plazos de toma de decisión más allá de los 90 días previstos en el Entendimiento sobre solución de diferencias (artículo 17 numeral 6) ${ }^{271}$. Este punto es significativo, porque el propio órgano ha hecho referencia al aumento del volumen de trabajo y el número mínimo de miembros con el que cuenta en el 2019 para operar (OMC, 2019). Por tanto, la dinámica de funcionamiento institucional lo lleva a entrar en un círculo vicioso: no cumple con los plazos por el aumento del número de casos y la falta de cuatro miembros, hechos que lo llevan a no cumplir con los plazos y así sucesivamente.

La negativa de Estados Unidos no deja de ser una muestra de cómo medidas unilaterales son capaces de cuestionar al sistema en su conjunto, como resultado de la hegemonía ostentada (Tussie, 2006: 2). Asimismo, si se contextualiza al momento en el que se produce el bloqueo en la toma de decisiones en la OMC: la "guerra comercial" entre Estados Unidos y China. En este punto Estados Unidos pone en evidencia el dilema: seguridad nacional y libre comercio, esto es, defensa del espacio de política pública en materia de seguridad frente a los principios fundamentales del libre comercio. En definitiva, el cuestionamiento no tiene como foco el funcionamiento del Órgano de Apelación, sino todo el multilateralismo en materia comercial. En palabras de Sanahuja (2018), Trump se ha convertido en

el primer presidente de ese país que desde los años treinta cuestiona abiertamente el internacionalismo liberal a través de una agresiva política de revisión del multilateralismo vigente, y en particular de las normas comerciales en las que se sustenta la globalización, y de

\footnotetext{
${ }^{270}$ Este punto es sostenido por Estados Unidos en numerosas intervenciones en la OMC, por ejemplo en la realizada el 22 de junio de 2018. Disponible en: https://geneva.usmission.gov/wpcontent/uploads/sites/290/Jun22.DSB_.Stmt_.as-delivered.fin_.public.rev_.pdf

${ }^{271}$ En particular véase la exposición del Representante de Estados Unidos ante el Consejo General de la OMC de fecha 15 de octubre de 2019. Texto disponible en: https://geneva.usmission.gov/2019/10/15/statements-by-the-united-states-at-the-wto-general-councilmeeting/
} 
las instituciones y reglas en las que se ha basado el vínculo noratlántico, económico y de seguridad. (Sahanuja, 2018: 38)

En consecuencia, ¿cuáles son los posibles caminos frente al bloqueo en las designaciones de miembros del Órgano de Apelación? Aplicando el trilema de Zelicovich (2019), los caminos deben elegir entre dos de los tres vértices: efectividad, legitimidad y profundidad. En consecuencia, la primera opción es la proliferación de acuerdos entre miembros para la aplicación del artículo 25 del Entendimiento sobre solución de diferencias ${ }^{272}$, esto es, optar por el arbitraje como mecanismo de apelación de carácter interino en caso de insuficiencia de miembros en el Órgano de Apelación. Un ejemplo es el acuerdo entre la UE y Canadá el 25 de julio de $2019^{273}$, el cual dejará de aplicarse cuando el Órgano de Apelación cuente con su totalidad de componentes, aunque cualquier arbitraje pendiente deberá ser completado salvo acuerdo en contrario.

Este tipo de tratados apuesta a la efectividad y la profundidad, descartando la legitimidad que brinda una salida que comprenda a todos los miembros de la OMC. Cabe recordar que el propio Órgano de Apelaciones en su informe anual correspondiente a 2018 cuestiona que un menor número de miembros en su composición se traduce en una menor representación de Estados que conforman la organización y en consecuencia amenaza su legitimidad (OMC, 2019: 5). Aplicando el mismo razonamiento, la legitimidad también se ve menoscabada de proliferar una apuesta a acuerdos bilaterales o plurilaterales respecto a la aplicación del artículo 25 .

La segunda opción sería una salida negociada de la crisis, esto es, un acuerdo light que permita una reforma puntual del mecanismo de apelación o del sistema de solución de diferencias, que priorice la efectividad y la legitimidad. Sin embargo, al relegar la profundidad en el elenco de temas regulados, no sería viable pensar en una reforma que abarque todo el sistema de la OMC. Si bien este parece ser el camino más razonable, en

\footnotetext{
${ }^{272}$ Artículo 25. Arbitraje: "1. Un procedimiento rápido de arbitraje en la OMC como medio alternativo de solución de diferencias puede facilitar la resolución de algunos litigios que tengan por objeto cuestiones claramente definidas por ambas partes.

2. Salvo disposición en contrario del presente Entendimiento, el recurso al arbitraje estará sujeto al acuerdo mutuo de las partes, que convendrán en el procedimiento a seguir. El acuerdo de recurrir al arbitraje se notificará a todos los Miembros con suficiente antelación a la iniciación efectiva del proceso de arbitraje.

3. Sólo podrán constituirse en parte en el procedimiento de arbitraje otros Miembros si las partes que han convenido en recurrir al arbitraje están de acuerdo en ello. Las partes en el procedimiento convendrán en acatar el laudo arbitral. Los laudos arbitrales serán notificados al OSD y al Consejo o Comité de los acuerdos pertinentes, en los que cualquier Miembro podrá plantear cualquier cuestión con ellos relacionada.

4. Los artículos 21 y 22 del presente Entendimiento serán aplicables mutatis mutandis a los laudos arbitrales."

${ }^{273}$ Texto disponible en: https://trade.ec.europa.eu/doclib/docs/2019/july/tradoc_158273.pdf
} 
el corto plazo no parece ser factible. En efecto, el representante de Estados Unidos reforzó su postura en el Consejo General de la OMC, al darse a conocer el reporte del facilitador David Walker, nombrado por el Consejo General para afrontar la crisis del Órgano de Apelación (15 de octubre de 2019) ${ }^{274}$. Destacó el incumplimiento normativo manifiesto por parte del Órgano de Apelación e interpeló a los demás miembros de la organización que toleran esas acciones, al afirmar que "(b)y denying that they are concerned about persistent rule-breaking by the Appellate Body, some WTO Members seek to avoid the deeper question: why did the Appellate Body feel free to disregard the clear text of the agreements?" 275 .

Si bien la visión de Estados Unidos es clara, el día 23 de octubre de 2019, grupos afines al libre comercio 276 enviaron una carta al Presidente Trump instándolo a "state publicly that the goal of the United States is not to kill the Appellate Body, but rather to reform $i t^{, 277}$, y por tanto presentar a los demás miembros de la OMC una propuesta de reforma, haciendo énfasis en que su implementación permitiría retomar el proceso de nombramiento de los cargos vacantes del Órgano de Apelación ${ }^{278}$. Por tanto, de cambiar de posición, Estados Unidos contaría con apoyo de actores domésticos relevantes.

Finalmente, la tercera y última posibilidad es continuar apostando a la legitimidad del sistema (basada en el apego a la regla del consenso y reciprocidad en la toma de decisiones) y la profundidad del Entendimiento de solución de diferencias. El escenario resultante es el de parálisis por inoperancia del Órgano de Apelación a posteriori del 10 de diciembre de 2019. Este lado del triángulo deja afuera la efectividad de las normas, puesto que Estados Unidos no prestaría su consentimiento para nuevos nombramientos, y el sistema correría el riesgo de perecer. Al ser el régimen internacional de la OMC de tipo rule-oriented cualquier conducta contraria a sus principios, reglas y valores afecta al régimen en su conjunto, por tanto se hace necesario que el conflicto sea resuelto poniéndose en marcha un mecanismo de solución de controversias jurisdiccional o

\footnotetext{
${ }^{274}$ Texto disponible en: https://geneva.usmission.gov/2019/10/15/statements-by-the-united-states-at-thewto-general-council-meeting/

275 "Negando que les preocupa la persistente violación de las normas por parte del Órgano de Apelación, algunos miembros de la OMC tratan de evitar la cuestión más profunda: ¿por qué este se siente libre de hacer caso omiso del texto claro de los acuerdos?" (Traducción propia)

${ }^{276}$ Los grupos son: Americans for Prosperity, The LIBRE Initiative, American Legislative Exchange Council, ALEC Action, Center for Freedom and Prosperity, Coalition of American Metal, Manufacturers and Users, Competitive Enterprise Institute, National Taxpayers Union, Precision Metalforming Association, R Street Institute.

${ }^{277}$ Instándolo a "manifestar públicamente que el objetivo de los Estados Unidos no es matar al Órgano de Apelación, sino más bien reformarlo" (Traducción propia).

${ }^{278}$ Texto disponible en: https://americansforprosperity.org/wp-content/uploads/2019/10/WTO-AB-letterto-president-10-23-2019-2.pdf
} 
diplomático, que permita la restitución del status quo. Un mecanismo que cuente con una instancia inoperante tendría un efecto contrario para los miembros pero también para el régimen en sí mismo.

En definitiva, la crisis del Órgano de Apelación de la OMC puede ser analizada desde otras aristas, además de la legitimidad. Esta crisis demuestra una necesidad de reequilibrar las fuerzas dentro del sistema, de manera de poder evitar un estancamiento en las negociaciones que ponga en jaque todo el sistema de solución de disputas en la OMC. Si bien hay diferencias sustanciales con el régimen de solución de controversias inversor-Estado, en particular que se trata de un sistema entre Estados, este es otro botón de la muestra de la crisis del multilateralismo. En este marco, retomando el tema central de esta investigación, ¿es posible visualizar cambios que busquen reequilibrar el régimen de solución de controversias inversor-Estado en un escenario en crisis? El siguiente apartado examinará el proyecto revisado del instrumento vinculante sobre empresas y derechos humanos y su antecedente, el borrador cero, que la UNCTAD (2019: 4) califica como un camino hacia el reequilibrio.

\subsection{Reequilibrando el régimen: proyecto del instrumento vinculante sobre empresas y derechos humanos}

\subsubsection{Apuntes iniciales}

En la nota temática sobre acuerdos internacionales de inversiones número 1 de 2019 de la UNCTAD, en el apartado titulado "Rebalancing investment dispute settlement: sustainable developement and human rights" ${ }^{279}$, la institución reconoce el impacto de la agenda 2030 sobre desarrollo sostenible en el régimen de solución de controversias inversor-Estado (UNCTAD, 2019). El espíritu general de la resolución sobre la agenda 2030 (Asamblea General de la ONU, número A/RES/70/1, del 25 de setiembre de 2015) queda de manifiesto en el punto 3 de la declaración de los Estados miembros que afirman

Estamos resueltos a poner fin a la pobreza y el hambre en todo el mundo de aquí a 2030, a combatir las desigualdades dentro de los países y entre ellos, a construir sociedades pacificas, justas e inclusivas, a proteger los derechos humanos y promover la igualdad entre los géneros y el empoderamiento de las mujeres y las niñas, y a garantizar una protección duradera del planeta y sus recursos naturales. Estamos resueltos también a crear las condiciones necesarias para un crecimiento económico sostenible, inclusivo y sostenido, una prosperidad compartida y

\footnotetext{
279 "Reequilibrio de la solución de controversias en materia de inversiones: desarrollo sostenible y
} derechos humanos" (Traducción propia). 
el trabajo decente para todos, teniendo en cuenta los diferentes niveles nacionales de desarrollo y capacidad. (punto 3 de la declaración)

En este sentido, el objetivo número 16 (Promover sociedades pacíficas e inclusivas para el desarrollo sostenible, facilitar el acceso a la justicia para todos y construir a todos los niveles instituciones eficaces e inclusivas que rindan cuentas) implica cambios en torno al régimen de solución de controversias inversor-Estado. La UNCTAD (2019: 23) destaca el objetivo 16.3 que insta a los Estados a "promover el estado de derecho en los planos nacional e internacional y garantizar la igualdad de acceso a la justicia para todos”. El régimen bajo análisis es objeto de diversas críticas, una de ellas es la ausencia de una instancia de reclamación por parte de los Estados, puesto que son los inversores extranjeros los únicos que poseen jus standi, salvo que los tratados prevean la posibilidad de presentar demandas reconvencionales como se analizó en el capítulo 5 de este trabajo en relación al caso Urbaser contra Argentina.

La UNCTAD considera que el balance del régimen puede pensarse desde algunos instrumentos internacionales existentes o en gestación, como ser los Principios de la ONU sobre Empresas y Derechos Humanos (texto no vinculante) o el Instrumento jurídicamente vinculante para regular, en el marco del Derecho Internacional de los derechos humanos, las actividades de las empresas transnacionales y otras empresas (proyecto revisado). De esta manera se podría "adress the "one-way-street" nature of ISDS (to improve access to remedies) and/or focus on ways to mitigate potential negative impacts on access to remedies "280 (UNCTAD, 2019: 23).

Embarcada en un proceso de reforma más de tipo marginal que estructural, o más abocada a la esfera procesal que sustancial, la UNCTAD reconoce que es necesario abordar una de la falencias procesales del régimen. Esta es precisamente la imposibilidad de acceso directo de los Estados, quienes en casos excepciones podrán reconvenir si el instrumento en el que se basa la demanda del inversor extranjero así lo permite. Este aspecto se relaciona directamente con el estudio de la subjetividad jurídica de las empresas transnacionales (véase 1.5.2), en particular con el hecho que la regulación internacional actual no ha dado solución al problema de las empresas transnacionales como titulares de obligaciones (Theilbörger y Ackermann, 2017). El rechazo de la personalidad jurídica de las empresas transnacionales, en palabras de

\footnotetext{
${ }^{280}$ De esta manera se podría "abordar la naturaleza "unidireccional" de la solución de controversias inversor-Estado y/o centrarse en formas de mitigar los posibles impactos negativos en el acceso a los recursos jurídicos" (Traducción propia).
} 
Sornarajah (2015: 40), "enabled the continued maintenance of a curtain so that abuses by multinational corporations could remain beyond scrutiny"”281, y abona las diferencias entre los dos regímenes jurídicos.

Al comparar el Derecho Corporativo Global (concibiendo dentro de él al régimen de solución de controversias inversor-Estado) y el Derecho Internacional de los Derechos Humanos, González (2017: 28) afirma que existe una asimetría normativa, esto es, mientras el primero es imperativo, coercitivo y ejecutivo, el segundo es frágil, limitado a Estados, y carece de instancias de control y seguimiento. Los pasos tendientes a la elaboración de un instrumento vinculante para regular, en el marco del Derecho Internacional de los derechos humanos, las actividades de las empresas transnacionales y otras empresas, en particular el proyecto revisado, son vistos por Fabio Morosini como

una respuesta a la crisis de legitimidad del régimen de inversiones, en la que pretende alcanzar un equilibro de fuerzas entre los Estados y los inversores (...) En consecuencia, considero que el tratado propuesto (paradigma de la responsabilidad del inversor) es un contrapeso al mecanismo de solución de controversias inversor-Estado (paradigma de protección del inversor). (comunicación personal, 4 de octubre de 2019).

En consecuencia, en los siguientes apartados se analizará el proyecto revisado del instrumento vinculante para regular, en el marco del Derecho Internacional de los derechos humanos, las actividades de las empresas transnacionales y otras empresas, hecho público el 16 de julio de 2019, desde una perspectiva del régimen de solución de controversias inversor-Estado.

\subsubsection{El camino hacia el instrumento vinculante}

A nivel de la ONU, la obligación de las empresas de respetar los derechos humanos ha sido indirectamente incluida en el artículo 30 de la Declaración Universal de Derechos Humanos, dada su redacción laxa ${ }^{282}$. Durante la década de los setenta, el tema había sido objeto de debate a nivel de la ONU, sin lograr su consagración en una serie de principios básicos no vinculantes o un instrumento vinculante. En 1974, por ejemplo, en el seno del Consejo Económico y Social se constituyó la Comisión de Sociedades Transnacionales con el fin de crear un Código de Conducta para las empresas

\footnotetext{
281 "Permite mantener una cortina para que los abusos de las corporaciones multinacionales permanezcan fuera de la vista" (Traducción propia).

282 "Nada en esta Declaración podrá interpretarse en el sentido de que confiere derecho alguno al Estado, a un grupo o a una persona, para emprender y desarrollar actividades o realizar actos tendientes a la supresión de cualquiera de los derechos y libertades proclamados en esta Declaración" (artículo 30)
} 
transnacionales. Como explica Teitelbaum (2014), el texto fue discutido durante diez años sin llegar a un acuerdo. En la década de los noventa e inicios de la primer década del siglo XXI, tuvo lugar el siguiente paso tendiente a resolver la problemática de la inexistencia de obligaciones internacionales a cargo de las empresas. El tema se discutió en la Comisión de Derechos Humanos (antecesora del Consejo de Derechos Humanos), cuya Subcomisión de Promoción y Protección de Derechos Humanos trabajó junto a la Asociación Americana de Juristas y el Centro Europeo-Tercer Mundo. El proyecto elaborado no fue implementado por la Comisión y el tema pasó a manos de un Representante Especial nombrado por el Secretario General (Teitelbaum 2014).

Es en este punto que tiene lugar uno de los pasos más relevantes: la resolución 17/4 (16 de junio de 2011) del Consejo de Derechos Humanos. Se trata de una puesta en práctica del marco jurídico elaborado en 2008 por John Ruggie, ex Representante Especial del Secretario General para la cuestión de los derechos humanos y las empresas transnacionales y otras empresas (2005-2011) ${ }^{283}$. Esta implementó 31 principios rectores no vinculantes respecto a las empresas y los derechos humanos, que funcionan bajo tres pilares: proteger, respetar y remediar. La protección de los derechos humanos refiere a la obligación esencialmente estatal y su responsabilidad en caso de incumplimiento, el pilar de respeto se enfoca en la responsabilidad de las empresas por su conducta, y la remediación refiere a las acciones estatales tendientes a asegurar los recursos jurídicos y/o administrativos para la reparación de los daños sufridos.

En suma, los caminos que hasta ese momento han adoptado las normas demuestran dos posibilidades para establecer el respeto de los derechos humanos por parte de empresas privadas que realizan negocios fuera de frontera: imponer obligaciones a los Estados o desarrollar instrumentos de soft law que establezcan obligaciones morales para las empresas, más que obligaciones legales (Mouyal, 2016: posición 3829). Sin perjuicio de lo anterior, Schell señala que una norma de soft law "no es suficiente para regular la relación entre los intereses de las empresas inversoras y la protección de los derechos humanos. Sin embargo, colabora con la legitimación y gobernanza global" (Schell, 2017: 168).

Considerando los casos concretos de cuestionamiento de la responsabilidad empresarial por vulneración de derechos humanos, comienza a tomar relevancia la propuesta realizada por Ecuador respecto a iniciar la discusión tendiente a la celebración de un

${ }^{283} \mathrm{El}$ análisis de los principios excede los objetivos de este trabajo. En este sentido véase Werhane (2015). 
instrumento internacional legalmente vinculante sobre empresas y derechos humanos (24 período de sesiones del Consejo de Derechos Humanos, 9 al 27 de setiembre de 2013). El camino continúa con la resolución $26 / 22$ (25 de junio de 2014), mediante la cual el Consejo de Derechos Humanos decidió establecer un grupo de trabajo intergubernamental (GTI) para "elaborar un instrumento internacional jurídicamente vinculante para regular las actividades de las empresas trasnacionales y otras empresas en el derecho internacional de los derechos humanos" (punto 1). El 29 de setiembre de 2017 fue emitido un informe donde se señalan los elementos centrales de la discusión en aras de redactar el borrador cero, extremo que se cumple el 16 de julio de 2018. Un año después, el 16 de julio de 2019, es presentado el proyecto revisado que recoge las opiniones y propuestas de cambio vertidas por los Estados ante el borrador cero.

Por primera vez se está negociando a nivel de la ONU un tratado internacional en materia de derechos humanos y empresas, sean empresas transnacionales $\mathrm{u}$ otras empresas, como su denominación indica. Este constituye un paso más para garantizar el efectivo cumplimiento de los derechos humanos por parte de todos los actores internacionales. La clave estará en el número de Estados que ratifiquen o adhieran al instrumento, y que dentro de estos se encuentren no solo aquellos en los que las empresas desarrollan actividades transnacionales sino también los principales Estados en que estas se domicilian.

\subsubsection{Aspectos generales del proyecto revisado}

El proyecto revisado ${ }^{284}$, amplía su número de artículos de los 15 inicialmente incluidos en el borrador cero ${ }^{285}$ a 22 artículos divididos en tres secciones. El primer elemento a subrayar es que en su preámbulo destaca la universalidad, indivisibilidad e interdependencia de los derechos humanos, siendo el Estado el sujeto obligado primordialmente a promover, respetar, proteger y hacerlos efectivos. No obstante, esta afirmación se torna incompleta cuando los Estados están obligados internacionalmente al cumplimiento de normas de derechos humanos y de protección de inversiones, igualmente válidas y en vigor pero que presentan soluciones contrapuestas. La colisión

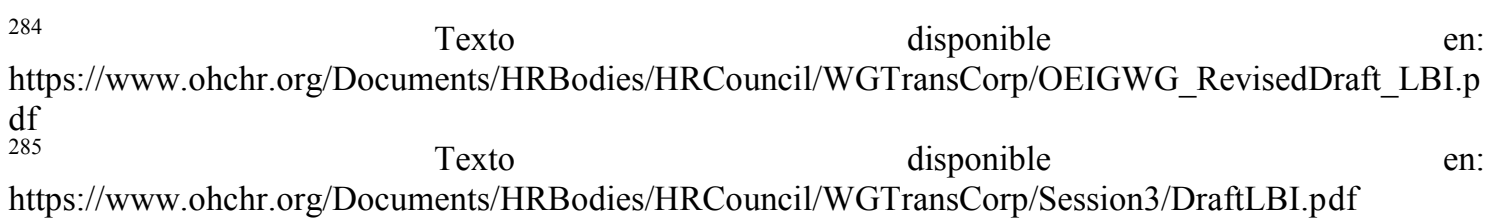


entre regímenes jurídicos autocontenidos no es resuelta o tomada en cuenta por el proyecto, aun cuando existen leading cases en la materia.

A nivel internacional, ejemplos de la colisión entre dichos regímenes autocontenidos son las disputas Philip Morris contra Uruguay relativa a la salud pública (caso CIADI número $\mathrm{ARB} / 10 / 7$ ) (véase punto 5.2 de este trabajo), Pac Rim contra El Salvador en torno a la protección del medioambiente en explotaciones mineras (caso CIADI número $\mathrm{ARB} / 9 / 12$ ) (véase punto 4.2), Chevron contra Ecuador en relación a la protección del medioambiente frente a los efectos de las explotaciones petroleras (caso CPA número 2009-23) (véase punto 2.3.2). A nivel interno es pertinente citar el caso Aguinda Salazar contra Chevron Corporation en los tribunales ecuatorianos respecto a la responsabilidad de la empresa extranjera frente a ciertas colectividades indígenas en consecuencia del episodio de contaminación en la provincia de Sucumbíos (Amazonia Ecuatoriana), directamente vinculado con el caso Chevron contra Ecuador.

En relación a las empresas, el proyecto prevé que estas deben respetar los derechos humanos, evitar que sus actividades generen o contribuyan a generar consecuencias negativas sobre los derechos humanos, y reparar a los damnificados. Si bien el reconocimiento de la responsabilidad de las empresas es un punto a destacar, este se hace en el preámbulo, siendo este de discutible obligatoriedad ${ }^{286}$. Al definir el ámbito de aplicación, el proyecto avanza en claridad respecto al borrador cero, ya que indica que este será aplicable a las actividades empresariales, particularmente pero no exclusivamente a aquellas de carácter transnacional. Esto es, aquellas actividades desarrolladas en dos o más jurisdicciones nacionales, o bien en el territorio de un Estado pero parte del proceso empresarial se desarrolla en otro Estado, o tengan consecuencias sustanciales en otro Estado (artículo 3). Asimismo, es importante la aclaración que el texto comprende a todos los derechos humanos, sin dejar rastro de duda en su aplicación.

La definición es amplia, no se centra en el carácter subjetivo de la empresa sino en su actividad (elemento objetivo), y no se ciñe al ámbito privado, dejando de lado a las empresas estatales. Elemento este que en un futuro deberá ser regulado específicamente, por el impacto que puede generar un violación a los derechos humanos por parte de empresas de propiedad estatal (SOE por su sigla en inglés). Este tema cobra mayor

\footnotetext{
${ }^{286}$ Cabe señalar que la Convención de Viena sobre Derecho de los tratados entre Estados incluye al preámbulo dentro del contexto que debe tenerse en cuenta a la hora de interpretar los términos incluidos en el tratado, si bien no forma parte del texto per ser.
} 
trascendencia con el avance de las empresas chinas con participación directa del Estado como señala Fabio Morosini (comunicación personal, 4 de octubre de 2019).

\subsubsection{Responsabilidad y derechos de las víctimas}

El artículo 4 del proyecto establece que las víctimas tienen derecho a ser tratadas con humanidad y respeto, garantizándoles sus derechos, y protegiéndolas de cualquier interferencia ilegal contra su privacidad o de actos de intimidación. Por consiguiente, es obligación del Estado proporcionar el acceso legítimo, efectivo, rápido y no discriminatorio a la justicia para que esta analice la reclamación y en consecuencia pueda establecerse una eventual reparación ${ }^{287}$. No se trata meramente la existencia del mecanismo, sino que este sea adecuado. Como establece la Corte Interamericana de Derechos Humanos en la sentencia de fondo del caso Velásquez Rodríguez vs. Honduras (párrafo 64), un mecanismo resulta adecuado si su función "es idónea para proteger la situación jurídica infringida" más allá de su existencia formal ${ }^{288}$.

Los reclamos puede presentarse ante los tribunales internos del Estado donde se produjeron los actos u omisiones o el tribunal del Estado, el domicilio de la víctima, o donde esté domiciliada la persona física o jurídica o la asociación de estas, que se presuma que haya cometido tales actos u omisiones, sea el lugar donde tiene su sede social, administración central, interés empresarial principal filial, agencia, dependencia, subdivisión, oficina de representación o afín (artículo 7). La jurisdicción prevista es doméstica y no un tribunal de carácter internacional, aunque sea ad hoc como en el régimen de solución de controversias inversor-Estado.

En el informe de setiembre de 2017 del GTI, se planteaba la posible discusión sobre mecanismos domésticos e internacionales, judiciales y no judiciales, incluso el posible establecimiento de una Corte Internacional sobre Empresas Transnacionales y Derechos Humanos (GTI, 2017: 13). El camino tomado impidió que se diera un cambio sustancial en el sistema, dado que hubiera reforzado la idea del locus standi de las empresas

\footnotetext{
${ }^{287}$ Ya sea que se trate de: 1) restitución compensación, rehabilitación, satisfacción, garantía de no repetición; 2) reparación ambiental o restauración ecológica (artículo 4 numeral 5). No define a las dos últimas, por tanto su aplicación presenta dificultades de ser concretada o controlada eficazmente, al no contar con los estándares que pretende alcanzar, ni establece instituciones y/o mecanismos del control.

${ }^{288}$ El derecho de la víctima también implica que esta pueda acceder, en caso que sea necesario, a mecanismos diplomáticos y consulares apropiados, así como a mecanismos no jurisdiccionales en los Estados parte. Asimismo, las víctimas tienen derecho a acceder a información relevante sobre los recursos disponibles, aspecto que va de la mano con el Acuerdo Regional sobre el Acceso a la Información, la Participación Pública y el Acceso a la Justicia en Asuntos Ambientales en América Latina y el Caribe (2018).
} 
transnacionales con la posibilidad que sean demandadas en un foro internacional, además del actual rol de demandantes en el arbitraje inversor-Estado. Consultado sobre este punto, el profesor José Augusto Fontoura Costa concluyó que los procedimientos internos pueden ser suficientes. Aun así, destacó la importancia de que el sistema judicial cuente con una "regla amplia para el pronto cumplimiento de las decisiones provisionales y definitivas en los Estados donde las compañias tengan activos” (comunicación personal, 23 de setiembre de 2019), aspecto no previsto por el proyecto revisado.

Esta norma incluida en el proyecto fortalece la idea central del documento respecto a que la obligación primordial respecto a los derechos humanos recae en los Estados. Por tanto, la responsabilidad de las empresas se diluye al entrar en juego el interés o la capacidad del Estado en cumplir con su obligación, con la consecuente responsabilidad estatal en caso de omisión. Un avance del proyecto frente al borrador cero es que la responsabilidad de las empresas transnacionales estaba ceñida a las fronteras del Estado en que desarrollan su actividad o donde se domicilian. El proyecto amplía la jurisdicción al incluir a los tribunales del domicilio de las víctimas, elemento que facilita el acceso a la justifica dado que en la actualidad no es sencillo determinar con precisión el territorio de actuación de una empresa o incluso su domicilio con el uso de cadenas globales de valor.

El punto anterior no debe confundirse con el deber del Estado frente al incumplimiento de cualquier obligado en materia de derechos humanos, partiendo de una concepción amplia de obligados como la que propone el artículo 30 de la declaración Universal de los Derechos Humanos. El profesor Felipe Michelini sostiene que frente al incumplimiento de organizaciones o empresas

el Estado debe accionar los mecanismos correspondientes para la prevención, el cese de la violación, la investigación y la eventual sanción de los responsables, así como la reparación de las víctimas y sus familiares. Si no lo hace, será responsable por omisión. El Estado no puede renunciar a esa conducta ni pretender excepcionar su responsabilidad alegando el cumplimiento de otras normas como, por ejemplo, honrar una cláusula contractual. Asimismo, las organizaciones o empresas, no deberían aceptar obligaciones contractuales que violen en forma flagrante disposiciones de derechos humanos. (comunicación personal, 28 de setiembre de 2019)

En línea con lo anterior, es destacable la previsión del proyecto respecto a la responsabilidad penal de las personas jurídicas y físicas por violaciones a los derechos humanos o abusos en el contexto de las actividades estatales (artículo 6). Es en este marco que enumera a texto expreso los delitos a que los Estados se obligan a establecer 
en su Derecho Doméstico ${ }^{289}$. El listado comprende dese los crímenes de guerra, lesa humanidad y genocidio, tortura y tratos crueles, desaparición forzada, ejecución extrajudicial, trabajo forzado, uso de niños soldado, esclavitud, desplazamiento forzado, tráfico de personas y violencia basada en el género (artículo 6 numeral 7).

Dos elementos son destacables en la mencionada norma. El primero es la referencia expresa a las definiciones previstas en los tratados internacionales en la materia, como ser el Estatuto de la Corte Penal Internacional, despeja dudas en cuanto a la tipificación de conductas. El segundo, es que, la responsabilidad de las empresas que son personas jurídicas podría ser civil, administrativa o penal conforme a la jurisdicción y el texto tiene en cuenta esas posibilidades. Esta consideración es un avance del proyecto revisado, ya que Estados como Argentina y Rusia no reconocen la responsabilidad penal de las empresas que son personas jurídicas (López, 2019).

\subsubsection{Otras disposiciones: derecho aplicable, prevención e institucionalidad}

Merece especial consideración el artículo 9 del proyecto, referido al Derecho aplicable. Conforme a la norma, en aquellos temas no regulados por el acuerdo, los tribunales que entienden en el caso deberán aplicar sus normas jurídicas. La excepción a la lex fori, la presentan las normas sobre derechos humanos puesto que estos se regirán por la legislación del domicilio de la persona implicada en las actividades empresariales. En este sentido, puede derivar en un mecanismo de cherry picking, permitiendo a las empresas transnacionales emplear su estructura organizativa para ser juzgada conforme a las normas del Estado que le resulten más convenientes.

En el informe del GTI de 2017 se planteaba la discusión sobre el posible reconocimiento de la primacía de los compromisos en materia de derechos humanos sobre los tratados de comercio e inversiones (GTI, 2017: 3). La disposición finalmente incluida en el proyecto no establece una jerarquía entre normas según su objeto o su naturaleza doméstica o internacional. Únicamente refiere a la compatibilidad de las normas bilaterales o multilaterales con las obligaciones del instrumento vinculante, una vez que este entre en vigor (artículo 12 numeral 6).

El proyecto innova al aclarar que las obligaciones que de él emanen deben ser consistentes con los principios del Derecho Internacional (principio de igualdad soberana, integridad territorial y no intervención en la jurisdicción doméstica). La

\footnotetext{
${ }^{289}$ Para un análisis específico de las violaciones de los derechos humanos por parte de las empresas transnacionales desde un enfoque criminológico, véase: Böhm (2017).
} 
aclaración no es necesaria ya que se trata de normas de jus cogens y por tanto, cualquier tratado que nazca en su contra es nulo. En otros términos, si el instrumento vinculante no fuera compatible con los mencionados principios, sería absolutamente nulo aunque no existiera una norma como el artículo 12 numeral 1.

Por otra parte, cabe destacar que, al igual que el borrador, el proyecto revisado establece mecanismos de prevención que obligan a los Estados parte, cada uno dentro de su territorio (artículo 5). En efecto, es el Estado quien tiene el deber de controlar que se respeten las obligaciones de debida diligencia en las actividades empresariales de carácter transnacional, considerando los posibles efectos sobre los derechos humanos. La debida diligencia comprende la supervisión de los efectos, la identificación y evaluación de las violaciones reales o potenciales de los derechos humanos, la prevención de dichas violaciones, y la información pública y periódica, entre otros. No se prevén mecanismos de seguimiento.

Finalmente, en su artículos 13 y 14, el convenio establece mecanismos de gobernanza: el Comité y la Conferencia de los Estados Parte. El Comité estará compuesto por 12 expertos elegidos mediante un criterio de distribución geográfica equitativa y teniendo en cuenta los diferentes ordenamientos jurídicos y la representación de género. El número de expertos aumentará a 18 cuando el convenio alcance las sesenta ratificaciones o adhesiones. Al Comité se le asignan las clásicas funciones de monitorio del cumplimiento de la convención, esto es, formular observaciones sobre la aplicación de la convención, examinar y brindar observaciones y recomendaciones a los Estados parte, apoyar a los Estados en la recopilación de información de manera que la aplicación de la convención esté garantizada. Hernández Zubizarreta y otros (2018) y López (2018) son críticos respecto a la eventual actuación del Comité, en el sentido que este no tendrá capacidad de investigación ni posibilidad de recibir denuncias, quedando tales acciones restringidas a la jurisdicción estatal.

Juan Hernández Zubizarreta considera que más allá de las disposiciones sustantivas del borrador, los aspectos ejecutivos, tal y como están redactados, difícilmente podrán ser empleados para hacer valer los derechos fundamentales frente a las empresas transnacionales. Por consiguiente, es una demostración de

la gran desigualdad jurídica o asimetría frente a los sistemas de solución de controversias inversor-Estado, por eso desde la red (Desmantelando el Poder Corporativo) se exige un tribunal internacional que controle el poder de las empresas transnacionales y neutralice los efectos del régimen de solución de controversias inversor-Estado. Este régimen deja en un vacio jurídico a las personas, los pueblos e incluso a los Estados que no pueden hacer valer sus 
derechos e intereses. Hasta el momento no se ha logrado, las jurisdicciones deberían cruzarse en un tribunal internacional y no permanecer en paralelo.

(...) La idea de la seguridad jurídica de los inversores hay que respetarla", pero "en caso de confrontación entre inversiones y derechos humanos deben prevalecer los segundos. Por tanto, deben fortalecerse los mecanismos internos de protección de los derechos humanos, y establecer en un instrumento vinculante (por ahora es un proyecto revisado) un marco global en el cual puedan resolverse los conflictos que vinculen a los Estados pero que participen todas las partes involucradas (Estados, empresas transnacionales, pueblos, personas fisicas) (Juan Hernández

Zubizarreta, comunicación personal, 30 de setiembre de 2019).

En suma, la importancia del análisis de la relación entre empresas transnacionales y Estados, con los derechos humanos como epicentro, considerando que las empresas transnacionales "actúan permeando fronteras, normas y reglamentos y con ellos cuestionan los propios principios humanos sobre los cuales se edifica toda la legitimidad del pensamiento (y modelo) de crecimiento económico" (Bizzozero, 2017: 8). La problemática que aborda el proyecto revisado del Instrumento jurídicamente vinculante para regular, en el marco del Derecho Internacional de los derechos humanos, las actividades de las empresas transnacionales y otras empresas trasciende los aspectos jurídicos y atraviesa otras áreas: relaciones internacionales, políticas públicas, economía, etc. El texto, si bien tuvo muchos cambios desde la propuesta inicial, no deja de ser una manifestación institucional del reclamo estatal de recobrar los poderes regulatorios.

\subsection{Soberanía regulatoria: transición hacia el nuevo concepto}

\subsubsection{De las cuatro proyecciones de la soberanía a la soberanía regulatoria}

En el contexto de la crisis de la globalización, y más recientemente de la crisis del multilateralismo, el régimen de solución de controversias inversor-Estado atraviesa una crisis de legitimidad. La reacción de una de las audiencias relevantes, los Estados como uno de los actores clave en torno a la inversión extranjera, ya sea mediante el cuestionamiento o rechazo de los principios del sistema jurídico, o incluso la construcción de alternativas, es una manifestación de cambios profundos. Partiendo de las cuatro proyecciones de la soberanía que propone Krasner (2001), en este apartado se valorará si existe una transición hacia la construcción de una quinta proyección: la soberanía regulatoria.

El mencionado autor propone cuatro proyecciones de la soberanía, en otros términos, cuatro conceptos que definieron el instituto de la soberanía a lo largo de la historia conforme a los elementos vinculados: autoridad, control y legitimidad. Las cuatro proyecciones son: 1) soberanía de interdependencia, vinculada al control estatal de los 
movimientos a través de sus fronteras nacionales (notas de control); 2) soberanía westfaliana, aquella que aparece históricamente en función de las notas fundamentales de la Paz de Westfalia de 1648 y que consolida un sistema de Derecho basado en el principio de no intervención en los asuntos internos (notas de autoridad y legitimidad); 3) soberanía interna, relacionada a la existencia de estructuras de autoridad domésticas capaces de ejercer control efectivo dentro de fronteras (notas de autoridad, legitimidad y control); y 4) soberanía legal internacional, referida al reconocimiento mutuo entre Estados (notas de autoridad y legitimidad) (Krasner, 2001). En estudios posteriores, incorpora la soberanía de interdependencia a la soberanía interna, ya que ambas comparten las notas de control (Krasner, 2009, 2009b).

Krasner sostiene que "there is no accepted alternative to soverignity" (2011: 21306), afirmación que la realidad internacional confirma, sin embargo la soberanía se transforma según las necesidades de esta realidad. El autor no incluye dentro de su categorización ninguna definición que se focalice en el espacio de política pública del Estado, cuyo reconocimiento en el régimen de solución de controversias inversorEstado, se analizó en el apartado 6.3. En primer lugar el nuevo concepto de soberanía no se vincula con la soberanía westfaliana, porque no se plantea como una prohibición que se ejerce con exclusividad frente a la injerencia de otro actor estatal (principio de no intervención recogido originariamente en los Tratados de Westfalia y en la actualidad por la Carta de la ONU y la Declaración 2625). En la soberanía regulatoria la prohibición o limitación se ejerce frente a actores no estatales (empresas transnacionales) al cuestionar las medidas tomadas por los Estados. Tampoco se relaciona con la soberanía de interdependencia, ya que la nota de control no se encuentra priorizada como en ella. No existe un control de los flujos a través de fronteras, sino un espacio inquebrantable de elaboración normativa en el interior del Estado que se proyecta al exterior de este para la construcción, modificación y/o abandono de regímenes internacionales (conjunto de normas, principios y reglas que rigen la conducta de sus miembros).

Los poderes regulatorios están vinculados con la soberanía interna, ya que implican la existencia de una autoridad, que será legítima si las audiencias relevantes la aceptan como obligatoria, y tendrá control dentro de sus fronteras. Sin embargo, esta definición de soberanía no explica per se cómo un Estado, por el hecho de ser soberano (atributo), tiene poder de regular en determinadas áreas sin injerencia externa (sea de Estados u otros actores). El ejercicio de dicho poder, que es una condición del Estado, se plasma 
en el principio de libre determinación de los pueblos: elección libre de su condición política, y por tanto determinar de forma autónoma cuáles son las políticas de desarrollo económico, social y cultural que mejor considera. La libre determinación tiene sentido sin injerencia de otro Estado (punto de conexión con la soberanía westfaliana), ni de ningún otro actor no estatal (ejemplo: empresas transnacionales).

En relación a la soberanía legal internacional, la soberanía regulatoria podría presentarse como una fase doméstica de esta (como concepto antitético), una suerte de "soberanía legal interna". Sin embargo sería una lectura acotada, ya que la soberanía regulatoria no se circunscribe con exclusividad hacia el interior del Estado, sino que también se proyecta hacia el exterior del Estado moldeando las estructuras externas mediante la creación, modificación y/o abandono de regímenes internacionales. En "Changing state structures: Outside in"290, Krasner (2011) afirma que las instituciones internacionales pueden moldear las estructuras internas, especialmente cuando los Estados comprometen soberanía westfaliana mediante el ejercicio de la soberanía legal internacional (celebración de tratados básicamente).

Krasner no analiza el fenómeno inverso: cambio de estructuras internacionales como efecto de los cambios internos en los Estados, esto es, un proceso desde adentro hacia afuera (inside out) por oposición al proceso desde afuera hacia adentro (outside in). Como se verá en el apartado 7.4.4, las manifestaciones de la transición hacia un nuevo concepto de soberanía regulatoria son ejemplos de cómo la defensa del espacio de política pública al interior del Estado, impacta en las estructuras internacionales mediante el abandono del régimen internacional (situación de Bolivia, Ecuador, Sudáfrica y parcialmente Venezuela), la celebración de tratados que buscan balancear el régimen (los ACFI de Brasil con la exclusión del régimen, CPTPP con la excepción a las medidas de control del tabaco, el modelo de TBI de la India con un fortalecimiento del mecanismo de agotamiento de la jurisdicción doméstica), la creación de nuevas instituciones en paralelo de las actuales (el sistema de tribunales de inversiones de la UE).

Asimismo el acuerdo plurilateral de los 22 miembros de la UE para la terminación de sus TBI intra-UE es otro ejemplo, si bien este es parcial y particular por la presencia de una organización supranacional. La Comisión Europea ya ha manifestado con anterioridad, y vuelve a hacerlo en la declaración del 24 de octubre de 2019, que

290 “Cambiando las estructuras estatales: desde afuera hacia adentro” (Traducción propia). 
aquellos Estados que no terminen sus TBI intra-UE podrán ser objeto de procedimiento de infracción (artículo 258 del Tratado de Funcionamiento de la UE). El procedimiento tiene una etapa inicial prejudicial que comienza con una notificación de emplazamiento al Estado incumplidor del Derecho de la Unión. Este tiene un plazo que suelen ser dos meses para responder, pero en caso que la Comisión entienda que el Estado no cumple con el Derecho, emite un dictamen motivado instándolo a hacerlo. Si persiste el incumplimiento, la Comisión tiene facultad para llevar el caso ante el TJUE quien emite sentencia. Si la sentencia no es cumplida o no se informa su cumplimiento, el artículo 260 numerales 2 y 3 da la posibilidad de un seguro recurso de infracción ante el TJUE.

Dado el anuncio de la Comisión y el antecedente del dictamen del Tribunal de Justicia en torno al caso Achmea, podría darse una situación de negociación coercitiva. Esto es, los Estados que, aun sin ser firmantes originarios, decidan adherir al acuerdo plurilateral en el entendido que fuera del nuevo status quo estarán en peores condiciones que siendo parte (Krasner, 2011: 21305). Asimismo, tanto la aplicación efectiva del procedimiento de infracción como la negociación coercitiva son ejemplos de procesos desde afuera hacia adentro: las normas internacionales ${ }^{291}$ impactan en la política exterior de los miembros que no siguen la posición de la Comisión.

Si bien el rol de la Comisión es velar por el cumplimiento de los tratados fundamentales, la intención de iniciar los procesos de infracción manifiesta una clara posición política frente a los arbitrajes intra-UE. Ya sea que prime la narrativa jurídica o la narrativa política, ambas influyen desde la estructura del régimen internacional (UE) sobre la conducta de sus miembros, con el fin de encauzarlo al cumplimiento del Derecho. Dadas las características de organización internacional supranacional, la UE es uno de los casos donde se percibe con mayor claridad la construcción de estructuras de manera bidireccional (interna - externa).

\subsubsection{Autoridad, control y legitimidad en la soberanía regulatoria}

La soberanía regulatoria, en suma, teniendo en cuenta las tres notas básicas de la soberanía: control, autoridad y legitimidad, carece de la nota de control, ya que esta no se presenta en la vigilancia de flujos a través de fronteras, como en la soberanía de interdependencia, ni tampoco de lo que sucede dentro del Estado, como en la soberanía interna. Está presente la nota de autoridad, en el entendido que es mediante ella que se

\footnotetext{
${ }^{291}$ Estas normas pueden ser supranacionales o no.
} 
ejercen los poderes regulatorios sin limitaciones de terceros actores, sean Estados $\mathrm{u}$ otras entidades. En otros términos, la soberanía regulatoria no admite invitaciones válidas para su erosión o condicionamiento justamente porque vulnerarían su base: el espacio de política pública. A pesar de la interpretación que realiza la CPJ en el asunto del vapor Wimbledon (1923) respecto a que la soberanía no puede erosionarse por tratados concluidos por el Estado en ejercicio de dicha soberanía, en este trabajo se sostiene que la soberanía es un concepto absoluto (se es soberano o no se es, no tiene posibilidad de graduación). Si el Estado pierde su soberanía, o un porcentaje de ella, dejaría de ser Estado porque esta es el atributo de ese tipo de sujetos de Derecho Internacional. Si existen limitaciones son a la autonomía, como condición y no atributo del Estado.

La soberanía se tiene o no se tiene, no se limita por el ejercicio de esta. Cuando autores como Mouyal afirman que la soberanía no es un concepto absoluto (en términos de regular o no regular) y que como soberano un Estado puede elegir entre regulaciones que determinen desarrollo o bienestar social (Mouyal 2016, posición 6696), no tienen en consideración que la capacidad de elegir no es una consecuencia de la soberanía sino de la autonomía estatal. Por tanto, la limitación puede verse en la autonomía estatal, ya que es una condición y no un atributo del Estado.

Finalmente, la última nota distintiva de la soberanía regulatoria es la legitimidad. La consolidación del espacio de política pública implica la declaración y defensa de un conjunto básico de normas (legitimidad en términos jurídicos) y el apoyo de audiencias relevantes que las aceptan como indicadores de las conductas a seguir (legitimidad en términos sociológicos) (Krasner, 2006). ¿Es posible visualizar un criterio unívoco de actos estatales o áreas de regulación que conformen la soberanía regulatoria? Si hay un límite en su contenido está en construcción. De los instrumentos jurídicos analizados puede inferirse que están incluidas las normas relacionadas a la seguridad estatal, medioambiente, salud, medidas de control del tabaco, a lo cual debe sumarse la protección de los derechos humanos en la cúspide del sistema. De esta manera se haría frente al congelamiento o parálisis regulatoria en dichas áreas ${ }^{292}$.

En efecto, habitualmente los actos estatales vinculados con dichas áreas regulatorias son consideradas como medidas de expropiación indirecta, aplicación del principio de

\footnotetext{
${ }^{292}$ Para ganar en legitimidad sería necesario incluir la opinión de las "voces ausentes" en la régimen internacional de protección de inversiones, ya que sus intereses suelen estar en tensión con los principales actores vinculados a la inversión extranjera (Perrone, 2019).
} 
expropiación y debida compensación que deja más espacio a la interpretación arbitral (análisis caso a caso ${ }^{293}$ ). Ejemplo de lo anterior son los casos Eco Oro contra Colombia (apartado 4.3), Philip Morris contra Uruguay (apartado 5.2), Bear Creek contra Perú (apartado 4.4), entre otros. Cuando los tribunales arbitrales interpretan normas amplias o poco precisas, de cierta manera están dándole forma y definiendo conceptos como el derecho de regular (Perrone, 2019: 17), con la peligrosidad que esto implica como control externo de la actividad estatal.

La inexistencia de un elenco claro tiene como centro que casi la totalidad de temas susceptibles de regulación estatal a nivel doméstico, también son regulados internacionalmente. Esto se da en parte por interés político o económico de los Estados, haciendo uso de la soberanía legal internacional, y en parte porque "many policies have become internationalized trough happenstance or the operation of political lobbies rather than with any genuine economic justification " ${ }^{294}$ como indica Rodrik (2019) ${ }^{295}$. E1 autor señala que aun en el supuesto que los Estados apliquen de manera errada ciertas políticas, los Estados democráticos deberían estar autorizados a equivocarse (Rodrik, 2019). En definitiva, en el acierto o en el error, el ejercicio de la soberanía regulatoria debe ser protegido y no puede ser condicionado por otros actores.

\subsubsection{Los motivos}

En vista del análisis anterior, ¿cuál es el motivo de la gestación de una nueva concepción de la soberanía? Desde la perspectiva del régimen de solución de controversias inversor-Estado, la respuesta debe hacer foco en el impacto que generó el propio régimen internacional sobre los Estados miembros: la erosión o condicionamiento del espacio de política pública reconocida por la UNCTAD a partir del año 2003, ya que los tribunales arbitrales ad hoc se comportan como órganos de contralor externos de la actividad o inactividad de los Estados (Hernández González, 2017; Postiga: 2013: 182; Van Hurten y Loughlin, 2016: 149). Este impacto es señalado en la carta que un grupo de 230 profesores de Derecho y Economía de diferentes

\footnotetext{
${ }^{293}$ En este sentido véase OCDE (2004).

294 "Muchas políticas se han internacionalizado a través de la casualidad o el funcionamiento de los lobbies politicos en lugar de con cualquier justificación económica genuina” (Traducción propia).

${ }^{295295}$ El planteo del autor parte del trilema desarrollado en "La paradoja de la globalización" (2011). En esta obra Rodrik señala que no puede haber al mismo tiempo hiperglobalización, políticas democráticas y soberanía nacional. El Estado debe elegir dos de estas y descartar la tercera, de ahí el trilema.
} 
universidades de Estados Unidos ${ }^{296}$ enviaron al Presidente Trump el 25 de octubre de $2017^{297}$, instándolo a remover el régimen de solución de controversias inversor-Estado de la renegociación del Acuerdo de libre comercio de Norteamérica y cualquier tratado comercial o de inversiones que Estados Unidos firme en el futuro.

La carta desarrolla varios argumentos que pueden resumirse en dos ideas centrales: 1) los tribunales ad hoc en el régimen de solución de controversias inversor-Estado son quienes, en última instancia, determinan los límites de los actos administrativos, legislativos y judiciales del Estado al tener capacidad de controlarlos (establecer una indemnización por los actos estatales o incluso dejarlos sin efecto) sin posibilidad de apelación; y 2) los ciudadanos u otras entidades afectadas no cuentan con recursos para intervenir o participar significativamente en las disputas. En definitiva, el régimen no solo tiene un déficit democrático por el poder otorgado a los tribunales sino que no tiene en cuenta a los verdaderos afectados. Se trata de un "actor ausente", como denomina Perrone (2019: 16) a las comunidades locales, calificativo que puede ser extendido a cualquier persona física individual que se vea afectada. Su participación se encuentra circunscripta a la presentación de escritos amicus curiae que deben ser aceptados por el tribunal que entiende en la disputa, como se analizó en los casos Pac Rim contra El Salvador (véase apartado 4.2) y Eco Oro contra Colombia (véase apartado 4.3).

En definitiva, el impacto sobre el espacio de política pública tiene lugar ya que el régimen internacional de protección de inversiones, contentivo del régimen de solución de controversias inversor-Estado, se desarrolla y tiene su auge en plena globalización económica, momento de privatización y desnacionalización de políticas que anteriormente pertenecían a la esfera pública; privatización normativa; y transformaciones dentro del Estado que lo hacen funcionar en base a la lógica del capital global (Sassen, 2010: 107-108). Por consiguiente, Sassen (2010: 110) se interpela si en este marco el Estado tiene como destino reducir su autoridad o si, por el contrario, debe transformarse y así construir un corpus normativo y de decisiones judiciales frente al avance de la globalización.

En trabajos anteriores, la autora ya había afirmado que el Estado no puede quedar limitado a una significación declinante y que una reducción en su capacidad de regular no se explica exclusivamente porque opera en un mundo globalizado (Sassen, 2001:

\footnotetext{
${ }^{296}$ Universidades de Columbia, Yale, Fordham, Alabama, Denver, Florida, Notre Dame, San Francisco, Minnesota, Denver, Portland, Johns Hopkins. Ithaca, Harvard, Georgetown, American, entre otras.

${ }^{297}$ Texto disponible en: https://www.citizen.org/wp-content/uploads/migration/case_documents/isds-laweconomics-professors-letter-oct-2017_2.pdf
} 
45). Frente a un régimen internacional que condiciona o erosiona el espacio de política pública del Estado, son sus miembros quienes buscan caminos para recuperar los poderes regulatorios. ¿Por qué este proceso de recuperación de los poderes recuperatorios tiene lugar desde el año 2007, marcando como hito el retiro de Bolivia del CIADI? Este hito coincide con la crisis global de 2008, punto de quiebre en la globalización, como se analizó en el apartado 7.2.

El régimen internacional de protección de inversiones se consolidó durante el auge de la globalización, y se construyó una extensa red de más de 3000 instrumentos jurídicos internacionales que regulan la materia y que dan un marco a uno de esos nuevos actores, las empresas transnacionales, para demandar a los Estados en caso de incumplimiento. En los últimos años han surgido tratados que consagran el derecho de regular de los Estados, en mayor o menor medida y de manera más o menos clara. Sin embargo, no se ha resuelto la tensión entre la protección de inversiones y el espacio de política pública, ni siquiera en temas sensibles como puede ser la protección del medioambiente o los derechos humanos.

Por tanto, al presentarse un cambio de forma en el proceso globalizador, no es de extrañarse que aquellos regímenes que se vieron favorecidos comiencen a presentar quiebres. En materia normativa, este debilitamiento se vio enmarcado con una multiplicidad de instrumentos que regulan diversas áreas de la esfera internacional (regímenes jurídicos autocontenidos), incluso entrando en contradicción entre ellos a causa de la fragmentación del Derecho Internacional (véase apartado 1.2.3). La misma situación puede cuestionarse respecto a la soberanía, si la globalización debilitó al Estado, ¿es la slowbalisation un momento de retomar los poderes regulatorios vinculados a la soberanía como atributo del Estado? ¿Es necesario, entonces, una menor regulación a nivel internacional?

La respuesta no puede darse en términos cuantitativos sino cualitativos. La problemática central no es la regulación excesiva a nivel internacional, sino la fragmentación del Derecho Internacional y la colisión entre regímenes autocontenidos. Tampoco es una problemática que se resuelva desregulando en la esfera internacional, retomando la lógica liberal del laissez faire - laissez passer. Un ejemplo claro es el libre comercio, justamente un área que se rige por la lógica del mercado, es una de las más reguladas de las relaciones internacionales actuales: normas generales en materia de mercaderías, normas generales en materia de servicios, excepciones a la regla, tratamiento 
diferenciado según la categoría de los Estados, normas específicas en materia de obstáculos técnicos al comercio, subsidios, salvaguardias, etc.

En definitiva, el núcleo del problema no se encuentra en no tener normas, sino en tener mejores normas. En efecto, las manifestaciones que se analizarán en el siguiente apartado, especialmente aquellas vinculadas con el régimen de solución de controversias inversor-Estado, tienen como objetivo la construcción de nuevos regímenes o la reforma de los existentes, no su desaparición. Ya sea pensando en la construcción o reforma de un régimen internacional, la elaboración de normas jurídicas que protejan el espacio de política pública son esenciales.

\subsubsection{Las manifestaciones de la transición hacia la soberanía regulatoria: una visión de conjunto}

En vista de lo anterior, el reconocimiento de la soberanía regulatoria no solo tiene raíces domésticas, respecto a la toma de decisiones en materia ejecutiva, legislativa y judicial a nivel interno del Estado. Esta rompe la esfera doméstica y se ramifica hacia el exterior del propio Estado al moldear, abandonar o crear regímenes internacionales vinculados al área de regulación en defensa (proceso desde el interior hacia el exterior). El análisis realizado en el círculo 1 de este trabajo muestra ejemplos de este fenómeno.

El abandono del régimen internacional de solución de controversias inversor-Estado constituye la primera expresión (véase capítulo 2), cuyo hito inicial estuvo en manos de Bolivia en el año 2007 al denunciar el Convenio de Washington (1965) por parte de Bolivia, y posteriormente dar inicio a un proceso de terminación de los TBI que tenía en vigor. El proceso fue seguido por Ecuador y Venezuela que se retiraron del CIADI en 2009 y 2012 respectivamente, y la terminación de todos o parte de los TBI por Ecuador y Sudáfrica respectivamente. No obstante, Ecuador modificó esta línea con la llegada del Presidente Lenin Moreno y los cambios normativos establecidos en el nuevo Código Orgánico de la Producción (2018). El retorno al arbitraje internacional para contratos que superen los 10.000 millones de dólares incorporado a instancia del Presidente Lenin Moreno es una manifestación de soberanía regulatoria pero a su vez un retroceso en el camino que ese Estado había recorrido como disidente.

La segunda manifestación se encuentra en los nuevos modelos de acuerdos que regulan la protección de inversiones (véase capítulo 3). Estos caminan entre la necesidad de reequilibrar el sistema, con las excepciones sectoriales en el CPTPP (o incluso 
exclusión total en el marco de notas reversales entre algunas de sus partes), la exclusión total de los mecanismos arbitrales de solución de disputas inversor-Estado en el modelo ACFI de Brasil, y la creación de un complejo proceso para agotar la jurisdicción doméstica en el modelo de TBI de la India del año 2016. A estos podría sumarse el TBI Marruecos-Nigeria con una consagración y regulación profunda del derecho de regular (véase apartado 6.3.2). Estos acuerdos buscan brindar al mismo tiempo protección a las inversiones extranjeras y proteger el espacio de política pública de los Estados.

A nivel de la UE, el 24 de octubre de 2019 se concretó el compromiso de los 22 miembros firmantes de la declaración del 15 de enero de 2019 (véase apartado 6.4), quienes optaron por celebrar un acuerdo plurilateral para terminar sus TBI intra-UE en vez del camino de las denuncias bilaterales. En su comunicado del mismo día de la celebración del acuerdo 298 , la Comisión Europea "regrets that a small minority of Member States has not been able to endorse the text ${ }^{\prime 299}$. Asimismo, reafirma que iniciará procedimientos de infracción (artículo 258 del Tratado de Funcionamiento de la UE) a aquellos miembros que no terminen sus TBI intra-UE. Este argumento, en definitiva, es una nueva manifestación de la protección del espacio de política pública comunitario y su corazón, el derecho de regular de la UE. Su consagración dentro del núcleo duro del Derecho de la Unión determina que este prime por encima de los tratados que celebran los miembros. En caso de incumplimiento de los tratados fundamentales de la UE, la Comisión iniciará procedimientos de infracción.

Asimismo, en el sistema de tribunales de inversiones propuesto por la UE en los tratados bilaterales con terceros Estados, como ser el caso del CETA (véase apartado 6.4), es otra manifestación del camino que están transitando algunos Estados para cambiar el régimen internacional. La Comisión ya cuenta con mandato del Consejo para la negociación de un acuerdo multilateral, acuerdo que de concretarse presentaría una alternativa real al CIADI $\mathrm{u}$ otros foros actuales, siendo en el comienzo regímenes internacionales paralelos. No obstante, es criticable que el Tribunal de la UE al entender sobre el caso Achmea considere a los arbitrajes intra-UE contrarios al Derecho de la Unión, pero no así al sistema de tribunales de inversiones previsto en el CETA. Si bien 4-bilateral-investment-treaties_en.pdf

${ }^{299}$ La Comisión Europea "lamenta que una pequeña minoría de Estados miembros no haya podido respaldar el texto” (Traducción propia).
} 
hay una reivindicación del espacio de política pública, la dualidad en la postura es una extensión de su problemática interna.

Ahora bien, estas manifestación son puntuales, no abarcan a la totalidad de Estados miembros del régimen internacional, pero se están dando a paso firme. No es posible afirmar que el nuevo concepto de soberanía se encuentra consolidado sino que se está cristalizando, esto es, está en status nascendi. Se podría señalar que esas manifestaciones no se dan solamente en el régimen de solución de controversias inversor-Estado. La solución de controversias que involucran a Estados soberanos, en general, es el caldo de cultivo para nuevos desarrollos que impacten en la soberanía. El motivo es la posibilidad de revisión de las políticas soberanas ante la obligación de cumplir con resoluciones jurisdiccionales o administrativas. Si bien el centro de este trabajo es el régimen de solución de controversias inversor-Estado, a continuación se manejarán ejemplos que permiten muestran que existen manifestaciones de la soberanía regulatoria aun fuera de él.

El primero de ellos es en el marco de la actual crisis del Órgano de Apelación de la OMC y el bloqueo estadounidense al nombramiento de nuevos miembros o renovación de los mandatos de los actuales. La justificación es la oposición a la interpretación que el propio órgano hace sobre el incumplimiento de reglas de funcionamiento, especialmente la regla 15 sobre su funcionamiento: los miembros siguen en actividad entendiendo en los casos en los que estaban trabajando una vez expirado su mandato. La posición de Estados Unidos demuestra una reacción frente a la imposibilidad de ejercer su derecho a tomar decisiones en la OMC, y dadas las características del sistema, su negativa torna imposible el consenso.

Asimismo, la excepción de seguridad que argumenta Estados Unidos para el aumento de los aranceles al acero y el aluminio, inicio de la "guerra comercial" con China, y piedra angular de las disputas contra Estados Unidos en la $\mathrm{OMC}^{300}$, se basa en una norma amplia y que da espacio a la interpretación de diversas medidas tomadas en su marco al indicar que

No deberá interpretarse ninguna disposición del presente Acuerdo en el sentido de que: (...) b) impida a una parte contratante la adopción de todas las medidas que estime necesarias para la protección de los intereses esenciales de su seguridad, relativas:

\footnotetext{
${ }^{300}$ Disputas en orden cronológico conforme a la solicitud de inicio de consultas: DS544 (China, en curso), DS547 (India, en curso), DS548 (UE, en curso), DS550 (Canadá, resuelta por acuerdo de partes), DS551 (México, resuelta por acuerdo de partes), DS564 (Turquía, resuelta por acuerdo de partes), DS552 (Noruega, en curso), DS556 (Suiza, en curso). Datos disponibles en: https://www.wto.org/ (Fecha de consulta: 18 de octubre de 2019).
} 
i) a las materias fisionables o a aquellas que sirvan para su fabricación;

ii) al tráfico de armas, municiones y material de guerra, y a todo comercio de otros artículos y material destinados directa o indirectamente a asegurar el abastecimiento de las fuerzas armadas;

iii) a las aplicadas en tiempos de guerra o en caso de grave tensión internacional (artículo XXI: Excepciones relativas a la seguridad, GATT).

En la disputa entre Ucrania y Rusia (caso DS512), el 26 de abril de 2019, el Órgano de Solución de Disputas adoptó el informe del grupo especial ${ }^{301}$ que establece que Rusia no cumplió con los requisitos del artículo XXI y por tanto no puede considerarse que se configuró una excepción a la libertad de tránsito entre ambos Estados. Esta resolución es contraria a los intereses de Estados Unidos. Sin embargo, si se considera que la conducta estadounidense se enmarca en el artículo XXI del GATT (particularmente el inciso i del literal b) $)^{302}$, debe reconocerse que se trata de un área cuyo proceso de toma de decisiones se da a nivel doméstico y no internacional (Rodrik, 2019). Constituye una reivindicación del espacio de política pública, aunque vinculado también con la soberanía westfaliana por las propias características de la seguridad nacional como actividad estatal.

Este marco da fuerza a los cuestionamientos del presidente respecto a los efectos negativos del multilateralismo sobre Estados Unidos, en especial en términos antitéticos: seguridad nacional versus libre comercio, o más simplemente, la defensa del espacio de política pública en materia de seguridad como argumento frente a la arquitectura jurídica básica del comercio multilateral. En efecto, la reivindicación soberanista de Trump pone en jaque "los pilares históricos sobre los cuales descansaba la hegemonía de Estados Unidos": el libre comercio, el multilateralismo y la articulación de la alianza transatlántica (Tussie, 2019: 109-110).

Asimismo, es un tema que excede la narrativa netamente comercial y se mueve hacia una narrativa geopolítica-militar que asienta el poder estatal en la seguridad nacional. La gravitación de la seguridad nacional dentro del rol del Estado lleva a que Strange afirme que la estructura de la seguridad está construida en base a la figura del Estado, como actor que históricamente tuvo el monopolio del uso de la fuerza (Strange, 1994: posición 1049), aunque en la actualidad haya perdido exclusividad.

\footnotetext{
301 Texto del informe del Órgano de Solución de Diferencias (WT/DS512/7) disponible en: https://docs.wto.org/dol2fe/Pages/SS/directdoc.aspx?filename=q:/WT/DS/512-7.pdf

Texto del informe del grupo especial (WT/DS512/R) disponible en: https://docs.wto.org/dol2fe/Pages/SS/directdoc.aspx?filename=s:/WT/DS/512R.pdf

${ }^{302}$ Examinar si la conducta de Estados Unidos se enmarca en el artículo XXI del GATT excede los objetivos de este trabajo.
} 
Por otra parte, el hecho que los argumentos vengan de la mano de Estados Unidos, un actor del clásico centro imperial, genera mayor tensión sobre el sistema multilateral del comercio. Esta tensión se presenta en término de quién la genera (Estados Unidos como potencia del clásico centro imperial, pero también como el primer importador de mercaderías del mundo, y segundo exportador ${ }^{303}$ ), a quién se enfrenta (China como nueva potencia, pero también como primer exportador del mundo, y segundo importador $^{304}$ ), y cuáles son efectos institucionales en la OMC (eventual bloqueo del consenso en la toma de decisiones).

Podría argumentarse que la posición de Estados Unidos es un ejemplo más de la capacidad que tienen los Estados centrales de incumplir normas internacionales sin efectos negativos para sí mismos. En efecto, en 1982, durante la vigencia del GATT 1947, Strange ya había señalado como limitación de la teoría de los regímenes internacionales, que el incumplimiento de las normas se habían multiplicado en vez de descender por efecto de la construcción de un régimen internacional. Sin embargo, el cumplimiento de la norma debe estar apoyado por mecanismos de solución de controversias que permitan evaluar la conducta, determinen un castigo, y permitan volver a status quo inicial. Asimismo, estos mecanismos deben ser legítimos, en términos jurídicos y sociológicos, para no perder credibilidad.

En definitiva, la conducta estadounidense, ajena al régimen de solución de controversias inversor-Estado, es también una muestra de la resistencia del modelo relacional que propone Consani (2008) en el marco institucional del siglo XXI. El Estado, como actor principal del modelo relacional, vuelve a reivindicar su rol y centralidad en medio de un modelo institucionalizado que incluye otros actores. No significa que exista una reivindicación de un sistema sin represión del poder, la resistencia se presenta con elementos puntuales (especialmente en el rol del Estado) y no implica un regreso completo al modelo anterior ${ }^{305}$.

Otro ejemplo fuera del régimen de solución de controversias inversor-Estado también fue tratado en este capítulo y es el proceso de negociación de un instrumento vinculante en materia de derechos humanos y empresas transnacionales (actualmente en etapa de

\footnotetext{
303 Conforme a datos del año 2018 disponibles en la Sección de Estadísticas de la OMC (https://data.wto.org/). Fecha de consulta: 6 de noviembre de 2019.

304 Conforme a datos de años 2018 disponibles en la Sección de Estadísticas de la OMC (https://data.wto.org/). Fecha de consulta: 6 de noviembre de 2019.

${ }^{305}$ Es importante recordar que los modelos son ideales, por tanto son se visualizan de manera completa o perfecta en el sistema internacionales, existiendo tensiones entre el modelo imperante y la resistencia del anterior.
} 
proyecto revisado). Si bien los cambios entre la propuesta inicial de Ecuador y el proyecto revisado son profundos, es un paso hacia el reclamos de mayores poderes regulatorios por parte de los Estados para investigar y juzgar los actos corporativos que sean contrarios a los derechos humanos. Al dejar esta tarea exclusivamente en manos de los tribunales domésticos, la extensión hacia el exterior de los Estados y construcción de un nuevo régimen internacional sin mecanismos propios de solución de controversias, genera un panorama futuro más difuso.

Sin perjuicio de lo anterior, Saskia Sassen plantea que así como la globalización debilitó al Estado y fortaleció a los actores no estatales (ejemplo: empresas transnacionales), el actual proceso de slowbalisation no necesariamente generará un efecto contrario o una vuelta de un cierto tipo de poder o control a manos del Estado (Saskia Sassen, comunicación personal, 26 de octubre de 2019). El efecto de las altas finanzas sobre los Estados (deuda pública) y los ciudadanos (ejemplo: crisis de la deuda de los préstamos universitarios de Estados Unidos) son un ejemplo del poder de los actores no estatales sin que el Estado cuente con mayor incidencia.

Por tanto, de haber manifestaciones de una nueva definición de soberanía, Sassen considera que estas pueden variar de Estado a Estado, e incluso dentro de cada Estado pueden darse fenómenos contrarios. La profesora ejemplifica con Estados Unidos que al mismo de tiempo de facilitar "el auge y las ganancias del sistema de altas financias, no haya apoyado a la banca tradicional, que ha perdido mucha capacidad bajo las nuevas condiciones" (Saskia Sassen, comunicación personal, 26 de octubre de 2019). Al tratarse de un concepto en construcción, esta consideración resulta de relevancia, ya que los ejemplos que se plantean en este apartado son una muestra que, a escala global, aún no hay convergencia en las respuestas.

\subsection{Conclusiones del capítulo 7}

El concepto de soberanía no ha perdido vigencia en el siglo XXI, sin embargo es un concepto mutable conforme a la realidad del sistema internacional y los intereses de sus actores en general, no exclusivamente los Estados. Si bien Krasner plantea una evolución histórica de la soberanía en cuatro proyecciones (de interdependencia, westfaliana, interna y legal internacional), el autor no desarrolló una proyección que se base en la defensa del espacio de política pública frente a actores estatales o no 
estatales. En este capítulo se concluye que existe una transición hacia un nuevo concepto de soberanía (soberanía regulatoria).

La nueva definición conduce a dar una respuesta a la constatación de Sornarajah (2015: 75) respecto a "the increasing demands for the balancing of investment protection with other aims of international law, such as the eradication of poverty, the protection of the environment and the promotion of human rights" ${ }^{\prime 306}$. En concreto, la soberanía regulatoria busca defender el espacio de política pública de los Estados, en cuyo corazón se encuentra el derecho de regular. Dado que el concepto aún no está cristalizado, su contenido no está delimitado. En este punto el rol de los Estados es fundamental mediante la inclusión en los tratados de un elenco de temas a ser protegidos y que no puedan ser vulnerados por otras normas internacionales.

Al tratarse de un régimen internacional construido mayoritariamente en base a densas redes de acuerdos bilaterales, la reconstrucción del régimen también responde a esa complejidad. La UE representa un caso excepcional por la plurilateralidad y dualidad en sus medidas: al exterior plantea una propuesta del sistema de tribunales de inversiones (bilateral en el CETA y multilateral como escenario futuro), y al interior en el acuerdo del 24 de octubre de 2019, 22 miembros establecen la denuncia de sus TBI intrabloque por ser contrarios al Derecho de la Unión. Por otra parte, la excepción de las medida de control del tabaco en el CPTPP también constituyen una manifestación plurilateral, aunque más acotada a un área en particular. Las restantes expresiones en esta línea tienen carácter bilateral, por tanto su sumatoria aportará a la reconstrucción del régimen, aunque la multiplicidad y heterogeneidad de actores estatales enlentece la cristalización de los cambios, incluso desdibuja sus márgenes.

La reconstrucción del régimen mediante nuevos tratados o alternativas institucionales es una proyección de la soberanía regulatoria desde el interior de los Estados hacia el exterior, que complementa las ideas de Krasner (2011) en torno a que las instituciones internacionales moldean las estructuras internas de los Estados. Asimismo, es una comprobación que en un régimen que sigue un modelo institucionalizado, en palabras de Consani (2008), resisten vestigios del modelo relacional.

Ahora bien, la labor de los tribunales arbitrales también impacta en la delimitación de las áreas dentro del derecho de regular, o de manera más amplia del espacio de política

\footnotetext{
306 "Las crecientes demandas de equilibrio de la protección de las inversiones, que incluya otros objetivos del Derecho Internacional, como ser la erradicación de la pobreza, la protección del medio ambiente y la promoción de los derechos humanos" (Traducción propia).
} 
pública. En palabras de Perrone (2019: 17), "they are shaping and defining the public right to regulate ${ }^{307}$ al interpretar y aplicar al caso concreto las disposiciones de los tratados. Independientemente que la jurisprudencia arbitral ha incorporado el principio de proporcionalidad, teniendo en cuenta el abordaje del Tribunal Europeo de Derechos Humanos (Sornarajah, 2015: 365 y siguientes), disposiciones poco claras, laxas o que dejen un margen de maniobra para la interpretación en sede arbitral entraña un peligro: su aplicación queda supeditada a la interpretación caso a caso. De esta manera se desvanecen los límites del derecho de regular.

En un contexto histórico, la transición hacia la soberanía regulatoria surge como una de las aristas de la crisis de la globalización. La globalización coadyuvó al régimen de solución de controversias inversor-Estado al propulsar el debilitamiento del Estado como actor global, el ascenso de nuevos actores no estatales como las empresas transnacionales y la centralidad del mercado. La crisis de la globalización mostró las limitaciones del mercado e interpeló al Estado a reclamar sus poderes regulatorios disminuidos. Por este motivo las manifestaciones de la transición a un nuevo concepto de soberanía tienen lugar del 2007 en adelante. La crisis del multilateralismo también da un marco a este proceso de cambio, en particular si se tiene en cuenta que las instituciones de Bretton Woods son fuertemente cuestionadas y que el sistema de solución de disputas de la OMC, particularmente el Órgano de Apelación, no escapa a la necesidad de reforma.

En este marco podría inferirse que las empresas transnacionales han perdido poder, más si se parte de la base que el régimen internacional funciona en términos de un juego de suma cero. No obstante, la evidencia empírica y las opiniones de los especialistas consultados llevan a concluir que no hay una pérdida de poder sino una transformación de las empresas transnacionales. Puntualmente en materia de solución de controversias inversor-Estado el surgimiento del mercado de los seguros a las inversiones en el exterior son un ejemplo de nuevas modalidades de protección de los riesgos de invertir en el exterior.

En la reconstrucción del régimen internacional de protección de inversiones en general, o del régimen internacional de solución de controversias inversor-Estado en particular, también impactan cambios producidos en otros regímenes. En efecto, el Instrumento jurídicamente vinculante para regular, en el marco del Derecho Internacional de los

307 "Están dando forma y definiendo el derecho del Estado a regular" (Traducción propia). 
derechos humanos, las actividades de las empresas transnacionales y otras empresas (proyecto revisado) es interpretado por la UNCTAD (2003) como una manifestación de la búsqueda de balance en el régimen de protección de inversiones. El texto fortalece las jurisdicciones domésticas pero no crea un tribunal internacional con competencia en la materia o que permita un cruce entre el Derecho de las Inversiones y el Derecho de los Derechos Humanos.

En consecuencia, la pregunta a responder sería si es posible que exista un verdadero balance que provenga del exterior del régimen. En vista del análisis de las características del proyecto revisado, es posible sostener que si bien coadyuva a la reconstrucción de un régimen más justo y que proteja de manera balanceada el espacio de política pública de los Estados y la generación de riqueza de las empresas transnacionales, el balance debería forjarse dentro del propio régimen de protección de inversiones. Acuerdos como el TBI entre Marruecos y Nigeria, el modelo de TBI de India del año 2016, los ACFI, entre otros, cada uno con sus particularidades, se encaminan a sentar las nuevas bases jurídicas. De lo contrario, si la visión de los regímenes continúa siendo separada y autonómica se seguirá abonando la tesis del pluralismo jurídico, tirando por tierra una concepción integral y no fragmentada del Derecho Internacional. 


\section{Conclusiones del círculo 3}

El tercer y último círculo de este trabajo buscó dar respuesta a la interrogante: ¿ha evolucionado el concepto de soberanía hacia una nueva definición, que parte de supuestos diferentes a los que propone Krasner, explicativa de los cambios en el régimen de solución de controversias inversor-Estado? De ser así, ¿qué características tiene y en qué se fundamenta? Por consiguiente se trabajó en contrastar la siguiente hipótesis: "El concepto de soberanía estatal ha evolucionado hacia una nueva definición que se construye desde la defensa del espacio de política pública, generando cambios en las instituciones internacionales: régimen de solución de controversias inversor- Estado (proceso desde el interior al exterior del Estado)".

El análisis se estructuró en dos partes: el espacio de política pública y la transición hacia una nueva definición de soberanía. Del análisis realizado surgen tres conclusiones principales. En primer lugar, en el sistema internacional hay manifestaciones de la transición hacia un nuevo concepto de soberanía: la soberanía regulatoria, sin embargo este concepto está en construcción. Su base es la defensa del espacio de política pública del Estado y en su centro el derecho de regular, cuya erosión o condicionamiento en el marco de los procesos de solución de controversias inversor-Estado fue reconocido por la UNCTAD en el año 2003.

Las áreas susceptibles de regulación aún no están definidas en su totalidad. De los tratados internacionales analizados en otros círculos de esta investigación se infiere que debe incluirse la protección del medioambiente, la protección de los derechos humanos, o la seguridad nacional como áreas generales, y la protección de la salud pública o las medidas de control del tabaco en particular. La soberanía regulatoria muestra una evolución hacia un concepto que parte de la idea contraria a la manifestada por la Corte Permanente de Justicia Internacional en 1923 en el caso del vapor Wimbledon: la soberanía no puede verse erosionada por la asunción de compromisos internacionales por parte del Estado. En concreto, se perfila la existencia de un interés estatal en no ceder frente al régimen de solución de controversias inversor-Estado, por tanto un inversor extranjero no podría iniciar un mecanismo de solución de disputas ante medidas de este tipo.

La segunda conclusión a la que se arriba en este círculo es que las manifestaciones de la evolución hacia un nuevo concepto de soberanía, aun en transición, tienen lugar a partir 
del año 2007. Este año es significativo porque Bolivia se convierte en el primer Estado en el mundo en denunciar el Convenio del Washington y consecuentemente retirarse del CIADI. Asimismo, el 2007 es la antesala de la crisis económico-financiera de 2008, crisis que marca un hito en la globalización como uno de sus quiebres. El proceso actual de slowbalisation deja de manifiesto profundos cambios en la distribución del poder a escala global, el modelo de la transnacionalización de la producción, la gobernanza nacional e internacional, y las dimensiones sociales y ambientales del modelo. Este fenómeno se superpone y retroalimenta con la crisis del multilateralismo. Los quiebres en el régimen de solución de controversias inversor-Estado se nutren de los quiebres en la globalización y el multilateralismo, en particular el planteo de algunos Estados de recobrar sus poderes regulatorios.

En tercer lugar, en este círculo se concluye que las manifestaciones de la transición hacia el concepto de soberanía regulatoria son: el abandono del régimen internacional (Bolivia, Ecuador aunque con cambios durante el 2018, Venezuela, Sudáfrica de manera parcial), y la celebración de tratados que buscan un balance o excluir el régimen (los ACFI de Brasil, el CPTPP por la excepción de las medidas de control del tabaco, y el modelo de TBI de India de 2016) (analizados en el círculo 1). A estos ejemplos deben sumarse el TBI Marruecos-Nigeria con un enfoque más profundo de la protección del espacio de política pública. La soberanía regulatoria no es un concepto que se aplique con exclusividad al ámbito doméstico de los Estados, sino que se extiende hacia el exterior y moldea las instituciones internacionales, como los ejemplos anteriores demuestran.

El caso de la UE es paradigmático ya que muestra una dualidad en la postura ante el régimen. A su interior, el 24 de octubre de 2019, 22 Estados celebraron un acuerdo plurilateral por el cual dan término a sus TBI intra-UE, ya que a consecuencia del caso Achmea consideran que el régimen de solución de controversias inversor-Estado es contrario al Derecho de la Unión. A su exterior, el sistema de tribunales de inversiones previsto en el CETA con Canadá es considerado compatible con las normas comunitarias, sin infringir el espacio de política pública. Asimismo, los TBI con Estados no comunitarios no son cuestionados.

Otras manifestaciones de la soberanía regulatoria pueden visualizarse en áreas ajenas a la del régimen internacional bajo estudio. A modo de ejemplo pueden citarse la crisis del Órgano de Apelación de la OMC, la excepción de seguridad nacional que argumenta el gobierno de Trump para aumentar los aranceles al acero y el aluminio y que dio lugar 
a la "guerra comercial" con China, tema que trasciende al propio Estado y deriva en la arquitectura del sistema internacional en torno al concepto de poder. Por consiguiente, esta problemática muestra aristas heterogéneas, que pueden variar de Estado a Estado, y obstaculiza la cristalización del nuevo concepto de soberanía a escala global.

En suma, tomando como punto de partida las cuatro proyecciones de la soberanía propuso Krasner (soberanía de interdependencia, soberanía legal internacional, soberanía westfaliana y soberanía interna), se percibe una transición hacia la soberanía regulatoria. Esta tiene como centro la protección del derecho de regular, pero al encontrarse en construcción, aún no está delimitado específicamente su contenido. De los instrumentos internacionales analizados puede inferirse la protección de los derechos humanos, la protección del medioambiente y la seguridad nacional.

En el régimen internacional bajo análisis, la soberanía regulatoria excede una mirada exclusiva a la esfera doméstica del Estado y se extiende hacia el exterior al buscar moldear el régimen mediante nuevas normas e instituciones que involucran la protección del derecho de regular (proceso desde el interior hacia el exterior). Por consiguiente, en la transición hacia una reconfiguración del régimen internacional de solución de controversias inversor-Estado, un nuevo principio se deriva del principio general y se suma a los siete analizados en el apartado 1.2.3. El principio de protección del derecho de regular busca limitar el principio general de protección de la inversión extranjera. Este proceso aún no está consolidado.

En consecuencia, dado que la soberanía regulatoria es un concepto de transición, la hipótesis se confirma parcialmente: el concepto no ha evolucionado sino que está en evolución. 


\section{Conclusiones finales}

El régimen internacional de protección de inversiones, en el que se enmarca el régimen internacional de solución de controversias inversor-Estado, tuvo su momento de auge en la década de los noventa con la celebración de casi la mitad de los acuerdos actuales, gracias a su impulso por el consenso de Washington y otras instituciones vinculadas a la gobernanza del régimen, como la UNCTAD. A pesar de haberse construido una red de más de 3000 acuerdos en materia de inversiones, que establecen prórroga de jurisdicción al arbitraje internacional inversor-Estado, los mecanismos de solución de controversias inversor-Estado comenzaron a emplease de manera más dinámica a partir de la primera década del siglo XXI.

En este cambio actúan como catalizadores las crisis económicas atravesadas por los dos principales Estados demandados. Este es el caso de Argentina, Estado número 1 en el ranking (61 demandas). Las medidas tomadas para paliar los efectos de crisis económica del año 2001 dan lugar a 37 de demandas de inversores extranjeros, en particular producto de las normas que imponen la conversión a pesos argentinos de los precios y tasas en contratos públicos y el abandono de las cláusulas de ajuste en monedas extranjeras o parámetros internacionales.

La situación de Argentina no es diferente a la de España, Estado número 2 en el ranking (51 demandas). Puntualmente, el paralelismo se puede trazar con las 47 controversias en el sector energías renovables, particularmente energía solar. Las demandas tienen como base los recortes y posterior eliminación de los beneficios a las energías renovables que forman parte del paquete de medidas tomado por el Estado para mitigar los efectos de la crisis económica 2008-2014. La problemática de España y los arbitrajes de las energías renovables generan un nuevo pico en el número de demandas registradas desde el inicio del uso del sistema. Este se da en el 2015 con 83 demandas, de las cuales 18 corresponden a España.

En la actualidad, el régimen de solución de controversias inversor-Estado es blanco de fuertes críticas, entre las que se destaca que las demandas o amenazas de demandas, por parte de inversores extranjeros, inciden negativamente sobre el espacio de política pública del Estado, especialmente sobre su corazón: el derecho de regular. Este efecto se da, en primer lugar, en términos de congelamiento o parálisis normativa dentro del propio Estado u otros que, para evitar verse involucrados en disputas, se abstienen de 
regular. En segundo lugar, los tribunales arbitrales se han convertido en órganos de contralor externo de la actividad o inactividad estatal, incluso políticas vinculadas a la protección de los derechos humanos (salud pública, derechos de las comunidades indígenas, acceso al agua y saneamiento, entre otros) y el medioambiente.

Es un este contexto que la relación Estado-empresas transnacionales se desarrolla en la actualidad. El Estado cuestionado en su capacidad de regular y la privatización de la justicia en tribunales arbitrales ponen en el tapete el desbalance de poder a favor de los inversores extranjeros y en detrimento de los poderes estatales. En definitiva, cuestiona las bases mismas de la soberanía como atributo del Estado, no compartido por ningún otro sujeto de Derecho Internacional Público, y como piedra fundamental del sistema de coordinación actual. Asimismo, interpela al sistema internacional a debatir sobre las acciones de las empresas transnacionales, su subjetividad internacional, y los límites a su conducta desde la óptica del espacio de política pública.

En vista de lo anterior, este trabajo tuvo como objetivo general analizar la relación entre los principales actores vinculados a la inversión extranjera, Estados y empresas transnacionales, en el marco del régimen de solución de controversias inversor-Estado. De este objetivo general se desprendieron tres específicos que permitieron darle cumplimiento. Los objetivos específicos se organizaron en torno a tres círculos que visualmente forman un diagrama de Venn en cuya intersección se encuentra la relación Estado-empresas transnacionales.

En el círculo 1 se examinaron las alternativas planteadas por los Estados frente al régimen de solución de controversias inversor-Estado (período 2007- presente), su fundamento y el rol de los actores involucrados. La elección del marco temporal se debió a que el año 2007 marca uno de los hitos en el régimen: Bolivia se convirtió en el primer Estado del mundo en retirarse del CIADI al denunciar el Convenio de Washington. Asimismo, el 2007 fue la antesala de la crisis global de 2008, momento de quiebre en la globalización y que coadyuva, aunque no exclusivamente, a un proceso que al día de hoy puede ser visto como slowbalisation.

El abandono del régimen constituye la primera alternativa analizada, además del retiro del CIADI por parte de Bolivia en 2007, dos años después lo hizo Ecuador, y en 2012 Venezuela. Bolivia consolidó su proceso con la terminación de los TBI en vigor (salvo cuatro), Venezuela únicamente denunció el TBI con Países Bajos en el marco del cual se registró el mayor número de casos en su contra. La situación de Ecuador muestra 
diferencias, ya que si bien luego de presentado el Informe de la CAITISA (2017) denunció los TBI que aún estaban en vigor, en el año 2018 el Gobierno de Lenin Moreno incluyó el arbitraje inversor-Estado dentro de la reforma del Código Orgánico de la Producción.

Por otro lado, Sudáfrica constituye el único disidente africano, al haber terminado diez de sus TBI luego del impacto del caso Piero Foresti y otros. Los inversores cuestionaron las medidas tomadas para paliar los efectos del apartheid y posibilitar el acceso a la población históricamente desfavorecida a la explotación minera. A los motivos coyunturales se le suman otros de carácter político-ideológico (salida del apartheid y sostenimiento de un modelo democrático de inclusión) y jurídico (aplicación a sectores concretos del derecho a la igualdad consagrado en la Constitución de 1994).

Los disidentes sudamericanos también son movidos por la coyuntura, en particular la experiencia como demandados en arbitrajes de inversiones. Ejemplo de esta problemática son los casos Chevron III contra Ecuador o Aguas del Tunari contra Bolivia. Ambas tienen connotaciones económicas pero también sociales y medioambientales e involucran el efectivo goce de derechos humanos, como es el acceso al agua.

Los disidentes del régimen de solución de controversias inversor-Estado, ya sea por abandono total o parcial, también fundan su conducta en motivos políticos. Bolivia, Ecuador y Venezuela dieron los principales pasos para la salida del sistema durante gobiernos de corte progresista: primera presidencia de Evo Morales (2006-2010), segunda presidencia de Rafael Correa (2009-2013), y tercera presidencia de Hugo Chávez (2007-2013). Estos priorizaron una agenda de derechos sociales, protección del medioambiente y de los recursos estratégicos (hidrocarburos y gas, básicamente). Las reformas constitucionales de Bolivia (2009) y Ecuador (2008) aportaron dos elementos que determinan cambios en su política exterior y refuerzan las posiciones estatales desde una perspectiva jurídica: la consagración de los derechos de la naturaleza (siendo las industrias extractivas el centro de la mayoría de las demandas), y la prohibición de prórroga de jurisdicción al arbitraje internacional, salvo a tribunales de procesos de integración latinoamericanos y caribeños.

Aplicando la teoría de los regímenes internacionales y la tipología creada en 2017 (miembros, externos y disidentes), los cuatro Estados bajo análisis son disidentes. Esto significa que formaron parte del régimen: contaban con TBI en vigor y tres de ellos adhirieron al Convenio de Washington dejando de lado los preceptos de la doctrina 
Calvo. Sin embargo en años posteriores decidieron abandonar el régimen, mediante la terminación de todos o algunos de dichos instrumentos.

Inicialmente, la tipología se completó con los miembros: los Estados que son parte del régimen y no presentaron cambios en su posición (figura residual); y los externos: Estados que históricamente se ubicaron fuera del régimen. Para esta tesis, se reformuló la tipología, ubicando a los Estados en un tablero según: 1) se encuentren dentro o fuera del régimen bajo análisis, y 2) hayan cambiado o mantenido su posición. De esta forma, a los miembros, disidentes y externos se agregó el grupo de los confrontadores. Estos son Estados que, sin abandonar el régimen, presentan cambios en su posición original, especialmente mediante la propuesta de creación de un régimen alternativo o paralelo o buscan un escaso empleo del actual.

Para completar el círculo 1, se identificaron y examinaron los tratados que buscaban un balance o exclusión del régimen. En primer lugar se estudiaron los ACFI de Brasil, el único Estado de Sudamérica que históricamente ha mantenido el carácter de externo. El nuevo modelo de tratado sostiene su posición, ya que excluye la solución de disputas iniciadas por inversores extranjeros. Los motivos constitucionales prevalecen sobre los políticos. Desde el punto de vista jurídico el Congreso Brasilero (2002) consideró que los TBI eran contrarios a la Constitución al establecer una jurisdicción diferente a la doméstica y privilegiar más al inversor extranjero al darle derecho a demandar al Estado ante un tribunal arbitral internacional, mientras el inversor nacional no puede hacerlo. La misma lógica impera en los ACFI, así como el fin de defender la autonomía estatal con independencia de los aspectos político-ideológicos. En este sentido, la negociación de ACFI comenzó en 2015 y continúa hasta la actualidad (gobiernos de Dilma Rousseff, Michel Temer y Jair Bolsonaro). El modelo ACFI fue replicado en el Mercosur (2017) y Brasil propuso su discusión a nivel de la OMC (2018).

En el caso del CPTPP, el acuerdo sigue en líneas generales los modelos más actuales de TBI en lo que respecta a los mecanismos de arbitraje inversor-Estado. No obstante, tiene la particularidad de excluir a las medidas de control del tabaco. La experiencia de Australia (arbitraje de Philip Morris en la CPA) y el enfriamiento regulatorio en Nueva Zelanda impulsaron esta decisión. La excepción de las medidas de control del tabaco es una innovación que ya ha comenzado a replicarse en otros acuerdos, a saber: enmienda del TLC Singapur-Australia y TBI Singapur - Kazajistán. No es posible afirmar que se trata de una tendencia pero ya no es un caso aislado. 
En último lugar, se identificó el nuevo modelo de TBI de India (2016) que cuenta con un complejo procedimiento para agotar la jurisdicción doméstica, paso obligatorio y previo a dar inicio al arbitraje internacional. Si bien el mecanismo no impide ni prohíbe los arbitrajes, su complejidad desmotivará su inicio, y operará como mecanismo de protección estatal frente a demandas infundadas. La causa más profunda que lleva a India a terminar con sus TBI y elaborar un nuevo modelo de acuerdo también es coyuntural, principalmente los efectos del caso White Industries.

En suma, en el círculo 1 se concluye que si bien los motivos que movieron a los Estados examinados son coyunturales, políticos y jurídicos, el centro se encuentra en la protección de su soberanía interna y su soberanía regulatoria (concepto en transición que se desarrolló en el círculo 3) mediante el ejercicio de la soberanía legal internacional (que le permite celebrar o terminar tratados). De esta manera, se concreta el ejercicio pleno de la autonomía, esto es, determinar cuáles son las medidas a tomar en materia económica, social, política, cultural, etc. sin injerencia de terceros Estados ni actores no estatales. Este último punto es significativo, ya que la autonomía puede ser vulnerada por empresas transnacionales en caso de parálisis o congelamiento normativo. Asimismo, en las dos categorías de alternativas se visualiza una tendencia al retorno del Estado a parcelas de poder de las que previamente el Estado se había retirado: prórroga de jurisdicción hacia el arbitraje internacional para resolver disputas con inversores extranjeros y elección de las áreas que no serán susceptibles de controversias en la materia. La autonomía se ve fortalecida al priorizarse la jurisdicción doméstica (Sudáfrica, Brasil) y las jurisdicciones regionales (Bolivia, Ecuador, Venezuela) o al complejizar el pasaje a la jurisdicción internacional (India).

Sin perjuicio de lo anterior, la hipótesis 1 es confirmada parcialmente ya que se afirmó que las alternativas de los Estados estaban motivadas, principalmente, en cambios en normas fundamentales a nivel doméstico Del análisis surge que los fundamentos son jurídicos, vinculados especialmente a cambios constitucionales (protección de derechos humanos y sectores estratégicos), pero coadyuvan motivos políticos y coyunturales, en particular la experiencia como Estados demandados. Dentro de los aspectos coyunturales se destacan los casos relativos a derechos humanos, como se analizó en el círculo 2.

En el círculo 2 se buscó determinar el impacto de la regulación estatal en temas vinculados a derechos humanos sobre casos concretos de controversias inversor-Estado 
que involucren a Estados de Sudamérica y la UE. A tales efectos se seleccionaron seis controversias principales cuyo estudio se estructuró en dos partes: aquellas relacionadas al derecho humano a vivir en un medioambiente sano (casos Pac Rim contra El Salvador, Eco Oro contra Colombia y Masdar contra España) y aquellas conectadas con otros derechos humanos (casos Philip Morris contra Uruguay relativo a salud pública, Urbaser contra Argentina sobre el derecho humano al agua y Bear Creek contra Perú que involucra los derechos de las comunidades locales). Si bien El Salvador no se encuentra fuera del marco geográfico elegido, se optó por el caso Pac Rim para aportar elementos contrafácticos en virtud de su trascendencia post laudo: en 2017, El Salvador se convirtió en el primer Estado del mundo en prohibir la mega minería metálica. Se complementó el análisis con controversias vinculadas a los Estados o la temática de la disputa.

El examen de las controversias a la luz de la fragmentación del Derecho Internacional permite concluir que en todos los casos se constata una colisión entre regímenes internacionales. En las controversias vinculadas al derecho a vivir en un medioambiente sano, entra en juego, además de las normas del régimen de protección de los derechos humanos, un principio general del Derecho Internacional como es la soberanía permanente sobre los recursos naturales. Se trata de una norma de jus cogens, esto es, una norma imperativa de Derecho Internacional General, por oposición a una norma dispositiva, como las que habitualmente se incluyen en los TBI. En consecuencia cualquier norma que nazca en contra de una de jus cogens es absolutamente nula en aplicación del artículo 53 de la Convención de Viena de Derecho de los tratados entre Estados.

Asimismo, los riesgos del régimen internacional también quedan de manifiesto con la erosión del espacio de política púbica, especialmente en las situaciones de congelamiento normativo constatadas. Estas se presentan tanto en el caso Pac Rim contra El Salvador (sanción por el Parlamento de la ley que prohíbe la mega minería metálica una vez conocido el laudo favorable), como en el caso Philip Morris contra Uruguay (comienzo del proceso hacia la implementación del empaque neutro de cigarrillos una vez conocido el contenido del laudo). El caso Philip Morris Asia contra Australia también es una controversia destacable en este aspecto, pero el efecto del congelamiento normativo tiene lugar en su vecino, Nueva Zelanda, quien detiene el debate parlamentario relativo al empaque neutro de cigarrillos hasta tanto no fuera emitido el laudo. 
Por otra parte, el examen del caso Masdar contra España aporta otros elementos a la investigación. En este, el inversor extranjero invoca el Tratado de la Carta de la Energía frente a la suspensión, y posterior eliminación, de los subsidios a las energías renovables. Se trata de medidas de retroceso en materia del derecho a vivir en un medioambiente sano. No se prioriza la transición hacia energías más limpias, sino medidas para alcanzar la salida de la crisis económica de España. Si bien son medidas de retroceso, no dejan de ser tomadas en ejercicio válido del derecho de regular. Al tratarse de un tema en desarrollo, la situación de España en relación a los arbitrajes de las energías renovables, particularmente la ejecución de los laudos a la luz de los desarrollos en la UE (efectos de los casos Achmea y Micula) será parte de una agenda de investigación a futuro.

En relación al siguiente grupo de casos que se estudió: Philip Morris contra Uruguay, Urbaser contra Argentina y Bear Creek contra Perú, se reafirma la conclusión que las medidas cuestionadas por los inversores extranjeros se dieron en situaciones de ejercicio válido del derecho de regular. Suponer que el ordenamiento jurídico en el cual confiaron e invirtieron iba a mantenerse incambiado no se ajusta a los hechos (sistema internacional dinámico, impactos de las políticas exteriores de otros Estados, cambios sociales y económicos) ni al Derecho (no cercenamiento de los poderes regulatorios). La puja entre estabilidad y flexibilidad debe laudarse sin perder de vista el atributo de la soberanía. El análisis del contenido de las cláusulas de estabilidad, mencionadas en alguno de los casos analizados, así como su validez jurídica frente a la vulneración del derecho de regular formará parte de futuras investigaciones.

Adicionalmente, los tres casos traen al debate el cuestionamiento sobre cómo hacer valer los derechos humanos por parte de los Estados. Las demandas reconvencionales no siempre están previstas en los acuerdos internacionales en los que se basa la controversia, por tanto otros caminos pueden darse en la presentación de escritos amici curiae, pero su peso durante el arbitraje no es asimilable al de una demanda o contrademanda. El proyecto revisado del Instrumento jurídicamente vinculante para regular, en el marco del Derecho Internacional de los derechos humanos, las actividades de las empresas transnacionales y otras empresas, establece la competencia de los tribunales domésticos. Sin embargo, aun si se lograra construir una jurisprudencia sólida y con principios comunes en un grupo relevante de Estados, un tribunal doméstico no tendrá el mismo impacto en la conducta de las empresas transnacionales que la creación de una institución internacional que entienda en la materia y se encargue de cruzar 
ambos regímenes internacionales (protección de los derechos humanos y protección de las inversiones).

En vista de lo anterior, en el círculo 2 se refuta la hipótesis ya que la extensión de la regulación estatal lleva a las empresas transnacionales a iniciar controversias inversorEstado que cuestionan tanto el avance de los Estados en medidas de avance como de retroceso en materia de protección de los derechos humanos o el medioambiente. Por consiguiente, como primera conclusión de este círculo se retoma el abordaje de Strange respecto al poder ganado por las empresas transnacionales que les ha permitido iniciar arbitrajes a los Estados receptores de la inversión, aun en caso de medidas en protección de los derechos humanos y otras que hacen al derecho de regular. De esta manera queda en evidencia como los tribunales arbitrales ad hoc se comportan como órganos de contralor externo de los actos u omisiones estatales.

Como se indicara anteriormente, las disputas que involucran derechos fundamentales se destacan como leading cases, dadas sus implicancias sistémicas y domésticas en términos de erosión del derecho de regular. Sin embargo, el cuestionamiento corporativo no se focaliza exclusivamente en esta materia, y cuando lo hace, no distingue entre medidas de avance en la protección (ejemplo: caso Philip Morris contra Uruguay) o de retroceso (ejemplo: caso Masdar contra España). Esto lleva a la tercera conclusión, que refiere al medio más eficiente para hacer valer la protección de los derechos humanos en mecanismos que no los tienen en cuenta. Se concluye que, si el acuerdo internacional lo autoriza, son las demandas reconvencionales el camino más directo frente a otras posibilidades como ser los escritos amici curiae. Esto es sin perjuicio de la relevancia de estos últimos como medio para escuchar las voces de los grupos directamente afectados por las inversiones extranjeras.

El círculo 3 parte de los elementos constatados en el círculo 2, en particular la erosión del espacio de política pública, y en su corazón el derecho de regular, por los mecanismos de solución de controversias inversor-Estado. En este marco, se buscó valorar si el concepto de soberanía ha evolucionado hacia una nueva definición, que se funda en supuestos diferentes a los que propone Krasner, identificar sus características y su fundamento. Partiendo de las cuatro proyecciones del abordaje de Krasner: soberanía de interdependencia, soberanía westfaliana, soberanía interna y soberanía legal internacional, se arriba a la conclusión que ninguna de ellas tiene como centro el espacio de política pública. Este es el conjunto de medidas tomadas en las áreas 
susceptibles de decisión pública y en su corazón se encuentra el derecho de regular: el poder del Estado de limitar las libertades particulares con el fin de proteger un bien jurídico superior: el orden público.

En su informe del año 2003 (etapa actual del régimen internacional de protección de inversiones), la UNCTAD reconoce tardíamente que los mecanismos de solución de disputas entre inversores y Estados erosionan el espacio de política pública. Este fenómeno se constata particularmente bajo el efecto de la parálisis o congelamiento normativo, esto es, la abstención de regular o continuar un proceso normativo (discusión, elaboración, sanción, implementación o entrada en vigor) frente a una demanda o amenaza de demanda. Esta es la situación de El Salvador cuyo parlamento no aprobó la ley que prohíbe la mega minería metálica hasta tanto no tuvo un laudo a su favor (caso Pac Rim). Incluso, el congelamiento o parálisis normativa puede darse en otros Estados que, al encontrarse en una situación similar, sean disuadidos de regular. Este último fue el caso de Nueva Zelanda frente al arbitraje que Philip Morris Asia había iniciado contra Australia por el empaque neutro de cigarrillos.

La soberanía regulatoria tiene notas de autoridad y legitimidad, al igual que la soberanía interna, pero no cuenta con notas de control. Asimismo, es un concepto absoluto, por oposición a la afirmación de la Corte Permanente de Justicia Internacional en el caso del vapor Wimbledon (1923). La Corte sostiene que la soberanía estatal no puede verse erosionada por la asunción de compromisos internacionales, puesto que esta actividad se realiza justamente en ejercicio de la soberanía. Este ejercicio tiene un límite que es el derecho de regular. La soberanía regulatoria es la que plantea el límite al accionar estatal, para justamente no ingresar en el círculo vicioso que propone la sentencia de 1923: si el Estado al celebrar tratados no erosiona su soberanía, puede desarrollar esta práctica hasta perder todas las características y desaparecer como tal. Por consiguiente el Estado dejaría de ser Estado, aunque la Corte afirme que los tratados no erosionan su soberanía.

En este trabajo se sostiene que se es soberano o no se es, en otras palabras, se es Estado o no se es, sin posibilidad de graduación (soberano al 100\%, 90\%, 80\%, etc.). Las limitaciones, si existieran, refieren a la autonomía, como condición y no atributo del Estado. La autonomía está representada en la elección de los mecanismos que permitan al Estado desarrollarse como mejor lo entienda, y por ende ejercer su condición de soberano. En términos jurídicos, la autonomía se manifiesta en el principio de libre determinación de los pueblos que establece el derecho de estos a elegir libremente su 
condición política, y por tanto determinar de forma autónoma las políticas de desarrollo económico, social y cultural, excluyendo su ejercicio cualquier forma de injerencia externa.

Las relaciones internacionales, como disciplina, están en constante movimiento. Muestra de esto es la primera conclusión de este círculo. Aún no está definida la determinación de las áreas de regulación contenidas dentro del derecho de regular como corazón del espacio de política pública, y que por tanto no pueden ser objeto de injerencia externa. La soberanía regulatoria es un concepto en construcción, sin perjuicio que del análisis realizado se puede inferir que debe incluirse la protección del medioambiente, la protección de los derechos humanos, o la seguridad nacional como áreas generales, y la protección de la salud pública o las medidas de control del tabaco en particular.

El nuevo concepto de soberanía surge en un momento histórico significativo: crisis de la globalización y crisis del multilateralismo. La primera manifestación es el retiro de Bolivia del CIADI en 2007, año previo a la crisis global de 2008 que genera un quiebre en la globalización como modelo de gobernanza neoliberal. La crisis de las instituciones de Bretton Woods - OMC, cuna del régimen de solución de controversias inversorEstado, genera el ambiente ideal para el momento de mayor crítica de los mecanismos arbitrales y la presentación de propuestas alternativas. Es en este marco que comienza a gestarse el nuevo concepto de soberanía, al constatar los Estados su erosión y plantear la necesidad de cambios profundos.

¿Es la solución de controversias el catalizador de la necesidad de reforma del régimen internacional de protección de inversiones? Esta pregunta puede verse reforzada si se tiene en cuenta que en otra institución típica del multilateralismo como es la OMC, también su sistema de solución de disputas está en crisis, en particular el Órgano de Apelaciones. Los mecanismos de solución de disputas que involucran a Estados soberanos pueden poner en jaque políticas domésticas y permear directamente en los poderes regulatorios. En otros términos, el núcleo de la respuesta está en el concepto de soberanía y la erosión del espacio de política pública por los mecanismos de solución de disputas cuando las normas sustantivas no establecen límites claros. La relación entre la solución de disputas en la OMC y la seguridad nacional, tema en profundo movimiento, también constituirá parte de una futura agenda de investigación.

Finalmente, en este círculo se constata que existen manifestaciones de la transición hacia la soberanía regulatoria. Estas son: los casos de abandono del régimen (Bolivia, 
Ecuador, Venezuela y Sudáfrica, con diferente alcance cada uno), la celebración de tratados que buscan un balance (el CPTPP por la excepción de las medidas de control del tabaco, y el modelo de TBI de India de 2016 que fortalece la jurisdicción doméstica), o los tratados que excluyen los mecanismos de arbitraje inversor-Estado (los ACFI de Brasil). Los anteriores ejemplos fueron examinados en el círculo 1. Otra manifestación está representada en el texto del TBI Marruecos-Nigeria, que incorpora disposiciones con mayor grado de protección del espacio de política pública. Estos son ejemplos de cómo la soberanía regulatoria es un concepto que excede el ámbito doméstico de los Estados y busca transformar las instituciones internacionales (proceso que se construye desde el interior al exterior). Asimismo, a nivel de los principios que componen el régimen de solución de controversias inversor-Estado, un nuevo principio se deriva del principio general y busca limitar el principio general de protección de la inversión extranjera (principio de protección del derecho de regular). Este proceso aún no está consolidado.

Dos casos más fueron estudiados y presentan particularidades. El proyecto revisado del Instrumento jurídicamente vinculante para regular, en el marco del Derecho Internacional de los derechos humanos, las actividades de las empresas transnacionales y otras empresas es una muestra de la necesidad de balance entre los dos regímenes internacionales en juego. Se reconoce que es un paso, pero no termina de resolver los problemas que su colisión genera al simplemente reforzar las jurisdicciones domésticas. En segundo lugar, el caso de la UE presenta una dualidad. Por un lado, por efecto del caso Achmea, al interior se rechazan los arbitrajes intra-UE y sus laudos se consideran nulos. Asimismo, el 24 de octubre de 2019, 22 de los 28 miembros firmaron un acuerdo para terminar sus TBI intracomunitarios y quienes no lo hagan serán objeto de procedimiento de infracción por parte de la Comisión. Mientras que al exterior, se mantienen los TBI con terceros Estados y se propone una alternativa (sistema de tribunales de inversiones) que, de concretarse, a mediano plazo actuará en paralelo con el régimen actual. Conforme a la reformulación de la tipología de Estados según su posición respecto al régimen, la UE junto a India son confrontadores.

A pesar de la exclusión de los mecanismos de solución de controversias inversor-Estado del Acuerdo Mercosur-UE, la inclusión del tema en el relacionamiento externo de la UE es un tema que aún no está cerrado. Continúa su ciclo de negociación o renegociación de acuerdos comerciales y/o de inversiones con terceros Estados o grupos de Estados, 
como el acuerdo con México, o en lo que respecta a la entrada en vigor del CETA. Tampoco está cerrada la negociación de un sistema multilateral de tribunales de inversiones por parte de la UE, conforme al mandato que en 2018 obtuvo la Comisión. Por consiguiente, los impactos sistémicos y regionales de la posición externa de la UE constituirán una futura línea de investigación.

A modo de cierre del círculo 3, cabe afirmar que la soberanía es un concepto que tiene plena vigencia en el sistema internacional pero sufre transformaciones a lo largo de la historia. El concepto de soberanía regulatoria aún se encuentra en construcción. Por consiguiente, la hipótesis que guió la investigación en este círculo se confirma parcialmente: el concepto de soberanía está evolucionando hacia una nueva definición, que se construye desde la defensa del espacio de política pública. Está dando pasos para moldear las instituciones internacionales (proceso desde el interior al exterior del Estado), esto es, la reconstrucción del régimen internacional de solución de controversias inversor-Estado.

En síntesis, la dinámica de la relación Estado-empresas transnacionales en el marco del régimen de solución de controversias inversor-Estado puede explicarse mediante la unión de tres círculos en un diagrama de Venn (véase ilustración 5). En el primero se encuentran las alternativas al régimen actual que los Estados presentan en materia de tratados, ya sea su abandono mediante la denuncia de los acuerdos en vigor, la exclusión del régimen de los acuerdos de inversiones, o la elaboración de instrumentos que buscan un mayor balance en el régimen. Los Estados involucrados en las alternativas son motivados por aspectos político-ideológicos, jurídicos (especialmente el respeto a las normas constitucionales), y coyunturales (la experiencia como demandados en arbitrajes inversor-Estado).

En función de la experiencia en el régimen, se destacan aquellas controversias las que se cuestionan políticas públicas vinculadas a la mayor protección de los derechos humanos. Sin embargo, los arbitrajes tienen como objeto el cuestionamiento de medidas de extensión de la regulación en materia de avances en derechos humanos pero también de retroceso, así como cualquier otro cambio regulatorio que realice el Estado. En definitiva, el cumplimiento del Estado de su función de regular impulsa a las empresas transnacionales a iniciar arbitrajes, sea cual sea el contenido concreto de dichas nuevas medidas. 
Ahora bien, es la protección del espacio de política pública, o más precisamente de su núcleo: el derecho de regular, lo que lleva a constatar la transición hacia un nuevo concepto de soberanía: la soberanía regulatoria. Justamente, esta se basa en la protección del espacio de política pública y se manifiesta en las diferentes alternativas que han propuesto los Estados frente al régimen actual. Esto es, su abandono total o parcial, su exclusión de los acuerdos de inversiones, la celebración de acuerdos de mayor balance (exclusiones sectoriales o reforzamiento de la jurisdicción doméstica), así como nuevos acuerdos que profundizan en la protección del espacio de política pública. Dada la motivación de los Estados, el proceso tendiente a la reconstrucción del régimen internacional se desarrolla desde la esfera doméstica para moldear las instituciones internacionales. Se trata de cambios, en curso, en términos de estructura, de reconfiguración del régimen internacional. 


\section{Ilustración 5: Relación Estado-empresas transnacionales: una síntesis}

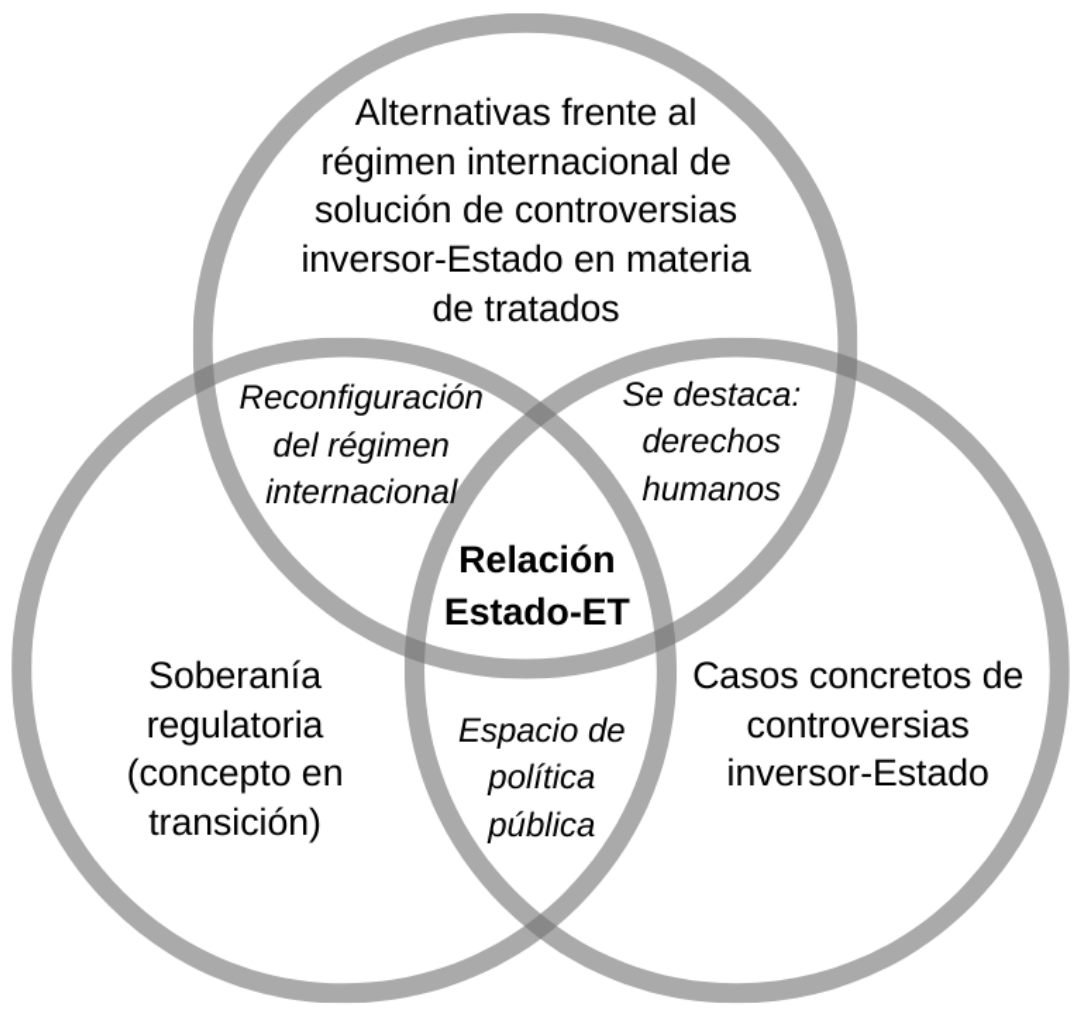

Fuente: Elaboración propia.

\section{Reflexiones finales}

A lo largo de esta tesis se desarrollaron una serie de ideas en torno a la relación Estadoempresas transnacionales en el marco de la solución de controversias inversor-Estado. En este sentido, se buscó aportar a las relaciones internacionales desde el debate sobre los mecanismos para resolver disputas internacionales así como el rol de los sujetos de Derecho Internacional Público y/o actores de las relaciones internacionales.

En este marco, en primer lugar esta tesis propone que las empresas transnacionales pueden ser consideradas sujetos de Derecho Internacional Público, aunque de carácter menor o limitado. Su subjetividad es oponible al Estado que las haya reconocido (no es erga omnes), si bien en el marco de un TBI u otro acuerdo de protección de inversiones, un Estado reconoce virtualmente a todas las empresas nacionales del otro Estado parte, cuyas inversiones en su territorio son protegidas. Asimismo, la subjetividad de las empresas se focaliza en las disposiciones de los instrumentos jurídicos en los que se enmarquen sus derechos y obligaciones. En suma, este trabajo se adscribe a la posición 
minoritaria de la doctrina que afirma que las empresas transnacionales son sujetos de Derecho Internacional Público.

Esta posición doctrinaria se refuerza en la necesidad de un instrumento jurídico vinculante que determine las obligaciones de las empresas en materia de derechos humanos y contenga mecanismos jurisdiccionales adecuados para que las víctimas puedan hacer valer los derechos en caso que sean vulnerados. Aun con cambios y con mucho camino por recorrer, el paso inicial esta dado en el proyecto de Instrumento jurídicamente vinculante para regular, en el marco del Derecho Internacional de los derechos humanos, las actividades de las empresas transnacionales y otras empresas. El rebalance del régimen internacional de protección de inversiones necesariamente debe ir de la mano de un instrumento de tales características, sin embargo el nuevo balance debería forjarse dentro del propio régimen para evitar una visión fragmentada y autonómica entre ambos.

El Estado es el otro actor central del régimen de solución de controversias inversorEstado. En relación a este, en la presente tesis se constata una transición hacia un nuevo concepto de soberanía, que excede los expuestos por Krasner y que sirven de marco teórico para la investigación (soberanía westfaliana, soberanía legal internacional, soberanía interna y soberanía de interdependencia). La soberanía regulatoria, concepto que se propone en este trabajo, se basa en la defensa del espacio de política pública, cuyo corazón es el derecho de regular. La necesidad de proteger el espacio de política pública es reconocida por la UNCTAD en 2003, al constatarse la erosión que el régimen internacional de protección de inversiones puede ocasionar sobre las políticas públicas. Por tanto, el concepto de soberanía regulatoria cuenta con las notas de autoridad y legitimidad, careciendo de la nota de control. La autoridad se expresa en el entendido que en la soberanía regulatoria el Estado no admite invitaciones válidas para su erosión o condicionamiento, porque correría el riesgo de vulnerar su sustento: el espacio de política pública. Si existieran limitaciones, estas serían a la autonomía estatal, como condición y no atributo del Estado. En este punto el concepto se posiciona en la vereda opuesta a la clásica sentencia de la CPJ en el asunto del vapor Wimbledom. La sentencia afirma que la soberanía no puede vulnerarse por tratados celebrados por el Estado en ejercicio de la soberanía, sin embargo en esta tesis se sostiene que la soberanía se tiene o no se tiene, por tanto no puede limitarse por su propio ejercicio. La soberanía regulatoria no hace foco en la capacidad de elegir entre diferentes políticas 
públicas, esta elección está en el ámbito de la autonomía, como ejercicio del principio de libre determinación de los pueblos.

En la actualidad no es posible identificar con precisión un elenco de actos estatales o áreas de regulación que conformen la soberanía regulatoria, ni un criterio unívoco para determinarlo. Si bien el trazado de los límites de la soberanía regulatoria se encuentra en construcción, las normas analizadas permiten inferir que se encuentran incluidas las normas sobre seguridad estatal, medioambiente, salud, y medidas de control del tabaco, posicionando en la cúspide a la protección de los derechos humanos. Así se podría evitar el congelamiento o parálisis regulatoria en dichas áreas. Es por esto que la nota fundamental de la soberanía regulatoria es la legitimidad, tanto en términos jurídicos (defensa de un conjunto de normas) y sociológicos (apoyo de las audiencias relevantes que aceptan dichas normas como las orientadoras de la conducta a seguir).

Otro aspecto a destacar es que el concepto de soberanía regulatoria, aun sin haber cristalizado o cerrado su evolución, surge en un contexto de crisis de la globalización y del multilateralismo. Justamente, el régimen internacional de protección de inversiones tiene su momento de auge durante la globalización, enmarcado en una tendencia hacia la desregulación, apertura económica y privatización de la justicia propulsadas por las instituciones vinculadas a la gobernanza del sistema. En consecuencia, un momento de marcada crisis del sistema actúa como catalizador de reivindicaciones soberanas y evolución hacia la protección del espacio de política pública.

En este sentido, la experiencia de los Estados, como demandados en el régimen de solución de controversias inversor-Estado, ha sido uno de los elementos que marcan el camino. En particular se destacan los casos vinculados a temas de derechos humanos (salud pública, agua, derechos de los pueblos indígenas y protección del medioambiente), que han determinado cambios en las posiciones estatales. Así se reformuló la tipología de Estados propuesta en una investigación anterior (2017), al identificar el agrupamiento en cuatro cuadrantes: miembros, externos (conforme sean parte o no del régimen y mantengan su posición incambiada), disidentes y confrontadores (conforme hayan cambiado su posición y cruzado o no el umbral del abandono del régimen).

En suma, sesenta años después de la celebración del primer TBI, el régimen internacional de solución de controversias inversor-Estado presenta quiebres cada vez más visibles. En este marco, la relación Estado-empresas transnacionales transita entre dos ideas en pugna: la estabilidad en la protección de la inversión y la flexibilidad desde 
la lógica de la protección del espacio de política pública. La evolución hacia un régimen más justo y balanceado, sea cual sea el camino, necesariamente deberá tener presente la protección del espacio de política pública o correrá el riesgo de perder toda legitimidad. 


\section{Referencias}

\section{Introducción}

ARATO, J. (2015). Corporations as Lawmakers. Harvard International Law Journal. Summer 2015. Vol. 56, No. 2, 229 - 295. Boston: Harvard University.

BERICAT, E. (1998). La integración de los métodos cuantitativo y cualitativo en la investigación social. Barcelona: Ed. Ariel.

BIZZOZERO, L. (2017). Introducción. Empresas transnacionales y derechos humanos. Seminario realizado el 28 de agosto de 2017, Cámara de Representantes, Escuela de Gobierno, Parlamento del Uruguay, 7-9. Escuela de Gobierno del Parlamento. Montevideo.

CONSANI, N. (Dir. y Comp.) (2016) Introducción. En: Nuevos desarrollos del Derecho Internacional, 9 - 20. La Plata: Instituto de Relaciones Internacionales de la Universidad Nacional de La Plata. Disponible en: http://www.iri.edu.ar/wp-content/uploads/2016/08/cat2manualderechoInternacionalP\%C3\%BAblico-completo.pdf

CONSANI, N. (2008). Los modelos en la sociedad internacional contemporánea. Serie Derecho Internacional Contemporáneo, No. 1. La Plata: Instituto de Relaciones Internacionales de la Universidad Nacional de La Plata.

CORBETTA, P. (2007). Metodología y técnicas de investigación social. Edición Revisada. Madrid: McGraw-Hill / Interamericana de España, S.A.U.

DEL ARENAL, C. (2008). Mundialización, creciente interdependencia y globalización en las relaciones internacionales. Cursos de Derecho Internacional de VitoriaGasteiz, 2008, No. 2, 181-268. Bilbao: Servicio Editorial de la universidad del País Vasco.

HERNÁNDEZ GONZÁLEZ, J. (2017). Regulación económica y arbitraje internacional de inversiones. RED: Revista Electrónica de Direito, No. 1. Porto: Facultad de Derecho de la Universidad de Porto. Disponible en: https://dialnet.unirioja.es/servlet/articulo? codigo $=6421947$ \&orden $=0 \&$ info $=$ link

HERNÁNDEZ SAMPIERI, R. Y OTROS (2010). Metodología de la investigación, Quinta edición. Ciudad de México: McGraw-Hill / Interamericana Editores, S.A. de C.V. 
JOMO, K. S. Y RODRIGUEZ, F. N. (2011). Structural causes and consequences of the 2008-2009 financial crisis. CALHOUN, C., Y DERLUGUIAN, G. (Eds.). (2011). Aftermath: A New Global Economic Order? Nueva York: NYU Press.

KEGLEY, C. W. Y BLANTON, S. L. (2012). World Politics. Trend and Transformation. 2012-2013 Edition. Boston: Wadsworth

KRASNER, S. (2001). Soberanía, hipocresía organizada. Barcelona, Paidós (1983). Structural causes and regime consequences: regimes as intervening variables. En: KRASNER, S. (Edit.) (1983). International regimes. Ithaca: Cornell University Press.

LEE, R. (2000). Unobtrusive Methods in Social Research. Serie Understanding Social Research. Buckingham: Open University Press

POSTIGA, A. (2013). A emergência do direito administrativo global como ferramenta de regulação transnacional do investimento estrangeiro direto. Revista de Direito Internacional, Vol. 10, No. 1, 171 - 193. Brasilia: UniCEUB. Disponible en: doi:10.5102/rdi.v10i1.2369

PUIG, J. C. (1986). Integración y autonomía en América Latina en las postrimerías siglo XX. Integración Latinoamericana, Vol. 11, No. 109, 40-62. Buenos Aires: Instituto de Integración Latinoamericana.

(1980). Doctrinas internacionales y Autonomía latinoamericana. Caracas: Universidad Simón Bolívar, Instituto de Altos Estudios de América Latina.

RAPOPORT, M. Y MIGUEZ, M. C. (2014). Desafíos y ejes para una inserción internacional autónoma de Argentina y América del Sur en el escenario mundial. En: BRICEÑO, J. Y SIMONOFF, A. (2014). Integración y cooperación regional en América Latina. Una relectura a partir de la teoría de la autonomía. Buenos Aires: Biblos.

RUSSELL, R. Y TOKATLIAN, J. (2001). De la autonomía antagónica a la autonomía relacional: una mirada teórica desde el Cono Sur. PostData, No. 7, Mayo 2001, 71-92. Buenos Aires. Disponible http://www.revistapostdata.com.ar/2011/12/de-la-autonomia-antagonica-a-laautonomia-relacional-una-mirada-teorica-desde-el-cono-sur-roberto-russelljuan-tokatlian

SANAHUJA, J. A. (2009). Desequilibrios globales el impacto de la crisis en los países en desarrollo. Anuario CEIPAZ, No. 3, 2009-2010 (Ejemplar dedicado a: Crisis 
y cambio en la sociedad global), 27-61. Madrid: CEIPAZ, Centro de Educación e Investigación para la Paz. Disponible en: https://dialnet.unirioja.es/descarga/articulo/3059499.pdf

SÁNCHEZ, L. E. (2013). Condicionantes internos de la política exterior argentina: La participación del cuerpo decisional legislativo en el diseño de la agenda internacional de la política exterior argentina (1999-2003). Tesis de posgrado. Universidad Nacional de La Plata. Facultad de Humanidades y Ciencias de la Educación.

Disponible

en: http://www.memoria.fahce.unlp.edu.ar/tesis/te.806/te.806.pdf

SASSEN, S. (2011). A Savage Sorting of Winners and Losers, and Beyond. CALHOUN, C., Y DERLUGUIAN, G. (Eds.). (2011). Aftermath: A New Global Economic Order? Nueva York: NYU Press.

SAUTÚ, R. Y OTROS. (2005). Construcción del marco teórico, formulación de los objetivos y elección de la metodología. Colección Campus Virtual. Buenos Aires: CLACSO.

SORNARAJAH, M. (2015). Resistance and Change in the International Law on Foreign Investment. Cambridge: Cambridge University Press.

STRANGE, S. (2001). La retirada del Estado. La difusión del poder en la economía mundial. Encuentro. Barcelona: Icaria Editorial. Intermón Oxfam,

UNCTAD (2003). World Investment Report 2003. FDI Policies for Development: National and International Perspectives. UNCTAD. Ginebra. Disponible en: https://unctad.org/en/Docs/wir2003light_en.pdf

VAN HARTEN, G. Y LOUGHLIN, M. (2006). Investment Treaty Arbitration as a Species of Global Administrative Law. The European Journal of International Law, Vol. 17, No.1, 121 - 150. Disponible en: 10.1093/ejil/chi159

WEBB, E. J. Y OTROS (1981) Nonreactive Measures in the Social Sciences. Dallas: Houghton Mifflin.

\section{Capítulo 1}

ARATO, J. (2015). Corporations as Lawmakers. Harvard International Law Journal. Summer 2015. Vol. 56, No. 2, 229 - 295. Boston: Harvard University. Disponible en: http://www.harvardilj.org/wp-content/uploads/562Arato.pdf 
BANIFATEMI, Y. (2009). The emerging jurisprudence on the Most-Favored-Nation Treatment in investment arbitration. En: BJORKLUND, A. Y OTROS (Edit.). (2009). Investment Treaty Law. Current Issues III - Remedies in International Investment Law: Emerging Jurisprudence of International Investment Law, 241 - 273. Londres: BIICL.

BARREIROS, L. (2008). Contemporary International Law and the question of the sovereignty: an attempt at reconciliation. Written work for the LL.M degree at Harvard Law School. Disponible https://www.academia.edu/1855862/Contemporary_International_Law_and_the _Question_of_Sovereignty_An_Attempt_at_Reconciliation

BAS VILIZZIO, M. (2018). Régimen de solución de controversias inversor-Estados: ¿resistencias del modelo relacional en un marco institucional de las relaciones internacionales?. Revista Relaciones Internacionales, No. 54, 163-178. Instituto de Relaciones Internacionales de la Universidad Nacional de La Plata. La Plata. Disponible en: https://revistas.unlp.edu.ar/RRII-IRI/article/view/5167/4642

(2017). América del Sur ante los tratados bilaterales de inversión: ¿hacia un retorno del Estado en la solución de controversias? Montevideo: Biblioteca Plural, Comisión Sectorial de Investigación Científica - Universidad de la República.

BERMEJO GARCÍA, R. (2015). Las empresas transnacionales como actores y sujetos «potenciales» en la sociedad internacional. En: BARRANCO AVILÉS, M. y otros (Coord.) Perspectivas actuales de los sujetos de Derecho, 90 - 116. Colección Gregorio Peces-Barba (2), Madrid: Dpto. de Derecho Internacional, Universidad Carlos III.

BIZZOZERO, L. (2017). Introducción. Empresas transnacionales y derechos humanos. Seminario realizado el 28 de agosto de 2017, Cámara de Representantes, Escuela de Gobierno, Parlamento del Uruguay, 7-9. Escuela de Gobierno del Parlamento. Montevideo.

(2011). Aproximación a las relacionales internacionales. Una mirada desde el siglo XXI. Montevideo: Ediciones Cruz del Sur.

BOEGLIN, N. (2012). Ecuador y el CIADI: nuevo pulso con posibles repercusiones. América Latina en Movimiento, publicado el 10 de octubre de 2012. Disponible en: http://alainet.org/active/58693 
BURGOS-DE LA OSSA, M. A. Y LOZADA-PIMIENTO, N. (2009). La protección diplomática en el marco de las controversias internacionales de inversión. International Law, Revista Colombiana de Derecho Internacional. No. 15, 243 278. Bogotá: Pontificia Universidad Javeriana. Disponible en: http://www.scielo.org.co/pdf/ilrdi/n15/n15a09.pdf

CANÇADO TRINDADE, A. (2007). La persona humana como sujeto del derecho internacional: avances de su capacidad jurídica internacional en la primera década del siglo XXI. Revista del Instituto Interamericano de Derechos Humanos, Vol. 46, 273 - 328. Disponible en: http://www.corteidh.or.cr/tablas/R22025.pdf

CONSANI, N. (Dir. y Comp.) (2016) Introducción. En: Nuevos desarrollos del Derecho Internacional, 9 - 20. La Plata: Instituto de Relaciones Internacionales de la Universidad Nacional de La Plata. Disponible en: http://www.iri.edu.ar/wp-content/uploads/2016/08/cat2manualderechoInternacionalP\%C3\%BAblico-completo.pdf (2008). Los modelos en la sociedad internacional contemporánea. Serie Derecho Internacional Contemporáneo, No. 1. La Plata: Instituto de Relaciones Internacionales de la Universidad Nacional de La Plata.

DOLZER, R. Y SCHREUER, C. (2008). Principles of International Investment Law. Oxford University Press. Oxford.

DOUGHERTY, J. Y PFALTZGRAFF, R. (1993). Teorías en pugna en las relaciones internacionales. Buenos Aires: Grupo Editor Latinoamericano.

DRNAS DE CLÈMENT, Z. (2012). Derechos especiales/regímenes autónomos y el derecho internacional. En: CARDONA LLORENS, J. (Coord.) (2012). Estudios de Derecho Internacional y de Derecho Europeo en homenaje al profesor Manuel Pérez González, Tomo I, 521-538. Valencia: Tirant lo Blanch.

DROUBI, S. (2016). Transnational Corporations and International Human Rights Law. Notre Dame Journal of International and Comparative Law, No. 1, Vol. 6, 119144. Disponible

en: https://discovery.dundee.ac.uk/ws/files/20207562/Transnational_Corporations_a nd_International_Human_Rights_Law.pdf

DUPUY, P. y VIÑUALES, J. E (2015). Human Rights and Investment Disciplines: Integration in Progress. En: BUNGENBERG, Marc y otros (Editores). International Investment Law, 65 - 113. Baden-Baden: Nomos. 
FACH GOMEZ, K. (2011). Latin America and ICSID: David versus Goliath? Law \& Business Review for the Americas, No. 2, Vol. 17, 195-230. Disponible en: https://scholar.smu.edu/lbra/vol17/iss2/4

FERRO, L. (1999). Regímenes Internacionales. Ficha Docente $N^{\circ} 1$, Diploma de Posgrado en Estudios internacionales - Sistema internacional e integración, Montevideo: Programa de Política Internacional y Relaciones Internacionales de la Facultad de Ciencias Sociales (UDELAR).

GHIOTTO, L. (2017). ¿UNCTAD pro-desarrollo o pro-liberalización? Un estudio de los cambios en el organismo a la luz de las políticas sobre inversiones. ECHAIDE, J. (Dir.) Inversiones extranjeras y responsabilidad internacional de las empresas. Problemáticas en torno al CIADI, los TBI y los derechos humanos, 53-78. BdeF. Buenos Aires.

HASENCLEVER, A. Y OTROS (1999). Las teorías de los regímenes internacionales: situación actual y propuestas para una síntesis. Foro Internacional, Vol. 39, No. 4 (158), 499 - 526. Ciudad de México: Colegio de México. Disponible en: http://aleph.academica.mx/jspui/bitstream/56789/22376/1/39-158-1999-0499.pdf

HERNÁNDEZ GONZÁLEZ, J. (2017). Regulación económica y arbitraje internacional de inversiones. RED: Revista Electrónica de Direito, No. 1. Porto: Facultad de Derecho de la Universidad de Porto. Disponible en: https://dialnet.unirioja.es/servlet/articulo? codigo $=6421947 \&$ orden $=0 \&$ info $=$ link

HURRELL, A. (1992). Teoría de regímenes internacionales: una perspectiva europea. Foro Internacional, Vol. 32, No. 5 (130), 644 - 666. Ciudad de México: Colegio de México.

Disponible

en: http://codex.colmex.mx:8991/exlibris/aleph/a18_1/apache_media/AGB9JAQE8 DCC5C5NNSS9RVL7KPVK8G.pdf

JAGUARIBE, H. (1979). Autonomía periférica y hegemonía céntrica. Revista Estudios Internacionales, No. 49, 91-130. Santiago de Chile: Instituto de Estudios Internacionales, Universidad de Chile. Disponible en: http://www.revistaei.uchile.cl/index.php/REI/article/view/16458

JIMÉNEZ DE ARÉCHAGA, E. y otros (2005). Derecho Internacional Público, Tomo I. Montevideo: Fundación de Cultura Universitaria.

KEOHANE, R. (1988). Después de la hegemonía. Cooperación y discordia en la política económica mundial. Buenos Aires: Grupo Editor Latinoamericano. 
(1982). The demand for international regimes. International Organization, No. 36 (2), 325 - 355. Cambridge: Massachusetts Institute of Technology.

KRASNER, S. (2011). Changing state structures: Outside in. Proceedings of the National Academy of Sciences, Vol. 108, Suplemento 4, 21302 - 21307. Princeton: Princeton University, Disponible https://doi.org/10.1073/pnas.1100244108

(2009). Power, the State, and Sovereignty. Essays on international relations. Nueva York: Routledge.

(2009b). Think again: sovereignty. Foreign Policy, 20 Noviembre 2009. Disponible en: http://foreignpolicy.com/2009/11/20/think-again-sovereignty/ (2001). Soberanía, hipocresía organizada. Barcelona, Paidós. (2001b). Abiding sovereignty. International Political Science Review, Vol. 22, No. 3, 229-251. Londres: Sage Publications. Disponible en: https://www.jstor.org/stable/1601484

(1999). Globalization and sovereignty. En: States and sovereignty in the global economy. Londres: Routledge

(1983). Structural causes and regime consequences: regimes as intervening variables. En: KRASNER, S. (Edit.) (1983). International regimes. Ithaca: Cornell University Press.

LIMA, G. (2014). Conceitos de relações internacionais e teoria do direito diante dos efeitos pluralistas da globalização: governança global, regimes jurídicos,direito reflexivo, pluralismo jurídico, corregulação e autorregulação. Revista de Direito Internacional, Vol. 11, no. 1, 215 - 228. Brasília: Centro Universitario de Brasília. https://www.publicacoesacademicas.uniceub.br/rdi/article/download/2069/pdf MAYER, J. (2009). Policy space: what, for what, and where? Development Policy Review, Vol. $27 \quad$ (A), 373-395. Disponible en: https://www.wto.org/english/res_e/reser_e/gtdw_e/wkshop08_e/mayer_e.pdf

NASSER, S. (2015). Direito Global em pedaços: fragmentação, regimes e pluralismo. Revista de Direito Internacional, Vol. 12, no. 2, 98 - 126. Brasília: Centro Universitario de Brasília, Brasília. Disponible en: https://www.publicacoesacademicas.uniceub.br/rdi/article/view/3707 
ONU (2015). Cuarto reporte del Experto Independiente sobre la promoción de un orden internacional democrático y equitativo. Documento A/70/285. Nueva York: ONU. Disponible

en: http://www.un.org/en/ga/search/view_doc.asp?symbol=A/70/285\&referer=http:/ /www.ohchr.org/EN/Issues/IntOrder/Pages/IEInternationalorderIndex.aspx\&Lan $\mathrm{g}=\mathrm{S}$

(2006). Fragmentación del Derecho Internacional: dificultades derivadas de la diversificación y expansión del Derecho Internacional, en: ONU (2006). Anuario de la Comisión de Derecho Internacional, $58^{a}$ periodo de sesiones de la Asamblea General, 192 - 202. Nueva York: ONU. Disponible en: http://legal.un.org/docs/index.asp?path=../ilc/reports/2006/spanish/chp12.pdf\&la ng=EFSRAC\&referer=http://legal.un.org/ilc/reports/2006/

PELLET, A. (2015). Police powers on the State's right to regulate. Building International Investment Law. The First 50 Years of ICSID, 447-462. Washington: Wolters Kluwer.

PEÑA, F. (2004). Una aproximación a nuevas tendencias en los mecanismos de solución de controversias de acuerdos comerciales preferenciales, en PEÑA, F. (2004). Solución de controversias comerciales intergubernamentales. Enfoques multilaterales y regionales, 217 - 229. Buenos Aires: BID-INTAL

(2003). Concertación de intereses, efectividad de las reglas de juego y calidad institucional en el Mercosur. Buenos Aires: Red Mercosur - Konrad Adenauer Stiftung

PÉREZ BERNADEZ, C. (2010). Tema 16: Otros sujetos no estatales. En: SÁNCHEZ, VÍCTOR M. (Dir.). Derecho Internacional Público. Barcelona: Huygens Editorial.

PETERSMANN, E. (2016). How to reconcile Health Law and Economic Law with human rights? Administration of justice in tobacco control disputes. Asian Journal of WTO \& International Health Law and Policy, Vol. 10.2, 27 - 78. Taipei: Asian Center for WTO \& International Health Law and Policy - National Taiwan University College of Law. Disponible en: http://ssrn.com/abstract=2763634

POLANCO, R. (2014). Lecciones Aprendidas y Lecciones por Aprender: ¿Qué Pueden Aprender los Países Desarrollados de la Experiencia de Latinoamérica en disputas sobre Inversión Extranjera? 20th Seminario en Latinoamérica de Teoría 
Constitucional y Política, Yale University (Lima, 20 al 22 de Junio de 2014). Disponible en: http://ssrn.com/abstract=2515265

PUIG, J. C. (1986). Integración y autonomía en América Latina en las postrimerías siglo XX. Integración Latinoamericana, Vol. 11, No. 109, 40-62. Buenos Aires: Instituto de Integración Latinoamericana.

(1980). Doctrinas internacionales y Autonomía latinoamericana. Caracas: Universidad Simón Bolívar, Instituto de Altos Estudios de América Latina.

RAPOPORT, M. Y MÍGUEZ, M. (2015). Desafíos y ejes para una inserción internacional autónoma de Argentina y América del Sur en el escenario mundial. En: BRICEÑO RUIZ, J. Y SIMONOFF, A. (Editores) (2015). Integración y cooperación regional en América Latina Una relectura a partir de la teoría de la autonomía. Buenos Aires: Editorial Biblios.

RAUSTIALA, K. (2003). Rethinking the sovereignty debate in International Economic Law. Journal of International Economic Law, Vol. 6, No. 4, 841-878. Disponible en: https://doi.org/10.1093/jiel/6.4.841

REMIRO BROTÓNS, A. (2007). Derecho Internacional. Valencia: Tirant Lo Branch.

ROSAS CASTAÑEDA, J. (2007). Hacia el Jus Standi del individuo en el procedimiento ante la Corte Interamericana de Derechos Humanos. Revista del Centro por la Justicia y el Derecho Internacional (CEJIL), Año II, No. 3, 80 89. Disponible en: http://www.corteidh.or.cr/tablas/r24782.pdf

RUGGIE，J. (2009). Epistemología, ontología y el estudio de los regímenes internacionales. Relaciones Internacionales, No. 12, Octubre 2009, 171 - 191. Madrid: Grupo de Estudios de Relaciones Internacionales (GERI) de la Facultad de Derecho, Universidad Autónoma de Madrid (Obra original publicada en 1998).

Disponible

en: www.relacionesinternacionales.info/ojs/article/download/178/164.pdf (1975). International Responses to Technology: Concepts and Trends. International Organization, No. 29 (3), 557 - 583. Cambridge: Massachusetts Institute of Technology. Disponible en: http://www.jstor.org/stable/2706342

RUSSELL, R. Y TOKATLIAN, J. (2001). De la autonomía antagónica a la autonomía relacional: una mirada teórica desde el Cono Sur. POSTData, No. 7 (Mayo 2011), 71-92. Buenos Aires: Grupo Interuniversitario POSTData.

SALACUSE, J. (2010). The Law of Investment Treaties. Oxford: Oxford Un. Press. 
SANAHUJA, J.A. (2007). El poder estructural y las transformaciones de la sociedad internacional contemporánea. Cursos de Derecho Internacional de VitoriaGasteiz, 2007, No. 1, 297-384. Bilbao: Servicio Editorial de la Universidad del País Vasco. Disponible https://eprints.ucm.es/42540/1/Un_mundo_unipolar_multipolar_o_apolar_E.pdf SASSEN, S. (2010). Desnacionalización de las políticas estatales y privatización de la producción de normas. En: GUNTHER, T. y otros (2010). Estado, soberanía y globalización. Bogotá: Siglo del Hombre Editores. Universidad de los Andes. Pontificia Universidad Javeriana-Instituto Pensar.

(2007). Una sociología de la globalización. Buenos Aires: Katz Editores.

(2001). ¿Perdiendo el control? La soberanía en la era de la globalización. Barcelona: Ediciones Bellaterra.

SCHELL, M. A. (2017). Inversiones y derechos humanos: avances en terrenos del soft law. ECHAIDE, J. (Dir.) Inversiones extranjeras y responsabilidad internacional de las empresas. Problemáticas en torno al CIADI, los TBI y los derechos humanos, 145-172. BdeF. Buenos Aires.

SORNARAJAH, M. (2015). Resistance and Change in the International Law on Foreign Investment. Cambridge: Cambridge University Press.

STRANGE, S. (2001). La retirada del Estado. La difusión del poder en la economía mundial. Barcelona: Encuentro - Icaria Editorial - Intermón Oxfam.

(1995). 1995 Presidential Address ISA as a Microcosm. International Studies Quarterly, Vol. 39, No. 3, 289-295. Wiley. Disponible en: http://www.jstor.org/stable/2600921

(1994). States and Markets. Londres: Bloomsbury Publishing. Edición de Kindle.

TAMBURINI, F. (2002). Historia y Destino de la Doctrina Calvo: ¿Actualidad u obsolescencia del pensamiento de Carlos Calvo? Revista de estudios históricojurídicos, No. XXIV, 81 - 101. Valparaíso: Escuela de Derecho de la Pontificia Universidad Católica de Valparaíso. Disponible en: http://www.rehj.cl/index.php/rehj/article/view/363/343

TEUBNER, G. (1997). Global Bukowina: Legal pluralism in the world society. En: TEUBNER, G. (Edit.) (1997). Global Law without a State, 3 - 28. Brookfield: Darmouth. 
TITI, A. (2014) The right to regulate in International Investment Law. Munich: Nomos.

TOMASSINI, L. (2006). El mundo y la sociedad en la era de la globalización. Revista Estudios Internacionales, No. 154, 23-55. Santiago de Chile: Instituto de Estudios Internacionales, Universidad de Chile. Disponible en: https://revistas.uchile.cl/index.php/REI/article/download/14470/18971/

TORREJA MATEU, H. (2012). Protección diplomática. En: SÁNCHEZ, V. (Director). Derecho Internacional Público, 315 - 330. Barcelona: Huygens Editorial.

TUSSIE, D. (2019). La reconfiguración global: Su capítulo en vivo para América Latina. ALTMANN, J. (Edit.) (2019). América Latina frente a la reconfiguración global, 107-119. San José de Costa Rica: FLACSO Secretaría General.

\section{Capítulo 2}

ALONSO OLLACARIZQUETA, L. (2011). Sudáfrica: El alcance del «milagro». En: FUNDACIÓN SEMINARIO DE INVESTIGACIÓN PARA LA PAZ (FUNDACIÓN SIP) (2011). África Subsahariana, continente ignorado. Colección «Actas» 79. Serie «Estudios para la paz» 25, 103 - 116. Aragón: Edición Gobierno de Aragón, Departamento de Educación, Cultura y Deporte

ANDES (2017). Gobierno de Ecuador denuncia y pone fin a 16 Tratados Bilaterales de Protección de Inversiones inconstitucionales. Andes, 17 de mayo de 2017. Disponible en: https://www.andes.info.ec/es/noticias/actualidad/1/57199/gobierno-ecuadordenuncia-pone-fin-16-tratados-bilaterales-proteccion-inversiones

BAS VILIZZIO, M. (2017). América del Sur ante los tratados bilaterales de inversión: ¿hacia un retorno del Estado en la solución de controversias? Montevideo: Biblioteca Plural, Comisión Sectorial de Investigación Científica - Universidad de la República.

BERNASCONI-OSTERWALDER, N. (2015). Repensando la Solución de Controversias Relativas a Inversión. Investment Treaty News, No. 2, t. 6, mayo 2015, 6 - 8. Ginebra: Instituto Internacional para el Desarrollo Sustentable. Disponible en: https://www.iisd.org/sites/default/files/publications/iisd-itn-may2015-sp.pdf 
BOHOSLAVSKY, J. (2010). Tratados de protección de las inversiones e implicaciones para la formulación de políticas públicas (especial referencia a los servicios de agua potable y saneamiento). Comisión Económica para América Latina y el Caribe (CEPAL). Colección Documentos de proyecto, No. 326. Santiago de Chile: Naciones Unidas.

BOND, P. Y SHARIFE, K. (2009).Apartheid reparations and the contestation of corporate power in Africa.Review of African Political Economy, no. 119, 115 137. Roape Publications.Disponibleen: http://ccs.ukzn.ac.za/files/Bond\%20Sharife\%20Roape\%20reparations.pdf

BORRÁS, M.R. (1998). El trasfondo del Acuerdo Multilateral de Inversiones (AMI): un proyecto político de graves consecuencias antidemocráticas. Mientras Tanto, No. 72, 21-36. Icaria Editorial. Disponible en: http://www.jstor.org/stable/27820382

BURGOS-DE LA OSSA, M. A. Y LOZADA-PIMIENTO, N. (2009). La protección diplomática en el marco de las controversias internacionales de inversión. International Law, Revista Colombiana de Derecho Internacional. No. 15, 243 278. Bogotá: Pontificia Universidad Javeriana. Disponible en: http://www.scielo.org.co/pdf/ilrdi/n15/n15a09.pdf

CAITISA (2017). Informe Ejecutivo. Auditoría integral ciudadana de los tratados de protección recíproca de inversiones y del sistema de arbitraje en materia de inversiones en Ecuador Disponible http://caitisa.org/index.php/home/enlaces-de-interes

CARIM, Xavier (2015). International investment agreements and Africa's structural transformation: a perspective from South Africa. Investment Policy Brief, No. 4, agosto 2015. Ginebra: South Center. Disponible en: https://www.southcentre.int/wp-content/uploads/2015/08/IPB4_IIAs-andAfrica $\% \mathrm{E} 2 \% 80 \% 99 \mathrm{~s}-$ Structural-Transformation-Perspective-from-SouthAfrica_EN.pdf

CERVANTES, A. (2017). Nuevo constitucionalismo latinoamericano y arbitraje de inversión. Spain Arbitration Review, No. 30, 81-99. Madrid: Club Español del Arbitraje.

DI JOHN, J. (2010). The "Resource Curse”: Theory and Evidence. ARI 172/2010. Madrid: Real Instituto Elcano. Disponible en: 
http://www.realinstitutoelcano.org/wps/portal/rielcano_en/contenido?WCM_GL OBAL_CONTEXT=/elcano/elcano_in/zonas_in/sub-saharan+africa/ari172-2010 FACH GOMEZ, K. (2011). Latin America and ICSID: David versus Goliath? Law \& Business Review for the Americas, No. 2, Vol. 17, 195-230. Disponible en: https://scholar.smu.edu/lbra/voll7/iss2/4

FERNÁNDEZ ALONSO, J. (2013). Controvérsias entre Estados e investidores transnacionais: reflexões sobre o acúmulo de casos contra a República Argentina. Revista Tempo do mundo, Vol. 5 No. 1, Abril 2013, 45 - 87. Brasília: Instituto de Pesquisa Econômica Aplicada. Disponible en: http://www.ipea.gov.br/portal/images/stories/PDFs/rtm/140903_rtmv5_n1_port cap2.pdf

FONTOURA COSTA, J.A. (2010). Direito Internacional do Investimento Estrangeiro. Curitiba: Jurúa Editorial.

FORERE, M. (2018). The new South African protection of investment act. Striking a balance between attraction of FDI and redressing the apartheid legacies. MOROSINI, F. Y SANCHEZ BADIN, M. (Ed.) (2018). Reconceptualizing International Investment Law from the global south, 251 - 283. Cambridge University Press. Cambridge.

GIANELLI, C. (2012). Acuerdos bilaterales de inversión: opciones para equilibrar los derechos y obligaciones de las partes. Documento de trabajo 17. Montevideo: CEFIR, GIZ, Somos Mercosur.

GUERRA, G. (2012). Las disposiciones legales que desarrollan los preceptos constituciones sobre la inversión privada extranjera en el Ecuador. Foro: Revista de Derecho, No. 17, 31 - 62. Quito: Universidad Andina Simón Bolívar, Corporación Editora Nacional.

MARTÍNEZ RANGEL, R. Y REYES GARMENDIA, E. (2012). El consenso de Washington: la instauración de las políticas neoliberales en América Latina. Política y cultura, No. 37, 35 - 64. Disponible en: http://www.scielo.org.mx/scielo.php?script=sci_arttext\&pid=S0188$77422012000100003 \& \operatorname{lng}=$ es\&tlng=es

MEZGRAVIS, A. (2012). El retiro de Venezuela del CIADI. Entrevista concedida a Ámbito jurídico, febrero 2012, 15. Disponible en: http://www.mezgravis.com/EntrevistaRetiroVzlaCIADI.pdf 
MINISTERIO DE RELACIONES EXTERIORES Y CULTOS DE BOLIVIA (2008). Bolivia y el CIADI: crónica de un divorcio anunciado. En: VALDOMIR, S. Y SANTOS, C. (Edición General). Soberanía de los pueblos o intereses empresariales, 103 - 128. Montevideo: Fundación Solón, Redes Amigos de la Tierra, Uruguay Sustentable, Amigos de la Tierra. Disponible en: http://209.62.67.242/wp-content/uploads/2008/08/libro_ciadi.pdf

MINISTERIO DE RELACIONES EXTERIORES Y MOVILIDAD HUMANA DE ECUADOR (2015). El caso Chevron /Texaco en Ecuador. Una lucha por la justicia ambiental y social. Disponible en: http://www.cancilleria.gob.ec/wpcontent/uploads/2015/06/Expediente-Caso-Chevron-abril-2015.pdf

MUCHLINSKI, P. (1999). The Rise and Fall of the Multilateral Agreement on Investment: Where Now? The International Lawyer, Vol. 34, No. 3, 1033-1053. American Bar Association. Disponible http://www.jstor.org/stable/40707575

ONU (2015). Cuarto reporte del Experto Independiente sobre la promoción de un orden internacional democrático y equitativo. Documento A/70/285. Nueva York: ONU. Disponible

en: http://www.un.org/en/ga/search/view_doc.asp?symbol=A/70/285\&referer=http:/ /www.ohchr.org/EN/Issues/IntOrder/Pages/IEInternationalorderIndex.aspx\&Lan $\mathrm{g}=\mathrm{S}$

POLANCO, R. (2014). Lecciones Aprendidas y Lecciones por Aprender: ¿Qué Pueden Aprender los Países Desarrollados de la Experiencia de Latinoamérica en disputas sobre Inversión Extranjera? 20th Seminario en Latinoamérica de Teoría Constitucional y Politica, Yale University (Lima, 20 al 22 de Junio de 2014). Disponible en: http://ssrn.com/abstract=2515265

RAPOPORT, M. Y MÍGUEZ, M. (2015). Desafíos y ejes para una inserción internacional autónoma de Argentina y América del Sur en el escenario mundial. En: BRICEÑO RUIZ, J. Y SIMONOFF, A. (Editores) (2015). Integración y cooperación regional en América Latina Una relectura a partir de la teoría de la autonomía. Buenos Aires: Editorial Biblios.

RICAURTE HERRERA, C. (2012). Las razones del Centro Internacional de Arreglo de Diferencias Relativas a Inversiones, CIADI: análisis y evaluación del caso CMS contra Argentina (Jurisprudencia). Foro: Revista de Derecho, No. 18. Quito: Universidad Andina Simón Bolívar, Corporación Editora Nacional. 
SALACUSE, J. (2010). The Law of Investment Treaties. Oxford: Oxford University Press.

SASSEN, S. (2016). Economic Cleansing: Failure Dressed in Fine Clothes. Social Research, Vol. 83, No. 3, 673-687. Disponible en: http://saskiasassen.com//PDFs/SS_EconomicCleansing.pdf

SCHREUER, C. (2009). The ICSID Convention: A Commentary, Second Edition. Cambridge: Cambridge University Press.

SHULTZ, J. (2008). La guerra del agua en Cochabamba y sus secuelas. En: SHULTZ, J. Y CRANE DRAPER, M. (Edit.) Desafiando la globalización. Historias de la experiencia boliviana. La Paz: The Democracy Center, Plural Editores.

SORNARAJAH, M. (2010). The international law on foreign investment. Tercera edición. Cambridge: Cambridge University Press.

TAMBURINI, F. (2002). Historia y Destino de la Doctrina Calvo: ¿Actualidad u obsolescencia del pensamiento de Carlos Calvo? Revista de estudios históricojurídicos, No. XXIV, 81 - 101. Valparaíso: Escuela de Derecho de la Pontificia Universidad Católica de Valparaíso. Disponible en: http://www.rehj.cl/index.php/rehj/article/view/363/343

TORREJA MATEU, H. (2012). Protección diplomática. En: SÁNCHEZ, V. (Director). Derecho Internacional Público, 315 - 330. Barcelona: Huygens Editorial.

\section{Capítulo 3}

ACTIS, E. (2015). Brasil frente al orden internacional liberal (2011-2013). Los límites de la posición reformista a la luz del régimen internacional de inversiones. Mural Internacional. Vol. 6, No. 1, 22-34. Rio de Janeiro: Programa de PósGraduação em Relações Internacionais da Universidade do Estado do Rio de Janeiro. Disponible en: 10.12957/rmi.2015.12838 (2014). Brasil y la promoción de Tratados Bilaterales de Inversión: El fin de la disyuntiva. Latin American Journal of International Affairs. Vol. 6, No. 1, $18-33$.

Disponible

en: http:/www.lajia.net/volumenes/LAJIA\%20vo16\%20n1\%20Art02.pdf?attredirect $\mathrm{s}=0 \& \mathrm{~d}=1$

ALVAREZ, J. (2016). Is the Trans-Pacific Partnership's investment chapter the new “gold standard"? Working Paper IILJ 2016/3 MegaRed Series. Nueva York: 
New York University, School of Law. Disponible en: https://wp.nyu.edu/megareg/wpcontent/uploads/sites/3134/2016/03/Alvarez_IILJ-MegaReg_2016-3.pdf

ARATO, J. (2015). Corporations as Lawmakers. Harvard International Law Journal. Summer 2015. Vol. 56, No. 2, 229 - 295. Boston: Harvard University. Disponible en: http://www.harvardilj.org/wp-content/uploads/562Arato.pdf

BANIFATEMI, Y. (2009). The emerging jurisprudence on the Most-Favored-Nation Treatment in investment arbitration. En: BJORKLUND, A. Y OTROS (Edit.). (2009). Investment Treaty Law. Current Issues III - Remedies in International Investment Law: Emerging Jurisprudence of International Investment Law, 241 - 273. Londres: BIICL.

BAS VILIZZIO, M. (2018). De la protección a la facilitación de inversiones: análisis particular del arbitraje de inversiones en el Mercosur. Revista de la Secretaría del Tribunal Permanente de Revisión, Año 6, No. 12, 45-67. Paraguay: Secretaría del Tribunal Permanente de Revisión del Mercosur. Disponible en: http://www.revistastpr.com/index.php/rstpr/article/view/310/155177

(2017). América del Sur ante los tratados bilaterales de inversión: ¿hacia un retorno del Estado en la solución de controversias? Montevideo: Biblioteca Plural, Comisión Sectorial de Investigación Científica - Universidad de la República.

BOLLYKY, T. (2016, 4 de febrero). TPP tobacco exception proves the new rule in trade. Council for Roreign Relations, 4 de febrero de 2016. Disponible en: http://www.cfr.org/trade/tpp-tobacco-exception-proves-new-rule-trade/p37509

BREWIN, S. (2018). Food for thought: Weighing up health and investment in the age of the new pandemic. International Institute for Sustainable Development, 14 de mayo de 2018. Disponible en: https://iisd.org/blog/food-thought-weighinghealth-and-investment-age-new-pandemic

CARDOSO, F. Y FALETTO, E. (2003). Desarrollo y dependencia en América Latina. Ensayo de interpretación sociológica. Buenos Aires: Siglo XXI Editores.

DE AZEVEDO, D. (2001). Os acordos para a promoção e a proteção recíproca de investimentos assinados pelo Brasil. Brasília: Câmara dos Deputados, Brasil. Disponible en: http://www2.camara.leg.br/documentos-epesquisa/publicacoes/estnottec/arquivos-pdf/pdf/102080.pdf/view 
DOUGLAS, Z. (2009). The International Law of Investment Claims. Cambridge: Cambridge University Press.

GHIOTTO, L. (2018). Una revisión crítica del Debate sobre Facilitación de Inversiones. Investment Treaty News, No. 3, Tomo 9, 4-7. International Institute for Sustainable Development. Ginebra. Disponible en: https://iisd.org/sites/default/files/publications/iisd-itn-octubre-2018-espanol.pdf GHIOTTO, L. Y ARROYO PICARD, A. (2017). Brasil y la nueva generación de Acuerdos de Cooperación y Facilitación de Inversiones: un análisis del Tratado con México. Revista Relaciones Internacionales, No. 52, 39-54. Instituto de Relaciones Internacionales de la Universidad Nacional de La Plata. La Plata. Disponible en: https://revistas.unlp.edu.ar/RRII-IRI/article/view/2727/3590

GHIOTTO, L. Y GUAMÁN, A. (2018). ¿Facilitación o protección para las inversiones extranjeras? Nuevos elementos del debate global. Ciclos, No. 51, Vol. XXV, 118. Facultad de Ciencias Económicas de la Universidad de Buenos Aires. Buenos Aires. Disponible en: http://ojs2.econ.uba.ar/ojs/index.php/revistaCICLOS/article/view/1329/1982

HERREROS, S. (2018). Facilitación de inversiones: una puerta hacia la convergencia entre la Alianza del Pacífico y el Mercosur. Puentes. Vol. 19, No. 3, 12 - 16. Ginebra: Centro Internacional para el Comercio y el Desarrollo Sostenible (ICTSD). Disponible en: https://es.ictsd.org/sites/default/files/review/puentes193_0.pdf

JAGUARIBE, H. (1979). Autonomía periférica y hegemonía céntrica. Revista Estudios Internacionales, No. 49, 91-130. Santiago de Chile: Instituto de Estudios Internacionales, Universidad de Chile. Disponible en: http://www.revistaei.uchile.cl/index.php/REI/article/view/16458

JOHNSON, L. Y SACHS, L. (2015). The TPP's investment chapter: entrenching, rather and reforming, a flawed system. CCSI Policy Paper. Columbia Center on Sustainable Investment. Nueva York: Columbia University. Disponible en: http://ccsi.columbia.edu/files/2015/11/TPP-entrenching-flaws-21-NovFINAL.pdf

LENCUCHA, R. (2016). Is it time to say farewell to the ISDS system? Comment on the “Trans-Pacific Partnership: is it everything we feared for health?" International Journal of Health Policy and Management, Vol. 6, No. 5, 289 - 291. Disponible en: 10.15171/IJHPM.2016.125 
LESTER, S. Y MERCURIO, B. (2017). Safeguarding policy space in investment agreements. Institute of International Economic Law Issue Brief 12/2017. Washington: Georgetown University, Law Center. Disponible en: https://iielaw.org/wp-content/uploads/2018/06/Simon-Lester-and-BryanMercurio-General-Exceptions-in-IIAs-IIEL-Issue-Brief-December-2017Accessible.pdf

MALHOTRA, S. (2016). India's Joint Interpretive Statement for BITs: An Attempt to Slay the Ghosts of the Past. Investment Treaty News, Análisis 12 de diciembre de 2016. Ginebra: International Institute for Sustainable Development. Disponible en: https://www.iisd.org/itn/es/2016/12/12/indias-joint-interpretivestatement-for-bits-an-attempt-to-slay-the-ghosts-of-the-past-sarthak-malhotra/

MOROSINI, F. Y SANCHEZ BADIN, M. (2018). Navigating between resistnace and conformity with the international investment regime. MOROSINI, F. Y SANCHEZ BADIN, M. (Ed.) (2018). Reconceptualizing International Investment Law from the global south, 218 - 250. Cambridge University Press. Cambridge.

NEDUMPARA, J. (2018). India's Trade and Investment Agreements. Striking a balance between investor protection rights and development concerns. MOROSINI, F. Y SANCHEZ BADIN, M. (Ed.) (2018). Reconceptualizing International Investment Law from the global south, 188 - 217. Cambridge University Press. Cambridge.

OMS (2017). "Mejores inversiones" y otras intervenciones recomendadas para la prevención y el control de las enfermedades no transmisibles. Ginebra: Organización Mundial de la Salud. Disponible en: https://apps.who.int/iris/bitstream/handle/10665/259351/WHO-NMH-NVI-17.9spa.pdf;jsessionid=A73210A86663B2B845E5B6F6F01BFAC6? sequence=1

ONU (2015). Cuarto reporte del Experto Independiente sobre la promoción de un orden internacional democrático y equitativo. Documento A/70/285. Nueva York: ONU. Disponible en: http://www.un.org/en/ga/search/view_doc.asp?symbol=A/70/285\&referer=http:/ /www.ohchr.org/EN/Issues/IntOrder/Pages/IEInternationalorderIndex.aspx\&Lan $\mathrm{g}=\mathrm{S}$

RANJAN, P. Y OTROS (2018). India's model bilateral investment treaty. Is India too risk adverse? Impact Series. Brooking India. Disponible en: 
https://www.brookings.edu/wp-content/uploads/2018/08/India\%E2\%80\%99s-

Model-Bilateral-Investment-Treaty-2018.pdf

RANJAN, P. Y ANAND, P. (2017). The 2016 Model Indian Bilateral Investment Treaty: A Critical Deconstruction. Northwestern Journal of International Law and Business, Vol. 38, No. 1, 1-54, Disponible en: https://scholarlycommons.law.northwestern.edu/njilb/vol38/iss1/1

RANIERI, A. (2015). Deuda soberana: problemas y soluciones en la encrucijada. Revista Pensar en Derecho, No. 6, 245 - 304. Buenos Aires: EUDEBA, Facultad de Derecho de la UBA. Disponible en: http://www.derecho.uba.ar/publicaciones/pensar-en-derecho/revistas/6/deudasoberana-problemas-y-soluciones-en-la-encrucijada.pdf

ROJAS, G. (2017). Retomando la agenda económica regional: el Protocolo de cooperación y facilitación de inversiones en el Mercosur. Análisis de coyuntura mensual: Economía y Sociedad. No. 48, Marzo 2017, 12 - 15. Asunción: Centro de Análisis y Difusión de la Economía Paraguaya. Disponible en: http://redrural.org.py/wp-content/uploads/2017/04/Revista-.pdf

SCHILL, S. Y VIDIGAL, G. (2018). Cutting the Gordian Knot: Investment Dispute Settlement à la Carte. Ginebra/Washington: International Centre for Trade and Sustainable Development (ICTSD) y Banco Interamericano de Desarrollo (BID). Disponible en: https://uncitral.un.org/sites/uncitral.un.org/files/rta_exchange__investment_dispute_settlement_-_schill_and_vidigal.pdf

TUNG, K. (2015). Investor-State dispute settlement under the Trans-Pacific Partnership. The California International Law Journal, Vol. 23, No. 1, Summer 2015, $\quad 19 \quad-\quad 25 . \quad 2 \quad$ Disponible http://www.mofo.com/ /media/Files/Articles/2015/08/150800InvestorStateDisp uteSettlement.pdf

VENKATESH, K. (2019). Business and Human Rights in India: Can investors be held accountable for human rights abuses? Opinio Juris, 29 de marzo de 2019. Disponible en: http://opiniojuris.org/2019/03/29/business-and-human-rights-inindia-can-investors-be-held-accountable-for-human-rights-abuses/ 


\section{Capítulo 4}

BAKER, B Y GEDDES, K. (2017). The Incredible Shrinking Victory: Eli Lilly v. Canada, Success, Judicial Reversal, and Continuing Threats from Pharmaceutical ISDS. Loyola University Chicago Law Journal, Vol. 49, 479513. Northeastern University Disponible en: https://ssrn.com/abstract=3012538 BERNASCONI-OSTERWALDER, N Y HOFFMANN, R (2012). The German Nuclear Phase-Out Put to the Test in International Investment Arbitration? Background to the new dispute Vattenfall v. Germany (II). Briefing note, June 2012. International Institute for Sustainable Development. Disponible en: https://www.iisd.org/sites/default/files/publications/german_nuclear_phase_out. pdf

CIEL (2019). Tribunal de arbitraje del Banco Mundial se niega a escuchar a afectados por minería en Santurbán, Comunicado del 27 de febrero de 2019. Disponible en: https://www.ciel.org/news/world-bank-arbitration-tribunal-refuses-listenaffected-mining-santurban-colombia/

DÍAZ PINILLA, L., GUEVARA, R., LAMPREA, N., Y LIZARAZO-CORTÉS, O. (2016). Caso Imatinib: análisis técnico y jurídico del trámite de patente en Colombia. Revista La Propiedad Inmaterial, No. 22, 141-172. Bogotá: Universidad del Externado de Colombia. Disponible en: https://doi.org/10.18601/16571959.n22.08

DIAZ POVEDA, A. (2018). Incidencia de la normatividad ambiental y minera colombiana frente a Eco Oro Minerals Corp en el marco del TLC CanadáColombia. Blog de Derecho de los Negocios, 22 de mayo de 2018. Bogotá: Universidad del Externado. Disponible en: https://dernegocios.uexternado.edu.co/negociacion/incidencia-de-laormatividad-ambiental-y-minera-colombiana-frente-a-eco-oro-minerals-corp-enmarco-del-tlc-canada-colombia/

EFE (2017). El Congreso de El Salvador aprueba una ley que prohíbe la minería metálica. Efe, 29 de marzo de 2017. Disponible en: https://www.efe.com/efe/america/economia/el-congreso-de-salvador-apruebauna-ley-que-prohibe-la-mineria-metalica/20000011-3222940

GÓMEZ ROBLEDO, A. (2003). Significación jurídica del principio de la soberanía permanente sobre los recursos naturales. Temas selectos de Derecho 
Internacional. México DF: UNAM, Instituto de investigaciones jurídicas. Disponible en: https://archivos.juridicas.unam.mx/www/bjv/libros/2/831/22.pdf

GUERRA BARÓN, A. (2011). Los acuerdos internacionales de inversión como una herramienta de relacionamiento internacional de Colombia con el Asia-Pacífico: El caso de Colombia y Corea del Sur. Diálogos de saberes: investigaciones y ciencias sociales. No. 35, 123-138. Bogotá. Disponible en: https://dialnet.unirioja.es/descarga/articulo/3871172.pdf

HERNÁNDEZ GONZÁLEZ, J. (2017). Regulación económica y arbitraje internacional de inversiones. RED: Revista Electrónica de Direito, No. 1. Porto: Facultad de Derecho de la Universidad de Porto. Disponible en: https://dialnet.unirioja.es/servlet/articulo? codigo $=6421947$ \&orden $=0 \&$ info $=$ link

HERNÁNDEZ ORDOÑEZ, S. (2019). El Acuerdo de Escazú. Revista Foreign Affairs Latinoamérica, Portada. Disponible en: http://revistafal.com/el-acuerdo-deescazu/

LÓPEZ, J. (2017). Minera Pacific Rim paga $\$ 8$ millones al Estado salvadoreño por demanda internacional. Elsalvador.com, 3 de julio de 2017. Disponible en: http://www.elsalvador.com/noticias/nacional/369324/empresa-minera-pacificrin-paga-8-millones-de-dolares-a-estado-salvadoreno-por-litigio-del-ciad/

PAULLIER, J. (2017). "Un día histórico": cómo El Salvador logró prohibir por ley la minería metálica en el país. BBC Mundo, Centroamérica, 31 marzo 2017. Disponible en: http://www.bbc.com/mundo/noticias-america-latina-39451498

SARMIENTO, J. (2018). Cuando el comercio internacional se encontró con el medio ambiente, entre el soft law y la prohibición a las barreras al comercio. Anuario Colombiano de Derecho Internacional, Vol. 11, 187 - 220. Bogotá: Universidad del Rosario. Disponible en: https://revistas.urosario.edu.co/index.php/acdi/article/view/6542

SORNARAJAH, M. (2015). Resistance and Change in the International Law on Foreign Investment. Cambridge: Cambridge University Press.

\section{Capítulo 5}

ABEL, P. (2018). Counterclaims based on international human rights obligations of investors in international investment arbitration. Fallacies and potentials of the 
2016 ICSID Urbaser v. Argentina Award. Brill Open Law, No. 1, Vol. 1, 61-90. Disponible en: https://doi.org/10.1163/23527072-00101003

BAS VILIZZIO, M. (2017b). Philip Morris contra Uruguay: protección de inversiones soberanía y salud pública. ECHAIDE, J. (Dir.) Inversiones extranjeras y responsabilidad internacional de las empresas. Problemáticas en torno al CIADI, los TBI y los derechos humanos, 81-106. BdeF. Buenos Aires.

BELTRAMINO, R. (2010). Promoción de inversiones en los acuerdos de inversiones firmados por Argentina, Documento de trabajo No. 49, Mayo 2010. Área de Relaciones Internacionales, FLACSO Argentina. Disponible en: http://rrii.flacso.org.ar/wp-content/uploads/2010/06/FLA_Doc49.pdf

COSTANTE, L. (2012). Soberanía nacional vs. CIADI: ¿Estados o mercados? Revista de Derecho Público, Año I No. 2, Setiembre 2012, 59 - 105. Buenos Aires: Ministerio de Justicia y Derechos Humanos de la Nación. Disponible en: http://www.infojus.gov.ar/_pdf_revistas/DERECHO_PUBLICO_A1_N2.pdf

DÍAZ INVERSO, R. (2018). El concepto de trato justo y equitativo en el laudo Philip Morris v. Uruguay. Tesis de Maestría en Derecho, orientación en Derecho Internacional. Facultad de Derecho, Universidad de la República.

ECCHR (2012). Human Rights inapplicable in International Investment Arbitration? A commentary on the non-admission of ECCHR and Indigenous Communities as Amici Curiae before the ICSID tribunal. Berlín. Disponible en: https://www.ecchr.eu/fileadmin/Kommentare_Konferenzberichte_Weiteres/Kom mentar_ICSID_tribunal_-_Human_Rights_Inapplicable.pdf

ECHAIDE, J. (2016). Demandas en el CIADI y el derecho humano al agua: ¿tratados de inversiones vs derechos humanos? International Law, Revista Colombiana de Derecho Internacional. No. 31, 81 -114. Univerisidad Javeriana. Disponible en: https://doi.org/10.11144/Javeriana.i114-31.dcdh

(2016b). El derecho humano al agua y el sistema de arbitraje de inversiones: un análisis del caso argentino. MINAVERRY, C. Y ECHAIDE, J. (Coord.) Derecho de Aguas y Derecho Ambiental. Revista Jurídica de Buenos Aires. No. 1, 125-168. Facultad de Derecho de la Universidad de Buenos Aires. AbeledoPerrot.

FERNÁNDEZ ALONSO, J. (2013). Controvérsias entre Estados e investidores transnacionais: reflexões sobre o acúmulo de casos contra a República Argentina. Revista Tempo do mundo, Vol. 5 No. 1, Abril 2013, 45 - 87. Brasília: 
Instituto de Pesquisa Econômica Aplicada. Disponible en: http://www.ipea.gov.br/portal/images/stories/PDFs/rtm/140903_rtmv5_n1_port_ cap2.pdf

OVEJAS, A. (2017). Análisis comparativo del Convenio 169. Convergencias entre OIT y Corte IDH. Documento de trabajo. Oficina Regional de la OIT para América Latina y el Caribe. Disponible en: https:/www.ilo.org/wcmsp5/groups/public/--americas/---ro-lima/documents/publication/wcms_548494.pdf

PERRONE, N. (2019). The "Invisible" Local Communities: Foreign Investor Obligations, Inclusiveness, and the International Investment Regime. AJIL Unbound, No. 113, 16-21. Disponible en: doi:10.1017/aju.2018.92

(2016). The international investment regime and local populations: are the weakest voices unheard? Transnational Legal Theory, Vol. 7, No. 3, 383-405, Disponible en: doi:10.1080/20414005.2016.1242249

(2008). Inversiones Extranjeras. Demandas contra la Argentina por controversias vinculadas con la crisis del año 2001. Documento de trabajo del Centro de Estudios Interdisciplinarios de Derecho Industrial y Económico (CEIDIE), UBA.

Disponible

en: http://www.derecho.uba.ar/investigacion/demandas.pdf

RICAURTE HERRERA, C. (2012). Las razones del Centro Internacional de Arreglo de Diferencias Relativas a Inversiones, CIADI: análisis y evaluación del caso CMS contra Argentina (Jurisprudencia). Foro: Revista de Derecho, No. 18. Quito: Universidad Andina Simón Bolívar, Corporación Editora Nacional.

STRANGE, S. (2001). La retirada del Estado. La difusión del poder en la economía mundial. Barcelona: Encuentro - Icaria Editorial - Intermón Oxfam.

SUR, S. (2017). Urbaser v. Argentina: Analysing the expanding scope of investment arbitration in light of human rights obligations. European Federation for Investment Law and Arbitration Blog. Disponible en: https://efilablog.org/2017/05/02/urbaser-v-argentina-analysing-the-expandingscope-of-investment-arbitration-in-light-of-human-rights-obligations/

UNCTAD (2003). World Investment Report 2003. FDI Policies for Development: National and International Perspectives. UNCTAD. Ginebra. Disponible en: https://unctad.org/en/Docs/wir2003light_en.pdf

VÁZQUEZ, T. (2010). Políticas públicas contra el tabaquismo. Revista Uruguaya de Cardiología, Volumen 25, Nro. 3, Diciembre 2010, 241-244. Montevideo: 
Sociedad Uruguaya de Cardiología. Disponible en: http://www.suc.org.uy/revista/v25n3/pdf/rcv25n3_7_3.pdf

(2009). Discurso ante la $64^{\circ}$ Asamblea General de la Organización de Naciones Unidas, 23 de setiembre de 2009. Disponible en: http://uruguayescribe.com/2009/09/23/discurso-del-presidente-dr-tabarevazquez-en-la-onu-el-23-setiembre-2009/

\section{Capítulo 6}

ASOCIACIÓN DE MAGISTRADOS DE ALEMANIA (2016). Opinion on the establishment of an investment tribunal in TTIP - the proposal from the European Commission on 16.09.2015 and 11.12.2015. Documento No. 04/16. Disponible en: https://www.foeeurope.org/sites/default/files/euus_trade_deal/2016/english_version_deutsche_richterbund_opinion_ics_feb201 6.pdf

BAS VILIZZIO, M. (2019). Acuerdo Mercosur-UE: un acuerdo sin solución de controversias inversor-Estado. Blog del Área de Relaciones Internacionales de FLACSO Argentina. Disponible en: http://rrii.flacso.org.ar/acuerdo-mercosurue-controversias/

(2017). América del Sur ante los tratados bilaterales de inversión: ¿hacia un retorno del Estado en la solución de controversias? Montevideo: Biblioteca Plural, Comisión Sectorial de Investigación Científica - Universidad de la República.

CIADI (2019). Proposals for amendment of the ICSID rules. Working Paper No. 3, Vol. 1. Disponible en: https://icsid.worldbank.org/en/Documents/WP_3_VOLUME_1_ENGLISH.pdf

CINGOTTI, N. Y OTROS (2016). El Sistema de Tribunales de Inversiones puesto a prueba. Ámsterdam/Bruselas/Berlín/Ottawa: Centro Canadiense de Políticas Alternativas, Corporate Europe Observatory, Amigos de la Tierra Europa, el Foro Alemán de ONG de Medio Ambiente y Desarrollo y el Transnational Institute. Disponible en: https://www.tni.org/files/publicationdownloads/el_ics_puesto_a_prueba.pdf 
CONSANI, N. (2008). Los modelos en la sociedad internacional contemporánea. Serie Derecho Internacional Contemporáneo, No. 1. La Plata: Instituto de Relaciones Internacionales de la Universidad Nacional de La Plata.

DE LA BAUME, M. (2016). Walloon parliament rejects CETA deal. Politico, 14 de octubre de 2016. Disponible en: https://www.politico.eu/article/walloonparliament-rejects-ceta-deal/

EBERHARDT, P. Y OLIVET, C. (2012). Cuando la injusticia es negocio. Bruselas/Ámsterdam: The Transnational Institute. Disponible en: https://www.tni.org/files/download/cuando_la_injusticia_es_negocio-web.pdf

FERNANDEZ ALONSO, J. (2013). Controvérsias entre Estados e investidores transnacionais: reflexões sobre o acúmulo de casos contra a República Argentina. Revista Tempo do mundo, Vol. 5 No. 1, Abril 2013, 45 - 87. Brasília: Instituto de Pesquisa Econômica Aplicada. Disponible en: http://www.ipea.gov.br/portal/images/stories/PDFs/rtm/140903_rtmv5_n1_port_ cap2.pdf

GAFFNEY, J. (2016). The EU proposal for an Investment Court System: what lessons can be learned from the Arab Investment Court? Columbia FDI Perspectives, No. 181. Nueva York: Columbia Center on Sustainable Development, Columbia University. Disponible en: http://ccsi.columbia.edu/files/2013/10/PerspectiveGaffney-Final-Formatted.pdf

GAZZINI, T. (2017). Nigeria and Morocco move towards a "new generation" of bilateral investment treaties. Ejll Talk!, 8 de mayo de 2017. Disponible en: https://www.ejiltalk.org/nigeria-and-morocco-move-towards-a-new-generationof-bilateral-investment-treaties/

GHIOTTO, L. (2017). ¿UNCTAD pro.desarrollo o pro-liberalización? Un estudio de los cambios en el organismo a la luz de las políticas sobre inversiones. ECHAIDE, J. (Dir.) Inversiones extranjeras y responsabilidad internacional de las empresas. Problemáticas en torno al CIADI, los TBI y los derechos humanos, 53-78. BdeF. Buenos Aires.

IRURETAGOIENA, I. (2018). La sentencia del TJUE en el asunto Achmea: el adíos al arbitraje de inversiones en los APPRI intra-UE en la Unión Europea (y algo más). La Ley Unión Europea, No. 60. Editorial Wolters Kluwer. Disponible en: https://dialnet.unirioja.es/servlet/articulo?codigo $=6483941$ 
KENDRA, T. Y OTROS (2017). The Morocco-Nigeria BIT: a new breed of investment treaty? Practical Law arbitration blog, 16 de noviembre de 2017. Disponible en: http://arbitrationblog.practicallaw.com/the-morocco-nigeria-bit-a-new-breed-ofinvestment-treaty/

KRASNER, S. (2009). Power, the State, and Sovereignty. Essays on international relations. Nueva York: Routledge. (2009b). Think again: sovereignty. Foreign Policy, 20 Noviembre 2009. Disponible en: http://foreignpolicy.com/2009/11/20/think-again-sovereignty/ (2001). Soberanía, hipocresía organizada. Barcelona, Paidós.

LESTER, S. Y MERCURIO, B. (2017). Safeguarding policy space in investment agreements. Institute of International Economic Law Issue Brief 12/2017. Washington: Georgetown University, Law Center. Disponible en: https://iielaw.org/wp-content/uploads/2018/06/Simon-Lester-and-BryanMercurio-General-Exceptions-in-IIAs-IIEL-Issue-Brief-December-2017Accessible.pdf

MOUYAL, L. (2016). International Investment Law and the Right to Regulate - A human rights perspective. New York : Routledge. Edición de Kindle.

NIKIÈMA, S. (2013). Compensation for Expropriation. Best practices series, Marzo 2013. Winnipeg: International Institute for Sustainable Development. Disponible en:

https://www.iisd.org/pdf/2013/best_practice_compensation_expropriation_en.pd $\mathrm{f}$

NWEKE-EZE, S. (2017). BIT between Morocco and Nigeria - a bold step in the right direction? Kluwer arbitration blog, 22 de junio de 2017. Wolters Kluwer. Disponible en: http://arbitrationblog.kluwerarbitration.com/2017/06/22/bitmorocco-nigeria-bold-step-right-direction/

PERRONE, N. (2008). Inversiones Extranjeras. Demandas contra la Argentina por controversias vinculadas con la crisis del año 2001. Documento de trabajo del Centro de Estudios Interdisciplinarios de Derecho Industrial y Económico (CEIDIE),

UBA. Disponible

en: http://www.derecho.uba.ar/investigacion/demandas.pdf

PUIG, J. C. (1986). Integración y autonomía en América Latina en las postrimerías siglo XX. Integración Latinoamericana, Vol. 11, No. 109, 40-62. Buenos Aires: Instituto de Integración Latinoamericana. 
REGÍ RODRÍGUEZ, J. (2016). La tutela del Derecho de la Unión Europea: La cuestión prejudicial y el recurso por incumplimiento. Revista Estudios Jurídicos. Segunda Época, No. 16. Universidad de Jaén. Disponible en: https://doi.org/10.17561/rej.n16.a6

RICAURTE HERRERA, C. (2012). Las razones del Centro Internacional de Arreglo de Diferencias Relativas a Inversiones, CIADI: análisis y evaluación del caso CMS contra Argentina (Jurisprudencia). Foro: Revista de Derecho, No. 18. Quito: Universidad Andina Simón Bolívar, Corporación Editora Nacional.

SASSEN, S. (2010). Desnacionalización de las políticas estatales y privatización de la producción de normas. En: GUNTHER, T. y otros (2010). Estado, soberanía y globalización. Bogotá: Siglo del Hombre Editores. Universidad de los Andes. Pontificia Universidad Javeriana-Instituto Pensar.

SCHILL, S. (2016). The European Commission's Proposal of an "Investment Court System" for TTIP: Stepping Stone or Stumbling Block for Multilateralizing International Investment Law? Insights, Vol. 20, No. 9. Washington: American Society of International Law (ASIL). Disponible en https://www.asil.org/insights/volume/20/issue/9/european-commissionsproposal-investment-court-system-ttip-stepping

SCHILL, S. Y VIDIGAL, G. (2018). Cutting the Gordian Knot: Investment Dispute Settlement à la Carte. Ginebra/Washington: International Centre for Trade and Sustainable Development (ICTSD) y Banco Interamericano de Desarrollo (BID). Disponible en: https://uncitral.un.org/sites/uncitral.un.org/files/rta_exchange__investment_dispute_settlement_-_schill_and_vidigal.pdf

SORNARAJAH, M. (2016). An International Investment Court: panacea or purgatory? Columbia FDI Perspectives, No. 180. Nueva York: Columbia Center on Sustainable Development, Columbia University. Disponible en: http://ccsi.columbia.edu/files/2013/10/No-180-Sornarajah-FINAL.pdf (2015). Resistance and Change in the International Law on Foreign Investment. Cambridge: Cambridge University Press.

UNCTAD (2015). World Investment Report 2015. Reforming international investment governance. UNCTAD. Ginebra. Disponible https://unctad.org/en/PublicationsLibrary/wir2015_en.pdf 
(2003). World Investment Report 2003. FDI Policies for Development:

National and International Perspectives. UNCTAD. Ginebra. Disponible en: https://unctad.org/en/Docs/wir2003light_en.pdf

WAGNER, M. (2014). Regulatory Space in International Trade Law and International Investment Law, University of Pennsylvania Journal of International Law, Vol. 36, No. 1, . Disponible en: https://scholarship.law.upenn.edu/jil/vol36/iss1/1

\section{Capítulo 7}

ARREDONDO, R. Y GODIO, L. (2019). La crisis del Órgano de Apelación de la Órganización Mundial del Comercio. Revista de la Secretaría del Tribunal Permanten de Revisión, Año 7, No. 13, 163 - 179. Disponible en: http://www.revistastpr.com/index.php/rstpr/article/view/301/155198

BIZZOZERO, L. (2017). Introducción. Empresas transnacionales y derechos humanos.

Seminario realizado el 28 de agosto de 2017, Cámara de Representantes, Escuela de Gobierno, Parlamento del Uruguay, 7-9. Escuela de Gobierno del Parlamento. Montevideo.

BÖHM, M. L. (2017). Empresas transnacionales, violaciones de derechos humanos y violencia estructural en América Latina: un enfoque crimonológico. Revista Crítica Penal y Poder. No. 17, 37-61. Observatorio del sistema penal y los derechos humanos de la Universidad de Barcelona. Barcelona. Disponible en: http://revistes.ub.edu/index.php/CriticaPenalPoder/article/view/19764/22496

CONSANI, N. (2008). Los modelos en la sociedad internacional contemporánea. Serie Derecho Internacional Contemporáneo, No. 1. La Plata: Instituto de Relaciones Internacionales de la Universidad Nacional de La Plata.

DEL ARENAL, C. (2008). Mundialización, creciente interdependencia y globalización en las relaciones internacionales. Cursos de Derecho Internacional de VitoriaGasteiz, 2008, No. 2, 181-268. Bilbao: Servicio Editorial de la universidad del País Vasco.

GONZÁLEZ, E. (2017). Lex Mercatoria vs. Derecho Internacional de los Derechos Humanos. Empresas transnacionales y derechos humanos. Seminario realizado el 28 de agosto de 2017, Cámara de Representantes, Escuela de Gobierno, Parlamento del Uruguay, 25-29. Escuela de Gobierno del Parlamento. Montevideo. 
GRABENDORFF, W. (2017). Los dueños de la globalización. Nueva Sociedad, No. 271, 55-69. Buenos Aires: Fundación Friedrich Ebert. Disponible en: https://nuso.org/media/articles/downloads/3.TC_Grabendorf_271.pdf

HELD, D. (2018). The overlapping crises of democracy, globalization and global governance. Social Europe, 3 de julio de 2018. Disponible en: https://www.socialeurope.eu/the-overlapping-crises-of-democracy-globalizationand-global-governance

HERNÁNDEZ GONZÁLEZ, J. (2017). Regulación económica y arbitraje internacional de inversiones. RED: Revista Electrónica de Direito, No. 1. Porto: Facultad de Derecho de la Universidad de Porto. Disponible en: https://dialnet.unirioja.es/servlet/articulo?codigo $=6421947 \&$ orden $=0 \&$ info $=$ link

HERNÁNDEZ ZUBIZARRETA, J. Y OTROS (2018). De qué va el tratado de la ONU sobre empresas y derechos humanos. El Salto, 19 octubre 2018. Disponible en: https://www.elsaltodiario.com/multinacionales/tratado-vinculante-onu-ginegrasobre-empresas-derechos-humanos

HILLEBRAND, J. (2019). Seven months until Appellate Body apocalypse: time to prepare for the worst case. Maastricht University Blog, 3 de mayo de 2019. Disponible en: https://www.maastrichtuniversity.nl/blog/2019/05/seven-monthsuntil-appellate-body-apocalypse-time-prepare-worst-case

HOEKMAN, B. Y MAVROIDIS, P. (2019). Party like it's 1995: Necessary but not sufficient to resolve WTO Appellate Body crisis. Vox, 26 de agosto de 2019. CEPR Policy Portal, Disponible en: https://voxeu.org/article/party-it-s-1995resolving-wto-appellate-body-crisis

HORN, H. Y OTROS (2009). Beyond the WTO? An anatomy of EU and US preferential trade agreements. Bruegel Blueprint Series, Vo. VII. Bruselas: Bruegel. Disponible en: http://bruegel.org/wpcontent/uploads/imported/publications/bp_trade_jan09.pdf

KAPUR, D. (2019). What next for the Bretton Woods Twins? Project Syndicate, 18 de octubre de 2019. Disponible en: https://www.projectsyndicate.org/onpoint/what-next-for-the-bretton-woods-twins-by-devesh-kapur2019-10

KEOHANE, R. (2006). The contingent legitimacy of multilateralism. NEWMAN, E. Y OTROS (Eds.). (2006) Multilateralism Under Challenge: Power, International Order, and Structural Change, 56-76. Nueva York: UNU Press. 
KRASNER, S. (2011). Changing state structures: Outside in. Proceedings of the National Academy of Sciences, Vol. 108, Suplemento 4, 21302 - 21307. Princeton: Princeton University, Disponible en: https://doi.org/10.1073/pnas.1100244108

(2009). Power, the State, and Sovereignty. Essays on international relations. Nueva York: Routledge. (2009b). Think again: sovereignty. Foreign Policy, 20 Noviembre 2009. Disponible en: http://foreignpolicy.com/2009/11/20/think-again-sovereignty/ (2001). Soberanía, hipocresía organizada. Barcelona, Paidós.

MITCHELL, J. (2019). The Long Road to the Student Debt Crisis. The Wall Street Journal, 7 de junio de 2019. Disponible en: https://www.wsj.com/articles/thelong-road-to-the-student-debt-crisis-11559923730

MOUYAL, L. (2016). International Investment Law and the Right to Regulate - A human rights perspective. New York : Routledge. Edición de Kindle.

LÓPEZ, C. (2019). El proyecto revisado de un Tratado sobre empresas y derechos humanos: mejoras innovadoras y perspectivas más claras. Disponible en: https://www.iisd.org/itn/es/2019/10/02/the-revised-draft-of-a-treaty-on-businessand-human-rights-ground-breaking-improvements-and-brighter-prospectscarlos-lopez/

(2018). Hacia una Convención Internacional sobre empresas y Derechos Humanos. Disponible https://www.iisd.org/itn/es/2018/10/17/toward-an-international-convention-onbusiness-and-human-rights-carlos-lopez/

LUND, S. Y OTROS (2019). The global economy's next winners. Foreign Affairs, Julio/Agosto 2019. Disponible en: https://www.foreignaffairs.com/articles/world/2019-06-11/global-economysnext-winners

OCDE (2004). "Indirect expropriation" and the "right to regulate" in International Investment Law. Working Papers on International Investment, No. 2004/4. Disponible en: https://www.ilsa.org/Jessup/Jessup07/basicmats/oecd_report.pdf

OCDE Y WTO (2019), Aid for Trade at a Glance 2019: Economic Diversification and Empowerment. Paris: OECD Publishing. Disponible en: https://doi.org/10.1787/18ea27d8-en. 
OMC (2019). Informe anual correspondiente a 2018. Órgano de Apelación. OMC, Ginebra. Diponible

en: https://www.wto.org/spanish/tratop_s/dispu_s/ab_anrep_2018_s.pdf

PERRONE, N. (2019). The "Invisible" Local Communities: Foreign Investor Obligations, Inclusiveness, and the International Investment Regime. AJIL Unbound, No. 113, 16-21. Disponible en: doi:10.1017/aju.2018.92

POSTIGA, A. (2013). A emergência do direito administrativo global como ferramenta de regulação transnacional do investimento estrangeiro direto. Revista de Direito Internacional, Vol. 10, No. 1, 171 - 193. Brasilia: UniCEUB. Disponible en: doi:10.5102/rdi.v10i1.2369

RODRIK, D. (2019). Can global rules prevet national self-harm? Project Syndicate, 11 de junio de 2019. Disponible en: https://www.projectsyndicate.org/commentary/global-rules-cannot-prevent-domestic-policymistakes-by-dani-rodrik-2019-06 (2010). La paradoja de la globalización. Barcelona: Antoni Bosch.

SANAHUJA, J.A. (2018). Crisis de globalización, crisis de hegemonía: un escenario de cambio estructural para América Latina y el. Caribe. América Latina y el Caribe frente a un Nuevo Orden Mundial: Poder, globalización y respuestas regionales. Colección Pensamiento Propio, 7-68. Barcelona: Icaria Editorial. Disponible en: http://www.cries.org/wp-content/uploads/2018/06/007-Sanahuja.pdf

SASSEN, S. (2011). A Savage Sorting of Winners and Losers, and Beyond. CALHOUN, C., Y DERLUGUIAN, G. (Eds.). (2011). Aftermath: A New Global Economic Order? Nueva York: NYU Press.

(2010). Desnacionalización de las políticas estatales y privatización de la producción de normas. En: GUNTHER, T. y otros (2010). Estado, soberanía y globalización. Bogotá: Siglo del Hombre Editores. Universidad de los Andes. Pontificia Universidad Javeriana-Instituto Pensar. (2001). ¿Perdiendo el control? La soberanía en la era de la globalización. Barcelona: Ediciones Bellaterra.

SCHNEIDER-PETSINGER, M. (2019). Stretching the rules will not save global trade. Financial Times, 13 de octubre de 2019. Disponible en: https://www.ft.com/content/92497c3e-e9bc-11e9-aefb-a946d2463e4b

SORNARAJAH, M. (2015). Resistance and Change in the International Law on Foreign Investment. Cambridge: Cambridge University Press. 
STRANGE, S. (1982). Cave! Hic Dragones: A critique of regime analysis. International Organization, Vol. 36, No. 2, 479-496. Disponible en: http://www.jstor.org/stable/2706530

TEITELBAUM, A. (2014). Nueva iniciativa para terminar con la impunidad de las sociedades transnacionales. Rebelión, 27 de mayo de 2014. Disponible en: http://www.rebelion.org/noticia.php?id=185201

THE ECONOMIST (2019). The global list. The Economist, 26 de enero de 2019, 23-26. Londres.

(2017). The retreat of the global company. The Economist, 28 de enero de 2017, 14-18. Londres.

THEILBÖRGER, P. Y ACKERMANN, T. (2017). A Treaty on Enforcing Human Rights Against Business: Closing the Loophole or Getting Stuck in a Loop? Indiana Journal of Global Legal Studies. Vol. 24, No. 1, 43-79. Disponible en: https://www.repository.law.indiana.edu/ijgls/vol24/iss1/3

TUSSIE, D. (2019). La reconfiguración global: Su capítulo en vivo para América Latina. ALTMANN, J. (Edit.) (2019). América Latina frente a la reconfiguración global, 107-119. San José de Costa Rica: FLACSO Secretaría General.

(2006). Nuevo enfoque del multilateralismo en una economía globalizada. Taller a distancia "Integración y Desarrollo Sostenible”. CLAES 2006. Disponible en: https://www.academia.edu/32450626/Nuevo_enfoque_del_multilateralismo_en_ una econom $\% \mathrm{C} 3 \% \mathrm{ADa}$ globalizada

VAN HARTEN, G. Y LOUGHLIN, M. (2006). Investment Treaty Arbitration as a Species of Global Administrative Law. The European Journal of International Law, Vol. 17, No.1, 121 - 150. Disponible en: 10.1093/ejil/chi159

WERHANE, P. (2015). Corporate Moral Agency and the Responsibility to Respect Human Rights in the UN Guiding Principles: Do Corporations Have Moral Rights? Business and Human Rights Journal, No. 1 (2015), 5-20. Disponible en: doi:10.1017/bhj.2015.1

ZELICOVICH, J. (2019). La crisis de la OMC y el trilema de las negociaciones comerciales internacionales. Relaciones Internacionales, No. 92, Vol. 11, 1-21. Disponible en: https://doi.org/10.15359/ri.92-1.1 


\section{Apéndice I: CV de los entrevistados}

\section{José Augusto Fontoura Costa}

Título de grado en Derecho Internacional de la Universidad de San Pablo, Brasil, doctorado en Derecho Internacional de la misma universidad. Profesor Asociado de la Universidad de San Pablo y Profesor de la Facultad de Derecho de Sorocaba, Brasil.

Es miembro del cuerpo editorial y revisor de numerosas publicaciones brasileras e internacionales en su especialidad actuando principalmente en los siguientes temas: inversión extranjera, regímenes internacionales, globalización, contratos internacionales, Derecho del Comercio Internacional, acuerdos internacionales de inversión.

\section{Alejandro Garro}

Es Profesor Adjunto e Investigador Senior de la Escuela Parker de Derecho Extranjero y Comparado de la Universidad de Columbia. Con anterioridad a esa fecha, fue profesor en Facultad de Derecho de la Universidad Estatal de Luisiana. Asimismo, es Profesor visitante en numerosas universidades e instituciones del mundo.

Es miembro del grupo de expertos de UNIDROIT en la preparación de los Principios Internacionales de Contratos, miembro de paneles arbitrales de Asociación Americana de Arbitraje, Asociación Nacional de Futuros, Federación Argentina de Arbitraje y Conciliación, Cámara Internacional de Comercio, Corte Internacional de Arbitraje de Londres y Centro de Resolución de Disputas de Asociación Nacional de Concesionarios de Valores.

\section{Carlos Gianelli}

Abogado graduado en la Universidad de la República, Uruguay, y Máster en Ciencias Sociales, Especialización en Asuntos Internacionales, de la Fundación Bariloche, Argentina. Es diplomático de carrera, y como tal ha actuado como Representante Alterno en la Misión de Uruguay ante las Naciones Unidas en Nueva York (19871991), Embajador en Arabia Saudita (1991-1993), México (1995-2000), Países Bajos (2003-2005) y Estados Unidos (2005-2012, 2015-actualidad), y Jefe de Gabinete del Secretario General de ALADI (1983-1986). Asimismo, se desempeñó como agente de Uruguay en el caso "Papeleras en el Río Uruguay", Argentina contra Uruguay, ante la 
Corte Internacional de Justicia (2006-2010), y como representante el Uruguay ante el CIADI en el caso Philip Morris contra Uruguay y otros casos ante el CIADI.

Actualmente, desde agosto de 2015 ejerce el cargo de Embajador de Uruguay en los Estados Unidos.

\section{Juan Hernández Zubizarreta}

Es Doctor en Derecho por la Universidad del País Vasco / Euskal Herriko Unibertsitatea (UPV/EHU) y profesor del Departamento de Derecho de la Empresa en dicha universidad. Investigador del Observatorio de Multinacionales en América Latina. Autor de diversos libros y artículos sobre distintas cuestiones relacionadas con las empresas transnacionales, los derechos humanos, la Responsabilidad Social Corporativa y la crisis de los sistemas normativos en la globalización económica. Miembro de la red Desmantelando el Poder Corporativo y colaborador del Tribunal Permanente de los Pueblos.

\section{Felipe Michelini}

Es Abogado especializado en derechos humanos y justicia internacional de la República (Uruguay), con una maestría (LL.M) en la Escuela de Derecho de la Universidad de Columbia en Nueva York. Actualmente es miembro "Consejo de Dirección del Fondo Fiduciario de la Corte Penal Internacional en Beneficio de las Victimas", miembro del “Grupo de Trabajo por Verdad y Justicia", Presidente de la Delegación Uruguaya en la Comisión Administradora del Río de la Plata. En la Universidad de la República se desempeña como Profesor Adjunto de Derechos Humanos y Coordinador de la Cátedra UNESCO de Derechos Humanos radicada en el Rectorado de dicha institución. Ex Diputado (1995 - 2015).

\section{Fabio Morosini}

Es Profesor de tiempo completo de la Facultad de Derecho en la Universidad Federal de Rio Grande del Sur (Brasil), donde dirige el Centro para el Derecho, la Globalización y el Desarrollo, y trabaja con temas relaciones al comercio internacional, inversions internacionales y métodos en Derecho. Es investigador del Consejo Nacional de Ciencia y Desarrollo Tecnológico de Brasil. Fue Investigador Global Hauser en la Facultad de Derecho de la Universidad de Nueva York (2015-2016). 
Es Doctor y Máster en Derecho de la Universidad de Texas, Máster de la Universidad de Paris 1 (Instituto de Ciencia Política). Realizó su posdoctorado en la Organización Mundial del Comercio.

\section{Cecilia Olivet}

Es Licenciada en Relaciones Internacionales de la Universidad de la República (Urugua) y Máster en Política Internacional y Asia Meridional de la Universidad de Warwick (Reino Unido). Está especializada en la agenda de comercio e inversión de la Unión Europea y en el régimen intenacional de inversiones. En 2005 comenzó a trabajar en el Transnational Institute (TNI), donde participa en el equipo del programa Justicia Económica, donde coordina el proyecto Comercio e Inversiones, al que contribuye con investigaciones y análisis, dinamización de campañas y facilitación de redes. Es integrante activa de la red Seattle to Brussels (S2B) y la red EU-ASEAN FTA.

De 2013 a 2015, presidió la Comisión CAITISA, establecida por decreto presidencial para auditar los tratados bilaterales de inversión y los casos de arbitraje internacional de Ecuador.

\section{Saskia Sassen}

Es Profesora de Sociología de la cátedra Robert S. Lynden de la Universidad de Columbia y miembro del Comité sobre Pensamiento Global. Obtuvo un máster y un doctorado en sociología y economía en la Universidad de Notre Dame (Estados Unidos), un máster en filosofía en Francia y un posdoctorado en el Centro de Estudios Internacionales de la Universidad de Harvard.

Su obra incluye publicaciones sobre urbanismo a nivel global y estudios sobre las cuestiones del poder y la desigualdad derivados de los procesos de globalización. Entre sus libros se incluyen "Expulsiones: brutalidad y complejidad de la economía global" (Harvard University Press/Belknap, 2014), “Territorio, autoridad, derechos: De los ensamblajes medievales a los ensamblajes globales" (Princeton University Press, 2008), "Una sociología de la globalización" (W.W.Norton, 2007). Sus obras han sido traducidas en más de 20 idiomas.

Fue reconocida por diversos premios y menciones, incluyen múltiples Doctorados Honoris Causa, y varias instituciones la seleccionaron como uno de los pensadores globales más importantes. Recientemente recibió el premio Príncipe de Asturias en 
Ciencias Sociales (2013) y fue elegida como Miembro extranjero de la Academia de Ciencias de Países Bajos. 
Apéndice II: Procedimientos arbitrales

Flujograma 1: Procedimiento arbitral ordinario en el CIADI

\section{Etapa 1: Solicitud de arbitraje} (artículo 36 del CW)

- Solicitud de iniciar un arbitraje inversor-Estado.

-Registro por el Secretario General del CIADI.
Etapa 2: Constitución del tribunal arbitral (artículo 37 del (W)

- Constitución del tribunal arbitral de árbitro único o de número impar de árbitros (generalmente tres).

-El tribunal establece su propia competencia y define si las excepciones de jurisdicción las resuelve previamente o junto al fondo del asunto.

\section{Etapa 4: Actuaciones orales} (Regla de Arbitraje $\mathrm{N}^{\circ} 32$ )

-Audiencias para que el tribunal escuche a las partes, representantes legales, testigos y peritos.

\section{Etapa 3: Actuaciones escritas} (Regla de Arbitraje $\mathrm{N}^{\circ} 31$ )

-Presentación del memorial y memorial de constestación.

-Eventualmente, presentación de una réplica y una dúplica.
Etapa 5: Laudo (artículos 48 a 52 del $\mathrm{CW}$ )

-Dictado de un laudo por mayoría de votos.

-Pasible de recurso de aclaración, revisión o anulación.

Fuente: Adaptado de Bas Vilizzio (2017: 87). 
Flujograma 2: Procedimiento arbitral del Reglamento de Arbitraje de la UNCITRAL (2010)

Etapa 1: Notificación del arbitraje (artículos 3 y 4 del RAU 2010)

- Notificación del arbitraje y respuesta a la notficación.
Etapa 2: Constitución del tribunal arbitral (artículos 7 a 15 del RAU 2010)

- Constitución del tribunal arbitral de árbitro único o tres árbitros.

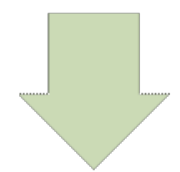

Etapa 4: Actuaciones orales (artículos 28 a 31 del RAU 2010)

-En caso de celebrarse audiencias, el tribunal notifica a las partes con suficiente antelación.

-Durante las audiencias el tribunal puede escuchar las exposiciones de las partes, testigos y peritos.

- Se realizan a puertas cerrados, salvo que las partes acuerden lo contrario.

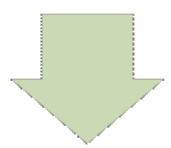

Etapa 5: Laudo (artículos 33 a 43 del RAU 2010)

-Dictado de un laudo por mayoría de votos.

-Público el con consentimiento de las partes o cuando una parte tenga obligación de darlo a conocer.

-Pasible de recurso de interpretación y rectificación.

- Modificación respecto al RAU de 1976: no se indica que el laudo sea definitivo e inapelable.
Etapa 3: Actuaciones escritas (artículos 20 a 22 del RAU 2010)

-Presentación de la demanda y su constestación.

-Eventualmente, modificación o complementación de la demanda y su contestación.

Fuente: Elaboración propia en base al Reglamento de Arbitraje de la UNCITRAL (2010). 


\section{Apéndice III: Jurisprudencia citada}

\section{Tabla 10: Arbitrajes inversor-Estado}

\begin{tabular}{|c|c|c|c|}
\hline ESTADO & INVERSOR & FORO & NÚMERO \\
\hline Alemania & Vattenfall AV y otros & CIADI & $\mathrm{ARB} / 12 / 12$ \\
\hline Alemania & Vattenfall Europe Generation AG & CIADI & $\mathrm{ARB} / 09 / 6$ \\
\hline Argentina & $\begin{array}{l}\text { Aguas Cordobesas S.A., Suez, y Sociedad } \\
\text { General de Aguas de Barcelona S.A. }\end{array}$ & CIADI & $\mathrm{ARB} / 03 / 18$ \\
\hline Argentina & AWG Group Ltd. & $\begin{array}{l}\text { Arbitraje ad hoc conforme } \\
\text { al Reglamento de Arbitraje } \\
\text { de la UNCITRAL }\end{array}$ & - \\
\hline Argentina & Azurix Corp. & CIADI & $\mathrm{ARB} / 01 / 12$ \\
\hline Argentina & Azurix Corp. & CIADI & $\mathrm{ARB} / 01 / 12$ \\
\hline Argentina & Azurix Corp. & CIADI & $\mathrm{ARB} / 03 / 30$ \\
\hline Argentina & BC Group PLC & $\begin{array}{l}\text { Arbitraje ad hoc conforme } \\
\text { al Reglamento de Arbitraje } \\
\text { de la UNCITRAL }\end{array}$ & - \\
\hline Argentina & CMS Gas Transmission Company & CIADI & $\mathrm{ARB} / 01 / 8$ \\
\hline Argentina & $\begin{array}{l}\text { Compañía de Aguas del Aconquija SA y } \\
\text { Vivendi Universal SA }\end{array}$ & CIADI & $\mathrm{ARB} / 97 / 3$ \\
\hline Argentina & Gas Natural SDG SA & CIADI & $\mathrm{ARB} / 03 / 10$ \\
\hline Argentina & Impregilo S.P.A. & CIADI & $\mathrm{ARB} / 07 / 17$ \\
\hline Argentina & National Grid PLC & $\begin{array}{l}\text { Arbitraje ad hoc conforme } \\
\text { al Reglamento de Arbitraje } \\
\text { de la UNCITRAL }\end{array}$ & - \\
\hline Argentina & SAUR International S.A. & CIADI & $\mathrm{ARB} / 04 / 4$ \\
\hline Argentina & $\begin{array}{l}\text { Suez, Sociedad General de Aguas de } \\
\text { Barcelona SA e InterAguas Servicios } \\
\text { Integrales del Agua SA }\end{array}$ & CIADI & $\mathrm{ARB} / 03 / 17$ \\
\hline Argentina & $\begin{array}{l}\text { Suez, Sociedad General de Aguas de } \\
\text { Barcelona SA y Vivendi SA }\end{array}$ & CIADI & $\mathrm{ARB} / 03 / 19$ \\
\hline Argentina & $\begin{array}{l}\text { Urbaser S.A. y Consorcio de Aguas Bilbao } \\
\text { Biskaia, Bilbao Biskaia Ur Partzuergoa }\end{array}$ & CIADI & $\mathrm{ARB} / 07 / 26$ \\
\hline Australia & Philip Morris Asia Limited & $\mathrm{CPA}$ & $2012-2$ \\
\hline Bolivia & Aguas del Tunari SA & CIADI & $\mathrm{ARB} / 02 / 3$ \\
\hline Bolivia & ETI Euro Telecom International NV & CIADI & $\mathrm{ARB} / 07 / 28$ \\
\hline Bulgaria & Plama Consortium contra Bulgaria & CIADI & $\mathrm{ARB} / 03 / 24$ \\
\hline Canadá & Lone Pine Resources Inc & CIADI & UNCT/15/2 \\
\hline Canadá & $\begin{array}{l}\text { Bilcon of Delaware Inc, William Ralph layton, } \\
\text { William Richard Clayton, Douglas Clayton, } \\
\text { Daniel Clayton }\end{array}$ & CPA & $2009-04$ \\
\hline Colombia & América Móvil SAB de CV & CIADI & $\mathrm{ARB}(\mathrm{AF}) / 16 / 5$ \\
\hline Colombia & $\begin{array}{l}\text { Cosigo Resources, Ltd., Cosigo Resources } \\
\text { Sucursal Colombia, Tobie Mining and Energy, } \\
\text { Inc. }\end{array}$ & $\begin{array}{l}\text { Arbitraje ad hoc conforme } \\
\text { al Reglamento de Arbitraje } \\
\text { de la UNCITRAL }\end{array}$ & - \\
\hline Colombia & Eco Oro Minerals Corporation & CIADI & $\mathrm{ARB} / 16 / 41$ \\
\hline Colombia & Galway Gold Inc. & CIADI & $\mathrm{ARB} / 18 / 13$ \\
\hline Colombia & Glencore International y C.I. Prodeco & CIADI & $\mathrm{ARB} / 16 / 6$ \\
\hline Colombia & Red Eagle Exploration Limited & CIADI & $\mathrm{ARB} / 18 / 12$ \\
\hline
\end{tabular}




\begin{tabular}{|c|c|c|c|}
\hline ESTADO & INVERSOR & FORO & NÚMERO \\
\hline Costa Rica & Santa Elena S.A. & CIADI & $\mathrm{ARB} / 96 / 1$ \\
\hline Ecuador & $\begin{array}{l}\text { Chevron Corporation \& Texaco Petroleum } \\
\text { Company }\end{array}$ & $\mathrm{CPA}$ & $2009-23$ \\
\hline Ecuador & Copper Mesa Mining & CPA & $2012-2$ \\
\hline Ecuador & $\begin{array}{l}\text { Occidental Petroleum Corporation y } \\
\text { Occidental Exploration and Production } \\
\text { Company }\end{array}$ & CIADI & $\mathrm{ARB} / 06 / 11$ \\
\hline El Salvador & Pac Rim Cayman LLC & CIADI & $\mathrm{ARB} / 09 / 12$ \\
\hline Eslovaquia & Achmea BV & $\begin{array}{l}\text { Arbitraje ad hoc en } \\
\text { territorio alemán }\end{array}$ & - \\
\hline España & Agustín Maffezini & CIADI & $\mathrm{ARB} / 97 / 7$ \\
\hline España & $\begin{array}{l}\text { DCM Energy GmbH \& Co. Solar } 1 \mathrm{KG}, \mathrm{DCM} \\
\text { Energy GmbH \& Co. Solar } 2 \mathrm{KG} \text {, Hannover } \\
\text { Leasing Sun Invest } 2 \text { Spanien Beteiligungs } \\
\text { GmbH, Hannover Leasing Sun Invest } 2 \\
\text { Spanien GmbH \& Co. KG, Edisun Power } \\
\text { Europe A.G. }\end{array}$ & CIADI & $\mathrm{ARB} / 17 / 41$ \\
\hline España & $\begin{array}{l}\text { EBL (Genossenschaft Elektra Baselland) y } \\
\text { Tubo Sol PE2 S.L. }\end{array}$ & CIADI & $\mathrm{ARB} / 18 / 42$ \\
\hline España & Eurus Energy Holdings Corporation & CIADI & $\mathrm{ARB} / 16 / 4$ \\
\hline España & Itochu Corporation & CIADI & $\mathrm{ARB} / 18 / 25$ \\
\hline España & Masdar Solar \& Wind Cooperatief U.A. & CIADI & $\mathrm{ARB} / 14 / 1$ \\
\hline $\begin{array}{l}\text { Estados } \\
\text { Unidos }\end{array}$ & Glamis Gold Ltd. & $\begin{array}{l}\text { Arbitraje ad hoc conforme } \\
\text { al Reglamento de Arbitraje } \\
\text { de la UNCITRAL }\end{array}$ & - \\
\hline $\begin{array}{l}\text { Estados } \\
\text { Unidos }\end{array}$ & $\begin{array}{l}\text { TransCanada Corporation y TransCanada } \\
\text { PipeLines Limited }\end{array}$ & CIADI & $\mathrm{ARB} / 16 / 21$ \\
\hline Hungría & $\mathrm{ADC}$ & CIADI & $\mathrm{ARB} / 03 / 16$ \\
\hline Hungría & Telenor Mobile Communications AS & CIADI & $\mathrm{ARB} / 04 / 15$ \\
\hline India & White Industrias Australia Ltd. & $\begin{array}{l}\text { Arbitraje ad hoc conforme } \\
\text { al Reglamento de Arbitraje } \\
\text { de la UNCITRAL }\end{array}$ & \\
\hline Italia & Eskosol S.p.A. in liquidazione & CIADI & $\mathrm{ARB} / 15 / 50$ \\
\hline Kenia & $\begin{array}{l}\text { Cortec Mining Kenya Limited, Cortec (Pty) } \\
\text { Limited and Stirling Capital Limited }\end{array}$ & CIADI & $\mathrm{ARB} / 15 / 29$ \\
\hline Lituania & Parkerings Companient AS & CIADI & $\mathrm{ARB} / 05 / 8$ \\
\hline México & Metalclad Corp. & CIADI & $\mathrm{ARB}(\mathrm{AF}) / 97 / 1$ \\
\hline Perú & Bear Creek Mining Company & CIADI & $\mathrm{ARB} / 14 / 21$ \\
\hline Rumania & $\begin{array}{l}\text { Ioan Micula, Viorel Micula, European Food } \\
\text { SA, Starmill S.R.L. y S.C. Multipack S.R.L. }\end{array}$ & CIADI & $\mathrm{ARB} / 05 / 20$ \\
\hline Sri Lanka & AAPL & CIADI & $\mathrm{ARB} / 87 / 3$ \\
\hline Sudáfrica & Piero Foresti, Laura de Carli y otros & CIADI & $\mathrm{ARB}(\mathrm{AF}) / 07 / 01$ \\
\hline Uruguay & $\begin{array}{l}\text { Philip Morris Brand Sàrl (Suiza), Phil Morris } \\
\text { Products S.A. (Suiza) y Abal Hermanos S.A. } \\
\text { (Uruguay) }\end{array}$ & CIADI & $\mathrm{ARB} / 10 / 7$ \\
\hline Venezuela & $\begin{array}{l}\text { ConocoPhillips Petrozuata BV, ConocoPhillips } \\
\text { Hamaca BV y ConocoPhillips Gulf of Paria } \\
\text { BV }\end{array}$ & CIADI & $\mathrm{ARB} / 07 / 30$ \\
\hline Venezuela & Crystallex International Corporation & CIADI & $\mathrm{ARB}(\mathrm{AF}) / 11 / 2$ \\
\hline Venezuela & Gold Reserve Inc. & CIADI & $\mathrm{ARB}(\mathrm{AF}) / 09 / 1$ \\
\hline Venezuela & Mobil Cerro Negro Ltd. & CCI & 15416/JRF \\
\hline
\end{tabular}




\begin{tabular}{|c|l|l|l|}
\hline ESTADO & \multicolumn{1}{|c|}{ INVERSOR } & FORO & NÚMERO \\
\hline Venezuela & $\begin{array}{l}\text { Phillips Petroleum Company Venezuela Ltd. y } \\
\text { ConocoPhillips Petrozuata BV }\end{array}$ & CCI & ARB/07/27 \\
\hline Venezuela & $\begin{array}{l}\text { Venezuela Holdings BV, Mobil Cerro Negro } \\
\text { Holding Ltd., Mobil Venezolana de Petróleos } \\
\text { Hondings Inc., Mobil Cerro Negro Ltd. y } \\
\text { Mobil Venezolana de Petróleos Inc. }\end{array}$ & CIADI & \\
\hline
\end{tabular}

Fuente: Elaboración propia en base a datos del CIADI, CPA, Investment Policy Hub de la UNCTAD e Investment Treaty Arbitration Law. Última fecha de consulta: 9 de octubre de 2019.

\section{Tabla 11: Corte Internacional de Justicia y la Corte Permanente de Justicia}

\begin{tabular}{|l|l|l|l|}
\hline \multicolumn{1}{|c|}{ ACTOR } & DEMANDADO & \multicolumn{1}{|c|}{ ASUNTO } & FORO \\
\hline $\begin{array}{l}\text { Gran } \\
\text { Bretaña, } \\
\text { Francia, } \\
\text { Italia, Japón }\end{array}$ & Alemania & Asunto del vapor Wimbledon (1923) & CPJ \\
\hline Francia & Turquía & Asunto del vapor Lotus (1927) & CPJ \\
\hline- & - & $\begin{array}{l}\text { Opinión consultiva relativa a las reparaciones a los daños } \\
\text { sufridos al servicio de la ONU (1949) }\end{array}$ & CIJ \\
\hline
\end{tabular}

Fuente: Elaboración propia en base a datos de la CIJ. Última fecha de consulta: 9 de octubre de 2019.

\section{Tabla 12: Unión Europea}

\begin{tabular}{|l|l|l|}
\hline \multicolumn{1}{|c|}{ SOLICITANTE } & \multicolumn{1}{|c|}{ ASUNTO } & \multicolumn{1}{|c|}{ FORO } \\
\hline $\begin{array}{l}\text { Tribunal Supremo de lo Civil } \\
\text { y Penal, Alemania }\end{array}$ & $\begin{array}{l}\text { Procedimiento prejudicial. Asunto C-284/16 (caso Achmea } \\
\text { BV) (2018) }\end{array}$ & TJUE \\
\hline Bélgica & $\begin{array}{l}\text { Dictamen 1/17 (consulta sobre la compatibiidad del } \\
\text { mecanismo de solución de controversias inversor-Estado del } \\
\text { capítulo 8 del CETA con el Derecho de la Unión) (2019) }\end{array}$ & TJU \\
\hline
\end{tabular}

Fuente: Elaboración propia en base a datos de la Unión Europea. Última fecha de consulta: 9 de octubre de 2019. 
Tabla 13: Corte Interamericana de Derechos Humanos

\begin{tabular}{|c|c|c|}
\hline DEMANDADO & ASUNTO & SENTENCIA \\
\hline Ecuador & $\begin{array}{l}\text { Caso Pueblo Indígena Kichwa de Sarayaku } \\
\text { contra Ecuador }\end{array}$ & $\begin{array}{l}\text { Sentencia de } 27 \text { de junio de } 2012 \\
\text { (Fondo y Reparaciones) }\end{array}$ \\
\hline Honduras & Caso Velásquez Rodríguez contra Honduras & $\begin{array}{l}\text { Sentencia de } 29 \text { de julio de } 1988 \\
\text { (Fondo) }\end{array}$ \\
\hline Honduras & $\begin{array}{l}\text { Caso Comunidad Garifuna de Triunfo de la } \\
\text { Cruz y sus miembros contra Honduras }\end{array}$ & $\begin{array}{l}\text { Sentencia de } 8 \text { de octubre de } \\
2015 \text { (Fondo, Reparaciones y } \\
\text { Costas) }\end{array}$ \\
\hline
\end{tabular}

Fuente: Elaboración propia en base a datos de la Unión Europea. Última fecha de consulta: 9 de octubre de 2019.

Tabla 14: Estados Unidos

\begin{tabular}{|c|c|c|c|}
\hline ACTOR & DEMANDADO & \multicolumn{1}{|c|}{ ASUNTO FORO } \\
\hline Argentina & BC Group PLC & Writ of Certiorari (2013) & $\begin{array}{l}\text { Suprema Corte de Justicia } \\
\text { de Estados Unidos }\end{array}$ \\
\hline
\end{tabular}

Fuente: Elaboración propia en base a datos del Investment Treaty Arbitration Law. Última fecha de consulta: 9 de octubre de 2019 .

Tabla 15: Organización Mundial del Comercio

\begin{tabular}{|c|c|c|c|}
\hline RECLAMANTE & DEMANDADO & ASUNTO & NÚMERO \\
\hline Canadá & Estados Unidos & $\begin{array}{l}\text { Determinadas medidas relativas a los productos de } \\
\text { acero y aluminio }\end{array}$ & DS550 \\
\hline China & Estados Unidos & $\begin{array}{l}\text { Determinadas medidas relativas a los productos de } \\
\text { acero y aluminio }\end{array}$ & DS544 \\
\hline Cuba & Australia & $\begin{array}{l}\text { Determinadas medidas relativas a las marcas de } \\
\text { fábrica o de comercio, indicaciones geográficas y otras } \\
\text { prescripciones de empaquetado genérico aplicables a } \\
\text { los productos de tabaco y al empaquetado de esos } \\
\text { productos }\end{array}$ & DS458 \\
\hline $\begin{array}{l}\text { República } \\
\text { Dominicana }\end{array}$ & Australia & $\begin{array}{l}\text { Determinadas medidas relativas a las marcas de } \\
\text { fábrica o de comercio, indicaciones geográficas y otras } \\
\text { prescripciones de empaquetado genérico aplicables a } \\
\text { los productos de tabaco y al empaquetado de esos } \\
\text { productos }\end{array}$ & DS441 \\
\hline Honduras & Australia & $\begin{array}{l}\text { Determinadas medidas relativas a las marcas de } \\
\text { fábrica o de comercio, indicaciones geográficas y otras } \\
\text { prescripciones de empaquetado genérico aplicables a } \\
\text { los productos de tabaco y al empaquetado de esos } \\
\text { productos }\end{array}$ & DS435 \\
\hline India & Estados Unidos & $\begin{array}{l}\text { Determinadas medidas relativas a los productos de } \\
\text { acero y aluminio }\end{array}$ & DS547 \\
\hline
\end{tabular}




\begin{tabular}{|c|c|c|c|}
\hline RECLAMANTE & DEMANDADO & ASUNTO & NÚMERO \\
\hline Indonesia & Australia & $\begin{array}{l}\text { Determinadas medidas relativas a las marcas de } \\
\text { fábrica o de comercio, indicaciones geográficas y otras } \\
\text { prescripciones de empaquetado genérico aplicables a } \\
\text { los productos de tabaco y al empaquetado de esos } \\
\text { productos }\end{array}$ & DS467 \\
\hline México & Estados Unidos & $\begin{array}{l}\text { Determinadas medidas relativas a los productos de } \\
\text { acero y aluminio }\end{array}$ & DS551 \\
\hline Noruega & Estados Unidos & $\begin{array}{l}\text { Determinadas medidas relativas a los productos de } \\
\text { acero y aluminio }\end{array}$ & DS552 \\
\hline Suiza & Estados Unidos & $\begin{array}{l}\text { Determinadas medidas relativas a los productos de } \\
\text { acero y aluminio }\end{array}$ & DS556 \\
\hline Turquía & Estados Unidos & $\begin{array}{l}\text { Determinadas medidas relativas a los productos de } \\
\text { acero y aluminio }\end{array}$ & DS564 \\
\hline Ucrania & Australia & $\begin{array}{l}\text { Determinadas medidas relativas a las marcas de } \\
\text { fábrica o de comercio y otras prescripciones de } \\
\text { empaquetado genérico aplicables a los productos de } \\
\text { tabaco y al empaquetado de esos productos }\end{array}$ & DS434 \\
\hline Ucrania & Rusia & Medidas que afectan al tráfico en tránsito & DS512 \\
\hline UE & Estados Unidos & $\begin{array}{l}\text { Determinadas medidas relativas a los productos de } \\
\text { acero y aluminio }\end{array}$ & DS548 \\
\hline
\end{tabular}

Fuente: Elaboración propia en base a datos dela OMC. Última fecha de consulta: 9 de octubre de 2019. 